




attuscum of Comparatibe oölogy, Cambrioge, Mass.

With the compliments of

ALEXANDER AGASSIZ. 



\section{Attemoirs of the attuseum of Comparative \%oologes}

AT HARVARD COLLEGE.

Vol. XVIII.

REPORTS ON AN EXPLORATION OFF THE WEST COASTS OF MEXICO, CENTRAL AND SOUTH AMERICA, AND OFF THE GALAPAGOS ISLANDS, IN CHARGE OF ALEXANDER AGASSIZ, BY THE U. S. FISH COMMISSION STEAMER "ALBATROSS," DURING 1891, LIEUT.-COMMANDER Z. L. 'TANNER, U. S. N., COMMANDLNG.

$\mathrm{XV}$.

\section{THE STALK-EYED CRUSTACEA.}

BY WALTER FAXON.

WITH SIXTY-SEVEN PLATES,

Ten of which are colored, and one Chart.

[Published by Permission of Marshali. MoDonald, U. S. Commissioner of Fish and Fisheries.]

CAMBRIDGE, U.S.A. :

隹rinted for the ftluseum.

A PrIL, 1895. 



\section{MEMOIRS}

OF THE

\section{IIUSEUII OF COMPARATIVE Z0ÖLOGY}

\section{HARVARD COLLEGE.}

VOL. XVIII.

CAMBRIDGE, U.S. A.

PRINTED FOR THE MUSEUM.

1895. 
University Press:

John Wilson and Son, Cambridge, U. S. A. 


\section{O N T E N T S.}

REPORTS ON AN EXPLORATION OFF THE WEST COASTS OF MEXICO, CENTRAL AND SOUTH AMERICA, AND OFF THE GALAPAgOS ISLANDS, in charge of Alexander Agassiz, by the U. S. Fish Commission Steamer "Albatross," during 1891, Lieut.-Commander Z. L. Tanner, U. S. N., Commanding. XV. The Stalk-eyed Crustaced. By Walter Faxod. 292 pp., 67 Plates. April, 1895. 

L R R A 'T'A.

On l'late VI., for 2 ETHUSA PUBEscens rend FTHUSA LATA.

On Plate VII., for Rhinolithodes CRISTAtipes real Glyptolithodes CRISTAtipes.

On Plate VII., for Echinocerus diomede rear Paralomis diomede瓜.

On Plate VIII, for PARALOMIS ASPERA real LEPTOLITHOdES ASPER.

On Plate IX., for PARALOMIS LONGIPES read LEPTOLITHOdEs LONGIPES. 



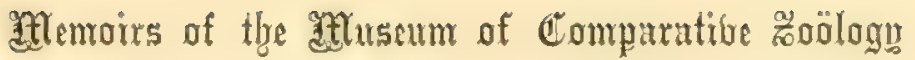

AT HARVARD COLLEGE.

Vol. XVIII.

REPORTS ON AN EXPLORATION OFF THE WEST COASTS OF MEXICO, CENTRAL AND SOUTH AMERICA, AND OFF THE GALAPAGOS ISLANDS, IN CHARGE OF ALEXANDER AGASSIZ, BY THE U. S. FISH COMMISSION STEAMER "ALBATROSS," DURING 1891, LIEU'T-COMMANDER Z. L。 TANNER, U. S. N., COMMANDING.

XV.

\section{THE STALK-EYED CRUSTACEA.}

BY WALTER FAXON.

WITH SIXTY-SEVEN PLATES,

Ten of which are colored, and one Chart. of Fish and Fisheries.]

CAMBRIDGE, U.S.A. :

farintex for the ftttsenm.

APRIL, 1895. 



\section{CONTENTS.}

\begin{tabular}{|c|c|c|c|c|c|c|c|c|c|c|c|}
\hline Systematic Account of the Species & & . & & & & & & & & & $\begin{array}{r}P_{A G E} \\
5-230\end{array}$ \\
\hline . . . . . . & . . & . & . . & . . & · & . & • & . . & . & . . & $5-215$ \\
\hline Schizoroda & . . & . & . . & . & . & . & . & . . & . & . . & $215-229$ \\
\hline STOMATOPODA & . . & . & . . & . . & . & . & . & . . & . & . & 230 \\
\hline eneral Considerations on the Distr & RIBU & UTION & & . & 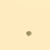 & . & . & . . & . & . & $231-250$ \\
\hline Colors of the Deep-Sea Crustacea & . & 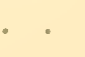 & . . & - . & . & . & . & .. & . & . . & $1-255$ \\
\hline List of Species arranged according T & To $\mathrm{G}$ & GEOGF & RAPI & & $A \mathbf{L}$ & REC & & vs . & . & & $256-259$ \\
\hline Table showing the Batmyaetrical Dist & TRIB & BUTIO: & ox or & & IE & Dif: & & RENT & & ECIES & $260-263$ \\
\hline Record of Subuatine Tow-Net Statio & oxs & . & . . & . . & . & . & & - & . & . & 264 \\
\hline Record of Dredging and Trawling S? & STATI & rions & & - $\cdot$ & . & $\cdot$ & - & $\cdot \cdot$ & . & - & 265,266 \\
\hline Explaxatiox of the Plates & · & • & . & . & · & & & & • & & $26 \pi-282$ \\
\hline D SPECII & & & & & & & & & & & $283-292$ \\
\hline
\end{tabular}





\title{
STALK-EYED CRUSTACEA.
}

\section{ORder PODOPHTHALMA.}

\author{
Suborder DECAPODA.
}

Fanily MaIID E.

LEPTOPODIA LEACH.

Zoölog. Misc., II. 15, 1815.

\section{Leptopodia debilis Sмгтп.}

Ann. Rep. Peabody Acad. Sci. for 1869 and 1870, p. 87, 1871.

Two specimens, male and female, were collected at low tide on the reef at Panama, Narch 12.

Leptopodia debilis is one of the many littoral Crustacea of Panama that are represented by very closely allied species on the Atlantic side of the Isthmus. It is distinguished from Leptopodia sagittaria (Fabr.), its Atlantic representative, chiefly by its shorter hand, relatively longer fingers, and greater breadth across the branchial region of the carapace. The rostrum is usually shorter and inclined upward more than in $L$. sagittaria; but in the type specimen (M. C. Z. No. 3948, है, Polvon, Nicaragua), it is exceptionally long, - more than one and a half times as long as the rest of the carapace. In average specimens of $L$. debitis the rostrum is about equal in length to the rest of the carapace. The difference in the form of the male abdomen in L. debilis and in Milne Edwards's figure of $L$. sagittaria (Cuvier's Règne Animal, Disciples' ed., Crustacen, Plate XXXVI. Fig. ${ }^{d}$ ), noted by Smith, arises from the inaccuracy of the figure, not from any real difference between the two species, which are alike in this regard. 
Leptopodia debitis has been found to the northward of Panama as far as the northern extremity of the Gulf of California, lat. $31^{\circ} 22^{\prime} \mathrm{N}$. A similar or possibly identical form, L. modesta A. M. Edw.,* occurs on the coast of Chile.

The bathymetrical range of Leptopodia debilis, so far as known, extends from low-water mark down to 29 fathoms. $L$. sagittaria has been recorded from as great a depth as 814 fathoms.†

EUPROGNATHA STIMPS.

Bull. Mus. Comp. Zoöl., II. 122, 1870.

Euprognatha granulata FAx.

Plate 1., Fig. 1, $1^{a}$.

Bull. MIus. Comp. Zoöl., XXIV. 149, 1893.

The carapace is coarsely granulated and furnished with a few scattered setx; there are two erect blunt spines in the median line of the carapace, one of them arising from the gastric region, the other from the cardiac region; in front of the gastric spine is seen a transverse row of four or five tubercles, which are somewhat larger and more prominent than the granules which cover the general surface of the carapace; from the middle of each branchial area there springs a spine which is longer than those in the median line, and curved slightly forward at the tip; there is also a smaller lateral spine below and a little in advance of this; the hepatic area bears a short, blunt, granulated spine on its most prominent part, and three or four prominent tubercles on the angle which divides it from the pterygostomian area; the antennal spine is very long, reaching some distance beyond the rostral horns, while the interantennular and lateral rostral horns are of about an equal length; the supraocular spines are well developed, and, like the antennal spine and the three horns of the rostrum, have a distinctly granulated surface; the postocular spines are even more coarsely tuberculated, and when viewed from above their margins are laciniated. The lower face of the basal segment of the antenna is granulated, and furnished beside with two to three spinules; the outer maxillipeds are also granulated. The sur-

* A Milne Edrards, Études sur les Xiphosures et les Crustacés de la Région Mericaine, p. 173, 1878 (Miss. Sci. au Mex. $5^{\text {ème }}$ Partie, T. I.). Milne Edwards treats both $L_{0}$ modesta and $L$ debilis as varieties of L. sagittaria.

† Mliers, Rep. Challenger Brachyura, p. 4, 1886. 
face of the abdomen is thickly beset with larger bead-like tubercles; the first segment bears a prominent, granulated, blunt, median spine, and there is a rudiment of one on the three following segments. The chela is slender and covered with small tubercles; the other segments of the cheliped and all the ambulatory legss are provided with small spines, tubercles, and scattered curled setæ. The spines attain their greatest development on the merus joints of the legs, the largest of all being on the proximal half of the merus of the chelipeds and at the distal end of the merus of the ambulatory legs.

Length of carapace, $7 \mathrm{~mm}$; breadth, $6 \mathrm{~mm}$.

Station 3369* 52 fathoms. 2 fem. ovig.

The genus Euprognatha is represented in the West Indian region by four species (E. rastellifera Stimps., E. inermis A. M. Edw., E. gracilipes A. M. Edw., and $E$. acuta A. M. Edw.), from depths ranging from 27 to 248 fathoms. The present species may be distinguished from all of these by its coarsely granulated carapace and abdomen, taken in connection with the laciniated and granulated spines of the frontal region, etc. One species, Euprognatha bifida Rathb., $\dagger$ has been recently described from the Gulf of California, 29-40 fathoms. It may be distinguished by the absence of an interantennular spine.

\section{SPHENOCARCINUS A. M. EDW.}

Crustacés de la Région Mex., p. 135, 1878.

\section{Sphenocarcinus agassizi Rarub.}

Plate I., Fig. 3, $3^{a}$.

Proc. U. S. Nat. Mus., XVI. 231, 1893.

In this species the whole surface of the body and limbs is clothed with a short, close pubescence. The rostral horns are long, horizontal, and terminate in blunt points. A more or less broken, longitudinal, rounded ridge runs along the median line of the carapace, from the base of the rostrum to the intestinal region, rising into a prominent tubercle on the gastric area. A transverse flattened tubercle on the cardiac region, and two roundish ones on each branchial region. The antero-lateral margin of the carapace is armed with four prominent tubercles or large teeth (counting the one at the external orbital angle); these teeth increase in size successively from

* A full record of the stations will be found on pp. 26t-266.

† Proc. U. S. Nat. Mus., XVI. 231, 1893. 
the first to the last one. The upper margin of the orbit is thickened and produced into a blunt proocular tooth. The outer margin of the pterygostomian region is furnished with two or three rounded tubercles. The merus of the chelipeds has two short spines at the proximal end on the superior border and one at the distal extremity; otherwise the limbs are unarmed; the fingers of the chela are short, gape slightly at the base, and have blunt tips; no teeth on cutting edges.

Length of carapace, including rostrum, $39 \mathrm{~mm}$. ; length of rostrum, 16 $\mathrm{mm}$.; breadth of carapace, including lateral teeth, $28 \mathrm{~mm}$.

Station 3368. 66 fathoms. 1 male.

Sphenocarcimus corrosus A. M. Edw., the type of this genus, was taken near the Barbadoes in 100 fathoms during the voyage of the "Hassler," and near the same locality in 94 fathoms by the "Blake." The two specimens secured are females. In S. agassizi there is a blunt præocular tooth, wanting in the typical species. The ends of the rostral horns do not lie in exactly the same plane in the single example before me, but this is probably due to accidental malformation. The abdomen (male) is seven-jointed. In both species there is a narrow fissure in the upper margin of the orbit, just anterior to the postocular tooth.

Sphenocarcimus agassizi was also obtained by the "Albatross" in 1889, in the Gulf of California, at depths of 14 and 71 fathoms.

ANAMATHIA Sмiтr.

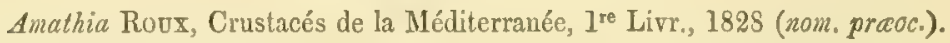

Anamathia Surit, Proc. U. S. Nat. Mus., VII. 493, 1884.

\section{Anamathia occidentalis FAx.}

Plate I., Fig. 2, $2^{a}$.

Bull. Mus. Comp. Zoöl., XXIV. 150, 1593.

Carapace piriform, strongly arched when viewed in profile, its surface clothed with tuberculiform cutaneous vesicles* and with delicate seta which are hooked at their tips. The spines and tubercles of the carapace are arranged as follows: four on the gastric region, two of which are in the median line and one on each side; the posterior median has the form of a blunt tubercle, from which a blunt low keel runs back to the cardiac region;

* Like those on the carapace of Anamathia carpenteri (Norman), described and figured by G. O. Sars, Norske Nordhavs-Exped., Crustacea, I. 7, Plate I. Fig. 7, $18 \$ 5$. 
one in the middle of the cardiac region; one (tubercle) on the intestinal region; one on each hepatic region; five on each branchial region. Of the branchial spines the one near the middle projects upward and forward, and is the longest spine on the carapace, being one half as long as the rostral horns; behind and inside of this there is a short, rather blunt spine in a transverse line with its fellow and the cardiac spine; the three remaining branchial spines are arranged in a triangle on the anterior part of the branchial area; those nearest the median line on the branchial areas are short and blunt - tubercles rather than spines. In addition to these prominent spines and tubercles of the carapace, there are four or five small tubercles on the outer border of the pterygostomian region. 'The rostrum is produced into two divergent awl-shaped horns, which are more than one fourth the length of the remaining portion of the carapace. The praocular spines are well developed and acute, the postocular processes obtuse. The basal segment of the antenna projects at the antero-external angle in the form of a short, blunt spine or tubercle. 'The antero-external angle of the buccal area projects, but does not form a dentiform process. The chelipeds are twice as long as the carapace, minus the rostral horns, and are but little more robust than the ambulatory limbs; the chela is a little longer than the merus, the basal part cylindrical, the distal part gradually widening a little to the base of the fingers; the fingers are slightly curved, less than one half as long as the basal portion, smooth, prehensile edges regularly dentate, closing throughout their length. The first ambulatory appendages exceed the chelipeds by the length of the terminal joint; the other pairs are successively shorter, the last pair being shorter than the chelipeds. The merus of all the legs has a small tubercular projection at the distal end above, most prominent on the anterior pair. The carpus of the chelipeds has two low ridges on the onter face; otherwise the legs are unarmed, but they are closely invested with minute papillæ, like the carapace. The abdomen is seven-jointed.

Length of carapace, without the rostral horns, $45 \mathrm{~mm}$; breadth of carapace, $38 \mathrm{~mm}$. ; length of rostral horns, $12 \mathrm{~mm}$; length of longest branchial spine, $7 \mathrm{~mm}$.

Station 3404. 385 fathoms. 1 male.

In the unique type specimen, the left hind leg has been broken off and restored. The chelipeds and the first pair of ambulatory appendages are unsymmetrical, the left being longer than the right. 
The name Anamathia has been substituted by Professor S. I. Smith for Amathia Roux, as the latter name had been previously used in another sense by Lamouroux. The type species of the genus is Amathia rissoana Roux from the Mediterranean Sea. Nine other species have been referred to the genus, viz.: A. hystrix Stimps., A. modesta Stimps., Scyra umbonata Stimps, A. crassa A. M. Edw. (二A. agassizii Smith), A.tameri Smith, - all from the east coast of North America and the Caribbean Sea, $-A$. carpenteri Norman from the coast of Europe, A. pulchra Miers from the Philippine Islands, A. livermorii. W.-M. from the Bay of Bengal, and $A$. occidentalis Fax. from near the Galapagos Archipelago. Most of them have been taken in rather deep water ( 88 to $56 \mathrm{l}$ fathoms). When all these species are compared with each other, considerable differences are observable as regards the structure of the orbital region, the armature of the basal antennal segment and the carapace, etc. In the typical species, A. rissoana, the upper surface of the carapace is rather 1lat, and armed with long, sharp spines; the basal antennal segment is unarmed; the upper margin of the orbit projects but slightly over the eye, and there is no præocular spine. In A. hystrix the carapace is more convex both in the longitudinal and transverse axes, and is armed with very long sharp spines; the basal antennal segment is produced into a blunt spine or tooth at its antero-external angle; the supraorbital margin or brow overhangs the orbit no more than it does in $A$. rissoana, but there is a long and sharp præocular spine. In $A$. crassa the carapace is strongly arched, and the spines with which it is furnished are short; the basal segment of the antenna is armed with two spines, one at the distal, the other near the proximal end; there is a præocular spine, and the upper border of the orbit beetles further over the eye than it does in $A$. rissoana and A. hystrix, but still falls short of forming that perfect roof bounded behind by an almost transverse fissure, such as is seen in the typical species of Hyastems and Naxia. In A. umbonata, A. carpenteri, and A. occidentalis, the conformation of the orbits and the convexity of the carapace are much the same as in $A$. crassa, but the basal joint of the antenna is unarmed, and in the two former (umbonata and carponteri) some of the spines of the carapace are transformed into flattened tubercles. For these two species A. Milne Edwards* has proposed to establish a new genus Scyramathia. G. O. Sars $\dagger$ adopts the genus Seyramathio, and adds to it Amathia crassa. He places the genus in the Maiine group, in close proximity to Hyastemus.

\footnotetext{
* Comptes Rendus de l'Acad. Sci., Paris, XCI. 356, 1850.

$\dagger$ Norske Nordhars-Exped, Crustacea, I. 1, 274, 1855.
} 
The orbital region of $A$. hystrix does not differ from that of $A$. vissoana but for the presence of a præocular spine, a character which by itself cannot be considered of generic importance, as Mr. Miers admits.* Through hystrix we pass by a gentle transition to such species as umbonata, carpenteri, and crassa (species placed in the genus Scyramathia), in which the orbit is better defined through the projection of the brow.

Thus the passage from the Inachine to the Maine type is so gradual as hardly to justify a family division such as is proposed by Mr. Miers. $\dagger$ In the series of species, all of which are assigned to the genus Anamathia, family Inachide, by Mr. Miers + (rissoana, hystrix, pulchra, crassa), we pass from the strictly Inachine orbit of rissoana to an orbit like that of crassa, which is practically the same as that of Choritia longipes, a species assigned by Miers to the grenus Hyastemus in the family Marido.

The orbital region is subject to a great amount of variation even in a single species (A. umbonatu), so that within the bounds of mere individual variation the passage is made from the Inachine to the Maiine type of orbit as exhibited in Chorilia. §

\section{MAIOPSIS FAX}

Bull. Mus. Comp. Zoöl., XXIV. 150, 1893.

Carapace subtriangular, as broad as long, spinose; rostrum produced anteriorly into two divergent horns with an accessory spine upon their outer margins; interorbital space broad. Hyes small, eyestalks slender, retractile within the orbits. Orbits large, with a forward aspect, incomplete below, the upper margin prominent, with two deep fissures, and supraocular spines. Epistome short. Basal segment of antennæ very broad, with three prominent spines upon its anterior margin; flagellum of the antenuæ widely separated from the cavity of the orbit by a broad process of the basal segment. Merus of outer maxillipeds notched at the antero-internal angle. Legs of moderate length; carpus of chelipeds elongated, not carinated; chela elongated and slender, fingers canaliculate within, but not spoon-shaped at their tips, their prehensile edges meeting throughout most of their length,

* Journ. Limn. Soc. London, Zoöl., XIV. 658, 1879.

† Op. cit., p. 640 .

Challenger Brachyura, p. 26, 1886.

\$ See M. J. Rathbun, Proc. U. S. Nat. Mus., XVII. 61, 62, Plate I., 1894. Cf. Fig. 3 (orbit of A. umbonata) with Fig. 1 (also A. umbonata), and then of. Fig. 1. with Fig. 5 (Chorilia longipes). 
not distinctly toothed; ambulatory legs spinose. Abdomen (male) sevenjointed, terminal joint short and broad.

This grenus is proposed for the reception of an interesting Maioid dredged in 182 fathoms on the west const of the Isthmus of Panama. It combines in one form characters of the genera Maia, Cyclumaia, Paramithax (subg. Leptomithrax), and Schizophrys. In its general aspect it bears a close resemblance to Maia, and the likeness is enhanced by the small eyes and slender eye-stalks, the elongated wrist and hand, and the short epistome. It differs from Maia in having a much broader carapace, a less deeply cloven rostrum, spinose less, supraocular spines, and trenchantly in the exclusion of the antennal flagellum from the orbit by a process of the basal segment of the antemna. In the latter regard it agrees with the genus Cyclomaia, the basal segment of the antenna being very broad, three-spined on its distal border, and giving off a process which separates the flagellum from the orbit by a wide interval; it also agrees with Cyclomaia in having a short epistome, a short and broad terminal abdominal segment, and supraocular spines. It differs from Cyclomaia by having a subtriangular carapace, longer rostral spines, and a less abruptly declivous front. It is like Paramithrax and Sclizophrys in the exclusion of the basal antennal segment from the orbit, but this segment is much broader than in these genera, and three-spined; moreover, Maiopsis differs from Paramithrax and Schizophrys in having a more broadly triangular carapace, supraocular spines, slenderer wrist and hand, less deeply cleft rostrum, and spinose ambulatory legs. Like Schizophrys and Maiclla, it has an accessory spine on each rostral horn. In the shape of the carapace Maiopsis is intermediate between Maia and Cyclomaia. In the form of the fingers it stands between Maia and Paramithrax on the one side and Schizophrys and Cyclomaic on the other, as the fingers, though canaliculate within, are but slightly excavated at the tips.

The synthetic character of the species upon which this genus is based suggests the propriety of extending the scope of the genus Paramithrax so that it may embrace this form, together with Cyclomaia and Schizophrys. 


\section{Maiopsis panamensis FAx.}

Plute II.

Bull. Mus. Comp. Zoöl, XXIV. 151, 1593.

Carapace subtriangular, as broad as long, convex, the anterior gastric region sloping rather abruptly down to the base of the rostrum, which is split about half way down to the front into two divergent horns; each rostral horn is armed with a stout basal spine directed upward and forward. The dorsal surface of the carapace is thickly set with spines of various sizes, and scattered hooked setre; the largest spines are arranged as follows: five on the gastric region (three in the median line and two lateral), one on the genital region, one on the cardiac region, four (three of which are submarginal) on the intestinal region, and about seven on each branchial region. The margin of the carapace is armed with about twelve prominent spines; three of these are on the hepatic region; the posterior one is much smaller than the two in front of it, which are confluent at their bases. The superior margin of the orbit is deeply cut by two open fissures; the eyebrow is armed with two stout spines. The branchio-cardiac lines approach one another closely at the anterior end of the cardiac area. The basal segment of the antenni is very broad; its distal margin is armed with a strong internal spine directed downward and forward; a second spine, pointing obliquely forward, arises from the external angle; while a third bilid spine lies between the other two; there are, besides, a few spinules on the lower side of this segment. The anterior margin of the third segment of the outer maxillipeds is denticulate. The sternum is ormamented with small tubercles along each side of the abdomen. The first abdominal segment is furnished with a bidentate tubercle.

The legs are long, and covered with numerous spiny tubercles; the meri are armed with three more prominent spines at the distal end. The first ambulatory leg is the longest, the others decreasing in length successively from before backward. The carpus of all the four pairs of ambulatory appendages is marked with a dorsal longitudinal groove. The chela is long and slender, the tubercles on the hand smaller than on the other parts of the legs, while the fingers are nearly smooth, subcanaliculate, and blunt-tipped; a deep pit is seen at the base of the movable finger.

Length from base of rostrum to posterior margin of carapace, $112 \mathrm{~mm}$; 
breadth, $113.5 \mathrm{~mm}$.; length of rostrum, $22 \mathrm{~mm}$.; length of rostral horns, $11 \mathrm{~mm}$; breadth between eyebrows, $38 \mathrm{~mm}$.; length of cheliped, $156 \mathrm{~mm}$. (merus, $44.5 \mathrm{~mm}$.; carpus, $25 \mathrm{~mm}$.; propodus, $67 \mathrm{~mm}$.; dactylus, $25 \mathrm{~mm}$.); length of second leg (first ambulatory), $195 \mathrm{~mm}$. (merus, $62 \mathrm{~mm}$., carpus, $32 \mathrm{~mm}$. ; propodus, $40 \mathrm{~mm}$., dactylus, $44 \mathrm{~mm}$.); width of sternum, $72 \mathrm{~mm}$. ; length of telson, $8.7 \mathrm{~mm}$; width of telson, $16.5 \mathrm{~mm}$.

Station 3355. 182 fathoms. 1 male.

\section{FAMLY PARTHENOPID E.}

\section{LAMBRUS LEACH.}

rans. Linu. Soc. London, XI. 308, 310, 1815.

\section{Lambrus hassleri Fax.}

Plate III., Fig. 1, $1^{a}$.

Bull. Mius. Comp. Zoöl., XXIV. 152, 1893.

The carapace is from one and a third to one and two fifths times as broad as long. A deep longitudinal depression separates the branchial from the gastric and cardiac regions and another separates the hepatic and branchin regions. The whole surface is tuberculous, granulated, and pitted. There are three large tubercles on the gastric region, one median and two smaller ones in a transverse line in front of the median. Three tubercles are found on the cardiac region in the median line, the middle one the largest. On the posterior margin there are three tubercles with smaller ones between them; the three larger ones are placed, one in the middle line of the carapace, one on each side. The largest of the numerous tubercles which lie on the gastric area is placed on the most prominent central point; four or five smaller ones are disposed in a somewhat irregular diagonal row on the side of the deep depression which divides the branchial from the cardiac area. The rostrum is directed forward and downward at an obtuse angle with the axis of the body; it is constricted in front of the antennular pockets, leaving a dentiform tubercle on each side; there is also, in most examples, a rudimentary tubercle on each side of the rostrum near the tip; the upper side of the rostrum is excavated between the eyes. The upper border of the orbits exhibits two tubercles. The antero-lateral border of the carnpace is armed anteriorly with rounded tubercles which pass into prominent 
laciniated teeth posteriorly; the largest of these teeth is situate at the lateral angle of the carapace. There is one very prominent tooth on the posterolateral margin, together with three or four smaller ones. The edges of the segments of the chelipeds are furnished with granulated spines and the exposed surfaces of all the segments are tuberculate; on the lower face of the propodus the more prominent tubercles are arranged in a longitudinal median row. The merus joints of all the ambulatory appendages are spinulose on their upper and lower edges, and on the last pair there are also a few rudimentary spines or tubercles on the carpus and one near the middle of the upper margin of the propodus. Distinct traces of red transverse bands are to be seen on the upper surface of the cheliped, two on the merus, one on the carpus, one on the propodus, and one on the base of the dactylus. Abdomen tuberculous in both sexes, the most prominent tubercles being on the middle of each segment from the second to the sixth inclusive.

Dimensions of a female: length of carapace, $27 \mathrm{~mm}$; breadth of carapace, including lateral teeth, $38 \mathrm{~mm}$.; length of merus of cheliped, $30 \mathrm{~mm}$.; length of propodus of cheliped (to base of dactylus), $33 \mathrm{~mm}$.

Station 3368. 66 fathoms. 1 fem.

$$
\text { "3427. } 80 \text { " } 1 \text { male, } 1 \text { fem. }
$$

This species was previously obtained during the voyage of the "Hassler" at Magdalena Bay, Lower California, August 14, 1872. The specimens then collected $(3 \delta, 1 \%$, dry) were apparently picked up dead on the shore. In three of these examples the more prominent tubercles on the carapace are longer and more spine-like than in those obtained by the "Albatross."

Lambms hassteri is the Pacific coast representative of $L$. pourtalesii Stimps. of the eastern coast of North America. The two species are very closely related, but $L$. hassleri differs from the eastern form in the following particulars: the carapace is broader in proportion to its length; the branchial regions are more expanded and inflated, and this inflation extends further in toward the cardiac area, so as to involve the oblique row of small tubercles: that is to say, this row of tubercles, which in L. pourtalesii lies low down in the fossa which separates the branchial from the cardiac area, is raised up in $L$. hassleri on the swell of the branchial region. The spines on the edges of the chelipeds, moreover, are not laciniated to such an extent as they are in L. pourtatesii.

Professor S. I. Smith, misled by imperfections in A. Milne Edwards's figure of $L$. pourtalesii, has redescribed that species under the name of Lambrus ver- 
rillii** I have compared specimens of L. pourtalesii dredged by Stimpson and A. Agassiz (specimens that served Milne Edwards for description and figures) with specimens of $L$. cemillie received from Professor Smith, and find them to be the same. L. porrtalesii has been taken at depths of 40-134 fathoms off Martha's Vineyard, Cape Hatteras, Florida, and the Antilles.

\title{
FAMILY CANCRIDA.
}

CANCER Linn. (restr.).

\begin{abstract}
Syst. Nat, ed. 10, I. 625, 1758. Restricted by Leacr, Trans. Linn. Soc. London, XI. $308,320,1815$.
\end{abstract}

\section{Cancer longipes BeLL.}

Proc. Zoölog. Soc. London, III. 87, 1835; Trans Zoölog. Soc. London, I. 337, Plates XLIII, XLVII. Fig. 1, 1835.

Station 3385. 286 fathoms. 4 males.

" 3389. 210 " 1 male, 1 fem.

The largest specimen measures $137 \mathrm{~mm}$. across the carapace.

Cuncer longipes has been known hitherto as a littoral species from Chile (Valparaiso) and Bolivia (Mexillones: specimens in Mus. Comp. Zoöl.). The "Albatross" specimens were dredged in the Bay of Panama; bottom temperatures $45.9^{\circ} \mathrm{F}$. and $48.8^{\circ} \mathrm{F}$. So Cancer borealis Stimps. of the northeastern coast of the United States and the British Provinces has been dredged in deep water ( 233 fathoms) off the coast of South Carolina, far to the south of its normal littoral range.†

ACT开A De HaAN。

Siebold's Fauna Japonica, Crustacea, p. 18, 1833.

\section{Actæa dovii Stımps.}

Ann. Lyc. Nat. Hist. N. Y., X. 104, 1871.

One male, from the reef at Panama.

* Proc. U. S. Nat. MIus., III. 415, 1881.

† See Smith, Bull. Mus. Comp. Zoölo, X. 5, 1882. 


\title{
GLYPTOXANTHUS A. MI. EDW.
}

Crustacés de la Région Mex., p. 253, 1879.

\section{Glyptoxanthus labyrinthicus (STrmes.).}

Actea labyrinthica Stumps, Anu. Lyc. Nat. 'Hist. N. Y., VII. 204, 1860.

Glyptoranthus labyrinthicus A. M. EDw., Crustacés de la Région Mex., p. 255, Plate XLIII. Fig. 4, 1879.

One male, from the reef at Panama.

\section{XANTHODES DANA.}

Proc. Acad. Nat. Sci. Phila., VI. 75, 1852; U. S. Explor. Exped, Crustacea, Pt. I., pp. 148, 175, 1852.

\section{Xanthodes sulcatus FAX.}

Plate III., Fig. 2, $2^{a}$.

\author{
Bull. Mus, Comp. Zoöl, XXIV. 152, 1893.
}

The carapace is rather convex from before backward, granulated, the granulation heaviest on the lower surface and near the borders of the upper surface. Deeply impressed grooves separate the gastric from the branchial regions, and the mesogastric lobe from the lateral gastric lobes. The groove which continues in the median line to the front, anteriorly to the mesogastric lobe, is crossed a short distance behind the frontal margin by a transverse groove which meets on either side another groove running parallel to the upper margin of the orbit. In this way there are marked off a pair of frontal and a pair of orbital areolets. The frontal margin is nearly straight, finely denticulated and separated from the orbital areolets by a groove. The margins of the orbit are also minutely denticulate, and there is a broadly open, triangular notch at the external orbital angle. The antero-lateral border of the carapace is armed with four spines or teeth, ENTS of Dana's nomenclature, there being no tooth at the outer angle of the orbit; of these teeth, the first is the smallest, the third the largest, and the second and fourth are of about equal size; the edges of all the teeth are denticulate. The lower margin of the orbit is produced into a prominent tooth at the inner angle. The basal joint of the antenna barely meets, by the inner angle of its distal end, a descending process of the frontal margin, and the next joint lies in, but does not nearly fill, the hiatus at the inner orbital angle. The merus of the outer maxillipeds is granulated like the under parts of the carapace. The chelipeds are short and unsymmetrical; the 
merus is granulated on its outer face, spinulose on the upper edge, and grooved near the articulation with the carpus; the carpus is granulated on its outer side and furnished with a median internal tooth; the propodus is inflated, granular along the superior margin and at the proximal end of the outer face where some of the granules are enlarged, and tubercular on the larger claw; the rest of the outer surface of the propodus is smooth in adult specimens. The meri of the ambulatory limbs are spinulose on their upper edges.

Dimensions of a male: length of carapace, $8 \mathrm{~mm}$; breadth of carapace, $11 \mathrm{~mm}$; length of larger chela, $10 \mathrm{~mm}$.; breadth of larger chela, $5 \mathrm{~mm}$.

Station 3355. 182 fathoms. 1 male, 1 fem.

66 3391. $153 \quad$ " 1 male, 3 fem.

PANOPEUS M. EDW.

Hist. Nat. Crust., I. 403, 1834.

Panopeus latus FAx.

Plate III., Fig. 3, 3.

Bull. Mus. Comp. Zoöl., XXIV. 153, 1893.

Carapace broad, convex in the antero-posterior direction, granulated, especially on the hepatic, branchial, and cardiac regions; areolations well marked and protuberant. Front divided by a small median incision into two slightly convex lobes whose edges are simple and not produced into teeth at the lateral angles. Antero-lateral margin cut into five teeth; postocular tooth small, separated from the second tooth by a shallow granulated sinus; the third tooth is the broadest, and rounded off at the apex; the fourth is the most salient, and acute; the fifth is very small and acute; all the teeth have crenate or else spinulose margins. The margin of the orbit is minutely crenulate; its upper part is marked by two closed fissures; the external hiatus of the orbit has the form of a triangular notch; the lower margin is produced to form an obtuse tooth at the inner angle. The subhepatic region is granulous, but not provided with a tubercle. The merus of the third pair of maxillipeds is also granulated. The carpus of the chelipeds is rough with small tubercles, grooved along the distal margin of the outer side, and armed internally with a small blunt 
tooth; the hands are robust, inflated, smooth, except near their articulation with the carpus, where scattering granules appear; upper and lower margins rounded; fingers long, down-curved, smooth, canaliculate, their cutting edges irregularly armed with small and rather sharp teeth, without any prominent basal tooth; when closed the fingers are separated by a slight gap, and their tips cross one another; the color of the fingers in alcoholic specimens is very light brown. The chelæe of the right and left sides are unequal in size, but similar in shape. The ambulatory appendages are setose, their merus joints furnished with small teeth along their upper edges. The seventh segment of the sternum in the male is entirely concealed by the base of the abdomen. 'The coxæ of the fifth pair of legs are in contact with the third abdominal segment. The penultimate segment of the abdomen has concave sides, the terminal segment is broad and rounded.

Length of carapace, $6.5 \mathrm{~mm}$; breadth of carapace, $10.25 \mathrm{~mm}$.

Station 3397. 85 fathoms. 1 male.

In this species the carapace is short, the posterior margin wider than usual in the genus. In its general aspect it recalls $P$. xanthiformis A. M. Edw.; the meri of the ambulatory legs are denticulated on their upper margins as in xanthiformis, but in latus the carapace is much broader and more convex in an antero-posterior sense, the front is less prominent and is destitute of lobes at the lateral angles; the carpal tooth is blunt, etc.

\section{Panopeus tanneri FAX.}

Plate III., Fig. 4, $4^{\text {a }}$.

Micropanope polila RatuB., Proc. U. S. Nat. Mus., XVI. 239, 1893.

Panopeus tunneri Fax., Bull. Mus. Comp. Zoöl., XXIV. 15t, 1893.

Carapace moderately convex both lengthwise and transversely, smooth and polished in the central and hinder parts, coarsely granular on the anterior gastric and hepatic regions. The gastric and hepatic areas are well marked off by depressions. Front nearly straight, divided by a median triangular fissure, and projecting as a blunt tooth at ench lateral angle; a double edge is formed by a groove which runs along the front, the lower edge projecting further forward than the upper edge; both upper and lower edges are finely granulate. The antero-lateral margins of the carapace are cut into triangular teeth; the first and second of these teeth are small, coalesced, connected by a shallow sinus; the third and fourth are of about an 
equal size; the fifth is much smaller; all the teeth are granulous on their anterior border, smooth on their posterior border; the depressions between the third and fourth and the fourth and fifth tecth are continued in as furrows for some distance on the carapace, finally uniting and meeting the cervical furrow. The upper margin of the orbit forms a tooth at the inner angle above and outside of the external marginal tooth of the front; there is a closed fissure near the middle of the superior orbital border; the external fissure is a triangular notch; a blunt tooth at the inner angle of the lower margin. There is no subhepatic tubercle. A transverse row of tubercles on the front of the eye-stalk (when viewed retracted within the orbit) just inside the eye. Chelipeds unsymmetrical; carpus squamoso-rugose, with a slight transverse groove, and armed with a prominent but not very sharp internal tooth; propodus stout, superior border rounded and squamoso-tuberculate, outer surface smooth; fingers of larger chela gaping, movable finger armed with a large blunt tooth at base; fingers of smaller chela slenderer, without prominent teeth; fingers of both hands black, hooked at extremities, tips crossing. Upper edge of merus of ambulatory appendages lightly denticulated, excepting the posterior pair. Base of abdomen entirely covers the sternal segments; penultimate segment of abdomen short, posterior angles prolonged backward; last segment short, pentagonal. In young specimens the granules of the carpus and propodus are more numerous and sharperpointed.

Length of carapace, $6.25 \mathrm{~mm}$; breadth, $10 \mathrm{~mm}$.

Station 3105 . 53 fathoms. 5 males ( 3 adults, 2 young). “ $3368.66 \quad$ 6 1 male.

The name Micropanope polita was published a short time before Panopeus tameri, but if this species is referred to the genus Panopers, the specific name politus cannot be used, since it was applied to a different species by Professor S. I. Smith in 1869. The genus Micropanope has not been clearly defined either by Stimpson or A. Milne Edwards. The type of the genus, Micropanope sculptipes Stimps. (= M. pugilutor A. M. Edw.), does not seem to belong to the same assemblage of species as Panopeus tameri, which differs from the typical species of Panopeus merely by the granulation of the carapace and the serration of the meri of some of the ambulatory appendages. These peculiarities do not, in my opinion, justify the separation of $P$.tamer from the genus Panopeus. 
OZIUS MI. EDW.

Hist. Nat. Crust, I. 404, 1834.

\section{Ozius verreauxii Sauss.}

Rev. et Mag. Zool., $2^{\circ}$ Sér., V. 359, Plate XII. Fig. 1, 1853.

One female, from Charles Island, Galapagos, April 1. This species was found at James Island, Galapagos, and also at Panama during the voyage of the "Hassler" from Boston to San Francisco in 1872. It has been recorded from Mazatlan, Mex., and Lower California.

MENIPPE DE HAAN.

Sıebold's Fauna Japonica, Crustacea, p. 21, 1833.

Menippe frontalis A. M. EDw.

Crustacés de la Région Miex, p. 261, Plate XLVIII. Fig. 2, 1879.

One male, collected at low tide on the reef outside Panama. Menippe frontalis has been previously recorded from Panama and the coast of Equador.

HETERACT届A LochingtoN.

Proc. Cal. Acad. Sci., VII. 97, 1877.

Heteractæa lunata (M. EDw, et Luc.).

Pilumnus lunatus M. EDw. et Luc, D’Orbigny's Voy. dans l'Amér. Mérid., Crust., p. 20, Plate IX. Fig. 2, 1843.

Heteractea lunata Kivgst., Proc. Acad. Nat. Sci. Plilad., 1879, p. 396, 1880; A. M. EDw., Crustacés de la Région Mex., p. 301, Plate LII. Fig. 2, 1880.

One specimen (male) from Panama. Previously recorded from the coast of Chile, the west coast of Central America, Cape St. Lucas, and the Gulf of California. There are specimens in the Museum of Comparative Zooblogy brought by the "Hassler" Expedition from Panama and San Diego, Cal.

PILUMNUS LEACH.

Trans. Linu. Soc. London, XI. 309, 321, 1815.

Pilumnus limosus Sмrтн.

Proc. Boston Soc. Nat. Hist., XII. 2S5, 1 S69.

One male from Panama. 


\section{FAMILY TRAPEZIID Æ.}

TRAPEZIA LATR.

Fam. Nat., p. 269, 1825 [Trapézie]; Eucycl. Méth., Hist. Nat., X. 695, 1825 [Trapezia].

Trapezia cymodoce (Herist)?

Pancer cymodoce Herbst, Naturgeschichte der Krabben und Krebse, III., Heft 2, p. 22, Plate LI. Fig. 5, 1801 (cf. Gerstacker, Arch. Naturgesch. XXII., 1, pp. 125, 126, 1856).

? Trapezia cymodoce Latr., Encycl. Métl., Hist. Nat., X. 695, 1825.

One female from Acapulco, Mex., April 18. It agrees with specimens from Panama doubtfully referred to $T$. cymodoce by Smith.* The epibranchial lateral spines are in a transverse line with the middle of the carapace, while in Herbst's type of $T$. cymodoce, according to Gerstrecker, they lie far behind the middle. Otherwise the specimen agrees pretty closely with Gerstacker's description of Herbst's type. It is the same as, or closely related to, Trapezia coemlea Rüppell, and T. miniata Jacquinot. There are specimens belonging to the same species in the Museum of Comparative Zooblogy collected by A. Agassiz at Acapulco in 1860, and at the Isles of Pearls, Panama Bay, in 1875. There is also in this Museum one of the specimens collected by the Wilkes Exploring Expedition at the Sandwich Islands, and referred to $T$. cymodoce by Dana. It agrees well with the Acapulco and Panama specimens.

Miers, $f$ influenced by Herbst's figure, assigns $T$. cymodoce to the group of species with the hand subcristate above, and hairy on the outer surface, a conclusion contradicted by Herbst's and Gerstacker's descriptions. The latter writer has shown that Herbst's figure is very incorrect.

\section{FAMILY PORTUNID E.}

AREN无US DANA.

Amer. Journ. Sci. and Arts, 2d Ser., XII. 130, 1851.

\section{Arenæus mexicanus (Gerst.).}

Euctenota mexicana Gerst., Arch. Naturgesch., XXII., 1, p. 131, Plate V. Figs. 3, 4, 1856.

Arencus bidens Smitr, Ann. Rep., Peabody Acad. Sci. for 1869 and 1870, p. 90, 1871.

Neptunus mexicanus A. M. EDw., Crustacés de la Région Mex., p. 212, Plate XLII. Fig. 3, 1879.

Three males, Cocos Island, Feb. 28. Previously known from the west coast of Mexico and Nicaragua.

* Proc. Boston Soc. Nat. Hist., XII. 287, 1869.

† Aum. Mag. Nat. Hist, 5th Series, II. 409, 1878, Rep. Challenger Brachyura, p. 165, 1886. 
ACHELOUS DE HAAY.

Siebold's Fauna Japonica, Crustacea, p. S, 1833.

\section{Achelous spinimanus (Lstro).}

Portunus spinimanus Latr. Nouv. Dict. d'Hist. Nat., 20 éd., XXVIU. 47, 1819.

Portunus (dchelous) spinimanus DE Hass, Fauna Japowica, Crustacea, p. 8, 1833.

Station 3368. 66 fathoms. 2 males.

These specimens differ from the typical form in having a shorter arm and hand, a longer spine on the inner side of the carpus; in having a short spine at the distal end of the superior border of the propodus and two small spines at the distal end of the merus of the last pair of legs. Of these two spines the larger is on the posterior lateral angle of the segment, the smaller one just above it. The carpal spine reaches half way to the extremity of the spine on the upper margin of the propodus when the hand is flexed. The length of the carapace is $44.5 \mathrm{~mm}$; breadth, $69.5 \mathrm{~mm}$; length of merus, $33 \mathrm{~mm}$.; length of chela, $47 \mathrm{~mm}$.; breadth, $15 \mathrm{~mm}$.; length of dactylus, 25 mm. length of carpal spine, measured from the anterior border of the carpus, $10.5 \mathrm{~mm}$.

If these differences prove to be constant in specimens from this region the form may be called Achelous breimanus.

Achelous spinimanus inbabits the Atlantic coast of America from Cape Hatteras to Rio de Janeiro, Brazil. It has also been recorded from the coast of Chile.

Achelous affinis FAx.

Plate IV., Fin. 1, $1^{n}, 1^{b}$.

Bull. Mus. Comp. Zoöl., XXIV. 155, 1893.

Carapace moderately convex both longitudinally and transversely, the frontal region depressed and horizontal; surface rugose, granular, and pubescent. Front not prominent, composed of four blunt teeth, not counting the internal angle of the orbit; the two teeth near the median line are equilaterally triangular, separated from one another by a triangular notch; the next teeth on the onter side are separated from those within by a shallow sinus, and fall off abruptly on the outer side into the deep notch which separntes the front from the inner orbital angle. The two middle teeth of the front are a trifle longer than the lateral teeth. 
The tooth formed by the projecting inner orbital angle does not attain the level of the frontal teeth, and it is double, the orbital margin just outside of it being slightly folded, raised, and projected forward so as to form a secondary tooth similar to that in $A$. spimimamis, but not so well-marked. The antero-lateral margin of the carapace is nine-toothed, including the tooth at the outer orbital angle; the posterior tooth is hardly larger than those in front of it; the posterior margin of these teeth is convex. The anterior edge of the merus of the chelipeds is armed with five spines. The carpus has an internal and a smaller external spine. There is a spine on the propodus at the base at the point of articulation with the carpus, and another on the upper margin a little distance back of the articulation with the dactylus. The distal edge of the fifth pair of legs is spinulose.

Length, $25 \mathrm{~mm}$. ; breadth, $39 \mathrm{~mm}$.; length of merus of cheliped, $24 \mathrm{~mm}$; length of propodus, including digit, $33 \mathrm{~mm}$.; length of internal carpal spine. measured from distal margin of carpus, $3.3 \mathrm{~mm}$.

Station 3379. 52 fathoms. 5 males, 4 fem.

$$
\text { "3390. } 56 \quad \text { " } 1 \text { male. }
$$

A large number were also taken in the tow-net on the surface at the following stations:-

Off Mala Point, Hydr. 2627, 3355, 3371, 3382, 3386, 3398, and 50 miles south of Guaymas.

The specimens taken at the surface are small, and much darker in color than those that came up in the trawl, but they show no structural differences. I take them to be the same species in the pelagic stage of its existence.

This species is related to Achelous depressifrons Stimps., from the Atlantic side of the Continent. Compared with $A$. depressifrons it is broader, and the curve formed by the front and the antero-lateral margin of the carapace forms an arc with a longer rudius; the lateral lobe of the front is broader; the tooth of the inner orbital angle is double, as above described; the teeth of the antero-lateral margin have broader bases, and the anterior one at the outer orbital angle is not so prominent; the protuberances on the cardiac and branchial areas are less prominent; the internal carpal spine is shorter, and the distal margin of the merus of the fifth pair of legs is denticulate behind the articulation of the carpus. 


\section{FAMILY CORYSTID E.}

\section{TRACHYCARCINUS FAX.}

Bull. Mus. Comp. Zoöl., XXIV, 156, 1593.

Carapace pentagonal, moderately convex, lateral margins long, nearly straight, toothed. Front narrow, produced, three-toothed. Orbits large, with forward aspect, imperfect, with two hiatuses above, one below, and one at the inner angle; lower wall formed chiefly by the carapace. Anterior margin of buccal cavity not distinctly defined, epistome short, ridges of the endostome developed. Sternum long and rather narrow. Abdomen of male narrow and five-jointed, the third, fourth, and fifth segments consolidated. Eye-stalks very small, retractile within the orbits. Antennules longitudinally folded. The antennx lie in the inner hiatus of the orbit; their basal segrnent is but slightly enlarged, not filling the hiatus at the inner angle of the orbit nor attaining to the front, subcylindrical, unarmed, imperfectly fused with the carapace; the second segment is longer and slenderer than the first, the third segment about equal to the second in length, but slenderer; all these segments are furnished with long and coarse setæ; the whole antenna is less than one half as long as the carnpace. The ischium of the outer maxillipeds is produced at its antero-internal angle; the merus of the same appendages is rounded at the antero-external angle, obliquely truncated but not emarginated at the antero-internal angle, where it articulates with the following segment. Legs of moderate length. Right and left chelipeds very unequally developed in the male. Dactyli of ambulatory legs styliform, straight, slender, longer than the penultimate segments.

The pentagonal shape of the carapace recalls the genus Telmessus White. But in Telmessus the front is divided by a median notch, the orbit is much more complete, the basal segment of the antenna sending off an external process that completely fills the hiatus at the inner angle of the orbit. Although Trachycarcinus bears but little resemblance superficially to Trichopeltarion A. M. Edw.* on account of the very different shape of the carapace, it is in reality closely related to the latter genus as is shown by the close resemblance between them as regards the orbits and antenna, the merus of the outer maxillipeds, the form of the chelipeds, etc.

The Corystoid crabs form a heterogeneous assemblage of rather primi-

* Bull. Mus. Comp. Zoöl., VIII. 19, Plate II., 1850. 
tive forms which show distinct affinities with the Maioids, Cancroids, and Portunidie.

\section{Trachycarcinus corallinus FAx.}

\section{Plate A.}

Bull. Nus. Comp. Zoöl., XXIV. 156, 1893.

The carapace is of an irregularly pentagonal shape, the antero-lateral borders being about twice the length of the postero-lateral; the general surface is densely clothed with a dark brown coat which under a lens is seen to be made of a multitude of close-set club-shaped setæ; when this covering is scraped off the shell appears smooth and white underneath. The various regions of the carapace are well marked out by intervening furrows, and from the more prominent parts of each region there arise groups of flattened turbercles of ivory whiteness which stand out in striking contrast to the sombre brown of the general surface of the carapace. These tubercles are arranged in groups or bunches, the principal of which are placed as follows: two anterior lateral and one posterior median on the gastric region; four disposed in two pairs on the cardiac region; five or six on each branchial region; and one, of a crescentic shape, on each hepatic region. Each group of tubercles resembles the crown of a complex molar tooth whose cusps have been worn down to a common level. The front is produced into three acute teeth, the median twice as long as the lateral. The walls of the orbit exhibit four teeth separated by deep hiatuses; these teeth are a proocular, supraocular, postocular, and subocular; the præocular tooth is compressed and blunt, its anterior edge denticulate. Behind the postocular spine the antero-lateral border of the carapace displays three prominent teeth, increasing in length successively from before backward; there is, too, a minute tooth just back of the largest, posterior lateral tooth. The posterior margin of the carapace is provided with small teeth and is concave at the middle part. The eye-stalks are very slender, far from filling the orbits. The eyes themselves are not larger than the extremity of the eye-stalk; they have an imperfectly faceted cornea, but show no trace of pigment. The basal segment of the antenna is small and cylindrical; it does not quite reach to the margin of the front, and is not firmly soldered to the carapace; the other two segments of the peduncle are longer and slenderer than the basal segment; the end of the peduncle does not quite reach to the extremity of the rostrum; all of the segments of the peduncle are furnished with long setr, while the 
flagellum (which is about as long as the two distal segments of the peduncle taken together, and composed of about fifteen segments) is nearly naked. The chelipeds are very unequal in size on the two sides of the body in the male sex. In four specimens the right is the larger, in two the left. In adalt specimens the large claw is naked, smooth, and ivory-white, like the tubercles of the carapace; the merus has a few small teeth along its upper margin, most of them near the two ends of the segment, and there are also a few still smaller teeth along the postero-inferior margin; the carpus is inflated, its upper margin armed with one strong tooth and denticulated alongr its whole length; the propodus is short and somewhat swollen, the finger bent down at an obtuse angle with the lower border of the palm; there are in most specimens two or three small tubercles or teeth on the superior margin of the propodus, besides a tubercular process at the articulation of the carpus; the dactylus is strong, down-curved, and furnished with small tubercles on its upper border; both fingers are armed with large blunt teeth on their opposed edges. The smaller chela is furnished with setx; it is slenderer than the large claw, and has proportionally longer fingers; it is also sparsely granulated. In the female both chelipeds are of approximately equal size, and they resemble, both in size and shape, the smaller cheliped of the male.

The ambulatory appendages are unarmed and clothed with coarse setæ, which are most thickly set upon the dactyli. The dactyli are considerably longer than the propodi, nearly cylindrical, very straight, and tipped with a small, acute, horny nail.

Dimensions of largest specimen (male): length of carapace, $26 \mathrm{~mm}$.; breadth of carapace, $27 \mathrm{~mm}$.; length of larger cheliped, $50 \mathrm{~mm}$.; propodus, $20 \mathrm{~mm}$.; breadth of propodus, $10.5 \mathrm{~mm}$; length of smaller cheliped, $24 \mathrm{~mm}$.; propodus, $9 \mathrm{~mm}$.; breadth of propodus, $4 \mathrm{~mm}$.; length of first ambulatory leg, $35 \mathrm{~mm}$.

The carapace of the smallest ovigerous female measures $22 \times 23 \mathrm{~mm}$.

The eggs are spherical and large for the size of the animal; they vary in size from one and a third to one and a half millimeters in diameter. About one hundred are linid by one female.

The depth at which this animal lives is very great for a Brachyuran. I believe that the only. species previously known that normally live below the 500 fathom line are certain species of Ethusa and Ethusina, and Geryon quinquedens Smith. 
The peculiar form and arrangement of the white tubercles on the carapace give to this animal the aspect of a piece of stone coral.

Station 3353. 695 fathoms. 1 female.

" $3356.546 \quad$ " 5 males, 4 fem. (2 ovig.).

"6 3418. 660 "6 1 male.

Family GECARCINID E.

GECARCINUS LEACr.

Trans. Limn. Soc. London, XI. 309, 322, 1815.

Gecarcinus malpilensis $\mathrm{F}_{\Delta \mathrm{x}}$.

Plate IV., Fig. 2, 2', $2^{b}$.

Bull. Mus. Comp. Zoöl., XXIV. 157, 1893.

Carapace very broad and convex anteriorly, flattened and narrowed posteriorly; surface microscopically granulated; antero-lateral margin rounded, not denticulated; the median gastric furrow is well marked; the furrow separating the gastric from the branchial regions does not extend forward far enough to separate the gastric from the hepatic area; the so-called genital area is separated by a pronounced groove from the branchial and cardiac regions, but not from the gastric; there is a deep indentation at the anterior extremity of the lateral genital furrows; the furrows bounding the cardiac region on either side are moderately developed. Front deflexed at a right angle to the axis of the body, deep, concave above the margin, margin not reflexed, granulated. The merus of the outer maxillipeds is five-sided, outer side convex, distal slightly notched, antero-internal straight and parallel to the long axis of the body, forming an obtuse angle with the postero-internal margin, which is slightly concave. Merus and carpus of chelipeds devoid of spines or teeth. Dactylus of the ambulatory legs furnished with six rows of spines.

Length, $55 \mathrm{~mm}$. ; breadth, $76 \mathrm{~mm}$. ; width of hind border of carapace, $19 \mathrm{~mm}$. ; width of front, $11 \mathrm{~mm}$.; depth of front, $7 \mathrm{~mm}$.

Milpe'o Island, March 5. 1 male.

This species is very distinct from any previously described. Compared with the previously known species from the Pacific coast, it is nearest to G. quadratus Sauss, but the outline of the carapace is very different, being 
similar to $G$. miricola, from the eastern coast. Moreover, the front is narrower, deeper, and bent down at a sharper angle than in $G$. quadratus, and the merus of the outer maxillipeds is very different in shape from that of $G$. quadratus or any other known species.

\section{Family OCYPODIDE.}

GELASIMUS LATR.

Nouv. Dict. d' Hist. Nat., $2^{e}$ éd., XI. 517, 1817.

\section{Gelasimus sp.}

A male specimen of a species of Gelasimus was collected on Chatham Island, Galapagos. It agrees with the figure of Gelasimus macrocluctylus M. Edw. et Luc., ${ }^{*}$ except in the proportions of the carapace, which is broader $(13 \times 19 \mathrm{~mm}$. $)$ in the Galapagos specimen.

\section{FAnILY GRAPSID E。}

PLANES Bowdich.

Excursions in Madeira and Porto Santo, p. 15, Fig. $2^{a}, 2^{b}, 1825$.

Planes, a MS. name of Dr. Leach's, was first published in T. Edward Bowdich's "Excursions in Madeira and Porto Santo, during the Autumn of 1823," London, 1825. In this work Bowdich figured and assigned to this genus the Cancer mimutus of Linné, under the name of Planes clypeatus. The name Planes was afterwards adopted by Bell, White, and Dana, and more recently by Miers $f$ and Haswell. $\neq$ But most recent authors have rejected Planes in favor of the later Nutilograpsus of Milne Edwards, $\$$ on account of the insufficiency of Bowdich's description. Accepting the judicious ruling of the American Ornithologists' Union committee on nomenclature $\|$ - that a recognizable published figure affords a valid basis for a generic name - I retain Leach's name for this genus; for Bowdich's figures, though rudely executed, are unmistakable.

\footnotetext{
* D’Orbigny's Voy. dans l’Amér. Mérid., Crust., p. 27, Plate XI. Fig. 3, 184.3.

+ Cat. Stalk- and Sessile-eyed Crust. New Zealand, p. 39, 1876.

‡ Cat. Australian Stalk- and Sessile-eyed Crust., p, 99, 1952.

$\S$ Hist. Nat. Crust.o, II. 89, 1537.

If The Code of Nomenclature and Check-List of North American Birds, adopted by the American Ornithologists' Union; being the Report, of the Committee of the Union on Classification and Nomenclature. New York, 1856. Canou XLII., p. 52.
} 


\section{Planes minutus (LinN.).}

Cancer minutus Lins., Syst. Nat., ed. 10, I. 625, 1758.

Planes minutus Whте, List Crust. Brit. Mus, p. 42, 1847.

Station 2628. 1 fem.

"3413. 2 males, 2 fem. ovig

Off Acapulco, Mex. 1 male.

No local.

2 males, 1 fem. ovig.

All of these specimens were taken from Green Turtles. The carapace of the largest one (a female) measures $23 \times 23 \mathrm{~mm}$.

GRAPSUS LaMARCK.

Système des Animaux sans Vertèbres, p. 150, 1801.

Grapsus grapsus (LiNNo).

Cancer grapsus Linv., Syst. Nat., ed. 10, I. 630, 1758.

Grapsus grapsus Ives, Proc. Acad. Nat. Sci. Phila., 1891, p. 190.

Indefatigable and Chatham Islands, Galapagos, 3 males, 3 fem. (1 ovig.). There are also specimens in this Museum from Charles Island in the same archipelago, collected during the voyage of the "Hassler."

Compared with the typical form from Florida, the Galapagos specimens have a higher and absolutely perpendicular front, the frontal lobes projecting even further forward than in specimens from Acapulco labelled "Grapsus altifrons" by Dr. Stimpson. "The spots upon the carapace and legs are fewer and more definitely circumscribed than in Florida specimens, and the outer face of the caipus and hand of the chelipeds is uniform red. 'The ambulatory legs are more robust. Carapace of a male, $63 \times 69 \mathrm{~mm}$.

\section{FANiLy PINNOTHERID de.}

PINNIXA White.

Aun. Mag. Nat. Hist, 1st Series, XVIII. 177, 1846.

\section{Pinnixa panamensis FAx.}

Plate V., Fig. 1, $1^{c}, 1^{b}$.

Bull. MIus. Comp. Zoöl., XXIV. 158, 1893.

Male. - Carapace short and very broad, smooth and punctate for the most part, granulated at the sides. The lateral angles form a prominent 
shoulder, back of which the carapace diminishes abruptly in width. A transverse depression involves the hind part of the gastric and the fore part of the cardiac regions. This depression is bounded behind by a ridge which extends across the carapace between the bases of the last pair of thoracic appendages. Back of this ridge the carapace is deflected at an angle of about forty-five degrees. Front depressed, divided by a median notch into two not prominent lobes; margin setose. The chelipeds are small, with very stout carpus and hand, destitute of spines, but furnished with some setre along their edges; carpus squamose on the anterior and superior parts of the outer side; propodus not broader than the carpus, laterally compressed; a row of tubercles along the superior border forms a sort of crest; a longitudinal row of setiferous squamoid tubercles runs lengthwise of the hand from the proximal end, stopping short of the base of the inmobile finger; the surface between this and the dorsal crest is thickly beset with tubercles, but below it the surface is almost smooth down to a row of tubercles which runs along the inferior margin; immovable finger straight, the dactylus closing against it throughout its length; dactylus furnisherd with long setæo on the upper margin; no prominent teeth or tubercles on the cutting edge of either finger. First and second ambulatory limbs of moderate length, nearly naked, with slender and straight dactyli; last three segments tuberculate on superior margin. Third pair very much enlarged; the merus has a convex anterior border, and is pubescent on the anterior third of the upper surface; posterior margin double, spinulose. Fourth ambulatory legs very small, not renching beyond the distal end of the merus of the third pair; upper surface smooth. Dactyli of penultimate and last pairs of legs short, acute, set at angle with the propodi so as to form prehensile hooks. End joint of abdomen broader than the preceding joint, semicircular. The dactylus of the outer maxillipeds articulates with the propodus near the distal end of the latter. The carapace is $5 \mathrm{~mm}$. long by $10 \mathrm{~mm}$. broad.

The female is larger than the male, the carapace is more highly polished, the transverse depression not so pronounced, and the appendages are more thickly. clothed with setre. Length of carapace, $6.3 \mathrm{~mm}$; ; breadth, $13 \mathrm{~mm}$.

Panama, March 12. 4 males, 6 fem. ovig. 


\section{FAMILY CALAPPID无.}

PLATYMERA II. END.

Hist. Nat. Crust, II. 107, 1837.

\section{Platymera gaudichaudii M. EDw.}

IIist. Nat. Crust., II. 109, 1837.

Station 3387. 127 fathoms. 2 males.

Both specimens are adult, the larger measuring $58.5 \times 105 \mathrm{~mm}$. (including the lateral spines). The more prominent parts of the carapace rise into small tubercles here and there, to the number of about twenty-five. The position of some of these tubercles appears to be indicated by reddish spots in Milne Edwards and Lucas's figure of this species.* In the "Albatross" specimens the teeth of the antero-lateral margin are sharper and smaller than in the figure, the meri of the ambulatory appendages narrower, and the dactyli are not expanded near their tips.

Plutymera gaudichoudii has hitherto been known as a Chilean species.

Through the kindness of Miss Rathbun I have had an opportunity to examine specimens of Platymera culifomicnsis, $\uparrow$ recently described by her. They are identical with the specimens which I have referred to $P$. gandichaudii. I do not think that the very slight discrepancies between these specimens and the figures in D'Orbigny's Atlas warrant their separation, especially as neither Miss Rathbun nor I have had specimens from Chile for comparison. The differences between our specimens and the figures might well arise from a slight inaccuracy of the draughtsman. The types of $P$. califomiensis were dredged off the coast of California, lat. $32^{\circ} 22^{\prime} 30^{\prime \prime} \mathrm{N}$. to $37^{\circ} 43^{\prime} 20^{\prime \prime} \mathrm{N}$., in 26-204 fithoms.

FAMILY MA'TUTID E.

OSACHILA STIMPS.

Bull. Mus, Comp. Zoöl., II. 154, 1570.

Osachila lata FAx.

Plute V., Figs. 2, $2^{a}, \mathscr{2}^{b}$.

Bull. Mis. Comp. Zoöl., XXIV. 159, 1893.

Carapace expanded laterally; length: breadth $=3: 4$; three low obtuse protuberances on the gastric region, one on the cardiac, three or four on the

\footnotetext{
* D'Orbigny's Voy, dans l'Amér. Mérid., Crust., Plate XIII

† Proc. U. S. Nat. Mus., XVI. 253, 1893.
} 
branchial; the surface of all of these protuberances is tuberculate, the tubercles coarsely punctate, the surface between the protuberances smooth and coarsely punctate. Front prominent, bilobed, the lobes separated by a completely closed fissure; frontal margin thick, rounded, with two punctate tubercles; antero-lateral margin of carapace sharp; behind the point where the subhepatic ridge joins this margin it is divided into five obtuse lobes, each of which is denticulate; postero-lateral margin single, tuberculated; posterior margin narrow, concave; two transverse rows of low tubercles on the hinder part of the carapace anterior to the hind margin. Beneath, the subhepatic region and the surface of the outer maxillipeds, sternum and abdomen are tuberculated and heavily pitted, presenting an eroded appearance. Subbranchial area smooth. The merus of the chelipeds is tuberculate along the upper edge and outside of it; carpus tuberculate externally, distal and superior margin produced to a cristiform tooth which continues back upon the carpus the crest of the superior border of the propodus; propodus tuberculate on outer face, the tubercles largest above, superior border forming a slight denticulate crest which is split into three indistinct lobes; lower margin of hand ornamented with a row of low, but rather large tubercles. The edges of the ambulatory limbs are slightly cristate; dactyli pubescent on distal portion. There are traces of transverse red bands on the ambulatory legs.

Length, $24.5 \mathrm{~mm}$., breadth, $32 \mathrm{~mm}$.

Station 3427. 80 fathoms. 1 male.

In this species there is a crescentic depression on the margin of the pterygostomian region in front of the base of the chelipeds, leading into the branchial chamber; this depression is much more strongly marked than in Hepatus or in Osachila tuberasa Stimps. (O. acuta Stimps. and O. stimpsomi Studer I have not seen). The third, fourth, and fifth abdominal segments in the male are fused into one, as in Hepatus and 0 .tuberosa. In the genus Osactita the apex of the merus of the outer maxillipeds is notched or concave, leaving an opening into the excurrent branchial canal when the outer maxillipeds are closely applied to the buccal area. This orifice does not exist in Hepatus or in Actaomorpha Miers, a genus which must be closely allied to Osachita. The second and third segments of the antennæe are present in Osachila, but only as the merest rudinents.

Three species of Osachila have been previously described: O. tuberosa Stimps.* from the Antilles and off Cape Hatteras, 36-164 fathoms; O. acuta 
Stimps.* from Panama and Manzanillo; and O. stimpsomii Studer, $†$ from near Ascension Island, 60 fathoms. The latter species appears to be very similar to, if not the same as, $O$. tuberosa. In the breadth of the carapace O. lata shows a closer approach to Hepatus than the more typical species of Osachile do.

\section{FAMILY DORIPPIDA.}

无THUSA Roux.

Crustacés de la Méditerranée, $4^{\text {ème }}$ Livr., 1830 [Ethusa].

Ethusa ciliatifrons FAx.

Plate V., Fig. 3, $3^{x}, 3^{b}$.

Bull. MLus. Comp. Zoöl., XXIV. 159, 1893.

Carapace broader than long, branchial regions much inflated; surface granulated on the branchial and cardiac regions, pubescent on the gastric region; front and anterior part of the lateral border ornamented with long up-turned cilia. Front between the orbits divided by a triangular median sinus and two slightly shallower lateral sinuses into four triangular teeth of equal length. The orbital sinuses are very deep, and the external orbital angles reach as far forward as the frontal teeth, so that the front margin of the carapace, viewed from above or from below, is cut into six teeth of equal length. The dorsal surface of the carapace is deeply areolated; the branchio-cardiac lines are deeply impressed and meet in the median line in front of the heart, cutting off the depressed cardiac area from the gastric. The gastric region is uneven with pits and furrows. The eyes are small, on very short peduncles, just reaching, when extended, to the posterior angles of the orbital sinuses; the eye is terminal, not wider than the peduncles, and is provided with pigment of a black color. The chelipeds are equal, small, and slender; the chela is smooth and not more robust than the carpus; the fingers are longer than the palm, laterally compressed, curved inward, longitudinally grooved, their prehensile edges straight and regularly denticulated. The ambulatory limbs are very long (the second considerably longer than the first), naked and granulated; the propodus is slightly shorter than the merus, slightly compressed, with a longitudinal groove on each side; the dactylus is one half longer than the propodus, laterally compressed,

* Ann. Lyc. Nat. Hist. N. Y, X. 114, 1871.

† Crustaceen der Gazelle, p. 16, Plate I. Fig. 4: Ablandl. Königl. Akad. Wissensch. zu Berlin, 1882. 
slightly curved, longitudinally grooved and ribbed, the upper edge very sharp. The last two pairs of limbs are of about an equal length, not reaching beyond the distal end of the merus of the second pair of ambulatory appendages, pubescent excepting the nail which tips their dactyli; their propodi are much shorter than the merus and not much longer than the carpus; dactyli very short and strongly curved. The sternum is rather coarsely granulate. Conspicuous red transverse bands adorn the chelipeds and first two pairs of ambulatory appendages; there are two of these bands on the merus, one on the carpus, one on the propodus, and one on the dactylus.

Dimensions of a male: length of carapace, $26.5 \mathrm{~mm}$; breadth of carapace, $29.5 \mathrm{~mm}$.; breadth of anterior margin between external orbital teeth, $12 \mathrm{~mm}$.; length of second ambulatory appendages, $74.5 \mathrm{~mm}$. (merus, $12 \mathrm{~mm}$.; propodus, $15.5 \mathrm{~mm}$.; dictylus, $22 \mathrm{~mm}$.).

Station 3389. 210 fathoms. 5 males, 2 fem.

63 3391. $153 \quad$ " 2 males.

" $3396.259 \quad$ " 251 male.

" $3387.127 \quad$ " 1 male juv.

In young small specimens the carapace is not so broad as in the adult (in fact the length of the carapace may be equal to its breadth), the anterolateral angles do not project so far forward, and the gastric area is not so deeply sunken beneath the level of the branchial regions.

\section{Æthusa lata RAtmB.}

Plate VI., Fig. 1, $1^{a}, 1^{b}$.

Ethusa lata RatinB., Proc. U. S. Nat. MI1s., XVI. 258, 1893.

Ethusa pubescens Fax., Bull. Mus. Comp. Zoöl., XXIV. 160, 1893.

Station 3367. 100 fathoms. 1 female.

After examining the type specimens of $A$. lata Rathb., I am inclined to attribute the slight differences between them and $\mathcal{E}$. mubscens to difference in age, the specimen which I described under the name of $E_{\text {. pubescens being }}$ more than twice the size of the type specimens of $A$. lata. In the male of E. lata the right and left chelipeds are very unequal.

This species was first obtained by the "Albatross" in 1889, in the Gulf of California at a depth of 14-33 fathoms. It is the Pacific representative of A. microphthalma Smith * of the Atlantic side of the continent.

* Proc. U. S. Nat. Mlus., III. 418, 1881; VI. 22, 1853. 
ÆTHUSINA SmTH.

Aun. Rep. U. S. Fish Comm. for 1582, p. 349, 1884 [Ethusina].

ÆÆthusina gracilipes (Mrers).

Ethusa (Ethusina) gracilipes MiEns, Rep. Challenger Brachyura, pp. 332, 333, Plate XXIX., 1886.

Station 3361. 1471 fathoms. 1 fem.

$\begin{array}{rrrcll}\text { " } & 3374 . & 1823 & \text { " } & 3 \text { males, } 2 \text { fem. } \\ \text { " } & 3380 . & 899 & \text { " } & 1 \text { male. } \\ \text { " } & 3398 . & 1573 & \text { " } & 2 \text { males. } \\ \text { " } & 3400 . & 1322 & \text { " } & 1 \text { male, } 2 \text { fem. } \\ \text { " } & 3407 . & 885 & \text { " } & 1 \text { fem. } \\ & 343 . & 1360 & \text { " } & 2 \text { males, } 1 \text { fem, }\end{array}$

In most of these specimens the spine at the antero-external angle of the carapace is long, as in the figure of the typical form of Miers's species, but it is bent outward at a sharper angle, as in Miers's var. robusta. The outer spine of the front is longer in proportion to the inner spine, and the carapace is rather narrower. The legs are shorter (as in var. robusta), while the chela is midway in form between the typical gracilipes and var. robusta.

The "Challenger" specimens were obtained near the Philippines in 700 fathoms, in the Arafura Sea in 800 fathoms, and in the Banda Sea in 1425 fathoms.

\section{Æ出thusina challengeri (MIERs)?}

? Ethusa (Ethusina) challengeri Mrers, Rep. Challenger Brachjura, p. 331, Plate XXVIII. Fig. 2, 1886.**

Station 3414. 2232 fathoms. 1 fem.

I refer this specimen with some doubt to $E$. challengeri. The fingers of the chelw are longer than in that species, the internal distal angle of the ischium of the external maxillipeds is more salient, and the merus more pear-shaped; the front, too, is narrower, the median sinus deeper, and the internal orbital angle less prominent.

I believe that the depth from which this specimen was brought is the greatest at which any Brachyuran has ever been taken. A. abyssicola Smith was dredged by the "Albatross" off the east coast of the United States in 2221 fathoms. Miers's specimen of $A$. challengeri was obtained from 1875 fathoms, in Japanese seas.

* On pp. 329, 332, Miers refers to this species by the name of 2 . sinuatifrons. 


\section{Ethusina smithiana FAx.}

Plate VI., Fig. $\mathscr{2}, \mathscr{2}^{a}$.

Bull. Mus. Comp. Zoöl., XXIV. 160, 1893.

In this species the carapace is a little longer than broad, and is not much narrowed anteriorly. The front is four-toothed, the middle pair of teeth large, triangular, separated from one another by a wide triangular sinus which is broader than the antennular sinus; between these teeth the margin is bent down till it meets the epistome below; the lateral teeth of the front are spiniform, and shorter than the middle teeth. The surface of the carapace is clothed with a short pubescence and is lightly granulous; the branchio-cardiac grooves are well marked. The postocular teeth are spiniform and they project far beyond the extremity of the small eye-stalks. The eyes are smaller than the extremity of their peduncles. The chelipeds are equal, smooth, naked, umarmed; the merus cylindrical, the carpus short and rounded; the fingers about equal in length to the body of the chela, compressed, prehensile edges sharp and not provided with distinct teeth or tubercles. The ambulatory legs are nearly naked, the second pair more than twice the length of the carapace, the dactylus longer than the propodus. The last two pairs of legs terminate in short recurved claws, which are setose on the posterior edge. The sexes do not seem to differ in any marked degree.

Length of carapace (male), $9.3 \mathrm{~mm}$; breadth, $8 \mathrm{~mm}$.

Station 3370. 134 fathoms. 3 fem.

" $3380.899 \quad$ " 8 males.

This species is nearly related to $A$. abyssicola Smith, but its carapace does not so much diminish in width anteriorly, the external frontal spines are less developed, the external orbital spines are much longer, and brought forward so that the orbits face more to the front. From $\mathbb{E}_{\text {. challengeri Miers it differs }}$ in the greater development of the frontal and external orbital spines. 
FAMILY CYMOPOLIIDA.

CYIMOPOLIA ROUX.

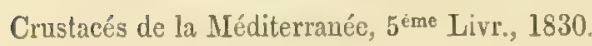

Cymopolia tuberculata FAx.

Plate VI., Fig. 3, 3a.

Bull. Mus, Comp. Zoöl., XXIV. 161, 1893.

Carapace very broad, subpentagonal, branchial regions swollen.. Front four-toothed, the teeth blunt, separated from each other by narrow sinuses which are rounded at the bottom; the two middle teeth are longer than the lateral ones, and the median sinus is deeper than the two lateral. The antero-lateral margin of the carapace is four-toothed, counting the prominent tooth at the external angle of the orbit; the posterior tooth of the series is the smallest. The upper margin of the orbit has three deep fissures defining two triangular teeth; the lower margin of the orbit has two fissures enclosing a broad truncate tooth or lobe; there is also a broad and prominent lobe just below the inner orbital angle; above this lobe is a single tooth at the inner angle. The surface of the carapace is ornamented with granulated tubercles; the parts between the tubercles are more finely granulated, and when viewed under a lens are found to be furnished with fine hairs. The chief tubercles are disposed as follows: one pair on the frontal region behind the margin; four in transverse row on the anterior part of the gastric area, and five on the posterior part of the same area arranged thus, $\because$ (of these the posterior pair is the smallest); four in a transverse line on the cardiac region and one median behind the transverse series; about six on each branchial area; six just anterior to the straight posterior margin of the carapace (three on each side). There are three small tubercles on each eye-stalk near the margin of the cornea. The chelipeds are small, slender, equal; the carpus tuberculate, the fingers as long as the hand proper, curved downward and inward, crossing at the tips, their prehensile edges finely denticulate in small specimens, nearly entire in larger ones. The second and third ambulatory limbs are very long, the second slightly larger than the third; their merus joints are granulated and costate above, and armed with a prominent spine at the anterior distal angle and a smaller one each side at the point of articulation with the carpus; this holds good of 
all three pairs of ambulatory appendages; the carpi are carinate on their anterior margin, with a vestige of a tooth at each end of the carina; the anterior edge of the propodus is also carinate. The ambulatory legs are ornamented with transverse bands of red, three of which cross the merus. The abdomen and sternum are granulated.

Length, $13 \mathrm{~mm}$.; breadth, $18 \mathrm{~mm}$.; length of ambulatory leg of second pair, $34 \mathrm{~mm}$. (merus, $9.3 \mathrm{~mm}$. ; carpus, $5.6 \mathrm{~mm}$; propodus, $9 \mathrm{~mm}$. ; dactylus $7.5 \mathrm{~mm}$.$) .$

Station 3355. 182 fathoms. 4 inales, 1 fem.

Cymopolix zonata Rathb., lately described from the Gulf of California, 40 fathoms, differs from C. tuberculata as follows: the carapace is narrower and more quadrangular. The median lobes of the front are small and inconspicuous, while the lateral lobes are very broad and are separated from the median lobes by a slight, shallow notch. In $C$. tuberculata the four frontal lobes take on the form of prominent, triangular teeth, clearly separated from each other by deep triangular sinuses. The antera-lateral margin of the carapace is three-toothed in $C$. zonata, four-toothed in C. tuberculata. The tubercles near the posterior margin of the carapace are more elongated in the former species than in the latter. The hand of the former is much broader, and is armed with prominent, spiny tubercles. Finally, the meri of the ambulatory legs are much shorter in $C$. zonata, and are armed at the distal end with a blunt, triangular tooth, while in $C$. tuberculata this tooth is transformed into a long, sharp spine, and a pair of smaller spines is present, one on each side of the proximal end of the carpus.

The unique type specimen of Cymopolia dilatata A. M. Edw. $\dagger$ from St. Kitts, 208 fathoms, has not yet been returned to this Museum. Judging from Milne Edwards's short diagnosis, it must be very similar to $C$. tuberculcta, but in the latter the first sternal segment does not bear the transverse crest which is said to be characteristic of $C$. dilatuta. I am therefore led to regard $C$. tuberculato and $C$. dilatato as closely allied representative species on the two sides of the continent.

* Proc. U. S. Nat. Mus., XVI. 259, 1893.

† Bull. Mus. Comp. Zoöl, VIII. 2S, 1850. 


\section{Cymopolia fragilis RAtrB.}

Plate VI., Fig. 4, $4^{a}$.

Proc. U. S. Nat. Mus., XVI. 259, 1893.

Carapace very short and broad, tuberculated, with granules scattered between the tubercles. Front cut into four blunt teeth, the two in the middle prominent, the outer ones short. Superior margin of the orbit cut by two fissures as is the lower margin also; there is a broad prominent lobe just below the internal orbital angle, with two teeth above it at the angle. The antero-lateral margin of the carapace is five-toothed, counting the prominent tooth at the outer angle of the orbit. There are two tubercles on the frontal region, twelve on the gastric, five on the cardiac (four of which are arranged in a transverse row and elongated transversely); eight or nine on each branchial, and a carina more or less broken up into tubercles just in front of the posterior margin of the carapace. The eye-stalks are furnished with two blunt tubercles near the edge of the cornea. The chelipeds are small, slender, equal. The third and fourth pairs of ambulatory limbs are very long, the merus joints with a low tubercular carina on their anterior margin and two longitudinal rows of tubercles on their upper face; the anterior distal angle is rounded off and not produced into a spine or tooth; the anterior edge of the carpi and propodi is sharp, and the upper face of these joints is two-ribbed. The abdomen and stemum are almost smooth. The difference in the shape of the abdomen between this species and the foregoing will be best appreciated by a reference to the figures.

Length, $7 \mathrm{~mm}$.; brealth, $11 \mathrm{~mm}$; length of ambulatory limb of the second pair, $26.5 \mathrm{~mm}$. (merus, $8 \mathrm{~mm}$.; carpus, $4.5 \mathrm{~mm}$.; propodus, $7 \mathrm{~mm}$.; dactylus, $5 \mathrm{~mm}$.).

Station 3369. 52 fathoms. 2 males, 12 fem. ovig. “ $3379.52 \quad$ " $52 \quad 3$ males.

Cymopolia fragilis was first discovered by the "Albatross" expedition of 1889, off Lower California, in 58 and 71 fathoms. 


\section{Fanily LEUCOSIID E.}

EBALTA LEACH.

Malacostr. Podophthal. Brit., Plate XXV., 1816 (?).

\section{Ebalia sp.}

A badly mutilated specimen of an Elalia was obtained at Station 3355 in 182 fathoms, - evidently belonging to an undescribed species. The carapace, as far as can be determined, is subrhomboidal, tuberculated, and thickly covered with round bead-like granules. The front is truncate; the gastric region roof-shaped, falling off on each side of the median line into the deep depression behind the antero-lateral margins. The antero-lateral border is produced into three lobes, one of which is on the hepatic region and two (larger) on the branchial, the postevior one forming the lateral angle of the carapace; there is also a prominent tubercle on the pterygostomian region. The central part of the branchial region is very prominent and obscurely divided into three secondary prominences made up of an agglomeration of larger and smaller sized granules. The posterior margin is bilobed, each lobe being convex above when the animal is viewed from behind. The buccal area is separated from the antennular fosse by a small epistome. The battered condition of the specimen (a male) does not admit of a more detailed description.

Family RANiniDf.

RANINOPS A. MI. EDW.

Bull. Mus. Comp. Zoöl., VIII. 34, 1850.

\section{Raninops fornicata $F_{A x}$.}

Plate VII, Fig. $1,1^{a}, 1^{b}$.

Bull. MIus. Comp. Zoöl., XXIV. 162, 1893.

Carapace very convex from side to side, naked, smooth or nearly so, punctate. Rostrum acute, lightly carinate, the carina extending back for a short distance on the carapace. Superior margin of orbit armed with three acute teeth, the second of which is curved forward; the anterior tooth is separated from the rostrum by a deep rounded sinus, from the second tooth by an angular notch; the second tooth is separated from the third by a 
nearly straight interval; the third tooth lies some distance in front of the posterior end of the orbit. Back of the orbit there is a strong, procurved spine on the margin of the carapace. Eye-stalks compressed, equal in length to one half the width of the carapace. Second joint of the third maxillipeds equal to the third joint, crossed obliquely by a piliferous line; third joint notched at the antero-internal angle. Cheliped: merus unarmed, microscopically spinose above, setose below; carpus minutely rugoso-spinulose, the superior distal angle projecting as a sharp tooth; propodite lightly rugose, upper and lower borders margined, unarmed, palmar edge irregularly and inconspicuously toothed; dactylus without any prominent tooth. The dactylus of the fourth pair of legs has a very convex internal border, the dactylus of the fifth is long, narrow, and spatulate. Abdomen setose, telson obtuse at the end.

Length of carapice, $12 \mathrm{~mm}$; breadth, $8.6 \mathrm{~mm}$.

Station 3369. 52 fathoms. 1 specimen.

A. Nilne Edwards's types of $R$. constricta and $R$. stimpsoni have not yet been returned from Paris. Compared with the descriptions of these species* $R$. fornicata differs from the first in having a shorter ocular peduncle (one half the width of the carapace instead of two thirds) and an unarmed merus joint of the cheliped; from $R$. stimpsoni it may be distinguished by the superior margin of the hand being unarmed.

This genus hardly seems to be satisfactorily separated from Notopus De Haan, $\dagger$ a genus to which three species have been assigned, viz., $N$. dorsipes (Fabr.), $+N$. atlanticus Studer, $\S$ and $N$. outilis Henderson. $\|$

\section{FAMILY LiTHODIDE.}

\section{GLYPTOLITHODES, gen. ㄲov.}

Cephalo-thorax subtriangular, anterior part only one half as wide as the posterior; gastric region of the carapace elevated, forming a high conical prominence; a prominent, crescentic, rounded ridge on each branchial area, enclosing the cardiac area in a deep fossa; upper portion of the rostrum straight, conical, subacute, much longer than the lower part, which has the

\footnotetext{
* Bull. Mus. Comp. Zoöl., VIII. 35, 1850.

† Fauna Japonica, Crustacea, p. 138, 1841.

+ De Haan, Fauna Jap, Crust, p. 139, Plate XXXV. Fig. 5, Plate J, 1841.

\$ Crustaceen der Gazelle, p. 17, Plate I. Fig. 5: Abliandl. Königl. Akad. Wissensch. zu Berlin, 1882.

|| Rep. Challenger Anomura, p. 31, Plate II. Fig. 6, 1885
} 
form of a laterally-compressed tooth projecting downward and forward between the bases of the eye-stalks. Antennal scales armed with a few blunt spines on each margin. Abdomen with three longitudinal rows of calcareous plates. Internal or superior margin of carpus of chelipeds produced to a dentate crest. Ambulatory legs short, flattened, spineless, with margins produced into dentated and crenated crests.

This genus is established to receive the species provisionally referred to the genus Rhinolithodes Brandt in my preliminary report on the Crustacen of the "Albatross" Expedition of 1891." Since the present memoir was sent to the press I have received from the United States National Museum, through the kindness of Mr. J. E. Benedict, a pair of Rhinolithodes wosnessenskii Brandt, the type of the genus Rhinolithodes. It is clear that the species described by me is generically distinct from Brandt's species. In Rhinolithodes the legs are of moderate length, their secrments subcylindrical and heavily armed with spines: in Glyptolithodes these appendages are very short (the meri projecting but little beyond the sides of the carapace), flattened, destitute of spines, their anterior and posterior edges produced so as to form prominent crests which on some of the segments are entire, on others crenate or dentate. In Rhinolithodes the upper part of the rostrum forms a rounded tubercle shorter than the lower uncinate process: in Glyptolithodes the upper part of the rostrum forms a conical subacute tooth, far surpassing the inferior process. 'The cardiac area in Rhinolithodes is elevated and spherical: in Glyptolithodes this area lies at the bottom of a deep fossa bounded by the raised portions of the branchial areas. On the whole, the relations between Rhinolithodes and Glyptolithodes are less close than those which exist between the former genus and Plyyllolithodes.

\title{
Glyptolithodes cristatipes FAx.
}

\author{
Plate VII., Fig. 2, 2a, $2^{b}, 2^{c}$. \\ Rhinolilhodes cristatipes FAX., Bull. MIus. Comp. Zoöl., XXIV. 163, 1893
}

The carapace is subtriangular in outline, its surface devoid of setre but covered with low squamiform tubercles; the whole gastric area is raised into a conical prominence; there is also a prominent crescentic rounded ridge on each branchial region, enclosing the cardine area in a deep fossa open only behind. The rostrum is straight and conical, with a vertical plate projecting

* Bull. Mus. Comp. Zoöl., XXIV. 163, 1893. 
below from the proximal half down between the eye-stalks; this plate is toothed anteriorly but does not reach forward nearly to the tip of the rostrum. The antero-lateral margin of the carapace is five-toothed; the second, third, and fourth of these teeth give rise to long thread-like cilia. There is another tooth at the angle between the postero-lateral and posterior margins; posterior margin straight. The upper surface of the eye-stalk is covered with sinall tubercles, and a blunt spine projects over the cornea. The movable scale of the antenna is spiniform and bears two blunt spinules on the outer side and two smaller ones on the inner. The chelipeds are unequal (the right being the larger); coxa granulated, setose on the lower inside margin; lower margin of the ischium and merus armed with three or four blunt teeth, superior margin of merus toothed, internal distal border setose, external distal border forming a bilobed crest; outer face of carpus flat, naked, squamous, margins cristate, the internal crest expanded and cut into setiferous lobes; propodite tuberculated without, smooth within, toothed and setose on superior margin; immobile finger, as well as the dactylus, excavated within, setose; the larger claw has blunt teeth on the fingers, while the fingers of the smaller claw have nearly straight cutting edges. The ambulatory appendages have cristiform anterior margins from the merus to the propodite inclusive; the crest of the carpus is entire or slightly crenate, but that of the merus is bilobed, of the propodite trilobed; the posterior margins of these appendages are dentate and more or less setose; two setiferous teeth near the proximal end of the upper face of the merus of the hind legs; the dactyli are provided with curved, acute, black tips, and with pencils of hair especially on anterior margins. The abdomen is indurated, with three rows of tuberculated plates; toward the posterior end there is a vestige of two marginal rows of small, imperfectly calcified plates.

Length of carapace, $16.5 \mathrm{~mm}$., breadth $16.5 \mathrm{~mm}$.

Station 3354. 322 fathoms. 1 male

PARALOMIS White.

Proc. Zoölog. Soc. London, XXIV. 134, 1856.

Through the courtesy of Mr. Benedict of the United States National Museum, I have had the privilege to examine a specimen of Lithodes gramulosus Hombr. et Jacq. (U. S. Nat. Mus. No. 12583, Straits of Magellan), the type of the genus Paralomis White. According to Mr. Benedict (in litt.), this 
species is congeneric with Echinocerus cibarius White.* He therefore proposes to treat Paralomis as a synonym of Echinocer'us in a paper soon to be published. The two "Challenger" species referred to Puratomis by Professor Henderson $\dagger$ are, as $M r$. Benedict points out, generically distinct from $P$. granulosa. In the latter the ambulatory appendages are comparatively short (not very much longer than the chelipeds) and are tucked in undementh the body during repose, while in Henderson's species the ambulatory legs are very long (much longer than the chelipeds) and are not capable of folding compactly beneath the body.

After a careful examination of Paralomis granulosa I am disposed to recognize the genus Puralomis as distinct from Echnocerus, and furthermore to assign Eehinocents dionedece of my preliminary report to Paralomis. In Echinocerus as exemplified either in the type species, E. cibarius, or in $E$. forminatus Stimps., the ambulatory legs are about the same length as the chelipeds and fall below the lateral dimension of the carapace; not only do all the legs fold under the body but their segments are so modified that in an attitude of repose all of the opposed surfaces and edges are fitted together with admirable nicety, and the animal is boxed up as effectually as a tortoise in its shell. The dactyle of the left cheliped shuts over the dactyle of the right as in Calappa and, as in that genus, the immobile fingers are shortened and bent down so that their cutting edges are nearly at right angles with the long axis of the chela ; the outer edgre of the left dactyle fits throughout its whole length exactly against a tuberculous ridge along the anterior border of the right hand. The antero-inferior angle of the merus is bevelled off for the reception of the chela when flexed, so that the exposed face of the chela is then on a level with the flat expanse formed by the stemal plastron and the bases of the ambulatory legs. Furthermore, a special process developed on the anterior border of the basal segment of the chelipeds locks the tips of the chelipeds to the sternum when those appendages are folded in. In order that the ambulatory legs when flexed may not project below the level of the sternal plastron, their meral segments are set at an angle with the ischia, whose inferior distal borders are raised into prominent ridges. The propodites and dactyli, when folded, impinge on these ridges, but hardly project beyond them.

* Proc. Zoölog. Soc. London, XVI. 48, 1848.

$\dagger$ Paralomis aculeata Hend., Rep. Challenger Anomura, p. 45, Pl. V. Fig. 1, and P. formosa Hend., op. cit., p. 46, Pl. V. Fig. 2. The two species assigned to Paralomis in my preliminary report, P. aspera and P. longipes (Bull. Mus. Comp. Zoöl., XXIV. 161, 165) belong to the aculeata group, which Mr. Benedict proposes to call Leptolithodes. 
In the genus Paralomis, as typified by $P$. gramulosa and illustrated also by $P$. diomedec, the ambulatory appendages are considerably longer than the chelipeds, and much longer than the carapace is broad; when flexed beneath the thorax, the tips of the dactyli extend over the ischia even to the basal segments; although the legs are folded beneath the body when at rest, there are none of those special modifications of structure resulting in that perfect fitting together and fixity of parts exhibited in the genus Echinocerus, as described above.

The natural position of Paralomis lies between Echinocerus and Leptolithodes.

\section{Paralomis diomedeæ FAX.}

Plate VII., Fig. 3, $3^{a}, 3^{b}$.

Echinocerus diomedece FaX., Bull. Mus. Comp. Zoöl., XXIV. 164, 1893.

Carapace subpentagonal, gastric and branchial regions inflated, the whole surface beset with tubercles which give rise to minute setæ. There is one rather more prominent tubercle in the depression on each side of the gastric area. Rostrum short, three-spined; one of the spines is median and inferior, two are paired near the base above; in one of the two specimens obtained the median spine is toothed below. The antero-lateral margin of the carapace is irregularly toothed. Eye-stallss spinulose above, with one prominent spine projecting forward over the cornea. The movable scale or spine of the antenna is spinulose on each side (four or five spines on each margin). The merus of the cheliped bears a spine on the inner side at the distal end; the carpus is smooth outside, the inner border expanded into a seven-toothed crest setose within, the outer border straight, naked, and keeled; the chelæ are of unequal size (the right being the larger), setose, spiny on the upper edge, fingers spoon-shaped within, setose and somewhat gaping.

Ambulatory appendages: the meri are spinose on their edges; the anterior border of the carpus of the first pair is furnished with a crest whose edge is even and entire; the propodite of the first pair is crested along the proximal half of its anterior border, while the distal half is armed with two or three teeth; the carpus and propodite of the second and third pairs are toothed on the anterior margin, the propodite of the third pair is also toothed on the posterior margin; all the segments are hirsute, especially the dactyli. When the legs are closely folded against the sides of the carapace a wide interval is left between the carpi of the cheliped and first pair of ambulatory 
appendages, bounded by the opposite crests of these semments, and forming a passage for the admission of water to the gills. This orifice is similar to that seen in Echinocerus foraminalus Stimps, but it is not so perfectly formed.

The apex of the abdomen (in the female) is turned to the right (most strongly in the larger specimen); the marginal plates are wanting on the left side; all the abdominal appendages excepting the first are aborted on the right side.

Length, $64 \mathrm{~mm}$.; breadth, $75 \mathrm{~mm}$.; length of cheliped, $73 \mathrm{~mm}$.; length of first ambulatory leg, $92 \mathrm{~mm}$. (merus, $24 \mathrm{~mm}$; carpus, $20.5 \mathrm{~mm}$.; propo. dite, $18 \mathrm{~mm}$.; dactylus, $18.5 \mathrm{~mm}$.).

Station 3384. 458 fathoms. 1 fem.

$$
\text { "3394. } 511 \text { " } 1 \text { " ovig. }
$$

The previously known species of Paralomis comes from the Straits of Magellan.

\title{
LEPTOLITHODES BeNedict MS.
}

As before stated on page 45, a specimen of Puralomis gramulosa in the United States National Museum clearly demonstrates the generic diversity of that species and the two forms assigned to Paralomis by Henderson in his report on the Anomura of the "Challenger" Expedition. In a paper which will be published, before the present memoir, in the serenteenth volume of the Proceedings of the United States National Museum, Mr. J. E. Benedict has established the genus Leptolithodes for the reception of 1 aralomis aculeata Hend. and allied species. To this genus both $P$. aspera and $P$. longipes of my preliminary report belong.

\section{Leptolithodes asper Fax.}

\author{
Plate VIII. \\ Paralomis aspera FAX., Bull. Mus. Comp. Zoöl., XXIV. 164, 1593.
}

Carapace pentagonal, as broad as long; gastric, cardinc, and branchial regions well defined and prominent; the posterior portion of the posterolateral margin is raised into a rounded irregular ridge, and there is a roundish hump on each branchial region in front of the posterior margin of the carapace; whole surface of carapace and abdomen thickly beset with papillæ or tubercles, each one of which is encircled with a crown of stiff setæ. Rostrum short, indistinctly tripartite, multispinose, lower part armed with as 
many as five spines. A sharp dark-tipped spine at the external orbital angle, another at the antero-lateral angle of the carapace, and four or five, irregularly arranged, on the margin of the branchial region.

The dorsal face of the second abdominal segment consists of a single plate, undivided by longitudinal sutures, with a deep depression on each side of the middle. The following segrnents are unsymmetrical on the two sides in the unique type specimen (female), the abdomen being twisted to the right. The lateral margins of these segments are laciniated.

Eye-stalks spinulose above, eyes very black, with downward aspect. Distal segment of antennule mnch longer than the antecedent segment, tuberculous above. Antennæe of moderate length; outer margin of first segment spinulose; second segment spinulose and produced on the outer side to a long spine; movable acicle reaching to the distal end of the peduncle, spinose, the longer spines marginal, one spinule on the lower side and another on tl? upper side near the base; the penultimate and ultimate segments of the peduncle bear small setiferous tubercles. Right cheliped more robust than its fellow, thickly beset with strong. spines. Ambulatory legs of moderate length for this genus, stout, spinose like the chelipeds; their basal segments are well-nigh covered by the overlapping margin of the abdomen (in the female).

Length of carapace, $113 \mathrm{~mm}$.; length of rostrum; $9 \mathrm{~mm}$; breadth of carnpace, $113 \mathrm{~mm}$; length of posterior ambulatory legrs, $255 \mathrm{~mm}$. (merus, $68 \mathrm{~mm}$.; carpus, $39 \mathrm{~mm}$.; propodite, $72 \mathrm{~mm}$; dactylus, $56.5 \mathrm{~mm}$.).

Station 3353. 695 fathoms. 1 fem.

The specimen above described was infested with a huge Peltoguster, $36 \mathrm{~mm}$. in breadth.

\section{Leptolithodes longipes FAx.}

Plate IX.

Paralomis longipes FAX., Bull. Mus. Conıp. Zoül., XXIV. 165, 1893.

Mrale. - Carapace triangular; gastric, cardiac, and branchial regions well definer, protuberant; the most prominent part of the cardiac area attains to a higher level than the branchial areas; whole surface of the carapace thickly covered with blunt tubercles; viewed under a lens each tubercle is seen to be encircled with a ring of short stiff setx; one of the tubercles, situated in front of the centre of the gastric region, is spiniform. Rostrum furnished with three prominent spines, one median and inferior, two lateral and su- 
perior; the latter are not so long as the inferior spine; there is, besides, a spinule on the lower side of the inferior spine, and a still smaller one above, between the roots of the superior pair. There are two pairs of long spines on the anterior margin of the carapace, one at the external orbital angles, the other at the antero-lateral angles of the carapace. There are also three or four prominent spines on the side of each branchial area.

Eye-stalks spinulose above. Basal segrment of the antenna armed with an external spine, the second segment with several spines, the most prominent of which is on the outer side; acicle furnished with five prongs or spines, the largest median, the others lateral; flagellum much longer than the carapace. Cheliped of moderate size (the right one is lost from the only male specimen secured), coxa tuberculate on the lower face, the following segments armed with strong spines, fingers excavated within, slightly gaping, penicillate, cutting edges entire. Ambulatory appendages very long, second and third pairs of about equal length and longer than the first pair; all of them armed, like the chelipeds, with spines; the spines tend toward a regular arrangement in longitudinal rows, and the spaces between the spines are smooth and naked, i. e. nearly free from spinules, tubercles, and setæe.

Second segment of the abdomen composed of a single calcified plate, marked by a deep hollow on ench side of the middle. The other segments of the abdomen are of a leathery, semi-membranaceous consistency, and are made up of five longitudinal rows of plates; viz., one median row, flanked by a row on each side, the latter in turn bounded externally by a marginal series. The whole surface of the abdomen is verrucose.

Length of carapace, including rostrum, $84 \mathrm{~mm}$; greatest breadth of carapace, $78 \mathrm{~mm}$; breadth between the antero-lateral angles of carapace, 34 mm.; length of last ambulatory appendages, $242 \mathrm{~mm}$. (merus, $76 \mathrm{~mm}$., carpus, $36 \mathrm{~mm}$., propodite, $64 \mathrm{~mm}$., dactylus, $47 \mathrm{~mm}$.).

In the female the right chela is larger than the left, and the prehensile edges of the fingers are furnished with blunt teeth. The abdomen is unsymmetrical, the apex turned to the right, the marginal plates absent from the left side; the right side bears but one ovigerous appendage (the first). The abdomen nearly conceals the basal segments of the thoracic legs, which in the male are almost wholly exposed.

Station 3371. 770 fathoms. 1 male, 1 fem. ovig.

The egg measures $2 \mathrm{~mm}$. in diameter.

In this species the abdominal segments posterior to the second are mem- 
branaceous, as in the genus Dermaturus Brandt.* In all essential structural fentures, however, it agrees with the preceding species (Leptolithodes asper) and conforms to the genus Leptolithodes.

A Leptolithodes, in some respects intermediate between $L$. longipes and L. asper, inhabits both the east and west coasts of the North Pacific (British Columbia and Japan). From this species (which is apparently undescribed) both $L$. longipes and $L_{0}$ asper of the tropical Pacific coast of America are probably derived.

\section{LITHODES LATr.}

Gen. Crust., I. 39, 1806.

\section{Lithodes panamensis FAx.}

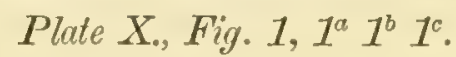

Bull. Mus. Comp. Zoöl., XXIV. 166, 1893.

Carapace subpiriform, of about equal length and breadth; gastric and branchial regions very convex; a deep depression on each side at the anterior limit of the branchial areas, and another between the gastric and cardiac areas. Rostrum cylindrical, terminating in three spines or teeth, one of which is median, the other two lateral; a long horn, slightly upcurved, is given off from the lower side of the proximal end of the rostrum. The whole surface of the carapace is rough with low warty protuberances; the gastric region bears two pairs of spines, the anterior pair separated by a greater interval than the posterior pair. Two small spines on each branchial area and two on the intestinal region. The orbit is bounded externally by a prominent spine, and there are five more spines on the lateral border of the carapace; viz., one at the antero-lateral angle, one on the hepatic region, and three on the branchial. Besides these, there is a rudimentary lateral spine near the anterior limit of the branchial region. The posterior margin of the carapace is tuberculated, not spinose. The third segment of the antennular peduncle is equal to the first segment in length and considerably longer than the second segment. The antennæ are about equal in length to the carapace without the rostrum; the second segment is armed with a long and sharp external spine; there is, moreover, on the antenna of the right side a movable thorn-like acicle equal in length to the last two segments of

* Bull. Phys.-1Iatl. Acad. Impér. Sci. St. Pétersbourg, VIII. 268, 1850. 
the peduncle together; the acicle is armed with a small tooth on the external margin midway between the base and the tip. There is no trace of an acicle on the left antenna in the type specimen, which is the only one obtained. The last segment of the peduncle is nearly twice as long as the penultimate segment. The chelipeds are furnished with scattered tubercles, a few of which assume a spiny character. The left cheliped is rather slenderer than its fellow. The ambulatory legs are long and rather slender, their meri sparsely furnished above with tubercles, which tend to assume a spiny form on the anterior and posterior margins; at the distal end of the anterior margin of the meri there is a prominent spine-like tooth; the carpi and propodites are armed with teeth, as shown in the figure; the dactyli are equipped with four short spines (two superior and two lateral) near the proximal end. The abdominal segments (of the female) are roughened by low tubercles and dentate on their margins. The lateral teeth of the marginal plates of the right side are drawn out into long spines, as shown in Fig. $1^{c}$, Plate X. The tergal plate of the second abdominal segment is completely fused with the epimera, showing no trace of an intervening suture. The marginal (episternal ?) plates of this segment are bounded within by a distinct suture.

Length of carapace, excluding rostrum, $79 \mathrm{~mm}$; rostrum, $14 \mathrm{~mm}$.; breadth of carapace, $79.5 \mathrm{~mm}$; length of posterior pair of ambulatory legs, $193 \mathrm{~mm}$. (inerus, $58.5 \mathrm{~mm}$; carpus, $31 \mathrm{~mm}$., propodite, $54 \mathrm{~mm}$., dactylus, $33 \mathrm{~mm}$.).

Station 3384. 458 fathoms. 1 fem.

Lithodes panamensis finds its nearest relatives in $L$. turritus Ortm., from Japan, and L. murrayi Hend., from Prince Edward Island in the Southern Ocean.

Two more species of Lithodes were obtained, but they are represented by specimens too young to furnish specific characters. One of these immature forms very closely resembles young individuals of Lithodes agassizii Smith, such as are represented on Plate I., Fig. 2, of Bull. Mus. Comp. Zoöl., Vol. X., No. 1, and probably belongs to the same or a closely allied species. It is represented by three individuals (the largest $14 \mathrm{~mm}$. long) from Station 3365, 1010 fathoms, Station 3407, 885 fathoms, and Station 3418, 660

* Ortmann, Zoolog. Jahrb., Abth. f. Syst., VI. 320, Taf. XII. Fig. 26, 1892.

† Henderson, Rep. Clallenger Auomura, p. 43, Plate IV., 1888. 
fathoms. The other species is represented by a single example from Station 3425, 680 fathoms, and is portrayed on Plate X., Fig. 2. The rostrum in this specimen is more than one half as long as the rest of the carapace, and is forked at the tip, as in L. main (Linn.) and L. murrayi Hend. There is a long spine on the lower side of the base of the rostrum, directed forward, and there are two pairs of lateral rostral spines. The second antennal segment is armed with a long spine which bears a short spinule on its outer side near the base. Length of carapace without the rostrum, $17 \mathrm{~mm}$. ; length of rostrum, $9 \mathrm{~mm}$.; breadth of carapace, $16 \mathrm{~mm}$.

\section{Family CeENOBITID E.}

COENOBITA LATR.

Fan. Nat. pp. 276, 277, 1825 [Cénobite]; Ouvier's Règne Animal, $2^{\circ}$ éd., IV. 77, 1829 [Caenobita].

Cœnobita compressus Gứr.

Voyage de "La Coquille," Zool., T. II., Part II., 1're Div., p. 28, 1830.

Indefatigable Island, Galapagos, 1 male in shell of Nerita scabricosta. Acapulco, Mexico, 21 specimens in shells of Nerita, Nassa, Murex, Terebra, Purpura, Nodulus, Cerithium, Natica, etc.

Guérin's types of this widely distributed and variable species came from Payta, Peru. A recent revision of the genus Cocnolita, by E. L. Bouvier, will be found in Bull. de la Soc. Philomath. de Paris, ${ }^{\text {eme }}$ Sér., II. 143-150, 1890, and III. 21, 1891.

\section{Fanily PAGURID \&.}

CANCELLUS M. EDW.

Anı. Sci. Nat., Zool., $2^{\circ}$ Sér., VI. 262, 256, 1836.

Cancellus tanneri Fax.

Plate XI., Fig. 1-1 $1^{d}$.

Bull. Mus. Comp. Zoöl, XXIV, 167, 1893.

The anterior part of the carapace, in front of the cervical suture, is calcified, about as broad as long; the anterior margin is produced to form a rudimentary triangular rostrum between the eye-stalks, and concave on each side of the median line; the antero-lateral angles project forward as far as the rostrum and are broadly rounded; the infero-lateral margin is densely 
pilose. Behind the cervical groove the cardiac area is conspicuous as a calcified plate, rounded behind; on ench side of the anterior part of the cardiac area there is a narrow, distinctly calcified area belonging to the branchial region; aside from this the branchial areas are soft and membranous. The abdomen is very short and obese, convex above in both directions, soft and clothed with a short velvety down, excepting the last three segments, which are calcified; the terminal segment or telson is broader than long, its sides regularly rounded, its hind margin nearly straight. The abdomen as a whole is not quite bilaterally symmetrical, the right side being more swollen than the left, a condition which gives the abdomen a slight twist to the left.

The eye-stalks are slender, cylindrical, slightly curved inward, and somewhat shorter than the anterior section of the carapace; the eyes are small, not broader than the eye-stalk, and of a dark brown hue. The opththalmic scales are triangular; short, acute, and produced to a prominent angle on the external side of the proximal end. 'The antennular peduncle is about one half as long as the eye-stalk; it bears a short flagellum which reaches beyond the eyes by one half of its length. The antemnal scale is short and triangular; it ends in a small distal spine; the external margin is armed with three, the internal margin with two, small spinous teetl..

The chelipeds are short, stout, and symmetrical. As in the other species of this grenus, the upper surface of the propodite and anterior part of the carpus are flattened so as to form, when the right and left chelipeds are brought together, a facet, - the front wall of the operculum which closes the orifice of the cavity in which the animal dwells. The inner margin of each demi-facet is raised into a crest, whose margin is cut into closely approximated quadrangular lobes by perpendicular fissures; the free margin of each lobe, moreover, is irregularly toothed; the whole upper and outer surface of the propodite is more or less rugose. The fingers are short and thick; they meet only at the tips, which are furnished with very large, horny, black nails; the opposed edges of the fingers are armed with coarse teeth; the movable finger is strongly curved and its surface is tuberculose; both fingers are fumished with pencils of long and coarse bristles. The movable finger (dactylus) inoves in a plane oblique to the plane of symmetry of the body. 'The superior face of the anterior part of the carpus, together with the corresponding face of the propodite and dactylus of the second pair of legs, is flattened to form the external part of the operculum. As in the chelipeds, so here the margins of the opercular facet are cut into denticulated lobes; 
they are, furthermore, furnished with numerous light-colored setx. The opercular face between the lobulated margins is granulated. The dactylus is about equal to the propodite in length, and ends in a brown, horny claw. The third pair of appendages is furnished with scattered amber-colored setæ, those on the superior margin arising from tubercles or blunt teeth, which are found on the merus, carpus, propodite, and dactylus. The dactylus of these appendages again is equal in length to the propodite, and is tipped with a horny nail or claw. The coxal segment of the last pair of thoracic appen. dages lias the anterior border convex, but not produced to form a prominent lobe.

The calcified parts of the test are white, spotted with red. On the eyestalks and legs the spots show a tendency to coalesce in transverse bands.

Length of carapace, $7 \mathrm{~mm}$; breadth of carapace, $5 \mathrm{~mm}$; eye-stalk, $3 \mathrm{~mm}$. Station 3368. 66 fathoms. 1 male.

The sole specimen obtained was found within a cavity formed in a piece of dead coral rock.

Three other species of Cancellus have been described, viz., Cancellus canaliculatus (Herbst) ${ }^{*}$ from the Fast Indies, C.typus M. Edw.,t habitat unknown, and C. parfaiti A. M. Edw. et Bouv. + from the Cape Verde Islands. Compared with $C$. canaticulatus, $C$. tameri is distinguished by its much shorter and stouter abdomen, by the lobation of the marginal crests of the chelipeds and second pair of legs, by the pubescence of the thorax and abdomen, and the shortness of the antenns. From C.typus it differs in having the anterior border of the carapace less deeply incised on either side of the rostrum, and the telson squarely truncated posteriorly and not notched in the middle; the coxæ of the last pair of legs, too, present a very different shape in that they lack the prominent anterior lobe observable in. C. typus. C. parfaiti has not been figured. It is said to agree closely with $C$. canaliculatus, save that the margins of the opercular facets of the legs are cut into quadrangular lobes as in C.tameri. Judging from Milne Edwards and Bouvier's diagnosis, it would seem to differ from C. tameri in having longer eyestalks, less pubescence upon thorax and abdomen, and the coxal segments of the posterior legs far more protuberant.

* Cancer canaliculatus Herbst, Naturgeschichte der Krabben und Krebse, Bd. III., Heft IV., p. 22, Plate LX. Fig 6, 1804 .

† Amn. Sci. Nat., Zool., 2e Sér., VI. 286, 287, Plate XIV. Figg. 3, 3a, 1836; Hist. Nat. des Crustacés, II. $243,1837$.

‡ Bull. Soc. Philomath. de Paris, geme Sér., III. 69, 70, 1891. 
In the unique type specimen of $C$. tameri the abdomen is not quite symmetrical, but this may be an individual peculiarity resulting from the shape of the cavity in the stone which formed its abode.

\section{CALCINUS DaNa.}

Proc. Acad. Nat. Sci. Phila,, V. 268, 1851.

Calcinus obscurus STIMPs.

Ann. Lyc. Nat. Hist. N. Y, VII. 83, 1859.

Two specinens, collected at Panama. The larger specimen is in the shell of Nerite scabricosta.

EUPAGURUS Brandt (restr.).

Middendorff's Sibirische Rëise, Bd. II., Th. 1, p. 105, 1851. Restricted by Strmpson, Proc. Acad. Nat. Sci. Pliila. X. 236, 1858.

\section{Eupagurus californiensis BENEDICT.}

Plate XI., Fig. 2-2f.

Proc U. S. Nat. Mus, XV. 2l, 1892.

This species belongs to the E. temuimanus group (subgenus Elassochimis Benedict*), which includes smooth species with broadly oval right hand, very small left hand, and ophthalmic scales usually long, pointed, and concave above. The species belonging to this group in many ways approach the genus Pylopagurus A. M. Edw. et Bouv., $\dagger$ but the right hand is not transformed into the highly specialized operculun of Pylopagurus, and there are no paired sexual appendages on the abdomen in either sex.

Description of a male. - Body and appendages, in general, smooth and free from hairs. Carapace shorter than the abdomen; anterior section longer than the posterior, indurated, smooth, polished, naked, convex from side to side, longer than wide; gastric region bounded on each side by a conspicuous longitudinal furrow; median projection of the front short and acute, produced beyond the lateral projections, which are angular but not acute; a stiff hair springs from each side of the base of the median projection of the front. Fye-stalks rather long, curved slightly outward, somewhat enlarged at the distal end, and furnished with a few small tufts of hair arranged in a longitu-

* Proc. U. S. Nat. Mus., XV. 1, 1892. † Mem. Mus. Comp. Zool, Vol. XIV., No. 3, p. 74, 1893. 
dinal line on the middle of the dorsal side. Ophthalmic scales long, pointed, grooved on the dorsal side. Antennular and antennal peduncles not much longer than the eye-stalk. Second segment of antemna produced on the outer side into an acute process which reaches about one third of the way to the tip of the antemnal acicle; there is also a minute acute tooth at the inner distal angle of this segment of the antenna. The acicle is somewhat shorter than the eye-stalk.

Chelipeds very unequal in size. Right cheliped reaching forward about the same distance as the ambulatory legs. The merus of this appendage reaches but little beyond the eye; it is trigonal, the surface for the most part smooth and naked, the upper margin obtuse and tinarmed, the distal dorsal border armed with three small acute teeth; the lower face of the merus is somewhat hollowed out and the antero-lateral margins on either side of the articulating membrane between this segment and the carpus are cristate and denticulate. The carpus widens from the proximal to the distal end where the width exceeds the length of the segment; its upper surface is convex, naked, rather sparsely ornamented with very minute tubercles visible under a lens, its inner margin armed with about nine coarse blunt teeth (alternately larger and smaller), its outer margin clearly defined by a low, obscurely toothed ridge. 'The hand is very broad, its upper face convex in both directions, and set with minute rounded tubercles which increase in size on the distal part of the segment, especially on the immovable fingrer; the inner border produced into bluntly toothed crest which projects far beyond the corresponding border of the dactylus; the outer margin is defined by a crenate rim; the lower face is beset with low, inconspicuous, granular tubercles. 'The outer margin of the dactylus is cut into rounded teeth, and a conspicuous blunt-toothed ridge runs the length of the upper face; the surface between this ridge and the outer edge is deeply concave; the prehensile edges of both fingers are armed with coarse calcareous teeth.

The left cheliped is very small and slender, reaching only to the distal end of the carpus of the left ambulatory appendages. The merus is laterally compressed; its upper margin is rounded, the lower external margin is spinulose at the distal end, near the articulation with the carpus. The upper side of the carpus is concave and bordered on each side with a row of spines; there is a sharp tooth at the distal end of the external inferior margin. 'The chela is longer than the carpus, with fingers longer than the palm; the dorsal face of the hand is convex, rising into an obscurely tuberculated ridge which 
runs from the carpal articulation to the base of the immovable finger; scattered hairs are found on the chela; they are most numerous near the tips of the fingers.

The ambulatory legs are pretty smooth, with rounded margins. The dactylus of the first pair is equal to the propodite in length, while the dactylus of the second pair exceeds the propodite. The dactyli of both pairs are furnished with stiff setre, most conspicuous along the lower margin; a curved, sharp nail tips the dactyli. At the distal end of the upper margin of the carpi a small, sharp tooth is seen projecting over the proximal part of the propodite.

The fourth pair of legs is sub-chelate, the rasp upon the propodite is formed by a single series of scales. The propodite of the fifth pair of legs is furnished with a tuft of long setxe and a broad rasp whose posterior margin is concave.

'The left side of the abdomen carries three two-branched appendages. The telson is divided by a broad notch into two somewhat unsymmetrical lobes; the posterior margin is spinulose.

Length of body, $23.5 \mathrm{~mm}$; length of carapace, $9 \mathrm{~mm}$.

Station 3368. 66 fathours. 2 males, without carcinoecia.

These specimens agree closely with types of $E$. californiensis in the U. S. National IIuseum from Catalina Harbor, Cal., 30 to 60 fathoms.

MM. Milne Edwards and Bouvier have lately described and figured a Eupagurus from Sand Key, Fla., under the name E. smithii.* Since this name had been previously used by Mr. Benedict for another species of Euparums from the Gulf of California, $f$ it becomes necessary to change the name of Milne Edwards and Bouvier's species, which may be called Eupagums bouvieri.

CATAPAGURUS A. M. EDW. Bull. Mus. Comp. Zoöl., VIII. 46, 1880.

Catapagurus diomedeæ $\mathrm{F}_{\Delta x}$.

Plute XIII., Fig. 2-2d.

Bull. Mus. Comp. Zoül., XXIV. 171, 1893.

The carapace is smooth and naked, and divided into an anterior and posterior section by the cervical groove. The anterior margin projects slightly

* Mem. Mus. Comp. Zoöl., Vol. XIV., No. 3, p. 140, Plate X. Fig. 1-12, 1893.

+ Proc. U. S. Nat. Mus., XV. 4, 1892. 
between the eye-stalks, forming a blunt rudimentary rostrum. The gastric region is sharply defined, and presents an indistinct longitudinal furrow on each side of the median line; it is lightly convex in both directions. 'The branchial regions of the right and left sides are strongly inflated, and sharply separated from one another by a re-entrant angle formed by the curving. forward of the posterior border of the carapace on each side of the median line.

The eye-stalks are rather long and slender, being about equal in length to the anterior section of the carapace. The ophthalmic scales are very small and minutely bifid at the tip. The third segment of the antennular peduncle is about two thirds the length of the eye-stalk, and increases in diameter from the base to the distal end; the superior flagellum is rather longer than the distal segment of the peduncle, and its enlarged, ciliated basal portion forms rather more than one third of its whole length. The inferior flagellum is about one half as long as the superior, and is composed of about eleven segments. The peduncle of the antenna surpasses the eye-stalk by one half the length of its distal segment; the acicle is long and slender, tipped with a few setre; it reaches forward a little beyond the eye; the flagellum reaches beyond the tips of the ambulatory legs. The chelipeds are nearly alike in shape and size; their segments are clothed with long setx, which assume a tomentose appearance on the chelæ; the carpus is about equal in length to the chela, its inner face is perpendicular, the inner margin of the upper side is armed with seven small spines, and there is also a spine at the distal end of the superior margin; the chela is short and thick, the fingers about the same length as the basal portion of the propodite, slightly downcurved, meeting throughout their length, working horizontally. The ambulatory legs are of nearly equal length, surpassing the chelipeds, setose, the carpus armed with a sharp tooth at the distal end of its upper side; the propodite is twice as long as the carpus, the dactylus is considerably longer than the propodite, and like that segment is distinctly curved; it is tipped by a small horny nail. The fourth pair of legs are but slightly subcheliform; the rasp is formed of a single row of scales.

There are three small, rudimentary appendages on the left side of the abdomen; the first and second of these are two-branched, the secondary branch being exceedingly minute. The sexual tube which issues from the coxal segment of the last thoracic appendage of the right side is very long. 
Length of carapace, $5.5 \mathrm{~mm}$; abdomen, $8 \mathrm{~mm}$.; cheliped, $12.5 \mathrm{~mm}$; last ambulatory leg, $17.5 \mathrm{~mm}$; ocular peduncle, $2.5 \mathrm{~mm}$.

Station 3355. 182 fathoms. 1 male, without carcinœecium.

This species differs much from the more typical species of Catapagurus, C. sharreri A. M. Edw. and C. gracilis Smith, in the shortness of its chelipeds and ambulatory limbs, the symmetry of its chelipeds, and the length of the protruded vas deferens. It is more nearly related to $C$. australis Henderson.* It would seem to have a close general likeness to Pagurodes pilifer Henderson, but the gills in $C$. diomedco are of the phyllobranchiate type.

\section{SPIROPAGURUS STIMPs.}

Proc. Acad. Nat. Sci. Phila., X. 236, 1858.

\section{Spiropagurus occidentalis Fax.}

Plate XIV., Fig. 1-1 ${ }^{d}$.

Bull. Mus. Comp. Zoöl., XXIV. 172, 1893.

The carapace is smooth and naked except on the sides of the branchial regions where a few hairs arise; the branchial regions are swollen, membranaceous, and covered with a net-work of white lines; the cardiac region is long and narrow; the portion of the carapace in front of the cervical groove is calcified, produced in the median line anteriorly to form a short, broad, and obtuse rostrum, which does not conceal the ophthalmic segment; the lateral teeth are acute and project as far as the rostrum does; they form a sharp demarcation between the front and the oblique antero-lateral border of the carapace.

The ophthalmic scales are triangular, with simple tips. The ocular peduncles are enlarged at the distal end, hardly overreaching the distal end of the second segment of the antennular flagellum, and the third segment of the antennal flagellum. The last segment of the antennular peduncle is more than twice as long as the penultimate segment. The second segment of the antennal peduncle is produced externally into a long, sharp tooth; the antero-internal angle is likewise armed with a small spine; the acicle is long, sharp, curved, and furnished with setæ, as are also the several joints of the peduncle.

The chelipeds are subequal, the right chela being appreciably larger

* Rep. Challenger Anomura, p. 76, Plate VIII. Fig. 1, 1588. 
than the left; the ischium is armed with about five denticles along the internal margin; the inner margin of the merus is armed with the same number of rather larger teeth; the inner margin of both of these segments is furnished with long and slender setx; the surface of the carpus is rough with setiferous rugx, and is armed with scattered spinules upon its upper face, and with a row of larger spines along the internal margin of the upper face. The external fice of the propodite is armed with spines which are regularly aranged in five longitudinal rows; only at the distal end of the propodite, at the base of the fingers, do these spines lose their regular serial arrangement; from the bases of these spines spring long setæ; the fingers are acute, tuberculo-spinose and setose, like the hand. 'The fingers of the left hand are longer in proportion to the palm than those of the right hand.

The ambulatory legs are rather stout and longer than the chelipeds; their lateral surfaces are smooth; the upper margin of the carpi is armed with a row of little spines, and the corresponding margin of the propodites is denticulated; the dactyli are longer than the propodites, but not so long as the propodites and carpi combined; the anterior pair of ambulatory legs differs from the posterior pair in having the dactylus and propodite a little shorter, and the lower edge of the merus more hairy and minutely spinulose. The telson is deeply cut by a broad median notch in its hind margin into two lobes, the left of which is the larger. The margins of both lobes are spinose.

There is (in the alcololic specimens) a narrow red ring around both fingers near their tips, a broader band of the same color around the base of the fingers, and a red spot on the inner side of the anterior face of the hand.

Length of carapace, $6.5 \mathrm{~mm}$.; greatest breadth of carapace, $6 \mathrm{~mm}$; length of ocular peduncles, $2.3 \mathrm{~mm}$.

Station 3368. 66 fathoms. 1 male.

$$
\text { “ } 3379.52 \quad \text { " } 50
$$

Carcinoecium : Phos.

This species, like $S$. inis A. M. Edw., is characterized by the spiny armature of the chelipeds. It differs from $S$. $i$ is in having a smaller number of spines upon the anterior face of the chela, and in their arrangement in a few definite longitudinal rows, the surface between the rows being spineless and reticulated. The chela does not display the lively iridescence so striking in Milne Edwards's species, nor are the ophthalmic scales bidentate at the end. The merus of the third maxillipeds is not armed with a distal spine as in S. iris. 
PYLOPAGURUS A. M. Enw. et Bouv.

Bull. Soc. Plilomath. de Paris, seme Sér., III. 108, 1591 (type species mentioned-Eupagurus discoidalis A. M. Edw.); Mem, Mus. Comp. Zoöl., Vol. XIV., No. 3, p. 74, 1893 (genus described).

Eight species of Pylopagumus have hitherto been described, all of them restricted to the West Indian region with the exception of one species, $P$. ungulatus (Studer), which has been found also near the Cape of Good Hope. They inhabit moderate depths (20-508 fithoms). Three species were secured during the "Albatross" Expedition, all of them closely allied to West Indian forms.

\section{Fylopagurus longimanus Fax.}

Plate XII., Fig. 1-1e.

Bull. MIus. Comp. Zoöl., XXIV. 168, 1893.

Carapace smooth, naked, polished, very convex from side to side; rostrum short, triangular, subacute, advanced further than the rounded lateral angles. Abdomen longer than the cephalo-thorax. Eye-stalks equal in length to the first two segments of the antennular peduncle, smooth, polished, with a few setx on the dorsal face. Ophthalmic segment uncovered. Ophthalmic scales separated by a considerable interval, triangular, their tips split in a horizontal plane so that they end in two acute teeth, one above the other, the lower tooth the longer. Last segment of the antennular peduncle very long and slender (much longer than the eye-stalk), with long setre on its lower side. Second segment of antennal peduncle armed with a small and acute median tooth at the distal end of the dorsal face, and prolonged into a short and broad triangular external process; third segment robust, reaching nearly to the end of the eye-stalk; distal segment long and slender; flagellum setose, reaching to the distal end of the carpus of the larger cheliped when this appendage is extended; antennal acicle reaching the end of the eye, curved upward, and furnished with many long setæ, especially on the superior border and near the tip. The right cheliped attains an enormous size, much exceeding the whole body in length; the outer face of the merus is nearly smooth, but the lower and inner faces of this segment are granulated; the carpus is very large, equalling in length all the preceding segments combined; it broadens gradually from the proximal to the distal end, is subquadrate in shape, the height equalling the 
breadth of the distal end; its whole surface is granular, the granules assuming the form of small spinulous tubercles on the dorsal face, which is limited within by a row of larger teeth. The chela is irregularly oval, the external side is flattened to form an opercular facet whose proximal limit falls short of the articulation with the carpus; the opercular face is surrounded by a margin of denticles, and its whole surface is thickly set with granules or minute tubercles; the inner or lower side is very convex, granulated, and deeply excavated at the proximal end to receive the carpus when the chela is flexed; the outer margin of the dactylus is somewhat concave toward the distal end; the inner or prehensile edges of both fingers are denticulated, and there is a single tooth of larger size near the middle of the immovable finger which is received in a shallow concavity opposite to it on the inner margin of the dactylus.

The left cheliped is very small in comparison with its fellow, its distal end hardly reaching beyond the middle of the carpus of the latter; its segments are much more hairy than those of the right cheliped; the surfuce of the merus is pretty smooth barring a few spinules on the inferior margin; the carpus is equal in length to the merus, and is armed with a series of teeth on the upper margin; these teeth increase in length toward the distal end of the segment; the basal part of the propodite is short and swollen, the fingers very long, gaping at the base; the outer or upper faces of the propodite and dactylus are granulated and definitely bounded by a line of regularly arranged granules on the outer margin of the dactylus and the inferior margin of the propodite; the inner or lower face of the chela is pretty fiee from granules, but is furnished with numerous setre, those on the dactylus being grouped in conspicuous tufts or pencils.

The two pairs of ambulatory legs are of about equal length, but those of the right side are much longer than those on the left. The former reach as fur as the middle of the large claw, while the latter only reach to its proximal end. Both pairs of ambulatory legs are laterally compressed. Those of the first pair are armed with a row of spiny teeth on the upper margin of the carpus and propodite, and a series of smaller denticles is observable on the distal half of the lower edge of the merus. In those of the second pair the same armature is found on the carpus, but it is hardly visible on the propodite and merus. The dactyli are somewhat longer than the propodites; they are tipped with acute, horny claws and furnished with short, stiff setre along their margins. 
The hand of the next pair of appendages is almost perfectly chelate, and is furnished with but few hairs; its rasp is restricted to the distal part of the claw, but is nevertheless broad and composed of many rows of scales. The hand of the last pair of thoracic appendages is cheliform, ornamented with a tuft of very long and curved hairs on the upper border; the proximal or hind border of the rasp is concave.

The abdomen is longer than the carapace; the integument is very thin and soft, barring the last two segments, whose dorsal walls are well calcified. Asymmetry is but little apparent except through the disparity of the terminal appendages, and the absence of false feet on the right side. False feet are found on the left side to the number of three (in the male). Each of them consists of a basal stem which carries two setiferous branches of very unequal size. The sixth somite is divided into two unequal parts by a transverse suture; of the appendages borne by this somite the one on the left side is much larger than that on the right. The telson is imperfectly divided by a transverse suture, and a notch in the posterior margin divides the hinder portion into two lobes which are not quite symmetrical. The posterior margin is armed with a few minute denticles.

Traces of color are still perceptible in the alcoholic specimens, especially upon the legs, which are yellowish, variously banded and mottled with red.

Length of carapace, $10 \mathrm{~mm}$.; length of carapace in front of cervical groove, $5 \mathrm{~mm}$; ; length of eye-stalk, $4 \mathrm{~mm}$; length of right cheliped, $34.5 \mathrm{~mm}$. (merus, $8 \mathrm{~mm}$., carpus, $11 \mathrm{~mm}$., propodite, $14.8 \times 8 \mathrm{~mm}$., dactylus, $10 \mathrm{~mm}$.) ; length of left cheliped, $18 \mathrm{~mm}$. (chela, $6 \mathrm{~mm}$.), length of first right ambulatory leg, $7 \mathrm{~mm}$; dactylus of first right ambulatory leg, $8.5 \mathrm{~mm}$.

In younger and smaller specimens the chelipeds are shorter in proportion to the length of the body and the major claw is shorter, broader, and more regularly oval in outline. A specimen whose carapace is $6.5 \mathrm{~mm}$. long gives the following dimensions for the right cheliped: total length, $16.5 \mathrm{~mm}$. merus, $4.5 \mathrm{~mm}$; carpus, $5.5 \mathrm{~mm}$.; propodite, $7.5 \mathrm{~mm}$.; dactylus, $4.5 \mathrm{~mm}$.

Station 3368. 66 fathoms. 5 males.

One specimen is in a Gastropod shell thickly encrusted with Bryozoa, the others are without carcinoecia.

Pylopagurus longinamus is similar to $P$. ungulatus (Studer), * but may be

* Eupagurus unqulatus Studer, Crustaceen der Gazelle, p. 26, Plate IT. Fig. 13: Abhandl. Königl. Akad. Wissensch. zu Berliu, 1852; Pylopagurus ungulatus A. M. Edw. et Bouv., Mem. Mus, Comp. Zoöl., Vol. XIV., No. 3, p. S0, Plate VI. Fig. 15-18, 1593. 
readily distinguished from the latter by the great size of the right cheliped, the irregularly oval outline of the right chela, the great length of the distal segment of the antennular peduncle, etc.

\section{Pylopagurus affinis FAX.}

$$
\text { Plate XII., Fig. 2-2e. }
$$

Bull. Mus. Comp. Zoöl., XXIV. 169, 1893.

This species is nearly related to $P$. ungulatus, from which it differs in the following respects : the eye-stalks are longer, and narrower at the distal end; the external prolongation of the second segment of the antenna is longer and slenderer; the upper margin of the carpus of the right cheliped is armed with two or three spines, the largest of which is close to the anterior border; the onter face of the carpus is smooth save where a light tubercular ridge runs along the middle. In $P$. ungulatus this face of the carpus is thickly covered with spinulous granules which assume larger proportions and a uniserial arrangement on the superior and inferior margins. On extending the comparison to the large chela, further differences between the two species become apparent. In both species the external face is flat, covered with minute spinulous granules, and surrounded by a border of sharp spines; but in $P$. affinis the marginal spines are larger and more irregular, and the flat opercular facet is not sharply defined at the proximal end by the regular arrangement of the marginal spines as in $P$. ungulatus; instead, one finds the marginal series of spines broken down at this point, thus effacing any distinct limit between the opercular face of the chela and the articular surface which connects the propodite with the carpus. The inner or lower surface of the linge chela is smooth in $P$. affinis, granulated in $P$. umgulatus. The left cheliped is quite different in the two species: in $P$. affinis the several segments of which it is composed grive rise to long setx which give the appendage a very hairy appearance when contrasted with $P$. ungulatus; the inferior border of the chela is conspicuously toothed, while in $P$. ungulatus it is entire. The ambulatory legs are more hairy in the Pacific species than in $P$. ungulatus, and their carpal joints are not so distinctly dentate on the superior border. The rasps of the fourth pair of legs are multiserial in both species. The telson $P$. affinis is symmetrical, subcircular in outline, its posterior border convex and entire; in $P$. ungulatus, the telson has a deep and wide posterior median notch. 
Length, about $12 \mathrm{~mm}$; ; length of carapace, $4.5 \mathrm{~mm}$.

Station 3397. 85 fathoms. 1 male.

There are three simple, unpaired abdominal appendages on the left side, in the type specimen. The vasa deferentia are extruded from the base of the fifth legs on each side. They appear as slender threads, the one on the right side much longer than its fellow, and twisted (see Plate XII. Fig. $2^{c}$ ).

The type specimen inhabited a Nassa shell whose orifice was built out and enlarged by an encrusting, branching Bryozoon.

\section{Pylopagurus hirtimanus FAx. \\ Plate XIII., Fig. 1, 1e. \\ Bull. Mus. Comp. Zoöl., XXIV. 170, 1893.}

This species closely resembles $P$. rosaccus A. M. Edw. et Bouv., ${ }^{*}$ from the West Indian seas. Compared with the type of $P$. rosacens it presents the following differences: the eye-stalks are a little slenderer, and together with the ophthalmic scales are separated by a wide interval, in which the antennules lie, exposed from above. In $P$. rosacens, on the contrary, the ophthalmic stalks and scales are closely approximated, concealing the antennules beneath. The outer face of the right chela is ornamented with conical tubercles whose bases are expanded into circular plates; these plates are closely packed over the surface of the chela so that no interstices are left between them; their borders are cut into a large number of minute radiating processes; on the basal half of the propodite the tubercles give rise to long setæe which render that part of the claw conspicuously hirsute, in contrast with the distal part which is naked; furthermore, on the distal half of the propodite, especially on the concave surface of the immovable finger, the tubercular processes tend to become obsolete, leaving only the basal circular radiate plates; the bases of the conical teeth along the outer margin of the hand and movable finger are expanded into flattened roundish surfaces with radiate margins; these surfaces form a conspicuous outer border to the hand; the inner face of the hand is tuberculated. In $P$. rosacens the tubercles of the outer face of the chela are encircled by rounded granules much less numerous than the radiating points in $P$. hirtimanus; the tubercles are so loosely arranged that numerous interstices are apparent between them; the hairs on the basal half of the hand are not so well 
developed as in the Pacific species, the whole outer face of the immovable finger is strongly tuberculated, the teeth of the lower margin are not expanded into conspicuous plates, and the inner face of the chela is nearly smooth. The carpus in $P$. hirtimanus is armed with larger spines on the internal margin, is more hairy, and more coarsely granulated on its inner, inferior, and outer surfaces than it is in $P$. rosacens. The left chela is comparatively smaller than in $P$. rosacens, is more strongly toothed along the internal margin of the propodite and dactylus, and exhibits, besides, most of the above-specified peculiarities of the right claw. The primary branch of the unpaired abdominal appendages is shorter and broader than in P.rosaceus. The rasp on the propodus of the fourth pair of legs is uniserial as in P. rosacens.

Length of carapace of largest male, $12 \mathrm{~mm}$.; length of carapace in front of cervical groove, $7 \mathrm{~mm}$; ; breadth across the branchial regions, $9.5 \mathrm{~mm}$.; length of large claw, $11 \mathrm{~mm}$; breadth of large claw, $7 \mathrm{~mm}$.

Station 3367. 100 fathoms. 2 males, 1 fem.

" 3368. liti " 50 " 50 “

Carcinøecia: Phos, Columbella, Nassa.

A good deal of the color is still preserved in alcohol. The lower surface of the eye-stalk is quite a deep red, while the upper surface is a pale yellow. The merus and carpus of the chelipeds and all the segments of the ambulatory legs from the ischium to the dactylus inclusive are banded transversely with bright red on a yellowish ground.

\section{PAGURISTES DANA.}

Proc. Acad. Nat, Sci. Phila, V. 269, 271, 1851.

\section{Paguristes fecundus Fax.}

Plate XIV., Fig. 2-2e.

Bul1. Mus. Comp. Zoöl., XXIV. 173, 1893.

The anterior or gastric section of the carapace is smooth in the central and hinder parts, rugose near the front, and tuberculose in the anterolateral region, where a few of the tubercles assume a spiny form; from the tubercular surface spring long slender setæ. The anterior margin of the carapace is produced in the median line so as to form an acute triangular rostrum which projects beyond the subacute lateral processes; between 
the rostrum and the lateral processes the anterior border is concave and thickened so as to form a rim. The anterior gastric lobes are clearly defined anteriorly.

The ocular peduncles are long and cylindrical, reaching considerably beyond the antennal peduncle, but not quite so far as the antennular peduncle. The ophthalmic scales are of moderate size and bidentate at the tip, the external tooth very minute. The antennal acicle reaches almost to the end of the peduncle; it is setose, and armed with six spines, two of which form a terminal fork, the others being marginal. The external prolongation of the second antennal segment is narrow, setose, and minutely spinulose; there is, moreover, a spinule on the upper face of this segment behind the base of the acicle; the antennal flagellum is very short (about equal in length to the anterior section of the carapace). The third pair of maxillipeds are closely approximated at their bases; their merus joints are armed with three or four denticles on the lower margin and one at the distal end of the upper margin.

The chelipeds are short and of like size and shape; the merus is smooth within, rugose without; the two inferior margins armed with minute blacktipped spinules. The carpus is tomentose and spinulose, the largest spines occurring along the superior border; the hand is both spinulose and pubescent, but the hair is less dense upon the fingers than upon the basal portion of the hand, which is short and swollen below. The fingers are short, excavated within, and terminate bluntly in dark, corneous nails. The ambulatory limbs are pubescent, particularly on the upper and lower margins; the distal end of the merus, and also the carpus, propodite, and dactylus are armed with numerous spines, the most prominent of which are arranged in a row along the upper border of the carpus and propodite; the dactylus is about equal in length to the propodite and carpus together. The legs of the fourth pair are furmished with long hairs on their upper margin, and there are a few spines on the upper margin of the carpus; the propodite is rather longer than the dactylus, and the rasping surface on its lower margin occupies two thirds of its length. The last pair of legs are much less hairy than the preceding pair; the rasping surface, which is truncate posteriorly, falls a little short of reaching the middle of the hand. The telson is divided by a pair of lateral incisions and a median one into four lobes, those on the left side the larger; the pair of terminal lobes are obscurely toothed on their margins. 
Length of carapace, $9.5 \mathrm{~mm}$; breadth, $7 \mathrm{~mm}$; length of ocular peduncle, $4 \mathrm{~mm}$.

Station 3368. 66 fathoms. 2 fem. ovig, in shells of Mitra and Phos.

This species is nearly related to $P$.lymani A. M. Edw. et Bouv.* of the West Indian region, and to $P$. subpilosus Hend. $\dagger$ of New Zealand. From the former it is distinguished by the more prominent and acute rostrum which overhangs the ocular segment, by the smaller number of spines on the antennal acicle, and by the armature of the telson, the margin of which is ornamented with obscure teeth, while in $P$. lymani it is furnished with numerous spines whose tips are horny and dark colored. From $P$. subpilosus it differs in having shorter eye-stalks and antennal acicle, fewer spines on the antennal acicle, a longer and narrower external prolongation of the second joint of the antenna, and a differently shaped telson.

The ovisacs of both specimens are large and filled with eggs.

\section{PARAPAGURUS SMITH.}

Trans. Conn. Acad. Arts and Sci., V. 50, 1879.

\section{Parapagurus pilosimanus abyssorum (HeND.).}

Parapagurus abyssorum A. M. EDw. MIS., HEND., Rep. Challenger Anomura, p. 87, Plate IX. Fig. 2, 1888.

Parapagurus pilosimanus, var. abyssorum A. M. EDw. et Boov., Ann. Sci. Nat., Zool., jème Sér., XIII. 205, 1892.

$\begin{array}{rrrrr}\text { Station } & 3362 . & 1175 & \text { fathoms. } & 1 \text { male. } \\ \text { " } & 3363 . & 978 & \text { " } & 5 \text { males, } 5 \text { fem. } \\ \text { " } & 3364 . & 902 & \text { " } & 1 \text { male. } \\ \text { " } & 3366 . & 1067 & \text { " } & 2 \text { males, } 3 \text { fem. } \\ \text { " } & 3371 . & 770 & \text { " } & 6 \text { males, } 15 \text { fem. } \\ \text { " } & 3374 . & 1823 & \text { " } & 1 \text { fem. } \\ \text { " } & 3375 . & 1201 & \text { " } & 1 \text { male. } \\ \text { " } & 3376 . & 1132 & \text { " } & 2 \text { males, } 2 \text { fem. } \\ \text { " } & 3380 . & 899 & \text { " } & 1 \text { male. } \\ \text { " } & 3392 . & 1270 & \text { " } & 1 \text { male, } 1 \text { fem. } \\ \text { " } & 3393 . & 1020 & \text { " } & 2 \text { males, } 2 \text { fem. } \\ \text { " } & 3400 . & 1322 & \text { " } & 4 \text { males, } 3 \text { fem. } \\ \text { " } & 3407 . & 885 & \text { " } & 1 \text { male. }\end{array}$

* Mem. Mus. Comp. Zoöl., Vol. XIV., No. 3, p. 49, Plate IV. Fig. 13-22, 1893.

t Rep. Challenger Anomura, p. 77, Plate VIII. Fig. 2, 2a, 1888. 
Station 3413. 1360 fathoms. 2 males, 6 fem.

$\begin{array}{rrrrr}\text { " } & 3429 . & 919 & \text { " } & 2 \text { males. } \\ \text { " } & 3431 . & 995 & \text { " } & 1 \text { male, } 2 \text { fem. } \\ & 3432 . & 1421 & \text { "6 } & 1 \text { male, } 1 \text { fem. }\end{array}$

The carcinoecia are Gastropod shells which support, and in most cases are more or less completely absorbed by, a sea-anemone or a colony of Epizoanthus. Among the determinable shells are Sotariella, Natica, and Phos.

Family PORCELLANID E.

PETROLISTHES STMPS.

Proc. Acad. Nat. Sci. Phila., X. 227, 1858.

\section{Petrolisthes occidentalis Strmss.}

Ann. Lyc. Nat. Hist. N. Y., VII. 73, 1859.

Reef at Panama, March 12. 4 males, 8 fem. ovig.

In recent alcoholic specimens the transverse ridges and squamiform tubercles of the carapace are dark red, the intervening spaces yellowish. The lower surface, including the abdomen, deep madder.

\section{Petrolisthes agassizii FAx. \\ Plate XV., Fig. 1, $1^{a}$. \\ Bull. Mus. Comp. Zoöl., XXIV. 174, 1893.}

In this pretty species the whole upper surface of the carapace is crossed by piliferous plications or ruga which are broken and irregular on the anterior half of the carapace, but posteriorly they extend across the whole upper surface without a break. The length of the carapace is equal to the breadth, the front is prominent, somewhat deflexed, not trifid; a longitudinal median sulcus extends back some distance on the gastric region. The supraorbital margin is convex and thickened, separated from the front by a deep groove; the posterior angle of the orbit is obtuse, but denticulated. On the lateral inargin of the carapace a minute spine is discernible just behind the cervical groove. The pterygostomian region is clothed with a dense pubescence. The basal joint of the antenna has a prominent denticulated lobe on its inner side. Chelipeds: merus rugose, armed with a strong tooth on the distal internal angle; carpus long, thickly set with flat, squamous tubercles both above and below, anterior border three-toothed, upper surface with two lon- 
gitudinal depressions ruming the length of the segment; propodite long, closely set with piliferous squames on both surfaces; a longitudinal depression runs from the articulation of the dactylus back to the carpus; both fingers densely pubescent within at base. Ambulatory appendages: meri rugose, with spinules on anterior margin, and a spine at the posterior angle of the distal end of the first and second pairs. The surface of the abdomen, sternum, and outer maxillipeds is thrown into setiferous folds or ridges.

Color (in alcohol): reddish, lighter below, the pigment assuming the form of spots on the basal parts of the abdomen; a large blood-red spot on the propodite of the outer maxillipeds.

Carapace, $5 \times 5 \mathrm{~mm}$; cheliped, $34 \mathrm{~mm}$. ; carpus, $10.5 \mathrm{~mm}$. ; chela, $20 \mathrm{~mm}$.

One male, taken with the preceding species on the reef at Panama at low tide, March 12.

In the shape of the carapace and the front this species bears a close resemblance to Petrolisthes scxspinosus (Gibbes) and $P$. occidentalis Stimps., but the transverse ridges are more broken anteriorly, while posteriorly they extend uninterruptedly across the whole width of the carapace, being here more perfectly developed and less broken than in the two species named above. The carpus and claw, moreover, are longer and narrower, the anterior margin of the carpus is three-toothed instead of five-toothed. The squames of the carpus and claw do not tend to widen out into ridges or folds on either the upper or lower surfaces, but preserve the form of close set imbricated scales over the whole surface, including the space between the longitudinal depressions of the carpus and along the depressed line of the propodite. The form of the carpus approaches nearer to that of Petrolisthes armatus (Gibbes), * but the present species may be readily distinguished from $P$. armatus by the prominent rugre of the carapace, and squames of the chelipeds. From P.edururdsii (Sauss.) the present species is distinguished by its longer chelipeds, by the ridges of the hinder part of the carapace extending elear across the carapace without interruption, etc. The ridges of the frontal lobes are much more strongly developed in $P$. agassizii than in any of the allied species mentioned above.

* Porcellana armata Gibbes, Proc. Amer. Assoc. Adv. Sci., 3d Meeting, p. 190, 1850. Dr. Stimpson, when libelling the Crustacen in the Smithsonian Institution and Museum of Comparative Zoölogy, separated the Panama specimens of Petrolisthes armatus under the name of Petrolisthes similis, sp. uov, and specimens so labelled were afterward sent to the Jardin des P'lantes, laris. These were secn by Professor Henderson, and are referred to in his report on the "Challenger" Anomura, p. 109, as P. similis Stimps. But Stimpson, in publication, referred these specimens to P. armatus (Anu. Lyc. Nat. Hist. N. Y., VII. T4, 1859), and nerer, so far as I can learn, published his $P$. similis. 
PACHYCHELES STIMPS.

P'roc. Acad. Nat. Sci. Phila., X. 228, 1858.

\section{Pachycheles panamensis $F_{A X}$.}

Plate XV., Fig. 2, 2a.

Bull. MLus. Comp. Zoöl., XXIV. 175, 1893.

Carapace subcircular, the longitudinal and transverse diameters nearly equal, upper surfice flattened, granulate and setose, especially on the gastric and anterior portion of the branchial regions, posterior portions of the branchial regions lightly rugose. Front broad, produced to a rounded median lobe, lateral portions straight, inner orbital angle rounded, not produced; outer orbital angle projecting as a triangular tooth between the eye and the base of the antenna. Lateral border of the carapace with a concavity behind the antenna; the margin is slightly raised as a rim which is lost in one of the branchial rugx before reaching the hind border of the carapace; hind border slightly concave. Chelipeds unequal, the right being the larger; upper surface of the merus rugose and setose, under surface smooth, internal distal angle produced as a denticulated tooth; carpus short and broad, upper surface tuberculous and setose, internal border armed with a large tooth at the base, followed by one or two smaller teeth, lower surface smooth and naked; upper surface of the propodite furnished with small tubercles which bear stiff bristles, imner margin rounded, not toothed, outer margin granulated, lower suface convex, naked and polished near the centre (where the surface is reticulated in the larger claw), squamoso-granular and setose near the edges; fingers gaping, crossing at tips, toothless on both the inner and outer margins (or at most slightly denticulated on the outer margin). Ambulatory appendages setose.

Length of carapace, $6.5 \mathrm{~mm}$, breadth, $7 \mathrm{~mm}$. ; breadth of frontal margin, $2 \mathrm{~mm}$.

Panama, March 12. 1 fem. ovig.

Puchycheles mulis Stimps. is a larger species, with the posterior margin of the carapace more concave (the concavity having almost the shape of a triangular notch); the carapace and chelipeds are less setose than in $P$. pancomensis, the anterior margin of the carpus not prominently toothed, and there is a strong protuberance near the middle of the upper surface of the propodite. In $P$. tuberculipes Lockington the central part of the front is triangular and 
deeply furrowed along the median line, the chelipeds and ambulatory legs are knobbed so as to present "a mass of tubercles above." $P$. panamensis appears to be near P. barbulus $\Lambda$. MI. Edw. from the Azores, but in the latter species the front is broader and the carpus more denticulated.

FAMILY GALATEIDÆ.

PLEURONCODES STIMPS.

Aun. Lyc. Nat. Hist. N. Y., VII. 245, 1560.

Pleuroncodes monodon (M. Evw.)?

Plate $X V .$, Fig. 3-3.

? Galathea monodon MI. EDw., Hist. Nat. Crust., II. 276, 1837.

P Plenroncodes monodon Strups., Ann. Lyc. Nat. Hist. N. Y., VIJ. 245, 1860.

Pleuroncodes monodon? FAX., Bull. Mus. Comp. Zoöl., XXIV. 176, 1893.

Station 3385. 286 fathoms. 16 males, 7 fem. (" half a bushel rejected").

$\begin{array}{rrrrrrrr}\text { " } & 3356 . & 242 & \text { " } & 9 & \text { " } & 14 & \text { " } \\ \text { " } & 3396 . & 259 & \text { " } & 2 & \text { " } & 2 & \text { " } \\ & 3423 . & 94 & \text { " } & 15 & \text { " } & 11 & \text { " }\end{array}$

Compared with Milne Edwards's figure* of $P$. monodon, the "Albatross" specimens, especially the males, present a more obese appearance; their greatest width is across the cardiac region, while in the figure of $P$. monodon (which undoubtedly represents a female) it is near the posterior end of the carapace; the cardiac aren, in the examples before me, is sunk below the level of the rest of the carapace, and the transverse piliferous lines are more broken at this point, as well as on the gastric region, than appears to be the case in $P$. monodon, to judge from the figure referred to. Unless these discrepancies are due to the inaccuracy of Milne Edwards's draughtsman, the "Albatross" specimens belong to a new species. The type specimens of $P$. monodon came from the coast of Chile.

In $P$. planipes Stimps. the penultimate segments of the ambulatory appendages are flattened and ciliated, and the cardiac area is not depressed as in the "Albatross" specimens. $P$. planipes appears to be a pelagic form. It has been taken off the coast of California and western Mexico.

The lateral expansion of the carapace of $P$. monodon carries the anterolateral angle some distance outward beyond the antero-lateral spine. This

* Ann. Sci. Nat., Zool., 3èrue Sér., XVI., Plate XI. Fig. 6-9, 1851. 
point is not brought out in the figure on Plate XV., but the reader is cautioned against inferring that there is any difference in this regard between the "Albatross" specimens and the one figured by Milne Edwards. The length of the rostral horn is somewhat variable, being often considerably longer than in the specimen figured.

\section{MUNIDA LEACII.}

Dict. Sci. Nat., XVIII. 52, 1820.

About forty-five species of Munida are now known. The "Albatross" collection of 1891 contains five species, four of which were previously unknown. Professor Alphonse Milne Edwards's final illustrated report on the Galateide collected by the "Blake" Expeditions has not yet appeared, but I have before me the types of the ten species of Munida briefly diagnosed in his preliminary report which was published in 1880.* The specimens ("Blake" Sta. No. 36) recorded by Milne Edwards as Munida caribbca Stimps. are the same species as those described on the same page as a new species under the name Munida irrasa. The specimens doubtfully referred to Munida caribboa Stimps. by Prof. S. I. Smith $\nmid$ are Munida iris of Milne Edwards. Stimpson's Munida caribbce is absolutely indeterminable from his brief notice of it, and the types were burned in the great Chicago fire. The name caribboca should, then, be dropped and Milne Edwards's iris and irrasa should be retained.

Professor Henderson § considers Munida valida Smith to be identical with Munida miles A. M. Edw. On comparing the types of M. miles with Smith's figure of $\boldsymbol{M}$. valida, it appears that the supraocular spines are much longer and more divergent in the latter than they are in $M$. miles.

Munida obesa Fax.

Plate XVI., Fig. 1, $1^{a}$.

Bull. Mus. Comp. Zoöl., XXIV. 176, 1893.

In this species we see an approach to the genus Pleuroncodes, since the sides or latero-inferior walls of the carapace are somewhat swollen, so that

* Bull. Mus. Comp. Zoöl., VIII. 47-52, Dec. 1880.

$\dagger$ Proc. U. S. Nat. Mus., III. 42S, Jan. 1851; Bull. Mus. Comp. Zoöl., X. 22, Plate X. Fig. 1, 18s2 ; Proc. U. S. Nat. Mus., VI. 40, Plate III. Fig. 11, 1853; Am. Rep. U. S. Fish Comm. for 1582, p. 355, 1894 ; id. for 1885, p. $613,1856$.

+ Ann. Lyc. Nat. Hist. N. Y., VII. 244, 1860.

$\$$ Rep. Challenger Anomura, p. 126, 1SsS. 
they show a little when the animal is viewed from above. The basal segment of the antennæ, moreover, is more exposed from above than it is in the more typical species of Munida.

The lateral rostral spines, or supraocular spines, are curved upward more than the median rostral spine, and the three are nearly parallel; the lateral spines reach about half way to the tip of the median; all three are microscopically spinulose on their upper edge. There are two pairs of spines on the anterior part of the gastric region in line with the lateral rostral spines. Of these two pairs the anterior is the larger. There is also a longitudinal line of spinules in the median line between the two pairs just spoken of. The arrangement of the other spines on the anterior portion of the carapace will be best understood by reference to the figure on Plate XVI. The cardiac area is somewhat sunk below the level of the surrounding parts, its anterior margin is denticulated, with a larger spine on each side. The lateral margins of the carapace are armed with ten or eleven spines, the one on the antero-lateral angle being the longest. The second abdominal segment is ornamented with a transverse row of eight small spines. The other abdominal segments are normally destitute of spines, but in a few of the many specimens before me there are two or four small spinules on the third segment. The pleuræ of the third, fourth, and sixth abdominal segments are acute, the rest blunt. The eyes are large and are provided with rather long cilia on the edge of the cornea. The basal joint of the antenna is armed with a long and sharp spine which reaches forward beyond the eyes; the second joint also has a long spine on each side. The chelipeds are long and hairy; the merus, carpus, and basal part of the propodite are spiny, the fingers long, slender, the cutting edges straight and finely spinulous.* The ambulatory appendages are setose, the upper and lower edges of the merus are spinulose, and there is, moreover, a row of spinules on the outer surface, this external line of spinules being best developed on the proximal end of the segment; the carpus is armed with small spines on the upper margin and

* In some of the males the chela is broader than in others, and the basal part of the propodal digit is curved so that there is a distinct gap at the base of the fingers, with one or two rather prominent teeth on the base of the cutting edge of the dactylus. This difference in the form of the chela is generally found among the males of the different species of Mrunita, and has been referred to by Henderson (Challenger Amomura, p. 127), as a case of dimorphism. I have elsewhere (Amer. Journ. Sci., 3d Ser., XXVII. 42-44, 1884) shown that the two forms of the male in the genus Cambarus are alternating stages in the life of the same individual, one plase being assumed during the breeding periods, the other during the interrening seasons or sexual quiescence. Jules Bonnier (Comptes Rendus de l'Acad. Sci., CXI. 957, 1590) has shomn that the same condition of things exists among the Amphipoda. I have no doubt that the two forms of the male in the genus. Munida are to be explained in the same way. 
one spine on the distal end of the lower margin; the penultimate and terminal joints are unarmed.

Length, $65 \mathrm{~mm}$.; length of carapace, $34.5 \mathrm{~mm}$. ; breadth of carapace between epimeral sutures, $21 \mathrm{~mm}$. ; length of rostrum, $11 \mathrm{~mm}$.; length of cheliped, $84 \mathrm{~mm}$. (nertus, $26 \mathrm{~mm}$., carpus, $10 \mathrm{~mm}$., basal portion of chela, 18 mm., dactylus, $21 \mathrm{~mm}$.).

Station 3389. 210 fathoms. 2 males, 7 fem.

"3355. 182 " 5 young.

Munida refulgens FAX.

Plate XVII.

Bull. MIus. Comp. Zoöl., XXIV. 177, 1893.

In this species the setre on the ridges of the thorax and abdomen and on the legs are resplendent with iridescent hues. The carapace narrows anteriorly. The rostrum is long, triangular in cross section, the upper surface scabrous, the lateral margins armed with two to four spines, which are generally unsymmetrically placed on the two sides. The supraocular spines are short. There is a transverse line of spinules back of the base of the rostrum, the two which lie on each side of the median line being larger than the others. Seven marginal spines on each side of the carapace, the ones at the antero-lateral angles the largest. There are no spines on the abdominal segments. The abdominal pleurre are acute. The basal joint of the antenna has a plate-like expansion, but is not spinose; the second joint is furnished with an extermal spine. The inferior border of the merus of the third maxilliped is furnished with four spines, the proximal of which is the longest. Chelipeds very long, squamose, and clothed with silky setæ; the merus has a row of spines on the upper margin, another on the inner side, and a row of smaller ones on the outer side; the carpus is provided with three or four spinules at the distal end; the chela is slender, the outer finger flattened, ribbed above, the outer edge rather convex and expanded toward the base; cutting edges of fingers finely denticulated. The anterior border of the merus and carpus of the ambulatory appendages is spinose.

The general color in life is red, deepest on the carapace and chelæ; the transverse setiferous lines of the carapace as well as the dactyli of the ambulatory legs are yellow; eyes black. In the alcoholic specimens the color is retained in the chelæ, and particularly in the rostrum. 
Dimensions of largest specimen (male): length, $91 \mathrm{~mm}$; length of carapace, including rostrum, $43 \mathrm{~mm}$; breadth of carapace, $34 \mathrm{~mm}$.; length of cheliped, $211 \mathrm{~mm}$.; merus, $90 \mathrm{~mm}$., carpus, $15 \mathrm{~mm}$., basal part of chela, $56 \mathrm{~mm}$., dactylus, $42 \mathrm{~mm}$.

Station 3367. 100 fathoms. 13 males, 18 fem. ( 7 ovig.).

" 3378. 112 " 15 males, 19 fem. (14 ovig.).

" 3379. 52 " 1 young.

"3. 3427. 80 " " $\quad 1$ "

In M. iris A. M. Edw., the setæe are iridescent, as in this species, but the rostrum lacks the lateral spines, and the supraocular spines are much longer, reaching beyond the eyes. From M. irrasa A. M. Edw., which is also an iridescent species, M. refulgens differs in the shape of the hand, in the relatively shorter median rostral spine, which is provided with lateral spines, etc.

\section{Munida propinqua FAx.}

Plate XVIII., Fig. 1, $1^{a}$.

Bull. Mus. Comp. Zoöl., XXIV. 178, 1893.

The carapace of this species is rather flat; the rostral spines are scabrous, the supraocular reaching to a point beyond the eyes; there is a promiinent spine on the gastric area behind each suprocular spine, another on each side behind and external to these, and a pair of very small ones on the median line at the base of the rostrum; besides these there are about four small spines on the anterior half of the carapace. The anterior lateral angle of the carapace is truncated, the lateral border seven-spined. The pleure of the abdomen are rounded, short, and broad; the second abdominal segment is furnished with a transverse row of about eight spines, the rest of the segments being destitute of spines; the terga of the second to the fourth segments are very smooth behind the central transverse fossa. The first joint of the antenna is armed with a long spine, the second joint with one on each side. There is a minute spine at the antero-inferior angle of the carapace. The chelipeds are robust, setose, and spiny; rnerus spiny on upper and inner parts; carpus spiny on all sides; the hand is furnished with two rows of spines on the lower side, another along the middle of the outer face, and three irregular series along the upper side; both the fingers are spinulose. Ambulatory limbs setose, spiny along the superior and inferior edges.

In small specimens the supraocular spines may be shorter than the eyestalks. 
Length, $84 \mathrm{~mm}$; carapace (including the rostrum), $45.5 \mathrm{~mm}$; breadth, $26 \mathrm{~mm}$. ; length of cheliped, $96 \mathrm{~mm}$.

Station 3384. 458 fathoms. 11 males, 6 fem. (ovig.).

" 3394. 511 "6 1 male,

"3404. 385 " 1 male juv.

This species resembles $\boldsymbol{M}$. validu Smith and $\boldsymbol{M}$. mites $\mathbf{A}$. M. Edw., but the carapace of $M$. propinqua is flatter, the cardiac aren is more distinctly circumscribed by a furrow, the abdomen bears spines on the second segment only, and the abdominal segments are not so much sculptured.

\section{Munida gracilipes $\mathrm{F}_{A X}$.}

Plate XVI., Fig. 2-2 ${ }^{b}$.

Bull. Mus. Comp. Zoöl., XXIV. 179, 1893.

Carapace rather flat and quadrangular. Supraocular spines less than one half the length of the rostrum, shorter than the ocular peduncle. Four spinules on the gastric area arranged in the form of a square, - two behind each supraocular spine; a longitudinal row of obsolescent spinules in the median line from base of rostrum to the cardiac area; one spine on the cardiac region, a pair on the intestinal region, and one on each side of the cardiac region just back of the cervical suture. The lateral margins of the carapace are armed with about seven spines, the first of which is the largest. The second abdominal segment is armed with a transverse row of six spines, the third with a row of four, the fourth with a row of four, and one median spine behind the transverse row. This is the normal arrangement, but in one specimen out of the four there is an additional pair of spines on the second and third segments back of the transverse row. 'The pleurre of the third, fourth, and fifth abdominal segments are acute. Eyes very large, reniform. The chelipeds are very long and slender, the merus spinose (the chief of the spines being on the inner side of the joint), the carpus also is spinose. The hand has about eight spines on the upper margin and one on the lower; there are several acute spines on the outer border of the movable finger, the cutting edges of the fingers are straight, finely denticulated or spinulose.

Length, $24 \mathrm{~mm}$; breadth, $8 \mathrm{~mm}$; length of cheliped, $34 \mathrm{~mm}$.

Station 3391. 153 fathoms. 4 specimens.

Munida gracitipes is nearly allied to M. stimpsoni A. M. Edw., which it 
appears to represent on the Pacific side of America. When compared with the type specimens of $M$. stimpsoni the differences are very evident, though somewhat difficult to describe. The carapace of $M$. gracilipes is much flatter, smoother, and more shining than in MI. stimpsoni; the transverse ridges are more prominent, fewer in number, and do not show that tendency to break up into imbricated, granulated scales which is so characteristic of MI. stimpsoni. The supracular spines are shorter, closer to the median rostral spine, and fused more completely with the latter at the base. The eye is larger, the transverse ridges on the abdominal somites fewer in number. The lateral spines of the carapace and the abdominal spines are more fully developed. The cardiac area is narrower and bounded by more distinct furrows.

\section{Munida microphthalma A. M. Evw.?}

? Munitla microphthalma A. M. EDW., Bull. Mus. Comp. Zoöl., VIII, 51, 1880. Mrnida microphthalma? FAX., Bull. Mus. Comp. Zoöl., XXIV. 179, 1893.

Station 3370. 134 fathoms. 1 fem. ovig., $20 \mathrm{~mm}$. long.

Compared with the type specimens of Mr. mieroplthalma, the "Albatross" specimen has the rostrum shorter and less strongly upturned; the supraocular spines, too, are shorter (shorter than the eyes). There is no row of spines, but mereiy a ridge, along the superior or external face of the hand. The second abdominal somite bears only two spines instead of eight, as in the type; but this is of no great importance, since the spines of that segment are altogether absent in one of the "Blake" specimens (Station No. 2), and in one noticed by. Henderson in the "Challenger" collections.

Mr. microphthatme was taken by the "Blake" among the West Indies in 573-1030 fathoms, and by the "Challenger" in the same region in 390 fathoms, north of Kermadec Islands in 600 fathoms, and near Ascension Island in 425 fathoms.

GALACANTHA A. M. EDw.

Bull. Mus. Comp. Zoöl., VIII. 52, 1880.

Galacantha rostrata A. M. EDw.

Plate $B$, Fig. 1, $1^{a}$.

Bull. Mus. Comp. Zoöl., VIII. 52, 1850.

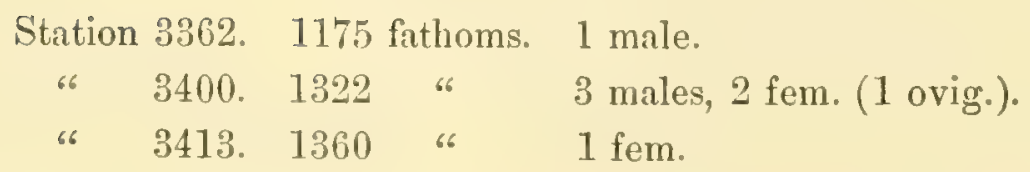


The "Albatross" specimens differ constantly from the typical West Indian form in the following particulars: The spines at the antero-lateral angles of the carapace are more divergent, the anterior spine being more nearly parallel with the axis of the body; the posterior spine is relatively longer; the abdomen is smoother toward the central part of the segments; the dorsal spine of the fourth abdominal segment is smaller. In other regards there is considerable variation among different individuals. The color in life is orange-red, fading into pale yellowish on the carapace and abdomen.

The characters pointed out by Henderson* to separate G. bellis from $G$. rostrata can hardly be deemed of specific value, nor does it seem probable that $G$. talismanii $\dagger$ is anything more than individual, age, or perhaps local variation of the same species. G. talismanii is a manuscript name of A. Milne Edwards's; but this writer appears to have abandoned its claims to recognition as a valid species, since it is not included in his enumeration of the known species of Galacantha given in the "Considérations Générales sur la Famille des Galathéidés." $\ddagger$ Finally, as far as can be determined by WoodMason's short description, G. areoluta $\$$ differs from $G$. rostrata chietly in the coarser granulation of the carapace, and may perhaps be viewed to more advantage as an East Indian race of G. rostrata. If my suspicions concerning the relationship of the above-named forms be well founded, we behold in $G$. rostrata a somewhat variable abyssal species of world-wide distribution, represented on both sides of the Atlantic, off the Pacific coast of America, in the Banda Sea, and in the Bay of Bengal.

The typical form of $G$.rostrata comes from the West Indian region, 10981591 fathoms. It has been figured by S. I. Smith. \|

\section{Galacantha diomedeæ FAx. Plate $X X V$.}

Bull. Mus. Comp. Zoöl., XXIV. 150, 1893.

Rostrum without lateral spines; distal part turned upward at an angle of less than $95^{\circ}$ in most specimens, but in some cases the inclination is greater;

* Ann. MIag. Nat. Hist., 5th Ser., XVI. 418, 1895; Rep. Challenger Anomura, p. 167, Plate XIX. Fig. 6, 1899.

† Henderson, Rep. C'ballenger Anomura, p. 167, Plate XX. Fig. 1, 1889.

† A. Milne Edwards et Bouvier, Ann. Sci. Nat., Zool, fème Sér., XVI. 270, 1594.

\$ Amn. Mag. Nat. Hist., 6tı Ser., VII. 200, 1891.

$\|$ Bull. Mus. Comp. Zoöl., Vol. X., No. 1, Plate IX. Fig. 2, 2a, 1982; Amn. Rep. U. S. Físh Comm. for 1S85, Plate VI. Fig. 1, 1 ${ }^{a}, 1886$. 
basal part marginate, the margin running for some distance along the anterior edge of the carapace; a slight keel runs back from the rostrum to the median gastric spine. Gastric spine smaller than in G. rostrata; anterior lateral spine much longer than the posterior; there is an additional small spine on each side of the carapace just behind the anterior branchial lobe. Anterior half of the carapace ornamented with setiferous squamous tubercles; on the posterior half of the carapace the tubercles assume the form of interrupted transverse ridges. The median spines of the abdomen are small, diminishing successively in size from the first to the third, which is obsolete in many examples. Upper surface of abdomen rather hairy, the transverse ridges devoid of teeth or tubereles, pleurx tuberculose, angles rounded. The legs are rough with granular setose tubercles. There are two prominent spines at the distal end of the carpus of the chelipeds, and one at the distal end of the carpus and merus of the ambulatory limbs. The antennæ are twice and a half as long as the body.

Dimensions of a female specimen: length of body, $79 \mathrm{~mm}$.; length of carapace, $39 \mathrm{~mm}$; breadth of carapace, not including the lateral spines, $25 \mathrm{~mm}$.

This species runs into a well-marked variety in which the anterior lateral spines as well as the median gastric spine are very much smaller than in the typical form. This variety, which I have named Galacantha diomedea, var. parvispina, is figured on Plate XXV., Fig. 2. At one Station (3429) both forms were obtained at the same haul.

G. diomedece differs from all other known species of Galacantha by the rugose character of the sculpture on the hinder half of the carapace. In the relative proportion of the anterior and posterior lateral spines it agrees with $G$. spinosa. It may be easily distinguished from $G$. spinosa by the entirely different sculpture of the carapace, by the absence of transverse rows of tubercles on the abdominal terga, etc.

$\begin{array}{lrrrr}\text { Station } & 3357 . & 782 \text { fathoms. } 1 \text { fem. juv. } \\ \text { " } & 3363 . & 978 & \text { " } & 3 \text { males, } 3 \text { fem. ovig. } \\ \text { " } & 3364 . & 902 & \text { " } & 1 \text { fem. } \\ \text { " } & 3366 . & 1067 & \text { " } & 3 \text { males, } 1 \text { fem. ovig. } \\ \text { " } & 3371 . & 770 & \text { " } & 5 \text { males, } 2 \text { fem. ( } 1 \text { ovig.). } \\ \text { " } & 3373.1877 & \text { " } & 1 \text { male. } \\ \text { " } & 3393.1020 & \text { " } & 3 \text { males. } \\ \text { " } & 3407 . & 885 & \text { " } & 2 \text { males, } 1 \text { fem. }\end{array}$


Station 3429. 919 fathoms 1 male.

Var. parispina.

Station 3418. 660 fathoms. 1 male.

"3419. $772 \quad$ " 1 fem. ovig.

" 3424. 676 " " 1 male.

" 3429. $919 \quad$ " $\quad 1$ male.

6 $3435.859 \quad$ " $\quad 18$ males, 17 fem. (6 ovig.).

"3436. 905 " 6 males, 4 fem. (3 ovig.).

In both $G$. rostrata and $G$. diomedece there is a curious sexual difference In the male the proximal half of the telson is furnished on each side with long, amber-colored setre which are entirely wanting in the female. The same difference between the sexes is found in some species of Mumidopsis.

$G$. diomedece is often invested with parasites. One of the males from Station 3371 bears a Peltogaster, while seven specimens (5 males, 2 females) of var. parvispina house a Bopyrus in the left branchial chamber.

The egrs of this species measure $3 \times 2.5 \mathrm{~mm}$.

\section{MUNIDOPSIS WHITEATES.}

Amer. Journ. Arts and Sci., 3d Ser., VII. 212, 1874.

The type species of this genus is Munidopsis curvirostra Whiteaves, from the eastern coast of North America. The genus has been redescribed by A. Milne Edwards, under the name Gatathodes in the Bulletin of the Museum of Comparative Zoölogy, Vol. VIII., p. 53, 1880. In the same paper Milne Edwards proposed the two genera Orophormynchus and Elasmonotus for the reception of certain species closely allied to Munidopsis. Orophorrhynchs has already been united with Elasmonotus by Henderson. Elasmonotus was instituted to embrace the species characterized by a flat, quadrangular carapace revoid of spines. But such species are connected with the typical Munidopsis by so many intermedinte forms, which may be assigned to either genus at the whim of the describer, that I have united Elasmonotus and Mrmidopsis as one genus. As the genus Anoplonotus of Smith * does not seem to be sufficiently distinct from Elasmonotus, it is here merged, with the latter, in Mumidopsis.

The union of Munidopsis, Orophorrhynchus, and Elasmonotus, necessitates renaming two of Henderson's species, viz. Munidopsis brevimana and Elasmo. notus latifrons, since both of the trivial names had been previously employed

$$
\text { * Proc. U. S. Nat. Mus., VI. 50, } 1 \text { S\$3. }
$$


for other species by A. Milne Edwards (Elasmonotus brevimanus and Galathodes latifrons). For Minidopsis brerimana Hend. may be substituted Mnunidopsis ciliata, a name lately given by Wood-Mason to a Munidopsis from the Bay of Bengal, which does not appear to be distinct from Henderson's species.* Elasmonotus latifrons Hend. may be called Minnidopsis latirostris.

The genus Mfuridopsis, taken in this extended sense, contains about seventy species, sixteen of which were discovered during the voyage of the "Albatross" in 1891, and were first described in my preliminary report on the Crustacea of the expedition in 1893.

After the present report was written I received a memoir entitled "Considérations Générales sur la Famille des Galathéidés," † written by Prof. Milne Edwards conjointly with Mr. E. L. Bouvier. In this memoir the classification of the Galateidee is treated anew and in more detail. All of the genera proposed by the senior anthor in 1880 are retained, although transformed almost beyond recognition by the imposition of new diagnoses and new limitations. Gulathodes is restricted to the species characterized by a broad, flat, triangular rostrum, often carinated on its upper side, and armed towards its anterior end with a pair of prominent lateral spines or teeth, in front of which the distal extremity of the rostrum suddenly contracts. This new diagnosis of the genus Galatiodes eliminates eight of the ten species upon which the genus was originally based, leaving G. latifrons and G. tridens alone in Galathodes, the eight others being transferred to Munidopsis. So of the six species of Orophorrhynchus of the original paper three are now transferred to Munidopsis, one to Elasmonotus, one (O. spinosus) is ignored, leaving but one of the original species, O. wries, in Orophorrhynchus, of which genus it becomes the type.

The difficulty encountered by Prof. Milne Edwards in distributing his own species among his own genera would seem clearly to show the artificial nature of the genera proposed, and amply to vindicate the course of those naturalists who have refused to adopt them.

It is true, as Milne Edwards and Bouvier maintain, that the most characteristic of the species ranged by them in the genera Orophorrhynchus and Elasmonotus differ from the more typical species of Alunidopsis as much as or more than the species assigned to the genus Galacantha. But there is this difference: the species of Galacantha, although they differ but slightly in structure from Minidopsis, yet form a sharply defined and natural group dis-

$$
\text { * See p. 84. † Ann. Sci. Nat., Zool., 7ème Sér., XVI. 191-327, } 1894 .
$$


connected from the latter genus in the absence of transitional species. Galathodes, Orophorrhynchus, and Elasmonotus, on the contrary, are bound by a perfectly graduated series of numerous connecting forms with the typical species of Munidopsis.*

In the large and plastic genus Munidopsis, evolution has progressed along several lines of species, and for the purposes of a monographer it may be useful to assign names to the extremes of modification found within the limits of the genus, in order that the interrelations of the species may be brought into view. This is the function, as I understand it, of the category of classification known as subgemus, in which we see a genus in the process of forming, as it were. By the more or less complete extinction of intermediate species we may assume that genera of the present have come from subgenera of the past, and that future genera will be evolved from subgenera of the present. I would distinguish between genera and subgenera much as the American ornithologists do between species and subspecies. $f$ Viewed in this light, subgenera may play a very useful part in a philosophical system of nomenclature.

\section{Munidopsis bairdii Sмптн.}

Galacantha bairdii Surm, Proc. U. S. Fish Comm. for 1882, p. 356, 1884.

Munidopsis bairdii Sumtı, Proc. U. S. Nat. Mus., VII. 493, 1854; Aun. Rep. U. S. Fish Comm. for 1885, p. 649, Plate V. Fig. 2, 1886.

Station 3381. 1772 fathoms. 1 male.

Differs from the type, as described by Sinith, as follows: the central pair of spines of the gastric area and the anterior pair of spines of the cardiac area are absent; the rostrum has three spines on the right side, four on the left; the posterior margin of the carapace has three spines on the right side, two on the left; the body is slenderer. The differences are perhaps partly individual, partly sexual, Smith's description and figure having been made from a female specimen.

* Professor Henderson in 1855 (Ann. Mrag. Nat. Hist., 5th Ser, XVI. 417) proposed the genus Galathopsis as a refuge for certain species intermediate betreen Mrunidopsis and Elasmonolus. This only added to the difficulty by drawing two arbitrary lines of division in place of one. In his final report on the "Clallenger" Anomura, Henderson suppressed the genus Galathopsis and assigned the intermediate species to Elasmonolus, expressing at the same time his grave doubts concerning the separability of Elasmonotus from IIunidopsis (Challenger Anomura, pp. 158, 165). It is of interest in tlis connection to note that Milne Edwards and Bouvier (op. cit., p. 283) incline to place these same species in Munidopsis rather than in Elasmonotus.

$\dagger$ The Code of Nomenclature and Check-List of North American Birds adopted by the American Ornithologists' Union, being the Report of the Committee of the Uwion on Classification and Nomenclature, p. 31. New York, 1886. 
MT. bairdii has been taken off the east coast of the United States in 1497 and 1742 fathoms.

\section{Munidopsis ciliata WooD-MAson. Plate XVIII., Fig. 3.}

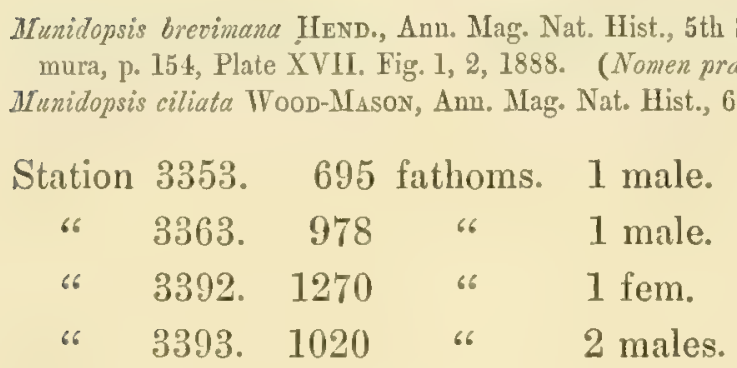

Most of the "Albatross" specimens are more hairy than those described by Henderson. In this respect they agree with $M$. ciliata Wood-Mason. These specimens also show that the number of lateral spines of the carapace, relied upon by Wood.Mason to distinguish his species from M. brevimana Hend., is inconstant.

In some specimens there is an extra spine on each side of the front margin of the carapace, between the suprantennal spine and the spine at the antero-lateral angle.

Just as these pages are going to press, the type specimen of Munidopsis mitida (A. M. Edw.) $\dagger$ is returned from Paris. It is a male $23 \mathrm{~mm}$. long ("Blake" Sta. 163, Guadaloupe, 769 fathoms), and differs from M. ciliate but very slightly. The carapace is less hairy and more polished; the transverse squamiform ridges, which are very evident in $M$. ciliata, are obsolescent. The transverse furrow which divides the terga of the second, third, and fourth abdominal somites into two prominent ridges in $M$. ciliata is but faintly indicated in $M$. nitida. The tubercles on the superior face of the merus of the ambulatory appendages, moreover, are much less pronounced in Milne Edwards's species. In short, M. nitida is a less heavily sculptured and less hairy form than $M$. ciliata. The characters that separate the two forms appear to be of racial or varietal, rather than specific, value, but the name M. ciliata may be provisionally retained for the Pacific and Indian Ocean form until the distribution of each form is more fully known.

* See pp. 81, 82.

† Orophorrhynchus nitidus A. M. Edw., Bull. Mus. Comp. Zoöl., VIII. 59, 1850; Mranidopsis nitida A. M. Edw. et Bouv., Ann. Sci. Nat., Zool., 7ềne Sér., XVI. 275, 1894. 


\author{
Munidopsis vicina $\mathrm{F}_{\mathrm{Ax}}$. \\ Plate XVIII., Fig. 2, $2^{a}$. \\ Bull. Mus. Comp. Zoöl., XXIV. 181, 1893.
}

Near M. ciliata, from which it differs as follows: it is a very much smaller species, the adult ovigerous female being only twenty-nine millimeters long; the anterior margin of the propodite of the ambulatory appendages bears two very prominent spines; on comparing the telson of $M$. vicina with that of M. ciliata a marked difference is apparent in the division of the telson by sutures, - a difference most readily comprehended by a glance at Figs. 2 and 3 of Plate XVIII. The pair of long and narrow plates which lie on each side of the small central plate in $M$. ciliata are entirely wanting in $M$. vicina. As in $M$. ciliata, the carapace of $M$. vicina is covered with squamoid tubercles, the rostrum is curved slightly upward, and the chela is short.

Length, $29 \mathrm{~mm}$; breadth, $9.5 \mathrm{~mm}$.

Station 3360. 1672 fathoms. 1 fem.

“ 3382.1793 " 1 fem. ovig.

The specimen from Station 3360 is a smoother, less setose form than the specimen from Station 3382.

\title{
Munidopsis subsquamosa Hend.
}

Ann. Mag. Nat. Hist., 5 th Ser., XVI. 414, 1S55; Rep. Challenger Anomura, p. 152, Plate XVII. Fig. 4, 1888.

Station 3360. 1672 fathoms. 1 male. “ 3361. 1471 6 1 fem.

The rostrum is curved upward to a considerable degree in the "Albatross" specimens (most strongly in the female), and there are but three spines on the gastric area, - two in a transverse line at the base of the rostrum, and a smaller one in the median line a little further behind. The outer or lower margin of the hand, too, is more concave than in Henderson's figure of $M$. subsquamosa.

The types of this species were taken off Japan in 1875 fathoms. A nearly allied form, $M$. subsquamosa pallide Alcock, ${ }^{*}$ has been dredged in the Bay of Bengal, 1803 fathoms.

\footnotetext{
* Amn. Mag. Nat. Hist., 6rh Ser., XIII. 331, 1894.
} 


\title{
Munidopsis subsquamosa aculeata Hexp.
}

Munidopsis subsquamosa, var. aculeata HEND., Rep. Challenger Anomura, p. 153, Plate XVI. Fig. 1, 1888.

Station 3382. 1793 fathoms. 2 males, 1 fem. ovig.

The rostrum is shorter than is represented in Henderson's figure. In the two males the hind border of the sixth abdominal somite is produced in the median line into a prominent rounded process. The outline of the telson in Henderson's figure is apparently very incorrectly drawn.

The eggs measure $3 \times 3.3 \mathrm{~mm}$.

The "Challenger" specimens were captured between Marion Island and the Crozets in 1375 fathoms, and off the west coast of Patagonia in 1450 fathoms.

This form is closely allied to M. crassa Smith, from off the east coast of the United States, 1742-2620 fathoms. The latter species is distinguished by its large rostrum and the spine which projects from the outer edge of the eye-stalk just behind the cornea.

\author{
Munidopsis villosa FAx. \\ Plate XIX., Fig. 2. \\ Bull. Mus. Comp. Zoöl., XXIV. 182, 1893.
}

The whole surface of the body and limbs is beset with setx which arise from low squamous tubercles and transverse rugx on the carapace and from the transverse ridges of the abdominal segments. The rostrum is triangular, the distal half strongly upturned, cylindrical and pointed, the proximal half naked below and slightly carinated in the median line. A pair of tubercles ending in spiny points lie on the anterior part of the gastric region. One spine at antero-lateral angle of carapace, one at the front end of the anterior branchial lobes, and a rudimentary one further behind on the side of the branchial region. Frontal border armed on each side with a spine over the base of the antenna. There is a median spine on the second, third, and fifth abdominal segments, and a rudiment of one on the fourth. The abdominal pleuræ have rounded external angles. The eyes are freely movable and destitute of spines. The second antennal segment is armed with a prominent

\footnotetext{
* Proc. U. S. Nat. Mlus. VII. 494, 1884; Ann. Rep. U. S. Fish Comm. for 1885, p. 645, Plate IV., 1886.
} 
external spine. The chelipeds are robust, setose, and granulate; the merus has a short superior spine and two lateral spines at the distal end; the carpus is similarly equipped, though on one side the superior spine is obsolescent; the chela is broad and strong, the fingers excavated, denticulated on their cutting edges and at their tips. The merns of the first pair of ambulatory appendages has an external distal spine; the carpus of all the ambulatory limbs has two low longitudinal ridges, and the carpus of the first and second pair has a spine on the upper border at the distal end of the joint.

Length, $55 \mathrm{~mm}$.; breadth, $18 \mathrm{~mm}$.; length of carnpace, $31 \mathrm{~mm}$. ; rostrum, $8 \mathrm{~mm}$.

Station 3394. 511 fathoms. 1 male.

Mruidopsis villosa is very closely allied to the West Indian Minnidopsis abbreviata (A. M. Edw.), ${ }^{*}$ from which it differs as follows: the tubercles and ridges of the carapace are more pronounced and the whole surface of the animal more hairy. The frontal border is armed on each side with a sharp spine, which is wanting in M. abbreviata. The median dorsal spine on the fourth abdominal somite is obsolete, while the fifth somite bears a welldeveloped acute spine, like those on the second and third somites. In M. abbreviata the fifth somite is unarmed. The distal half of the rostrum is curved upward much more strongly in M. villosa than it is in M. abbreviata.

Mtunidopsis villosa is represented by a single specimen in the "Albatross" collection. It is very much larger than the type specimen of $M$. abbreviata from the "Blake" dredgings, and it is possible that the peculiarities above specified may be due to age or individual variation. But I think it more probable that we have to do with two closely allied or representative species on the Atlantic and Pacific sides of the continent.

\section{Munidopsis ornata FAx.}

Plate XX., Fig. 1, $1^{a}$.

Bull. Mus. Comp. Zoöl., XXIV. 186, 1893.

Carapace convex, the whole upper surface, including the rostrum, thickly covered with low squamous tubercles; under a magnifying power the surfice of each tubercle is seen to be made up of a number of secondary scale-like prominences; the tubercles are not lengthened out transversely to form ridges in any part of the surface; two of the tubercles on the gastric

* Galathodes abbreviatus A. M. Edw., Bull. Mus. Comp. Zoöl., VIII. 55, 1880; Munidopsis abbreviata A. M. Edrv, et Bouv., Ann. Sci. Nat., Zool., 7ène Sér., XVI. 275, 1594. 
region take on a spiny character. The rostrum is nearly horizontal, triangular in cross-section, the margins serrate; the anterior border of the carapace is convex between the eyes and the antenne, but has no spine at this point; lateral border four-toothed, one of the teeth lying at the antero-lateral angle, two on the hepatic region, and one on the edge of the branchial region behind the cervical suture; the posterior border is delicately festooned, but not armed with spines. The abdomen is spineless, its surface punctate, anterior half of the pleuræ of the second segment tuberculate, all the pleuræ rounded. The eye has a transverse granulated tubercle running over the cornea from the inner side. The antennæ are very slender and do not exceed the carapace in length. The chelipeds are moderately robust, the merus tuberculate and armed with a row of short spines along the upper edge; the carpus spino-tuberculate, with two longitudinal furrows on the outer side; hand almost smooth on the inner side, outer side and superior surface roughened with low tubercles; fingers curved slightly upward, spoonshaped at the denticulate and setose tips. Ambulatory appendages: meri flattened, tuberculate, upper edge produced to a spinose carina; the carpi have three denticulate ridges; propodites scabrous, with an irregular row of spines on under side; the dactyli have black tips and are finely spinulose on their posterior edges.

Length, $23 \mathrm{~mm}$.; length of carapace, $12 \mathrm{~mm}$.; breadth, $8 \mathrm{~mm}$.; length of rostrum, $3 \mathrm{~mm}$.

Station 3404. 385 fathoms. 1 male.

\section{Munidopsis agassizii FAX.}

Plate XVIII., Fig. 4, $4^{\circ}$.

Bull. Mus. Comp. Zoöl., XXIV. 182, 1893.

The carapace of this species is moderately convex, with a deep transverse depression across the anterior part of the cardiac area. The rostrum is long, slightly upturned, and armed near the middle with a pair of lateral spines. The gastric area has three pairs of spines, the anterior pair the largest. There is one spine on each anterior branchial lobe. The cardiac area bears two or three pairs of spines. The lateral margins of the carapace carry from six to eight spines each, and there is a longitudinal series of small spines within the margin on the branchial area. A small spine is situated on the anterior margin between the eye and the antenna. The posterior 
border of the carapace is ornamented with six (in one specimen seven) spines. There are also several spines on the sides of the carapace below the epimeral suture. There is a very small spine over each eye. The antennæe are shorter than the body, the first joint bears a long external spine, the second joint two lateral spines, the third joint two lateral spines and one superior. The chelipeds are long and slender, the merus and carpus have no long spines, the propodite carries four spines on the upper edge and several rudimentary spinules; the fingers are spinulose, their cutting edges straight and denticulated. The ambulatory appendages have spiny meri and carpi, the longest spines being one at the distal superior border of each of these joints. The second, third, and fourth abdominal terga bear four spines each, and the pleura of the second abdominal somite carry a few spinules. The abdominal pleurxe are rounded:

Length, $23 \mathrm{~mm}$.; length of carapace, $12.4 \mathrm{~mm}$.; breadth of carapace, $8 \mathrm{~mm}$.; length of rostrum, $4.5 \mathrm{~mm}$.

Station 3389. 210 fathoms. 1 male, 1 fem.

This species bears a general resemblance to $M$. erinacea (A. M. Edw.) and MI. spinifera (A. MI. Edw.). It differs from both of these in having a flatter carapace marked by a deeper transverse depression across the cardiac area; in having a larger number of spines on the sides of the carapace; in the presence of spines on the pterygostomian regions, and a small but distinct spine over the eye. It also has strong spines on the superior edge of the hand which are wanting in $M$. erinacen and M. spinifera. In the possession of three pairs of gastric spines it agrees with $M$. spinifera, but differs from M. erinacea.

\section{Munidopsis hystrix FAX.}

Plate XIX., Fig. 1, $1^{a}$.

Bull. Mus. Comp. Zoöl., XXIV. 183, 1893.

Carapace setose and thickly covered with small spinous tubercles; three spines of special prominence on the gastric area disposed in the form of a triangle, with apex directed backward; one on the cardiac area; two (rarely six) on the hind margin of the carrapace; one on each branchial area. There is a spine at the external angle of the orbit, and the lateral margin of the carapace is spinose. The rostrum is long, lightly curved upward from the base to the tip, and armed with from two to five spines on each side; these spines are unsymmetrically arranged on the two sides The second, third, 
and fourth abdominal segments are conspicuously two-ridged; the second segment has a pair of small spines on the anterior ridge, and another pair nearer the median line on the posterior ridge; the third segment also has a pair of spines on the anterior ridge, and in some specimens a third spine in the median line on the posterior ridge. The abdominal pleurae are truncate. The chelipeds are long, very spiny from the proximal end of the merus to the base of the fingers; the chief spines of the propodite are on the upper margin of the segment; there are two spines near the base of the dactylus. The ambulatory appendages are long, setose, and spinose, excepting the dactylus. None of the legs are furnished with epipodites. A spine over the eye. Antennæ shorter than the body; a spine on the outer side of the first segment, one on each side of the second and third segments, and one on the upper surface of the third segment.

Length of ovigerous female, $48.5 \mathrm{~mm}$; length of carapace, $26 \mathrm{~mm}$.; breadth, $15 \mathrm{~mm}$.; rostrum, $8 \mathrm{~mm}$.

Station 3417. 493 fathoms. 1 male, 2 fem. ovig.

" $3424.676 \quad$ " 4 fem. (2 ovig.).

"3425. $680 \quad$ " 7 males, 5 fem. (2 ovig.).

\section{Munidopsis sericea $\mathrm{F}_{\Delta \mathrm{X}}$.}

Plate XIX., Fig. 3, 3a.

Bull. Mus. Comp. Zoöl., XXIV. 184, 1893.

The whole surface of the body and limbs is covered with a silky pubescence. The rostrum is long, curved gently upward, convex above, but not carinated, armed with a prominent spine on each side near the middle, and with three minute spinules near the base. Gastric region swollen, armed with two conical spines and ten or twelve small spinoid tubercles. The cardiac region has a prominent transverse ridge near the centre, in front of which is a deep depression separating it from the gastric region; the ridge is armed with a pair of short spinules. There is a small spine on the anterior border between the eye and the antenna, a large one at the antero-external angle, three on the border of each anterior branchial lobe (the middle one of these three spines is the largest), and one small one on the border of each branchial region just behind the posterior branch of the cervical groove; there are besides about ten spinous tubercles on each branchial area, and five or six pairs of spinules on the posterior margin of the carapace. Ptery- 
gostomian regions granulated. There is a pair of spines on the second, third, and fourth abdominal segments; besides these there are several small spinules on the terga and pleuræe of these segments; the pleuræ are rather narrow, with rounded lateral angles. The chelipeds are wanting in the unique specimen. The ambulatory appendages are spinulose, the spinules of the dactyli restricted to the hind margin. The eye is provided with a a very minute spine. The antennx are rather longer than the body, the basal joint has a short external spine, a longer one at the lower internal angle, and a smaller one at a higher level on the inner side. The latter spine shows, when the animal is viewed from above, between the eye-stalk and the antenna. The subsequent segments of the antenna are armed as usual in this genus.

Length, $39 \mathrm{~mm}$. ; length of carapace, $12 \mathrm{~mm}$; length of rostrum, $8 \mathrm{~mm}$. ; breadth of carapace, $12 \mathrm{~mm}$.

Station 3394. 511 fathoms. 1 male.

\section{Munidopsis margarita FAX. \\ Plate XX., Fig. 2. \\ Bull. Mus. Comp. Zoöl., XXIV. 181, 1893.}

In this species the rostrum has a gentle upward curve near the tip; it is carinate above, and minutely spinulous on the margins. The surface of the carapace is rough with squamous tubercles and forward-pointed spines. The gastric and cardiac regions are prominent, and separated from one another by a deep depression; a pair of spines on the gastric region, and one spine on the cardiac region attain a special prominence. A long sharp spine outside the eye forms the outer wall of a well-marked orbit. There are eight spines on each lateral margin, six on the posterior margin (including those at the postero-lateral angles). The branchial areas are iridescent. Second abdominal segment: the anterior transverse ridge, which is broken down in the centre, bears on each side a prominent hooked spine, which is enlarged at the base, and denticulated on the outer margin; the posterior ridge is furnished with three hooked spines; the pleurx of this segment bear each a broad, flattened, forward-pointing tooth with denticulated edges; when the animal is viewed from above, this tooth appears to form the lateral extremity of the pleura, which really lies below it and is rounded. Third abdominal segment: both ridges are spiny and denticulate, three spines being 
specially prominent on each ridge. Fourth abdominal segment: armed with but one small median spinule. The sides of the carapace below the epimeral sutures are covered with spiny tubercles, and display an iridescent lustre. The eye has two spines projecting over the cornea from the inner side; the posterior of these spines is very minute. 'The antennæ are very slender, and about as long as the carapace; the first and second joints are provided with a prominent external spine, the third joint with three spines, viz. one external, one internal, and one superior. The chelipeds are absent in both the specimens. The ambulatory appendages are spinulose on all the segments except the dactyli, which are finely serrate on the hind margin. The legs, and more especially the sternum, are iridescent, like mother-ofpearl. This iridescence is seen in a less degree in several other species of this genus.

Length, $20 \mathrm{~mm}$. ; length of carapace, $11 \mathrm{~mm}$.; breadth, $7 \mathrm{~mm}$; length of rostrum, $3.5 \mathrm{~mm}$.

Station 3404. 385 fathoms. 1 male, 1 fem.

\section{Munidopsis crinita FAx.}

Plate XX., Fig. 3, 3\%.

Munidopsis crinitu FAx., Bull. Mus, Comp. Zoöl., XXIV. 185, 1893.

Galathodes crinitus A. M. EDw. et Bouv., Ann. Sci. Nat., Zool., fème Sér., XVI. 279, 1894.

The whole surface is clothed with long setæ, which are longest and densest on the chelipeds and ambulatory appendages. The rostrum is very broad at the base, and ends in three points, the middle of which is the longest; the rostrum is slightly carinate in the median line. The carapace is roughened by low setiferous ridges; the antero-lateral angles are obliquely truncate; a spine over the antenna, and four on the lateral margin, the last one just behind the posterior branch of the cervical suture, the third one obsolescent; hind margin unarmed. A pair of spines on the gastric region behind the base of the rostrum. The abdomen is devoid of spines, and there is no spine over the eye. The antennæ are slender, shorter than the body; the basal joint is provided with a long spine on the external side, and another on the internal side; the second joint has an external spine, the third an internal one. Chelipeds: internal edge of merus five-spined, superior edge also furnished with a row of smaller spines; carpus with one prominent internal spine; hand unarmed, broadest at base of fingers, cutting 
edges of fingers toothed. Ambulatory limbs setose, hind border of dactyli spinulose.

Length, $19.5 \mathrm{~mm}$; carapace, $11.5 \mathrm{~mm}$; rostrum, $2.6 \mathrm{~mm}$. ; breadth of carapace, $7.5 \mathrm{~mm}$.

Station 3384. 458 fathoms. 1 fem.

This species, which belongs to the genus Galathodes as recently restricted by MM. A. Milne Edwards and Bouvier, resembles M. tridentatu (Esmark), M. latifrons (A. M. Edw.), and M. tridens (A. M. Edw.). It differs from all these species by its dense pilosity, the shortness of the rostrum, and the great breadth of the hand at the base of the fingers. It firther differs from M. tridentata through the possession of a pair of gastric spines, and through the absence of prominent spines on the meri of the ambulatory appendages; from $M$. latifrons through the presence of gastric spines, and the absence of spines on the tergum of the second abdominal somite; from $M$. tividens through the presence of five internal meral spines and one powerful internal carpal spine borne by the cheliped. MI. tridentata comes from the eastern Atlantic, M. latifrons from the Barbadoes, M. tridens from St. Kitts.

\section{Munidopsis scabra FAx.}

Plate XXI., Fig. 1, $1^{\text {s. }}$

Bull. Mus. Comp. Zoöl., XXIV. 186, 1893.

The rostrum is triangular, slightly curved upward, carinated above, the lateral edges and the carina lightly denticulated. The carapace is covered with squanous setiferous tubercles, which end in spiny points. There is a transverse row of six more prominent spiny tubercles on the gastric region. The posterior border of the carapace is ornamented with a denticulated rim (about eight denticles). There is a spine between the eye and the antenna below the anterior margin of the carapace. The abdomen is devoid of spines, the pleuræ have truncated lateral angles. A very short spine projects over the cornea of the eye. The antenna are shorter than the body; a spine on the outer side of the basal joint, one on each side of the second joint, and one on each side, and one on superior margin of the third joint. 'The chelipeds are long, spinose, except the fingers; hand long, the basal part longer than the fingers. All the joints of the ambulatory appendages are spiny, except the dactyli. 
Length (ovigerous female), $40 \mathrm{~mm}$.; length of carapace, $13.5 \mathrm{~mm}$; breadth, $14 \mathrm{~mm}$; rostrum, $5 \mathrm{~mm}$.

Station, 3424. 676 fathoms. 2 males, 1 female ovig.

3425. 680 " 1 male, 1 " "

Mimidopsis scabra resembles M. sharreri (A. M. Edw.), but may be at once distinguished from the latter by the shortness of the ocular spines, and the great development of the spiny-pointed tubercles of the carapace.

\section{Munidopsis tanneri FAx.}

Plate XXII., Fig. 1, $1^{a}$.

Bull. Mus. Comp. Zoöl., XXIV. 187, 1893.

Carapace flat, quadrangular, covered with squamous setiferous tubercles which have a tendency to develop spiny points on the gastric region. This is especially true of a transverse row of six on the anterior part of this region. The rostrum is triangular and horizontal. There is a prominent spine on each side of the anterior margin of the carapace between the eye and the antenna, another at the antero-lateral angle, and two or three on the side of the anterior branchial lobe; the hind border of the carapace is denticulated. A small spine over the eye. Antenna shorter than the body; one spine on the outer side of the first joint, two lateral and one superior on the second and third joints. Cheliped (present in only one specimen) long, slender; merus and carpus many-spined; propodite spiny along the upper and lower margins; tips of fingers enlarged and denticulated. Ambulatory limbs: a prominent row of spines on the upper edge of the merus and carpus, propodite and dactylus devoid of spines. Abdomen without spines; pleuræ narrow, angles rounded.

Length, $41 \mathrm{~mm}$; length of carapace, $23.5 \mathrm{~mm}$; breadth, $15.5 \mathrm{~mm}$.; rostrum, $6 \mathrm{~mm}$.

Station 3396. 259 fathoms. 2 males, 1 fem. (1 male with Bopyrus.)

$$
\text { "3397. } 85 \quad \text { " } \quad 1 \text { male. }
$$

This species is nearly related to $M$. scabra, but differs from the latter species in having the carapace broader and flatter, with squamous tubercles which are not produced into points, except a few on the gastric area. The spine between the eye and the antenna is longer; the propodites of the ambulatory legs are smoother, with no well-developed spines. 


\section{Munidopsis hamata Fax.}

Plate XXI., Fig. $\mathscr{2}, \mathscr{2}^{a}, \mathscr{2}^{b}$.

Bull. Mus. Comp. Zoöl., XXIV. 187, 1893.

Body and limbs clothed with short, scattered setx. Rostrum long, curved slightly upward, basal half furrowed longitudinally, with a row of short spines on each side of the furrow; infero-lateral edges of rostrum also furnished with small spines. Carapace quadrangular, anterior border forming a right angle with lateral border, both borders spinulose; lateral border with an indentation at anterior boundary of anterior branchial lobe; a deep depression back of each anterior branchial lobe, and another across the anterior part of the cardiac region; the upper surface of the carapace is adorned with spinulose tubercles, and a median longitudinal row of more prominent spines runs along the gastric and cardiac regions; the anterior spine of the cardiac region overhangs the transverse depression, the posterior spine of the row springs from the hind rim of the carapace. There is a median hooked spine on the tergum of the second, third, fourth, and fifth abdominal segments, and many spiny tubercles irregularly disposed on these segments; the pleuræe of the third to the sixth abdominal segments are narrow but blunt, those of the second to the fifth are costate. The ocular peduncle is movable, and devoid of a spine. The antenna are about as long as the body; the basal joint has an inferior spine and a small external spine; the second joint also bears an external spine. The chelipeds are long and slender, all the joints from the ischium to the propodite are equipped with longitudinal rows of small spines; the chela is not broader than the basal part of the propodite, the fingers are straight, their prehensile edges denticulate. The ambulatory appendages are spinulose. There are no epipodites on the five pairs of legs.

Length of a male, $49 \mathrm{~mm}$. ; length of carapace, $25 \mathrm{~mm}$; breadth of carapace, $14 \mathrm{~mm}$.; length of rostrum, $9 \mathrm{~mm}$; length of cheliped, $47.5 \mathrm{~mm}$. (merus, $15 \mathrm{~mm}$. , carpus, $5.5 \mathrm{~mm}$., chela, $19 \mathrm{~mm}$.).

Station 3394. 511 fathoms. 13 males, 16 fem. ovig.

" $3395.730 \quad$ 6 3 males. 


\section{Munidopsis depressa FAx. \\ Plate XXII., Fig. 2, $2^{a}, 2^{b}$. \\ Bull. Mus. Comp. Zoöl., XXIV. 189, 1593.}

Closely allied to M. hamata, but differs as follows: the cephalothorax is more swollen, so that the sides of the carapace are visible below the epimeral sutures when the animal is viewed from above. The median row of spines on the carapace consists of a smaller number of spines (two on the gastric region, one on the cardiac region, and one on the posterior margin). The spinules of the lateral margin of the carapace are less developed. The depression on the carapace involves the gastric region to a greater degree. The anterior margin of the carapace is not so straight, and it is not spinuliferous. The antero-lateral spine is more prominent, the eyes smaller, and the antennse shorter (shorter than the carapace). There is, moreover, no spine on the fifth abdominal segment.

Length, $32 \mathrm{~mm}$. ; carapace, $19 \mathrm{~mm}$.; rostrum, $5 \mathrm{~mm}$; breadth of carapace, $12.5 \mathrm{~mm}$.

Station 3425. 680 fathoms. 1 male.

\section{Munidopsis aspera (HEND.).}

Elasmonotus asper Hend., Aun. Mag. Nat. Hist., 5th Ser., XVI. 416, 1S85; Rep. Challenger Anomura, p. 163, Plate XIX. Fig. 4, 1888.

MIunidopsis aspera FAx., Bull. Mus. Comp. Zoöl., XXIV. 188, 1893.

Station 3357. 782 fathoms. 1 fem. ovig.

$\begin{array}{lllll}\text { " } & 3358 . & 555 & \text { " } & 1 \text { male. } \\ \text { " } & 3370 . & 134 & \text { " } & 1 \text { fem. } \\ \text { " } & 3402 . & 421 & \text { " } & 2 \text { males, } 5 \text { fem. ( } 3 \text { ovig.). } \\ \text { " } & 3403 . & 384 & \text { " } & 1 \text { male. } \\ & 3406 . & 551 & \text { " } & 2 \text { males. }\end{array}$

This species is subject to considerable variation. In the specimens from Stations 3402, 3403, and 3406, the tubercles of the carapace are more numerous and less spiny than in those secured at the other stations. The ambulatory appendages of all the "Albatross" examples are apparently more spiny than in the types from the "Challenger." The latter came from the Straits of Magellan, 245 fathoms. 


\section{Munidopsis quadrata FAX}

Plate XXIII., Fig. 1, $1^{a}, 1^{b}, 1^{c}$.

Munidopsis quadrata Fax., Bull. Mus. Comp. Zoöl., XXIV. 188, 1893.

Elasmonotus quadratus A. M. EDw. et Bouv., Ann. Sci. Nat., Zool., 7ème Sér., XVI. 281, 282, 1894.

Carapace quadrangular, the anterior and lateral margins forming a right angle; upper surface llat, spineless, but furnished with low squamous tubercles. Rostrum curved upward, broad at base, narrowing anteriorly to form a long sharp acumen. Central part of gastric region prominent above the anterior branchial lobes, from which it is separnted by deep pits. A prominent transverse ridge on cardiac region forming the posterior wall of a deep fossa. Antero-lateral angles rounded. Second segment of abdomen armed with a median spine, which is curved forward; third and fourth segments with a very prominent ridge, which bears an acute median tooth; pleurx of second segment faintly tuberculate, the others narrow, with the external angles rounded but not truncate. Eye spineless, almost concealed by the base of the rostrum. Antennæe about as long as the carapace; a conspicuous spine on the upper side of the third segment. Cheliped long, tuberculate, with the exception of the fingers; chela slender, fingers not gaping. Ambulatory legs tuberculate, with the exception of the dactyli, which are furnished with small teeth on their posterior margins.

Length of body, $29 \mathrm{~mm}$. ; length of carapace, 15.5. mm.; breadth of carapace, $9 \mathrm{~mm}$.; length of rostrum, $6 \mathrm{~mm}$; length of cheliped, $30 \mathrm{~mm}$.

There is some variation in the length and upward curvature of the rostrum among the different specimens. A female from Station 3424 (Plate XXIII., Fig. $1^{c}$ ), differs markedly from the males, in having the tubercles on the carapace and appendages much more strongly developed.

Station 3424. 676 fathoms. 2 males, 1 fem. ovig.

$$
\text { "3425. } 680 \quad \text { "6 } 1 \text { male. }
$$

\section{Munidopsis carinipes Fax.}

$$
\text { Plate XXIV., Fig. 1, } 1^{a}, 1^{b} \text {. }
$$

Munidopsis carinipes Fax., Bull. MIus. Comp. Zoöl., XXIV. 159, 1893.

Elasnonotus carinipes Alcock, Ann. Mag. Nat. Hist., 6th Ser., XIII. 333, April, 1894.

" "A. M. EDw. et Bouv., Ann. Sci. Nat., Zool., 7ème Sér., XVI. 281, 282, Mã, 1894.

Carapace quadrangular, flat, marked by a median tuberculated ridge on the gastric and cardiac regions; sides converging a little from front back- 
ward; the antero-lateral angles form a rounded shoulder. Rostrum broad at base, nearly horizontal; sides converging near tip, which is blunt; upper surface nearly flat, lightly granulated. The rest of the upper surface of the carapace has a coarser granulation. There is a conspicuous hooked tooth on the third and the fourth abdominal segments, and in some specimens there is a rudimentary one on the second and the fifth segments; the teeth on the third and fourth segments have denticulated margins in adult specimens; abdominal pleurse long and narrow. Chelipeds very long, lightly tuberculate; chela long, slender; fingers rather short, smooth, with straight, denticulated prehensile margins. The meri of the ambulatory legs granulated; superior border produced to a crest, the edge of which is entire; the lower margin of the meri is also entire; the carpi have three tuberculated ridges, one of which is superior, two external ; the propodites lightly tuberculated; dactyli smooth, their hind margins armed with about five teeth. Eye spineless, nearly hidden under the rostrum. Antennæ shorter than the carapace; first, third, and fourth joints armed with an external spine.

Length, $30 \mathrm{~mm}$. ; carapace, $16 \mathrm{~mm}$. ; breadth, $9.5 \mathrm{~mm}$. ; rostrum, $5 \mathrm{~mm}$. ; cheliped, $40 \mathrm{~mm}$. (merus, $13 \mathrm{~mm}$., carpus, $4.5 \mathrm{~mm}$., propodite, $17 \mathrm{~mm}$., dactylus, $7 \mathrm{~mm}$.).

Station 3353. 695 fathoms. 2 males, 1 fem. ovig.

Near M. longimana (Elasmonotus longimanus A. M. Edw.), from which it differs in having the rostrum more nearly plane and more tapering, the merus of the cheliped much less strongly tuberculated, the meri of the ambulatory limbs more strongly carinated, with lower margin entire instead of denticulate; the spine on antennal peduncle is more prominent, while the tooth on the second segment of the abdomen is absent, or at best rudimentary. The chelipeds of the female specimen of $M$. carinipes are lost.

Munidopsis inermis FAX.

Plate XXIII., Fig. 2, 2a.

Bull. Mrus. Comp. Zoöl., XXIV. 191, 1893.

In this species the whole surface of the body and appendages is naked and free from spines and tubercles. The carapace is rather flat above, with subparallel sides; the gastric region is protuberant, and separated from the kepatic and cardiac areas by conspicuous furrows. The surface of the carapace is punctate, lightly granulate and rugose on the branchial regions. 
The rostrum is triangular, blunt at the apex, bent strongly downward, and slightly carinate above. The antero-lateral angle is rounded, and a rounded lobe projects from the anterior margin above the base of the antenna. The abdomen is smooth, naked, devoid of spines and ridges; the abdominal pleuræ are rounded. Ocular peduncle free, spineless. The peduncle of the antenna is also destitute of spines; the flagellum is wanting in the only specimen obtained. The chelipeds are also missing. The ambulatory appendages are smooth, unarmed; the dactyli long (equal to the propodites in length), slightly curved, acute at the tips. The appendages of the third, fourth, and fifth abdominal segments are simple and rudimentary. The merus of the third maxillipeds is short, its antero-internal margin three-toothed; the palpus of this appendage is nearly as long as the merus and ischium combined.

Length $12 \mathrm{~mm}$.; carapace, $6 \mathrm{~mm}$. ; breadth, $4 \mathrm{~mm}$.

Station 3354. 322 fathoms. 1 male.

This species nearly resembles $\boldsymbol{M}$. polita (Anoplonotus politus Smith), but the carapace of the former is longer and narrower, the rostrum is curved more strongly downward, and the propodites of the ambulatory limbs are much shorter in proportion to the dactyli.

\section{Munidopsis latirostris FAx.}

Elasmonotus latifrons Hexd., Ann. Mag. Nat. Histo, 5th Ser., XVI. 416, 1885; Rep. Challenger Anomura, p. 160, Plate XIX. Fig. 1, 15s8. (Nom. preoc.)*

Orophorhynchus latifrons A. MI. EDw. et Bouv., Ann. Sci. Nat., Zool., 7'ìmo Sér., XVI. 287, 1894.

Station 3381. 1772 fathoms. 1 fem.

“3391. $153 \quad$ " 301 “

In his first description of this species Prof. Henderson describes the eye-stalks as fused with the sides of the rostrum, while in his final report he states that they are slightly movable. In the "Albatross" specimens they are firmly soldered to the rostrum. Henderson also says that the ambulatory limbs have a few short blunt spines on the anterior margin of the meri, carpi, and propodites. In the "Albatross" specimens the spines of the meri are on the posterior margin of the joint, but these specimens agree so well with Henderson's description in other respects that I do not doubt that they belong to the same species. The unique "Challenger" specimen was obtained between Papua and the Admiralty Islands at a depth of 1070 fathoms. 


\section{Munidopsis hendersoniana FAx.}

$$
\text { Plate XXIV., Fig. } 2, \mathscr{2}^{a}, \mathscr{2}^{b}, \mathscr{2}^{c} \text {. }
$$

Munidopsis hendersoniana Fax., Bull. Mus. Comp. Zoöl., XXIV. 190, 1893.

Orophorhynchus hendersonianus A. M. Edw. et Boov., Ann. Sci. Nat., Zool., 7ème Sér., XVI. 287, 1894.

In this species, as in $M$. marginata (Elasmonotus marginatus Hend.), $M$. cdvardsii (Elasmonotus edwardsii W.-M.), etc., the lateral margins of the carapace are produced into sharp crests which overhang the sides of the body. The upper surface of the carapace is rather flat, and is clothed with a close, short pubescence; the sides of the carapace are nearly parallel. The rostrum is long, acute, nearly horizontal, the upper surface roof-shaped. There is a prominent tooth at the external orbital angle, and another smaller one at the antero-external angle of the carapace; otherwise the carapace is unarmed. The eye-stalks are immovable, their proximal ends being anchylosed with the ocular segment; they project forward far beyond the eye, forming sharp horns one half as long as the rostrum; seen from above, the eye-stalks appear like lateral spines of the rostrum; they are pubescent, like the carapace. The antennx are shorter than the body; their basal segments are armed with a prominent triangular tooth on the anterior margin of the lower side, while the second segments are similarly equipped with a tooth on the outer side. The chelipeds are short and pubescent; there is a prominent spine at the distal superior angle of the ischium, and a tooth near the distal end of the internal margin; five or six teeth along the superior margin of the merus, and one on each side of the distal end of the same segment; the carpus bears a superior tooth near the proximal end, together with three teeth on the distal margin; the chela is short and thick, the hand devoid of teeth or spines; the fingers are very short and thick, meeting one another only at their spoon. shaped denticulated tips; there is a rounded tubercle at the base of the inner margin of the immovable finger; the outer margin of this finger is denticulated. Ambulatory limbs: five to seven spines on the superior and external inferior margin of the meri (those on the superior margin the largest); upper edge of carpus three to four-spined; propodites unarmed; inner margin of dactyli denticulated. Abdomen without spines, somewhat tomentose.

Length, $37 \mathrm{~mm}$. ; carapace, $20 \mathrm{~mm}$. ; rostrum, $6.5 \mathrm{~mm}$; breadth of carapace, $12 \mathrm{~mm}$; length of cheliped, $28 \mathrm{~mm}$.

Station 3393. 1020 fathoms. 3 males, 1 fem. (with Pellogaster). 
Nearly allied to M. edwardsii (IVood-Mason)* of the Bay of Bengal, but easily distinguished from that species by the lateral margins of the carapace, which in Wood-Mason's species are divided into two lobes, whilst in M. hendersoniana they are entire.

UROPTYCHUS HEND.

Diptychus A. M. Eprr., Bull. Mus. Comp. Zoöl, VIII. 61, 1850 (nom. preoc).

Uroptychus HeNd, Rep. Challeuger Anomura, p. 173, 1588.

\section{Uroptychus nitidus occidentalis $F_{A x}$.}

Plute NIII., Fig. 1, $1^{\text {. }}$.

Uroptychus nitidus occidentalis FAX., Bull. MIus. Comp. Zoöl., XXIV. 192, 1893.

Diptychus nitidus, var. occidentalis A. M. Edw. et Bouv., Ann. Sci. Nat, Zool., fème Sér., XVI. 306, 1894.

Differs from the typical Uroptychus mitidus (A. M. Edw.) $\dagger$ as follows: the branchial regions are more swollen, giving to the posterior half of the carapace a more convex lateral outline; the rostrum is shorter, the chelipeds shorter and more robust, the fingers shorter in proportion to the length of the basal part of the propodite; the branchial regions are more distinctly margined. It approaches in some respects $U$. uncifer (A. M. Edw.), in which the rostrum and chelipeds are still shorter. U. politus Hend., another closely related form, is distinguished by its short antennal acicle.

Length of body of a female, $29 \mathrm{~mm}$.; length of carapace, $15 \mathrm{~mm}$.; length of rostrum, $4 \mathrm{~mm}$. ; breadth of carapace between antero-lateral spines, $5 \mathrm{~mm}$. breadth across the branchial region, $10 \mathrm{~mm}$; length of cheliped, $44.5 \mathrm{~mm}$. (merus, $11 \mathrm{~mm}$., carpus, $12.5 \mathrm{~mm}$., chela, $17.5 \mathrm{~mm}$., dactylus, $6 \mathrm{~mm}$.).

Station 3384. 458 fathoms. 2 males, 2 fem. ovig.

\section{Uroptychus pubescens Fax.}

$$
\text { Plate XXVI., Fig. 3, } 3^{a}, 3^{b} \text {. }
$$

Uroplychus pubescens Fax., Bull. MIus. Comp. Zoöl., XXIV. 192, 1893.

Diptychus pubescens A. M. Eow. et Boov., An». Sci. Nat., Zool, 7 ème Sér., XVI. 306, 1 S94.

Carapace, without including rostrum, broader than long, pubescent; a transverse row of spines across the gastric region from one side of the carapace to the other; lateral border of carapace spinose; the anterior margin

* Ann. Mag. Nat. Hist., 6th Ser., VII. 201, 1591.

† Bull. Mus. Comp. Zoöl., ViII. 62, 1850. 
has a deep concavity above the eye, outer angle of the concavity armed with a spine. Rostrum one half as long as the rest of the carapace, bent downward a little, acute, with entire setiferous margins. Eye small, not broader than the eye-stalk, with brown pigment. Abdomen naked, smooth, pleuræ subacute. Antennx equal in length to the carapace with the rostrum; acicle shorter than the peduncle. Chelipeds long, all the joints as far as the fingers spinulose, the spinules with broad bases; propodite not broader than the carpus; carpus equal in length to the basal portion of the propodite; fingers straight, a slight tooth near the base of the dactylus; the tips of the fingers cross. Meri of ambulatory legs minutely spinulose on the superior margin, distal end of propodite spiniferous on the hind margin, whole hind margin of dactylus armed with spines; all the joints of the ambulatory limbs furnished with long setæ.

Length (female), $44 \mathrm{~mm}$; breadth, $17.5 \mathrm{~mm}$.; length of carapace, $21 \mathrm{~mm}$.; length of rostrum, $7.5 \mathrm{~mm}$. ; length of cheliped, $57 \mathrm{~mm}$. (merus, $12 \mathrm{~mm}$., carpus, $15 \mathrm{~mm}$., chela, $24 \mathrm{~mm}$., dactylus, $9.3 \mathrm{~mm}$.).

Station 3354. 322 fathoms. 2 fem. ovig. " $3355.182 \quad$ " 1 fem. ovig.

This species is more nearly related to $U$. insignis Hend. than to any other described species.

\author{
Uroptychus bellus Fax. \\ Plate XXVI., Fig. 2, $2^{a}, \mathscr{2}^{b}$.
}

Uroptychus bellus FAx., Bull. Mus. Comp. Zoöl, XXIV. 193, 1893.

Diplychus bellus A. M. Enw. et Bovv., Ann. Sci. Nat., Zool., Tème Sér., XVI. 306, 1894.

Carapace broad, branchial regions inflated, upper surface naked, smooth, and polished; the branchio-cardiac lines meet in the median line of the carapace; the anterior margin has a concavity above the eye, forming an orbit with a spinule at its external angle. There is one spine at the anterolateral angle of the carapace, and ten or eleven on the lateral margin; the lateral spines decrease in size posteriorly. The rostrum is long, tapering, acute at the apex, and concave at the base above. The abdomen is smooth, the pleuræ subacute. The eye-stalks are short and stout, the eye not wider than the peduncle, black. The antennx are very slender, shorter than the carapace, the acicle considerably shorter than the peduncle. Chelipeds very long, naked except for a few setw on the fingers, polished; the ischium bears a spine on the superior margin and several others on the 
lower side; the merus and carpus are armed with spines arranged in longitudinal rows; there is a row of spines on the upper margin of the propodite (the row is double at the proximal end), another series on the outer face reaching from the proximal end about half way to the distal end, and another still shorter row of more rudimentary spines just outside the latter series; the fingers are separated by a gap; their prehensile edges are denticulate, with one or more prominent teeth near the base of the dactylus. Ambulatory appendages: meri and carpi of the first and second pairs spinulose along the upper edge, these joints being spineless on the third pair. All of the ambulatory appendages are subchelate, the distal end of the propodite being enlarged and furnished with spines against which the spined dactylus closes.

Length (male), $17 \mathrm{~mm}$; carapace, $10.5 \mathrm{~mm}$. ; rostrum, $4.5 \mathrm{~mm}$.; breadth of carapace, $7.7 \mathrm{~mm}$; cheliped, $31 \mathrm{~mm}$. (merus, $7 \mathrm{~mm}$., carpus, $9 \mathrm{~mm}$., chela, $14 \mathrm{~mm}$., dactylus, $5 \mathrm{~mm}$.).

Station 3354. 322 fathoms. 1 fem. ovig.

"3355. 182 " 1 male.

FAMILY AXIIDA.

AXIUS LEach.

Trans. Linn. Soc. London, XI. 335, 343, 1815.

Axius acutifrons (Bate).

Plute XXVIII., Fig. 2.

Eiconaxius acutifrons BATE, Rep. Challenger Macrura, p. 40, Plate V. Fig. 2, 1588.

Axius acutifrons Fax., Bull. Mus. Comp. Zoöl., XXIV. 193, 1593.

Station 3358. 555 fathoms. 2 males, 4 fem. ovig.

" 3359. 465 " " 3 males, 3 fem. (2 ovig.).

The Challenger specimens were taken off Banda, lat. $4^{\circ} 31^{\prime} \mathrm{S}$., long. $129^{\circ} 57^{\prime} 20^{\prime \prime} \mathrm{E}$, in 360 fathoms.

The females carry about nine eggs, which are large for the size of the animal $(1.5 \times 1 \mathrm{~m}$. $)$.

Spence Bate established the genus Eiconaxins to receive three species from the "Challenger," which differ from Axius stirhynchus Leach - the type of the genus Axius - in the presence of a long spine (stylocerite) on the second joint of the external antennw outside of the movable acicle (scapho- 
cerite). In the figures of Axius stirhynchus given by Leach, and by Milne Edwards, $\uparrow$ a short stylocerite is discernible, and in some of the species referred to Axius by recent authors, this structure appears to assume larger proportions. For instance, in Axius armatus Smith, $\neq$ the stylocerite is described as "slender, acute, and more than half as long as the rest of the segment, while the acicle [scaphocerite] is slender, straight, and as long as the fourth segment." I have therefore provisionally united the genera Eiconaxius and Axius.ई

\section{Axius crista-galli $\mathrm{F}_{\mathrm{Ax}}$.}

Plate XXVIII., Fig. 1-1 $1^{h}$.

Bull. Mus. Comp. Zoöl., XXIV. 193, 1893.

This species agrees closely with $A$. acutifrons in all its parts except the rostrum and the larger claw, which differ as follows: the margins of the rostrum, which in $A$. acutifrons are only microscopically denticulated, are in the present species armed with prominent teeth; the median carina of the rostrum, entire, or at most but slightly serrate in the former species, is here cut into about seven prominent teeth, so as to resemble a low cock's-comb. The larger claw (which is on the left side in three specimens, on the right side in two) differs from the corresponding structure of $A$. acutifrons in lacking the serration on the superior margin of the propodite, in the presence of a strong tubercle on the anterior border of the hand between the bases of the fingers, and in the absence of prominent teeth on the prehensile edges of the fingers. For a comparison of the claws of these two species, see Plate XXVIII., Fig. 1, 2. The eyes are faceted, but nearly colorless in this species and in A. acutifrons. If Bate's genus Eiconaxius be adopted as a valid one, this species will be included in it.

Length of a male, $24.5 \mathrm{~mm}$.; length of carapace, $10 \mathrm{~mm}$.

Station 3359. 465 fathoms. 3 males, 1 fem. ovig.

The female carries eighteen egrgs of large size $(2 \times 1.5 \mathrm{~mm}$.).

* Malacostraca Podophtlu. Brit., Plate XXXIII. Fig. 2.

† Cuvier's Règne Auimal, Disciples' ed., Plate XLVIII. Fig. $2 a$.

+ Proc. U. S. Nat. Mus., III. 433, 1881.

$\S$ According to Ortmann (Zoolog. Jahrb., Abth. f. Sjst., VI. 46, 1891) the presence of sexual appendages on the first abdominal somite of the male is characteristic of the family Axiide. But in Eiconarius aculifrons Bate, and in the closely related species Axius crista-galli Fax., the first abdominal somite is entirely devoid of appendages in the male sex, and Ortmann (op. cit., p. 50) states that the abdominal appendages of Eiconaxius farrece are like those of $E$. acutifrons. 


\section{CaLastacUs Fax.}

Bull. Mus. Comp. Zoölo, XXIV. 194, 1993.

Cephalo-thorax laterally compressed. Abdomen long, enlarged in the middle, narrowed at each extremity, pleuræ broad and rounded. Rostrum long, pointed; eyes rudimentary, subglobose, without pigment and unfaceted. Second antennæ on a horizontal line with the first antennæ; the second segment is armed with a long external spine (stylocerite), and a still longer articulated style-shaped scale (scaphocerite). Third maxillipeds pediform. First and second pairs of legs chelate. First abdominal appendages of the male modified to serve as sexual organs (gonopods). Outer branch of the swimmerets divided near the posterior margin by a diagonal suture. T'elson long, quadrangular. Gills composed of a central stem, bearing two rows of filaments. The number and arrangement of the gills are shown by the following formula:-

$\begin{array}{lcccccccc}\text { Somites } & \text { VIII.* } & \text { IX. } & \text { X. } & \text { XI. } & \text { XII. } & \text { XIII. } & \text { XIV. } & \\ \text { Epipods } & 1 & 1 & 1 & 1 & 1 & 1 & 0={ }^{(6)} \\ \text { Podobranchiæ } & 0 & 1 & 1 & 1 & 1 & 0 & 0=4 \\ \text { Arthrobranchiæ } & 0 & 2 & 2 & 2 & 2 & 2 & 0=10 \\ \text { Pleurobranchiæ } & 0 & 0 & 0 & 0 & 0 & 0 & 0=0 \\ & & & & & & & & \end{array}$

This genus is closely related to Calocaris Bell. In both genera the condition of the aborted eyes is the same; the two anterior pairs of legs alone are chelate; the first abdominal segment bears, in the male, a pair of specialized sexual appendages, and the outer plate of the sixth pair of abdominal appendages is divided near the end by a diagonal suture. I have not seen females of either genus, nor have I examined the gill arrangement of Calocaris, there being but two specimens of Calocaris macandrea in this Museum. $\dagger$

The presence of a long styloid scaphocerite appended to the peduncle of

* The somite which bears the second pair of maxillipeds is here reckoned as the eighth.

† According to Ortmann (Zoolog. Jahrb., Abth. f. Syst., VI. 50, 1891) the branchial formula for Calocaris macandrece is as follows:-

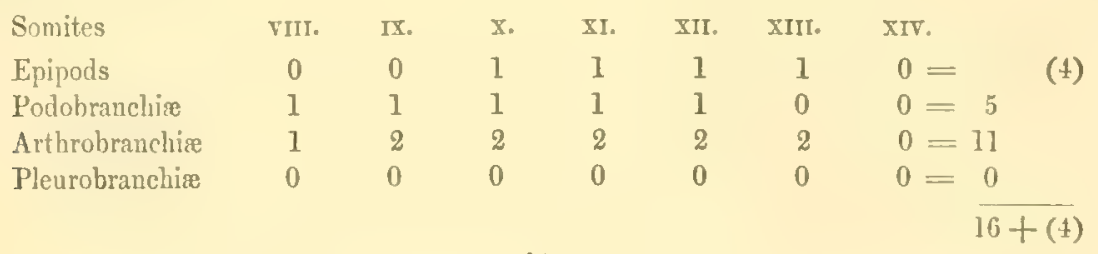


the second antennæ distinguishes Calastacus from Calocaris. The second antenna of Calocaris macandrea is represented on Plate XXVII., Fig. 2, 2a, for comparison with the same organ of Calastacus (Fig. $1^{c}$ ).

\section{Calastacus stilirostris FAX.}

Plate XXVII., Fig. 1-1 $1^{f}$.

Bull. Mus. Comp. Zoöl. XXIV. 194, 1893.

Male. - Carapace laterally compressed, naked, punctate ; rostrum long, narrow, acute, apex slightly upturned; two strong spines directed upward and forward at the base of the rostrum; from the root of the rostrum the median dorsal line of the carapace is very convex; a light median carina runs along the back from the base of the rostrum, fading out before reaching the hind border of the carapace. The gastric area is lightly corrugated on each side of the carina. Abdomen longer than the carapace (including the rostrum), naked, smooth; first segment small, with rudimentary pleural projections; pleurse of the succeeding segments broad, rounded, and bent outward; telson long, quadrangular, with convex hind border.

Eyes rudimentary, subglobose, devoid of pigment and corneal facets. Peduncle of first antenna composed of three stout segments, decreasing in size successively from the first to the third. Basal segment of second antenna provided with a sharp spine on inner edge of lower side; second segment armed with a long and sharp distal external spine (stylocerite); from between the base of this spine and the following segment springs a slender, sharp, articulated spine (scaphocerite) which nearly reaches the end of the succeeding segment; inner edge of the second joint also carries a median and a distal spinule, the latter of which is the larger; the third and fourth segments are unarmed, the latter short and carrying a long flagellum, which exceeds the whole length of the body. Epistome largely developed, terminating anteriorly in a triangular process at the base of the antennules.

Chelipeds long, symmetrical on the two sides; coxa furnished with a small spine on the anterior border of the distal end; the ischium has from one to four spines on the lower margin; merus laterally compressed, armed with a spine on the upper edge near the distal end, and a variable number of spines (four to eight) on the lower edge; one of these, near the distal end of the segment, is very long; there is also a small spine on the ex- 
ternal margin of the merus at its point of articulation with the carpus. Carpus triangular, unarmed. Chela with sharp upper and lower margins; upper margin with five to seven spines, inner and outer faces with a few scattered spinules; fingers with denticulate prehensile margins and curved crossed tips. Second pair of legs also chelate, but the chela is small. The remaining pairs of legs are not chelate, the dactyli curved, slender, and acute.

The first abdominal appendages are modified for copulatory purposes; they are composed of a basal stem which bears an expanded terminal plate concave on its inner face (Plate XXVII., Fig. $1^{d}$ ). The second abdominal limb consists of a basal stem which carries a three-jointed inner and a multiarticulate outer branch; at the proximal end of the second joint of the inner branch is a minute blunt process (stylamblys of Bate). The three following pairs of abdominal appendages are made up of a stem and two terminal branches, the inner of which bears a rather long and slender stylamblys. 'The last pair of abdominal appendages, or swimmerets, are broad; both branches have a longitudinal median rib, and the outer branch is divided near the tip by a suture that runs diagonally from the external margin to the posterior margin; along this suture are seen articulated spinules, and there is also an unarticulated spine on the external border of the inmer plate near the distal end.

For the branchial formula, see p. 105, under the generic diagnosis.

Length of carapace, $22.2 \mathrm{~mm}$.; rostrum, $5.5 \mathrm{~mm}$. ; abdomen, $30 \mathrm{~mm}$.; cheliped, $39 \mathrm{~mm}$.; merus of cheliped, $14 \mathrm{~mm}$.; chela, $17 \mathrm{~mm}$.

Station 3418. 660 fathoms. 9 males.

\section{Famity PALINURIDA.}

PANULIRUS GRAY.

List Crust. Brit. Mus., p. 69, $18 \pm 7$.

\section{Panulirus sp.}

A small specimen of Pamulirus, $23 \mathrm{~mm}$. long, was taken at Station 3354 , 322 fathoms. It is too young to show its specific characters.

The only other representatives of this family found in the collection are seven specimens in the Phyllosoma stage. 


\section{FAMILY ERYONTID $\approx$.}

ERYONICUS BATE.

Amn. Mag. Nat. Hist., 5th Ser, X. 456, 1882; Rep. Challenger Macrura, p. 122, 18s8. [Eryoneicus.]

The genus Eryonicus was established by Spence Bate for the reception of a remarkable Eryonid, Eryonicus ccens Bate, secured during the voyage of the "Challenger," Feb. 11, 1873, off the Canary Islands, ostensibly from a depth of 1620 fathoms. This specimen, which was only $13 \mathrm{~mm}$. $\left(\frac{1}{2} \mathrm{in}\right.$.) long, remained unique until 1890, when a similar specimen was captured in the Bay of Bengal, 690-920 fathoms, by the naturalists of H. M. S. "Investigator." The latter specimen, which was larger than the one obtained by the "Challenger" (36 mm. long), was recorded but not described by WoodMason in the Annals and Magazine of Natural History, 6th Series, VII. 199, 1S91. Wood-Mason believed it to be an immature form of some species of Pentacheles (Polychcles), as had already been suggested by Spence Bate.

Eight specimens of Eryonicus were secured by the "Albatross" in 1891, the largest of which measures $62.5 \mathrm{~mm}$. (nearly $2 \frac{1}{2} \mathrm{in}$.) in length. With so many and such large individuals at my disposal, I have been able to correct some of the errors and supply some of the deficiencies in Spence Bate's account of this interesting animal.

The first abdominal somite, which was destitute of appendages in the type described by Bate, in the largest of the "Albatross" specimens (a male) bears a pair of limbs specialized for sexual functions, very like the corresponding appendages in the genus Polycheles. The inner branch of the appendages of the second abdominal somite bears two processes (stylamblydes), as in the other genera of Eryontides. The first abdominal somite of the female, also, carries a pair of less highly modified, simple, two-jointed appendages. The existence of well developed external sexual organs, taken in connection with the dimensions of the largest of the "Albatross" specimens, at once disposes of the theory that Eryonicus is an immature stage in the development of some other genus.

The ophthalmopoda, far from being absent in this genus, as Bate asserts, present in the adult (see Plate XXX., Figs. 1, $1^{a}, 1^{c}$ ) the same form and dimensions as in the genus Polychcles. They consist of a large lobe, immovably fixed in a deep sinus in the anterior border of the carapace; this lobe sends forth an elongated cylindrical process outward and downward 
below the antero-lateral angle of the carapace; the anterior maryin of the lobe, moreover, bears a prominent papilla, or tubercle. The ophthalmopoda are distinct even in the smallest of the "Albatross" specimens, which mensures only nineteen millimeters in length (Plate XXX., Fig. $1^{e}$ ); but here the lobes are smaller, not filling the ophthalmic sinuses nor giving off the lateral processes which, in the adult, project over the base of the antennal peduncles beneath the antero-lateral angles of the carapace. The tubercle on the anterior margin of the ophthalmic lobe is present in the young as in the adult. On the whole, the condition of the ophthalmic lobes in the immature Eryoniens approaches that of Willemoesia.

The mouth parts of Eiyonicus are for the first time described and figured on pp. 112, 113, and Plate XXIX., Figs. 2-2e. A comparison of these organs with the corresponding organs in Polycheles as described and figured by Spence Bate in his report on the "Challenger" Macrura, and by S. I. Smith in Bull. Mus. Comp. Zoöl., X. 26, 27, Plate 1V., Figrs. 2-7, will show how closely they resemble each other in the two genera.

In the largest male the fifth pair of legs is chelate, but the propodal digit is only one half as long as the dactylus. In small, immature individuals the propodal digit is undeveloped, the leg terminating simply in the dactylus. In the largest of the females the chela of the fifth pair of legs is more perfect than in the male, owing to the greater relative length of the propodal digit.

Spence Bate's description and illustration of the structure of the gills apply to the immature stage only. In the adult the gills are similar to those of the other genera of Eryontide, consisting of a stem which gives off long, very delicate lateral filaments; the filaments decrease in length at the distal end of the stem, until, near the very tip, they are reduced to mere papillw. The number and arrangement of the gills and epipods are exhibited in a tabular form on page 114. The epipods are for the most part reduced to abortive rudiments, as in those species of Polycheles upon which Spence Bate founded the genus Stercomastis.

Analysis reveals a close structural similarity between the genera Eryomous and Polychcles. The only important features distinguishing the former genus from the latter appear to be the following: 1st, the great inflation of the globular cephalo-thorax; $2 d$, the comparatively small size of the abdomen; $3 d$, the form of the process of the basal segment of the second pair of antenna (phymacerite), which assumes the form of a long cylindrical rod, 
free throughout its length, whereas in Polycheles this process is short and curved, with the distal end flattened in such a fashion as to form a facet which slides over the lower face of the basal segment of the antennules.

The huge spherical carapace of Eryonicus perhaps serves as a hydrostatic apparatus, by means of which the animal is enabled to lead a free-swimming life at some distance above the ocean bottom. The great depths of the soundings at some of the stations where Eryonicus has come up in the trawl may be delusive, as in the case of swimming Hoplophoridce and Sergestida, which are often found in the trawl that has been lowered to great depths. At Station 3888, twenty-five miles from the nearest land, where the depth was 1168 fathoms, the Tanner self-closing net* was lowered to 400 fathoms and towed for seventeen minutes. The net was then hauled up to the surface after the lower part had been securely closed by the messenger at 400 fathoms. The lower part of the net was found to contain absolutely no life, while the upper part, which had remained open all the way from 400 fathoms to the surface, contained four specimens of Eryonicus, 19-29 mm. long, together with other

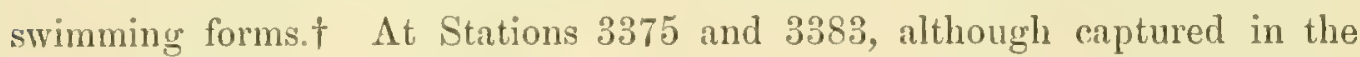
trawl which had been lowered to the depths of 1201 and 1832 fathoms, Eryonicus was found associated with several swimming forms. At Station 3403 a specimen of Eryonicus spimulosus was brought up in the trawl where the bottom was only 384 fathoms.

From these facts it is possible, if not probable, that Eryonicus leads a freeswimming existence at depths moderate compared with those frequented by truly abyssal species. On the other hand, the structure of its visual organs and its absence from collections made with the surface tow-net preclude the thought of its living at or very near the surface.

\section{Eryonicus cæcus Bate?}

Plate B., Fig. 2; Plate XXIX., Fig. 2-2f ; Plate XXX.

? Eryoneicus cuecus Bate, Ann. Nag. Nat. Hist., 5th Ser, X. 457, 1982 ; Rep. Challenger Macrura, pp. 122126, Fig. 30, Plate XII. E, 1888.

Eryonicus caecus? FAX., Bull. Mus. Comp. Zoöl. XXIV. 197, 1893.

Male. - The rostrum consists of a pair of very small spinules. The median ridge of the carapace is armed with small spines arranged thus: 2 (rostral). 1.2.1.1 - 2.2.1.2. There are four minute spinules on each side of the

* For a description of the Tamner net, see A. Agassiz, Bull. MIus. Comp. Zoöl., XXIII. 46-48, 1892. † See A. Agassiz, Bull. Mus. Comp. Zoöl., XXIII. 4S, 49, 1592. 
gastric region arranged in a longitudinal series behind the orbital sinus, one at the bifurcation of the cervical ridge, and one at the anterior end of the anterior branch of the cervical ridge. The subdorsal or branchial ridge of each side bears five spinules, and there is one spinule on the branchial area between the median and branchial carinx. The lateral carina, which runs from the external angle of the orbit to the posterior margin of the carapace, and is homologous with the lateral margin of the carapace in Polycheles and Willemoesia, bears sixteen spines arranged thus: $6-3-7$; of these the last four are the largest. Below this lateral carina there are two longitudinal ridges on each side of the carapace, the upper of which extends from the outer side of the base of the second antenna almost to the hind border of the carapace, and is spinulose along the anterior third of its course; the lower carina starts on the margin of the pterygostomian region one third of the way from the anterior end of the carapace, curves outward and extends back to the posterior margin of the carapace; this carina is very prominent posteriorly, and bears five spines, decreasing in length from the first to the fifth, and followed by small denticles; the anterior spines in this series are the largest on the body; on the line of this ridge the carapace is bent sharply inward and becomes horizontal. The internal orbital angle is furnished with a minute spine not in advance of the rostrum. 'The external orbital angle has a strong spine, the first of the lateral ridge. The orbital sinus is deep, and its posterior or blind end is broad and romded. The ophthalmic lobes are armed with an outward-turned spine on their front margins.

The abdomen is adorned with five longitudinal rows of spines, one median and two pairs lateral; the median or dorsal row is made up of one spine on the first abdominal somite, two on the second, third, fourth, and fifth, one on the sixth, and two on the proximal end of the telson; of the two dorsal spines on the second, third, fourth, and fifth somites, the anterior one is the longer, and is connected with the minute posterior one by an elevated ridge; the single dorsal spine of the sixth somite is sharp and erect. The upper of the two lateral abdominal rows consists of a single spine just above the pleura of each somite from the second to the sixth, while the lower lateral row consists of one small spine on the upper portion of the pleurse of the second to the fiftl somites. The pleurre of the first abdominal somite are small, turned forward, and articulated with the hind part of the carapace; the second, third, fourth, and fifth pleura are rounded, their mar- 
gins spinulose; the sixth are acute, and armed with a small spine at the point, but otherwise unarmed. The telson, besides bearing the two spines above-mentioned, is sparsely spinulose along its margin; it bears two longitudinal dorsal ridges, and its posterior end is subacute.

The proximal segment of the first antemne is short and broad, and is produced at the imner distal angle into a long, sharp, tooth-like process, which is hairy along the basal part of the inner side, but not armed with spines; the outer side of the segment is swollen and furnished with two small spines at the distal end; the second and third segments diminish successively in size; the third segment bears two flagella, the upper and onter of which is only one half as long as the lower and inner one; the shorter one is composed of about thirty segments, the lower one of about fifty. The basal segment of the peduncle of the second antenna is short and broad, and carries a long, slender, cylindrical process (phymacerite of Bate) on its inner side ; this process is directed inward and forward, is nearly as long as the peduncle of the antenni, obliquely truncate at the tip in the left one, while the one on the right side is rounded at the tip; the distal end of the phymacerite is free, and does not slide upon the basal segment of the first antenna as it does in Polycheles and Willemoesia; the second segment also is short and broad, and bears an external foliaceous scale (scaphocerite) which is oval and hairy on the margins, but destitute of spines; its tip reaches to the end of the peduncle; the third and fourth segments are longer, cylindrical, subequal; the flagellum is abont equal in length to the longer of the antennulary flagella, and contains about fifty segments.

The mouth is bounded in front by a large, protuberant labrum (Plate XXX., Fig. 1, $\zeta$ ), and is flanked by the broadly expanded mandibles (Plate XXIX., Fig. 2). The latter are without molar areas; their crowns are serrated on their cutting edges with fourteen triangular teeth, of which one at the anterior angle, one in the middle, and two at the posterior angle are larger than the others; the mandibular palpus is triarticulate, the terminal segment setose. Directly below and behind the base of the mandibles lie the widely separated, palpiform lobes of the metastoma (Plate XXX., Fig. 1, Э).

The first maxilla (Plate XXIX., Fig. $2^{a}$ ) is reduced to two slender, strongly incurved, protognathal lobes, the anterior of which is the larger. Both lobes are setiferous. There appears to be no trace of the endognath.

The second maxilla (Plate XXIX., Fig. $2^{b}$ ) has two small and slender protognathal lobes, the anterior of which is much the longer. The endo- 
gnath is represented by a small rounded lobe on the outer side of the base of the anterior lobe of the protognath. The scaphognath is very large, broadly rounded posteriorly, while the anterior portion is much narrower.

The first maxillipeds (Plate XXIX., Fig. $2^{c}$ ) display a large triangular protognathal lobe, setiferous along its free margin. The endopod is slender, divided into two segments, and lies along the inner edge of the exopod. The exopod is of a peculiar shape, broad, and divided at the distal end into two lobes. The epipod is long and broad, and terminates anteriorly in a rounded lobe outside the base of the exopod.

The second maxillipeds (Plate XXIX., Fig. $2^{i}$ ) are very short, scarcely reaching beyond the ischia of the third maxillipeds. They consist of a single series of six segments, being wholly without exopodal or epipodal branches. The first, second, and third segments are short, setigerous on their inner margins; the second segment is also provided with small teeth on the inner margin. The fourth segment is by far the longest of the whole series; it is very broad, too, much broader in the middle than at either end. The terminal segment is tipped with a slender spine, and, like the antecedent segment, is furnished with many long setæ.

The third maxillipeds (Plate XXIX., Fig. $2^{e}$ ) are much longer than the second, reaching forward to the base of the antennx. They consist of a series of seven segments, the first of which bears a very small epipod $(a)$. There appears to be a slight vestige of the exopod, in the shape of a rounded tubercle on the outer side of the second segment. This tubercle is too slender and acute in the figure.

The great chelipeds are similar in form and proportions to those of other recent Eryontidce; there are a few obsolescent spinules along the inner margin of the merus, and a procurved spine near the distal end of the outer margin of the same joint; the carpus is long, and is armed with a spine near the distal end of the external margin, and with another at the distal end of the internal margin; a spine at the distal end of the superior margin of the hand, distal half of the inferior margin of the hand obsoletely spinulose, fingers long and very slender, strongly incurved through their distal third, their tips very acute, and probably abruptly crossed (they are imperfect in the specimen in hand), prehensile edges microscopically pectinated.

The succeding four pairs of thoracic appendages diminish successively in length and breadth. The first are rather stout, and end in a strong and perfect chela; the merus is armed with a pair of sharp spines beyond the middle, 
and another pair of very long ones at the distal end; the carpus is threespined (one external proximal, two inferior distal); chela unarned, fingers crossed at tips. The next pair of appendages (second ambulatory) show a merus armed with a long and slender spine at the distal end of the lower side; there is a minute spine at the corresponding place on the carpus; the chela is perfectly formed, but weak, the fingers not crossed. The next pair (Plate XXX., Fig. $1^{f}$ ) are similar in form and armature to the second, but a little shorter. The last pair of thoracic appendages (Plate XXX., Fig. $1^{g}$ ) are much smaller, reaching only to the end of the carpus of the antecedent pair; they bear no spines and end in an imperfectly formed chela, the pollex consisting of a blunt process only one half as long as the index or dactylus, which is long-haired on its external margin.

The first pair of abdominal limbs (Plate XXX., Fig. $1^{j}$ ) are specialized to serve as sexual organs (gonopods); they are similar in form to those of Polycheles and Villemoesio, consisting of a basal stem and a terminal spatulate blade. The second abdominal appendage (Plate XXX., Fig. $1^{k}$ ) consists of a basal stalk and two terminal branches; near the base of the inner branch are two long blunt processes (stylamblydes), the outer of which is longer than the inner one. The third (Plate XXX., Fig. $1^{l}$ ), fourtl, and fifth pairs of abdominal appendages are similar in form to the second pair, but they are furnished with only one stylamblys, which is longer than either of those borne by the second pair. The sixth abdominal appendages (Plate XXIX., Fig. $2^{f}$ ) are similar to those in the other genera of this family, and are equal to the telson in length.

The number and arrangement of the gills and epipods are exhibited in detail in the subjoined table:-

\begin{tabular}{|c|c|c|c|c|c|c|c|c|}
\hline Somites & VII. & VIII. & IX. & $\mathbf{x}$. & $\mathrm{xI}$. & XII. & XIII. & xiv. \\
\hline Pleurobranchiæ & 0 & 0 & 0 & 0 & 1 & 1 & 1 & $1=4$ \\
\hline Arthrobranchix & 0 & 0 & 1 & 2 & 2 & 2 & 2 & $0=9$ \\
\hline Podobranchiæ & 0 & 0 & 0 & 1 & 1 & 1 & 1 & $0=4$ \\
\hline Epipods & 1 & 0 & 1 & 0 & 0 & 0 & 0 & $0=$ \\
\hline
\end{tabular}

The arthrobranchia and the epipod of the ninth somite are very small, and the three gills appertaining to the tenth somite, although larger than the gill borne on the ninth, are smaller than those on the following somites. The epipods of the tenth to the thirteenth pairs of appendages are represented merely by thin membranous expansions of the basal part of the 
podobranchial stems, a condition which also exists in those species of Polycheles assigned by Spence Bate to the genus Stereomastis.

Length from rostrum to end of telson, $62.5 \mathrm{~mm}$.; length of carapace, $34.5 \mathrm{~mm}$; length of abdomen, $30 \mathrm{~mm}$.; length of large cheliped, $59 \mathrm{~mm}$. (merus, $12 \mathrm{~mm}$., carpus, $9 \mathrm{~mm}$., basal part of propodite, $9 \mathrm{~mm}$., dactylus, $13.5 \mathrm{~mm}$.).

Color in life, purplish red, the branchial regions livid.

Station 3375. 1201 fathoms. 1 male, $62.5 \mathrm{~mm}$. long.

" 3377.764 " 1 fem., $40 \mathrm{~mm}$. "

" 3383.1832 " 1 juv., $37 \mathrm{~mm}$. "

"3 3388. Surface to 400 fathoms.* 4 juv, 19-29 mm. long.

Bate's description of Eryonicus caecus was drawn up from a single inmature specimen, $13 \mathrm{~mm}$. long, captured during the voyage of the "Challenger," off the Canary Islands, ostensibly at a depth of 1620 fathoms. In this specimen the first abdominal appendages were undeveloped. The above-described specimen from the "Albatross" collection is a sexually mature male with well developed gonopods. It differs from Bate's specimen in having much shorter spines upon the carapace and abdomen, and the spines of the lowest series on the branchial region decrease in length posteriorly, while in Bate's type the longest spines in this row are the posterior ones. Whether these differences are due to the difference in age or whether they are specific cannot be determined until more mature specimens are obtained from the Atlantic. In the smallest of the "Albatross" specimens, which have attained a length of only $19 \mathrm{~mm}$., the spines, especially those of the abdomen, are relatively longer than in the adult, although not so long as in the "Challenger" specimen. In these small individuals the first abdominal appendages are imperfectly developed, and the last thoracic end simply in a short dactylus.

The specimen from Station 3377 is a female, $40 \mathrm{~mm}$. long. The appendages of the first abdominal somite are two-jointed and one-branched, the branch being narrow, flat, ciliated along its margin, and terminating in an obtuse apex (Plate XXX., Fig. $1^{h}$ ). The second abdominal appendage is two-branched, but differs from the corresponding organ of the male in bearing but one stylamblys. The armature of the carapace differs somewhat from that of the other specimens secured by the "Albatross," and it is possible that this individual belongs to a different species. The median carina is fur- 
nished with spines arranged thus: 2.1.1.2.1.1-2.2.1.2. The lowermost carina of the branchial region bears thirteen small subequal spines. There is a pair of spines near the point of bifurcation of the cervical ridge.

\section{Eryonicus spinulosus Fax. \\ Plate XXIX., Fig. 1-1 ${ }^{a}$.}

Bull. Mus. Comp. Zoöl., XXIV. 198, 1893.

In this species the spines of the carapace, instead of being well-nigh limited to the nine longitudinal ridges, as in $E$. coccus, are thickly strewn over the whole surface. The intervals between the spines give rise to slender, hair-like setæ. The arrangement of the spines of the median carina of the carapace is shown in the following formula: 2. 1.1.1.2.1.1-2.2.1.2. The sublateral carina bears fourteen small spines, the lateral $5-2-13$ or 14. The uppermost of the two carinæ below the lateral is denticulated anteriorly, and armed with a spine at the front end behind the second antenna. The lowest ridge carries twelve spines, which increase slightly in length posteriorly. As before stated, the spaces between these rows of spines are beset with spines of about the same length with those of the normal series, so that the latter are not conspicuous, as they are in E. caccus, where the intervening spaces are nearly devoid of spines and the ridges themselves are much more distinct. The rostral spines are very small, but on each side of the rostrum the front margin of the carapace is produced so as to form a pair of horns over the base of the first pair of antennw.

The abdomen is ornamented with seven longitudinal rows of spines, one dorsal and median, the others lateral and paired. The lowest of the lateral rows is on the upper part of the pleuræ. The detailed arrangement of the spines in each row with reference to the somites is shown by the subjoined table : -

$\begin{array}{lccccccc} & \text { T. } & \text { II. } & \text { III. } & \text { IV. } & \text { v. } & \text { VI. } & \text { TELSON. } \\ \text { Median } & 1 & 3 & 3 & 3 & 2 & 5 & 2 \\ \text { Superior lateral } & 1 & 1 & 1 & 1 & 1 & 0 & 0 \\ \text { Middle lateral } & 0 & 1 & 1 & 1 & 1 & 0 & 0 \\ \text { Inferior lateral } & 0 & 1 & 1 & 1 & 1 & 1 & 0\end{array}$

The two anterior spines of the trio on the second, third, and fourth somites are fused together at the base. There is also a spine on each side at the point of junction of the posterior abdominal appendages with the sixth somite. The abdominal pleure are rounded, with the exception of the 
sixth, which ends in an acute spine; their margins are lightly denticulate; the pleuræe of the second somite have a peculiar shape, their anterior part flaring out laterally into an angular wing.

The chelipeds are rather slender; the merus is very lightly spinulose along each margin, and is provided with one or two spines at the distal end; the carpus is short and armed with a spine at the distal end of both the superior and inferior borders; the hand is armed with about ten spines on the upper margin and is lightly spinulose on the lower margin. Of the four succeeding pairs of legs the first three are chelate, while the fourth or posterior thoracic is not chelate, but ends in a simple dactylus; all of these four pairs are clothed on their outer side with long hạirs, and a few slender spines are irregularly disposed on the three anterior pairs.

The first abdominal somite is devoid of appendages in the unique example obtained, which is doubtless immature. The second somite bears a pair of long two-branched appendages; the inner branch supports a slender process (stylamblys) on its inner border. The succeeding pairs decrease in length.

Length, $37 \mathrm{~mm}$. ; carapace, $21 \times 17 \mathrm{~mm}$.; abdomen, $17 \mathrm{~mm}$.

Station 3403.384 fathoms. 1 specimen.

\section{POLYCHELES HELLER}

Sitzungsber. Kais. Akad. Wissensch. Wien, Math.-Naturw. Cl., XLV., Abtl. I., 359, 1 S62.

In 1878 Spence Bate established the genus Pentachcles for the reception of several species of Hacrura from the "Challenger" collection, which differ in no way from Polycheles except in the chelate structure of the posterior thoracic appendages. It has since been shown that in some species these appendages are chelate in the female while they are simple in the male; that among the adults of those species which have the posterior thoracic appendages chelate in both sexes there is a gradual transition from a perfect chela to an imperfect one, in which the "thumb" is rudimentary and the structure of the appendage closely approaches to that of Polycheles; that in species in which the appendages in question are chelate or subchelate in the adult male they are simple in small, immature individuals. Chelation of the posterior pair of thoracie limbs in this family is not accompanied by any other differences, species which have been assigned to different genera resembling each other so closely in every other regard that they 
are hardly distinguishable. It follows that unless the adult male be known, a species cannot be referred to its proper genus in Bate's system. 'That author was most arbitrary in the disposal of his own species, for three of those which he placed in Pentacheles, viz. obscums, lavis, and gracilis, were known to him only through the female. Keeping the above-mentioned facts in view, I have deemed it advisable to unite Pentacheles and Polycheles, provisionally at least. For similar reasons I have not recognized Bate's genus Stcrcomastis, which was instituted in 1888 , * for the reception of two species which lack epipods on the thoracic appendages, but in all other respects agree with Pcntacheles. An examination of a large number of species discloses a gradual transition in the development of the epipods, from large well developed organs throngh small, delicate and thin ones, to merest rudiments in the shape of small expansions at the base of the stem of the gill.

Furthermore, a nomenclatural difficulty confronts him who treats of this family, arising from our imperfect knowledge of the structure of the eye in P.typhlops Heller, the type of the genus Polycheles. In Polycheles of this report (= Polycheles + Pentacheles + Stercomastis of Bate) the ophthalmic lobes are lodgred in a deep notch or sinus of the anterior margin of the carapace and send off from their anterior portion a long cylindrical process beneath the anterior lateral angle of the carapace. In Willemoesia Grote (type, W. leptodactyla W. Suhm) the ophithalmic lobe is situate in the metope and is not lodged in a sinus of the carapace, nor does it send off a process beneath the anterior lateral angle of the carapace. Of Polycheles typhlops Heller says: $\dagger$ "Die Augen fehlen fast ganz, nur an der Basis der oberen Antennen gewahrt man an der Stelle, wo sich der Stirnrand nach unten umbiegt, zwei schwarze rundliche Flecken als Rudimente derselben." This description applies more nearly to the eye of Willemoesia than to that of Poly-

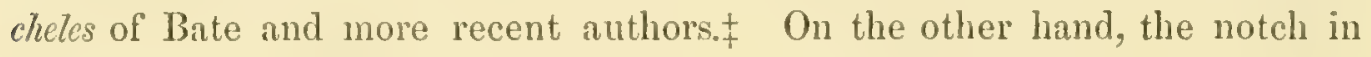
the anterior margin of the carapace, although rather shallow, and the general character of the carapace as shown in Heller's figure, indicate a species congeneric with those which have since been placed in Polycheles. Should a re-examination of the type of Polycheles typhlops reveal an eye constructed as

* Rep. Clallenger Macrura, p. 154, Is8s.

+ Sitzungsber. Kais. Akad. Wissensch. Wien, XLV., Abth. I., 390, 1862.

\$ In Willemoesia the posterior thoracic feet are chelate in both sexes, while in the type specimen of $P$.typhlops (a male) these appendages are simple. But much stress cannot be laid upon this difference, since Heller's unique specimen of $P$. typhlops was only two inches in length. Norman's description of $P$. typhlops (Anu. Mag. Nat. Hist., 5 th Ser, IV., 176, 1879) has uo bearing on the point here under consideration, since it is very doubtful whether the specimens described by him are the same as Heller's species. 
in W. leptoductyla, then Willemoesic would become a synonyme of Polycheles Heller (type, P.typhlops), and Polycheles of this memoir would become Pentacheles Bate, with $P$. euthrix as its typical species.

\section{Polycheles tanneri Fax. \\ Plute XXXI.}

Bull. Mus. Comp. Zoül., XXIV. 196, 1993.

Surface of shell pubescent. Carnpace broadest at the middle, narrowing anteriorly and posteriorly. Orbital sinus rounded at the posterior end, outer margin spinulose. Ophthalmic lobes armed with an anterior spine. Basal segment of antennules furnished with two external spines. Median carina of the carapace furnished with two anterior rostral spines, followed by five (or six) spines in front of the cervical groove, the fourth (or fifth) of which is double. This arrangement of spines may be formulated thus: 2. 1. 1. 1. 1.2.1 (or 2. 1. 1. 1.2.1). Back of the cervical groove the spines of the median carina are 2. 2.2. Marginal spines of the carapace are thus arranged: five on each side of anterior part, three on the middle, and thirteen or fourteen on the posterior $(5-3-13$ or 14). There is a longitudinal row of four small spinules on the anterior division of the carapace midway between the median and marginal rows, and a row of twelve to fifteen on the branchial regions inside the margin of the carapace. There are also two or three spines on each side of the hind margin of the carapace and a few along the cervical groove. The first five somites of the abdomen are carinated dorsally, the carina projecting forward on each segment in the form of a spine; on the sixth segment the carina is double and denticulate. The base of the telson is adorned with a short denticulated crest. The pleuræe of the first and second abdominal segments are armed with a spine at the antero-external angle, and the margins of the third, fourth, and fifth pleuræe are slightly denticulated; there is a granulated crescentic ridge on the outer face of the third, fourth, and fifth pleurs. The upper and lower edges of the merus of the chelipeds are armed with from five to seven spinules; the carpus is short, furnished with three to five spinules on the upper border and with one below at the articulation with the propodite; basal portion of propodite spinulose on both upper and lower margins. The terminal joint of the posterior pair of thoracic legs is chelate in the mature female, subchelate in the young female, simple in the males that I have examined. 
Length (female adult), $96 \mathrm{~mm}$; length of carapace, $41 \mathrm{~mm}$.; breadth of carapace, $31 \mathrm{~mm}$; length of cheliped, $87 \mathrm{~mm}$. (ischium, $16 \mathrm{~mm}$, merus, 23 mm., carpus, $9 \mathrm{~mm}$., basal part of propodite, $15 \mathrm{~mm}$., dactylus, $18 \mathrm{~mm}$.).

Station 3354. 322 fathoms. 1 male.

$\begin{array}{llllrl}\text { "6 } & 3402 . & 421 & \text { " } & 2 \text { males, } 1 \text { fem. } \\ \text { " } & 3403 . & 384 & \text { " } & 12 \text { males, } 14 \text { fem. } \\ & 3409 . & 327 & \text { " } & 1 \text { fem. }\end{array}$

This species nearly resembles $P$. nams (Smith), but may be easily distinguished by the difference in number of spines on the median and sublateral carins of the carapace, by the presence of a spine on the antero-external angle of the first and second abdominal pleura, and by the greater number of spines on the merus, carpus, and propodite of the chelipeds. P.nams is also described as having the posterior pair of thoracic legs chelate in the male.

Compared with the types of $P$.agassizii (A. M. Edw.), the carapace of the present species is seen to be broader and fewer-spined on the margins; the first and second abdominal pleuræe are armed with an anterior lateral spine; the rostral spine is double instead of being single; the orbital sinus is broad and round at the bottom instead of being narrow and acute, etc. $P$.agassizii, like $P$.tameri, has non-chelate posterior legs in the male.

The branchial formula is as follows:-

$\begin{array}{lcccccccc}\text { Somites } & \text { VIII. } & \text { IX. } & \text { X. } & \text { XI. } & \text { XII. } & \text { XIII. } & \text { XIV. } & \\ \text { Pleurobranchiæ } & 0 & 0 & 0 & 1 & 1 & 1 & 1=4 & \\ \text { Arthrobranchiæ } & 0 & 0 & 2 & 2 & 2 & 2 & 0=8 & \\ \text { Podobranchiæ } & 0 & 0 & 1 & 1 & 1 & 1 & 0=4 & (4+1 r) \\ \text { Epipods } & 0 & r & 1 & 1 & 1 & 1 & 0=\overline{16}+(4+1 r)\end{array}$

The epipods of the second, third, and fourth pairs of chelate appendages are very delicate in texture and about half as long as the podobranchix borne by the same appendages. The epipod of the first pair of chelate appendages is smaller than those back of it, while the one on the third maxilliped is reduced to a mere rudiment. 


\section{Polycheles nanus (Smin).}

Plate XXXIII., Fig. 1, $1^{a}, 1^{b}$.

Pentacheles nanus Suitr, Ann. Rep. U. S. Fish Comm. for 1852, p. 359, 1854; id. for 1885, p. 651, Plate VII. Fig. $1,1^{a}, 1886$.

$\begin{array}{rrrrl}\text { Station } & 3362 . & 1175 & \text { fathoms. } & 2 \text { fem. } \\ \text { " } & 3380 . & 899 & \text { " } & 1 \text { fem. } \\ \text { " } & 3392 . & 1270 & \text { " } & 3 \text { males, } 3 \text { fem. ( } 1 \text { ovig.). } \\ \text { " } & 3393 . & 1020 & \text { " } & 1 \text { fem. } \\ \text { " } & 3400 . & 1322 & \text { " } & 6 \text { fem. }(1 \text { ovig.). }\end{array}$

These specimens differ slightly, but constantly, from the type specimens from the Atlantic. The edges of the sulcated carina on the sixth abdominal somite are less prominently denticulated and the tubercle at the posterior end of this carina is lower. Further, the spine near the base of the dorsal surface of the telson of the type specimens is reduced to a blunt tubercle in the Pacific examples. In these regards, the Pacific form resembles $P$. sculptus, adding weight to Professor Smith's suggestion that $P$. nams may be only a dwarf deep-water variety of $P$. sculptus.

An adult ovigerous female measures $58 \mathrm{~mm}$. in length; carapace 24.5 $\mathrm{mm}$. by $16.5 \mathrm{~mm}$.

The posterior thoracic appendages are chelate in both sexes.

The branchial formula is as follows:-

$\begin{array}{lcccccccc}\text { Somites } & \text { VIII. } & \text { IX. } & \text { X. } & \text { XI. } & \text { XII. } & \text { XII. } & \text { XIV. } & \\ \text { Pleurobranchiæ } & 0 & 0 & 0 & 1 & 1 & 1 & 1=4 & \\ \text { Arthrobranchiæ } & 0 & 0 & 2 & 2 & 2 & 2 & 0=8 & \\ \text { Podobranchiæ } & 0 & 0 & 1 & 1 & 1 & 1 & 0=4 & (5 r) \\ \text { Epipods } & 0 & r & r & r & r & r & 0=\underline{16}+(5 r)\end{array}$

The epipods of the tenth to the thirteenth appendages are represented merely by a plate-like expansion of the base of the stem of the podobranchia. The epipod of the third maxilliped is very minute and bears no true gill. The podobranchia and the two arthrobranchix of the tenth somite (cheliped) are much reduced in size. 


\section{Polycheles sculptus pacificus Fax.}

Plate C., Fig. 1, $1^{a}$.

Bull. Mus. Comp. Zoöl., XXIV. 196, 1893.

This form differs from its Atlantic representative, $P$. sculptus Smith (Pentacheles spinosus A. M. Edw.), as follows: the carapace is broader in proportion to the breadth of the abdomen, the lateral margins converging strongly at the posterior end, where, in $P$. sculptus, they continue nearly parallel to one another; there is a small spine on each branchial region inside of, and on a level with, the second spine of the submarginal carina, - this spine is entirely wanting in the type form from the Atlantic; the spine on the anterior border of the ophthalmic lobe is larger and blunter; the pleuræ of the second abdominal somite have a different shape, their anterior margins being in line with the anterior margin of the tergum, whereas in $P$. sculptus they form a strong obtuse angle with the anterior margin of the tergum. In other words the anterior part of these pleuræe is not so strongly produced forward in the Pacific form as it is in the Atlantic. (Cf. Figs. $1^{a}$ and 2 ; Plate C.) These differences, though slight, are constant, and should be recognized in our nomenclature if any significance is attached to geographical variation.

$\begin{array}{lrrrr}\text { Station } & 3353 . & 695 & \text { fathoms. } & 1 \text { male. } \\ \text { " } & 3392 . & 1270 & \text { " } & 1 \text { fem. } \\ \text { " } & 3393 . & 1020 & \text { " } & 3 \text { males, } 3 \text { fem. } \\ \text { " } & 3394 . & 511 & \text { " } & 12 \text { males, } 20 \text { fem. } \\ \text { " } & 3418 . & 660 & \text { " } & 1 \text { male, } 1 \text { fem. } \\ \text { " } & 3419 . & 772 & \text { " } & 1 \text { fem. } \\ \text { " } & 3424 . & 676 & \text { " } & 1 \text { fem. ovig. }\end{array}$

The last thoracic appendages are chelate in the adult female, while they are but imperfectly so in breeding males. That is, in the male the "thumb" is very much shorter than the index.

The arrangement of the gills is shown in the following table:-

$\begin{array}{lcccccccc}\text { Somites } & \text { VIII. } & \text { IX. } & \text { X. } & \text { XI. } & \text { III. } & \text { III. } & \text { XIV. } & \\ \text { Pleurobranchiæ } & 0 & 0 & 0 & 1 & 1 & 1 & 1=4 \\ \text { Arthrobranchiæ } & 0 & 1 & 2 & 2 & 2 & 2 & 0=9 \\ \text { Podobranchix } & 0 & 0 & 1 & 1 & 1 & 1 & 0=4 \\ \text { Epipods } & 0 & r & r & r & r & r & 0=\frac{(5 r)}{17+(5 r)}\end{array}$


What I have here considered to be the rudiments of epipods on the tenth to the thirteenth pairs of appendages are simply thin membranous expansions at the base of the podobranchia similar to those of $P$.namus. The third maxilliped carries a minute epipod but no podobranchia. Connected with the articular membrane at the base of this appendage is a single minute arthrobranchia. This is present in the typical $P$. sculptus also, in which it has been interpreted by Smith as a questionable podobranchia.*

Dimensions of a female: length, $110 \mathrm{~mm}$.; length of carapace, $48 \mathrm{~mm}$; breadth of carapace, $35 \mathrm{~mm}$.; length of antennal scale, $10 \mathrm{~mm}$.; length of telson, $20 \mathrm{~mm}$.; length of cheliped, $123 \mathrm{~mm}$. (ischium, $21 \mathrm{~mm}$., merus, $36 \mathrm{~mm}$., carpus, $23 \mathrm{~mm}$., propodite, $39 \mathrm{~mm}$., dactylus, $24 \mathrm{~mm}$.).

A sketch of a living specimen (Sta. 3353, 695 fath.), made by Mr. Westergren, and reproduced on Plate $\mathrm{C}$, shows the color to be a pale rose purple on the dorsal side of the carapace and abdomen, deepening to a brighter orange red on the thoracic appendages, the branches of the posterior abdominal appendages, and the flagella of both pairs of antenne, and fading to a delicate bluish white on the hepatic and anterior branchial regions. The raised ridges of the carapace and abdomen are whitish, the setwe on the margins of the basal parts of the antennæ, swimmerets, etc., are yellow. Some of the depressed areas of the hinder portion of the carapace and abdomen display a greenish tint in the colored drawing, but I suspect that this hue was derived from a little of the adhesive green mud which formed the bottom from which the specimen came.

\section{Polycheles granulatus FAx.}

\section{Plate XXXII., Fig. 1; Plate XXXIII., Fig. 2, 2*.}

Buil. Mus. Comp. Zoöl., XXIV. 197, 1893.

Carapace long oval, its greatest width at the anterior branchial region; the dorsal surface of the carapace is furnished with microscopic setre and is granulated but almost destitute of spines; there are two small rostral spines, and back of these, on the low granulated median carina, lie four spinules arranged in two pairs, the posterior pair closely followed by a single spinule; all of these spinules are on the anterior half of the gastric area; the submarginal ridge on the branchial regions is incurved and composed of minutc spinulose granules; the hepatic region is but indistinctly separated from the

\footnotetext{
* Buil. Mus. Comp. Zoöl, X. 29, 1582.
} 
anterior branchial lobe; the orbital notch is narrow, and armed with a spine at its internal angle, and with another at its external angle. A spinule on anterior end of the opththalmic lobe and another at the outer anterior angle of the basal joint of the antennule. The marginal spines of the carapace are thus arranged: 9 (or 10) $-3-15$. Of the two longitudinal ridges on the infero-lateral wall of the carapace, the upper one is visible only in front of the cervical groove, the lower one is denticulated. The dorsal abdominal carina is obsolete on the sixth somite, obsolescent on the fifth, and toothed only on the first, second, and third; a shallow groove runs outward and backward from the dorsal carina to the point of articulation with the succeeding somite on the second, third, fourth, and fifth somites; a low, triangular tubercle at base of telson; telson tapering to a slender and acute tip; anterior abdominal pleuræe rounded, gradually becoming acute as one passes backward to the sixth. The ischium of the cheliped is unarmed; the merus is furnished with spines on the anterior edge, and is very minutely serrate on the posterior edge, which terminates distally in a long curved spine; the carpus is long and slender, and is equipped with a prominent sharp spine at the distal end of the outer margin; the basal portion of the propodite is spinulose along the upper margin, more minutely so on the lower margin. The fingers are spineless.

The posterior thoracic limbs in the unique female specimen end in a small but perfect chela (Plate XXXIII., Fig. $2^{a}$ ).

Length, $99.5 \mathrm{~mm}$. ; length of carapace, $45.3 \mathrm{~mm}$. ; greatest width of carapace, $38.5 \mathrm{~mm}$.; * length of cheliped, $118 \mathrm{~mm}$. (ischium, $19 \mathrm{~mm}$, merus, $33 \mathrm{~mm}$., carpus, $22 \mathrm{~mm}$., basal part of propodite, $14.5 \mathrm{~mm}$., dactylus, $22 \mathrm{~mm}$. .).

Station 3380. 899 fathoms. 1 fem.

This species somewhat resembles $P$. lavis (Bate), $P$. validus (A. M. Edw.), and $P$. debilis (Smith). Compared with the type of $P$. validus the carapace of this species is bronder anteriorly, there is but one spine at the external orbital angle in place of two, the formula for the lateral spines is 9 (or 10) $-3-15$ in place of $8-4-30$, the dorsal surface of the carapace is thickly beset with granules instead of being sparsely spinulose, the submarginal line is evident instead of being obsolete, the posterior abdominal pleuræ are subacute instead of being broadly rounded, etc. The differences between the present species and $P$. locris and $P$. debilis will be readily seen

* The carapace is too broad by $2.3 \mathrm{~mm}$. in the figure on Plate XXXII. 
by reference to the descriptions and figures of those species by Bate and Smith.

But an East Indian species, Polycheles beamontii,* bears the closest likeness to $P$. gramulatus. Indeed, the resemblance between these two forms is so great that $\mathrm{I}$ am inclined to regard $P$. beamontii as, at most, but a geographical race of $P$. granulatus. $P$. beamontii is known through a single male specimen captured at a depth of 675 fathoms, off Colombo, Ceylon. I have no doubt that its most striking peculiarity, viz. the absence of the usual internal lobe or "scale" of the basal segment of the antennule, is due to malformation or mutilation. The other characters which distinguish this species from $P$. granulatus are very slight: the number of lateral spines on the carapace is 7 (or 8) - 3-13 in $P$. beaumontii, 9 (or 10)-3-15 in $P$. gramilatus; the ophthalmic sinuses are a little broader in the former species than in the latter; the arrangement of the spinules in the median line of the gastric area of the carapace is 1.2 .1 in the former, 2.2.1 in the latter; the larger spines on the lower margin of the merus of the great chelipeds are rather nearer the proximal end of the segment in $P$. beaumontii than in $P$. gramulatus.

As there is but one specimen of Polycheles gramulatus in the "Albatross" collection, I have not examined the arrangement of the branchix in detail. I have noted, however, that the normal epipods are present and well developed.

\section{WILLEMOESIA Grote.}

Deidamia W.-Su世3, Nature, VIII. 51, 1873 (nom. prooc.).

IVillemoesia Grote, Nature, VIII. 485, 1873.

\section{Willemoesia inornata FAr.}

Plate XXXII., Fig. 2; Plate XXXIII., Fig. 3.

Bull. Mus. Comp. Zoöl., XXIV. 195, 1893.

Similar to W. leptodactyld (W.-Suhm), but readily distinguished from that species by the small number of spines on the margin and dorsal ridges of the carapace. The armature of spines may be formulated as follows:-

$$
\begin{aligned}
& \text { Marginal .... } 5 \text { to } S-2 \text { to } 3-0 \text { to } 6 \text {. } \\
& \text { Median ridge } .1 \text { to } 5-0 \text {. }
\end{aligned}
$$

* Pentacheles bcaumontii Alcock, Ann. Mag. Nat. Hist., 6th Ser., XIII. 236, 1894; Ill. Zoöl. R. I. M. S. "Investigator," Crustacea, Plate VIII., Fig. 3, 1894. 
In W. leptodactyla the armature, as given by Spence Bate, is as follows :-

$$
\begin{aligned}
& \text { Marginal ... } \\
& \text { Median ridge }
\end{aligned}
$$

The marginal spines which lie behind the cervical groove, when present in $W$. inomata, are but rudimentary, while there are no spines on the submarginal carina or along the lateral boundaries of the cardiac area, where they are present in $W$. leptodactyla. The spine on the anterior margin of the carapace at the internal orbital angle is smaller than in W. leptodactyla. If the figure of $W$. ieptodactyla given by Bate is correct, there is an important distinction between the two species in the tergum of the sixth abdominal somite and in the pleure of the second abdominal somite. In W. inomata the dorsal carina of the sixth segment is double anteriorly and in the quadrangular depression on either side there is a raised crescentic figure with its concavity turned outward. The horizontal axis of the second abdominal pleuræe is much longer in proportion to their vertical axis than it is in W. leptodactyla and these pleure are much narrower and more produced anteriorly. In $W$. forceps A. M. Edw., the carapace is more inflated, closely beset throughout with minute spinules, its sides more convex.

Station 3374. 1823 fathoms. 8 males, 6 fem.

$\begin{array}{llllll}\text { " } & 3381 . & 1772 & \text { " } & 1 \text { male, } 1 \text { fem. ovig. } \\ \text { " } & 3382 . & 1793 & \text { " } & 2 \text { males, } 4 \text { fem. ( } 1 \text { ovig.). } \\ \text { " } & 3399 . & 1740 & \text { " } & 2 \text { males, } 1 \text { fem. }\end{array}$

As in $W$. leptodaclyla, the posterior thoracic appendages are perfectly chelate in both sexes.

The branchial formula is as follows :-

$\begin{array}{lcccccccc}\text { Somites } & \text { VIII. } & \text { IX. } & \text { X. } & \text { XI. } & \text { XII. } & \text { XIII. } & \text { XIV. } & \\ \text { Pleurobranchix } & 0 & 0 & 0 & 1 & 1 & 1 & 1=4 \\ \text { Arthrobranchiæ } & 0 & 1 & 2 & 2 & 2 & 2 & 0=9 \\ \text { Podobranchix } & 0 & 0 & 1 & 1 & 1 & 1 & 0=4 & \\ \text { Epipods } & 0 & 1 & 1 & 1 & 1 & 1 & 0=\frac{(5)}{17+(5)}\end{array}$

The gills and epipods in general are large and well developed, the epipods equalling the podobranchix in length. The third maxilliped carries only a slender epipod, and the membrane that connects this appendage with 
the body bears a small but perfectly formed gill (arthrobranchia). According to Spence Bate, ${ }^{*}$ this gill is entirely wanting in $W$. Teptodactyla.

Dimensions of a female: length, $125.5 \mathrm{~mm}$; length of carapace, $52 \mathrm{~mm}$; greatest breadth of carapace, $38 \mathrm{~mm}$; length of antennal scale, $5.5 \mathrm{~mm}$; length of telson, $23 \mathrm{~mm}$.

FAMiLY ASTACID E.

NEPHROPSIS WOOD-MLASON.

Journ. Asiatic Soc. Bengal, Vol. XLII., Part II., p. 40, 1873.

\section{Nephropsis occidentalis F Fx.}

Plate D., Fig. 1, $1^{a}, 1^{b}$.

Bull. Mus. Comp. Zoöl., XXIV. 195, 1893.

Carapace covered with a soft, furry pubescence; branchial areas convex. Rostrum densely ciliated on the margins, armed with a pair of lateral teeth near the middle; a double row of prominent granulations on the dorsal surface, diverging posteriorly and continued back for some distance on the gastric area. A small blunt papilla in the median line of the gastric area, a pair of acute teeth near the anterior margin at the base of the rostrum, and another pair on the anterior margin just above the insertion of the second pair of antennz. There are scattered granules on the gastric area and a small papilla is seen in the median line on the intestinal region. A trace of an interrupted median carina is visible on the abdomen; it is most evident posteriorly. The abdominal terga are clothed with a soft fur like that on the carapace. The abdominal pleura are rather longer-pointed than in $\lambda$. steverti, but not so much so as in $N$. agassizü and $N$. atlentica; their anterior borders are finely denticulated, but destitute of spinous processes; both anterior and posterior margins are furnished with long hairs. The sides of the pleura of the sixth abdominal segment form a sharp right angle with one another, and the posterior angle is produced to a prominent, sharp spine. The telson is armed with a sharp spine in the median dorsal line, near the proximal end. The chelipeds are densely pubescent above; in shape and armature they are similar to the other described species of the genus.

The color of this species, as shown in a sketch from life by Mr. Westergren, reproduced on Plate D, is dusky olive-green on the dorsal surface, * Rep. Challenger Macrura, pp. 167, 168, 1989. 
while the lateral parts of the carapace, the abdominal pleuræe, and the appendages are bright red.

Length of a large female, $119 \mathrm{~mm}$.; carapace, $51 \mathrm{~mm}$; rostrum, $14 \mathrm{~mm}$; second antenna, $225 \mathrm{~mm}$.

Station 3418. 660 fathoms. 23 males, 32 fem. (2 ovig.).

$$
\begin{array}{ccccl}
* & 3424 . & 676 \text { " } & & 2 \text { males. } \\
& ? & ? & & 1 \text { male, } 2 \text { fem. }
\end{array}
$$

In some small specimens the granulations arranged in two longitudinal rows on the gastric region are transformed into small spines. In one young example the rostrum is armed with two spines on one side and with one on the other side.

The prominent spine on the basal end of the telson at once separates this species from any hitherto described. The roundness of the cephalothorax resulting from the convexity of the branchiostegites is also characteristic. The abdominal pleuræ are intermediate in shape between those of $N$. stexcarti and $N$. agassizii. There is but one pair of spines (the anterior pair) behind the orbit, where there are two pairs in $N$. agassizii and N. atlantica.

All the forms of Nephropsis hitherto described are very closely related to each other, and might be treated as geographical races of one widely distributed species. The distribution, so far as known, is as follows: $N$. stewarti W.-M., Bay of Bengal; N. carpenteri W.-MI., Bay of Bengal ; N. agassizii A. M. Edw. (= $N^{T}$. aculeata Smith, and $N$. rosea Bate), West Indian region, off the Bermudas, and off the south const of New Ingland; $N$. attantica Norman, Füröe Channel and Arabian Sea; $N$. suhmi Bate, ${ }^{*}$ off Arru Island; N. occidentalis Fax., of 'Acapulco, Mexico.

\section{FAMILY CRANGONTD A:}

\section{PARACRANGON DANA.}

Proc. Acad. Nat. Sci. Phila., VI. 16, 1852 ; U. S. Explor. Exped., Crustacea, Part I., pp. 533, 537, 1852.

* Rep. Challenger Macrura, p. 181. This species is referred to by Bate on pp. 171, 175 of the same work, under the name of Nephropsis orientalis. Nephropsis cormubiensis Bate and Rowe (Rep. Brit. Assoc. Adv. Sci., 1880, p. 160) is not a Nephropsis at all (see Rep. Clallenger Macrura, p. 177). 


\section{Paracrangon areolata FAx.}

\section{Plate XXXIV.}

Bull. Mus. Comp. Zoöl., XXIV. 200, 1893.

Body robust, integument indurated, keeled and sculptured. Rostrum long, acute, strongly upturned, laterally compressed, superior margin entire, inferior margin armed with two spines, one long one near the base above the eyes, and one small one near the tip. A prominent carina, continuous with the rostrum, extends the length of the carapace in the median line; it is armed with four spines, three of which are on the gastric region, one (obsolescent) on the cardiac region. Orbit incomplete, bounded externally by a slender spine. Outside of, and just below the base of the second antenna the antero-lateral angle of the carapace is drawn out into another rather stouter spine. Just behind this, and from a little higher level, a strong, sharp flattened horn is directed outward, forward, and a little upward; this horn is broad at the base, and furnished with a low carina above, which is continuous with a rounded ridge, which runs inward to the external orbital spine. A longitudinal carina on each side of the gastric region, armed with a small spine a little way behind the middle; from this spine another ridge runs upward and inward, meeting the median carina at the base of the third spine. The branchial regions are traversed by a series of ridges which anastomose in such a way as to divide these regions into a number of cells of various sizes, and they are armed with three small spines, the anterior of which is the largest. The arrangement of these branchial ridges and spines will be understood by a glance at the figures on Plate XXXIV. The hepatic region is much inflated.

The abdomen is ornamented with a low carina, most conspicuous on the third segment, and on the sixth where it is double. 'There is also an indistinct and interrupted carina on each side, at the base of the pleuræ. The pleuræe of the abdominal somites are acuminate, the posterior ones longer pointed than those in front; each abdominal somite except the first is furnished with a transverse median ridge, interrupted in the middle; on the first segment this ridge is confined to the pleurx. 'There is a small spine at the base of the hind margin of the pleura of the fourth and fifth somites. The sixth somite has two pairs of lateral spines (the posterior pair the larger), and another pair at the hind end at the base of the telson. The telson is long and acute, with a pair of longitudinal ribs on the dorsal side; two pairs 
of small spines on the dorsal ribs of the telson, and sometimes the rudiment of a third pair near the tip.

The thoracic sterna are armed with two median spines, one of which is situate on the somite which normally bears the second pair of legs, the other on the following somite.

The sternum of the first to the fifth somites of the abdomen bears a long spinous median tooth, while the sixth somite is armed with a pair of smaller spines on the anterior margin of the sternum.

The eyes are of moderate size, black, and situated on short, rather stout peduncles.

The first segment of the antennular peduncle is long, enlarged proximally, and furnished with a rounded external plate at the proximal end; it is thickly clothed with hairs on its inner margin. The second segment is shorter, more nearly cylindrical, and is likewise furnished with hairs along its inner and inferior margin. The third segment is much shorter than the second, and bears two flagella, the outer of which is about twice as long as the inner, much broader, and composed of about twenty-two flattened segments.

The peduncle of the antenna considerably overreaches the antennal scale, and is of nearly the same length as the antennular peduncle. The antennal flagellum is about equal in length to the whole body.

The third maxillipeds are long and pediform, surpassing the antennal peduncle when directed straight forward. The terminal segment is somewhat flattened, but not enlarged.

The chelipeds are of moderate length, reaching forward slightly beyond the peduncle of the antenna; there is a spine on each side of the distal end of the carpus, and another long and acute one at the antero-internal angle of the propodite. Of the second pair of legs there is no trace. The third pair is very slender and longer than the first pair. The fourth and fifth pairs are more robust than the third pair and also longer, the fifth pair surpassing the fourth. They terminate in a curved and very sharp dactylus.

The abdominal appendages are biramose, the inner branch being well developed and subequal to the outer branch, except in the first pair, where it is very small in both sexes. In the male the inner branch of the second pair carries a stylamblys on its internal margin. The terminal pair is much shorter than the telson.

Length of a female from tip of rostrum to end of telson, $85 \mathrm{~mm}$.; length 
of carapace, including rostrum, $30 \mathrm{~mm}$. ; length of rostrum, $12 \mathrm{~mm}$; length of telson, $16 \mathrm{~mm}$.

Station 3424.676 fathoms. 2 males, 3 fem. (1 ovig.). "3425. $680 \quad$ " 1 male.

The males (all of which are much smaller than the females) differ from the other sex in having the various spines longer, the abdominal pleuræ narrower and produced to longer spinous points.

The egg measures $1.5 \times 1.3 \mathrm{~mm}$.

The number and arrangement of the gills are the same as in the type species of the genus, $P$. echinata Dana, as shown by the following formula:

$\begin{array}{lcccccccccc}\text { Somiles, } & \text { VII. } & \text { VIII. } & \text { IX. } & \text { X. } & \text { XI. } & \text { XII. } & \text { XIII. } & \text { XIV. } & & \\ \text { Pleurobranchix, } & 0 & 0 & 0 & 1 & 1 & 1 & 1 & 1= & 5 \\ \text { Arthrobranchix, } & 0 & 0 & 0 & 0 & 0 & 0 & 0 & 0= & 0 & \\ \text { Podobranchix, } & 0 & 0 & 0 & 0 & 0 & 0 & 0 & 0= & 0 & \\ \text { Epipods, } & 1 & 1 & 0 & 0 & 0 & 0 & 0 & 0= & & (2) \\ & & & & & & & & & & 5+(2)\end{array}$

Paracrangon hystrix A. MI. Edw.* is not a Paracrangon. The second pair of legs (which are non-chelate) are not completely suppressed, and there are two arthrobranchiæ on each side of the ninth (third maxillipedal) somite. Although differing much in aspect from the typical species of Sabinea, it agrees in the essential structural features, and is correctly referred to that genus by Professor S. I. Smith. It is identical with the species afterward described by Smith under the name of Sabinea princeps.

Paracrangon echinata Dana, the only other species of Paracrangon known, has been found at Vancouver's Island, Puget's Sound, California, and Japan.

\section{PONTOPHILUS LEACH.}

Malacostr. Podophthal. Brit., Plate XXXVII. A., 1816 (?).

\section{Pontophilus occidentalis Fax.}

Plate D., Fig. 2-2d.

Bull. Mus. Comp. Zoöl., XXIV. 200, 1893.

Closely allied to $P$. abyssi Smith, and $P$. batei Fax. F From the former it differs in having a shorter rostrum, larger eyes, and more strongly developed

* Ann. Sci. Nat., Zool., 6ème Sér., Vol. XI., No. 4, p. 6, 1851.

$\dagger$ Bull. Mus. Comp. Zoöl., X. 35, 1882.

¥Pontophilus batei Fax., Bull. MIus. Comp. Zoöl. XXIV. 200, 1593, = Pontophilus gracilis Bate (nom. preoc.). Ortmann (Decapoden u. Schizopoden der Plankton-Expedition, p. 49, 1593) also has pro- 
carinæe on the carapace. From the latter it also differs in its shorter rostrum armed with two pairs of lateral teeth; in the presence of a sharp spine on the sternum between the second pair of legs; in the length of the antennal scale, which is equal to the distance from the tip of the rostrum to the cardiac spine; in the shortness of the second pair of legs, which reach only half way to the distal end of the merus of the first pair; and in the absence of the spine on the outer margin of the merus of the first pair of legs.

The eyes are as large as those of $P$. gracilis. Smith (much exceeding the rostrum in length), but they are nearly colorless and unfaceted, as in $P$. abyssi and $P$. batei.

The color in life is shown on Plate $D$.

Length $73 \mathrm{~mm}$; length of carapace, $21 \mathrm{~mm}$.

Station 3361. 1471 fathoms. 2 specimens.

\begin{tabular}{|c|c|c|c|c|}
\hline 66 & 3363. & 978 & 66 & \\
\hline 66 & 3366 . & 1067 & 6 & \\
\hline 66 & 3381. & 1772 & 66 & \\
\hline 66 & 3382. & 1793 & 6 & \\
\hline 66 & 3392. & 1270 & 66 & \\
\hline 66 & 3398. & 1573 & 6 & \\
\hline 66 & 3413. & 1360 & 56 & \\
\hline 6 & 3414. & 2232 & 66 & \\
\hline 66 & 3415. & 1879 & 6 & \\
\hline
\end{tabular}

This is an abyssal species, like the closely related $P$. abyssi and $P$. batei. It is very probable that future explorations will prove that all these three forms are geographical races of one widely distributed species.

SCLEROCRANGON G. O. SARS.

Norske Nordhars-Exped., Crustacea, 1. 14, 1885.

Sclorocrangon atrox FAx.

Plate $X X X V$ :

Bull. Mus. Comp. Zoöl., XXIV. 199, 1893.

Rostrum large, with a prominent keel below, which is produced anteriorly into a prominent tooth reaching as far forward as the tip of the rostrum; posed a new name, Pontophilus challengeri, for Bate's species. I do not know which name has the priority, Ortmann's or my own. Ortmann's memoir was received in Cambridge, Oct. 4, 1893. My paper in Bull. Mus. Comp. Zoöl,, Vol. XXIV., was published, and copies were distributed, Aug. 19, 1593. 
median carina of the carapace armed with three prominent, acute teeth; antero-lateral angles produced into large acute, wing-like processes; behind these, and on a line with them, the lateral carinæ are armed with two teeth; there is a small sharp spine at the external angle of each orbit, and a small pterygostomian spine lies below each of the antero-lateral wings. Median dorsal carina of the abdomen well developed on the first to the fifth somites; the sixth somite and the telson are furnished with a pair of longitudinal dorsal carinæ, which are armed with two pairs of spines on the telson, but are unarmed on the sixth somite save a pair of minute spines at the posterior end; there is, besides, a less distinct lateral abdominal carina, which becomes double on the fourth and fifth somites; the pleuræ of the first abdominal somite are unidentate, those of the second to the fifth bidentate; in old specimens the pleural teeth tend to become obsolete. The telson ends in three spinous teeth, the middle one the largest. The four posterior thoracic sterna are armed each with an acute procurved spine; these spines diminish in length from before backward; the abdominal sterna likewise are armed with a median spine (second and third the largest); all of the sternal spines are very much reduced in size in the full-grown female. The eyes are large for the genus and are furnished with a small spine above the cornea. Antennal scale broad, its internal margin convex. Legs as in $S_{0}$ ferox G. 0 . Sars. Outer lobe of the bilobed inner branch of second abdominal appendage of male very short.

Length of largest specimen (female), $162 \mathrm{~mm}$.

Station 3418. 660 fathoms. 3 males, 2 fem. (1 ovig.).

$$
\text { "3424. } 676 \text { "6 } 4 \text { fem. }
$$

The ovum measures $3.33 \times 2.62 \mathrm{~mm}$.

In the number and arrangement of the gills this species agrees with S. ferox, the branchial formula being:-

\begin{tabular}{|c|c|c|c|c|c|c|c|c|c|}
\hline Somites, & viI. & virt. & $\mathrm{rx}$. & $\mathrm{x}$. & XI. & $\mathrm{XII}$ & XIII. & xiv. & \\
\hline Pleurobranchiæ, & 0 & 0 & 0 & 1 & 1 & 1 & 1 & $1=$ & 5 \\
\hline Arthrobranchiæ, & 0 & 0 & 0 & 0 & 0 & 0 & 0 & $0=$ & 0 \\
\hline Podobranchix, & 0 & 0 & 0 & 0 & 0 & 0 & 0 & $0=$ & 0 \\
\hline Epipods, & 1 & 1 & 0 & 0 & 0 & 0 & 0 & $0=$ & (2) \\
\hline
\end{tabular}

The upper end of each gill is thrown forward, the lower end backward, as in Crangon and other genera. The three pairs of maxillipeds are furnished with well developed exopods, but there is no trace of this organ on the first 
pair of legss. A flat, rather stiff, rounded plate projects outward from the second segment of the third maxilliped, as in S. ferox, agassizii, and procax. A similar but narrower process is found on the proximal segment of the second pair of legs, closely applied to the outer and hinder part of the basal segment of the first pair of legs. 'This process is also found in S. ferox, although it is not mentioned nor figured by G. O. Sars. It is present, too, in S. agassiaii and S. procax.

Of the five hitherto known species of Sclerocrangon, viz. boreas (Fab.), salebrosa (Owen), angusticanda (De Haan), ferox (G. O. Sars), , jacqueti (A. M. Edw.), $\uparrow$ and agassizii Smith, $S$. ferox bears the closest resemblance to the present species. The peculiarities of the genus Sclerocrangon are so fully described and figured by Sars in his account of $S$. forox (Norske Nordhavs-Exped., Crustacen, I. 15-26, Plate II., 1885), that it would be superfluous to give a detailed description of $S$. atrox. Let it suffice to point out the specific differences between these two species: in $S$. ferox the upturned rostrum is simple, while in $S$. atrox a long acute tooth, given off from its ventral side, reaches as far forward as the tip of the rostrum; in other words the rostrum is bifid in the vertical plane. In the former species the dorsal carinx of the sixth abdominal segment bear two pairs of well developed spines, while in the latter we find but one pair of very small spines at the posterior end of the carins. 'The pleural spines of the abdomen are much longer in the former species than in the latter, and on the fifth somite there are four to five spines on each pleura, against two in S. atrox. The eyes are much smaller in $S$. fcrox, and are destitute of the spine above the cornea which is seen in S. atrox. Finally, in Sars's species the antennal scale is much

* Cheraphilus ferox G. O. Sars, Arch. for Mathematik og Naturvidenskab, II. 339, 1877 ; Sclerorrungon salebrosus G. O. Sars, Den Norske Nordhars-Exped., Crustacea, I. 15, 1585 (nec Owen); Sclerocrangon ferox Hanseu, Dijmphua-Togtets Zoolog.-Bot. Udbytte, p. 236, 1857. G. O. Sars says that the Mediterranean species, Cancer cataphractus Olivi (Egeon loricalus Risso), perlaps belongs to the geuus Sclerocrangon. If this were so, the name Sclerocrangon would lave to give way to Egeon Risso. But examination of Olivi's species shows that Sars's surmise is incorrect. The rostrum in this species is short and bifid, the antemual scale short and broad, the inner branch of the abdominal appendages is large (subequal to the outer branch), and furnished with a stylamblys on every pair; there are six well developed gills on each side of the body, a small podobranchia at the base of thie second maxilliped, and the basal segment of the first pair of legs bears a uniarticulate exopod. Risso's genus Ëgeon [Eggon] (Hist. Nat. des Crustacés des Euvirons de Nice, p. 99, 1816), established to receive this species, is based on valid structural characters and should be restored (v. Ortmann, Zoolog. Jahrb., Abth. f. Syst., V. 530, 535̆, 1890). Spence Bate's Pontocaris (Rep. Challenger Macrura, p. 495), appears to be the same as Egeon. Miers (Ann. Mag. Nat. Hist. 5th Series, VIII. 365,1851 ) assigns Cancer cataphractus Olivi to the genus Cheraphilus, although this species was made the type of the gom Egeon by Risso forty-six years before the name Cheraphilus was proposed by Kinahan!

$\dagger$ Poniophilus jacqueti A. M. Edw., Comptes Rendus, XCIII. 935, 1881; Recueil de Figures de Crustacés nouv. ou peu comus, 18S3. Closely allied to, if not the same as, S. agassizii Smith (Bull. Mus. Comp Znöl., X. 32, 1882) 
narrower and less convex along its internal margin than it is in the species above described.

\section{Sclerocrangon procax FAx.}

Plate XXXVI.

Bull. Mus. Comp. Zoöl., XXIV. ]99, 1593.

Rostrum small, simple, acute, inclined upward at an angle of $45^{\circ}$, not longer than the spines at the external orbital angle, overshadowed by the great anterior spine of the dorsal carina of the carapace. This carina is armed with two spines; the anterior of these is very long, nearly erect, and arises from a point just back of the rostrum; the posterior is shorter and curved forward; between these two spines is the rudiment of a third, anterior to the middle of the carina. The external orbital spines, as before said, reach as fir forward as the tip of the rostrum. The anteroexternal angles of the carapace are drawn out into long, acute spines that trend upward and outward. From the orbital spine a ridge runs backward on each side of the carapace, and meets a similar ridge ruming from the posterior margin of the carapace forward to a lateral spine on the front part of the branchial region. There is another small spine on each side of the gastric region between the median and lateral carinx. From the lower side of the lateral spine a ridge runs downward and backward on the branchial regions, meeting an interrupted ridge which extends from the antero-lateral spines nearly to the posterior margin of the carapace. A flat-topped median dorsal ridge extends along the abdomen from the first to the fifth somites; on the sixth somite this ridge is supplanted by a pair of carinx. An indistinct and interrupted ridge runs the length of the abdomen on each side, at the upper boundary of the pleura. The first pleura ends below in a sharp tooth; this tooth becomes smaller as one passes backward until it disappears in the pleura of the fourth somite. The telson is long, quadrangular in cross-section, grooved above, acute at posterior end; its base is flanked by a pair of spines arising from the hind end of the sixth abdominal somite. The eyes are small; a small tubercle arises from the stiperior margin of the cornea. The appendages are like those of $S$ agassizii Smith, with the following exceptions: the two flagella of the first pair of antennx in the male are subequal in length, while in the male of $S$. agassiz $\ddot{2}$ the outer flagellum is much longer than the inner; the scale of the second antenna is narrower; the terminal segment of the inner 
branch of the second abdominal appendage in the male bears on its inner margin a short blunt stylamblys, which is absent in S. agassizii; in neither of these two species is this segment produced into a lobe at the base of its outer margin as it is in the more typical species of Sclerocrangon, e. g. S. ferox and S. atrox. There are four thoracic and five abdominal sternal spines in the male, as in $S$. agassizii. In the mature female these spines are obsolete as in the female $S$. agassizii.

Length of a male specimen, $49 \mathrm{~mm}$. ; carapace, $13.3 \mathrm{~mm}$. ; abdomen, 36 $\mathrm{mm}$. ; length of a female, $64 \mathrm{~mm}$., carapace, $18 \mathrm{~mm}$., abdomen, $46 \mathrm{~mm}$.

Station 3380. 899 fathoms. 1 male, juv.

$\begin{array}{lllll}\text { " } & 3418 . & 660 & \text { " } & 2 \text { males, } 3 \text { fem. (1 bopyrized). } \\ \text { " } & 3435 . & 859 & \text { " } & 2 \text { fem. ovig. } \\ & 3436 . & 905 & \text { " } & 1 \text { fem. }\end{array}$

This species is very nearly related to $S$. agassizii Smith, of the east coast of North America. In addition to the differences between the two species already noticed, I may mention the following:- the rostrum of $S$. procax is longer and inclined upward at a much sharper angle than in the Atlantic species; the same is true of the antero-lateral spines of the carapace; the most conspicuous difference is found in the anterior spine of the median carina of the carapace, which is much longer and nearly erect in S. procax. The arrangement of the carinæe and spines is the same in the two species.

I agree with Professor Smith in consigning these two species to the genus Sclerocrangon, although G. O. Sar's's diagnosis of this genus must be somewhat modified for their inclusion. In the typical species of Sclerocrangon, the rostrum is expanded into a keel below, while in $S$. agassizii and $S . p^{\text {rocax }}$ it is spine-like; the terminal segment of the inner branch of the second abdominal appendage is bilobed in the male of the typical Sclerocrangon, whereas in $S$. agassiz $\ddot{n}$ it is simple, and in $S$. procax it consists of a single lobe which bears a stylamblys on its inner edge. In other respects these two species agree with the more typical species of Sclerocrangon.

* Ceraphilus agassizii Smith, Bull. Mus. Comp. Zoöl., Vol. X., No. 1, pp. 32-34, Plate VII. Fig. 4-5a, 1852; Sclerocrangon agassizii Smith, Ann. Rep. U. S. Fish Comm. for 1555, p. 652, 1856. This species, as before stated, is apparently the same as Pontophilus jacqueti A. M. Edw. (Comptes Rendus, XCIII. 935, 1881;

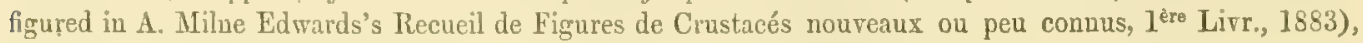
collected off the south coast of Europe by the "Travailleur" expedition. 


\section{FAMILY GLYPHOCRANGONID A.}

GLYPHOCRANGON A. M. EDW.

An». Sci. Nat., Zool., 6ẻme Sér,, Vol. XI., No. 4, p. 3, $18 \$ 1$.

\section{Glyphocrangon alata FAx.}

Plate XXXVII.

Bull. MIus. Comp. Zoöl, XXIV. 201, 1893.

The rostrum is armed with a pair of lateral spines on a level with the - anterior end of the eye; posterior to this pair of spines follows a variable number of smaller marginal spines (three to five on each side). The anterior half of the rostrum is unarmed, although the margins are ciliated. A light spinulose carina runs along the median line of the rostrum firom the base to the anterior third (in some specimens this carina is obsolete). On each side of the median line there are, on the basal portion of the rostrum, four or five small spinules.

The carapace and abdomen are thickly tuberculated. On the anterolateral regions of the carapace and on the abdominal pleuræ the tubercles assume a spiny character. For the rest, the tubercles are for the most part laterally compressed, their tops truncated and more or less eroded. It is further to be observed of these tubercles that they are arranged in longitudinal rows, and six of these rows on each side of the carapace by their greater prominence form imperfect carinæ corresponding in position to those commonly found in species of this genus. The external orbital spine is directed upward at an angle of $45^{\circ}$, is curved (with the concavity inward), but hardly deflected outward. The spine at the antero-lateral angle of the carapace is turned somewhat downward and outward. Between these two spines and just behind them is a strong spinous tooth, acute at the end, and vertically compressed, its base broadening out in such a fashion that the whole tooth forms an acute-tipped wing-like expansion. This is, in fact, the greatly developed anterior portion of the fourth carina (counting from the median line). Behind it the carina continues on, as a low toothed ridge, to the cervical groove. The broad triangular area between this carinal tooth and the gastric region is thickly beset with laterally compressed spinous tubercles like those which adorn the other parts of the carapace.

An interrupted median dorsal carina runs along the abdomen. Upon the 
first somite this carina projects forward as a sharp tooth. On each side of this somite there is a prominent acute tooth directed obliquely forward. The median carina is continued on the base of the telson, where it is broken into two teeth, the anterior of which is the larger. There is, beside, a pair of spinulose carina on the dorsal side of the telson, and the lateral margins of the telson are also spinulose. The lower margins of the pleuræe are spined in the way common to species of this genus. The eyes are large, and dark brown or black in color. The antennal scale is shorter than the rostrum, broadly ovate, and devoid of spines on either surface.

The posterior pair of abdominal appendages are also destitute of spines, save the customary one on the outer margin of the external branch. The two branches are of about equal length and shorter than the telson.

The dactyli of the ambulatory legs are lanceolate.

In this species, as in G. aculeata A. M. Edw. (= Rhachocaris agassiäii Smith), G. regalis Bate, G. investigatoris W.-M., G. smithii W.-M., G. creca W.-M., and G. loricato Fax., the fourth carina is expanded anteriorly into a very large, vertically compressed spine. In other respects the species here described is very different from those, as will be readily perceived by comparison of the figures and descriptions.

Length of a female, $116 \mathrm{~mm}$.; length of carapace (including rostrum) $45 \mathrm{~mm}$.; length of rostrum, $20 \mathrm{~mm}$.; length of telson, $12 \mathrm{~mm}$.; length of antennal scale, $11.5 \mathrm{~mm}$. ; breadth of antennal scale, $7.3 \mathrm{~mm}$.

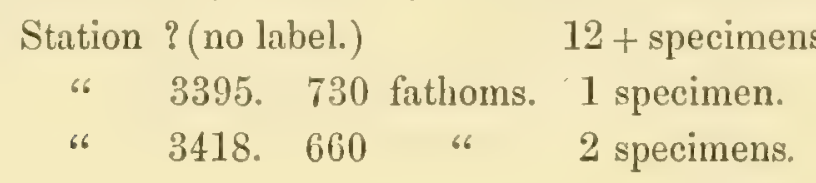

\section{Glyphocrangon spinulosa FAx.}

Plate XXXVIII.

Bull. Mus. Comp. Zoöl., XXIV. 202, 1893.

Rostrum long, acute, margins armed with vertically flattened spinouis teeth from base to the level of the anterior extremity of the eyes, beyond which point the margins are unarmed; the anterior pair of the lateral spines are the largest. A median longitudinal row of smaller spines extends from the anterior boundary of the gastric area to the anterior fourth of the rostrum; anteriorly these spines are confluent at their bases, forming a carina which is continued forward beyond the spines to the tip of the rostrum. Just inside 
the marginal spines there is an irregular longitudinal row of very small spinules on each side of the rostrum.

The carapace is thickly strewn with spinules which are laterally com. pressed. Along six longitudinal lines on each side of the carapace the spines are larger, more flattened laterally, forming interrupted carinæ. The third carina (reckoning from the dorsal line) ends anteriorly at the deep branchiohepatic sulcus. The fourth carina, on the contrary, is especially prominent on the hepatic region, where it is broken up into two or three prominent teeth. The two lowermost carinx are obsolescent. The anterior margin of the carapace is produced into a large external orbital spine directed obliquely upward and outward. The hind margin of this spine or tooth is armed with a variable number of spinules. The antero-external angle of the carapace is produced into a strong spine directed downward and a little outward.

The abdomen, like the carapace, is spinulose on the dorsum and pleuræ. An interrupted carina extends the length of the median dorsal line. On the sixth segment this carina is toothed along its edge. On the first segment, on each side of the inedian carina, in line with the second carina of the carapace, there is a prominent acute tooth directed obliquely forward. The pleura of the first segment are for the chief part converted into smooth facets which lie beneath the next pleuræ when the abdomen is flexed; their free margins are unarmed. The second to the fourth pleuræ are armed inferiorly with two spines curved outward and backward, the anterior of the two being the larger. The fifth pleuræe are likewise armed with two spines, but in this case the posterior spine is the larger. The sixth pleuræe end posteriorly in a single spine directed outward at a greater angle than those on the antecedent segments. The median dorsal carina of the abdomen is continued along the basal part of the telson in the shape of a line of four or five teeth, decreasing in size from before backward. On either side of the median dorsal line there is a lateral carina which is spinous anteriorly, but entire toward the tip. The lateral margins of the telson are similarly carinated and spinulose.

The eyes are very large and colored with a dark pigment. The antennal scale is much shorter than the rostrum, ovate, its margins ciliated; the median longitudinal rib is spinulose as well as the portion of the field lying external to the rib. The lower side of the scale is also spinulose, although in a less degree than the upper side.

The dactyli of the fourth and fifth pairs of legs are lanceolate, compressed vertically, concave above and convex below. 
The rami of the last abdominal appendages are subequal in length, shorter than the telson, spinulose above and (to a less degree) below.

Length of a male, $105 \mathrm{~mm}$. ; length of rostrum from tip to anterior gastric groove, $20 \mathrm{~mm}$; length of carapace (including rostrum), $44.5 \mathrm{~mm}$.; length of telson, $18.5 \mathrm{~mm}$; length of antennal scale, $11.5 \mathrm{~mm} . ;$ breadth of antennal scale, $7 \mathrm{~mm}$.

The egg (from a female $114 \mathrm{~mm}$. long) measures $3 \times 2.5 \mathrm{~mm}$.

This landsome and very distinct species was taken at the following stations :-

\begin{tabular}{lrrrrrr} 
Station & 3353. & 695 fathoms. & \multicolumn{5}{l}{ specimens. } \\
" & 3418. & 660 & " & 91 & " & \\
" & 3419. & 772 & " & 1 & " & \\
" & 3424. & 676 & " & 19 & " & (1 with Bopyrus). \\
" & 3425. & 680 & " & 1 & " & \\
" & 3435. & 859 & " & 2 & "
\end{tabular}

\section{Glyphocrangon loricata, sp. nov.}

\section{Plate XXXVIII. ${ }^{\text {bis. }}$}

Rostrum furnished with three pairs of lateral spines, the anterior pair the largest and situate just in front of the eyes, the other two pairs behind the eyes and near the base of the rostrum; sides of rostrum fringed with long hair in front of the anterior pair of spines. Gastric region separated from the rostrum by a transverse depression. The first or dorsal pair of carinæ on the carapace are broken up into laterally compressed, truncate tubercles. Between these crests, at the anterior limit of the gastric area, lie three small tubercles, one median, two lateral and paired; from the median one a very light carina runs backward along the median line of the gastric region, flanked by two rows of very faint tubercles. Outside of the dorsal carinx the gastric region is irregularly tuberculous. The second carina is explicit only behind the cervical groove, where it is divided by shallow notches into four sections which are hardly prominent enough to be called teeth. The third carina is entire; near its anterior end is seen a slightly projecting, rounded angle which is not produced so as to form a spine or tooth; a similar, but still less evident, rounded angle is visible near the middle of the same carina. Only in very young and small individuals do these angles attain to prominence, and even then they do not assume the form of spines, but end bluntly. The fourth crest is produced to a long, 
vertically compressed spine, which reaches forward to the level of the middle of the eye, and is directed outward at an angle of about forty-five degrees with the axis of the body. Behind this hepatic spine, the margin of the fourth carina is entire. The fifth and sixth carinæe present an eroded surface, but are not toothed. The branchial regions are adorned with three longitudinal rows of not very distinct tubercles between the first and second, second and third, and third and fourth carinx. The hepatic area also bears about ten very small and inconspicuous tubercles. The external orbital spines are directed nearly straight forward, but are inclined upward at a considerable angle when viewed from the side; they reach a little beyond the hepatic spines, but not so far as the branchiostegal spines. The latter attain to the anterior end of the eye; they form but a very slight angle with the axis of the body, whether they are viewed from below or from the side.

Along the median dorsal line of the abdomen there runs a carina from the anterior end to the base of the telson, where it ends in a single prominent tooth. On the first abdominal segment, this carina is produced forward, in the shape of a stout tooth, over the anterior border of the segment; on the second, third, fourth, fifth, and sixth segments, this carina is divided into two parts by a transverse furrow. The first abdominal segment also bears a pair of strong, forward-pointing, lateral teeth on its anterior border. Terga and pleurse of all the abdominal segments tuberculose. Pleurx of first segment curved forward and terminated by a blunt tooth; margin of second pair of pleurx three-toothed, the middle tooth by far the most prominent, the posterior tooth obsolescent; pleurse of third, fourth, and fifth segments twotoothed, - of sixth segment one-toothed. Telson longer than the posterior' pair of appendages, armed at the proximal end, as aforesaid, with a single, prominent, median tooth; the lateral carinæ of the telson are also furnished with teeth (about eight in number on each side) on the anterior two-thirds; there is, moreover, a longitudinal row of six or seven smaller teeth at a lower level, on each side of the anterior third of the telson.

The dactyli of the third, fourth, and fifth pairs of thoracic appendages are of the usual form, - lanceolate, with very acute tips.

Length, $82 \mathrm{~mm}$; carapace, $35 \mathrm{~mm}$.; rostrum, $16 \mathrm{~mm}$; telson, $15 \mathrm{~mm}$.; extent between tips of hepatic spines, $24 \mathrm{~mm}$.; extent behind cervical groove, $16 \mathrm{~mm}$.

$$
\begin{aligned}
& \text { Station } 3402.421 \text { fathoms. } 1 \text { male, } 3 \text { juv. } \\
& \text { " } 3410 . \quad 331 \text { " }
\end{aligned}
$$


This species, which was captured near the shores of the Galapagos Islands, is comparable with G. aculeata A. M. Edw., G. regalis Bate, G. investigatoris W.-M., and G. smithii W.-M. It differs from all of these in having three pairs of rostral spines in front of the gastro-frontal sulcus, and in the length, slenderness, and strong outward trend of the hepatic spines. It differs furthermore from $G$. aculeata and $G$. investigatoris in being much more lightly tuberculated; from $G$. aculeate and $G$. smithii in lacking the spine at anterior end of the third carapacial carina, behind the cervical groove; from all of the above-named species, except $G$. investigatoris, in the spiny armature of the telson.

Glyphocrangon nobilis A. M. EDw.?

? Glyphocrangon nobile A. M. EDw., Am. Sci. Nat., Zool., 6 ème Sér., Vol. XI., No. 4, p. 5, 1881; Recueil de Figures de Crustacés nouveaux ou peu conmus, 1883 (fig.).

\begin{tabular}{|c|c|c|c|c|c|}
\hline Station & 3363. & 978 & thoms. & & \\
\hline “6 & 3366. & 1067 & $" 6$ & 1 & 66 \\
\hline 66 & 3371. & 770 & 66 & 4 & 66 \\
\hline 66 & 3375. & 1201 & 6 & 1 & \\
\hline 66 & 3376. & 1132 & " & 1 & \\
\hline 66 & 3392. & 1270 & 66 & 2 & 6 \\
\hline 66 & 3400. & 1322 & 66 & 1 & 66 \\
\hline 66 & 3411. & 1189 & $" 6$ & 4 & \\
\hline 66 & 3413. & 1360 & 6 & 3 & \\
\hline 6 & $3+19$. & 772 & "6 & 3 & \\
\hline 66 & 3431. & 995 & "6 & 1 & \\
\hline
\end{tabular}

Of Glyphocrengon nobilis A. M. Edw., I have only small, immature specimens before me, and I am not sure that the "Albatross" specimens here referred to this species are really the same. In any event they are very closely allied. In typical specimens of the "Albatross" species, the distance from the tip of the rostrum to the small tubercle that lies in the median dorsal line at the anterior boundary of the gastric region is equal to the distance of this tubercle from the posterior margin of the carapace, measured along the median dorsal line. But the length of the rostrum varies to a considerable degree in different specimens. When it attains its maximum length, the distance from the tip to the basal lateral spines alone equals the length of the rest of the carapace, measured along the median line. The margins are thickened and concave between the two pairs of lateral spines. A median 
dorsal keel, most pronounced near the anterior end, runs backward, becoming obsolete abreast of the posterior pair of lateral spines. In nearly all of the specimens the dorsal side of the rostrum is roughened in the middle portion of its length by transverse corrugations on each side of the median carina. The lower face of the rostrum is distinctly margined; the margins gradually converging at each end, leaving between them a lanceolate field which is divided anteriorly by a light median carina. This median ventral carima of the rostrum is characteristic. I have found it wanting in but one or two out of the twenty-three specimens examined. The general trend of the rostrum is lightly downward to a point near the tip, then upward to the tip.

The two or three tubereles that represent the anterior part of the second lateral carina of the carapace are produced to spinous points, the foremost forming a pair of prominent spines at the front part of the gastric region. The prominent carina (fourth) which runs along the hepatic area is produced at its anterior end into a distinct, acute, though not large spine, which is divided from the rest of the carina posteriorly by a notch or sinus. All the carinæ except the two uppermost have a worn and eroded surface. The anterior part of the third crest is represented by a single tubercle on the hepatic area. The lower margin of the second abdominal pleura is often onetoothed, the anterior and posterior angles being rounded off and destitute of spines. The tubercles of the abdomen are more sparse and less pronounced than in the type of $G$. nobilis, as inferred from Milne Edwards's figures. The telson, like the rostrum, varies in length in different specimens. In those with the longest rostrum the telson is one-third longer than the swimmerets, while in others it is not over one fifth longer than these appendages. It is upturned at the tip, very lightly in the majority of specimens, but very strongly so in the specimens with the longest telson. There is a laterally compressed tooth in the median dorsal line at the base of the telson which forms the posterior end of the median carina of the abdomen. The dorsal pair of longitudinal carine are obsoletely spinose on their anterior third.

In the type specimen of $G$. longirostris Smith, the rostrum is widened midway between the anterior pair of lateral spines and the tip, thus assuming a lanceolate outline; the corrugation of the dorsal surface of the rostrum is more emphatic than in the "Albatross" specimens, and the median dorsal carina is continued backward to the gastric area; the tubercles on the an- 
terior gastric region are not prolonged into spines, and the eye lacks any dark pigment. The absence of pigment in the eye, however, I think may be dive to the action of alcohol. The spine at the antero-lateral angle of the carapace is bent down at a greater angle with the axis of the body than it is in the "Albatross" species, and I think this is also true of the typical G. nobitis.

Bate's $G$. acuminata appears to be very closely allied to $G$. nobilis, and perhaps will prove to be only a smooth form of the latter species.

G. gilesii Wood-Mason is a smoother form characterized by the full development of the anterior part of the third crest of the carapace. In G. mnguculatu Wood-Mason, the carapace and abdomen are covered with a velvety pubescence, the postero-inferior corners of the second and third pairs of abdominal pleuræe are angular rather than spinose, and the outer margins of the dactyli of the fourth and fifth pairs of legs are produced near the apex into a minute, incurved claw.

The type specimen of $G$. nobilis was taken in 1131 fathoms near the Island of Dominica, W. I.

\section{Glyphocrangon sicaria FAx.}

\section{Plate $X X X I X$.}

Bull. Mus. Comp. Zoöl., XXIV. 202, 1893.

Rostrum equal in length to the rest of the carapace, armed with a pair of short, blunt lateral teeth a little in advance of the front of the eyes, and another pair of obsolescent ones at the root. Between these two pairs of teeth the margins of the rostrum are concave and a little raised. From the anterior teeth the rostrum tapers regularly to the point. The upper surface is plane and smooth (neither corrugated nor ciliated). A slight median carina, most obvious near the tip, runs the whole length of the rostrum from the anterior boundary of the gastric area to the tip, and the lateral margins are lightly rimmed. The lower surface is grooved longitudinally, and wholly devoid of a median keel.

The orbital spine is rather short and thick, and is directed a little outward and upward. The spine at the antero-external angle of the carapace is also short and thick, but slightly exceeding the orbital spine; it is turned but very slightly outward, but its downward deflection is stronger. From its base a low carina extends backward over the hepatic area. 'This carina 
is unarmed with spines, but is broken into two tubercles, the posterior of which is the more prominent. In the triangular area between this carina and the gastro-hepatic sulcus are several small tubercles disposed for the most part in single row. 'The gastric region is free from tubercles in the median line, barring a minute one at the anterior boundary near the base of the rostrum. But on either side, this region is ornamented with tubercles; these are not spinous, nor do they tend to form very well-marked carinæ. On the branchial regions there are three carinæ on each side; the uppermost of these is broken up into five or six tubercles; the tops of these tubercles, as well as of the other carinx on the branchial and the hepatic areas, exhibit a coroded surface, and a similar appearance is manifest on the whole lower surface of the carapace where it is bent beneath the thorax.

The abdomen is irregularly bestrewn with low tubercles, which, as commonly in this genus, take on the form of a low interrupted keel along the median line. The lower margins of the second to the fifth segments are armed with two spines, the posterior of which is the smaller on the second, third, and fourth, but the larger on the fifth segment. 'The sixth segment is armed with a single spine on each side, at the postero-lateral angle. The telson is straight and much shorter than the rostrum; it is furnished with a small laterally compressed tooth in the median dorsal line at the base, and both the dorsal carinx and the lateral margins are obsoletely dentate along their basal half.

The eyes are rather small, and their pigment is apparently not so dark as in most species of this genus.

The antennal scale is about one half as long as the rostrum, oval, ciliated on the border, but not furnished with any spinules except the small one on the outer border.

The dactyli of the three posterior pairs of legs are lanceolate.

The posterior pair of abdominal appendages are shorter than the telson; both the dorsal and ventral faces of these appendages are free from spines or tubercles.

Length, $124 \mathrm{~mm}$; length of rostrum from tip to anterior gastric groove, $30.5 \mathrm{~mm}$.; length of carapace, including rostrum, $58 \mathrm{~mm}$.; length of telson, $20 \mathrm{~mm}$.; length of antennal scale, $13 \mathrm{~mm}$.; breadth of antennal scale, $7.5 \mathrm{~mm}$.

Station 3382. 1793 fathoms. 2 specimens.

This species is nearly related to the preceding ( $G$. nobilis). It differs 
from the latter as follows: the rostrum is straighter, its upper surface flatter and smoother, and its lateral teeth (especially the posterior pair) smaller. None of the tubercles of the gastric region are spinous. The orbital spines are not turned so much outward, and the spines at the antero-lateral angles of the carapace are shorter and more robust. There are no spines on the anterior portion of the fourth carina. The eyes are smaller.

From $G$. Tongirostris Smith, it may be distinguished by the rostrum, which

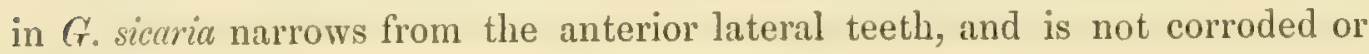
corrugated on the upper surface; its lateral teeth, moreover, are not so prominent. The orbital spines are smaller, less deflected outward, and they are separated by a wider interval from the spine at the antero-lateral angle of the carapace. In both species the anterior portion of the fourth carina is divided by a sinus into two prominences: in $G$. longirostris the anterior of these prominences is the more salient, while in $G$. sicaria the posterior one is the more pronounced.

G. crecescens W.-M., another similar species, may be distinguished by the lanceolate outline of the rostrum and the presence of two spines on the anterior moiety of the fourth carina of the carapace.

\section{FAMLY GNATHOPHYLLID E.}

\section{GNATHOPHYLLUM LATR.}

Nouv. Dict. d'Hist. Nat., 2e éd., XXX. 72, 1819 [Guatophyllum].

\section{Gnathophyllum panamense Fax.}

Plate $E$.

Bull. Mus. Comp. Zoöl., XXIV. 198, 1893.

This species resembles $G$. elegans (Risso) of the Mediterranean Sea so closely that I was at first disposed to consider it identical in spite of the remoteness of its habitat. A close comparison, however, discloses a clear specific difference: in the Panama form a prominent, conical, obtuse protuberance, pigmented with black, arises from the upper part of the cornea. In $G$. elegans this tubercle is wanting or reduced to the merest vestige, discernible only with a strong lens. The rostrum of $G$. panamense is furnished with seven teeth above, and one below near the tip. The intervals between the superior rostral teeth are furnished with long setx. In $G$. elegans the num- 
ber of rostral teeth appears to vary somewhat. In two males in this Museum the number is four above and one below. In Risso's original description and figure * the rostrum is represented as bearing six teeth above. In the same author's later description or this animal t the rostrum is said to bear six teeth above and one below, while in the accompanying figure (Plate I., Fig. 4) there are five teeth above and one below. Milne Edwards $\neq$ describes the rostrum as armed with six to seven teeth above.

G. panamense, like G. clegans, is very gaily attired. A colored sketch of the former species, drawn from life by Mr. Westergren, represents the general ground color of the body to be a dark brown, ornamented with a multitude of whitish spots, among which are sixteen red spots regularly arranged as shown on Plate E, Fig. 1. The rostrum, eyes, and antennæe are pale ochre (the flagellum of the second antennx orange), the fifth and sixth abdominal segments, telson, and swimmerets are also ochre. The basal joints of the second pair of chelipeds are violet, the merus, carpus, and fingers ochre, the basal part of the propodite orange. The third, fourth and fifth pairs of legs are violet. According to Risso and Heller, G. clegans is spotted with goldenyellow, and otherwise differs in details of coloration from its western relative. In the form described by Gourret $\S$ as $G$. elegans, var. brevirostris, from Marseilles Bay, the ground color is brick-red.

Length, $22.5 \mathrm{~mm}$.; length of carapace, including rostrum, $7.5 \mathrm{~mm}$.

Taken on the reef at Panama, at low tide, March 12. One ovigerous female.

Gnathophyllum fasciolatum Stimps.,\| from Australia and Amboyna, agrees very closely in form with $G$. elegans, but differs wholly in the pattern of its markings and in coloration from both $G$. clegans and $G$. panamense. G.zelra Richters, ${ }^{*}$ from Mauritius, is without much doubt the same as G. fasciolatum. Ortmann $\dagger$ has lately recorded a Gnathophyllum from Tahiti as a new species, G. pallitum. It differs from $G$. fasciolatum only in the absence of colormarks. This difference may be due to the action of alcohol.

In the genus Gnathophyllum, the external flagellum of the antennule is double, producing a short third flagellum similar to that of the Palamonida.

\footnotetext{
* Hist. Nat. des Crust. des Environs de Nice, p. 93, Plate II., Fig. 4, 1816.

† Hist. Nat. de l'Europe Mérid., V. 71, 1826.

‡ Hist. Nat. des Crustacés, II. 369, 1837.

\$ Comptes Rendus, CV. 1034, 1857.

॥ Proc. Acad. Nat. Sci. Plila., 1860, p. 28.

* Beitr. zur Meeresfauna der Insel Mauritius und der Seychellen, p. 161, Plate XVII. Fig. 18-20, 1880.

+ Zoolog. Jahrb., Abth. f. Syst., V. 537, 1890.
} 


\section{Fanily PALAMONIDA.}

PAL无MON FABR. (restr.).

Suppl. Ent. Syst., pp. 378, 402, 1793. Restricted by Strmpson, Proc. Acad. Nat. Sci. Plila., 1860, p. 41.

\section{Palæmon jamaicensis (Herbst).}

Cancer (Astacus) janaicensis Herbst, Naturgesch. der Krabben und Krebse, II. 57, Plate XXVII. Fig. 2, 1796.

Palcemon jamaicensis Olivier, Encycl. Méth., Insectes, VIII. 659, 1811.

Six specimens from Panama, March 12.

This well known fresh-water prawn inhabits the Atlantic coast of America from the West Indies and the Gulf of Mexico to Rio São Francisco, Brazil. It has been found also on the Pacific side at Polvon, Nicaragua,* and there are specimens in this Museum collected by Dr. Gustav Eisen, in fresh water near Cape St. Lucas, Lower California.

\section{FAMILY PANDALID A.}

HETEROCARPUS A. M. EDW.

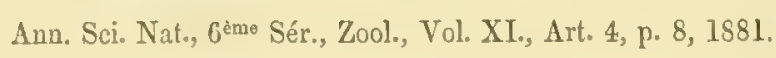

Heterocarpus vicarius FAx.

Plate XL., Fig. 1, $1^{a} 1^{b}$; Plate XLI., Fig. 2, $2^{a}$.

Bull. MIus. Comp. Zoöl., XXIV. 203, 1893.

The rostrum is considerably shorter than the remaining portion of the carapace (in very small, immature individuals it is relatively much longer), and its distal part is turned obliquely upward; it is armed above with seven or eight teeth, below with about tivelve. 'The median dorsal line of the carapace is very convex and furnished with a prominent keel which is continuous anteriorly with the superior keel of the rostrum and terminates posteriorly a short distance before attaining the posterior border of the carapace; this keel is armed with four or five teeth on the gastric area, back of the base of the rostrum. On each side of the carapace there are, in addition to the light marginal keel along the infero-lateral border, two prominent longitudinal ridges or carinæ. $\dagger$ 'The upper one begins near the posterior margin

* Smith, Ann. Rep. Peabody Acad. Sci. for 1869 and 1870, p. 97, 1571.

+ The carina of the carapace play such an importaut part in descriptions of the species of the genus Heterocarpus that they deserve to be considered here in some detail. When they are developed to the fullest degree, we find, in addition to the median dorsal and the inferior marginal carina, three lateral carinæ on 
of the orbit, on a level with the base of the eye-stalk, runs backward and a little downward along about two fifths the length of the carapace, then

each side of the carapace. The uppermost of these, lettered $a$ in the accompanying cuts, begins at the pos. terior boundary of the orbit, just behind the base of the eye-stalk, runs backward defining the lower limit of the gastric and cardiac regions, and ends near the hind margin of the carapace just at the point where the hind margin curves backward to form the hind margin of the branchiostegite. The middle lateral carina ( ()

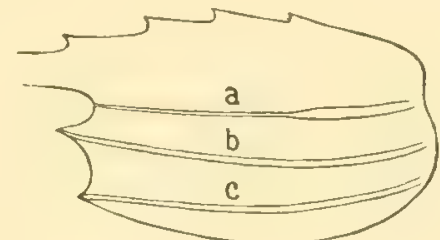

FIG. 1.

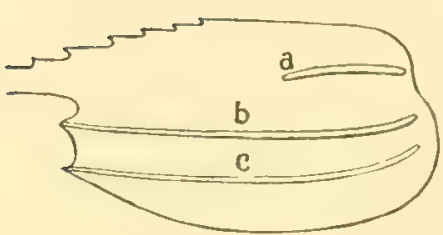

FIG. 2.

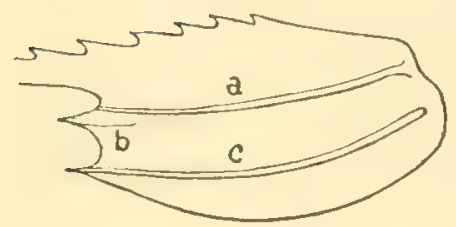

Fig. 3.

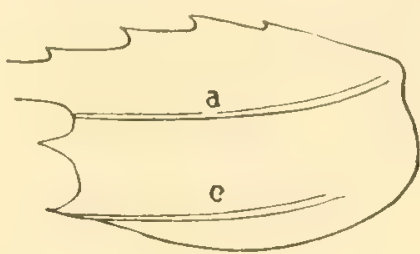

FIG. 4.

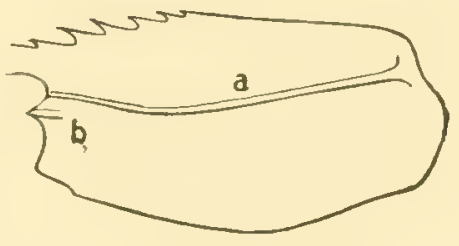

FIG. 5.

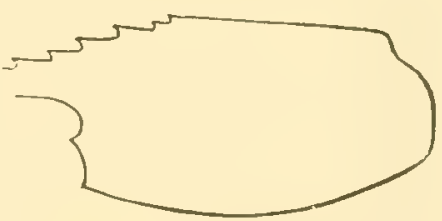

FIG. 6.

originates anteriorly in the orbital spine and courses backward over the hepatic and branchial regions, below carina $a$. The lowermost lateral carina $(c)$ is continuous in front with the lower spine of the antero-lateral border (the branchiostegal spine of Stimpson), and sweeps backward below $b$ along the brauchial area until it is lost near the hind bolder of the carapace. This complete expression of all the carinæ is represented in the first diagram (Fig. 1). It is realized in $H$. curinalus Smith (=H. ensifer, juv. :), in which all the carinæ are developed throughout their whole course, although $a$ is not so sharply defined on the anterior half of the carapace as it is posteriorly. Still it can be followed quite up to the margin of the orbit. The next diagram (Fig. 2) shors the complete suppression of the anterior lialf of $a$. This condition is exemplifed in $H$. ensifer A. M. Edw. In the majority of the known species, however, $a$ is perfectly developed, while $b$ is well-nigh conmpletely obsolete (Fig. 3). We then have two lateral carinæ. These are not homologous with the two complete caring of $H_{0}$ ensifer, but with the upper half-carina and the lowest one of that species. A slight vestige of the anterior end of $b$ appears in the form of a short ridge continued backward from the base of the orbital spine. In this category come the following species: $H$. vicarius Fax., gibbosus Bate, ory $x$ A. M. Edw., dorsalis Bate, alphonsi Bate, hostilis Fax., and affinis Fax. The next stage in the suppression of the carinæ is shown in Fig. 4 , where, besides the absence of $b$, we note the obsolescence of the posterior fourth of $c$ (H. lovigatus Bate). In H. alexandri A. M. Edw., $c$ has completely disappeared, leaving only one lateral cariua, a (Fig. 5). Finally, in H. lovis A. M. Edw., all the carinæ are obsolete (Fig. 6), and we have a smooth carapace, as in Pandalus.

The homology of these carinæ has been misapprehended by some writers. A. Milne Edwards, for instance, says that the superior lateral carina of $H$. ensifer is absent in $H$. ory $x$, whereas it is in fact the middle one that is obsolete in the latter species. 
curves upward, defining the upper limit of the branchial region, and is finally lost just before reaching the hind margin of the carapace. The anterior part of this carina is separated from the orbital spine and the hepatic area by a deep groove; below this carina there is a deep vertical indentation on the side of the carapace between the hepatic and branchial areas, as in all the species of this genus in which the middle lateral carina is obsolete. The inferior lateral carina extends from the branchiostegal spine, with which it is continuous, backward, pursuing a more nearly horizontal course than the upper one, and stops before reaching the hind border of the carapace.

The third abdominal segment is keeled along the median dorsal line. Its hinder half is sharply bent down at angle of about $90^{\circ}$, forming a prominent lnee. There are no median teeth on this or any of the other abdominal segments. The end of the telson is acutely triangular, and is armed with three pairs of articulated spines; the intermediate pair of these spines are much the stoutest and longest. The dorsal face of the telson is armed with four pairs of spines articulated at their bases.

The two flagella of the antennule are subequal, and about as long as the whole body minus the rostrum. The basal segment of the antennule is armed externally with a spine whose acute tip reaches forward to the middle of the second segment of the peduncle. The antenna with its flagellum is about twice as long as the body (rostrum included); the scale is one half the length of the rostrum, its sides convex, its external spine subterminal.

The right carpus of the second pair of legs is composed of nine or ten segments, the left of twenty-two to twenty-four. The merus of the left leg of the second pair is also obscurely divided up into many (nine or ten) secondary segments or annuli, as in other species of this genus.

The last pair of abdominal appendages are about as long as the telson, the outer branch being slightly longer than the inner.

Length, $110 \mathrm{~mm}$; rostrum, $26 \mathrm{~mm}$.; carapace with rostrum, $55 \mathrm{~mm}$.; antenna, $219 \mathrm{~mm}$.; antennal scale, $14 \mathrm{~mm}$.; telson, $17 \mathrm{~mm}$.

This species was taken at four stations in the Gulf of Panama, viz:-

Station 3385. 286 fathoms. 49 specimens (" a peck rejected").

$$
\begin{array}{llllcc}
\text { “ } & 3386 . & 242 & \text { " } & 91 & \text { " } \\
\text { " } & 3389 . & 210 & \text { " } & 7 & \text { " } \\
\text { " } & 3396 . & 259 & \text { " } & 18+50 \text { juv. }
\end{array}
$$

Heterocarpus vicarius is closely related to $H$. gibbosus Bate, described from 
a single specimen procured by the "Challenger" in 700 fathoms among the Philippine Islands.* The habitats of the two species are separated by the whole breadth of the Pacific Ocean.

Compared with $H$. gibbosus, its western representative, $\boldsymbol{H}$. vicarius, differs ns follows: the carapace is very much longer both in proportion to its own height and to the length of the rostrum, and its dorsal margin is not so convex; the teeth of the upper edge of the rostrum are more numerous and closely set; the lateral carinx of the carapace are more prominent; the third abdominal segment forms a sharper angle or knee; and the antennular flagella are longer and subequal in length.

In $H$. vicarius the third maxilliped is not furnished with an exopod. In place of it there is merely a small papilla on the outer side of the basipodite. This is also the case in the type of $H$. ory $x$ and, according to Bate, in H. dorsalis. In $H$. hostilis and $H$. affuis the exopod is present, though rudimentary, being not more than one fifth as long as the ischium. In other species, e. g. ensifer, carinatus (=ensifer?), alexandri, and levis, the exopod forms a prominent appendix to the third maxilliped, one half or two thirds as long as the ischium.

The number and arrangement of the gills in the genus Ileterocarpus are correctly given by Prof. S. I. Smith in Bull. Mus. Comp. Zoöl., X. 66, and erroneously by Spence Bate in the Report on the Crustacea Macrura of the "Challenger" Expedition, p. 629.

\section{Heterocarpus hostilis FAx. \\ Plate XLI., Fig. 1-1'. \\ Bull. Mus. Comp. Zoöl, XXIV. 204, 1893.}

The rostrum, measured from the tip to the posterior boundary of the orbit, is from one and a half to two and a third times as long as the rest of the carapace; its basal fourth is nearly horizontal, while the remaining portion is bent up at an angle of about $22^{\circ}$; it is armed with seven or eight teeth above, nine to fourteen below. The dorsal carina of the rostrum extends back on the median line of the carapace nearly to the hind border of the carapace. There is but one tooth on this carina posterior to the base of the rostrum, and that is on the gastric region.

On each side of the carapace there are two lateral carinæ. The upper

* Cf. Wood-Mlason and Alcock in Amn. Mag. Nat. Hist., 6th Ser., IX. 369, Fig. 6, 1992. 
one begins at the orbit and runs backward and then obliquely upward to the hind border of the carapace. It is separated anteriorly from the base of the external orbital spine by a deep but narrow groove. The inferior lateral carina is continuous in front with the inferior (branchiostegal) spine of the anterior margin of the carapace. It trends backward nearly parallel with the superior lateral carina, and becomes obsolete a little way from the lind margin of the carapace. A smaller carina runs close to the lower margin of the carapace.

The first, second, and sixth seginents of the abdomen are not carinated. The third, fourth, and fifth segments are carinated along the median dorsal line. On the third segment the carina is broken into two moieties, the anterior of which is fluted above and terminates in a sharp spine a little behind the middle of the segment, while the posterior portion is rounded above and ends in a spine on the posterior border of the segment. The carina on the fourth and fifth segments is unbroken, and ends in a longer spine at the posterior border of each of these segments. Thus there are four spines in the median dorsal line of the abdomen, two on the third segment, one on the fourth, and one on the fifth.

The telson ends in a long, acute, median tooth, which is flanked by two pairs of movable spines. Of these the distal exceed the median tooth in length; the proximal, on the contrary, are very small and short. There are, moreover, three pairs of spines on the dorsal surface of the telson.

The basal segment of the antennule is furnished with a long external spine (stylocerite) which reaches nearly to the end of the second segment of the antennule. At the base of this spine, against the eye-stalk, is a rounded lobe.

The antennx are twice the length of the whole body, including the rostrum. The antennal scale reaches nearly half way to the end of the rostrum; its external lateral tooth is situate some distance behind the front extremity.

The third maxillipeds bear a rudimentary exopod hardly a fifth as long as the ischium.

The carpus of the right leg of the second pair is composed of ten segments; on the left leg of the same pair the carpus contains from twenty-two to twenty-seven segments.

Dimensions of a male: length from tip of rostrum to end of telson, $197 \mathrm{~mm}$. : length of rostrum, $70 \mathrm{~mm}$; length of carapace, including rostrum, 
$108 \mathrm{~mm}$.; length of antenna, $400 \mathrm{~mm}$.; length of antennal scale, $27.5 \mathrm{~mm}$; length of telson, $27 \mathrm{~mm}$.

$\begin{array}{crrrrr}\text { Station } & 3353 . & 695 & \text { fathoms. } & 22 & \text { specimens (" } 1 \text { doz. rejected"). } \\ \text { " } & 3363 . & 975 & \text { " } & 24 & \text { "6 } \\ \text { " } & 3364 . & 902 & 6 & 3 & \text { "6 } \\ \text { " } & 3371 . & 770 & 6 & 20+ & \text { "6 } \\ \text { " } & 3380 . & 899 & 6 & 6 & \text { "6 } \\ \text { " } & 3393 . & 1020 & \text { "6 } & 8 & \text { "6 } \\ \text { " } & 3395 . & 730 & \text { "6 } & 2 & \text { "6 }\end{array}$

This species is nearly related to $H$. alphonsi Bate, from off the Philippine Islands and Japan, but may be easily distinguished from the latter species by the more upturned rostrum, by the presence of but one tooth in the median dorsal line of the carapace back of the base of the rostrum (in $H$. alphonsi there are two*), and by the two spines on the third abdominal segment.

In one ovigerous female from Station 3353 the teeth on the upper side of the rostrum are reduced to four (there are seven below). This is probably an abnormal variety merely. This specimen was drawn in color from life by Mr. Westergren. The ground color is bright red, with large patches of green on the carapace and abdomen. The green areas in the sketch correspond in their position to patches of mud still adhering to the specimen in alcohol, so that I think the green color is attributable to the mud, not to color-markings in the shell of the prawn. The bottom on which the specimen lived was composed of green mud.

In another specimen, also a female, from Station 3395, the rostrum is very different from the normal type, being shorter - equal in length to the rest of the carapace - and armed with a single tooth, near the base, above. The inferior rostral teeth are smaller, more closely set, and more numerous (eighteen) than in the normal form. The carapace of this specimen is represented on Plate $\mathrm{XI} I_{\Delta}$. (Fig. $1^{d}$ ). As this unique specimen differs in no other respect from $H$. hostilis, and comes from the same locality, I an disposed to regard it also as a mere variety or "sport" of that species.

From Station 3363 (978 fathoms), 3370 (134 fathoms), and 3406 (551 fathoms) come seven small specimens, ranging from 48 to $81 \mathrm{~mm}$. in length, that differ considerably from the adult specimens of $H$. hostilis. The rostrum is more nearly horizontal, and has about twelve teeth above and fourteen

* Among the large number of specimens of $H$. hostilis examined, I have found a very few (four) with two spines on the carapace back of the rostrum, as in $H$, alphonsi. 
below. The carina on the third abdominal segment is not broken into two parts (except in one specimen), and is armed with only a single spine, at the posterior end. This carina is fluted above, as in $H$. hostilis, from its anterior end to a point corresponding with the position of the anterior spine in the adult $H$. hostitis. I am inclined to consider these specimens as young stages of $H$. hostilis, especially since in one of those from Station 3363 the carina of the third abdominal segment, although not two-spined, is nevertheless cut by a notch into an anterior and a posterior section.

\title{
Heterocarpus affinis FAX.
}

\author{
Plate XL., Fig. 2, 2a, $2^{b}$; Plate XLI., Fig. 3, 3. \\ Bull. MIus. Comp. 'Zoöl., XXIV. 201, 1893.
}

This species is closely allied to the preceding ( $H$. hostilis), from which (comparing specimens of the same sex) it differs in the following particulars: the rostrum is much shorter in proportion to the length of the carapace; measured from the tip to the posterior limit of the orbit it about equals the rest of the carapace in length in some specimens, while in others it is only two thirds as long. There are, moreover, fewer teeth on its dorsal margin (five or six), the number of teeth on its ventral margin varying from six to ten. The median dorsal line of the carapace is more convex, and is armed, posteriorly to the base of the rostrum, with two acute teeth, whereas in $H$. hostilis there is but one tooth on this portion of the carapace, except in a few abnormal individuals.

It is also nearly related to $H$. dorsatis Bate, collected off Banda Island by the "Challenger," but differs from that species in having a shorter rostrum, and two median teeth on the third abdominal segment.

The exopods of the third maxillipeds are the same size as in $I$. hostilis, whereas in $\boldsymbol{H}$. dorsulis, according to Bate, they are reduced to a mere tubercle.

$H$. affinis and $I I$. hostilis belong to different geographical areas, as will be seen by inspection of the stations at which the two species were procured. $H$. affinis is the more northerly form, from the const of Mexico (off Acapulco and Cape Corrientes), while $H$. hostilis comes from the region about the Gulf of Panama.

Dimensions of a female specimen : length, $153 \mathrm{~mm}$.; length of carapace, including rostrum, $76 \mathrm{~mm}$; length of rostrum, $35 \mathrm{~mm}$.; length of antennal scale, $23 \mathrm{~mm}$.; length of telson, $23.5 \mathrm{~mm}$. 
Station 3418. 660 fathoms. 13 specimens.

$\begin{array}{llllll}\text { " } & 3424 . & 676 & 6 & 5 & \text { " } \\ & 3425 . & 680 & \text { " } & 9 & \text { "6 }\end{array}$

PANDALOPSIS BATE.

Rep, Challeuger Macrura, p. 671, 1858.

Pandalopsis ampla Bate.

Rep. Challenger Macrura, p. 671, Plate CXV. Fig. 3, 1858.

Station 3418. 660 fathoms. 1 specimen.

"3424. 676 " 6 specimens.

The types of this species were collected in 600 fathoms, off Monte Video.

Pandalopsis is a MS. name of A. Milne Edwards's, adopted by Bate. This genus is distinguished from Pandalus by the greatly elongated flagella of the antennules, and by the laminate expansions of the merus of the third maxillipeds and of the ischium of the first pair of legs. The third maxilliped has no exopod. The epipods of the legs are rudimentary, as in Pandalus and Heterocarpus. The branchial formula is the same as for Pandalus and Heterocarpus, viz: :

$\begin{array}{lccccccccc}\text { Somites } & \text { vIr. } & \text { VIII. } & \text { IX. } & \text { X. } & \text { XI. } & \text { XII. } & \text { XIII. } & \text { xIF. } & \\ \text { Pleurobranchix } & 0 & 0 & 0 & 1 & 1 & 1 & 1 & 1=5 \\ \text { Arthrobranchiæ } & 0 & 0 & 2 & 1 & 1 & 1 & 1 & 0=6 \\ \text { Podobranchix } & 0 & 1 & 0 & 0 & 0 & 0 & 0 & 0=1 \\ \text { Epipods } & 1 & 1 & 1 & 1 & 1 & 1 & 1 & 0=\frac{(7)}{12+(7)}\end{array}$

The generic distinctions between this genus and Pandalus drawn from the branchire and epipods, mentioned by Bate, ${ }^{*}$ do not exist.

The right and left legs of the second pair are of about equal length in $P$. ampla.

\section{FAMILY ALPHEID A.}

\section{ALPHEUS FABR.}

Suppl. Ent. Syst., pp. 380, 404, 1798.

\section{Alpheus panamensis Kingsu.?}

Bull. U. S. Geolog. and Geograph. Surv., Vol, IV., No. 1, p. 192, 1878.

Five specimens (two of them ovigerous females), without a label, agree pretty well with Kingsley's description of $A$. panamensis. There is a small

$$
\text { * Op. cit., p. } 671 \text {. }
$$


spine on the inner side of the propodite, at the point of articulation with the dactylus, and two pairs of spines on the dorsal side of the telson. These points are not specified in Kingsley's description. The rostrum is acute, its margins ciliated; it exceeds the orbital spines, reaching forward beyond the middle of the first segment of the antennule.

In a later paper* Kingsley says that $A$. panamensis may prove to be the same as A. spinifions M. Edw. $\dagger$ from the coast of Chile. But Milne Edwards states that the smaller chela of $A$. spinifrons is extremely short, while in A. pancinensis it is described as being nearly as long as the larger chela; in A. spinifrons the antennal scale is very small, while in A. panamensis it extends slightly beyond the peduncles of the antennules. If the "Albatross" specimens are correctly referred to $A$. panamenis, this species is further distinguished from $A$. spinifrons by the form of the front, which in the latter species is described as inclined and armed with three spines (the rostral and two ocular) of equal length, while in the specimens before me the rostrum is much longer than the ocular spines.

\section{Family nematocarcinid}

NEMATOCARCINUS A. M. EDW.

Ann. Sci. Nat., Zool., 6ème Sér., Vol. XI., Art. 4, p. 14, 1881.

\section{Nematocarcinus ensifer Sмiті.}

Eumiersia ensifera Surt!, Bull. Mus. Comp. ZoöI., X. 77, Plate XIII. Fig. 1-9, 1882.

Nematocarcinus ensiferus Suitu, Ann. Rep. U. S. Fish. Comm. for 1882, p. 368, Plate VII. Fig. 1, 1854; id. for 1855, p. 664, Plate XVII. Fig. 2, 1886.

Station 3363. 978 fathoms. 20 specimens.

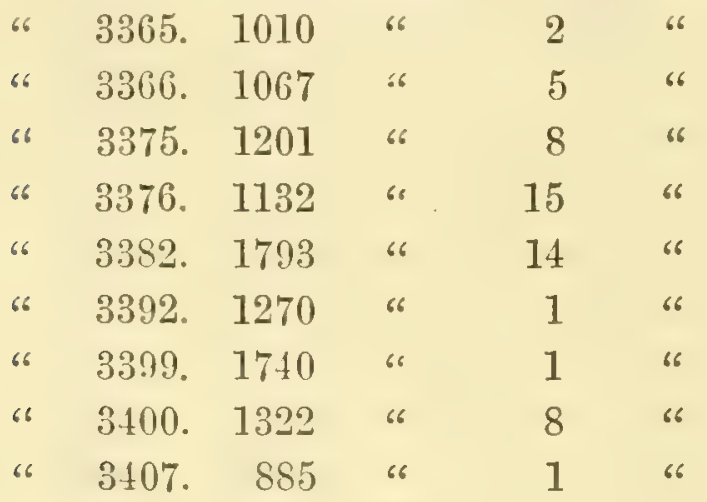

* Bull. Essex Inst., XIV. 116, 1883.

† Hist. Nat. Crust., II. 355, 1837. 


\begin{tabular}{crrrrr} 
Station & 3413. & 1360 & fathoms. & \multicolumn{2}{c}{1 specimen. } \\
" & 3415. & 1879 & " & 5 & " \\
" & 3415. & 660 & " & $80+$ & "6 \\
" & 3424. & 676 & " & 36 & "6 \\
" & 3425. & 680 & "6 & 41 & " \\
" & 3430. & 852 & "6 & 6 & " \\
" & 3431. & 995 & " & 3 & " \\
" & 3435. & 859 & " & 14 & " \\
" & 3436. & 905 & " & 17 & "
\end{tabular}

This species has been previously known from off the eastern const of the United States (lat. $31^{\circ} 41^{\prime}$ N. to $41^{\circ} 43^{\prime}$ N., 588 to 2033 fathoms) through the explorations of the "Blake" and the "Albatross." The Pacific specimens, like those from the Atlantic side of the continent, vary considerably in the length and trend of the rostrum, which may be either straight and horizontal, or curved considerably upward. In some specimens, moreover, the rostrum is armed on the lower margin with from one to three small teeth which are wanting in the typical form, and this variation is almost invariably accompanied by a difference in the abdominal segments. In the typical form, without inferior rostral teeth, the dorsum of the third abdominal segment is prolonged into an acute tooth over the fourth segment, while the succeeding segments are laterally compressed near the dorsum so strongly as to present an almost carinated appearance. In the specimens with inferior rostral teeth the third abdominal segment is prolonged backward over the following segrnent in a less degree, and the prolongation is rounded off behind instead of ending in a sharp point. The dorsum of the succeeding abdominal segrnents, too, is rounder than in the typical form. The typical form is the more southerly in its distribution, ranging (as far as the collection at hand determines) from $0^{\circ} 36^{\prime} \mathrm{S}$. to $7^{\circ} 5^{\prime} 30^{\prime \prime} \mathrm{N}$. (Stations $3363-3413$ ), while the other form is found between $16^{\circ} 33^{\prime} \mathrm{N}$. and $27^{\circ} 34^{\prime} \mathrm{N}$. (Stations 3418-3436). In rare cases, as in the specimens from Station 3415 (an intermediate locality, be it observed), we find the rostrum of the typical form combined with the abdomen of the more northern race. 


\section{Nematocarcinus agassizii FAx.}

Plate XLII.

Bull. Mus. Comp. Zoöl., XXIV. 201, 1893.

The rostrum is one fifth longer than the rest of the carapace (in some small specimens only equal to the rest of the carapace), slender, nearly horizontal for the basal two fifths of its length, the remaining portion gently upturned and ending in a very acute point; its upper margin is continued backward in the form of a carina, which becomes obsolete on the hinder part of the grastric region; this carina is pectinate, or armed with close-set, forwardpointing teeth on the anterior part of the gastric region, and the teeth are continued on the upper margin of the rostrum through one third or two fifths of its length, the distal third or three fifths of the rostrum being entirely free from teeth above; the lower edge of the rostrum is ciliated above the eyes and armed with three (rarely four) teeth, separated by wide intervals, on the distal half.

The third abdominal segment is somewhat prolonged posteriorly over the next segment, but the hind margin is rounded off and does not form a prominent tooth. The telson is tipped with three pairs of spines, the intermediate pair the longest; there are, besides, about six pairs of small spines on the dorsal side of the telson.

The flagella of both the antennules and antenna are prodigiously developed, the antennule being nearly twice, the antenna more than twice the length of the whole body including the rostrum; excepting the proximal part of the organ, the annuli of the antennal flagellum are enlarged at the distal end, giving a beaded appearance to the flagellum; the antennal scale reaches rather more than half-way to the end of the rostrum; it is truncate at the distal end and armed externally with an apical spine.

The legs have the characteristic shape and proportions of the genus. The dactyli of the third and fourth pair are slender, acute, somewhat curved, and invested with a pencil of long hairs. The dactyli of the fifth pair are stouter but very short, and hidden in the tuft of hairs which arises from the distal end of the propodite.

The outer blade of the swimmeret slightly surpasses the telson. It is fringed with long hairs along the internal and distal margin, and furnished with a minute tooth and a movably articulated spine on the external border 
near the distal end. The inner blade is a trifle shorter than the telson; it is also fringed along its whole margin with long hairs.

Dimensions of a female specimen: length of body, rostrum included, $139 \mathrm{~mm}$. ; length of rostrum, $35 \mathrm{~mm}$; length of carapace, rostrum included, $61 \mathrm{~mm}$.; length of telson, $20 \mathrm{~mm}$. ; length of antennule, $267 \mathrm{~mm}$. ; length of antenna, $315 \mathrm{~mm}$.; length of antennal scale, $19 \mathrm{~mm}$.

This species, like all the Nematocarcini, is very fragile. The long and slender rostrum is often broken off during life, and the attempt to restore it sometimes results in an abnormally small and otherwise monstrous rostrum, which might easily be mistaken for a specific character if ample material were not at hand.

\begin{tabular}{|c|c|c|c|c|c|c|}
\hline Station & 3353. & 695 & fathoims. & & cimens. & \\
\hline 6 & 3354. & 322 & 66 & 4 & 66 & \\
\hline 66 & 3358. & 555 & 66 & 90 & 66 & \\
\hline 6 & 3359. & 465 & “6 & 2 & 66 & \\
\hline " & 3364. & 902 & 6 & 4 & 66 & \\
\hline 66 & 3370. & 134 & 66 & 8 & 66 & \\
\hline 6 & 3380. & 899 & 66 & 7 & 66 & \\
\hline 66 & 3384. & 458 & " & 1 & 66 & \\
\hline 66 & 3393. & 1020 & 66 & 8 & 6 & \\
\hline 66 & 3395. & 730 & 6 & 3 & 6 & \\
\hline 66 & 3406. & 551 & 66 & 1 & 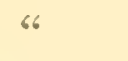 & \\
\hline 66 & 3407. & 88 & 66 & 14 & 66 & (1 bopyrized). \\
\hline 6 & 3418. & 660 & 66 & 4 & 66 & \\
\hline 66 & ? & $?$ & 66 & 24 & 66 & \\
\hline
\end{tabular}

\section{FAMITY HOPLOPHORID $A$.}

Oplophorina Kingstey, Bull. Essex Inst, X. 68, 1878; id., Proc. Acad. Nat. Sci. Phila., 1879, p. 426. Partim; cf. KINGsLeY, Bull. Essex Inst., XIV. 127, 1883. Type genus, Oplophorus M. Edw.

Ephyrine Sщiтr, Bull. Yus. Comp. Zoöl., X. 66, 1882 (partim, Eumiersia (= Nematocarcinus) excl.); id., Ann. Rep. U. S. Fish Comm. for 1892, p. 372, 189t. ? = Ephyrine Kingster, 1879 (type genus, Miersia Kingsl., = Ephyra Roux, a genus not sufficiently known).

Ephyride G. O. SARs, Norske Nordhars-Exped., Crustacea, I. 35, 1885.

Miersiide (nom. nov. vice Ephyride) Surt, Amm. Rep. U. S. Fish Comm. for 1885, p. 667, 18S6; WoonMasov, Ann. Mag. Nat. Hist., 6th Ser, VII. 194, 1891; Faxov, Bull. Mus. Comp. Zoölo, XXIV. 206, 1893.

Acanthephyride (Campylonotus excl.) + Tropiocaridce Bate, Rep. Challenger Macrura, pp. 481, 927, 1888. Type genera, dcanthephyra A. M. Edw., et Tropiocaris Bate (=Ephyrina Smith).

Acanthephyridre Tood-Masov, Ann. Mag. Nat. Hist., 6th Ser, IX. 359, 1892; Stebbing, Hist. Crust., p. 242, 1593; Orturann, Decap. u. Schizop. der Plankton-Exped., p. 42, 1893. 
ACANTHEPHYRA A. M. EDW.

? Ephyra Roux, Mém. sur la Classif. des Crustacés de la Tribu des Salicoques, p. 24, 1831 (type, Alpheus pelagicus Risso).

? Miersia (nom. nov. vice Ephyna præoc.) Kingstey, Proc. Acad. Nat. Sci. Phila, 1879, p. 416 (same type).

Miersia Surtu, Bull. Mus. Comp. Zoöl., X. 66, 1882.

Acanthephyra A. M. Edrards, Aun. Sei. Nat., Zonl., Gème Sér., Vol. XI., Art. 4, p. 12,1881 (type, Acanthephyra armata A. M. Edw.); id., Recueil de Figures de Crustacés nouv. ou peu connus, lère Livr., Plate XXXIII., 1893 ; Suiti, Amm. Rep. U. S. Fish Comm. for 1882, p. 372, 1884 ; id., Proc. U. S. Nat. Mus., VII. 502, 1835; id., Ann. Rep. U. S. Fish Comm. for 1595, p. 667, 1856; Wood-Mason, Ann. Mag. Nat. Hist., Gth Ser., VII. 195, 1S91, IX. 358, 1892; Stebbing, Hist. Crust., p. 243, 1S93 ; Fason, Bull. Mus. Comp. Zoöl., XXIV. 206, 1893; Orminns, Decap. u. Schizop. der Plankton-Exped., p. 43, 1893.

Acanthephyra + Systellaspis Bıte, Rep. Challenger Macrura, pp. 730, 757, 1559 (type of Systellaspis, S. lanceocaudata Bate).

So little is known concerning the structure and affinities of Alphens pelagicus Risso, * the type species of the genus Micrsia Kingsl. (= Ephyra Roux, nom. prococ.), that it seems best to ignore Micrsia (Ephyra) as based upon a species at present indeterminable, and to suppress family and subfamily names derived therefrom. 'The lower Atyide, genera characterized by palpless mandibles and by the presence of exopods on all the thoracic legs, $\dagger$ may receive the subfamily name Paratyina, from Paratya Miers $\$$ (type, Ephyra? compressa De Haan). § The genus Atyephyra, with Caridina-like chelæe and with exopods on only the first two pairs of legs, forms a transition from the Paratyina to the Atyina. Ephyra heckelii v. Mart.** belongs to the family Hoplophoridce and probably to Acanthephyra, subgen. Systellaspis Bate.

* Alpheus pelagicus Risso, Hist. Nat. des Crustacés des Envirous de Nice, p. 91, Plate II. Fig. 7, 1816. Pandalus pelagicus Risso, Hist. Nat. de l'Europe Mérid., V. 79, Plate II. Fig. 5, 1826.

† Such forms lave been called Niersiidee by Pocock (Ann. Mag. Nat. Hist., 6th Ser., III. 17, 1889), Ephyrine by Ortmann (Zoolog. Jalırb., Abth. f. Syst., V. 456, 1890).

‡ Ann. Mag. Nat. Hist., 5th Ser, IX. 194, 1852.

§ Siebold's Fauna Japonica, Crustacea, p. 186, Plate XLVI. Fig. 7, Plate O, 1849.

|| Aiycephyra Brito Capello, Descripção de algunas Especies Novas ou pouco conhecidas de Crustaceos, etc., p. 5, Plate I. Kig. 1-1e, 1866; in Mem. Acad. Sci. Lisboa, Cl. de Sci. Math., Nova Serie, T. IV. Part I., type, Alyaephyra rosiana Brito Capello. Ortmann (Zoolog. Jahrb., Abth. f. Syst., V. 464, 1590) has recently established the genus Hemicaridina for the reception of Hippolyle desmarestii Millet (Caridina desmarestii Joly). Since this species is strictly congeneric with Atyephyra rosiana, Hemicaridina becomes a syuouyme of Alyephyra.

*** Arcl. f. Naturgescli., XXXIV. I. 52, Plate I. Fig. $7 a, 7 b, 1865$. 


\section{Acanthephyra agassizii Sнтт?}

?.Miersia agassizii Smite, Bull. Mus. Comp. Zoöl., X. 67, Plate XI. Fig. 5-7, Plate XII. Fig. 1-4, 1852.

? Acanthephyra agassizii SurtI, Ann. Rep. U. S. Fish Coinm. for 1882, p. 372, Plate VIII. Fig. 1, 1851; id. for 18s5, p. 667, Plate XV. Fig. 1, 6, 6a, 7, Plate XVI. Fig. 2, 1896.

Station 3383. 1832 fathoms. 1 fem. ovig. " 3398.1573 " 1 " 13

In the type specimen of $A$. agassizii the rostrum, although broken off at the tip, is as long as the rest of the carapace, and is armed with eight teeth above, and five below; the carina of the fourth abdominal segment is not prolonged to a spine or tooth posteriorly; the telson is armed with four pairs of spines on the dorsal side in front of the terminal spines. In the two specimens which I have doubtfully referred to this species, the rostra fall short of the length of the carapace by one fifth, and one sixth the length of the latter; the formula for the rostral teeth of one is $\frac{7}{5}$, of the other $\frac{8}{6}$; the carina of the fourth abdominal segment is produced into a sharp tooth posteriorly, as in A. sanguinea Wood-Mason; * the telson bears three pairs of dorsal spines. The branchiostegal spine, moreover, is smaller than in the type, $\dagger$ and the enlarged portion of the external antennular flagellum is shorter. In other respects my specimens agree well with the type. In specimens subsequently referred to $A$. agassizä by Smith, the rostrum is even shorter than in my specimens, and the telson is armed with as many as nine pairs of dorsal spines, thus closely resembling $A$. sica Bate (1888). Bate considers A. agassizii Smith to be synonymous with A. purpurea A. M. Edw., obtained by the "Travailleur" off the coast of Portugal; but in the latter species the rostrum is longer than in $A$. agassizii, and the second abdominal segment is not carinated dorsally according to Milne Edwards's figure $\S$ and Bate's diagnosis.

The form of the eye in A. agassizii is not described by Professor Smith, and in his type specimen of this species the eyes are so much mutilated that their true form cannot be satisfactorily determined. In the specimens referred to A. agassizii in Smith's later papers, - specimens which differ from the type, as above indicated, - there is an oblong black "ocellus," barely

* Ann. Mag. Nat. Hist., 6th Ser., IX. 35S, Fig. 1, 1892; Ill. Zoöl. H. M. I. M. S. "Investigator," Crustacea, Plate 1II. Fig. 3, 1892.

f In this respect also like $A$. sanguined Wood-Mason:

+ Comptes Rendus, XCIII., 935, 1581.

$\$$ Recueil de Figures de Crustacés nouv, ou peu connus, 1ère Livraison, 1883 
connected with the eye, on the dorsal surface of the ocular peduncle. In the two specimens from the "Albatross" collection of 1891, this ocellus does not exist. At the corresponding point the integument of the peduncle invades the eye to a slight degree, forming a notch in the otherwise entire outline of the eye, but no part of the cornea is thereby cut off from the main eye.

\section{Acanthophyra approxima Bate?}

Rep. Challenger MIacrura, p. 755, Plate CXXVI. Fig. 8, 1888.

Station 3384. 458 fathoms. 2 specimens.

"3388. $1168 \quad$ " 31 specimen.

"3403. $384 \quad$ "6 6 specimens.

Bate's description of A. approxima was based on a unique specimen obtained in Sarmiento Channel, Patagonia (400 fathoms). The rostrum of this specimen is broken off just in front of the seventh dorsal tooth, which lies directly over the posterior tooth of the lower margin. 'The four posterior teeth of the upper margin are more closely set together than the three anterior ones. In the specimens from the "Albatross" collection the rostrum is a little shorter than the carapace, and is armed with from eight to ten teeth above, four to seven below; the posterior teeth of the upper margin are not so closely set as in Bate's type specimen, so that the posterior tooth of the lower margin underlies the fifth or the sixth superior tooth, or else the interval between these teeth. The integument is thin and membranous - a character not specified by Bate in his description of A. approxima. The posterior angles of the pleuræe of the fifth abdominal segment are rather sharper than indicated in Bate's figure, and the eye is narrower. The telson is furnished with a few pairs of very minute dorsal spines, which tend to become obsolete in many specimens.

\section{Acanthephyra cristata FAx. \\ Plate XLIII., Fig. 1, $1^{a}, 1^{b}$. \\ Bull. Mius. Comp. Zoöl., XXIV. 206, 1893.}

The rostrum, measured from the tip to the hind border of the orbit, is three quarters the length of the rest of the carapace, measured from the hind wall of the orbit to the hind border of the carapace in the median dorsal line; its upper margin rises into a prominent crest, which continues backward over the anterior part of the gastric region, and sinks into a blunt 
carina, which becomes obsolete just before it reaches the posterior margin of the carapace; this crest is ornamented with seven teeth, and the anterior part of the rostrum bears four more teeth on its upper margin; the lower margin of the rostrum is armed with three or four teeth. The wall of the orbit is entire, the lower margin being continuous with the antennal spine by suppression of the normal infra-orbital angle. A simuous carina runs from the antennal spine backward to the hind margin of the carapace, forming the inferior boundary of the gastric and cardiac areas. Below the branchiostegal spine a second lateral carina runs backward, and becomes submarginal on the posterior border of the branchiostegite. The first and second segments of the abdomen are destitute of a dorsal carina; the third and fourth are carinated, and armed with a posterior tooth, largest on the third segment; the fifth and sixth segments are rounded dorsally, and the fifth is furnished with a minute posterior dorsal median spine; the posterior lateral margin of the tergum of the fourth and fifth segments is armed with a minute denticle just above the point of articulation with the next segment. In one specimen the telson is armed with about six pairs of minute dorsal spines, which are obsolete in the other specimen. In both, the posterior half of the lateral margins of the telson is spinulose; the apex of the telson is imperfect in both the specimens examined. The eye is large, black, and set obliquely on its peduncle; the inner margin of the peduncle is furnished with a rather long, blunt process, or tubercle. The antennal scales are about equal in length to the rostrum; they are armed with an external apical tooth, and are serrate on their inner margin.

Length, $78 \mathrm{~mm}$; rostrum, $13 \mathrm{~mm}$; carapace, including rostrum, 27.5 mm. ; antennal scale, $12 \mathrm{~mm}$.

Station 3361. 1471 fathoms. 1 specimen.

$$
\text { " } 3381.1772 \text { " } 6
$$

This species, like A. debilis A. M. Edw. (=A.gracilis Smith) and SystelTaspis lanceocaudeta Bate, has no carina on the dorsal surface of the fifth and sixth abdominal segments, and the orbit is continuous below with the antennal spine. On these characters, taken in connection with the large size and small number of the eggs, Spence Bate established the genus Systellaspis.* A genus founded on a physiological peculiarity combined with such trivial structural characters can hardly be accepted as a valid one. A. cristata differs from $A$. debilis in having a much shorter and fewer-spined rostrum,

* Rep. Challenger Macrura, p. 757, 1588. 
two pairs of longitudinal lateral carinæ on the carapace, a dorsal carina on the fourth abdominal segment, and in the absence of a series of denticles on the posterior margin of the tergum of the fourth and fifth abdominal segments. From A. Lanceocandata (Bate) it also differs in its shorter rostrum, more prominent lateral and dorsal carinæ of the carapace, and the absence of a prominent tooth on the anterior margin of the first abdominal segment.

Acanthephyra curtirostris Wood-Mason.

$$
\text { Plate XLIII., Fig. 2-5. }
$$

Ann. Mag. Nat. Hist, 6th Ser., VII. 195, 1891, IX. 364, Fig. 5, 1892 ; Ill. Zoöl. H. M. I. M. S. "Investigator," Crustacea, Plate III. Fig. 4, 1892.

This species is thus briefly characterized by Wood-Mason: "Closely allied to $A$. acutifrons Spence Bate, differing therefrom in its shorter and smaller carapace and in its much less produced rostrum, which does not reach beyond the middle of the terminal joint of the antennulary peduncle and is armed on its upper margin with nine minute saw-like teeth, on its lower with a single strongish spine. The ocular papilla embraces the cornea." The type specimens were taken in the Bay of Bengal in 840 fathoms, and in the Laccadive Sen in 1000 fathoms.

In specimens from the "Albatross" dredgings, which I take to be of the same species, the integument is smooth and of a firm consistence. The length of the carapace, including the rostrum, is equal to the distance from the anterior end of the abdomen to the middle of the fourth abdominal somite. The rostrum does not reach beyond the second segment of the antennular peduncle; it is very deep at the base, and ends in a short and acute tip; the superior margin is inclined upward at a small angle with the axis of the body, and is armed with a line of eight or nine teeth which runs nearly to the tip of the rostrum; the lower margin is armed with one strong tooth. Behind the superior row of teeth the dorsal margin is continued back as a low rounded ridge, which disappears before it attains to the hind margin of the carapace. 'The anterior margin of the carapace is prominently angulated below the eye, above the antennal spine. The antennal spine is short, flattened, and continuous with a longitudinal carina on the hepatic area. A low, obtuse ridge bounds the branchial regions above, and the gastric region is separated from the cardiac by a shallow, obsolescent furrow. The second to the sixth abdominal somites are carinated in the median dorsal line, the carina terminating in a sharp tooth at the posterior 
extremity of the third, fourth, fifth, and sixth segments; the tooth on the third segment is the largest, those which follow decreasing in size successively. The telson is equal in length to the fifth and sixth abdominal somites combined; it is armed with ten submarginal spines on each side. The eye is dark brown, not wider than its peduncle, its proximal margin entire, the ocellus wanting; the ocular peduncle is furnished with a long, blunt tubercle or papilla on the inner side close to the margin of the comea. The external spines of both pairs of antenna are short and acute; the antennal scale is long, broad near the base, tapering distally to the small apical tooth. The external branch of the swimmeret is shorter than the telson, but considerably longer than the inner branch.

Length of a male, $85 \mathrm{~mm}$; rostrum from tip to posterior dorsal tooth, $8.5 \mathrm{~mm}$; carapace, including rostrum, $25 \mathrm{~mm}$; telson, $18.5 \mathrm{~mm}$.; antennal scale, $14 \mathrm{~mm}$.

The above described form I have considered as typical, but the "Albatross." specimens show that this species is subject to great variation. In a single specimen from Station 3431 (an ovigerous female) there is a marked swelling in the median line of the gastric region; the rostrum is not so high at the basa as in the typical form, and ends in a longer, tapering acumen; the upper margin of the rostrum is in a line with the dorsal line of the carapace and the carapace is rather longer in proportion to the abdomen. The form. ula for the rostral teeth is $\frac{7}{1}$. This form I have catalogued as Var. a (Plate XLIII., Fig. 3).

Other specimens agree with the last in most regards, but lack the protuberance on the gastric area. The rostrum reaches to the end of the antenuular peduncle or a little further. The dental formula is variable: $\frac{7}{1}, \frac{7}{2}, \frac{8}{2}$, and $\frac{9}{2}$. These specimens I have designated as V Tr. $\beta$ (Plate XLIII., Fig. 4).

In others the rostrum is yet longer, with upturned acumen; the telson is equipped with twelve pairs of lateral spines; the rostral teeth vary in number within the limits shown in the following formulx: $\frac{9}{2}, \frac{9}{1}, \frac{8}{2}$. This form may be called Var. $\gamma$ (Plate XLIII., Fig. 5).

It will be seen on looking at the list of stations given below that the typical form has a more southern distribution than the varieties.

The extremes of variation here exhibited appear very great, but they are connected by transition forms in such a way that $I$ am led to treat them as of merely varietal importance. 
In the subjoined list I have arranged the specimens, in so far as their variability admits, in accordance with the division into varieties above made.

\section{Forma typica.}

Station 3358. 555 fathoms. 1 fem.

$\begin{array}{rrrrll}\text { " } & 3361 . & 1471 & \text { " } & 1 \text { " } \\ \text { " } & 3375 . & 1201 & \text { " } & 1 \text { male. } \\ \text { " } & 3381 . & 1772 & \text { " } & 1 \text { fem. ovig. }\end{array}$

$\operatorname{Var} \alpha$.

Station 3431. 995 fathoms. 1 fem. ovig.

$\operatorname{Var} \beta$.

Station 3414. 2232 fathoms. 3 males.

" 3415.1879 " 1 male, 1 fem. ovig.

" 3418. 660 " 2 males.

"3433. 1218 " 1 fem.

$\operatorname{Var} . \gamma$.

Station 3393. 1020 fathoms. 1 male.

\begin{tabular}{ccccccc} 
" & 3430. & 852 & " & \multicolumn{3}{c}{1 fem. ovig. } \\
" & 3436. & 905 & " & 1 & " & "6 \\
? & $?$ & & 1 & " & "
\end{tabular}

In the typical form the short rostrum overhangs the face like a hood. Upon two species with rostra like this, Bate based his genus Tropiocaris.* T. plunipes, the type of the genus, appears to be the same as Smith's Ephyrina benedicti. Neither Epluyrina nor Tropiocaris seem to be separated from Acanthephyra on sufficient grounds.

A. curtivostris in its typical form resembles A. temipes (Tropiocaris temipes Bate), but judging from Bate's figure and description, it differs from the latter in the following regards: the presence of a prominent tooth on the lower edge of the rostrum, and a dorsal carina on the second abdominal segment; the great prominence of the tubercle on the inner side of the eyestalk; and the shape of the antero-lateral margins of the carapace, which are much less oblique than in $A$. temipes.

* Rep. Challenger Macrum, p. S34, 1989.

+ Proc. U. S. Nat. Mus, VII. 506, 1855; Ann. Rep. U. S. Fish Comm. for 1885, p. 674, Plate XIV. Fig. 3, Plate XVI. Fig. 4, $15 s 6$. 
Through Var. $\gamma, A$. curtirostris approaches $A$, acutifrons Bate, but in the latter the carapace is much larger and longer in relation to the abdomen, the dorsal carina of the carapace is more complete behind the rostral teeth, the first abdominal segment is carinated, the telson is shorter and bears fewer lateral spines, and, finally, an ocellus is present.

\section{Acanthephyra brevirostris Sмiтн.}

Proc. U. S. Nat. Mus., VII. 504, 1885; Ann. Rep. U. S. Fish Comm. for 1885, p. 670, Plate XIV. Fig. 2, Plate XV. Fig. 2, 8, Plate XVI. Fig. 1, 6, 1886.

Station 3399. 1740 fathoms. 1 male.

In this specimen there is a small tooth on the lower margin of the rostrum which is wanting in the specimens from the Atlantic side of the continent, and the great tooth of the third abdominal segment is not quite so large as in the typical specimens.

The integument in this species is soft and membranaceous, as in the genus Hymenodora. Spence Bate has described a closely allied form under the name of Hymenodora duplex.**

Spence Bate in 1888t applied the specific name brevirostris, already appropriated by Smith, to a very different species of Acanthephyra from the tropical Atlantic. It hence becomes necessary to change the name of Bate's species, which I propose to call, in memory of its describer, Acantheplyra batci.

\section{Acanthephyra cucullata FAx.}

Plate XLIV., Fig. 1, $1^{n}, 1^{b}$.

Bull. Mus. Comp. Zoöl., XXIV. 206, 1593.

The integument is soft, membranaceous, and transparent in alcohol. The carapace is carinated in the median dorsal line anteriorly; this carina is furnished with seven minute teeth, and is continued forward to a very small acicular rostrum, which hardly reaches forward to the end of the eyes; the infero-lateral margins of the rostrum are continued downward for some distance, nearly parallel with one another, in an almost vertical direction, and then they suddenly diverge and trend backward, forming the upper wall of the orbit; a sort of hood is thus formed of the anterior part of the carapace, overhanging the facial region. The infra-orbital angle is rounded, not spiniferous. The antennal spine is acute, and advanced forward of the infra-

* Rep. Challenger Macrura, p. 843, Plate CXXXV1. Fig. 3, $18 s 8$.

† Op. cit., p. 751. 
orbital angle. The branchiostegal spine is small, and continuous with a longitudinal carina that runs along the branchial region of the carapace. A low fold or ridge marks the upper boundary of the branchial region.

The abdomen is carinated in the median dorsal line on the second to the sixth segments inclusive; the carina is most prominent on the third segment, where it is produced into a strong posterior tooth, which overhangs the anterior part of the fourth segment; the three following segments are furnished with minute posterior teeth. The posterior half of the telson in the unique specimen at hand is missing; there is one pair of minute marginal spines at the hind end of the remaining proximal half. The eyes and eyestalks are well developed, the stalks broadening toward the distal end and projecting a slender blunt process on the inner side close to the cornea; the eye itself is as broad as the distal end of the peduncle.

The basal segment of the antenna is armed with an acute external spine; the antennal scale is long, gradually narrowing distally to the apex, which is furnished with a small spine.

The thoracic appendages have the form characteristic of the genus Acanthephyra, and appear to offer no important specific characters.

Length, $87 \mathrm{~mm}$; carapace, $27 \mathrm{~mm}$; antennal scale, $16 \mathrm{~mm}$.

Station 3381. 1772 fathoms. 1 male.

HYMENODORA G. O. SARS.

Arch. for Math. og Naturvid., II. 240, 1877.

Hymenodora glacialis (Buchrolz).

Pasiphae glacialis Bucturouz, Zweite Deutsclue Nordpolarfalrt, II. 279, Plate I. Fig. 2, 1874.

Hymenodora glacialis G. O. SARS, Arch. for Math. og Naturvid., II. 241, 1877; Norske Nordhavs-Exped., Crustacea, I. 37, 275, Plate IV., 1885. Norman, Proc. Roy. Soc. Edinburgh, 1881-52, pp. 683, 684, 1882. Sumpr, Proc. U. S. Nat. MIus., VII. 501, 1885; Rep. U. S. Fish Comn. for 1885, p. 678, Plate XV. Fig. 3, 10, Plate XVI. Fig. 5, $18 s 6$.

Station 3383. 1832 fathoms. 3 fem.

"3399. 1740 " 2 males, 1 fem.

"3433. 1218 " 6 4 " 3 " 3

" $3436.905 \quad$ 66 1 fem.

This interesting animal was first discovered by the second German North Polar Expedition in 1869, near the 74th parallel of latitude, off the east coast of Greenland. The solitary specimen obtained was found on the surface at a considerable distance from the limit of the pack-ice. It was 
next obtained by the Norwegian North Atlantic Expedition, 1876-1878, at several stations between Norway and Greenland, lat. $63^{\circ}-80^{\circ} \mathrm{N}$. All the specimens were brought up from great depths, 452-1862 fathoms. It has been taken more lately by the "Knight Errant" in Färöe Channel, and by the "Albatross" off the east coast of the United States, lat. $37^{\circ} 12^{\prime} 20^{\prime \prime} \mathrm{N}$., and $38^{\circ} 19^{\prime} 26^{\prime \prime} \mathrm{N}$., in 2369 and 2949 fithoms. The rudimentary condition of the eyes would seem to indicate that the first specimen obtained was bronght to the surface by some accidental cause. It should be noted that the identity of Buchholz's specimen with those more lately obtained rests upon the assumption of error in Buchholz's figure, in which the abdominal pleuræ present a very different outline from that exhibited by the examples subsequently secured.

The uniformity of the conditions affecting animal life in the abysses of the ocean the world over could not be exemplified more strikingly than by the discovery of this animal in the tropical Pacific to within $1^{\circ} 7^{\prime}$ of the equator.

The number of teeth on the median keel of the carapace varies in different specimens from one to four. The acumen of the rostrum also varies in length, even in specimens from the same haul of the dredge.

I have examined the structure of the second maxilliped in four specimens, - two from Station 3383, and two (males) from Station 3433. In the first two there is no trace of a podobranchia. In one of the specimens from Station 3433 there is likewise no vestige of a gill, while in the other, although it does not differ in any other regard, there is a distinct, though small, podobranchia, composed of three plates, attached to the base of the epipod. I therefore incline to the opinion that Professor Smith's II. gracilis, * characterized by the presence of a podobranchia on the second maxilliped, was injudiciously separated from $H$. glacialis. It is to be observed that the gill varies much in its degree of development in different specimens of $H$. gracilis.

The telson in the Pacific specimens is seen in its integrity in but two cases. In these the number of terminal spines is six and eight.

* Ann. Rep. U. S. Fish Comm. for 1855, p. 650, Plate XII. Fig. 6, 1896. 
NOTOSTOMUS A. M. EDw.

Anu. Sci. Nat., Zool., 6 $6^{\text {eme }}$ Sér., Vol. XI., Art. 4, p. 7, 1881.

Notostomus fragilis FAx.

Plate XLIV., Fig. 2, 2a $\mathscr{2}^{b}$.

Bull. Mus. Comp. Zoöle, XXIV. 207, 1893.

Dorsal line of carapace convex, and keeled from anterior to posterior margin, anteriorly produced into a short, acute rostrum, which does not exceed the eye-stalks in length; the dorsal carina is armed with seven or eight minute teeth on the anterior gastric region and the basal portion of the rostrum; lower margin of rostrum unarmed. A longitudinal carina on each side of the carapace begins near the orbit, above the infra-orbital spine, and runs back to the posterior margin; another carina runs obliquely downward and backward, dividing the branchial from the hepatic region. The inferior lateral carina is obsolete except for a short distance behind the spine which lies near the anterior margin of the carapace behind the base of the second antenna.

The abdomen is strongly compressed, the third, fourth, fifth and sixth segments dorsally carinated; the carina terminates in a small tooth at the hind end of the fourth, fifth, and sixth segments; on the fourth segment the carina is divided into two parts by a deep notch about two thirds of the distance from the anterior to the posterior margin of the segment. The telson is channeled on the dorsal side, and is tipped with two long spinelike setre.

The eye-stalks taper from the base to the tip ; their outer and upper margins are nearly straight, but their inner and lower surfaces are swollen; on the inner side of each stalk, a little way behind the eye, there is a blunt tubercle. The eye itself is small and black. The integument of the eyestalk is transparent, and when held to the light, discloses the optic ganglion within, giving off a nerve to the retina, and another to the tubercle on the inner side of the stalk.

The basal segment of the antennule is armed with a very small but sharp external spine. The outer side of the second antenna, on the contrary, is unarmed. The antennal scale is very broad, oval, and furnished with a small spine on the external border, near the distal end. The third 
maxillipeds are robust; they reach forward far beyond the end of the antennal scales; their terminal segment is triangular in cross section. The first pair of legs are also robust, about equal in length to the third maxillipeds, and their chela is strong, with fingers about equal to the hand in length. The second pair of legs are longer, but much weaker than the first pair, the carpus and propodite much elongated, and the fingers not more than a third as long as the hand. The ischium and merus of both the first and the second pairs are flattened, and the same compression is seen in the three following pairs of legs, which have the form and proportions characteristic of the genus. The inner branches of the swimmerets are about the length of the telson, while the outer branches are rather longer.

Length, $70 \mathrm{~mm}$. ; carapace, $30 \mathrm{~mm}$.; telson, $14 \mathrm{~mm}$.; antennal scale, $11 \mathrm{~mm}$.

Station 3371. 770 fathoms. 1 specimen.

In this specimen the integument is soft and membranaceous, and the carapace is so collapsed that it is difficult to restore its true outline. In several respects this species shows an approach to the genus Hymenodora, as, the soft integument, small eye, and the reduction of the rostrum.

\section{Notostomus westergreni FAX.}

Plate $F$.

Bull, Mus. Comp. Zoöl., XXIV. 20s, 1393.

The rostrum is horizontal and armed on the inferior margin with at least twelve teeth; the tip is broken off in the unique specimen obtained, but the total length is probably equal to, or a little less than, the antennal scale; the superior margin is also armed with a series of teeth, which are continued back on the dorsal carina to the posterior margin of the carapace, becoming smaller posteriorly. The dorsal median line of the carapace is nearly horizontal from the anterior gastric region to the posterior border of the carapace, and but moderately elevated above the level of the rostrum. A carina runs along each side of the rostrum below the superior teeth, and continues backward along the base of the rostrum to the anterior part of the gastric region. The lateral margins of the rostrum are continued backward and downward, forming the upper part of the antero-lateral wall of the carapace above the eye; they become obsolete just behind the base of the eye-stalk, and are not continuous with the orbital carina. The orbital carina begins 
just behind the margin of the orbit, and extends to the posterior border of the carapace, forming the upper boundary of the hepatic and branchial areas. The antennal carina takes its origin in a strong spine on the anterior margin of the carapace at the base of the second antennx, and runs backward on the branchial region nearly to the hind margin of the carapace; it is connected with the orbital carina by an oblique carina which divides the hepatic from the branchial regions. Between the orbital and antennal carinæ, nearest to the former, is a half-carina, which extends from the posterior margin of the carapace forward to a point a little distance behind the branchio-hepatic carina. Below the antennal carina are two more longitudinal carinæ subparallel with one another and with the inferior margin of the carapace; the uppermost of these does not quite reach the margin of the carapace at either end; the lowermost begins at the antero-lateral margin, courses backward as a submarginal carina, and is continuous posteriorly with the light carina which runs along the posterior border of the carapace; through this medium it is continuous with its fellow on the opposite side of the carapace. The infra-orbital angle is not spinous, but a short distance below it a small acute spine occurs at the base of the antennule. The surface of the carapace is corrugated, most emphatically in the field betwixt the dorsal and orbital carinæ.

All the abdominal segments are carinated in the dorsal median line, and the third, fourth, and fifth are armed with a posterior tooth; the first and second segments are notched posteriorly in the dorsal median line. The telson is channeled on the dorsum, and furnished with about four pairs of dorsal, but no marginal, spines; its tip is broken off and its armature thus obliterated.

The third maxillipeds and legs are moderately tomentose. The second pair of legs are a little longer and slenderer than the first pair. The ischium and merus of the last three pairs are spinulose on their inferior margins.

Length, $127 \mathrm{~mm}$. ; length of carapace, including rostrum, $61 \mathrm{~mm}$. ; height of carapace, $31 \mathrm{~mm}$.; length of antennal scale, $19.5 \mathrm{~mm}$.

Station 3399. 1740 fathoms. 1 male.

This species is nearly related to $N$. patentissimus Bate, with which it agrees in nearly all the details of carinæ, etc.; but it differs much frum that species in its general form and proportions, the carapace being much longer in proportion to its height, and less convex along the dorsal line than in $N$. patentissimus. The rostrum, too, is armed with many more spines on its inferior 
margin. Bate says that in $N$. patentissimus the antennal carina terminates in the posterior margin of the carapace, where it is confluent with the lowermost, submarginal carina. This is not the case in $N$. westergroni.

I have named this species for the artist of the expedition, Mr. A. M. Westergren, whose drawing of the type specimen, colored from the life, is reproduced on Plate $\mathrm{F}$.

\section{Family PASIPHAEIID AE.}

PASIPHAEIA SAV.

Mém. sur les Animaux sans Vertèbres, I. 50, 1816 [Pasipha̛u].*

Pasiphaeia americana $F_{A x}$.

Plate XLV., Fig. 1-1

Pasiphaeia cristata americana FAX., Bull. Mus. Comp. Zoöl., XXIV. 208, 1893.

Body strongly compressed laterally. Carapace from three tenths to one third as long as the whole body; dorsum extremely compressed but rounded, rising into a thin, triangular, sharp-pointed crest in the median line a little way back of the anterior margin; anterior margin slightly advanced in the form of a rounded lobe between the bases of the eye-stalks, but not produced to a distinct rostrum; infra-orbital angles rounded, projecting a little beyond the median inter-orbital process; at the level of the base of the second antennse, the margin of the carapace trends backward nearly horizontally, and then turns downward at a right angle (rounded), and also slightly inward, forming an efferent channel from the branchial chamber behind and beneath the basal segment of the second antenna; on the upper margin of the efferent branchial opening there is a slender, acute, procurved spine; a low distinct longitudinal ridge runs along the superior half of the branchial area.

The abdominal segments are rounded dorsally, not carinate, although the sixth is strongly pinched in on each side of the median dorsal line. The sixth segment is one third longer than the telson, which is equal in length to the fifth segment; the posterior margin of the telson is notched in the middle and armed on each side with about eight spines, the outer one the longest, the others diminishing in importance from without inwards.

The antennules are furnished with a stylocerite on the external side of

* Pasipheca was clianged to Pasiphae by Risso (Hist. Nat. de l'Europe Mérid., V. 81, 1826), and by Kröyer (Naturhist. Tidsskr., 2 R., I. 453, 1545), and this emendation has been accepted by G. O. Sars and S. I. Smith. It seems more probable that Pasiphein (i.e. Phrdm) was the word intended by Savigny. 
the basal segment. This stylocerite assumes anteriorly the form of a vertical scale which does not reach forward. so far as the distal end of the segment; it is armed with a minute, sharp spine at the anterior extremity of its superior margin. The basal segment of the second antenna is armed with a slender, sharp spine at the anterior end of its lower surface. The antennal scale is lanceolate, truncate at the apex, and furnished with a spine at the distal extremity of the outer margin; the flagellum of the antenna is very slender and longer than the body. The third maxillipeds reach forward beyond the tip of the antennal scale; their distal segment is setose on the inner side, rounded at the apex, and nearly twice the length of the antecedent segment; the exopod reaches beyond the proximal end of the carpus. The second pair of legs are a little longer than the first pair, the chela being somewhat slenderer and longer-fingered; the carpus of the second pair is armed with a prominent spine on the antero-inferior border, and the merus of the same appendage is likewise furnished with a single spine near the middle of its inferior margin. The third pair of legs are very slender, reaching forward as far as the proximal end of the carpus of the second pair; the merus is very long, - by far the longest segment of the appendage, - the carpus short and cylindrical, the propodite long and thread-like, the dactylus short, slender, and acute. The fourth pair of legs are very short, reaching, when extended forward, hardly to the proximal end of the merus of the second pair of legs; the dactylus is slender, blunt at the end, and it, as well as the propodite and, to a less degree, the carpus, is furnished on the inner side with stiff hairs. The fifth pair of legs, when stretched forward, fall a little short of the middle of the merus of the second pair; their terminal segment is spatulate and fringed with long setx. The outer.plates of the last pair of abdominal appendages are considerably longer than the inner plates, and these are much longer than the telson.

Length, $65 \mathrm{~mm}$.; carapace, $22 \mathrm{~mm}$; telson, $7.5 \mathrm{~mm}$.

Station 3385. 286 fathoms. 4 specimens.

$\begin{array}{llllll}\text { " } & 3396 . & 259 & \text { " } & 2 & \text { " } \\ \text { " } & 3403 . & 384 & \text { " } & 2 & \text { " } \\ & 3406 . & 551 & \text { " } & 3 & \text { " }\end{array}$

This form is closely allied to $P$. cristata Bate, of which one specimen was dredged by the "Challenger" in 315 fathorns off the Feejee Islands.

On comparing the American species with Bate's figures of the type of $P$. cristata, it appears that the carapace of the former is considerably longer 
in proportion to the whole body than it is in the latter, and that the dorsal crest is smaller and somewhat differently shaped. Comparison of the figures of the two species reveals, moreover, a difference in the outline of the anterolateral margin of the carapace. The fifth and sixth abdominal segments are much shorter in proportion to the length of the telson in $P$. americuna than in $P$. cristatu. The antennular peduncle in the former is only one third as long as the carapace, while in the latter it is about one half as long. Finally, the flagellum of the antenna in the former is longer than the body, while in the latter it is described as being only one half as long.

Ergrs, taken from beneath the abdomen of a female specimen, measure $2 \mathrm{~mm}$. by $1.3 \mathrm{~mm}$.

\section{Pasiphaeia princeps Sмит.}

Pasiphae princeps Surti, Ann. Rep. U. S. Fish Comm. for 1882, p. 351, Plate V. Fig. 2, 1854.

Station 3376. 1132 fathoms. 1 specimen.

The distal end of the basipodite of the first and second pairs of legs is armed with a spine below. The merus of the first pair of legs is destitute of spines, while the merus of the second pair is armed with six spines on the inferior border. Length from tip of postfrontal spine to end of telson, $70 \cdot \mathrm{mm}$.

The type specimen of Pasiphacia princeps was obtained by the "Albatross" off the east coast of the United States in 1883, lat. $39^{\circ} 29^{\prime} \mathrm{N}$., long. $70^{\circ} 58^{\prime} 40^{\prime \prime} \mathrm{W} ., 1342$ fathoms. It is a very large specimen, measuring $215 \mathrm{~mm}$. in length. Smaller specimens were secured in the same region during the cruise of the "Albatross" in 1884, from depths varying from 444 fathoms to 693 fathoms.*

The late J. Wood-Mason $†$ established a new genus, Phye, for Pasiyhacia alcocki, $P$. princeps, $P$. acutifrons, etc., in which the carapace and abdomen are more or less carinated dorsally, the telson forked, and branchiostegal spines present.

\section{Pasiphaeia acutifrons BATE.?}

P Pasiphea acutifrons BATE, Rep. Challenger Macrura, p. 571, Plate CXLI. Fig. 3, 1888.

Station 3402. 421 fathoms. 2 specimens.

" 3403.384 " 3406

"3406. 551 " 4

* S. I. Smitl, in Ann. Rep. U. S. Fish Comm. for 1885, p. 6\$2, 1886.

† Ill. Zoöl. H. M. I. M. S. "Investigator," Crustacen, Plate III., 1S92; Ann. Mag. Nat. Hist., Gth Ser., XI. 161, 1593. 
The eggs, from a female $74 \mathrm{~mm}$. long, Station 3403, measure 2 min. by $1.5 \mathrm{~mm}$.

Bate's description and figure of $P$. acutifrons are so imperfect that I am not sure that the "Albatross" specimens belong to the same species. The latter differ from Bate's figure in the following ways: the tooth at the anterior end of the dorsal carina of the carapace is not, at least in most examples, inclined upward so much; the merus of the first pair of legs is armed with three or four spines on the distal half of the inferior margin, while in Bate's figure of $P$. acutifrons this joint is furnished with six spines, which are regularly arranged along the whole length of the inferior margin; moreover, the notch in the end of the telson is shallower, and the stylocerite of the antennule falls considerably short of the distal extremity of the first segment. The second segment of the second pair of legrs in the "Albatross" specimens is produced to an acute tooth at the distal end of the inferior margin, but this margin is not spinulose. The inferior margin of the fourth segment (merus) of the same pair is armed with from eleven to fifteen spines.

Compared with $P$. tarda Kröyer, the carapace in our specimens increases much more in height posteriorly, the dorsal crest of the carapace is smaller and does not project so fur forward, the notch in the distal extremity of the telson is much shallower, and the second segment of the second pair of legs is devoid of spines on the inferior margin. In $P$.noregica Sars $(=P$. tarda, juv. ?) the dorsal crest of the carapace is more advanced, the antennal scale narrower, the notch in the telson deeper, and the whole inferior margin of the merus of the first pair of legs is spined, as in Bate's figure of $P$. acutifions; furthermore, the second segment of the second pair of legs is armed with a series of spines, which is not the case in $P$. aculifrons. In $P$. minceps Smith, only the anterior third of the carapace is carinated above, and the merus of the first pair of legs is devoid of spines.

The original specimens of $P$. acutifions Bate were collected off Port Churruca, Patagonia, 245 fathoms, and south of Japan, 775 fathoms.

\section{Pasiphaeia magna FAx.}

Plate XLV., Fig. 2-2c.

Bull. MIus. Comp. Zoöl. XXIV. 209, 1893.

The carapace, measured along the dorsal line from the tip of the rostrum to the posterior margin, is a little less than two fifths of the length of the 
whole body; it is laterally compressed, and rises into a ridge along the whole length of the dorsum; the ridge is rounded, except on the anterior part of the gastric area, where it assumes the form of a sharp keel, and is continuous with the acute-tipped, blade-like tooth which simulates a true rostrum; this tooth reaches forward nearly to the anterior extremity of the eyes; its lower margin is convex, with its hinder part resting closely upon, and apparently anchylosed with, the frontal region of the carapace; the frontal margin is convex, rounded, and furnished below with long cilia; it is free from, and not continuous with, the carinal tooth. The infra-orbital and antennal angles are rounded; a sharp spine lies just back of the antero-lateral margin, on a level with the middle of the basal segment of the antenma; below this spine, the antero-lateral margin turns backward, and after running horizontally for a short distance, turns downward at a (rounded) right angle, and joins the infero-lateral margin. There is a well defined, blunt ridge on each side of the carapace, running from the hepatic area backward over the branchial region and becoming obsolete just before attaining the posterior border of the carapace.

All the abdominal seginents are carinated in the median dorsal line, though on the first segment the carina is obsolescent. The sixth segment is one third longer than the fifth segment; it is marked on either side by a curved longitudinal ridge. The dorsal face of the telson is channeled; its posterior margin in the sole specimen procured is injured, so that its contour and armature cannot be discerned.

The eyes are of moderate size, black, and borne on stont peduncles.

The flattened antennular spine (stylocerite) is equal in length to the basal segment. The outer antennular flagellum is about equal to, the inner a little shorter than, the length of the carapace.

The second antenna is equal in length to the whole body. There is an acute spine on the peduncle, below the articulation of the scale. The scale is long oval in form, armed with a small tooth at the distal end, and overreaches the antennular peduncle by one half its length.

The third maxillipeds extend forward as far as the end of the antennal scale.

The first pair of legs, when extended forward, surpass the third maxillipeds by the length of the dactylus. The merus is armed with four or five spines on its inferior edge. The basal part of the propodal segment is somewhat shorter than the dactylus. 
The second pair of legs are a little longer than the first pair, with a longer and slenderer chela. The second segment (basipodite) is armed with a small spine at the distal end of the inferior edge. The inferior edge of the merus is armed with thirteen spines. The carpus is armed with one long spine at the distal end of its lower margin. The chela is unarmed, excepting the pectinate grasping edges of the fingers.

The third pair of legs reaches forward a little beyond the proximal end of the chela of the preceding pair. The coxa and basis are robust, the succeeding segments tapering to a thread-like tenuity in the propodite and dactylus. All of the segments are naked and unarmed. The merus contributes one half to the length of the whole appendage, being more than twice as long as the propodite. The dactylus is shorter than the carpus.

The fourth pair of legs are very short, reaching only to the proximal end of the merus of the second pair of legs. The inferior margin of the dactylus, propodite, and distal end of the carpus is beset with coarse bristles.

The fifth pair of legs, when extended, attain to the middle of the merus of the second pair. The dactylus is flattened, broad, rounded at the distal end, and furnished with long marginal setx.

Length, $145 \mathrm{~mm}$; carapace, including the anterior dorsal tooth, $55 \mathrm{~mm}$.

Station 3384. 458 fathoms. 1 specimen.

This species is second only to $P$. princeps Smith, in size. It is most nearly related to $P$. $\operatorname{tarda}$ Kröyer, ${ }^{*}$ from the North Atlantic. It differs from the latter in having the dorsal line of the carapace more convex, the posterior part of the carapace higher in proportion to the anterior part, the dorsal keel of the carapace rounded except on the anterior gastric region, and the anterior rostrum-like tooth longer and differently shaped. The proportional length of the segments of the third pair of legs appears to be quite different in the two species: in $P$. tarda, according to Kröyer, the propodite and dactylus are of equal length and four times as long as the carpus, while in $P$. magna the dactylus is even shorter than the carpus, which is itself only one sixth as long as the propodite. In $P$. tarda, according to Kröyer, the lower margin of the second segment of the second pair of legs is furnished with three spines; in $P$. magna this margin is unarmed but for the tooth at its distal end.

* Naturhist. Tidsskr., 2 R., I. 453, 1845; Voyages de la "Recherche" en Scandinavie, etc., Crustacés, Plate VI. Fig. 1. 


\section{FAMILY PENEID A.}

SICYONIA MI. EDW.

Ann. Sci. Nat., XIX. 339, 1830.

Sicyonia affinis FAX.

Plate XLVI., Fig. 1-1 ${ }^{c}$.

Bull. Mus. Comp. Zoöl, XXIV. 209, 1893.

This species is the Pacific coast representative of Sicyonia edwardsï of

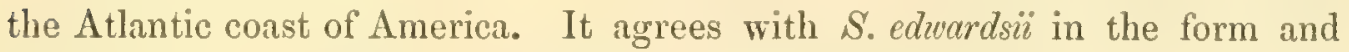
dentition of the carapace, but differs in the form and sculpture of the abdominal segments. In S. edwardsii the first four abdominal segments are rugose, and ornamented on the sides with two deeply impressed transverse lines, followed by another less deeply incised, near the hind margin of each segment; moreover, the pleura of these segments are angulated below. In S. affinis these segments are smooth, the impressed lines are absent with the exception of the hinder one of the deeply cut pair, and the pleuræ are broadly rounded below; the peduncle of the second antenna is not much over one half the length of the antennal scale, and the whole antenna is but little longer than the carapace.

Length, $62 \mathrm{~mm}$. ; carapace, $20 \mathrm{~mm}$.

Station 3367. 100 fathoms. 1 male, 1 fem.

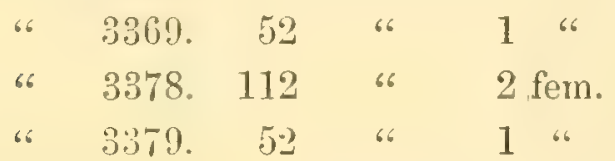

The color in life, as shown in a sketch made by Mr. Westergren, is light greenish yellow, banded with vermilion on the branchial regions and abdomen. Appendages red, antennal flagellum transversely banded with light and dark. The coloration is quite different from that of $S$. edwardsii as given by Dana.†

* Sicyonia edwardsii Miers, Aun. Mag. Nat. Hist., 5th Ser, VIII. 367, 1881; Siryonia carinata (Olivier) Milne Edwards, Ann. Sci. Nat., XIX. 34t-346, Plate IX. Fig. 9, 1830; nec Sicyonia carinata (Olivi).

+ U. S. Explor. Exped., Crustacea, Pt. I., p. 602, 1852. 


\section{Sicyonia picta FAx.}

Plute XLVI., Fig. Q2-2c.

Bull. Mus. Comp. Zoöl, XXIV. 210, 1893.

Rostrum a little shorter than the eye-stalks, laterally compressed, elevated, armed with six teeth, three superior, three terminal ; inferior margin ciliated. Carapace carinate in the median dorsal line; the carina is furnished with two teeth, one minute one on the anterior part of the gastric region at the base of the rostrum, the other larger, over the cardiac region. An infraorbital and an hepatic spine are present. General surface of carapace punctate, and sparsely clothed with setæ. Abdominal segments smooth, with a median dorsal carina, which rises into a strong tooth on the first segment, directed upward and forward; on the fifth and sixth segments the carina is drawn out into an acute tooth, which is directed horizontally backward. The pleuræe of the abdominal segments are margined, and armed with a tooth on the lower border: on the second, third, and fourth segments the tooth is hamulate, being directed outward and backward. The general surface of the abdomen is smooth, with a transverse groove on each side of each segment. The telson is channeled above, acute at the tip, and armed with a pair of small lateral spines near the distal end.

The eyes are very large, horizontally flattened.

Basal segment of antennule armed with two spines on its exterior border. Flagella shorter than the peduncle.

The peduncle of the second antenna reaches about two thirds of the way to the end of the scale. The flagellum is about equal to the abdomen in length. The basal segment of the peduncle is furnished with a long and acute external spine.

The sternum is armed with a long spine between the bases of the second, third, and fourth pair of legs, as is usunl in species of this genus.

The last pair of abdominal appendages are a little shorter than the telson.

Length, $70 \mathrm{~mm}$. ; carapace, $24 \mathrm{~mm}$.

Station 3355. 182 fathoms. 1 male.

"6 3387. 127 " 6 males, 4 fem.

On the hinder part of each branchial region there is a dark (in alcohol) ring of pigment. S. ocellata Stimpson and $S$. penicillata Lockington are similarly ornamented. The flagellum of the antenna is banded alternately 
with light and dark color, and there are traces of color on the margins of the rostrum, on the dorsal carinæ and on the appendages.

This species resembles is. lovis Bate, from the region north of New Guinea, but may be easily distinguished from that species by the teeth on the margins of the abdominal pleuræ. Other differences are apparent on comparing Bate's figure of $S$. lavis with the figure of $S$. picta on Plate XLVI.

\section{PENEUS FARR.}

Suppl. Ent. Syst., pp. 385, 408, 1795 [Pencus].

Peneus balboæ Fax.

Plate XLVII., Fig. 1-1c.

Bull. Mus. Comp. Zoöl, XXIV. 211, 1593.

Integument thin and membranaceous, its surface, when viewed through a lens, thickly beset with minute squamiform tubercles. The rostrum of the unique type specimen is broken off a little short of the anterior limit of the eye; on the upper margin of the part remaining, and on the median line of the gastric region, there is a series of eight slender, acute teeth, three of which lie behind the orbit; the intervals between the teeth are ciliated, and the lower margin of the rostrum is also furnished with long cilia. The rostrum is continuous posteriorly with a sharp, non-sulcated carina, which becomes obsolete before reaching the posterior margin; the anterior, dentate moiety of the dorsal carina is very thin, and sharply defined below. The antero. lateral border of the carapace is ciliated; the suborbital angle is prominent, but not armed with a spine; a small brachiostegal spine projects from the margin, on a level with the second antenno. Neither the cervical nor any other groove of the carapace is apparent. A faintly marked longitudinal ridge runs along the side of the carapace, on a level with the orbit; this carina is most conspicuous on the gastric region, becoming obsolete before attaining either the anterior or posterior margin of the carapace. Another longitudinal ridge runs from the suborbital angle, dividing into two branches near the middle of the carapace; the upper branch defines the upper limit of the branchial area, the lower branch trends diagonally, and then horizontally backward, fading out before attaining the posterior border of the carapace. A third ridge extends from the branchiostegal spine to the lower branch of the ridge last described. The fourth, fifth, and sixth abdominal segments 
are dorsally carinated, and the sixth is armed with a small, sharp, slender, horizontal spine. The fourth, fifth, and sixth segments are also ornamented with a lateral ridge; on the fourth segment the lateral ridge runs downward and backward, while on the fifth and sixth segments it is nearly horizontal. The sixth abdominal segment is equal in length to the fourth and fifth combined. The telson is about equal in length to the sixth segrment of the abdomen; it tapers to a slender point, is deeply channeled above, and armed with a few minute lateral spinules near the distal end.

The eye-stalks are short, the eyes large, subspherical and black.

The external margin of the basal antennular segment is raised to form a perpendicular wall outside the eye; the surface of this elevated margin is granulated, its margin ciliated; there is no apparent stylocerite; the internal process, or prosartema, is narrowly spatulate in form, ciliated, and a little shorter than the eyes; the dorsal face of the basal segment, in front of the eyes, as well as of the second segment, is tomentose; the antennular flagella are thickened at the proximal end; the outer flagellum is con. siderably longer than the inner, being about equal in length to the carapace without the rostrum.

The peduncle of the antenna is unarmed; the scale exceeds the peduncle of the antennule by a little; the llagellum is very slender, and nearly twice the length of the body.

The terminal segment of the mandibular palpus is broad oval in form, narrowing at distal half.

The endopod of the first maxilla is elongated and segmented. The endopod of the first maxilliped is slender, and composed of four segments; the exopod is laminate and unsegmented.

The exopods of the second and third pairs of maxillipeds are very long, reaching forward to beyond the base of the antennal scale; they are fringed with long and delicate setæ. The five pairs of legs are rather short. Their proportions are accurately given in the accompanying figure, which renders a detailed description unnecessary; they are all furnished with very small exopods; the inferior distal angle of the ischinm of the first and second pairs is furnished with a small, somewhat curved, sharp spine.

The inner branch of the first pair of abdominal appendages is completely obsolete (in the female). The posterior pair of abdominal appendages have the two branches of unequal length, the outer exceeding the inner, the latter in turn surpassing the telson. 
'The branchial formula is as follows :-

$\begin{array}{lcccccccc}\text { Somites } & \text { VII. } & \text { VIII. } & \text { IX. } & \text { x. } & \text { XI. } & \text { xII. xII. } & \text { XIV. } \\ \text { Pleurobranchiæ } & 0 & 1 & 1 & 1 & 1 & 1 & 1 & 1=7 \\ \text { Arthrobranchiæ } & 0 & 1 & 2 & 2 & 2 & 2 & 1 & 0=10 \\ \text { Podobranchiæ } & 0 & 1 & 0 & 0 & 0 & 0 & 0 & 0=1 \\ \text { Epipods } & 1 & 1 & 1 & 1 & 1 & 1 & 0 & 0=\frac{(6)}{18+(6)}\end{array}$

The gill on the eighth somite entered as a pleurobranchia in the above table has been considered an arthrobranchia by some recent authors, but from its relative position it would seem to be the equivalent of the pleurobranchix of the following somites. The epipods consist of a horizontal stem directed backward from the basal segment of the limb, and a vertical forked blade which lies between the gills.

Length, $93 \mathrm{~mm}$; carapace, exclusive of the rostrum, $29.5 \mathrm{~mm}$.

Station 3371. 770 fathoms. 1 male.

SOLENOCERA LUCAS.

Ann. de la Soc. Entomol. de France, 2d Sér., VIII. 219, 1850.

Solenocera agassizii FAX.

Plate XLVII., Fig. 2-2c.

Bull. Mus. Comp. Zoöl., XXIV. 211, 1893.

Closely related to $S$. siphonocera (Philippi), but differing from the latter in having the antennular flagella much shorter and subequal, and more teeth on the upper margin of the rostrum and gastric region. Comparison of a specimen with one of $S$. siphonocera of equal size (57 $\mathrm{mm}$. long) from the Bay of Naples shows that in $S$. agassizii the antennular flagella are only four fifths the length of the carapace, and that there are eight teeth on the rostrum and gastric region, while in $S$. siphonocera the antennular flagella are as long as the distance from the tip of the rostrum to the middle of the third abdominal segment, - or once and two fifths the length of the carapace, - and there are but six teeth on the rostrum and gastric region. Moreover, not only is the upper flagellum broader ( $1 \mathrm{~mm}$.) and blunter in $S$. agassizii than it it is in $S$. siphonocera (where it is only $\frac{1}{3} \mathrm{~mm}$. in breadth), but also subequal in breadth to the lower flagellum, whereas in the Mediterranean species the upper flagellum is conspicuously narrower than the lower one. 
In full grown specimens of $S$. agassizii, which attain a length of $150 \mathrm{~mm}$, the antennular flagella are only one half as long as the carapace, or even less. The flagella of the second pair of antenna are very slender and enormously long, - more than two and two thirds times the length of the whole body. The number of teeth on the rostrum and gastric region in full-grown individuals is nine. The sharply defined cervical groove does not quite reach the median dorsal line of the carapace, although the dorsal carina is interruptea at that point. The sides of the rostrum are tomentose, as appears to be the case in S. siphonocera and $S$. distincta (De H.).

Mensurements of a female (Station 3391): length of body, $149 \mathrm{~mm}$.; length of carapace, including rostrum, along median dorsal line, $54 \mathrm{~mm}$; length of rostrum, $13.5 \mathrm{~mm}$; length of antennule, $46.5 \mathrm{~mm}$.; length of antennular flagella, $28 \mathrm{~mm}$; length of antenna, $410 \mathrm{~mm}$; merus of third legs, $21 \mathrm{~mm}$.; carpus of do., $36.5 \mathrm{~mm}$. ; chelit of do., $10 \mathrm{~mm}$. ; antennal scale, $22.5 \mathrm{~mm}$; t telson, $22 \mathrm{~mm}$.

Station 3389. 210 fathoms. 2 males, 8 fem.

.. $3: 391$. 1.5:) “ 5 males, 6 fem.

The branchial formula of Solenocera agassizii is as follows:

$\begin{array}{lccccccccc}\text { Somites } & \text { VII. } & \text { VIII. } & \text { IX. } & \text { X. } & \text { XI. } & \text { XII. } & \text { XII. } & \text { XIV. } \\ \text { Pleurobranchiæ } & 0 & 0 & 1 & 1 & 1 & 1 & 1 & 1=6 \\ \text { Arthrobranchix } & 0 & 2 * & 2 & 2 & 2 & 2 & 2 & 0=12 \\ \text { Podobranchiæ } & 0 & 1 & 0 & 0 & 0 & 0 & 0 & 0=1 \\ \text { Epipods } & 1 & 1 & 1 & 1 & 1 & 1 & 1 & 0=\frac{(7)}{19+(7)}\end{array}$

The pleurobranchia on the last thoracic segment is small but functional. The lateral branches of each gill are alternately arranged on each side of the main stem. and are curved so that their distal ends meet the ends of their fellows on the opposite side of the stem, and thus form a hollow tube which is open and obliquely truncated at the distal end. There are small exopods attached to all the legs. On the second maxillipeds the exopods reach to the end of the merus, but they gradually decrease in length through the series of following appendages.

The geographical distribution of this interesting genus, as far as known, is as follows: S. siphonocera, the type of the genus, is found in the Mediter-

* One of these is possibly a pleurobranchia ratlier than an arthrobranchia.

+ Pencers membranaceus M. Edw. (Hist. Nat. Crust., II. 417, 1837), nec Risso; Peneus siphonoceros Philippi (Arch. Naturgesch., VI. Jahrg., I. 190, Plate IV. Fig. 5, 1940); Solenocera philippii Lucas (Ann.

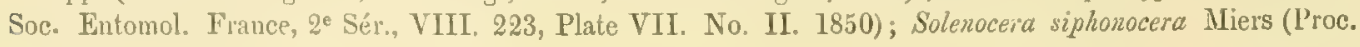
Zoölog. Soc. Loudon, 1878, p. 301). 
ranean Sea, and specimens thought by Professor S. I. Smith to belong to the same species, were obtained by the "Albatross" Expedition of 1884 in the Gulf of Paria, Venezuela.* S. distinctu $\uparrow$ is a native of the seas of Japan. It has never, I believe, been figured, but from De Haan's description would seem to be nearly allied to $S$. siphonocera. Bate, who examined the type specimen of Peneus crassicomis M. Edw., from Bombay, in the collection of the Jardin des Plantes, Paris, assigned that species to the genus Solenocera in 1881, $\neq$ and described a new species Solenocera lucasii, taken by the "Challenger" Expedition, suuth of New Guinea. But in his later report on the "Challenger" Macrura, 1888, he removes S. lucasii from Solenocera on ac. count of the different structure of the antennules, and leaves the reader in doubt as to the proper position of Peneus crassiconis, though from his remarks on page $285 \mathrm{I}$ infer that Milne Edwards's species does not belong to the genus Solenocera. A common littoral Indian species of Solenocera is doubtfully referred to Peneus crassicomis M. Edw., by Wood-Mason. Unlike S. siphonocera and $S$. agassizi, it lacks branchiostegal spines and has a simple unarmed telson. Finally, a Solenocera has been recorded by Wood-Mason from the Bay of Bengal, 65-240 fathoms. In this species, Solenocera hextii, as in S. agassiani, the antennular flagella are shorter and broader than in any of the previously described species, but the branchiostegal spine is wanting. The spiny armature of the carapace of $S$. agassizii agrees with that of $S$. siphonocera, consisting of an antennal, an hepatic, and a branchiostegal spine, and a sharp lateral spine on the edge of the cervical groove; the supra-orbital angle is prominent, but is not produced to a spine.

PENEOPSIS BATE.

Aun. Mag. Nat. Histo, 5th Ser., VIII. 182, 1881 [Pencopsis].

Peneopsis diomedeæ Fax.

Plate $G$.

Bull. Mus. Comp. Zoöl., XXIV. 212, 1593.

Integument hard, firm, and smooth. Carapace, including rostrum, about four fifths the length of the abdomen. Rostrum long, nearly horizontal

* Proc. U. S. Nat. Mus., VIII. 186, 1585.

+ Pencus distinchus De Haan (Fuuna Japonica, Crustacea, p. 194, 1849); Solenocera distincta Miers (Proc. Zoölog. Soc. London, 187s, p. 302).

+ Ann. MIag. Nat. Hist., 5th Ser., VIII, 185.

$\$$ Ann. Mag. Nat. Hist., 6th Ser, VIII. 275, 1891.

II Wood-Mason, Ann. Mag. Nat. Hist., 6th Ser., VII. 188, VIII. 275, 1891. 
except near the tip, where it is bent up at a small angle, acute, armed with four teeth above. A dorsal carina, continuous with the rostrum, runs the length of the carapace; it is armed with one tooth on the posterior part of the gastric region. The cervical groove is very deep, but does not cut the dorsal carina. Another deep groove runs backward and then diagonally upward from the cervical groove toward the posterior border of the carapace, stopping just short of the posterior margin. The antennal region is well defined by the cervical groove below and a gastro-antennal groove above. There is a strong antennal tooth on the margin of the carapace, below the orbit, another at the antero-inferior angle of the carapace, a third just behind the groove that marks the posterior limit of the antennal region, on a level with the antennal tooth, and a fourth on the hinder edge of the cervical groove, at a lower level than the third. Above and behind the last mentioned tooth the cervical groove is indented, and the upper angle of this indentation tends to assume the form of a small tooth or spine.

The fourth, fifth, and sixth abdominal segments are carinated on the median dorsal line and produced into teeth posteriorly. Of these teeth the one on the sixth segment is the longest, and it is directed horizontally backward. The telson is deeply grooved on the dorsal side, and armed near the tip with one pair of spiniform lateral teeth.

The eyes are very large, black, mounted on short stalks. The antennules, with their long flagella, surpass the length of the whole body; the external margin of the basal segment of the peduncle is armed with two small teeth, one of which is situated near the middle, the other at the distal end; the process to which Spence Bate gave the name prosartema is oval, foliaceous, and reaches forward as far as the posterior border of the upper face of the cornea.

The peduncle of the second antennæ is armed with a prominent external spine. The scale is nearly as long as the rostrum, very broad to the distal end, membraneous in texture, with the exception of the outer side, which is stiffened by calcareous deposit. The flagellum is very long, exceeding by much the antennular flagellum.

The mandibular palpi are long triangular in shape, setose, the terminal segment narrow; they extend forward to the middle of the fourth segment of the antennal peduncle.

The third maxillipeds reach forward to a point a little beyond the distal end of the antennal scales. 
The legs are of moderate length for this family; they increase in length in successive order from the first pair to the last.

The abdominal appendages are very long'. Their proportions will be best understood by reference to the figure.

The exopods of the second maxillipeds are very small, - not longer than the short ischial segments of these limbs. Upon the appendages behind these, the exopods are reduced to the merest rudiments, to be detected only by the use of a lens. In some specimens, indeed, the exopods of the posterior appendages are altogether wanting.

The branchial formula is as follows:-

$\begin{array}{lccccccccc}\text { Somites } & \text { VII. } & \text { VIII. } & \text { IX. } & \text { X. } & \text { XI. } & \text { XII. } & \text { XII. } & \text { XIV. } & \\ \text { Pleurobranchiæ } & 0 & 0 & 1 & 1 & 1 & 1 & 1 & 1=6 & \\ \text { Arthrobranchiæ } & 1 * & 2 & 2 & 2 & 2 & 2 & 2 & 0=13 & \\ \text { Podobranchix } & 0 & 1 & 0 & 0 & 0 & 0 & 0 & 0=1 & \\ \text { Epipods } & 1 & 1 & 1 & 1 & 1 & 1 & 1 & 0=\frac{(7)}{20+(7)}\end{array}$

Length (female) $215 \mathrm{~mm}$.; carapace, $101 \mathrm{~mm}$. ; rostrum, $42 \mathrm{~mm}$. ; antennal scale, $33 \mathrm{~mm}$; t telson, $33 \mathrm{~mm}$.

$\begin{array}{rrrrl}\text { Station } & 3353 . & 695 & \text { fathoms. } & 2 \text { fem. } \\ \text { " } & 3358 . & 555 & \text { " } & 1 \text { male. } \\ \text { " } & 3384 . & 458 & \text { " } & 3 \text { fem. } \\ \text { " } & 3393 . & 1020 & \text { " } & 3 \text { fem. } \\ 6 & 3394 . & 511 & \text { "6 } & 3 \text { males, } 1 \text { fem. } \\ \text { "6 } & 3395 . & 730 & \text { " } & 1 \text { male, } 1 \text { fem. }\end{array}$

I have assigned this species to the genus Pencopsis after some hesitation. Pencopsis, a MS. name of A. Milne Edwards's adopted by Spence Bate, has never been properly characterized. According to Bate, it was separated from Peneus chiefly on account of the length of the antennular flagella, which surpass the carapace in length. I have examined with some care a specimen in this Museum from the "Blake" collection, labelled "Pcneopsis ocularis" by A. Milne Edwards. In this specimen the cervical sulcus is deeply imprinted upon the surface of the carapace, but the posterior oblique portion of the conspicuous groove which runs from the cervical groove to the hinder part of the carapace in $P$. diomedea is obsolete. There is a very minute supra-orbital spine on the anterior margin of the carapace, a strong antennal spine at the lower limit of the orbit, a small spine (hepatic?)

* Very minute, but functional. 
midway between the anterior margin and the cervical groove, at a rather higher level than the antennal spine, a lateral spine on the posterior edge of the cervical groove a little lower down than the antennal spine, and another (the branchiostegal spine) at the anterior end of the cervical groove, just behind the antero-lateral margin of the carapace. The antero-inferior angle of the carapace is not armed with a spine. The antennular flagella are missing; the prosartema is somewhat longer and narrower than in $P$. diomedew. The antennal scales are broad and foliaceous. The antennal flagella are more than twice the length of the body. The terminal segment of the mandibular palpi is elongated and much narrower than the preceding segment, but neither segment is so narrow as in $P$. diomedew. The legs do not differ in any important regard from those of $P$. diomedece save that the exopods attain a greater development; on the second maxillipeds the exopods are equal in length to the meri, while on the succeeding pairs of appendages these organs, though small, assume macroscopic proportions even unto the posterior thoracic legs. The number and arrangement of the gills are expressed by the following table:-

\begin{tabular}{|c|c|c|c|c|c|c|c|c|c|}
\hline Somites & vir. & virr. & Ix. & $\mathrm{x}$ & $\mathrm{xi}$. & xis. & xir. & xiv. & \\
\hline Pleurobranchiæ & 0 & 0 & 1 & 1 & 1 & 1 & 1 & $1=6$ & \\
\hline Arthrobranchiæ & 0 & 2 & 2 & 2 & 2 & 2 & 2 & $0=12$ & \\
\hline Podobranchiæ & 0 & 1 & 0 & 0 & 0 & 0 & 0 & $0=1$ & \\
\hline Epipods & 1 & 1 & 1 & 1 & 1 & 1 & 1 & $0=$ & $(7)$ \\
\hline
\end{tabular}

It thus appears that the most important structural differences between $P$. diomedece and $P$.ocularis are these: the strong emphasis of the branchiocardiac groove in the former species, together with the smaller size of the exopods of the maxillipeds and legs, the presence of a minute branchial plume on the seventh (first maxillipedal) somite, and the position of the lowest of the spines on the side of the carapace which in $P$. diomedece is marginal, but in $P$. ocularis lies a little way behind the margin. It does not seem to me that these differences are of sufficient weight to be esteemed of generic value.

In all important structural characters, including the disposition of the gills, Pencopsis agrees with Haliporus. The latter genus may be conveniently retained, however, to include the soft-shelled species with long abdomen and long posterior legs. Pleolicus Bate * does not seem to be sufficiently distinct

* Rep. Challenger Macrura, p. xii. = Philonicus Bate, op. cit., p. 273 (nom. preoc.). 
from Peneopsis, although it is said to have but one arthrobranchia on the eighth (second maxillipedal) somite. Xiphopeneus Smith* is distinguished from Pencopsis by the long styliform posterior legs, the absence of gills on the posterior thoracic somite, etc.

\section{HALIPORUS BATE.}

Ann. Mag. Nat. Hist., 5th Ser., VIII. 185, 1S\$1; Rep. Challenger Macrura, p. 284, 1 S88.

Haliporus nereus FAx.

Plate XLVIII., Fig. 1-1

Bull. Mus. Comp. Zoöl., XXIV. 213, 1893.

Integument membranaceous. Carapace lightly granulated. Rostrum about one third the length of the rest of the carapace, horizontal, armed with six teeth above (the hindmost one situated a little back of the orbit), ciliated below. Median dorsal line of carapace carinate, with two teeth on the posterior half of the gastric region. The sides of the carnpace are armed with spines as follows: two on the antero-lateral margin, one of which is at the lower angle of the orbit (spina antennalis of Stimpson), the other over against the second antenna, at the anterior end of the cervical groove (spina branchiostegiana); a third spine (spina hepatica) lies on the hepatic region, behind the antemnal spine; a fourth is behind and on the same level with the branchiostegal spine; a fifth still further back and on nearly the same level, on the hind edge of the cervical groove. The cervical groove is deeply impressed, and the orbital region is definitely bounded by an hepatic and a gastro-hepatic sulcus. The hindmost of the lateral spines of the carapace lies in the anterior angle of a triangular field enclosed by branches of the cervical groove. From the infero-posterior angle of this triangle two carinx run backward along the branchial area; the upper one ends at the posterolateral margin of the carapace, the lower one meets the inferior sub-marginal carina of the branchial area before attaining the posterior border of the carapace. These two carinæ, with the submarginal ridge of the carapace, enclose a long oval area, which forms a conspicuous figure on the branchial regions. The third to the sixth abdominal segments are carinated, their pleuræ broad and rounded. On the sixth segment the carina terminates in a small, acute, horizontal tooth. The sixth segment is twice as long as the

* Trans. Coun. Acad. of Arts and Sci., II. 27, 1869. 
fifth, but shorter than the telson, which is narrow, triangular, grooved above, and armed with one pair of lateral spines about quarter way from the tip.

The eye-stalks are about one half the length of the rostrum, and are furnished with a small tubercle on the inner side; the eyes are large, black, much broader than their stalks. Antennules longer than the carapace. Antennæ as long as the body; scale narrow, margined within with long cilia; a small spine on the outer side of peduncle at the base of the scale. The following pairs of appendages have the form characteristic of the genus.

In the female there is a large process, covered with stiff hairs, and flattened on its inner side, developed from the base of the third pair of legs. Behind this process lies a pair of flattened, setiferous, sternal processes. Between the legs of the fourth pair there hangs in the median line a nearly vertical curtain-like partition, notched on the free lower margin, and flanked by two lower, blunt, setiferous tubercles. The sternum of the posterior thoracic segment has a slightly elevated median longitudinal ridge, and a low transverse ridge at the posterior boundary of the segment. The form of the petasma of the male is best understood by inspection of Figure $1^{d}$ on Plate XLVIII.

Length of a female specimen, $81 \mathrm{~mm}$.; carapace, $31 \mathrm{~mm}$.; rostrum, $8 \mathrm{~mm}$.

$\begin{array}{crrrrl}\text { Station } & 3353 . & 695 & \text { fathoms. } & 1 \text { fem } \\ \text { " } & 3360 . & 1067 & \text { " } & 1 \text { " } \\ \text { " } & 3382 . & 1793 & \text { " } & 2 \text { " } \\ \text { " } & 3398 . & 1573 & \text { " } & 2 \text { " } \\ \text { " } & 3399 . & 1740 & \text { " } & 1 \text { male. } \\ \text { " } & 3400 . & 1322 & \text { " } & 2 \text { fem. } \\ \text { " } & 3407 . & 885 & \text { " } & 1 \text { " } \\ \text { " } & 3413 . & 1360 & \text { " } & 1 \text { male, } 2 \text { fem. }\end{array}$

This species is apparently very similar to $H$. lcevis Bate, but the eye of the latter species is much smaller, the areolation of the carapace different in some regards, and, if Bate's figure* can be relied on, the telson is much shorter. The two dorsal spines of the gastric region are situated much further forward in $H$. lavis than in $\Pi$. nerens.

In Bate's description of the genus Haliporus in the "Challenger" Report (p. 284), the legs are said to be devoid of exopods, but on page 287

* Rep. Challenger Macrura, Plate XIII. Fig. 2, 1895. 
II. obtiquirostris is described as having small exopods on all the legs, and these organs are represented on the posterior pair of legs of the female II. cequalis on Plate XLI., Fig. $1^{\prime \prime \prime}$. In H. nerens there are rudimentary exopods attached to all the legs, as well as to the third maxillipeds.

Hymenopeneus Smith,* appears to be equivalent to Haliporus Bate.

Haliporus doris $\mathrm{F}_{\mathrm{AX}}$.

Plate XLIX., Fig. 1-1 ${ }^{c}$.

Bull. Mus. Comp. Zoöl., XXIV. 214, 1593.

This is a larger and more robust species than II. nerens, with the rostrum more upturned. In all other respects, excepting the structure of the sexual organs on the sternum of the female (the male has not been seen), the two forms agree so closely that one description would serve for both. The character of the parts above referred to is so constant in the same species among the Crustacea, that, in the light of our present knowledge, the form here treated of must be considered a distinct species. The tubercular processes of the third pair of legs, together with the sternal tubercles immediately behind them, are very like the same structures in $I I$. nerens. But here the likeness ends. Betwixt the fourth pair of legs there is a transverse diaphragm consisting of a median tongue, concave on its anterior face, and with its lower free edge entire, supported on cach side by a strong, blunt, triangular process, of equal height with the median tongue-like plate. Between the bases of the legs of the fifth pair, in place of the low longitudinal median ridge seen in $H$. nereus, there is in this species a large, setiferous, trigonal tooth or tubercle, acnte at the tip, equalling in height the transverse partition on the sternum of the antecedent segment. The posterior median angle of this tooth abuts against the low transverse ridge that forms the posterior limit of the last thoracic sternum.

The differences between these structures in the two species II. nercus and II. doris will be easily understood by reference to the figures on Plate XLVIII. and Plate XLIX.

The third maxillipeds and all the legs carry rudimentary exopods, as in II. nereus.

Length, $104 \mathrm{~mm}$; rostrum, $10 \mathrm{~mm}$; whole carapace, $42 \mathrm{~mm}$.

* Bull. Mus. Comp. Zoöl., X. 91, 1882. 
Station 3114. 2232 fathoms. 4 fem.

"3415. 1879 " 1 fem.

In his General Sketch of the "Albatross" Expedition of 1891, Mr. Agassiz * records the capture of some transparent Peneida at Station 3414 by means of the Tamner net towed at 100 and 200 fathoms below the surface. The only Peneide that I find in the collection from Station 3414 are Huliporus doris and Benthesicymus altus. The accompanying labels do not indicate that these specimens were caught in the tow-net.

\author{
Haliporus thetis FAx. \\ Plute XLVIII., Fig. 2-2". \\ Bull. IIus. Comp. Zoöl., XXIV. 214, 1893.
}

Integument membranaceous. Rostrum rather less than one third as long as the remaining part of the carapace, strongly upturned, upper margin convex, armed with five teeth, the distal of which is near the tip and very minute. A distinct carina bearing three teeth, runs the length of the median line of the gastric area, from the base of the rostrum to the cervical groove. Behind the cervical groove the carina continues as a low, blunt ridge along the median line of the back to the posterior border of the carapace. Posteriorly this ridge gives off two pairs of lateral branches, which course diagonally backward to the posterior margin of the carapace, and mark off two triangular fields on the cardiac region, one enclosed within the other. The median ridge is obsolete for a short distance behind each point of bifurcation as well as at the posterior margin of the carapace. The spiny armature of the carapace consists of an antennal, a very small branchiostegal, an hepatic, and a lateral spine on the posterior border of the cervical groove, four in all. The spine which lies a little way behind, and on a level with, the branchiostegal spine in $H$. nereus and $H$. doris is lacking in this species. The antennal region is separated from the adjacent orbital and hepatic regions by a well pronounced depression, and, in a similar way, the orbital region is separated from the gastric by a gastro-orbital sulcus. Behind the cervical groove, defined by shallow furrows, lies a triangular area, the anterior limit of which is formed by the cervical groove itself. The hindmost of the lateral spines lies on the anterior margin of this area. The cardiac area is separated from the branchial by a rather deep furrow, each edge of which rises into

* Bull. Mus. Comp. Zoöl., XXIII. 52, 1892. 
a low keel. The inferior keel gives off a branch from its lower or external side, near the posterior border of the carapace. There is, besides, an inferior submarginal keel running from the branchiostegal spine back to the hind border of the carapace. The several fields or areas included betweon the grooves and carinx above mentioned are more or less rough with corrugations of the integument.

All the segments of the abdomen are carinated along the median dorsal line. Their pleuræ are shallow and rounded. On each side of the segments is seen a longitudinal furrow, whose edges tend to rise into carinæ. This furrow is most emphatic on the fifth and sixth segments. The sixth segment is once and a quarter as long as the fifth segment, but only two thirds the length of the telson, which is armed with a pair of conspicuous lateral spines near the tip and about four pairs of very minute spinules on the margin in front of them.

The ophthalmic peduncles are one half as long as the rostrum. On their inner side is borne a small tubercle. The eyes are large, black, broader than their peduncles. The basal segment of the antennule is armed on the external margin with two small spines, one near the middle, the other at the distal end; the second segment is nearly twice the length of the succeeding one, hairy, with both the inner and outer edges of its upper surface raised into visible carinx; the flagella are lost in the single specimen examined. The basal segment of the antenna is equipped with an external spine directed downward and forward; the scale is longer than the antennular peduncle, rather broad, thin and membranaceous in texture. The tips of the third maxillipeds when extended forward reach beyond the distal end of the antennal scale; the carpus joint is expanded, and flat on its inner surface. The third pair of legs reach forward about as far as the third maxillipeds. The last pair of legs, althongh rather short for the genus, reach forward beyond the distal ends of the third pair ; the merus and carpus are of equal length, the propodite half the length of the preceding segment, and curved. The dactylus is one half as long as the propodite. The exopods of the third maxillipeds are small, and throughout the series of legs these organs are so small that they may be considered rudimentary. There are rudimentary podobranchial plumes, discernible by the aid of a lens, attached to the epipods of the third maxillipeds and the first three pairs of legs.*

* According to Spence Bate, there are rudimentary branchial plumes attached to the epipods of the third maxillipeds and the first pair of legs in the genus Haliporus. In $H$. nereus and $H$. doris (as in Hyme- 
The epipods themselves consist of a thickened basal segment which bears a thinner flabelliform terminal segment.

Length, $94 \mathrm{~mm}$.; rostrum, $9 \mathrm{~mm}$.; carapace, including rostrum, $33 \mathrm{~mm}$. Station 3413. 1360 fathoms. 1 fem.

\title{
ARISTAUS DUternot.
}

Anu. Sci. Nat. 2e Sér., XV. 104, 1841 [Aristeus].

\section{Aristæus occidentalis FAX.}

\author{
Plate XLIX., Fig. 2-2e.
}

Bull. Mus. Comp. Zoöl, XXIV. 215, 1893.

Rostrum much longer than the rest of the carapace, armed with two teeth near the proximal end of the upper margin, its distal two thirds curved upward. Anterior half of the carapace with a median dorsal carina, armed with one tooth on the anterior part of the gastric region. Cardiacobranchial groove distinct. Antero-lateral margin armed with a sharp tooth at the lower orbital angle. Below this there is a submarginal spine on a level with the second antennæ. Fourth abdominal segment carinated on its distal half, and armed with a small posterior tooth. Fifth abdominal segment carinated on the distal two thirds, and produced to a tooth on the posterior margin. Sixth abdominal segment carinated throughout its whole length, and armed with a posterior tooth. Margin of telson excavated near the base.

External spine (stylocerite) of the basal segment of the antennule a little longer than the segment, closely applied to the external margin of the segment, but not fused with it. Prosartema wanting.

Antennal scale broad, membranaceous, reaching beyond the superior antennular flagellım, and a little beyond the middle of the rostrum; antennal peduncle unarmed. Terminal segment of mandibular palpus not bilobed. Exopod of second maxilliped equal in length to the whole endopod. Exopod of third maxilliped equal in length to the ischium and merus together. There are no exopods on any of the legs. Carpus and propodite of the legrs ornamented with a longitudinal series of small pits defined (in alcohol) by red pigment. External branches of abdominal appendages very long, diminish-

nopeneus as described by Smith), there are none on the third maxillipeds or any of the legs, while in $H$. thetis rudimentary podobranchiæ are found on the third maxillipeds and the first, second, and third pairs of legs. 
ing posteriorly. External branch of swimmeret much longer than the inner branch, which in turn far surpasses the telson.

Length, $158 \mathrm{~mm}$.; carripace, including rostrum, $85 \mathrm{~mm}$.; rostrum, 49 $\mathrm{mm}$.; antennal scale, $25 \mathrm{~mm}$.; telson, $18.5 \mathrm{~mm}$.

Station 3403.384 fathoms. 1 male. "3410, 331 " 2 fem.

This species appears to be very closely related to Aristcous antemnatus* of the Mediterranean Sea. Risso's description and figure of the latter species are too faulty to be of any service for comparison. By comparison with Duvernoy's figures it appears that the Pacific species differs from the Nediterranean in having a much longer and more upwardly inclined rostrum, a carinated and posteriorly toothed sixth abdominal segment, and much longer abdominal appendages. These differences, taken in connection with the remote habitats, leave little doubt that the two forms are specifically distinet.

In any event, there is no doubt that they are strictly congeneric. In A. occidentalis, as in A. antematus, according to the detailed account of Duver. noy, there is no epipod on either the ultimate or the penultimate pair of legs, the branchial arrangement in $A$. occidentalis being as follows:-

$$
\begin{array}{lccccccccc}
\text { Somites } & \text { VII. } & \text { vIII. } & \text { IX. } & \text { X. } & \text { XI. } & \text { XII. XIII. XIV. } & \\
\text { Pleurobranchiæ } & 0 & r & r & r & r & r & r & 1=1+6 r \\
\text { Arthrobranchiæ } & 1 & 1 & 2 & 2 & 2 & 2 & 2 & 0=12 \\
\text { Podobranchiæ } & 0 & 1 & 1 & 1 & 1 & 0 & 0 & 0=4 & (6) \\
\text { Epipods } & 1 & 1 & 1 & 1 & 1 & 1 & 0 & 0=\frac{(6)}{17+6 r+(6)}
\end{array}
$$

The rudiments of the pleurobranchix of the eighth to the thirteenth somites can hardly be detected except with a lens. They consist of a mere vestige of the stem of the gill, without any lateral filaments excepting in those of the eighth and ninth somites. The single arthrobranchia of the seventh segment; although functional, is very small and might easily have been overlooked by Duvernoy. Setting aside the six almost microscopic rudimentary pleurobranchix and the minute arthrobranchia of the seventh somite, the gills agree in number and position with those of $A$. antematus as shown on Plate V., Fig. 2, of Duvernoy's memoir. $\dagger$

* Peneus antennatus Risso, Hist. Nat. des Crustacés des Environs de Nice, p. 96, Plate II. Fig. 6, 1816; Aristeus antennatus Duvernoy, Ann. Sci. Nat., 2e Sér., XV. 10t, Plate IV. A, V., 1841.

$\dagger$ As Duvernoy wrote thirtyeight jears before Husley gave us a philosophical method of describing the complex branchial arrangements among the Crustacea, his statements concerning the point of attachment of 
Two of the "Challenger" Peneids assigned to the genus Aristaus by Bate, viz. $A$. armatus and $A$. rostridentatus, and the two species* doubtfully referred to the same genus by Smith differ from the true species of Aristceus in some important respects: the penultimate pair of thoracic appendages are furnished with epipods, the antepenultimate pair bear a podobranchia, and there are functional pleurobranchix on each somite from the eighth to the fourteenth, the branchial formula in these species being as follows:-

\begin{tabular}{|c|c|c|c|c|c|c|c|c|c|}
\hline Somites & VII. & viII. & IX. & $\mathbf{x}$ & $\mathbf{X I}$. & XII. & xIII. & XIV. & \\
\hline Pleurobranchiæe & 0 & 1 & 1 & 1 & 1 & 1 & 1 & $1=$ & 7 \\
\hline Arthrobranchiæ & 1 & 1 & 2 & 2 & 2 & 2 & 2 & $0=$ & 12 \\
\hline Podobranchix & 0 & 1 & 1 & 1 & 1 & 1 & 0 & $0=$ & 5 \\
\hline Epipods & 1 & 1 & 1 & 1 & 1 & 1 & 1 & $0=$ & (7) \\
\hline
\end{tabular}

The peculiarities here exhibited appear to be of generic import, and these species should be placed together in a genus distinct from Aristcens, to which Bate's provisional name Plesiopeneus $†$ may be applied. Penens edwardsianus Johnson, $\neq$ assigned to the genus Aristous by Miers, $§$ has the terminal segment of the mandibular palpus bilobed as in the species of Plesiopeneus, and very probably belongs to the latter genus.

Two of the species (A. semidentatus and $A$. tomentosus) included in the genus Aristocus [Plesiopeneus] by Bate in 1881, were transferred to Hemipeneus in the final "Challenger" Report of 1888. I suspect that these two species, together with Hemipeneus viritis Bate, which is probably the male of $H$. tomen-

the gills must not be taken too strictly. He assigns anterior artlirobranchiæ to the appendages and posterior arthrobranchix to the body wall. His description and figure of the gills of A. antennatus are misinterpreted by Professor Smith (Ann. Rep. U. S. Fish. Comm. for 1852, p. 409), whose hypothetical formula involres twenty-one gills, while Duvernoy states the number to be sixteen. My interpretation of Duvernoy's figure, by aid of the light thrown upon it by $A$. occidentalis, is as follows (the Roman uumerals are the index numbers of the gills in Duvernoy's figure) :-

I. Podobranchia of 8 th somite.

II. Anterior arthrobranchia of 9 th somite.

III. Podobranchia of 9 th somite.

IV. Anterior arthrobranchia of 10 th somite.

V. Podobranchia of 10 th somite.

VI. Anterior arthrobranchia of 11 th somite.

VII. Podobranchia of 11 th somite.

VIII. Anterior arthrobranchia of 12 tll somite.

IX. Posterior arthrobranchia of 12 th somite.
X. Anterior " " " 13 th "
XI. Posterior 13 th "
XII. Pleurohranchia of 14th somite.
XIII. Arthrohranchia of 8th somite.
XIV. Posterior arthrobranchia of 9 th somite.
XV. "
XVI. "

* Aristoens? tridens Smith, Ann. Rep. U. S. Fish Comm. for 1882, p. 104, Plate IX. Fig. 1-6, 1854; and Aristcus? foliaceus Smith (= Penens foliaceus Risso?), Proc. U. S. Nat. Mus., VIII. 188, 1885. The former species is identical with $A$. armatus Bate.

† Ann. Mag. Nat. Hist, 5th Ser., VIII. 188, 1881. The type of Plesiopeneus is Aristcus armatus Bate.

† Proc. Zoölog. Soc. London, 1867, p. 897.

$\S$ Proc. Zoölog. Soc. Luondon, 1879, p. 308, Plate XVII. Fig. 3. 
tosus, really belong to Duvernoy's genus Aristous. The branchial formula of Homipencus, as given on page 228 of the "Challenger" Report, is the same as in Aristaus Duvernoy, and the rostrum and general facies of these two species are like those of Aristaus rather than the typical species of Hcmipeneus.

Since the above was written, Wood-Mason's paper on the Crustacea dredged off the coast of India by H. M. S. "Investigator" during 189091, * has come to hand. 'The author's views concerning the affinities of the species just considered agree very closely with my own. A new generic name Aristocopsis is given to the "Aristous" armatus group, for which Spence Bate had already furnished the provisional name Plesiopeneus, and A. rostridentatus Bate is made the type of another genus, Aristaomorphu, on what scem to me too trivial characters, viz. the large number of rostral teeth, the presence of an hepatic spine, mucronate postero-lateral angles of abdominal somites, and the setaceous character of the dactyli of the last two pairs of thoracic appendages. If Aristcomorpha be recognized as a valid genus, it should probably include "Aristeus?" foliaceus Smith, along with A. rostridentatus. Two new species of Aristans are described by Wood-Mason, one of which (Aristcens coruscans) appears to be very closely allied to Aristous occidentalis. It differs from the latter, however, in having a shorter rostrum, and more strongly defined ridges and grooves on the sides of the carapace. Furthermore, the three rostral spines are placed further forward in $A$. coruscans than in $A$. occidentatis, the posterior spine being directly over the posterior wall of the orbit in the former species, while in the latter this spine lies further back on the anterior gastric region. The dorsal carina which runs back from this spine along the median line of the carapace continues nearly to the posterior edge of the carapace in $A$. coruscans, while in $A$. occidentalis it does not extend beyond the gastric region.

The somewhat complicated synonymy of the genera Arislous, Hemiponeus and Plesiopeneus appears to be as follows:-

\section{Aristæus DuverN.}

Aristeus Duvern., Ann. Sci. Nat., $2^{\circ}$ Sér., XV. 104, 1841. Type, Peneus antennatus Risso. Aristeus Bate, Ann. Mag. Nat. IIist., 5 th Ser., VIII. 187, 1881. (In part.)

Hemipencens Bate, Ann. Mag. Nat. Hist., 5th Ser., VIII. 186, 1881; Rep. Challenger Macrura, p. 299, 1888. (In part.)

Avistous Wood-MIason, Ann. MIag. Nat. Hist., 6th Ser., VIII. 27S, 1891.

Aristeus Fax., Bull. Mus. Comp. Zoöl., XXIV. 215, 1893.

* Ann. Mag. Nat. Hist., 6th Ser., VIII. 268 et seqq., 1891. 
1. Aristeus antennatus (Risso).

Peneus antennatus Risso, Hist. Nat. Crust. Nice, p. 96, Plate II. Fig. 6, 1816 ; Hist. Nat. de l'Europe Mérid., V. 68, 1826.

Aristeus antennatus Duvern., Ann. Sci. Nat., 2e Sér., XV. 104, Plate IV. A, V., 1841.

\section{Aristades virilis (Bate).}

Hemipenceus viritis Bate, Ann. MIag. Nat. Hist., 5th Ser., VIII. 187, 1881; Rep. Challenger Macrurn, p. 303, Plate XLIV. Fig. 4, 1888. Male.

Aristeus tomentosus Bate, Ann. Mrag. Nat. Hist., 5th Ser., VIII. 189, 1881; Rep. Challenger Macrura, p. 307, Plate XLIX. Fig. 2, 3, L。, 1888. Female.

Aristoens virilis Wood-Mason, Ann. Mag. Nat. Hist., 6th Ser., VIII. 278, 1891.

\section{Aristaus semidentatus Bate.}

Aristens semidentatus Bate, Ann. MIng. Nat. Hist., 5th Ser., VIII. 189, 1881.

Hemipenous semidentatus Bate, Rep. Challenger Macrura, p. 305, Plate XLIX. Fig. 1, 1888.

Aristceus semidentatus Wood-Mason, Ann. Mag. Nat. Hist., 6th Ser., VIII. 280, 1891.

\section{Aristeus coruscans Wood-Mason.}

Ann. Mag. Nat. Hist., 6th Ser., VIII. 280, Fig. 6, 1891; Ill. Zoöl. H. M. I. M. S. "Investigator," Crustacea, Plate II. Fig. 3, 1892.

\section{Aristeus crassipes Wood-Mason.}

Ann. Mag. Nat. Hist., 6th Ser., VIII. 281, Fig. 7, 1891.

$$
\text { 6. Aristeus occinentalis Fax. }
$$

Bull. MIus. Comp. 'Zoöl., XXIV. 215, 1893.

\section{Hemipeneus BaTE.}

Hemipenous Bate, Ann. Mag. Nat. Hist., 5th Ser., VIII. 186, 1881; Rep. Challeuger Macrura, p. 299, 1888. (In part.) Type, Hemipenceus spinidorsalis Bate.

Hemipenceus Wood-Mason, Ann. Mag. Nat. Hist., 6th Ser., VII. 189, VIII. 286, 1891.

Hemipeneus Fax., Bull. Mus. Comp. Zoöl., XXIV. 215, 1893.

\section{Hemipeneus spinidorsalis Bate.}

Hemipenceus spinidorsalis Bate, Ann. Mag. Nat. Hist., 5th Ser., VIII. 186, 1881; Rep. Challenger Macrura, p. 301, Plate XLIV. Fig. 1, 1888.

Iemipeneus spinidorsalis Fax., Bull. Mus. Comp. Zoöl., XXIV. 215, 1893.

2. Hemireneus speciosus Bate.

Hemipenceus speciosus Bate, Ann. Mag. Nat. Hist., 5th Ser., VIII. 186, 1881; Rep. Challenger Macrura, p. 303, Plate XXXVII. Fig. 3, XliV. Fig. 3, 1888.

\section{Hempeneds gracilis Bate.}

Hemipenceus gracilis Bate, Rep. Challenger Macrura, p. 302, Plate XLIV: Fig. 2, 1888. 
4. Hemipeneus carpenteri Wood-Mason.

Memipenceus carpenteri Wood-Mason, Ann. Mag. Nat. Hist., 6th Ser., VII. 189, VIII. 286, 1891.

5. Hemipeneus triton Fax.

Bull. Mus. Comp. Zoöl., XXIV. 215, 1893.

\section{Plesiopeneus Bate.}

Plesiopencus Bate, Ann. Mag. Nat. Hist., 5th Ser., VIII. 188, 1881. Type, Aristeus armatus Bate.

Aristens Bate, Anu. Mag. Nat. Hist., 5th Ser., VIII. 187, 1881 (in part); Rep. Challenger Macrura, p. 309, 1888.

(Aristoopsis Wood-Mason, Ann. Mag. Nat. Hist., 6th Ser., V1II. 282, 1891. Type, Pencus edwardsianus Johnson.

Aristceomorpha Wood-Mason, Aun. Mag. Nat. Hist., 6th Ser., VIII. 286, 1891. Type, Aristeus rostridentatus Bate.

\section{Plesiopeneus emwardiands (Johnson).}

Penceus edwardsianus Johnson, Proc. Zoölog. Soc. London, 1867, p. 897.

Aristeus edwardsianus Miers, Proc. Zoölog. Soc. London, 1878, p. 308, Plate XVII. Fig. 3 Aristens corulinus A. M. Elw., Bate's Rep. Challenger Macrura, p. xxxii. Fig. 10, 1888.

Aristcopsis edwardsiana Wood-Mason, Ann. Mag. Nat. Hist., 6th Ser., VIII. 283, Fig. 8, 9, 1891 ; I11. Zoöl. H. M. I. M. S. "Investigrator," Crustacea, Plate I., 1892.

\section{Plesiopeneus armatus (Bate).}

Aristeus armatus Bate, Ann. Mag. Nat. Hist., 5th Ser., VIII. 188, 1881; Rep. Challenger Macrura, p. 312, Plate XLV., XLVI., 1888.

Aristeus? tridens Smith, Ann. Rep. U. S. Fish Comm, for 1882, p. 404, Plate IX. Fig. 1-6, 1884 ; id. for 1885, p. 698, Plate XIX. Fig. 2, $2 a, 1886$.

Aristceopsis armata Wood-Mason, Ann. Mag. Nat. Hist., 6th Ser., VIII. 285, 1891.

3. Puesiopeneus rostridentatus (Bate).

Aristeus rostridentatus Bate, Ann. Mag. Nat. Hist., 5th Ser., VIII. 189, 1881; Rep. Challenger Macrura, p. 317, Plate LI., 1888.

Aristceomorpha rostridentata Wood-Mason, Ann. Mag. Nat. Hist., 6th Ser., VIII. 286, 1891; Ill. Zoöl. H. M. I. M. S. "Investigator," Crustacea, I'late II. Fig. 1, 1892.

\section{Plesiopeneus foliaceds (Smith).}

?Peneus foliaceus Risso, Hist. Nat. de l'Europe Mérid, V. 69, Plate II. Fig. 6, 1826.

? Penceus foliaceus Heller, Sitzungsber. Kais. Akad. Wissensch. Wien, Math.-Naturwissensch. Cl., XLV. 424, Plate II. Fig. 50, 1862; Crust. Südl. Europa, p. 297, 1863.

Aristeus? foliaceus Smith, Proc. U. S. Nat. Mus., VIII. 188, 1885.

\section{Plesiofeneus gigliolianus (Wood-Mason).}

Aristcemorpha giglioliana Wood-Mason, Ill. Zoöl. H. M. I. M. S. "Investigator," Crustacea, Plate II. Fig. 2, 1892. 


\section{HEMIPENEUS BATE.}

Ann. Mag. Nat. Hist., 5th Ser, VIII. 186, 1881; Rep. Clallenger Macrura, p. 299, 188S [Hemipenous].

\section{Hemipeneus spinidorsalis BATE.}

Plate L., Fig. 2.

Ann. Mag. Nat. Hist., 5th Ser., VIII. 186, 1881; Rep. Clallenger Macrura, p. 301, Plate XLIV. Fig. 1, 1888 .

Station 3374. 1823 fathoms. 3 males, 1 fem.

$\begin{array}{llllll}\text { " } & 3375 . & 1201 & \text { " } & 1 \text { fem. } \\ \text { " } & 3398 . & 1573 & \text { " } & 2 \text { males. } \\ \text { " } & 3399 . & 1740 & \text { " } & 1 \text { male, } 2 \text { fem. } \\ \text { " } & 3400 . & 1322 & \text { " } & 1 \text { male, } 1 \text { fem. }\end{array}$

This species, the type of the genus Hemipeneus, was discovered by the naturalists of the "Challenger" Expedition near Tristan d'Acunha in the South Atlantic, and near the Philippine Islands. Three specimens were captured, all at great depths (1,900 and 2,050 fathoms). Bate's figure was drawn from a small specimen, $57 \mathrm{~mm}$. in length. The differences apparent when one compares this figure with the much larger "Albatross" specimens may be plausibly attributed to the disparity of age and to errors of the draughtsman. The great length of the ischium joint of the chelipeds, a feature not mentioned in Bate's description, nor seen in any other species of the genus, is doubtless due to an error in the drawing. In the "Albatross" examples the median dorsal line of the carapace is distinctly convex and rises into a low carina which is continuous from the base of the rostrum to the posterior border of the carapace. The dorsal carina is apparent also on the posterior half of the third, fourth, and fifth abdominal segments, and, to a greater degree, through the whole length of the sixth abdominal segment. The eye-stalks are flattened horizontally, and furnished with a small tubercle on the middle of the internal margin. The flagellum of the second antenna is enormously long, much more than twice the length of the body. The meri of the chelipeds are compressed.

The rostrum of the adult male varies in length from one third to nearly one half the length of the remaining portion of the carapace. It is always much shorter than the antennular peduncle. In the adult female, on the contrary, the rostrum is much longer than the antennular peduncle, varying 
in length, according to the size of the individual, from three fifths to four fifths of the length of the rest of the carapace. At its maximum it is equal in length to the antennal scale. This remarkable difference between the sexes as regards the length of the rostrum is constant in the "Albatross" specimens.

In the male there is a roundish, shield-shaped disk or plate, pointed anteriorly, on the sternum of the antepenultimate thoracic somite. The second segment of the posterior thoracic legs is armed with a small tooth on the internal side. The inner branch of the first abdominal appendages is represented by a large membranous petasma, while the proximal segment of the inner branch of the second abdominal appendages bears three branches, viz. an outer and anterior horny plate, concave within and furnished with setx on its distal border, and two inner and posterior branches, one of which has the form of a long triangular tooth shorter than the outer plate, the other being a longer multiarticulate flagellum, homologous with the inner branch of the following pairs of appendages. The sterna of the first three abdominal segments are produced into a median tooth between the bases of the appendages.

In the female there is on the posterior part of the thorax a sternal disk similar to, but less circular in form than, that of the male, and it is backed by an overlapping transverse plate arising from the sternum of the posterior thoracic somite. The second segment of the last pair of thoracic legs lacks the tooth found in the male. The first pair of abdominal appendages has only a rudiment of the internal branch in the shape of a short, slender filament. The inner branch of the second pair is similar to the corresponding part in the succeeding pairs. The abdominal sterna are toothed as in the male. A very large female, with a rostrum as long as the antennal scales, from Station 3400, is interesting as showing a tendency to assume a masculine character in the development of a petasma on each anterior abdominal leg. The organ is quite similar in form to the normal petasma of the male, only it is much smaller. In other respects this specimen is a normal female with well developed genital orifices at the base of the third pair of legs.

The second and third maxillipeds are furnished with long exopods. In the second maxilliped the exopod exceeds the length of the endopod, while in the third maxilliped it attains to the proximal end of the carpus of the endopod. The following pairs of thoracic appendages are provided with rudimentary exopods. 
The branchial formula is as follows:-

$\begin{array}{lcccccccc}\text { Somites } & \text { VII. } & \text { VII. } & \text { IX. } & \text { X. }_{0} & \text { XI. } & \text { XII. } & \text { XIII. } & \text { IIV. } \\ \text { Pleurobranchix } & 0 & 1 & 1 & 1 & 1 & 1 & r & 1=6+1 r \\ \text { Arthrobranchix } & 1 & 1 & 2 & 2 & 2 & 2 & 2 & 0=12 \\ \text { Podobranchix } & 0 & 1 & 1 & 1 & 1 & 1 & 0 & 0=5 \\ \text { Epipods } & 1 & 1 & 1 & 1 & 1 & 1 & 0 & 0=\frac{(6)}{23+1 r+(6)}\end{array}$

With the exception of those on the tenth and fourteenth somites the pleurobranchiæ are very small and might be called rudimentary if it were not for the plumose structure of all but the one on the thirteenth somite. The podobranchiæ decrease in size posteriorly until, on the antepenultimate pair of legs, they are reduced to small and weak organs.

If the branchial formula of Hemipeneus be compared with that of Aristceus (page 195), it will be seen that they are very nearly alike; the difference consisting in the further reduction in size of the pleurobranchix in the latter genus, and the complete disappearance of the podobranchia of the twelfth somite, which is very small, be it observed, in Hemipeneus. In its facies Hemipenens differs considerably from Aristaus. It has a slenderer body, flattened eye-stalks, longer antennular peduncles and antennal scales, peculiarly long-fingered chelæe and flattened meri on the chelipeds, and long, exceedingly slender, styliform ultimate and penultimate thoracic appendages.

The largest specimen of this species, - a female from Station 3400, mensures $245 \mathrm{~mm}$. from the tip of the rostrum to the end of the telson. The rostrum of this specimen is $56 \mathrm{~mm}$. long, the whole carapace, including rostrum, $116.5 \mathrm{~mm}$.

\section{Hemipeneus triton $F_{A X}$.}

Plate L., Fig. 1-1

Bull. Mus. Comp. Zoöl, XXIV. 215, 1893.

This species, like $H$. spinidorsalis, is remarkable for having a long, curved spine on the dorsal side of the third abdominal segment. It differs from $H$. spinidorsalis in having a very much shorter rostrum and longer, more flattened, ribbon-like outer antennular flagella. The rostrum is shorter than in any previously described species, being much shorter than the eye-stalks; it is armed above with two to four teeth, the posterior of which lies a little way behind the orbit; the fourth tooth, when present, is very minute, and is situate near the distal end of the rostrum. The rostrum is the same length 
in the two sexes. The dorsal portion of the cervical groove is more distinct than in $H$. spinidorsalis. The sixth abdominal segment is longer than in $H$. spinidorsalis, and there is a difference affecting the inner branch of the second abdominal appendages of the male, viz. the tooth-like process, which is in $H$. spinidorsalis shorter than the external plate, in $H$. triton is developed into a broad plate which exceeds in length the external plate. This difference will be most easily comprehended by inspection of Figs. $1^{e}$ and 2 on Plate L.

The podobranchia of the twelfth somite is even smaller than in $H$. spinietursulis.

Length, $127 \mathrm{~mm}$.; carapace, $44.5 \mathrm{~mm}$.; rostrum, $6 \mathrm{~mm}$.

Station 3360. 1672 fathoms. 1 fem.

" 3374. 1823 " 1 male, 5 fem.

"3381. 1772 " 3 males, 1 fem.

This species is perhaps identical with Hemipeneus carpenteri Wood-Mason,* dredged in the Laccadive Sea and in the Bay of Bengal, 1091-1644 fathoms.

BENTHESICYMUS BATE.

Ann. MIag. Nat. Hist, 5 th Ser., VIII. 190, 1881; Rep. Challenger Macrura, p. 326, 1888

\section{Benthesicymus altus BATE.}

Ann, Mag. Nat. Hist., 5th Ser., VIII. 191, 1881; Rep. Challenger Macrura, p. 336, Plate LVIII. Fig. 1, 1858.

$\begin{array}{crrrll}\text { Station } & 3360 . & 1672 & \text { fathoms. } & 1 \text { male, } 3 \mathrm{fem} . \\ \text { " } & 3361 . & 1471 & \text { " } & 1 \text { fem. } \\ \text { " } & 3374 . & 1823 & \text { " } & 1 \text { male, } 1 \text { fem. } \\ \text { " } & 3381 . & 1772 & \text { " } & 1 \text { male, } 2 \text { fem. } \\ \text { " } & 3382 . & 1793 & \text { "6 } & 2 \text { males, } 5 \text { fem. } \\ \text { " } & 3398 . & 1573 & \text { "6 } & 1 \text { male, } 1 \text { fem. } \\ \text { " } & 3399 . & 1740 & \text { "6 } & 1 \text { fem. } \\ \text { " } & 3413 . & 1360 & \text { " } & 1 \text { male, } 1 \text { fem. } \\ \text { " } & 3414 . & 2232 & \text { " } & 2 \text { males, } 1 \text { fem. } \\ \text { " } & 3415 . & 1879 & \text { " } & 2 \text { males, } 9 \text { fem. }\end{array}$

In Bate's figure of this species there appears to be a small spine on the side of the carapace, although none is mentioned in his description. In the "Albatross" specimens there is no spine at this place. The fragile filiform 
appendages of the last two thoracic segments are rarely preserved in their integrity. It would seem from the perfect specimens, that these appendages are longer than represented by Bate, the hindmost pair being the longest of all the legs, reaching forward to the distal end of the antennal scale. The dactylus of this appendage is less than one half as long as the propodite, the latter segment a little longer than the carpus. In Bate's diagnosis of the genus it is said that the legs all bear small exopods that become rudimentary posteriorly. No special mention of the exopods is made in his description of $B$. altus, neither are they shown in his figure of this species. In the "Albatross" specimens there are no exopods on any of the appendages behind the third maxillipeds. In other respects these specimens agree so closely with Bate's description and figure that I do not doubt that they belong to the same species.

Specimens from different stations vary to some extent in the degree of induration of the integument. In all the examples, nevertheless, it is rather soft and membranaceous in its texture.

The terminal segment of the third maxillipeds in this species, as well as in the following (B.tameri), is short, broad, curved, and compressed. In the female the external margin of this segment is regularly convex. In the males, this segment exhibits two forms: one like that of the female, the other conspicuonsly different, the external margin being produced into a large rounded tooth or lobe. In the latter form the whole segment assumes a bilobed outline as shown on Plate H., Fig. $1^{e}$. This difference in the form of the dactylus of the third maxillipeds in the males is accompanied by a difference in the petasma, or sexual appendage of the first abdominal limbs. In those males which have the third maxillipedal dactylus of the form first described the petasma is comparatively small, feeble, and free from calcareous deposit. In the males with bilobed third maxillipedal dactylus the petasma is larger, more perfectly finished, and stiffened by calcareous matter. It is clear that the latter form of the male is a state equipped for reproduction (see foot-note on page 74 ).

Spence Bate, in his generic diagnoses of Benthesicymus and Gemadas, says that in the former genus the dactylus of the third maxillipeds is cylindrical and sharp. But the figures of most of his species of Benthesicymus show a broad compressed dactylus like that seen in the species in the "Albatross" collection. Professor Smith's genus Bcnthocetes* is synonymous with Benthesicymus. 


\section{Benthesicymus tanneri Fax.}

Plate $H$.

Bull. Mus. Comp. Zoölo, XXIV. 215, 1593.

Integument smooth, membranaceous. Rostrum short, acute, laterally compressed, raised above the orbit into a crest which is armed with two slender acute teeth; the lower margin of the orbit is fringed with long closely set hairs. The rostral crest is continued backward as a sharp keel on the median line of the carapace, as far as the cervical groove; posterior to this the carina is obsolescent. The lower angle of the orbit is prominent, but not spiniform, the branchiostegal spine is prominent, the pterygostomian angle sharp but unarmed. The dorsal portion of the gastro-hepatic groove is pronounced, and is followed by another obsolescent, transverse, cervical furrow further back on the carapace, - a furrow which forms the anterior boundary of the cardiac area. The branchial area is bounded above by a blunt ridge and is separated from the pterygostomian area by an oblique suture. A slight carina runs from the branchiostegal spine to the branchiopterygostomian suture. The infero-lateral margin of the carapace is nearly straight.

The first three segments of the abdomen are thick, rounded, and devoid of dorsal carina or tooth; the fourth segment is faintly carinate but not toothed; the fifth and sixth are distinctly carinate and armed with a small acute posterior tooth. The telson is short, convex above, and armed with three pairs of minute lateral spines.

The eye-stalks are about as long as the rostrum and have the form characteristic of the genus; the eyes are of a dark brown color. The basal segment of the antennule is armed externally with a stylocerite which is much shorter than the segment, and with a small acute spine at the distal external angle. The antennular flagella are nearly as long as the body. The second segment of the antenna is devoid of an external spine; the scale is broad, folinceous, narrowed at the distal end; the flagellum is slender and much longer than the body. The merus of the second maxilliped is long and narrow, its inferior distal angle not produced beyond the base of the carpus; the exopod is much longer than the endopod, reaching forward to the distal end of the antennal peduncle; it is fringed on both sides with very long, delicate setx. The terminal segment of the endopod of the third maxilliped is flattened, truncate, and armed with abont four strong spines on 
the distal part of the outer, and on the distal, margins. The posterior thoracic appendages, when stretched forward, reach to the distal end of the antennal scales. There are no exopods on any of the thoracic appendages behind the third maxillipeds. In the median line of the sternum of the first abdominal segment there arises a long, laterally compressed, vertical tooth.

Length, $112 \mathrm{~mm}$; carapace, $44.5 \mathrm{~mm}$; rostrum, $8 \mathrm{~mm}$.

$\begin{array}{crrll}\text { Station } & 3358 . & 555 \text { fathoms. } & 3 \text { males, } 2 \text { fem. } \\ \text { " } & 3362 . & 1175 & \text { " } & 1 \text { male, } 1 \text { fem. } \\ \text { " } & 3363 . & 978 & \text { " } & 3 \text { males, } 5 \text { fem. } \\ \text { " } & 3364 . & 902 & \text { " } & 2 \text { males. } \\ \text { " } & 3365 . & 1010 & \text { " } & 1 \text { fem. } \\ \text { " } & 3366 . & 1067 & \text { "6 } & 1 \text { male, } 1 \text { fem. } \\ \text { " } & 3376 . & 1132 & \text { " } & 2 \text { fem. } \\ \text { " } & 3377 . & 764 & \text { " } & 1 \text { male. } \\ \text { " } & 3380 . & 899 & \text { " } & 1 \text { male. } \\ \text { " } & 3384 . & 458 & \text { " } & 27 \text { males, } 36 \text { fem. } \\ \text { " } & 3393 . & 1020 & \text { " } & 2 \text { males, } 3 \text { fem. } \\ \text { " } & 3400 . & 1322 & \text { " } & 1 \text { fem. } \\ \text { " } & 3403 . & 384 & \text { " } & 1 \text { male, } 1 \text { fem. } \\ \text { " } & 3404 . & 385 & \text { " } & 1 \text { fem. } \\ \text { " } & 3407 . & 885 & \text { " } & 5 \text { fem. } \\ \text { " } & 3410 . & 331 & \text { " } & 2 \text { males, } 3 \text { fem. } \\ \text { " } & 3411 . & 1189 & \text { " } & 1 \text { male, } 1 \text { fem. } \\ \text { " } & 3418 . & 660 & \text { " } & 7 \text { males, } 8 \text { fem. } \\ \text { " } & 3424 . & 676 & \text { " } & 1 \text { male. } \\ \text { " } & 3425 . & 680 & \text { "6 } & 1 \text { male. } \\ \text { " } & 3435 . & 859 & \text { " } & 3 \text { males, } 2 \text { fem. } \\ \text { " } & 3436 . & 905 & \text { " } & 5 \text { fem. }\end{array}$

In this species the carina on the fifth and sixth abdominal segments terminates posteriorly in a small acute tooth, whereas in the preceding species, $B$. allus, these segments are destitute of teeth, the posterior margin of the sixth rising to form a peculiar transverse ridge. B. brasiticnsis Bate differs from the present species in having the carapace higher, with more convex infero-lateral borders, the third, fourth, and fifth abdominal segments toothed, the sixth toothless, and in the lack of the tooth or tubercle on the sternum between the first pair of abdominal appendages. B. bartlcti Smith, from the Atlantic side of the continent, resembles $B$. tameri in many respects, 
but is distinguished at a glance by the long spine on the tergum of the fifth abdominal somite. B. moratus Smith, another allied species, differs in having a distinct hepatic spine, a much broader merus joint in the second maxilliped, a differently shaped distal joint in the endopod of the third maxilliped ( $v$. Ann. Rep. U. S. Fish Comm. for 1882, Plate X., Fig. 5), and in the existence of small exopods at the bases of all the thoracic appendages.

In one abnormal specimen (a female) from Station 3436 the anterior tooth of the upper margin of the rostrum is wanting. The rostrum of this specimen has thus the general form of the rostrum of $B$. iridescens Bate.

The number and arrangement of the branchix of this species are shown in the following table:-

$\begin{array}{lccccccccc}\text { Somite } & \text { VII. } & \text { VIII. } & \text { Ix. } & \text { x. } & \text { xI. } & \text { XII. } & \text { xIII. } & \text { xIV. } & \\ \text { Pleurobranchiæ } & 0 & 0 & 1 & 1 & 1 & 1 & 1 & 1=6 & \\ \text { Arthrobranchiæ } & 1 & 2 & 2 & 2 & 2 & 2 & 2 & 0=13 & \\ \text { Podobranchiæ } & 0 & 1 & 1 & 1 & 1 & 1 & 0 & 0=5 & \\ \text { Epipods } & 1 & 1 & 1 & 1 & 1 & 1 & 1 & 0=\frac{(7)}{24+(7)}\end{array}$

The posterior of the two arthrobranchiae of the eighth somite is perhaps homologous with the pleurobranchix of the following somites. It is a small organ, as is the pleurobranchia of the ninth somite also. The epipods borne by the appendages of the seventh to the tenth somites inclusive are vesicular.

Color when alive, deep red, with a large patch of bright blue on the back of the second, third, and fourth abdominal segments; eyes black.

\section{GENNADAS BATE.}

Anu. Mag. Nat. Hist., 5th Ser, VIII. 191, 1891 ; Rep. Challenger Macrura, p. 339, 1888.

\section{Gennadas sp.}

Hydr. 2638. 500-570 fathoms. Sub-marine tow-net.

Station 3399. $1740 \quad$ " 1 male.

The specimen from Station 3399 is $60 \mathrm{~mm}$. in length. It is badly mutilated, wanting the third pair of maxillipeds and the last two pairs of thoracic appendages. The tubercle on the inner side of the eye-stalk is pointed, as in $G$. intermedius Bate, but the mandibular palpus is much longer than described for that species, reaching nearly to the middle of the antennal scale.

The merus of the second maxilliped is broad and operculiform. The 
penultimate thoracic legs carry an epipod but not a podobranchia, the three pairs of chelate legs are furnished with small epipods and also with a podobranchia. This specimen doubtless belongs to Bate's genus Gennadas which, it seems to me, hardly deserves to be separated from Benthesicymus. Smith's genus Amatopencus * closely resembles Gemadas in its general form, but is said to lack the podobranchix throughout the series of thoracic legs.

The other specimen, from Station 2638, is in a still worse state of preservation. It was taken in the Tanner net towed at a depth of from 500 to 570 fathoms over a bottom of 622 fathoms, off Guaymas.

FAMILT SERGESTIDE.

SERGESTES M. EDW.

Ann. Sci. Nat., XIX. 316, 1830.

Sergestes inous Fax.

Plate LI., Fig. 2-2d.

Bull. Mus. Comp. Zoöl., XXIV. 216, 1893.

Integument soft, membranaceous. Carapace devoid of spines. Gastro. hepatic groove distinct across the dorsum. Rostrum short, triangular, blunt at the tip, bounded on each side by a distinct sulcus. The orbital area of the carapace is likewise circumscribed by a shallow sulcus which unites posteriorly with the anterior part of the cervical sulcus. The upper limit of the branchial area is defined by a prominent ridge which gives off from its anterior end an inferior branch obsolescent before reaching the posterior border of the carapace. The excurrent branchial orifice is bounded externally by a shallow concavity in the antero-lateral margin of the carapace.

The abdomen is unarmed, the terga of the several somites rounded above, the pleuræ with rounded and ciliated lower margins. A distinct longitudinal groove courses over the side of the fourth, fifth, and sixth somites of the abdomen, beginning at the posterior end of the anterior third of the fourth somite and ending a little way in front of the posterior border of the sixth. The sixth abdominal somite is once and one half as long as the fifth and about equal in length to the telson, which is sulcate above and on each side and tipped by a small acute spine.

The eye-stalks are shorter than the proximal segment of the first pair

* Bull. Mus. Comp. Zoöl, X. 86, 1882. 
of antennx; the eyes are black and small, not exceeding the eye-stalks in diameter. The first segment of the antennular peduncle is somewhat shorter than the second; the second and third segments are about equal in length. The second segment of the antenna is unarmed; the scale is broad to the tip, and reaches a little way beyond the proximal end of the third segment of the antennular peduncle. The second pair of maxillipeds are robust and reach forward to the distal end of the proximal segment of the antennular peduncle. The third maxillipeds and the third pair of legs are the longest of the appendages; they are subequal in length, reaching much beyond the distal end of the antennular peduncle. The second and third pairs of legs are furnished with a minute terminal chela, the fingers of which are tipped with a brush of setre. There is a tuft of sete at the distal end of the inferior margin of the carpus, corresponding to a similar tuft near the proximal end of the propodite. The penultimate pair of legs are about as long as the carapace; they are flattened and furnished with long cilia, as is customary in this genus. The posterior pair of legs is wanting in the only specimen obtained.

The abdominal appendages are very long, diminishing in length posteriorly. The external branch of the caudal fin or swimmeret appears to be without an external spine, but an angle in the onter margin, one quarter of the way from the distal end, marks the position of the spine commonly found on this appendage.

Length, $113 \mathrm{~mm}$; ; carapace, $34.5 \mathrm{~mm}$.

Station 3380. 899 fathoms. 1 female.

The branchial organs are arranged as follows:-

\begin{tabular}{|c|c|c|c|c|c|c|c|c|c|}
\hline Somite & VII. & VIII. & $\mathrm{IX}$. & $\mathrm{x}$. & XI. & XII. & XIII. & $\mathrm{XIV}$ & \\
\hline Pleurobranchix & 0 & $0+l$ & $1+l$ & $1+l$ & $1+l$ & 2 & 2 & $0=7+4 l$ & \\
\hline Arthrobranchie & 0 & 0 & 0 & 0 & 0 & 0 & 0 & $0=0$ & \\
\hline Podobranchice & 0 & 1 & 0 & 0 & 0 & 0 & 0 & $0=1$ & \\
\hline Epipods & 1 & 1 & 0 & 0 & 0 & 0 & 0 & $0=$ & (2) \\
\hline
\end{tabular}

In the above formula the letter $l$ stands for the simple lamella which represents the second pleurobranchia on the eighth to the eleventh somites. The pleurobranchix of the tenth and eleventh, and the anterior pleurobranchia of the twelfth, somite are of about an equal size, and are the largest of all the gills. The posterior pleurobranchia of the twelfth somite (Plate LI., Fig. $2^{d}, p l_{0}^{\prime}$ ), though smaller than the anterior, is perfect in form 
and unconcealed. The posterior gill of the thirteenth segment is smaller than the anterior gill of the same segment, being a little smaller than the podobranchia attached to the second maxilliped.

This species bears a close resemblance to Sergestes mollis Smith* from the Atlantic coast of North America, but differs from the latter species in an important structural feature. In S. mollis the posterior pleurobranchia of the antepenultimate thoracic somite is replaced by small simple lamella, which is concealed beneath the following gill, while in $S$. inous the posterior pleurobranchia of the said somite is well developed and unconcealed. The difference between the two species is at once apparent on lifting the lateral flap of the carapace.

\section{Sergestes bisulcatus Wood-Mason.}

\section{Plate LII.}

Sergestes bisulcatus Wood-Mason, Aun. Mag. Nat. Hist., 6th Ser, VII. 190, VIII. 353, 1891.

Sergestes phorens FAX., Bull. Mus. Comp. Zoöl., XXIV. 217, 1893.

Carapace devoid of spines; gastro-hepatic and cervical grooves well pronounced across the dorsal part of the carapace; a ridge runs along the upper border of the branchial area, giving off from its anterior end a branch which runs backward at a lower level along the branchial area; dorsal side of the carapace slightly convex in an antero-posterior sense; rostrum cristiform, short, laterally compressed, directed obliquely upward, subquadrate in outline, the anterior margin produced to form a short point near the middle; antero-lateral margin of the carapace nearly perpendicular from the base of the rostrum to the level of the lower side of the peduncle of the antennule, whence it recedes to an angle over against the base of the second antenna; from this point it becomes concave, sweeping downward and backward, and forming the ciliated margin of the excurrent branchial orifice.

The second, third, and more especially the fourth abdominal somites are lightly sulcate in the median dorsal line; the abdominal pleuræe have rounded, ciliated margins; the sixth somite is armed with a minute posterior dorsal spine, and is marked by a not very distinct lateral longitudinal sulcus. The telson is sulcate above, and on each side; it is shorter than the sixth abdominal segment; distal end triangular; margins ciliated.

The eye-stalk, with the eye, is considerably shorter than the proximal segment of the antennular peduncle; the eye itself is subspherical and much

* Ann. Rep. U. S. Fish Comm. for 18s2, p. 419, 1884; id. for 18s5, Plate XX. Fig. 3, 3a, 4, 5, 1886. 
larger in diameter than the eye-stalk; it rests in a depression of the proximal segment of the antennule. The first and second segments of the antennular peduncle are of equal length, while the third is considerably shorter; the proximal segment of the upper, principal flagellum is enlarged, and one third as long as the distal segment of the peduncle; the form and proportions of the secondary flagellum, two-branched in the male, simple and multiarticulate in the female, will be easily appreciated by glancing at Figs. $1^{d}$ and $1^{g}$ on Plate LII. The antennal scale reaches a little beyond the proximal end of the last segment of the antennular peduncle; it is broader at the distal end than is common in species belonging to this genus.

The thoracic appendages have much the same form and relative proportions as in S. robustus Smith.* 'The third maxillipeds reach beyond the distal extremity of the antennular peduncle. The first pair of legs reach to the end of the antennal scale; there is a tuft of setre near the distal end of the carpus corresponding to a similar tuft near the proximal end of the propodite. 'The second pair of legs extend beyond the peduncle of the antenuules; they are terminated by a small but perfect chela, each finger of which is provided at its tip with a brush of hairs. The legs of the third pair are similar to those of the second pair, but longer. The fourth and fifth pairs are flattened and furnished with long hairs, serving as natatory organs; the fourth pair reaches to about the end of the carpus of the third pair, while the fifth pair only attains to the middle of the merus of the fourth pair.

The complex form of the petasma of the male is portrayed on Plate LII., Fig. $1^{h}$.

The inner lamella of the posterior abdominal appendages is once and a half as long as the telson; the outer lamella is nearly twice as long as the telson, and is equipped with a spine on the external margin about one third of the way from the distal end, which is narrowed, though rounded.

The branchial formula is as follows:-

$\begin{array}{lccccccccc}\text { Somites, } & \text { vII. } & \text { VIII. } & \text { IX. } & \text { X. } & \text { XI. } & \text { XII. } & \text { XIII. } & \text { XIV. } & \\ \text { Pleurobranchiæ, } & 0 & 0 & 1 & 1 & 1 & 2 & 2 & 0=7 & 7 \\ \text { Arthrobranchiæ, } & 0 & 0 & 0 & 0 & 0 & 0 & 0 & 0= & 0 \\ \text { Podobranchiæ, } & 0 & 1 & 0 & 0 & 0 & 0 & 0 & 0= & 1 \\ \text { Epipods, } & 1 & 0 & 0 & 0 & 0 & 0 & 0 & 0= & \frac{(1)}{8+(1)}\end{array}$

The posterior gill of the antepenultimate thoracic somite is small and

* Bull. NIus. Comp. Zoölo, X. 97, l'late XVI. Fig. 5-8, 1882. 
concealed; the anterior gill of this segment, as well as the two gills on the penultimate somite, is large and conspicuous.

\begin{tabular}{|c|c|c|c|c|}
\hline tation & 3382. & 1793 & fathoms. & 1 male. \\
\hline 66 & 3386 . & 242 & "6 & 1 fem. \\
\hline 66 & $338 s$. & 1168 & 6 & 26 \\
\hline “" & 3401. & 395 & " & 1 \\
\hline "6 & 3437. & 628 & 6 & $\begin{array}{l}1 \\
1 \mathrm{mal}\end{array}$ \\
\hline
\end{tabular}

I assign this species to S. Zisulcatus Wood-Mason with some doubt, as the description of the latter species is not detailed enough to make its identity sure. Wood-Mason's specimens were taken in the Arabian Sea and the Bay of Bengal, 738-840 fathoms.

There is nothing on the labels to indicate that the specimens from Stations 3382 and 3388 did not come up in the trawl, which had been dragged over a bottom of 1793 and 1168 fathoms; but it should be observed that at Station 3382 a net was towed at a deptl of 200 fathoms for fifteen minutes, and then brought open to the surface, and that at Station 3388 the Tanner net was towed at a depth of 400 fathoms, bringing up specimens in its upper part only, which was open all the way from 400 fathoms to the surfice. Perhaps the specimens of Sergestes bisulcatus from these two stations were in reality captured in the tow-nets.

\section{Sergestes edwardsii $\mathrm{Kr}$.}

Plate LI., Fig. 1-1

Kongel. Danske Vidensk. Selsk. Skr. 5 Række, naturvidensk. matlem. Afd., IV. 246, 277, Plate IV. Fig. $9^{a}-9^{k}, 1859$.

In this species the gastro-hepatic groove is well-nigh obliterated on the dorsal part of the carapace, and the dorsal portion of the cervical furrow, which in some species of Sergestes forms the front boundary of the cardiac area, is obsolete. There is a sharp spine near the antero-lateral margin of the carapace, behind the base of the eye-stalk, and another on the hepatic area. A longitudinal ridge runs from the base of the antenna backward, dividing at the hepatic spine into a superior and an inferior branch. The former forms the upper boundary of the branchial area, the latter courses as a carina along the middle of the branchial region, and fades ont before reaching the posterior border of the carapace. The rostrum is cristiform, 
tapering anteriorly in the largest individuals to a slender acute point, which overreaches the anterior margin of the ophthalmic segment.

The abdominal somites are unarmed, rounded above, the third, fourth, and fifth longitudinally sulcated on the dorsal face. The telson is sulcated on the dorsum and on each side, and ends in a blunt, ciliated point.

The eye-stalks are shorter than the proximal segment of the antennule; the eyes are black, and somewhat greater in diameter than the stalks. The first and second segments of the antennule are of about equal length, while the third segment is longer than the first or the second by one half. The second segment of the antenna of the second pair is armed with a small external spine; the scale is lanceolate, terminating in an apical spine; it falls short of reaching the distal end of the antennular peduncle. The second and third pairs of maxillipeds are robust organs compared with the following thoracic appendages; the second pair reach forward as far as the distal end of the peduncle of the second antenns; the third pair are equal in length to the whole body, minus the telson and half the sixth somite; the distal part of these appendages is armed with spines of various lengths; four of these spines, one of which is terminal, are exceedingly long and acute. The following pairs of thoracic appendages have the form characteristic of the genus to which this species belongs.

The petasma of a large male is figured on Plate LI., Fig. $1^{e}$.

The two branches of the last pair of abdominal appendages are longer than the telson, the outer branch longer than the inner. The external margin of the outer branch is not armed with a spine, but about one third of the way from the proximal end this branch of the swimmeret suddenly narrows by a change in the trend of the external margin.

There are six large pleurobranchix on ench side of the body, two on the thirteenth, or penultimate thoracic, somite, and one on each of the four antecedent (ninth to twelfth) somites; a smaller but perfectly formed podobranchia is attached to the base of the second maxilliped.

Length of one of the largest specimens (Station 3388), $29 \mathrm{~mm}$.; carapace, $9.3 \mathrm{~mm}$.

A good many specimens of this pelagic species were taken in the surface tow-net and also in the upper, open part of the submarine tow-net at the following stations: hydr. 2619, hydr. 2627, hydr. 2628, 3382, 3388, 3409, 3412,3414 .

Three large males from Station 3388 (one of which is figured on Plate 
LI., and described above) differ from typical specimens, as described and figured by Kröyer, in having a larger and somewhat differently shaped rostrum, and in the form of the petasma. These specimens were separated from $S$. cdwardsii as a distinct species, $S$. halia, in my preliminary report on the "Albatross" Crustacea.* But I am now inclined to regard them as large and mature individuals of S.edvardsü. Kröyer $\dagger$ notes a "rare variety" of $S$. c devardsii distinguished by a larger rostrum.

S. edvardsii nppears to be a surface species of wide distribution in the tropical Atlantic and Pacific Oceans.

\section{Sergestes oculatus Kr.}

Kongel. Danske Vidensk. Selsk. Skr., 5 Række, naturvidensk. mathem. Afd., IV. 243, 277, Plate III. Fig. $5 a-5, f, 1859$.

One specimen from Station 3412, surface.

This is also a surface species found in the tropical parts of both the Atlantic and Pacific Oceans. Cf. Kröyer (op. cit.), Bate ("Challenger" Macrura), and Ortmann (Decapoden und Schizopoden der Plankton-Exped.).

\section{Sergestes longispinus Bate.}

Rep. Challenger Macrura, p. 417, Plate LXXVI. Fig. 2-2k, 1888.

One specimen, 250 miles S.E. of Acapulco, lat. $13^{\circ} 33^{\prime} 30^{\prime \prime}$ N., long. $97^{\circ} 57^{\prime} 30^{\prime \prime} \mathrm{W}$. Tanner net towed at 175 fathoms, and hanled to surface open, 8 P. м.

This species, originally described from specimens secured by the "Challenger " in the warmer portions of the Atlantic, has been previously recorded from the Pacific $\left(12^{\circ} \mathrm{S} ., 113^{\circ} \mathrm{W}\right.$.) by Ortmann.

\section{LUCIFER J. V. THоMPS.}

Zoölog. Researches, p. 58, 1829.

\section{Lucifer acestra DANA.}

? Leurifer reynaudii MI. EDw., Hist. Nat. Crust., II. 469, Plate XXVI. Fig. 10, 1837.

Lucifer arestra Daxa, U. S. Explor. Exped., Crustacea, Part I., p. 671, 1852, Atlas, Plate XLIV. Fig. 9, 1855 ; Streets, Bull. U. S. Nat. MLus., No. 7, p. 122, 1877.

Lucifer reynaudii BATE, Rep. Challenger Macrura, p. 466, Plate LXXXIV., 1858.

Lucifer reynaudi Orтм., Decap. u. Schizop. der Plankton-Exped,, p. 40, 1893.

A good many specimens, including both sexes, were captured on the surface of the sea at the following places:-

* Bull. Mus. Comp. Zoöl., XXIV. 217, 1893.

† Decap. u. Schizop. der Planktou-Exped., p. 36, 1 s93. 


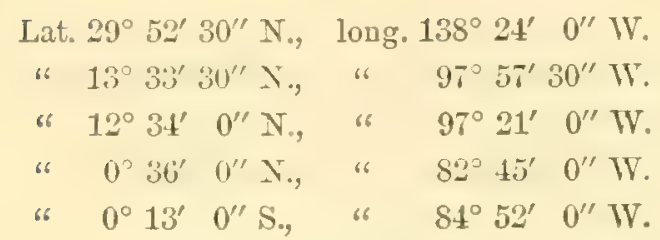

Spence Bate and Ortmann consider this species to be Lucifer reynaudii M. Edw., but Milne Edwards's description and figure are not sufficient for identification.

Lucifer acestra has an enormous horizontal distribution-throughout the warmer parts of both the Atlantic and Pacific Oceans. See Ortmann, l.c.

\section{Suborder SCHIZOPODA.* \\ Family LOPHOGASTRIDE.}

GNATHOPHAUSIA W.-SUH.

Nature, VIII 400, 1873; Trans. Linn. Soc. London, Zoöl., 2d Ser., I. 36, 1875.

\section{Gnathophausia zoea W.-SuHm.}

Nature, VIII. 401, Fig. 6, 1873; Traus. Limu. Soc. London, Zoöl., 2 d Ser., I. 32, Plate IX. Fig. 2-15, Plate X. Fig. 4, 1875.

Station 3403.384 fathoms. 3 specimens.

" 3406.581 " 1 specimen.

\section{Gnathophausia willemoesii G. O. Sars.}

Plate K, Fig. 1.

Forhandl. Vidensk.-Selsk. Christiania, 1883, No. 7, p. 6; Rep. Challenger Schizopoda, p. 38, Plate V. Fig. 1-6, 1885.

Station 3392. 1270 fathoms. 1 specimen.

$\begin{array}{llllll}\text { " } & 3417 . & 493 & \text { " } & 1 & \text { " } \\ \text { " } & 3420 . & 664 & \text { " } & 1 & \text { " } \\ \text { " } & 3425 . & 680 & \text { "6 } & 1 & \text { " }\end{array}$

The dorsal spine is longer than in the type specimen figured by Sars, and it is minutely denticulated along the margins, as in $G$. sarsii Wood-Mason, $\uparrow$ a form probably not specifically distinct from $G$ willcmoesii.

* Only the deep-sea Schizopods of the expedition are included in this report. An account of the pelagic species, by Dr. Arnold Ortmann, has been published in the Bulletin of the Museum of Comparative Zoölogy, Vol. XXV., No. 8, pp. 97-111, 1 Plate, 1894.

t Ann. Mag. Nat. Hist., 6th Ser, VII. 187, 1591. 
In small individuals of this species the rounded lateral expansions of the carapace behind the antennal spines are more prominent and the antennal spines relatively smaller than in full grown specimens.

G. willemoesii was discovered by the naturalists of the "Challenger" Expedition in 1874. 'Two specimens were procured south of Amboina, lat. 4 $21^{\circ}$ S., long. $129^{\circ} 7^{\prime}$ E. ; depth, 1425 fathoms.

\section{Gnathophausia brevispinis Wood-Mason.}

\section{Plate J.}

Guathophausia gracilis, var. brevispinis Wood-Masov, Ann. Mag. Nat. Hist., 6th Ser., VII. 188, 1891.

Gnathophausia brevispinis Wood.Mason, Ann. Mag. Nat. Hist, 6th Ser., VIII. 269, 1891.

Gnathophausia dentata FAx, Bull. MIus. Comp. Zoöl., XXIV. 217, 1893.

Rostrum somewhat shorter than the remaining part of the carapace, slender, gently up-curved, its three margins armed with teeth, those of the superior margin the largest. At the base of the rostrum, over the anterior part of the gastric region, rises a prominent thin triangular crest, produced at the apex to a spine; there are in most specimens a minute denticle near the anterior, and one to three near the posterior, end of the crest. Supraorbital spines small, not distinctly defined from the base of the rostrum. Antennal spines of moderate length, slender and acute. Branchiostegal spines very long, their bases expanded into wing-like processes on each side of the carapace. Cervical groove distinct. Dorsal keel obsolete on the posterior gastric region, distinct behind the cervical groove and armed with a row of small teeth. Posterior dorsal spine rather short, scarcely projecting beyond the first abdominal somite; it is directed upward at a much stronger angle than is common in this genus. Near the infero-posterior angles of the carapace are two spines, the upper of which is long and slender, equalling the dorsal spine in length, while the lower one is reduced to a tooth, obsolete in some specimens. The lower lateral keel is distinct, terminating in the upper of the two spines at the infero-posterior angle. Below this another minutely denticulated submarginal keel runs from the branchiostegal spine backward to the lower and smaller spine of the infero-posterior angle of the carapace. The upper lateral keel is obsolete.

The abdomen is rather slender, and is armed with a row of seven dorsal spines; two of these occur on the first segment, two on the second, and one on each of the three following segments; the two spines on the second segment, together with the posterior spine of the first segment, are much 
longer than the rest of the series. The pleurx of the abdominal segments are armed with two marginal spines, the sixth segment having in addition a tooth at the infero-posterior angle of its posterior section. The apical projection of the telson is divided into four terminal spines; there is, moreover, a small tooth on the external margin of the projection.

The eyes are small, not exceeding the eye-stalk in diameter; a small tubercle is situate on the inner side of the eye-stalk, a little way behind the cornea. The outer flagellum of the first pair of antennx is excessively long, being nearly twice the length of the whole body; the imner flagellum, on the contrary, is not longer than the carapace not including the rostrum.

The second segment of the second pair of antennæ is furnished with an acute tooth at the anterior end of its exterior border, and a slender spine is observable on the lower face of the following segment. The scale is broad, not more than twice as long as broad, the inner edge strongly arched, the outer edge slightly arched; the outer edge is armed with a few (two to four) small teeth on its distal half, and it terminates in an acute spine, which surpasses the distal extremity of the scale. The flagellum is somewhat shorter than the outer flagellum of the first pair of antennx.

The maxillipeds are provided with distinct exopods. The remaining pairs of appendages do not differ in any important regard from the gencric type.

Length, $60 \mathrm{~mm}$; carapace, including rostrum and dorsal spine, $33 \mathrm{~mm}$; rostrum, $14 \mathrm{~mm}$; dorsal spine, $4 \mathrm{~mm}$.

$\begin{array}{cccccc}\text { Station } & 3361 . & 1471 \text { fathoms, } & 1 \text { specimen. } \\ \text { " } & 3375 . & 1201 & \text { " } & 1 & \text { " } \\ \text { " } & 3400 . & 1322 & \text { " } & 1 & \text { "6 } \\ \text { " } & 3406 . & 551 & \text { " } & 1 & \text { " } \\ \text { " } & 3411 . & 1189 & \text { " } & 1 & \text { " } \\ & ? & ? & \text { "6 } & 1 & \text { " }\end{array}$

In two of the six specimens obtained (Stations 3361,3406 ), the tooth or short inferior spine at the infero-posterior angle of the carapace is nearly or quite obsolete.

This species is closely related to G. gracilis W.-Suhm, which was secured by the "Challenger" Expedition from a depth of 1500 fathoms in the Atlantic, lat. $1^{\circ} 22^{\prime} \mathrm{N}$, long. $26^{\circ} 36^{\prime} \mathrm{W}$. According to Sulım's description and figure the third and fourth abdominal segments of $G$.gracilis

* Trans. Linn. Soc. London, Zoölo, 2d Ser., I. 33, Plate IX. Fig. 1, 1875. 
are devoid of dorsal spines and the gastric region is armed anteriorly with two small teeth in the median line. The specimen was afterwards described and figured with more detail by G. O. Sars.* The third and fourth abdominal segments are represented as armed with dorsal teeth, similar to, though shorter than, those of $G$. Urevispinis, while the gastric region appears unarmed. The specimen was in a bad state of preservation when it reached Professor Sars, and Suhm's figure, which was probably drawn soon after the capture, is presumably correct as far as the gastric teeth are concerned. The "Albatross" specimens appear to be specifically distinct from the "Challenger" species, and may be diagnosed at once by the prominent dentate gastric crest, the small size or even absence of the lower spine of the infero-posterior angle of the carapace, and the great breadth of the antennal scale. The pleurre of the first four abdominal segments are expanded posteriorly into rounded lobes. A deep transverse dorsal fold separates the two dorsal spines of the second segment of the abdomen.

Wood-Mason describes the dorsal spines of the first abdominal somite of G. brerispinis as subequal. In the "Albatross" specimens the anterior of these spines is at the best only half as long as the posterior one.

G. brevispinis was first obtained in the Bay of Bengal (690-1748 fathoms) by II. M. Indian Marine Survey Steamer "Investigator."

\section{FAMILY EUCOPIIDA.}

EUCOPIA Dana.

Proc. Acad. Nat. Sci. Phila., VI. 19, 1852 ; U. S. Explor. Exped., Crustacea, Pt. I., p. 609, 1852.

Eucopia australis DANA.

Proc. Acad. Nat. Sci. Phila., VI. 28, 1852; U. S. Explor. Exped., Crustacea, Pt. I., p. 609, 1852, Atlas, Plate XL. Fig, 10, 1555.

Station 2627 Hyd. Between 1770 fathoms and surface, submarine townet (bottom, 1832 fathoms). 4 specimens.

Station 2637 Hyd. Between 700 fathoms and surface, submarine tow. net (bottom, 773 fathoms). 1 specimen.

Station 3377. 764 fathoms. 1 specimen.

" 3406.551 " 11 "

“ 3433.1218 " 1301 “

* Rep. Challenger Schizopoda, p. 48, Plate VII. Fig. 6-10, 1835. 
The type specimen of this interesting Schizopod was taken from the stomach of a penguin collected by the Wilkes Expedition in the Antarctic seas, lat. $66^{\circ} 4^{\prime} \mathrm{S}$., long. $149^{\circ} 44^{\prime} \mathrm{E}$. The subsequent explorations of II. M. S. "Challenger" showed that this animal enjoys an enormous geographical range, being found at great depths in the Atlantic, Pácific, Australian, and Antarctic Oceans. It has also been dredged at a recent date in the Bay of Bengal by the "Investigator." According to Willemoes-Suhm, who redescribed and figured this species under the name of Chalaraspis mnguiculala, ${ }^{*}$ it is the commonest Schizopod of the deep-sea fauna of the Atlantic. It has been described and figured with great care by G. O. Sars in the final Report on the "Challenger" Schizopods, pp. 55-62, Plate IX., X.

The finding of this species in the stomach of a penguin is taken by Sars as evidence of its occurrence, in the Antarctic Ocean, in comparatively shallow water. But perhaps a fish just risen from a depth far beyond the penguin's reach was the bird's purveyor.

\section{Eucopia sculpticauda FAX.}

\section{Plute K, Fig. 2, 2d ; Plate LIII., Fig. 1-1.}

Bull. Mus. Comp. Zoöl., XXIV. 218, 1893.

This species differs from $E$. australis in a striking manner as regards the form of the frontal margin of the carapace, the eyes, and the telson. In other respects it agrees so closely with $E$. anstralis as to render a detailed description superfluous.

The frontal margin of the carapace is very prominent, forming a threesided, blunt rostrum, which projects between the eye-stalks and wholly conceals the underlying ocular segment. The lateral margins of the rostrum form the upper wall of a deep, distinct orbit. In $E$. australis the frontal

* Trans. Linn. Soc. London, Zoöl., 2d Ser., I. 37, Plate VIII., 1875. This memoir was written on board the "Challenger" under date of Norember, 1873. In a letter from Dr. Willemoes-Suhm to Professor Siebold, dated April, 1574, and published on the 20th of October of the same year in the 21th volume of the Zeitschrift für wissenschaftliche Zoologie, occurs merely nominal mention of this species as Chalaraspis unguifera. The genus Chalaraspis was originally established (Trans. Iimn. Soc. London, as cited abore) for the reception of $C$. unguiculatis alone. Suhm afterwards discovered and referred to the same genus another Schizopod (Chalaraspis alata Sulım, Zeitschr. f. wissensch. Zool., XXIV., p. xx) which has been shown by G. O. Sars (Rep. Challenger Schizopoda, p. 50, 1SS5) to be not only generically but even familiarly distinct from Chalaraspis unguiculata. Chalaraspis unguiculata being synonymous with Eucopia australis Daua, Sars has seen fit to retain the generic name Chalaraspis for $C$. alala, a proceeding not in accordance with sound principles of nomenclature. The types of the genera Europin and Chaluraspis being nne and the same species, the name Chalaraspis should be dropped as a synonym of Europia, and a new generic name adopted for C. alata. I propose for the latter the generic name Eclytaspis (= Chalaraspis G. O. Sars, nec W.-Sulam). 
margin of the carapace projects but slightly, lenving the ocular segment exposed, and not forming anything that can be truly called a rostrum.

The eye with its peduncle attains a much greater degree of perfection than in E. australs. The peduncle is broadly expanded at the distal end so as to assume a triangular form, the distal extremity equalling in width the entire length of the peduncle. The upper side is flattened, and on the inner margin just back of the cornea, there is a slender ocular papilla. The eye itself is as broal as, or even a little broader than, the distal end of its peduncle, reniform, dark chestnut in color (in alcoliol), and perfectly faceted. The above description applies to the type specinen, a female. In the only male obtained, the eyes are not so well preserved, but the peduncle appears to be broader near the proximal end than it is in the female. In immature individuals, like the one represented on Plate K, Fig. 2, the pigment of the eye is of a very light color - yellowish, according to the sketch from life made by Mr. Westergren. In E. austrulis the eye-stalks are cylindrical, the cornea narrower than the stalk and the pigment and facets of the eye are very imperfectly developed.

In the form of the telson, E. sculpticauda exhibits one of its most marked peculiarities. The proximal part of this segment is deeply furrowed for a little less than one half its length, the furrow being bounded on each side by an elevated, rounded ridge. A low median keel, beginning in the anterior furrow, runs backward to the posterior end of the telson. A constriction a little way in front of the tip divides off a terminal plate which is broadly rounded at the end, its lateral margins being concave. The whole dorsal face of the telson from the posterior end of the anterior ridges to the terminal plate is beautifully ornamented with a net-work of ridges enclosing honeycomb-like cells. The distal half of the segment is armed with marginal spines, which are obsolete on the rounded posterior extremity. In $E$. australis the telson has an entirely different shape, the distal half tapering off regularly to the tip, which is armed with two long setre; the dorsal surface does not display the honeycomb structure which is so conspicuous in E. sculpticauda.

Length of female, $66 \mathrm{~mm}$.; carapace, measured from the lower angle of the orbit to the posterior end of the lateral wings, $23 \mathrm{~mm}$.

Station 2619 Hyd. 1000 fathoms ('Tanner net). 1 (fem. juv. ?).

$\begin{array}{lrrrr}\text { " } & 3407 & 885 & \text { " } & 1 \text { fem. } \\ & 3413 & 1360 & \text { " } & 1 \text { male. }\end{array}$


The specimen from Station 2619 (Plate K, Fig. 2) is apparently a young female. It was caught in the Tanner net which had been towed at a depth of 1000 fathoms (100 to 400 fathoms above the bottom), and drawn up closed.

\section{FAMILY MYSIDA.}

\section{PETALOPHTHALIMUS W.-SUHA.}

Zeitschr. wissensch. Zool., Vol. XXIV., p. xiv, 1874; Trans, Linn. Soc. London, 2d Ser., Zoöl., I. 43, 1875. (In part: so far as relates to the male.)

In the above-cited papers Willemoes-Suhm described as male and female of the same species Petalophthatmus armiger, two interesting Atlantic Schizopods from the "Challenger" Expedition characterized by the atrophy of the eye and the conversion of the eye-stalk into a leaf-like plate. 'The male differed in a singular manner from the female in the form of the carapace, antennæ, mandibles, maxillipeds, gnathopods, telson, etc. In the former the carapace was short, leaving the two posterior thoracic segments exposed; the second pair of antenux lacked the flagellum; the mandibular palps were enormously developed, forming a pair of very powerful prehensile limbs reaching far beyond the peduncle of the first pair of antennæ; the maxillipeds and the gnathopods were devoid of exopods; the telson was truncate and entire at the distal end. In the female, on the other hand, the carapace covered the posterior part of the thorax, the telson was deeply incised, and the appendages presented the normal form. There were seven pairs of incubatory lamellæ under the thorax, as in Boreomysis G. O. Sars, to which genus the specimen conformed in most regards. When the "Challenger" Schizopods were afterwards placed in Professor Sars's hands, the female of "Petalophthatmus armiger" had been lost, so that no further account of the specimen was published. The male was redescribed and figured by Sars with great care.*

In the "Albatross" collection of 1891 , I find one male specimen agreeing in all the essential structural features with the male of Pctulophthalmus armiger Suhm, but differing in some trivial characters of merely specific value. This specimen is figured on Plate LIV., under the name of Petalophthatmus pacificus. What is of more interest, I have discovered arnong the material dredged during the cruise of the "Blake" in 1877-78, a female Schizopod, $33 \mathrm{~mm}$. long (Station 29, lat. $24^{\circ} 36^{\prime} \mathrm{N}$, long. $84^{\circ} 5^{\prime} \mathrm{W} ., 955$ fathoms) that closely

* Rep. Challenger Schizopoda, pp. 174-177, Plate XXXII. Fig. 1-9. 
agrees with the male of $P$.amiger, barring the usual sexual peculiarities of an incubatory pouch and simple caudal limbs. The mandibular palpus and carapace have the same form and proportions as in the male. The telson, moreover, is truncate and entire, and the maxillipeds and gnathopods are devoid of exopods - features that Willemoes-Suhm thought were characteristic of the male. The brood-pouch of the "Blake" specimen consists of six pairs of incubatory lamellw and the rudiments of a seventh pair between the bases of the first pair of legs or gnathopods. From the posterior side of the base of the lamella of the posterior pair there springs a curled and ciliated lobe. This specimen, which is represented on Plate LIII., is probably the female of Petalophthalmus armiger, or at any rate of a closely related species.* The specimen that Suhm took for the female of $P$. armiger is clearly a Borcomysis, probably $B$. scyphops G. O. Sars, as Hansen $\dagger$ maintains.

Sulum and Sars both represent the carapace of the male $P$. armiger without lateral wings, the postero-lateral angles being obliquely truncated. But Sars explains this feature in his text (p. 175) as due to a folding of the carapace. In the female specimen from the "Blake" dredgings the carapace is produced posteriorly so as to form short, rounded lateral wings, just as in $P$. pacificus.

Accorling to Sars, the flagellum of the second antennx is imperfectly developed in the type specimen of $P$. armiger, consisting merely of a biarticulate peduncle, the terminal portion being absent. This defect is without doubt due to mutilation of the type specimen, for in the "Blake" specimen of $P$.armiger (female), and also in the specimen of $P$. pacificus (male) secured during the cruise of the "Albatross," the terminal portion of the flagellum is present as a slender lash about equal in length to the terminal segment of the peduncle, and composed of about six segments. f

The epipods of the maxillipeds, which Sars did not detect in the type of $P$. amiger, are plainly visible in the two specimens of $P$.amiger and $P \cdot p a-$ cificus now before me. They consist of delicate long appendages attached to the basal segment of the maxillipeds, and tucked away under the sides of the carapace.

In the light afforded by the "Blake" specimen of $P$. armiger, it be-

" The telson of the "Blake" female (Plate LIII. Fig. 2n) differs somewhat from the telson of the male $P$. armiger, inasmuch as it narrows posteriorly and is furnished with but seven setæo on the posterior margin. One of these setx (the shortest) is in the median line, the others form three pairs, the external ones twice the length of the next pair inside.

† Vidensk. Meddelelser fra den nafurhist. Forening i Kjöbenlavn for Aaret 1887, p. 212, 1888.

+ P'late LIII. Fig. $2^{b}$, Plate LIV. Fig. $1^{e}$. 
comes necessary to modify Sars's diagnosis of the genus Petalophthalmus * as follows:-

Sexes similar. Carapace short, leaving the last two thoracic segments exposed. Eye-stalks leaf-like, without any visual elements or pigment. Antennular peduncle greatly elongated in both sexes, and without the usual hirsute lobe in the male. Antennal flagellum small, antennal scale lanceolate or narrowly oval, setose on both margins. Mandibular palps prodigiously developed in both sexes, forming powerful prehensile organs. Maxillipeds devoid of exopods, but furnished with well developed epipods; meral segment expanded interiorly so as to form a large linguiform lobe. Gnathopods (or first pair of legs) short, strong, subcheliform, devoid of exopods; meral segment expanded on the inner side to form a very large, porrect lobe. Terminal segment of fourth pair of legs (counting the gnathopods as the first) obtuse and densely hirsute. Caudal limbs scarcely natatory even in the male. Marsupial pouch of female composed of seven pairs of incubatory lamellw, the anterior pair rudimentary. Apex of telson entire, not incised in the middle. Outer plates of the uropods distinctly jointed near the apex.

In the "Challenger" specimen of $P$. armiger, the second and third pairs of legs were imperfect, lacking all the joints of the endopods beyond the point of articulation with the exopods. It is remarkable that these same joints are lost from the same appendages both in the "Albatross" specimen of $P$. pacificus and in the $P$.armiger obtained during the cruise of the "Blake."

\section{Petalophthalmus pacificus FAX.}

\section{Plate LIV.}

Bull. Mus. Comp. Zoöl., XXIV. 218, 1893.

Similar to $P$. armiger W.-Suhm, but different in some particulars. The rostrum is more prominent, and there is a median tooth on the carapace behind the rostrum. The caudal limbs of the male are quite different from those of $P$. armiger as described and figured by G. O. Sars. In the latter each pair of caudal limbs bears a slender cylindrical external branch, whilst in $P$. pacificus the first pair is wholly destitute of an external branch, and the second pair (Plate LIV., Fig. $1^{g}$ ) discloses but the slightest rudiment of such a branch in the shape of a minute bud barely discernible with the aid of 
a strong lens; on the following pairs of limbs this little vestige of the outer branch becomes somewhat larger (see Plate LIV., Fig. $1^{h}$ ), but still remains a mere rudiment of the part as developed in $P$. armiger.

Length, $31 \mathrm{~mm}$.

Station 2637 Hydr. 700 fathoms (tow-net). 1 male.

The sounding at Station 2637 is 773 fathoms. The Tanner net was towed at 700 fathoms for twenty minutes, but it came up open all the way to the surface.

\section{SCOLOPHTHALMUS FAX.}

Bull. Mus. Comp. Zoöl., XXIV. 219, 1893.

Integument membranaceous. Carapace small, leaving the last two thoracic segments exposed; produced in front to a spiniform rostrum, and armed with a pair of antennal, and a pair of branchiostegal spines; cervical sulcus distinct, with a linguiform dorsal area behind it. Abdomen slender, subcylindrical, sixth segment the longest. Telson broad, apex truncate, not incised. Eye-stalks transformed to sharp spines, visual elements absent. Peduncle of first pair of antennæ robust, long, much exceeding the peduncle of the second pair of antemux, and reaching nearly as far forward as the tip of the scale of the second antennx; the three segments subequal. Peduncle of the second pair of antennæ rather short and slender; scale much longer than the peduncle, narrow, tapering at the distal end, proximal fourth of outer border smooth, naked, terminating in an angle which bears a strong spine-like seta; the rest of the outer border of the scale is fringed with hairlike setæ like the inner border. Mandibular palp stout, long, reaching beyond the middle of the peduncle of the first pair of antenna; first segment short, second segment very long, third segment narrowly oblong, one half as long as the second segment. Second maxillie with inner basal part expanded, three lobed, terminal segment expanded at the distal end, triangular; scaphognath rather small. Maxillipeds short, broad, third segment very short, fourth, fifth, and sixth segments about equal in length, seventh segment small and armed at the tip with one or two strong stiff setæ; the inner borders of the three antecedent segments also bear a few setæ; the sixth (penultimate) segment is broad and triangular; there is no porrect internal lobe to the maxilliped, such as found in some of the allied genera; neither is there any exopod, but the basal segment bears a long, well developed epipod. The first pair of legs (gnathopods) are of moderate length; 
the basal segment bears a small vesicular incubatory lamella, the second segment a well developed exopod; the body of the fourth segment is very short, but is expanded internally into a large and broad porrect lobe or plate, which reaches forward nearly to the end of the long fifth segment; the inner margin of this lobe is fringed with setæ; terminal segment small, its margin setiferous, and tipped with a strong spiniform seta. The following pairs of legs are long and slender, the antepenultimate reaching forward beyond the base of the antennal scale; the third and fourth pairs are imperfect in both of the specimens obtained, only the bases together with the exopods remaining; the distal segment of the second pair is short, unguiform, and partially concealed by long setre, which arise from the distal end of the antecedent segment; the distal segment of the fifth, sixth, and seventh pairs is lanceolate, and drawn out to an exceedingly long and acute point; the proximal end of the propodites of these three pairs of appendages is divided into three short segments. The first to the fifth abdominal appendages bear each a pair of simple appendages which increase in size successively from the first to the fifth; the inner branch of the posterior pair of abdominal appendages (uropods) is long, lanceolate, surpassing the telson and the outer branch, the latter of which is rounded at the distal end, and divided by a transverse suture; the inner branch is setose on both margins, the outer branch is setose on the inner margin and also the distal part of the outer margin, beyond the transverse suture; there is a spine at the point where the transverse suture meets the external margin of the outer branch. Marsupial pouch of female composed of seven pairs of incubatory lamellæ.

The natural position of this genus appears to be next to Hansenomysis, ${ }^{*}$ a genus based on a single mutilated specimen of $H$. fyllo taken off the west coast of Greenland in 80 fathoms. As far as can be determined by comparison with Hansen's description and figures, Scolophthatmus differs from Hansenomysis in having a prominent rostrum, spiniform eye-stalks (?) and long robust antennular peduncles which surpass in length the antennal peduncles and equal the antennal scales; moreover, the proximal part of the outer margin of the antennal scale is smooth and naked in Scolophthalmus, and the outer plate of the uropods is fringed with setx on the inner margin only. The maxillipeds of Scolophthatmus, like those of Hansenomysis, are devoid of exopods and internal meral lobes. The gnathopods are similar to those of

* Arctomysis Hansen, Vidensk. Meddelelser fra Naturhist. Forening i Kjöbenharn for Aaret 1587, p. 210, Plate VII. Fig. 5-5!, 1888 (nom. preoc.); Hansenomysis Stebbing, Hist. Crust., p. 268, 1893. 
Hansenomysis and Ceratomysis, being furnished with exopods and internal meral lobes.

Petalophthalmus, Scolophthalmus, Hansenomysis, and Ceratomysis, form a natural group of genera characterized by the development of seven pairs of incubatory lamellæ in the female (the anterior pair sometimes rudimentary), the absence of an exopod from the maxillipeds, the outgrowth of a large, porrect lobe from the inner margin of the merus of the gnathopods, and the imperfect development of the carapace, which leaves the last two segments of the cephalo-thorax free. This group is connected with the more normal genera of Mysidce through the genus Boreomysis, in which the incubatory pouch is likewise composed of seven pairs of lamellæ, but the maxillipeds are furnished with an exopod, the gnathopods lack the internal meral lobe, and the carapace covers all the thoracic segments. The maxillipeds have an internal meral lobe in Petalophthatmus, Ceratomysis, and Boreomysis; the gnathopoda are furnished with an exopod in all the genera excepting Pelalophthalmus. Petalophthalmus differs from all the other genera here mentioned in the absence of an exopod from the gnathopods and in the enormous development of the mandibular palps. In the great size of the antennular peduncle as compared with the second antennx, Scolophthalmus exhibits special affinity with Petalophthalmus.

\section{Scolophthalmus lucifugus $\mathrm{F}_{A X}$. \\ Plate LV., Fig. 1-1e.}

Bull. Mus. Comp. Zoöl., XXIV. 219, 1893.

Rostrum long, acute; antero-lateral margins of carapace oblique, armed with two spines, one behind the external side of the antennule, the other at the antero-inferior angle; posterior lateral wings short and rounded. Abdominal segments smooth and subcylindrical, sixth segment nearly as long as the two antecedent segments combined.

Length, $42 \mathrm{~mm}$.

Station 3400. 1322 fathoms. 1 fem. 


\section{CERATOMYSIS FAX.}

Bull. Mus. Comp. Zoöl., XXIV. 220, 1893.

Integument soft and membranaceous. Cephalo-thorax robust. Carapace short (leaving the last two segments of the thorax exposed), spinose; frontal margin truncate, armed at the external angles with a pair of long horn-like spines; a conspicuous rounded notch near the anterior end of the lateral margins, serving as in excurrent orifice from the branchial chamber. Abdomen cylindrical, spinose, sixth segment not much longer than the fifth; telson very long and narrow, truncate at the distal end, setose on both margins. Eyes absent, their stalks assuming the form of slender styles whose tips are soft and delicate, perhaps serving as tactile organs. Peduncle of the first antennæe rather short, reaching only to the proximal end of the last segment of the peduncle of the second antennæ; flagella much longer than the peduncle, flattened and fringed with long setæ on their margins. Peduncle of second antennx long and slender, distal segment the longest; scale long and very narrow, ciliate on both the internal and external borders. Mandibular palps long, reaching some distance beyond the distal end of the peduncle of the first antennæ; second segment longest, third segment long oval, its margins ciliate. Iaxillipeds devoid of exopods, but furnished with an internal porrect lobe; the fifth and sixth segments are somewhat pyriform, with their inner margins protuberant and furnished with setæ; the seventh or terminal segment is small and is armed with two or three stout spine-like setæ. The first pair of legs or gnathopods, like the following pairs, is furnished with long exopods; the fourth segment, moreover, is produced on the inner side to form a very long porrect lamina; the distal segment of these appendages is oval, and ciliated on the margin. The following pairs of legs are long and slender, the propodites of the last three pairs indistinctly segmented; the dactyli of the second, third, and fourth pairs are short and unguiform, those of the fifth, sixth, and seventh pairs long and lanceolate. The first to the fifth abdominal segments bear each a pair of appendages which increase in size from before backward; these appendages are all simple save the left one of the fifth pair which carries (in the unique type specimen) a slender lateral branch (Plate LVI., Firg. $1^{e}$ ). Both branches of the uropods are linear, setose on both margins, subequal in length, shorter than the telson; the outer branch is not divided by a transverse suture. Seven pairs of incubatory lamella in the female. 


\section{Ceratomysis spinosa FAx.}

Plate LV., Fig. 2; Plate LVI.

Bull. Mus. Comp. Zoöl, XXIV. 220, 1893.

The cephalo-thorax is somewhat longer than the abdomen minus the telson; the two posterior thoracic segments are completely exposed behind the short carapace, which is one half as broad at the anterior end as it is long. The anterior margin of the carapace is straight; not rostrate, but produced at each lateral angle to a long horn directed obliquely forward; the cervical groove is pronounced, as is also the tongue-shaped dorsal area behind it; in front of the cervical groove are three long erect spines in the median line, the foremost of which is on the frontal margin; there is, besides, a spine on each side of the carapace in a transverse line with the middle one of the median three; behind the cervical groove there is one spine in the median line near the posterior margin of the carapace, two on each side of the tongue-shaped dorsal area, and a long row of six on each side, in line with the lateral spines of the gastric area; a rounded notch in the anterior part of the lateral border of the carapace, in which the epipod of the second maxilla plays, serves as an outlet for the respiratory currents; behind this, the lateral margin is somewhat concave and terminates posteriorly in a sharp tooth; the hind border of the carapace is sinuous, but not produced into pronounced lateral wings. The last two thoracic segments, - those that are not covered by the carapace, - are each armed with a median dorsal spine; their lateral borders are drawn out into a long spine; the ultimate segment has in addition a spine on each side between the median and marginal spines. The row of median dorsal spines is continued along the abdomen, there being one spine on each segment except the first, which bears two, - the posterior one deeply bifid; the hindmost of the median abdominal spines is situate on the base of the telson, and is smaller than those in front of it; there are, moreover, two lateral longitudinal rows of spines on each side of the abdomen, one on the lower lateral margin, and one between this and the median dorsal row. The sixth abdominal segment is but little longer than the fifth. The telson is very narrow and long, nearly equalling, indeed, the length of the remaining portion of the abdomen; it narrows a little toward the hinder end, which is truncate; the margins are setose and slightly scalloped toward the posterior end.

The cye-stalks assume the form of two slender styles, the free ends of 
which appear to be of a soft consistency, suggesting a tactile office; no visual elements are discernible. The first antenns consist of a short three-jointed stalk, which bears two flattened and ciliate flagella, the inner one a little longer than the outer; the whole antennule is as long as the carapace. The antennal scale is linear, ciliated on both margins; the flagellum surpasses the antennular flagella. The mandibular palpi overreach the antennular peduncles by the length of their terminal segment, which is long, oval, and somewhat expanded; the margins of the segments of the mandibular palpi are prettily fringed with delicate setæ. The second, third, and fourth pairs of legs are very slender, the hinder three pairs being more robust and very long; the antepenultmate pair are the longest of all, reaching forward nearly to the end of the antennal scale; the dactyli of the last three pairs are long and rather straight.

The marsupial ponch of the female is composed of seven pairs of lamella.

The abdominal limbs (in the female) are simple, except the left one of the fifth pair, which bears a slender lateral branch; the first pair is the smallest; the fourth and fifth pair are considerably elongated, the fifth to the greatest degree, reaching backward beyond the distal end of the basal segment of the uropods. The two branches of the uropods are linear, of nearly the same length, shorter than the telson; the outer branch is not divided by a transverse joint; it is ciliate on both sides, the outer margin being furnished, besides, with a few stouter setx.

Length, $36 \mathrm{~mm}$.; carapace, $9 \mathrm{~mm}$.

Color in life, milk-white.

Of this curious Schizopod a single specimen, a female, was taken at Station 3357 in 782 fathoms; bottom, green sand; temperature, $38^{\circ} \mathrm{F}$. 


\section{Suborder STOMATOPODA.}

Family SqUillid a.

SQUILLA FABR. (restr.).

Species Insectorum, I. 514, 1781.

Squilla biformis BIGELow.

Johns Hopkins University Circulars, Vol. X., No. 88, p. 94, 1891; Proc. U. S. Nat. Mus., XVII. 532, Plate XXI., 1895.

Station 3389. 210 fathoms. 11 males, 8 fem.

$\begin{array}{rrrrrrrr}\text { " } & 3391 . & 153 & \text { " } & 8 & \text { " } & 5 & \text { " } \\ \text { " } & 3396 . & 259 & \text { " } & 16 & \text { " } & 18 & \text { " } \\ & 3397 . & 85 & \text { " } & 1 \text { male. } & & \end{array}$

The above stations are in the Gulf of Panama.

This species was first discovered in the Gulf of California, off the harbor of La Paz, by the "Albatross" Expedition of 1889. It is the only species of Squilla secured during the cruise of 1891. 


\section{GENERAL CONSIDERATIONS ON THE DISTRIBUTION.}

The route of the "Albatross," as will be seen by reference to the accompanying chart, traverses about twenty-nine degrees of latitude, from $1^{\circ} \mathrm{S}$. (Galapagos Islands) to $28^{\circ} \mathrm{N}$. (Guaymas, in the Gulf of California). In a longitudinal direction the region explored extends from $78^{\circ} 34^{\prime} 20^{\prime \prime} \mathrm{W}$. (Gulf of Panama) to $110^{\circ} 53^{\prime} 4^{\prime \prime} \mathrm{W}$. (Gunymas). An account of the topography of the region is given by Mr. Agassiz in his general sketch of the expedition.* The bathymetrical range explored is very great, extending as it does from the surface and the shore line to 2232 fathoms.

In order to apprehend the faunal relations of the Crustacea of this region it will be convenient to consider separately the littoral and the deep-sea species. The littoral as distinguished from the deep-sea fauna may be taken to include the animals living between the shore and a depth of 100 to 150 fathoms. But it must be borne in mind that there is no definite line dividing the littoral from the deeper fauna. In a general sense the depth specified may be taken as that above which we find, but in a slight degree at most, those structural modifications which respond to the peculiar conditions obtaining at greater depths.

That the temperature of the sea is the chief factor governing the distribution of marine Crustacea has been recognized by all writers on the subject. In 1838 Milne Edwards $\dagger$ wrote: "l'étude de la distribution géographique des Crustacés fait apercevoir aussi une coincidence remarquable entre la température des diverses régions carcinologiques et l'existence ou la prédominance de certaines formes organiques. Ainsi, quoique les Crustacés des Antilles et des mers de l'Inde soient tous ou presque tous d'espèces différentes, ils ont entre eux une analogie si grande, que les deux faunes offrent le même aspect général et se distinguent facilement de celles appartenant aux régions froides de l'un et de l'nutre continent. . . Les régions tempérées ont aussi entre

* Bull. Mus. Comp. Zoöl., Vol. XXIII., No. 1, with maps, 1892.

+ Ann. Sci. Nat., Zool., 2e Sér., X. 156, 157. 
elles des points de ressemblance multipliés." In 1852 Dana* published a chart to illustrate the distribution of marine animals. On this chart the waters of the globe are divided into five great circumterrestrial zones, whose potent influence controls the distribution of marine life. The limits of these zones are determined by isocrymal lines, or lines of equal mean temperature of the surface water during the coldest month of the year. The Torrid or Equatorial Zone is bounded north and south by the isocryme of $68^{\circ} \mathrm{F}$., the limit of reef-building corals. The North and South Temperate Zones are included between the isocrymal lines of $68^{\circ}$ and $35^{\circ}$, the North and South Frigid or Polar Zones between the isocrymes of $35^{\circ}$ and $26^{\circ}$.

The relations existing between littoral Crustacea from similar latitudes around the whole circuit of the globe make it clear that the primary faunal divisions should be drawn with reference to the isocrymal lines. Yet Dana $†$ proceeds to base his fundamental faunal areas or "kingdoms" chiefly on north and south lines running across the isocrymes, in accordance with the general trend of the great continental shores. His Arctic and Antaretic kingdoms alone are determined by latitude. Miers, $\ddagger$ Henderson, $\S$ and other recent carcinologists have followed Dana's method.

But other zoölogists who have treated of the distribution of the littoral marine fauna have based their primary divisions on the isothermal lines. Thus, according to the Danish conchologist Mörch, the marine fauna falls

* United States Exploring Expedition, Vol. XIII., Pt. II., p. 1451.

† Op. cit., pp. 1530, 1554, ete.

† Brachyura of the Challenger Expedition, p. xvii, 18S6. Dana's and Miers's primary faunal regions may be readily compared as follows:-

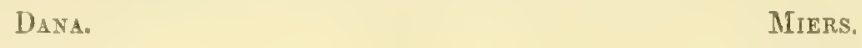

$\$$ Anomura of the Challenger Expedition, p. 197, 1888 .

II Malakozoolog. Blätter, VI. 104, 1860. 
into two great primary divisions, the Polar and the Tropical; the Polar being subdivided into North- and South-Polar and North- and South-Subpolar, the Tropical into Indo- and Atlantico-Tropical and North- and South-Subtropical. A similar mode of division is adopted by Ginther * and Gill $\dagger$ in treating of the distribution of shore fishes. Gill in particular protests against making the lay of the continents the prime factor in the distribution of littoral marine animals, re-affirming what had long before been pointed out by Milne Edwards and others: "The tropical faunas are much more closely related to one another than they are to the faunas along the same reach of shore toward the arctic or antarctic regions. This relationship is evinced more or less in every class and branch of animals. . . Consequently, the marine faunas cannot be at all correlated with the primary [terrestrial or inland] realms or regions of the globe." He then proceeds logically to divide the littoral marine fauna into five primary circumterrestrial realms whose boundaries are determined by the isocrymal lines. These realms are the Arctic, Pararctic or North Temperate, Tropical, Notalian or South Temperate, and Antarctic.

It is true, as Gill well says, that the relations between the littoral marine funæ in a longitudinal direction are traversed and complicated by relations existing in a latitudinal direction. This must necessarily result from the easy routes of migration afforded by the great coast lines and from the dispersal of the larve of tropical species northward and southward by the deflected equatorial currents. But, on the whole, the clange of temperature encountered in passing from low to high latitudes has proved a barrier to the sprend of tropical littoral types northward - a more effectual barrier, it would seem, than the immense distances between the tropical shores of the different continents have proved to be agrainst the intertropical dispersal of such types around the globe. Every summer myriads of delicate larva, belonging to tropical and subtropical genern, such as Ocypode and Calappa, are borne on the warm bosom of the Gulf Stream to the southern shores of New England, only to perish on the approach of the northern winter. Yet these same genera are represented by flourishing colonies established on tropical shores around the whole girdle of the globe. Geological evidence groes to show that the tropical Atlantic and Pacific were formerly connected over the region now occupied by the Isthmus of Panama, Central America, and parts

* Introduction to the Study of Fishes, p. 259, 1 sso.

+ The Nation, XXV. 43, 1877; Proc. Biolog. Soc. Washington, II. 32-36, 1855. 
of Mexico, and that this connection was not completely severed till late in the Tertiary period. It is obvious that the former uninterrupted sweep of the equatorial current from the Atlantic into the Pacific must have served as an important agent in disseminating tropical types around the earth.

Littoral species of the cold and temperate zones have this advantage over tropical types in the matter of distribution on north and south lines: the temperature of the sea rapidly falls in passing from the surface downward, so that even under the equator a temperate degree of heat is found at a moderate depth. Availing themselves of this, many littoral species of the North and South Temperate realms, by moving into the deeper and colder waters have extended their range toward the equator. For example, Cancer borealis, whose normal range as a strictly shore species is limited on the south by the New England coast, was found during one of the cruises of the "Blake" in 142 fathoms off the coast of South Carolina, living in a temperature of $56 \frac{1}{2} \mathrm{~F}$. under a surface temperature of $81^{\circ}$. Eluding in this way the fatal heat of the tropics, certain species of the temperate zone have actually passed under the equator and invaded the opposite hemisphere. Cancer longipes, a shore crab of Chile, was dredged by the "Albatross" in the Gulf of Panama at a depth of 210-286 fathoms, above the seventh parallel of north latitude. The bottom temperature here was $46^{\circ}$ to $49^{\circ} \mathrm{F}$., while the surface temperature was $72^{\circ}-74^{\circ}$. The extreme surface temperatures at Valparaiso are given as $52^{\circ}$ and $62^{\circ} .^{*}$ Platymera gaudichaudii is another crab long known to naturalists as a native of the shores near Valparaiso. This species also was found by the "Albatross" in the Gulf of Panama, living at a depth of 127 fathoms in a temperature of $56^{\circ}$ (surface temperature, $74^{\circ}$ ). The same species was secured during another cruise of the "Albatross" much further north, off the California coast from the latitude of San Diego to San Francisco. It is of interest to note that near the northern limit it was found even at as slight a depth as 26 fathoms, where it enjoyed the congenial temperature of $58^{\circ}$.

In this way, doubtless, it has come about that many littoral genera (e. g. Cancer and Lithodes) of the Arctic and North Temperate regions are represented on the shores of corresponding latitudes in the southern hemisphere, albeit they are unknown from the vast stretch of intervening coast.

This extension of the range of Aretic and Temperate littoral animals toward the equator in the cold off-shore waters finds a close parallel in the distribution of land animals. I refer to the well known influence which alti-

* The means of the coldest and warmest thirty consecutive days of the year. 
tude, with its accompanying low temperature, exerts in extending the southern limit of a northern fauna.

The western coast of Central America and Mexico from Panama to Guaymas - the region explored by the "Albatross" in 1891-forms a small part - the so-called Panama Province - of the great Tropical carcinological Realm. The immediate origin and special relations of this fauna remain to be considered.

As soon as the shore Crustacea of the Panama Province came to be known with any degree of fulness, chiefly through the publications of William Stimpson, it appeared that they belonged, with few exceptions, to genera living on the Atlantic side of the continent, in the Gulf of Mexico and the Caribbean Sea. It also appeared that although but few identical species inhabited the two coasts, ${ }^{*}$ yet a very large number of the Panamian species were represented by corresponding, closely related species in the Caribbean Sea. In many cases these "representative" species on the two sides of the continent are barely distinguishable, and, were it not for the continental barrier separating the seas inhabited by them, they would be deemed but varieties or geographical races of one species.

I have brought together in the following list some of the similar littoral species of the Panamian and Caribbean Provinces. Cosmopolitan species are of course omitted. $\dagger$

PaCific Coast.

Leptopodia debilis.

Podochela vestita.

Anasimus rostratus.

Collodes granosus.

"6 tenmirostris.

Batrachonotus nicholsi.

Euproguatha granulata.

Sphenocarcinus agassizi.

Epialtus sulcirostris.

Tyche lamellifrons.

\section{Atrantic Coast.}

Leptopodia sagittaria.

Podochela riisei.

Anasimus fugax.

Collodes trispinosus.

Batrachonotus fragosus. Euprognatha rastellifera. Sphenocarcinus corrosus. Epialtus aftinis. Tyche emarginata.

* The following Decapods, in addition to certain species of world-wide range, have been recorded from the Panamian and West Indian sides:

Microphrys aceddellii, Acanthomyx petiverii, Carcinus manas, Cronius ruber, Achelous spinimanus, Gelasimus maracoani, G. heterocheles, G. vocator, G. stenodactylus, Geograpsus lividus, Ocypode arenaria, Aratus pisoni, Goniopsis cruentata, Hippe emerita, Petrolisthes armatus, Alpheus minor, A. heterocheles. The species of Gelasimus and Alpheus are given on Kingsley's authority. Both of these genera need careful revision.

$t \mathbf{A}$ few species are included which are not very closely related, but which are the only species of the genus knovon, e. g.; the two species of Sphenocarcinus. Such cascs point in the same direction as the rest, $i . e_{0}$ to the West Indian origin of the Panamian littoral fauna. 
Pacific Coast.

Herbstia camptacantha.

Pelia pacifica.

Libinia macdonaldi.

Pericera fossata.

" triangulata.

Othonia sexdentata.

6. quinquedentata.

Thoe sulcata. ?

". erosia. $\zeta$

Mithrax armatus.

"s sinensis.

" tuberculatus.

Lambrus hassleri.

Solenolambrus arcuatus.

Mesorrhøa gilli.

Heterocrypta macrobrachia.

Actrea sulcata.

" dovii.

Glyptoxanthus labyrinthicus.

Iophactrea rotunclata.

Xantho stimpsoni.

Panopeus validus.

" latus.

Menippe obtusa. ?

"6 frontalis.

Leptodius occidentalis.

Ozius perlatus.

Heteractrea lunata.

Pilumnus xantusii.

$$
\text { " limosus. }
$$

Eriphia squamata.

Arenæus mexicanus.

Neptunus iridescens.

Achelous affinis.

Callinectes toxotes. "6 bellicosus.

Speocarcinus granulimanus.

Gelasimus gracilis.

Calappa conrexa.

Ethusa latr.

Uhlias ellipticus.

Ranilia angustata.

Raninops fornicata.

Cymopolia tuberculata.

$$
\text { " zonata. }
$$

\section{Atuantic Coast.}

Herbstia depressa.

Pelia mutica.

Libinia spinimana.

Pericera trispinosa.

"spinosissima.

Othonia lherminieri.

'Ihoe puella.

Mithrux spinosissimus.

" hispidus.

Lambrus pourtalesii.

Solenolambrus typicus.

Mesorrhoea sexspinosa.

\{ Heterocrypta granulata.

$\{$ " sp.non descr.

Actrea nodosa.

، setigera.

Glyptoxanthus erosus.

Lophactæa lobata.

Xantho denticulatus.

Panopeus herbstii.

" xanthiformis.

Menippe mercenaria.

Leptodius floridanus.

Ozius reticulatus.

Heteractra ceratopus.

Pilumnus aculeatus.

$$
\text { " gemmatus. }
$$

Eriphia gonagra.

Arenæus cribrarius.

Neptunus spinicarpus.

Achelous depressifrons.

Callinectes bocourti.

$\begin{cases}\text { " } & \text { ornatus. } \\ 6 & \text { tumidus. } \\ \text { danæ. }\end{cases}$

Speocarcinus carolinensis.

Gelasimus puguax.

Calappa galloides.

Ethusa microphthalma.

Uhlias limbatus.

Ranilia muricata.

\{ Raninops constricta.

$\left\{\begin{array}{l}\text { Raninops constricta. } \\ \text { " stimpsoni. }\end{array}\right.$

Cymopolia dilatata. dentata. 
Pacific Coast.

Hypoconcha panamensis.

Lepidopa myops.

Clibanarius panamensis.

Paguristes degueti.

Paguristes fecundus.

Pylopagurus longimanus.

$$
\text { " } \quad \text { aftinis. }
$$

Spiropagurus occidentalis.

P'etrolisthes occidentalis.

Sicyonia affinis.

Lysiosquilla desaussurei.

Squilla panamensis. ?

"biformis.
Atravtic Const.

$\left\{\begin{array}{c}\text { Hypoconcha sabulosa. } \\ 6 \text { areuata. }\end{array}\right.$

Lepidopa scutellata.

Clibanarius vittatus.

$\{$ Paguristes depressus.

$\{$ sericens.

Paguristes lymani.

Pylopagurus ungulatus.

" rosaceus.

Spiropagurus iris.

Petrolisthes sexspinosus.

Sicyonia edwardsii.

Lysiosquilla scabricauda.

Squilla intermedia.

But few characteristically Indo-Pacific genera are found in the Panaminn Province. An Ethra from the western const of Mexico has been describer by S. I. Sinith as a new species by the name of $\mathbb{E}$. scutata, but A. Milne Edwards regards it as a mere variety of the Indo-Pacific E. scruposa. Daira americand Stimps., a species closely related to the Indo-Pacific D. perlata (Herbst), inhabits the western coast of Central America and Mexico. Four species of Trapezia and one species of Quadrella have also been found on the same coast.* Of the two known species of Choritibinia, one comes from Northern Australia and New Guinea, the other from the Gulf of California. One species of Carpilodes ( $C$. cinctimanus), a genus rather characteristic of the Indo-Pacific region, is recorded from Cape St. Lucas. $†$ Still, the number of peculiarly Indo-Pacific genera is so small as barely to give a perceptible tinge to the Panamian fauna. The great sea-distances separating the tropical IndoPacific Province from the Panamian, together with the adverse equatorial current which sets against the richer fauna of the East, have allowed a marked differentiation to come about between these two provinces of the great 'Tropical Realm. On the other hand, the small number of genera peculiar to the Panama fauna, and the large number, not only of West In-

* Trapezia rufopunctata (Herbst), an Indo-Pacific species, recorded from the island of Socorro; T. cymodoce (Herbst), also an Indo-Pacific species, from Panama and Acapulco; $T$. formosa Smith, from Panama; T. nigrofusea Stimps., from Cape St. Lucas; Quadrella nitida Smith, from Panama. Two species of the eastern genus $M I y r a$, from the Gulf of California, have been recently described by Miss II. J. Rathbun (Proc. U. S. Nat. Mus., XVI. 255, 256, 1893). But this genus is hardly separable from the Americau genus Persephona.

+ Remipes testudinarius, although it belongs to a genus of circumterranean distribution, belongs in the category of species which liave reached the west shore of tropical America from the Iudo-Pacifie region. 
dian genera but also of species closely allied to those of the West Indies, point to a common origin of these two faunæ in the great Caribbæo-Mexican Gulf which formerly opened freely into the Pacific over the region now occupied by Central America and Mexico.* This communication between the Caribbean Sea and the Pacific was not barred at the Isthmus of Darien apparently before the Miocene.†

The relationship between the littoral faunæ of the Atlantic and Pacific consts of tropical America has often been pointed out by writers on the different classes of marine animals. Even before geological evidence was available a former water-way across the Isthmus of Darien was invoked to explain the existence of identical or analogous species on the opposite shores.

In 1856 Philip P. Carpenter $\ddagger$ made a comparison between the littoral Mollusca of the Atlantic and Pacific shores of tropical America, and listed as common to both shores 35 identical species, and 34 species likely to prove identical ; together with 67 Pacific species represented in the West Indies by closely allied or analogous species. He also pointed out the general dissimilarity of the Panamian and Indo-Pacific Molluscan faunæ. On comparing the marine Mollusca of Panama with those of the West Indies, Mörch $\S$ concluded that the Panama Province, although geographically a part of the Pacific, yet faunally belonged to the tropical Atlantic, its affinities with the Indo-Pacific region being comparatively remote.

Later conchologists, by nicer discrimination, have very much reduced the number of identical species, but have not thereby effaced the relationship between the two faunæ. Even Fischer,\| who believes that the affinity between the faunæ of the opposite sides of the Isthmus is much more remote than has been maintained by many writers, admits the striking distinctness of the Panama fauna from the Indo-Pacific.

Of the 193 kinds of Central American shore Fishes known to Dr. Guinther** in 1869,59 (or $30 \frac{1}{2}$ p. c.) were found on both the east and west coasts. In a later work t† the same author asserts that the genera of Fishes are with

* See A. Agassiz, Mem. IIus. Comp. Zoöl., X., No. 1, p. 82, 1853; Bull. Mus. Comp. Zoöl., XIV. 112, 1988 .

† See W. M. Gabb, Proc. Amer. Philosoph. Soc., XII. 571, 572, 1872, and Dall and Harris, Bull. U. S. Geolog. Surv., No. St, p. 151, 1892.

† Rep. Brit. Assoc. Adv. Sci. for 1856, pp. 362 et seqq., 1857.

§ Beiträge zur Molluskenfauna Central-Amerika's, vou O. A. L. Mörch. Malakozoolog. Blätter, herausgeg. v. Menke u. Pfeiffer, VI. 107, 1860.

|| Manuel de Conchyliologie, p. 167, 1581.

** Trans. Zoölog. Soc. London, VI. 397, 1869.

It Introduction to the Study of Fishes, pp. 279, 250, 1850. 
scarcely any exception identical on the two sides of Central America, and that one half of the species are common to both coasts. D. S. Jordan* considers the assumption of complete identity to be erroneous in 30 ont of Giinther's 59 cases, so reducing the percentage to 15 . Of 407 species of Fishes known in 1885 to inhabit the Pacific coast between Cape St. Lucas and Panama, only 71 species or $17 \frac{1}{2}$ p. c. are considered by Jordan to be common to both the Atlantic and Pacific coasts. He therefore concludes that "the two fauna show no greater resemblances than the similarity of physical conditions on the two sides would lead us to expect" without resorting to the hypothesis of a recent communication between the two oceans. Many of the species found on both coasts according to Jordan often ascend rivers and may have been diffused by crossing from marsh to marsh during the rainy senson.

In determining the genetic relationship between two faunæ one must take into account not merely the species that are absolutely indistinguishable to the discriminating eye of a modern systematist but also the number of common genera and the number of closely allied or representative species. The observations of Jordan and other recent ichthyologists have very much increased the percentage of representative species from the two coasts of Central America, at the expense of the identical ones. For it may be assumed that the Caribbean and Panmian Fishes considered conspecific by Dr. Guinther are at any rate closely allied. This degree of divergence between the faunx of the two coasts is only what one might expect to find, if the passage through the Isthmus of Panama has been closed, as seems probable, since the early Miocene.

The belief that the resemblance between the Panamian and Caribbean faun is due to the intercommunication of the tropical Atlantic and Pacific within comparatively late geological times does not rest upon a hypothetical basis, if we can rely upon the observations of the late W. M. Gabb, who spent three years in the exploration of San Domingo. This geologist found in the San Domingo Miocene 217 extinct, and 97 still living species of Mollusca, the still surviving forms existing on both sides of Central America, which barrier is capped by Miocene rocks. Fifteen of the 97 surviving species are now restricted to the Panama Province, having disappeared from the Caribbean waters since the Miocene period.

* Proc. U. S. Nat. Mus., VIII. 394, 1885. Cf. also Evermann and Jenkins, Proc. U. S. Nat. Mus., XIV. 123 et seqg., 1891.

† See Proc. Amer. Philosoph. Soc, XII. 571, 1872. 
According to A. Agassiz * the littoral Echinoid fauna of the Panama district is a mixed one, including generic elements from the adjoining districts. But the strictly Panamian species are with few exceptions representatives of the West Indian types. In a later work $\dagger$ the same author says that the principal differences in the Echinoid funna on the two sides of the Isthmus are due to the immigration of true Atlantic types into the West Indian faunal region during the 'Tertiary and Post-Tertiary periods, after the Gulf of Mexico and the Caribbean Sea ceased to be in freer communication with the Pacific than with the Atlantic.

The total dissimilarity of the Coral fauna on the opposite sides of the Isthmus cannot be ignored. $\neq$ It may be explained in part by the extreme sensitiveness of the reef-building species, such as flourish in the Caribbean Sea, to physical conditions. Mr. Agassiz $\S$ tells us that there could be no more striking contrast in topography than that between the Caribbean and the sea on the western side of Central America, with its abrupt continental slope and silt-covered floor. To the enormous amount of silt that covers the ocean bottom, $\Lambda$ grassiz attributes the absence of reef-building corals on the west coast, while Dama and others have ascribed it to the cold currents from the north and south that wash these shores, lowering the surface temperature at the Galapagos in the montl of November, it is said, to $62^{\circ} \mathrm{F}$. The affinity between the Miocene West Indian Corals and the recent species of the Pacific, which has been pointed out by Duncan.|| shows that the present dissimilarity is a result of the exclusion of the Pacific from the Caribbean Sea.

Below the littoral zone there lies a belt, extending say from 150 to 500 fathoms, which forms a sort of debatable ground, invaded on the one hand by littoral types from above, and on the other by characteristic deep-sea forms from below. Mingled with these are certain genera whose evolution finds its fullest expression in this intermediate zone. In illustration: Cancer longipes and Pleuroncodes monodon are shallow-water species of the coast of Chile which by descending into the cold waters of the intermediate belt have been enabled to extend their range into the heart of the tropics. Paralomis is a genus of probable Patagonian origin which in a similar way has worked northward in the cold waters of this intermediate bathy-

* Jiem. MIus, Comp. Zoöl., III. 22], 1572. † Mem. Mus. Comp. Zoöl., X, No. I, p. 79, 1883.

‡ See Verrill, in Proc. Boston Soc. Nat. Hist., X. 323, 1866.

\$ Bull. Mus. Comp. Zoöl, XXIII. 9, 1892.

|| Quasterly Journ. Geolog. Soc. London, XIX. 406-453, 1863; XX. 20-14, 1864. 
metrical belt. Lithodes, a shailow-water form in the cold seas of both the Northern and Southern Hemisphere, is found in the tropics only at considerable depths. Munida, too, is a type of world-wide distribution in comparatively shallow waters of the North and South Temperate regions. But it reaches its maximum development in moderately deep water (100-300 fithoms) within the tropics, and one species (Munida stimpsoni) has been found in the West Indian region at so great a depth as 1105 fathoms.* Xanthodes, Ebatia, Solenocera, and Sicyonia, are littoral or sublittoral genera of cosmopolitan range in the warmer seas of the globe. Cymopolia is also a genus of extended geographical range, with a vertical distribution from the shore to 298 fathoms. Catapagurus has been hitherto known from the east const of North Anerica, 50-300 fathoms, and from the Arafura Sea and the Feejee Islands, 28 fathoms; the "Albatross" species has most affinity with that from the Arafura Sea. Aithusa and Pasiphaeia are cosmopolitan genera with a bathymetrical range extending from the littoral belt and the surface to 1000 fathoms. Anamathia, Uroptychus, Iconaxius, and Aristceus have their fullest development in the intermediate zone between 150 and 500 fathoms. They are all genera of world-wide range, unless it be Iconaxins, which has hitherto been found only on the east and west sides of the Pacific. The following genera represented in the material collected by the "Albatross" at a depth less than 500 fathoms may be considered as deep-water types which overlap the limit of the intermediate belt: Mrunidopsis, Polycheles, Glyphocrangon, Heterocarpus, Nematocarcinus, Acanthephyra, Benthesicymus, and Gnathophausia.

The following list indicates the genera found below the 500 fathom line; those whose range extended beyond 1000 fathoms are printed in italics:-

$\begin{array}{lll}\text { Trachycarcinus. } & \text { Eryonicus. } & \text { Peneus (1 species). } \\ \text { Ethusina. } & \text { Sclerocrangon. } & \text { Peneopsis. } \\ \text { Leptolithodes. } & \text { Pontophilus. } & \text { Haliporus. } \\ \text { Lithodes } & \text { Paracrangon. } & \text { Hemipeneus. } \\ \text { Parapagurus. } & \text { Glyphocrangon. } & \text { Benthesicymus. } \\ \text { Galaccuntha. } & \text { Heterocurpus. } & \text { Gennadas. } \\ \text { Munidopsis. } & \text { Pandalopsis. } & \text { Sergestes? } \\ \text { Axius (Iconaxius) } & \text { Nematocarcinus. } & \text { Gnathophausia. } \\ \text { Calastacis. } & \text { Acanthephyra. } & \text { Encopia. } \\ \text { Nephropsis. } & \text { Hymenodora. } & \text { Petalophthalmus. } \\ \text { Willemoesia. } & \text { Notostomus. } & \text { Seolophthalmus. } \\ \text { Polycheles. } & \text { Pasiphaeia? } & \text { Ceratomysis. }\end{array}$

* As a result, chiefly, of the dredging expeditions of the last twenty years, the number of known species of . Iunida has been raised from six to about forty-five. 
An analysis of this list discloses the enormous - often cosmopolitan distribution of deep-sea types and their lack of special affinity with the nearest littoral fauma. Only four new genera were found among the Stalkeyed Crustacea taken at a greater depth than 500 fathoms, viz. Trachycarcinus, Calastacus, Scolophthalmus, and Ceratomysis. Of these, Trachycarcinus (a Corystoid crab from 546-695 fathoms) is represented in deep water in the Caribbean Sea by an undescribed species which is probably congeneric, and by Trichopeltarion (151 fathoms). Both of these genera are closely related to, and perhaps derived from, IIypopeltarium, a shallow water form found on the shore of South America from La Plata around Patagonia to Chile. Calastacus is allied to Calocaris of the North Atlantic, 150-400 fathoms. Scolophthalmus, a deep-sea Schizopod, is probably a near relative of Hansenomysis from off the west coast of Greenland, and it is worthy of note that both Scolophthalmus and Ceratomysis confess by their structure their kinship with Boreomysis, a genus which reaches its highest development near the arctic and antaretic regions.

Iconaxius has been previously known from remote parts of the Pacific, near the Celebes and Kermadec Islands. The only other known species of Paracrangon inhabits Puget Sound and the seas near Japan. Sclerocrangon is without doubt a genus of boreal origin. It is represented in high northern latitudes by circumpolar littoral species, and on both sides of the Atlantic by deep-water species that range as far south as $31^{\circ} 57^{\prime} \mathrm{N}$. (S. agassizii). One of the "Albatross" west coast species, S. procax, extends the range of this genus southward in deep water to within $4^{\circ} 3^{\prime}$ of the equator (Station 3380 , 899 fithoms, bottom temperature $37^{\circ}$ F.). The genus Pandalopsis is represented in the "Albatross" collection by the same species that was discovered by the "Challenger" off Monte Video. Petalophthatmus was known, prior to the "Albatross" Expedition, only through the unique specimen obtained by the "Challenger" Expedition from a great depth in the tropical Atlantic. Like Scolophthatmus and Ceratomysis, it is related to Boreomysis. All the other grenera included in the above list may be said to have a world-wide distribution.

That the truly deep-sea Crustacean fauna of the Panama region has no special affinity with the littoral fauna of the same region may perhaps be more clearly shown by placing in two columns the distribution of the Panamian species found below 500 fathoms, or the habitat of representative species, when such are known. 


\section{PANAMIAN.}

Trachycarcinus corallinus (546-695 fms.). Athusina gracilipes ( $885-1823$ fws.).

" challengeri (2232 fms.).

"s smithiana (13t-899 fms.).

Leptolithodes asper (695 fms.). " longipes (770 fms.).

Lithodes diomeder? juv. (660-1010 fms.).

Parapagurus pilosimanus abyssorum (7701823 fms.).

Galacantha rostrata (1175-1360 fms.).

6 diomeder (770-1877 fms.). Munidopsis bairdii (1772 fms.).

" ciliata (695-1270 fms.). )

" vicina (1672-1793 fms.).

"s subsquamosa (1471-1672 fms.).

66 subsquamosa aculeata (1793 fms.).

Munidopsis villosa (511 fms.).

" aspera (134-782 fms.).

“ carinipes (695 fms.).

" latirostris $(153,1772$ fms.).

"6 hendersoniana (1020 fms.).

Axius (Iconaxius) acutifrons (465-555 fms.).

Nephropsis occidentalis (660-676 fms.).

Willemoesia inoruata (1322-1823 fms.).
Trachycarcinus sp. non descr. Antillean Sea. Philippines, Arafura Sea, Banda Sea (7001425 fms.).

Japau Seas (1875 fms.).

Athusina abyssicola. E. coast North America (1497-2221 fuss.).

L. multispinus. British Columbia, Japan (?-\$76 fms.).

L. diomedeæ. Off coast of Chile.

L. grimaldii. No. Atlantic (410-1458 fms.).

L. agassizii. Off coast of Carolina (465850 fms.).

Bay of Biscay, Bermudas, Sierra Leone, Tristan d'Acunha, Patagonia, Valparaiso, Banda Sea, Philippines, I'apua, Japan, Bay of Bengal, Arabian Sea (740-1997 fms.).

E. coast Europe, West Indies, Juan Fernandez, Banda, Bay of Bengal ( $G$. areolata) (1095-1591 fms.).

Galacantha spimosa. West Indies (333 fms.).

E. coast United States (1497-1742 fms.).

M. ciliata. Bay of Bengal, Arru Is., between Papua and Admiralty Is. $(800$ 1310 fms.).

(1T. nitida. Caribbean Sea (769 fms.).

Japan Seas, Bay of Bengal (var. pallida) (1803-1875 fms.).

Between Marion I. and the Crozets; W. Patagonia (1375-1450 fms.).

II. crassa. E. coast United States (17422620 fms.).

M. abbreviata. Caribbean Sea (502-734 fms.).

Near Patagonia (245 fms.).

M. longimana. West Indies (372-502 fms.).

M. brevimana. West Indies (200 fms.).

II. cylindrophthalma. Bay of Bengal (188220 fms.).

Between Papua and Admiralty Is. (1070 fms.).

MI. edwardsii. Bay of Bengal (1310 fms.).

Off Banda (360 fus.).

Closely allied species in E. and W. Atlantic, off Arru Is., Bay of Bengal, Arabian Sea (188-922 fms.).

(W. leptodactyla. N. and S. mid Atlantic; Mediterranean Sea; off S.W. South America (1300-2000 fms.).

IV. forceps. West Indies (1920 fms.). 
Panamian.

Polycheles nanus (899-1270 fms.).

" sculptus pacificus (511-1270 fms.). Eryonicus cæcus (400-1832 fms.).

" spinulosus ( $384 \mathrm{fms})$.

Sclerocrangon atrox (660-676 fms.).

" procax (660-905 fms.).

Pontophilus occidentalis (978-2232 fms.).

Glyphocrangon nobilis (770-1360 fms.).

Heterocarpus hostilis (695-1020 fms.). ) " affinis ( $660-680 \mathrm{fms}.) . \quad$

Pandalopsis ampla (660-676 fms.).

Nematocarcinus ensifer (660-1879 fms.).

Acanthephyra agassizii (1573-1832 fms.).

" approxima (381-1168 fms.).

" curtirostris ( $458-1772$ fms.).

" brevirostris (1740 fms.).

Hymenodora glacialis (905-1832 fms.).

Notostomus westergreni (1740 fms.).

Pasiphaeia americana (259-551 fus.).

“ princeps (1132 fms.).

“ acutifrons (384-551 fms.).

Haliporus nereus (695-1793 fms.).

Hemipeneus spinidorsalis (1201-1823 fms.).

" triton (1672-1823 fms.).

Benthesicymus altus (1360-2232 fms.).

Gennadas sp. (570-1740 fms.).

Sergestes inous ( $899 \mathrm{fms}$.).

" bisulcatus (242-1793 fms.). Gnathophausia zoea (381-551 fms.).
Atlantic coast United States (705-1917 fms.).

P. sculptus. W. Atlantic (464-1400 fms.).

(E. cæcus. Off Canary Is. (1620 fms.).

E. sp. Bay of Bengal (690-920 fms.).

S. ferox. Arctic Ocean and high North Atlantic from Nova Zembla to Baffin's Bay (shore to 459 fms.).

S. salebrosa. IKamtchatka (shallow water.).

S. agassizii. E. and W. Atlantic (263-959 fms.).

P. abyssi. E. coast North America; Bay of Bengal (1917-2021 fms.).

( Near Dominica, W. I. (1131 fms.).

$\{$ G. acuminata. Feejee Is. (1350 fms.).

H. alphonsi. Philippines; Japan; Bay of Bergal; Arabian Sea (345-740 fms.).

Off Monte Video (600 fms.).

East coast North America (588-2033 fms.).

A. agassizii. E. coast North America (1052949 fms.).

A. purpurea. E. Atlantic (1000 fms.).

A. sanguinea. Bay of Bengal; Arabian Sea (490-1748 fms.).

Patagonia (400 fms.).

Bay of Bengal ; Arabian Sea (840-1043 fms.). E. coast United States (1395-2949 fms.).

North Atlantic, S. to $37^{\circ} 12^{\prime} 20^{\prime \prime}$ (E. coast U. S.) (452-2919 fms.).

N. patentissimus. S. of Philippines (2150 fms.).

P. cristata. Feejee Is. (315 fms.).

E. coast United States (444-1342 fms.).

Patagonia; Japan (245-775 fms.).

H. lævis. S. W. of Sierra Leone; off Ma= nila (1050-2500 fms.).

So. Atlantic, near 'Tristan d'Acunha; Philippines (1900-2050 fms.).

H. carpenteri. Bay of Bengal; Arabian Sea (1091-1614 fms.).

Tristan d'Acunha; off Feejee Is.; off Kermadee Is. ; Japan; Philippines ; between Papua and Australia (345-1900 fms.).

G. parvus. Cosmopolitan (346-3050 fms.).

S. mollis. E. coast United States; Arabian Sea (373-2949 fms.).

Arabian Sea; Bay of Bengal (738-840 fms.).

Bay of Biscay; North and Tropical Atlantic; Pacific, north of Kermadec Is. $(600-1850$ fms.). 
Panamian.

Gnathophausia willemoesii (493-1270 fms.). " brevispinis (551-1471 fms.). Eucopia australis (551-1770 fms.).

Petalophthalmus pacificus (700 fms.).
G. willemoesii. S. of Amboina in Banda Sea (1425 fms.). G. sarsii. Bay of Bengal (102 fins.). Bay of Bengal (690-1748 fus.).

North aud Tropical Atlantic; Southern Ocean; Autarctic Ocean; Japan; Bay of Bengal; Gulf of Manaar (350-2500 fms.). P. armiger. Tropical mid Atlantic (2500 fus.).

A study of the deep-sea Crustacea thus leads to the conclusion that this fuuna is one of cosmopolitan range, indivisible into subordinate local provinces like those of the littoral and terrestrial fauma. This is what one would expect from the uniformity of conditions prevailing at great depths and from the enormous length of time that has elapsed since modern types of marine Invertebrata came into existence. We have seen not only that many of the denizens of the cold waters of the intermediate zone, even within the tropics, are emigrants from the shallow water of cold and cold-temperate latitudes, but also that very many of the peculiarly deep-sen types betray their kinship with boreal genera. This, in the absence of much light from paleontology in this particular group of animals, may afford us the clew to the origin of a large part of the abyssal Crustacean fama. Rarely, as in the case of the recent Eryontide, do we find a deep-sea type that vividly recalls an ancient form. In this case, so good an authority as Boas thinks that the modern deep-water Polycheles is identical with the Jurassic Eryon. It is of interest to note that in the same beds at Solenhofen - beds of undoubted shallow-water origin - we find with Eryon another singularly antiquated type in Limulus. But the surviving descendants of Limulus are pre-eminently littoral. It is manifestly illogical to assume, as some have done, that because a certain form is now restricted to deep water the rocks in which it occurs as a fossil were deposited at a similar depth. The surviving representatives of an ancient shallow-water type may be littoral, as in the case of Limulus, or they may be found only in deep water, like the recent Eryontida. Some unquestionably bottom-living species at the present lany have a vertical distribution of 2000 fathoms. For instance, Parapagums abyssomm ranges from 250 to 2221 fathoms, ${ }^{*}$ and Dall $\dagger$ states that certain species of Mollusca

* Not taking into account the "Claallenger" record of this species in 45 fathoms off Patagonia (Henderson, Rep. Challenger Anomura, p. \$9, 1SSS).

† Bull. Mus. Comp. Zoöl., XII. 166, 1586. 
on the coast of Florida extend from a few fathoms off shore to 2000 fathoms. Considerations like these will put one on his guard against such an assumption as that above alluded to. Pourtalès was surprised at the bulk and massive type of the West Indian 'Tertiary simple corals as compared with their modern representatives which he dredged in the Caribbean Sea. But this difference is explicable if we suppose that the ancient forms were littoral. Under the enormous pressure which exists in deep water, great size is possible only when accompanied by a soft and freely permeable texture. The calcareous shells and corals from deep water are generally small, or if large, extremely thin and fragile. The deep-sea Crustacea, as a rule, lack the rigid calcareous coat which protects their littoral relatives. Species living under a pressure of a ton or more to the square inch are often so limp and delicate that it is difficult to secure a perfect specimen. By casting away their armor, their battle with the abyss was won.

The small number of ancient types of Crustacea preserved in the great depths of the ocean is not a subject for wonder if we bear in mind the fact that most of the fosill Crustacea known to us are probably littoral, or from the present point of view, shallow-water forms. The changes in environment to be met and overcome by a highly specialized littoral species in adapting itself to life at great depths are presumably as great, and lead to as much structural modification as those encountered by the littoral descendants of ancient species through the vicissitudes of the shores. As a concrete example, I will instance the family Galateidx. This family has a very extensive vertical distribution, being represented at all depths from the littoral zone to below 2000 fathoms. But this grent distance is apportioned in a rough way among the different genera of the family. In the shallower waters from the shore to 25 fathoms the genus Galatea prevails, in the deeper, but not abyssal belt Munida comes to the front, while in the greater depths below 500 fathoms the family is represented chiefly by the blind grenera Galacantha and Mrmidopsis. Now MM. Milne Edwards and Bouvier* have shown, in their interesting memoir on this group, that as we pass from the shallow-water Galatea, through Munida, to the deep-sea genera Galacantha and Munidopsis, we depart further and further from the more primitive, generalized, or Macruran type.

In some instances the more primitive types of Crustacen flourish in the

* Considérntions Générales sur la Famille des Galathéidés. Par MM. A. Milne Edwards et F. L. Bouvier. Ann. Sci. Nat., Zool., 7eno Sér., XVI. 315-317, 1994. 
sublittoral or intermediate depths, while the most lighly specialized forms are more characteristic of the very shallow waters. Such is the case with the Pagurida.*

Doubtless in certain groups of lowly organized animals many species cast in the antique mould survive in the abyssal depths of the ocean. But in highly specialized groups, like the Stalk-eyed Crustacea, - beings endowed with visual and respiratory organs of a very perfect grade, - the peculiar conditions that surround the dwellers of the deep work great structural changes. Correlated with the retrogression of the visual organs, marked changes take place affecting the antennx and anterior parts of the body generally. The purity of the water in these still regions often leads to a more or less complete disappearance of the epipods or "gill-scrapers."

So it comes about that the Crustacea living at a great depth are apt to be rather specialized types, - further removed from the primitive ancestral stock than are the allied species of the shore. Taking the animal kingdom as a whole, it is probable that the archaic forms now extant in the shallow waters of the land or coast, or in the moderate depths below the strictly littoral zone, far outnumber those surviving in the extreme depths of the sea. Heterodonta, the Ganoid fishes, Limulus, Pollicipes, Irigonia, and Linguta are all peculiar to shoal water. So are the Unionida of the rivers and ponds. Nautilus and Pleurotomaria come from very moderate depths. The Brachiopods, distributed from the shore-line to 2945 fathoms, attain their maximum development in from 50 to 250 fathoms. The wonderful Crinoid fields, - those lily beds of the Caribbean Sea, - lie at a depth of but 50 to 200 fathoms beneath the surface.

Only in a very broad and general sense may the deep-sea Crustacen, taken as a whole, be called antique types, inasmuch as they are to a very great degree members of the Anomuran or Macruran series, - low in the scale of classification, and in so far more primitive forms. Only four species (representing two genera) of Brachyura were discovered by the "Albatross" below 500 fathoms, $f$ and these low in the Brachyuran scale. As bearing on the suggestion of the boreal origin of the deep-sea Crustacen, it may be observed that the Brachyura, that great group which scarcely tinges the

* Milne Edwards and Bouvier, in Ann. Sci. Nat., Zool., 7 me Sér., XIII. 195, 1892; Mem. Mus. Comp. Zoöl., Vol. XIV., No. 3, p. 9, 1893.

+ In the vast amount of material obtained by the "Challenger" during the circumnavigation of the globe only four species (belonging to three genera) of Brachyura came from below 500 fathoms. "I'wo of these are the same as two of the four species secured by the "Albatross" below the 500 fathom line. 
complexion of the deep-sea fauma, attain their maximum development within the tropics.

So few pelagic or surface species are included in this Report, that a discussion of the distribution of the pelagic fauna would be out of place here. The experiments in towing at various depths with the self-closing Tamner net proved beyond question that the pelagic fauna may sink during the heat of the day, or under other adverse conditions of the surface, to a depth of 100 to 250 fathoms.*

With regard to the vertical distribution of the species that come up in the dredge or trawl, it may be taken for granted that the ambulatory forms, whose structure fits them only for life on the ocean floor, really come from the bottom. But many natatory species are also captured when dredging at great depths. Such are the swimming prawns belonging to the family Hoplophorida, certain Pasiphaeida, Peneidx, and Sergestidx, and the deep-sea Schizopods. It is evident that these ma never have come from the bottom, but that they may have entered the open trawl on its way up to the surface. The absence or rarity of some of these forms in collections made at or near the surface, taken in connection with structure and color of the animals themselves, signifies that they normally dwell at a great depth. The experiments with the Tamner net towed at great depths, within 100 fathoms or so of the bottom, are of great interest in this connection. At Hydr. Station 2619, the net was towed for sixteen minutes at a depth of 1000 fathoms (100-482 fathoms above the bottom). A specimen of Eucopia and a violet colored Amphipod came up in the lower part of the net, which had been closed at 1000 fathoms. At Hydr. Station 2627 (1832 fathoms) the net was towed at 1740-1770 fathoms for twenty minutes, but nothing was captured in the closed part of the net. In the upper part of the net, which came up open all the way from 1740 fathoms to the surface, were four specimens of Eucopia. A similar trial at Station 3436 failed through the water shoaling and the net dragging the bottom. At Station 2637 (Gulf of California, 773 fathoms) the net was towed at 70 fathoms above the bottom, but in this case the net came up open to the surface, bringing with it two deep-sea Schizopods, - Eucopia and the eyeless Petalophthalmus. Again, at Station 2638, in the Gulf of California, the net was towed at a depth vary-

* See A. Agassiz in Bull. Mus. Comp. Zoöl., XXIII. 48-56, 1892, and Ortmann in Bull. Mus. Comp. Zoöl., XXV. 108-110, 1594. 
ing from 500 to 570 fathoms, where the soundings indicated a depth of 622 fathoms. A red, deep-sea Peneid, belonging to the genus Gennadas was found in the lower, closed part of the net.*

There can be no doubt that the deep-sea natatory Crustacea occasionally come to, or very near to, the surface. The first known specimen of Hymenodora glacialis, a species whose rudimentary eyes and whose structure point to the depths as its normal dwelling-place, was taken at the surface, off the east coast of Greenland. An immature specimen of Acanthephyra agassizii was caught at the surface, in a dip-net, during the cruise of the "Albatross" off the east coast of the United States in 1884. This specimen was kept alive for half an hour before it was put into alcohol. $\dagger$ A female of the nearly related, if not identical, species, $A$. purpurea, was captured during the "National" Expedition, swimming at a depth of less than 200 fathoms. Spence Bate records a specimen of Gennadas secured at the surface on the voyage of the "Challenger." Amalopeneus, a genus identical with, or at any rate most closely allied to, Gennadas, was found during the "National" Expedition at a depth of less than 200 fathoms. Yet the same thing was captured in the closing-net between 500 and 570 fathoms (bottom 622 fathoms) during the "Albatross" Expedition of 1891, and between 650 and 750 fathoms during the "National" Expedition. The genus Eucopia was first made known to science through a specimen recovered from the stomach of a penguin killed in the Antaretic Sea. This specimen was presumably captured by the bird in comparatively shallow water. According to Mr. Agassiz's notes made on board the "Albatross," the same Schizopod was captured in the open part of the Tanner tow-net between the surface and 300 fathoms at Station 3414 (2432 fathoms). Another individual, as we have seen above, was taken in the closed portion of the net at a depth of 1000 fathoms.

Spence Bate suggested that some of the free-swimming Crustacea of the deep sea may approach the surface to spawn, - a plausible theory if one bears in mind the sensitiveness of young animals to cold. As the bottom Crustacea of the deep sea may be supposed, from their structure and affinities, to have originated directly from littoral ancestors, so the deep-sea swimming forms have probably come from pelagic or surface species. It

* At Challenger Exped. Station 267 (2700 fathoms), in the mid North Pacific, a specimen of Gennadus was captured in the open tow-net which had only been lowered to within 700 fathoms of the bottom.

† See S. I. Smith, in Ann. Rep. U. S. Fish Comm. for 1885, p. 667, 1836. 
may well be that after these types had become acclimated to the depths, their young still found in the ancestral surface life the conditions most favorable for their development. The toad still goes to the water to spawn, the land-crab goes to the sea. The journey of a swimming prawn from a depth of 1000 fathoms or more to the surface to spawn does not impress one as more remarkable than the periodic passage of anadronous fishes from the sea to fresh waters in their solicitude for the welfare of their young. The advantage gained for the race, too, through the wide dispersal of pelagic larve by the ocean currents is obvious.

Most of the Stalk-eyed Crustacea, as is well known, protect their eggs for a longer or shorter period after they are laid, either carrying them under the tail, or, as in the Schizopoda, brooding them in a special pouch beneath the breast. In many of the deep-sea species the eggrs attain an enormons size before they hatch. From analogy with certain land and fresh-water species, we infer that in these cases the young quits the egg, or, which is the same thing, leaves the mother in an advanced stage of development, ready to lead a life similar to that of its parents. But it is a remarkable fact that none of the deep-sea swimming forms belonging to the family Peneida are ever found carrying their eggs. The natural inference from this is that the young must be quickly hatched, in a very immature state, best fitted for surface life, like the larvæ of the littoral species belonging to the same family. This certainly adds weight to Spence Bate's suggestion concerning the occasional occurrence of such forms at the surface. It is also worthy of note in this connection, that Acanthephyra agassizii, one of the Hoplophoridx that has been taken at the surface, has eggs of normal size. 


\section{COLORS OF THE DEEP-SEA CRUSTACEA.}

By Mr. Agassiz's direction, colored drawings of many of the Crustacea secured during the cruise were made by Mr. A. M. Westergren. Some of these are reproduced on Plates $\mathrm{A}$ to $\mathrm{K}$ of this memoir. The late Professor J. Wood-Mason and Dr. A. Alcock have also published a very full set of notes on the living colors of the Crustacea dredged in the Arabian Sea and the Bay of Bengal by the Indian Marine Survey Steamer "Investigator." So that we now have a knowledge of the color variations exhibited by most of the important types of the deep-sea representatives of this class. It appears from a systematic tabulation of these notes on the colors, that a general tendency is manifested among the Crustacea from deep water to assume red tints, which pass through various shades of pink, orange, and yellow, to strawcolor and ivory-white.

Of eight species of Brachyura, ranging from 90 to 405 fathoms, four are pink, one yellowish red, one pinkish yellow, one straw-color, and one white, with a pink blush.

Out of twenty-two species of Anomura, coming from depths varying from 52 to 1997 fathoms, the majority are some shade of red, pink, or orange, while four species of Munidopsis (all of them blind, and obtained at great depths, 1310 to 2300 fathoms) are white. It is to be observed that five other species of this genus from lesser depths (117-740 fathoms), although they also are blind like all the species of Munidopsis, are more or less deeply tinged with orange.

Among the deep-sea bottom species of Macrura, pink is again the prevailing color, - pink of various shades, from a deep purplish pink to milky white, with merely a pink suffusion. Twenty-eight out of thirty-seven species are of this hue, while five are red, one orange, one chalky yellow, and two old-ivory white. 
Squilla temuirostris, from 90 to 100 fathoms, which is a great depth for this shallow-water genus, is deep pink. The more strictly littoral Stomatopods, on the other hand, although more or less fossorial in their habits, often display conspicuous color patterns in various shades of blue, green, and brown.

The deep-sea free-swimming Crustacea consist of the Hoplophorida, certain genera of Peneida, a few species of Pasiphaeiida and Sergestidx, and the deep-sea Schizopods. Of these, the Hoplophoridx are without exception blood-red, bright crimson, or crimson lake. The Peneids are mostly red, in a few cases fading to orange or milk-white. Haliporus aqualis (405 fathoms) is pink, Haliporus neptumus (1644 fathoms), Aristaus coruscans (561 fathoms), Hemipeneus carpenteri (1091-1310 fathoms), and Hepomadus tener (1310 fathoms) are orange colored. Benthesicymus tanneri, a Peneid of a deep red ground color, is remarkable for having a large patch of bright blue on the back of the second, third, and fourth abdominal segments.* The deepsea Pasiphaeiidx and Sergestidx are lurid red or else deep crimson or lake. Among the Schizopods the various species of Gnathophausia are bright red or crimson. So are Eucopia and (according to Willemoes-Suhm) the eyeless Petalophthalmus. Ceratomysis spinosa, a blind Schizopod from 782 fathoms, is milk-white.

The differences in the coloration of littoral Crustacen that are exposed to different degrees of light are sometimes very striking, individuals of the same species often displaying various tints, according as they live in the open and near the surface, exposed to the full influence of the sun, or in deeper water, ensconced under stones or within crevices, and thus removed from the glare of day. The pallor of most fossorial species is very marked, recalling the ghastly appenrance of cave inhabitants.

In connection with the prevalence of red colors among the Crustacea from great depths, certain experiments upon shore species are very suggestive. S. Jourdain $\dagger$ has shown that Nika edulis, which is brown in a bright light, turns to red when kept in the dark. Hippolyte varians will change from a lively emerald green to brown, if placed in partial darkness, while in total darkness it assumes a red hue $\neq$ Such experiments as these go far toward explaining the prevalence of red color among the Crustacea of the deep sea. It is due to a modification of the pigments, induced by the dark-

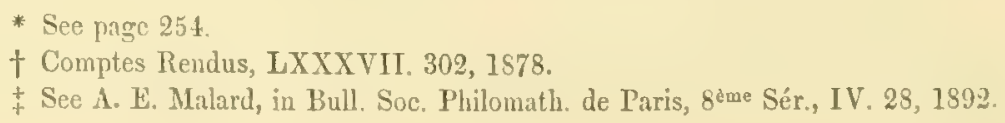


ness in which these creatures dwell, either through chemical action or more probably through a physiological process originating in the eye and affecting the pigment cells by a reflex action. In either case the prime cause is a purely physical one, - the more or less complete absence of light in the depths of the sea. This color, then, is to be regarded as entirely useless to its possessor.

The retention of pigment and functional eyes through a long succession of generations among the deep-sea Crustacea implies the existence of a certain amount of light at depths far beyond the point where it can be demonstrated by experiments with photographic plates.* Although many of these animals are blind and show a strong tendency to become colorless, yet many are endowed with very highly developed eyes and display pronounced colors, forming a strong contrast in both respects to the fauna of subterranean caverns. The free-swimming Crustacen from great depths are, as we have seen, commonly of a very bright red color and endowed with visual organs of a high order, while the bottom species, even those from much shallower depths, are most often pale of hue and frequently blind. This difference is to be explained through the different mode of life followed by the two classes. Powerful and active swimmers, such as the Notostomi and Gnathophausia, are fitted by their mode of life, to take advantage of what little light exists at those depths, whether it be some feeble rays which penetrate from above, or the pale phosphoric gleams evoked by their passage through the deep. The more sedentary, bottom species, on the other hand, would be prone to conceal themselves in the mud or whatever retreat the sea-floor might afford. Hence the aptness of these forms to lose both their pigments and their sense of sight.

Colors of the cyanic series, - blues and greens, - although not uncommon among surface and shore Crustacea, are almost never seen in the species from the deeper waters. It is remarkable, however, that the egrgs of many of the red deep-water Crustacea show during the period of incubation bright blue or sometimes green tints. Mr. Agassiz $†$ has noted this, and the late Professor J. Wood-Mason specified many such cases, in his account of the Crustacea dredged by the steamer "Investigator." It seems likely, therefore, that the blue pigments are not really lacking in the adult, but merely over.

* Cf. Fol and Sarasin, Comptes Rendus, XCIX. 793, C. 100, and Chun, Die pelagische Thierwelt, etc., p. 59 (Bibliotheca Zoologica, Erster Band, Heft 1, 1858).

† Bull. Mus. Comp. Zoül, XXIII. 82, 1892. 
whelmed to our eyes by the expansion of the red chromatoblasts under the influence of the darkness in which these animals live. According to Pouchet,* the pigments of the xanthic series (red, orange, and yellow) in Crustacea are contained in contractile anatomical elements, - the chromatoblasts, - while the blue pigment is never found in the substance of the chromatoblasts, but is held in free solution. Pouchet found that living prawns (Leander serrator) when placed in a vessel with a black bottom always assumed a brownish red color, but if they were transferred to a white-bottomed vessel they became yellowish, - the intrinsic color of their tissues. Extirpation of the eyes of the prawn had the same effect as a black bottom, specimens thus mutilated remaining permanently red. The change from yellow to red was accomplished much more quickly than the reverse change from red to yellow. In the latter case the change was effected in about twenty-four hours, during which the animal passed through a transitory bright blue stage, - a phase of color not exhibited during the passage from yellow to red.

"Le microscope explique cette triple apparence. Quand les chromoblastes sont contractés à l'état sphérique, ils sont trop petits pour faire une image perceptible sur la rétine, et sont de nul effet. Dès que l'animal est sur fond noir, les chromoblastes se dilatent; ils étendent de tous côtés des ramifications qui couvrent une grande surface; ils deviennent perceptibles et modifient l'image rétinienne. L'animal, sous cette influence, deviendrait d'un rouge ou d'un rose franc, si un autre pigment ne venait rabattre la vive teinte des chromoblastes. Mais, à mesure qu'ils étendent leurs ramifications sous l'hypoderme, on voit ce dernier tissu, à leur voisinage, prendre une belle nuance cobalt plus ou moins haute de ton. C'est ce bleu qui sert de bruniture au carmin des chromoblastes et donnent au Palémon sa couleur propre [rouge brunâtre] sur fond noir. Quand les chromoblastes dilatés se rétractent de noureau, ce bleu, qui s'est produit dans l'hypoderme et qui l'imprègne, persiste pendant six à sept heures et disparaît progressivement."

The prawn depicted on Plate $\mathrm{H}$ (Benthesicymus tamneri) was brought up from a depth of 860 fathoms and drawn as soon as it was taken from the trawl. The general color is a deep blood-red or crimson, passing into scarlet on the abdomen. The dorsal side of the first abdominal segment is adorned with a large squarish spot of a deeper red than the rest of the abdomen. This spot is repeated on the second, third, and fourth abdominal segments. On the third and fourth segments the spot is bright cobalt

* Journ. de l'Anat. et de la Pliysiol., VIII. 491, 1872. 
blue, ${ }^{*}$ but on the second segment it is parti-colored, - blue and light yellow. The two colors in the latter case are not disposed in accordance with the bilateral symmetry of the prawn, but the division between them forms a diagonal line across the middle of the segment, and results in a most abnormal color pattern.

The change of Pouchet's prawns, under the influence of light, from red, through blue, to light yellow, suggests the thought that the unique coloration of the deep-sea prawn figured on Plate $\mathrm{H}$ may be due to a change of color undergone by the animal as it was brought up into the full blaze of day. Such an interpretation is the more plausible, since the coloration shown in this specimen does not appear to be a specific character. Although upwards of 140 specimens of Benthesicymus tanneri had been collected through the whole course of the voyage, from a date as early as February 24, yet this peculiar pattern in blue and yellow was not observed until April 22, the last day of the cruise.

Viewed in this way, the blue is a transient tint assumed by the abdominal spots during their passage from a deep red, such as is still retained by the anterior one of the series, to the pale yellow which already pervades a considerable part of the second and begins to tinge the border of the third. This supposition, implying, as it does, the persistence of the cyanic pigments in the red, deep-sea Crustacea, accords well with the fact already noticed, that the eggs of these creatures are often brilliant blue.

* The blue color is much too light in the figure. 


\title{
LIST OF SPECIES ARRANGED ACCORDING TO GEOGRAPHICAL REGIONS.*
}

\author{
Gulf of Panama (Stations 3381-3397; 56-1832 fathoms).
}

Cancer longipes.

Xanthodes sulcatus.

Panopeus latus.

Achelous aftinis.

Platymera gaudichaudii.

Athusa ciliatifrons.

Paralomis diomeder.

Lithodes panamensis.

Pylopagurus affinis.

Parapagurus pilosimanus abyssorum.

Pleuroncodes monodon?

Munida obesa.

Munida propinqua.

Munida gracilipes.

Galacantha diomedex.

Munidopsis bairdii.

Munidopsis ciliata.

Munidopsis vicina.

Munidopsis subsquamosa aculeata.

Munidopsis agassizii.

Munidopsis villosa.

Mrunidopsis sericea.

Munidopsis crinita.

Munidopsis tanneri.

Munidopsis hamata.

Munidopsis latirostris.

Munidopsis hendersoniana.

Uroptychus nitidus occidentalis.

Willemoesia inornata.

Polycheles nanus.
Polycheles sculptus pacificus.

Eryonicus cæcus?

Pontophilus occidentalis.

Glyphocrangon alata.

Glyphocrangon nobilis?

Glyphocrangon sicaria.

Heterocarpus vicarius.

Heterocarpus hostilis.

Nematocarcinus ensifer.

Nematocarcinus agassizii.

Acanthephyra agassizii?

Acanthephyra approxima?

Acanthephyra cristata.

Acanthephyra curtirostris (incl. var. $\gamma$ ).

Acanthephyra cucullata.

Hymenodora glacialis.

Pasiphaeia americana.

Pasiphaeia magna.

Sicyonia picta.

Solenocera agassizii.

Peneopsis diomedeæ.

Haliporus nereus.

Hemipeneus triton.

Benthesicymus altus.

Benthesicymus tanneri.

Sergestes bisulcatus.

Gnathophausia willemoesii.

Eucopia sculpticauda.

Squilla biformis.

Off Mariato Point (Stations 3353-3359; 182-782 fathoms).

Maiopsis panamensis.

Xanthodes sulcatus.

'Trachycarcinus corallinus.

Ebalia sp.

Cymopolia tuberculata.

Glyptolithodes cristatipes.

Leptolithodes asper.

Catapagurus diomedeæ.

Munida obesa.
Galacantha diomedeæ.

Munidopsis ciliata.

Munidopsis aspera.

Munidopsis carinipes.

Munidopsis inermis.

Uroptychus pubescens.

Uroptychus bellus.

Axius acutifrons.

Axius crista-galli.

* Littoral and surface species are not included in this list. 
Polycheles tanneri.

Polycheles sculptus pacificus.

Panulirus sp.

Glyphocrangon spinulosa.

Heterocarpus hostilis.

Nematocarcinus agassizii.
Acanthephyra curtirostris.

Sicyonia picta.

Peneopsis diomedeæ.

Haliporus nereus.

Benthesicymus tanneri.

Ceratomysis spinosa.

Off Galera Point (Stations 3398, 3399; 1573 and 1740 fathoms).

Athusina gracilipes?

Willemoesia inornata.

Pontophilus occidentalis.

Nematocarcinus ensifer.

Acanthephyra agassizii?

Acanthephyra brevirostris.

Hymenodora glacialis.

Off Malpelo Island (Stations 3377-3380 ; 52-899 fathoms).

Achelous affinis.

Ethusina gracilipes?

Ethusina smithiana.

Cymopolia fragilis.

Spiropagurus occidentalis.

Paguristes fecundus.

Parapagurus pilosimanus abyssorum.

Munida refulgens.

Polycheles nanus.
Notostomus westergreni.

Haliporus nereus.

Hemipeneus spinidorsalis.

Benthesicymus altus.

Gennadas sp.

Eucopia australis.

Polycheles granulatus.

Eryonicus cæcus?

Sclerocrangon procax.

Heterocarpus hostilis.

Nemarocarcinus agassizii.

Sicyonia affinis.

Benthesicymus tanneri.

Sergestes inous.

Eucopia anstralis.

Between Mariato Point and Cocos Island (Stations 3360-3362; 1175-1672 fathoms).

Athusina gracilipes?

Parapagurus pilosimanus abyssorum.

Galacantha rostrata.

Munidopsis vicina.

Munidopsis subsquamosa.

Polycheles nanus.

Pontophilus occidentalis.

Off Cocos Island (Stations 3363-3372; 52-1067 fathoms).

Euprognatha granulata.

Sphenocarcinus agassizi.

Lambrus hassleri.

Pamopeus tanneri.

Achelous spinimanus.

Athusa lata.

Ethusina smithiana.

Cymopolia fragilis.

Raninops fornicata.

Leptolithodes longipes.

Lithodes diomedeæ?

Cancellus tanneri.

Eupagurus californiensis.

Pylopagurus longimanus.

Pylopagurus hirtimanus.

Spiropagurus occidentalis.
Acanthephyra cristata.

Acanthephyra curtirostris.

Hemipeneus triton.

Benthesicymus altus.

Benthesicymus tanneri.

Gnathophausia brevispinis.
Parapagurus pilosimanus abyssorum.

Munida refulgens.

Munida microphthalma?

Galacantha diomeder.

Munidopsis ciliata.

Munidopsis aspera.

Pontophilus occidentalis.

Glyphocrangon nobilis?

Heterocarpus hostilis.

Nematocarcinus ensifer.

Nematocarcinns agassizii.

Notostomus fragilis.

Sicyonia affinis.

Peneus balbor.

Haliporus nereus.

Benthesicymus tanneri. 
On course from Cocos Island to Malpelo Island (Stations 3373-3376; 1132-1877 fathoms).

Athusina gracilipes?

Parapagurus pilosimanus abyssorum.

Galacantha diomedeæ.

Willemoesia inornata.

Eryonicus cæcus?

Glyphocrangon nobilis?

Nematocarcinus ensifer.
Acanthephyra curtirostris.

Pasiphaeia princeps.

Hemipeneus spinidorsalis.

Hemipeneus triton.

Benthesicymus altus.

Benthesicymus tanneri.

Gnathophausia brevispinis.

Between Galera Point and Galapagos Islands (Station 3400 ; 1322 fathoms).

Ethusina gracilipes?

Parapagurus pilosimanus abyssorum.

Galacantha rostrata.

Willemoesia inornata.

Polycheles nanus.

Glyphocrangon nobilis?
Nematocarcinus ensifer.

Haliporus nereus.

Hemipeneus spinidorsalis.

Benthesicymus tanneri.

Gnathophausia brevispinis.

Scolophthalmus lucifugus.

Galapagos Islands (Stations 3401-3411; 53-885 and 1189 fathoms).

Anamathia occidentalis.

Panopeus tanneri.

Ethusina gracilipes?

Lithodes diomeder?

Parapagurus pilosimanus abyssorum.

Munida propinqua.

Galacantha diomeder.

Munidopsis margarita.

Munidopsis ornata.

Munidopsis aspera.

Polycheles tanneri.

Eryonicus spinulosus.

Glyphocrangon loricata.

Glyphocrangon nobilis?
Nematocarcinus ensifer.

Nematocarcinus agassizii.

Acanthephyra approxima?

Pasiphaeia américana.

Pasiphaeia acutifrons?

Haliporus nereus.

Aristæus occidentalis.

Benthesicymus tanneri.

Sergestes bisulcatus.

Gnathophausia zoea.

Gnathophausia brevispinis.

Eucopia australis.

Eucopia sculpticauda.

Between Galapagos Islands and Acxpulco (Stations 3413-3415; 1360-2232 fathoms).

Ethusina gracilipes?

Athusina challengeri?

Parapagurus pilosimanus abyssorum.

Galacantha rostrata.

Pontophilus occidentalis.

Glyphocrangon nobilis?

Nematocarcinus ensifer.
Acanthephyra curtirostris, var. $\beta$.

Haliporus nereus.

Haliporus doris.

Haliporus thetis.

Hemipeneus spinidorsalis.

Benthesicymus altus.

Eucopia sculpticauda.

\section{Off Acapulco (Stations 3416-3423; 94-772 fathoms).}

Trachycarcinus corallinus.

Lithodes diomedeæ?

Pleuroncodes monodon?

Galacantha diomedeæ parvispina.

Munidopsis hystrix.

Calastacus stilirostris.
Nephropsis occidentalis.

Polycheles sculptus pacificus.

Sclerocrangon atrox.

Sclerocrangon procax.

Glyphocrangon alata.

Glyphocrangon spinulosa. 
Glyphocrangon nobilis?

Heterocarpus affinis.

Pandalopsis ampla.

Nematocarciuus ensifer.
Nematocarcinus agassizii.

Acanthephyra curtirostris, var. $\beta$.

Benthesicymus tanneri.

Gnathophausia willemoesii.

\section{Near Las Tres Marias (Stations 3424-3428; 80-680 fathoms).}

Lambrus hassleri.

Osachila lata.

Lithodes sp.

Munida refulgens.

Galacantha diomedeæ parvispina.

Munidopsis hystrix.

Munidopsis scabra.

Munidopsis quadrata.

Munidopsis depressa.

Nephropsis occidentalis.
Polycheles sculptus pacificus.

Sclerocrangon atrox.

Paracrangon areolata.

Glyphocrangon spinulosa.

Heterocarpus affinis.

Pandalopsis ampla.

Nematocarcinus ensifer.

Benthesicymus tanneri.

Gnathophausia willemoesii.

Off Mazatlan (Stations 3429, 3430; 852 and 919 fathoms).

Parapagurus pilosimanus abyssorum.

Galacantha diomedex.
Nematocarcinus ensifer.

Acanthephyra curtirostris, var. $\gamma$.

Gulf of California (Stations 3431-3437 ; 628-1588 fathoms)

Parapagurus pilosimanus abyssorum. Galacantha diomedeæ parvispina.

Sclerocrangon procax.

Glyphocrangon spinulosa.

Glyphocrangon nobilis?

Nematocarcinus ensifel.

Acanthephyra curtirostris, $\operatorname{var}^{\text {tes }} \alpha, \beta, \gamma$.
Hymenodora glacialis.

Benthesicymus tanneri.

Gennadas sp.

Sergestes bisulcatus.

Eucopia australis.

Petalophthalmus pacificus. 
Nоте. - Strictly littoral and surface species are omitted. It should be observed that the free-swimming species, most of which occur merely indicate the soundiugs at the stations where these forms were captured. See page 248 .

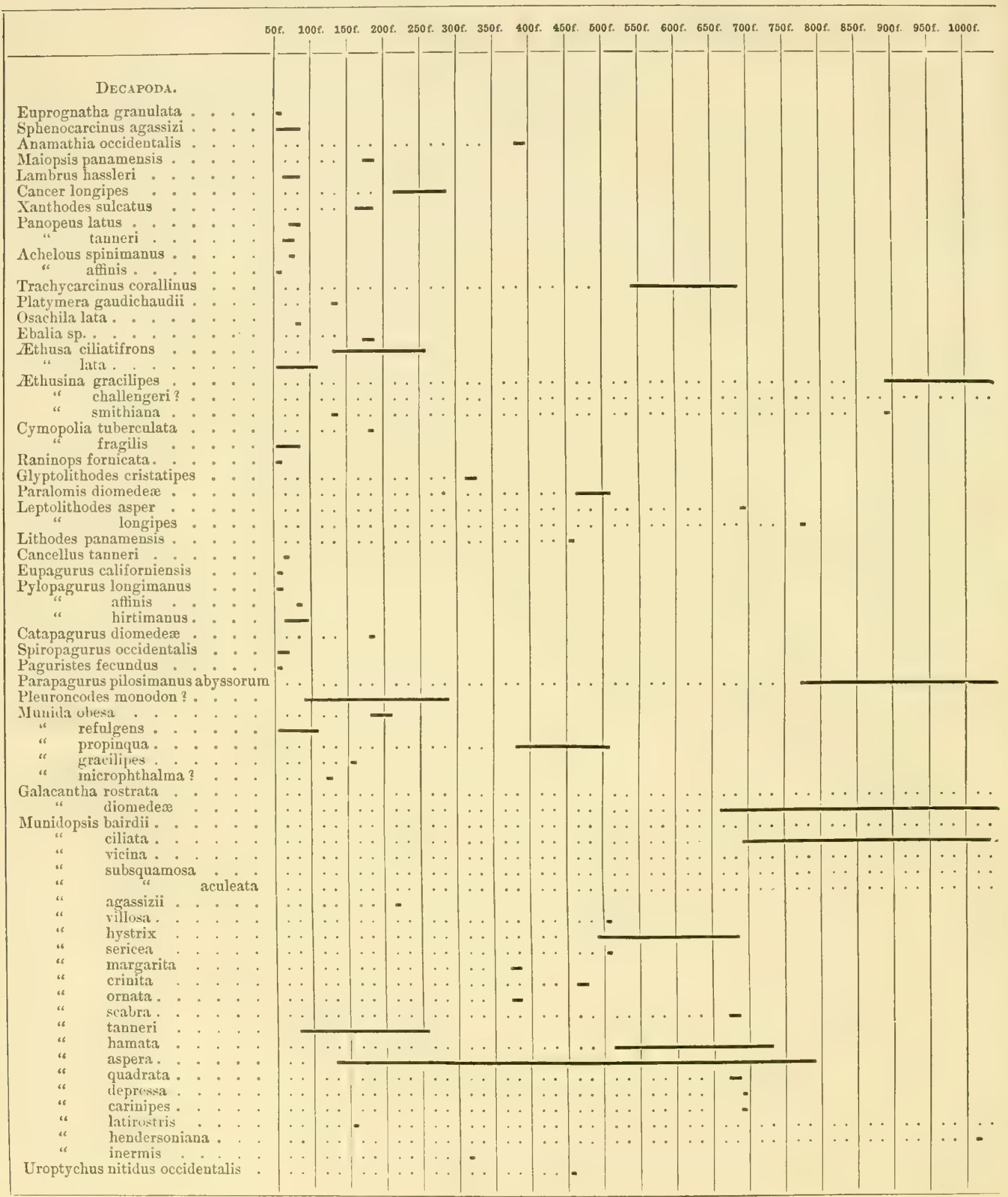




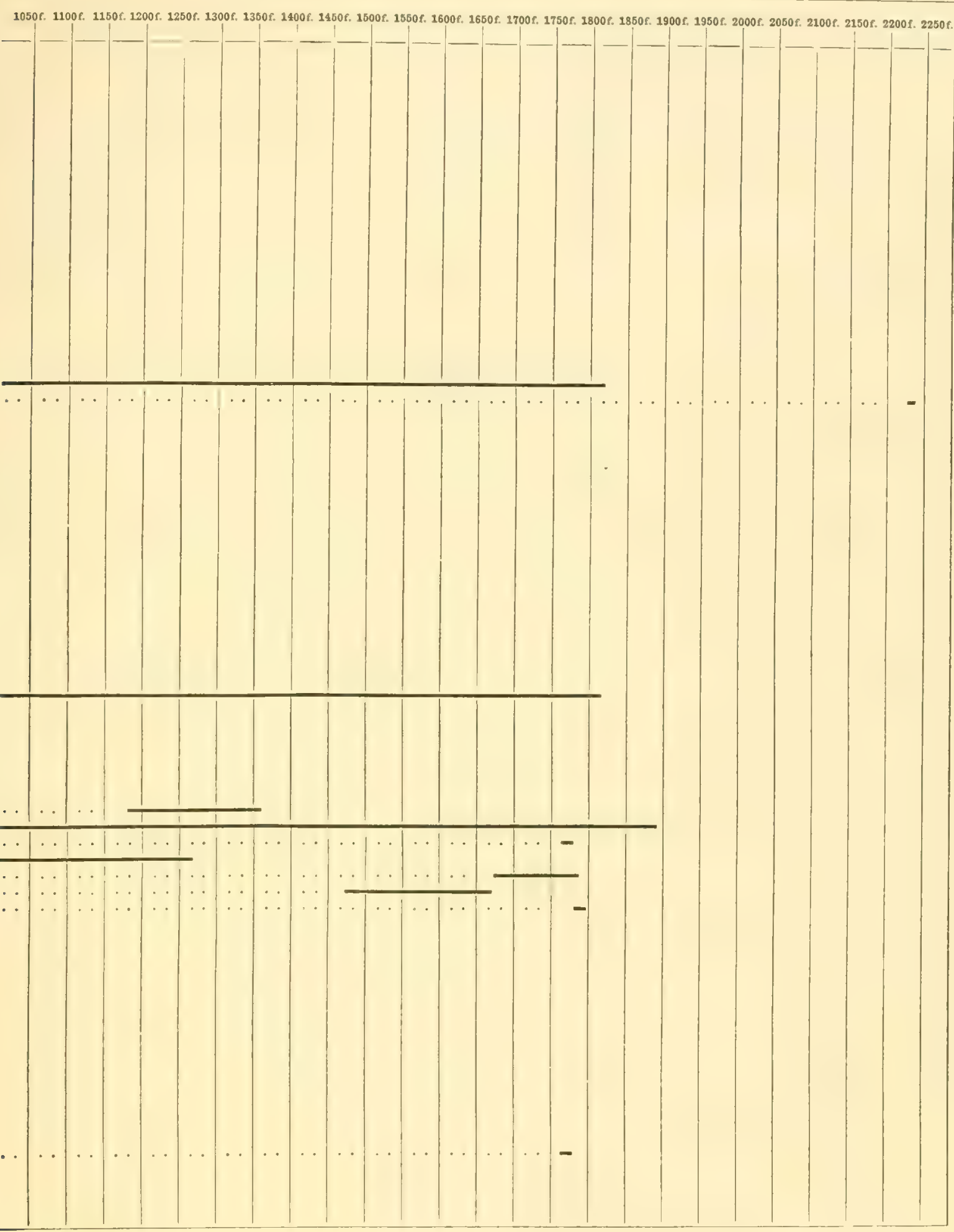




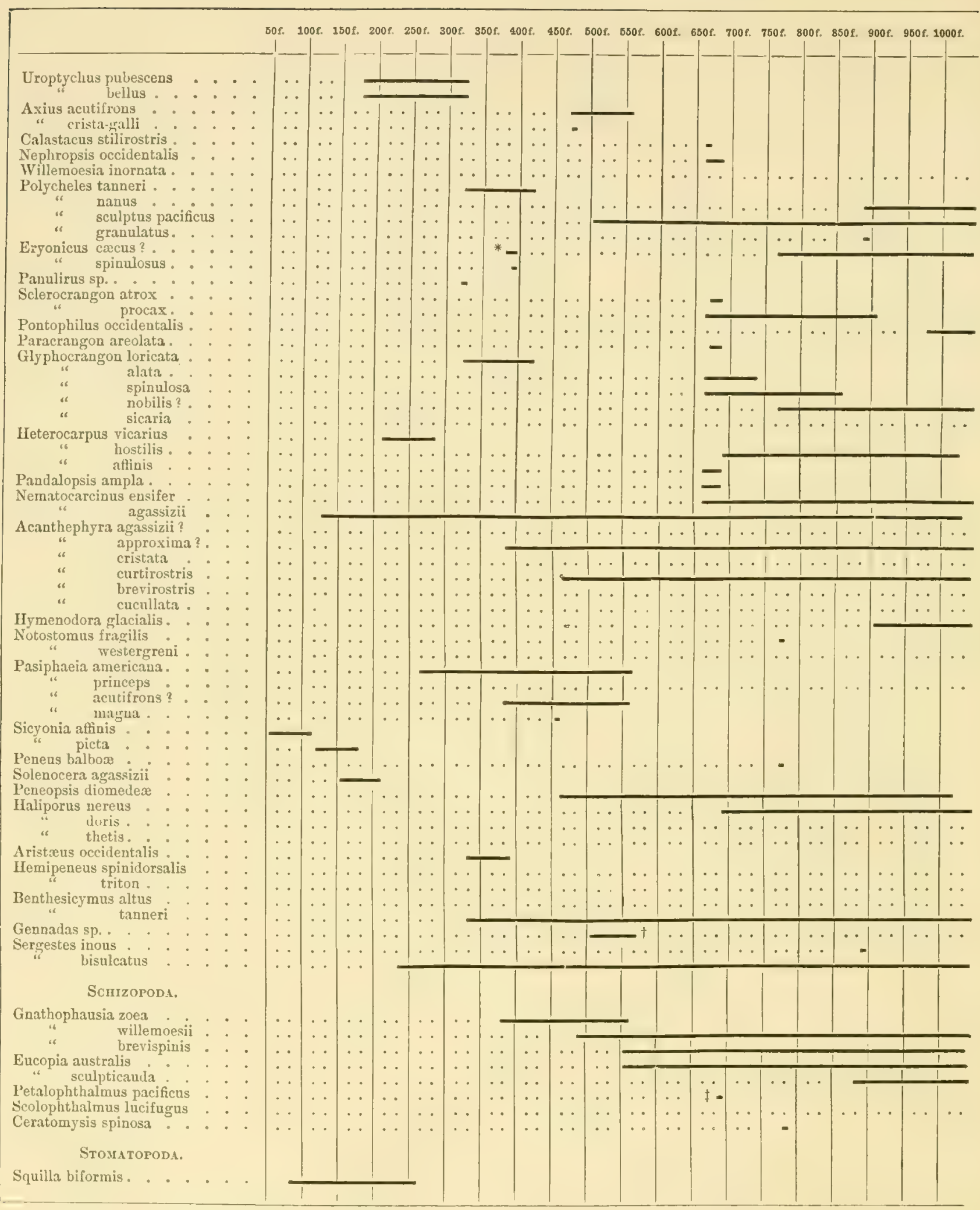

* Tanner tow-uet, 400 fathoms to surface. † Submarine tow-net, 500-570 fathoms. $\quad$ Submarine tow-net, 700 fathoms to surface. 


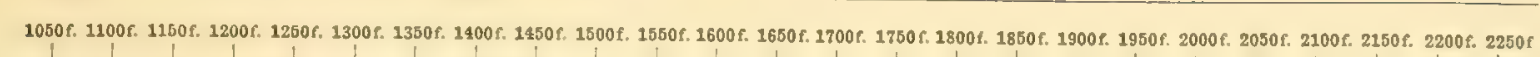
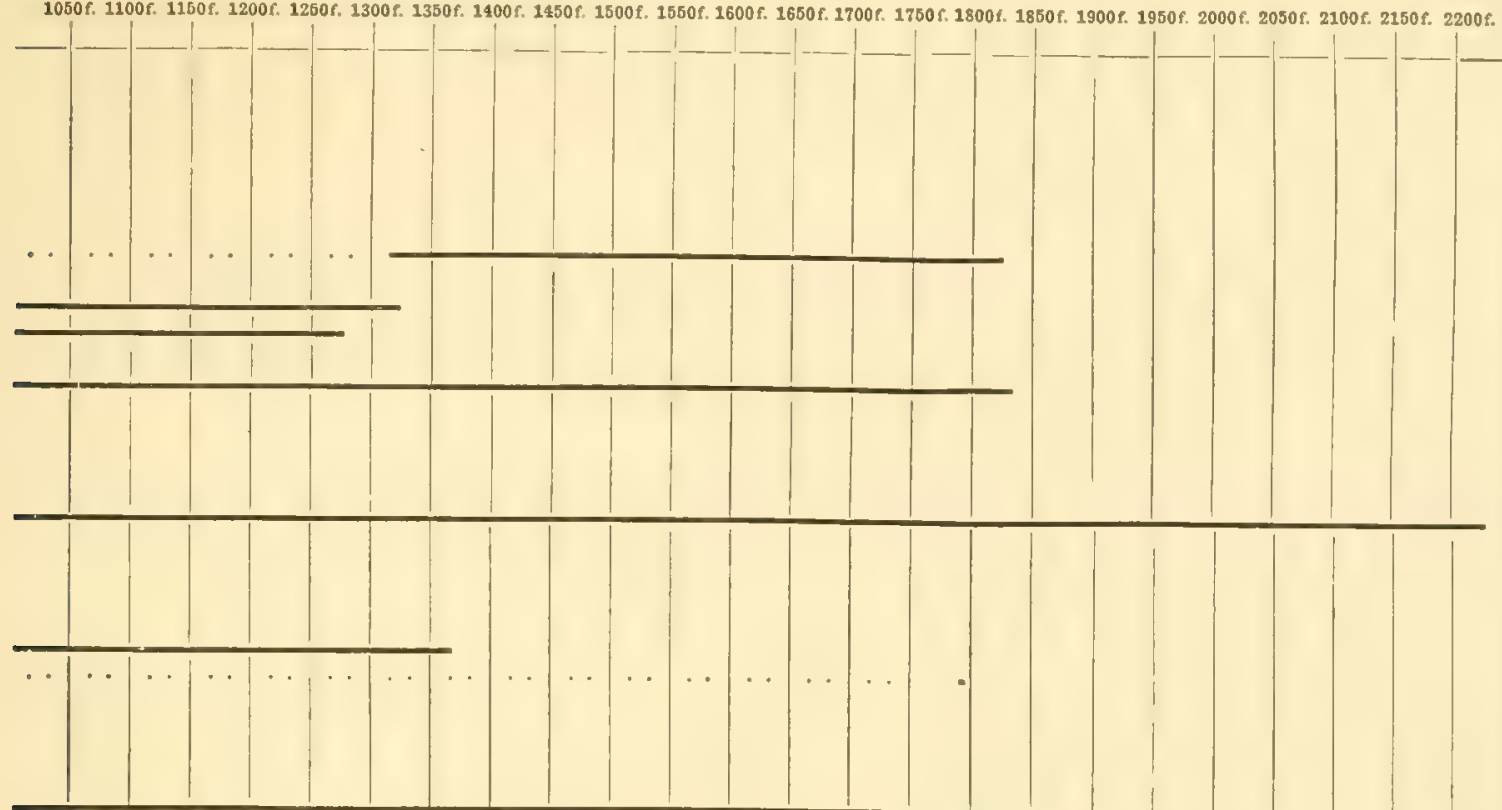

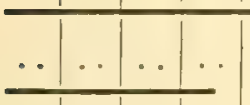

\begin{tabular}{l|l|l|l|}
\hline$\cdots$ & $\cdots$ & $\cdots$ & $\cdots$ \\
\hline
\end{tabular}
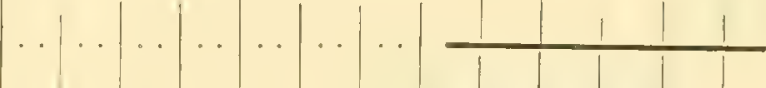

\begin{tabular}{l|l|l|l|l|l|l|l|l|l|l|l|l|l|l|l|}
\hline$\cdots$ & $\cdots$ & $\cdots$ & $\cdots$ & $\cdots$ & $\cdots$ & $\cdots$ & $\cdots$ & $\cdots$ & $\cdots$ & $\cdots$ & $\cdots$ & $\cdots$ & $\cdots$ & $\cdot$ \\
\hline
\end{tabular}

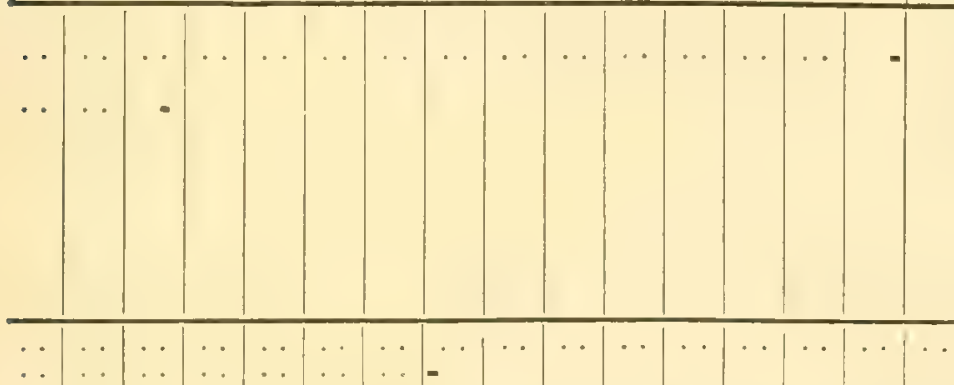

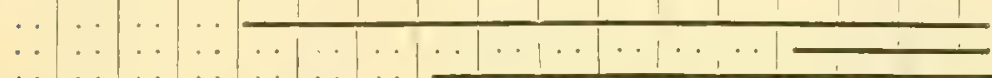

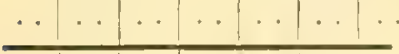

\begin{tabular}{l|l|l|l|l|l|l|}
\hline$\cdots$ & $\cdots$ & $\cdots$ & $\cdots$ & $\cdots$ & $\cdots$ & $\cdots$ \\
\hline
\end{tabular}
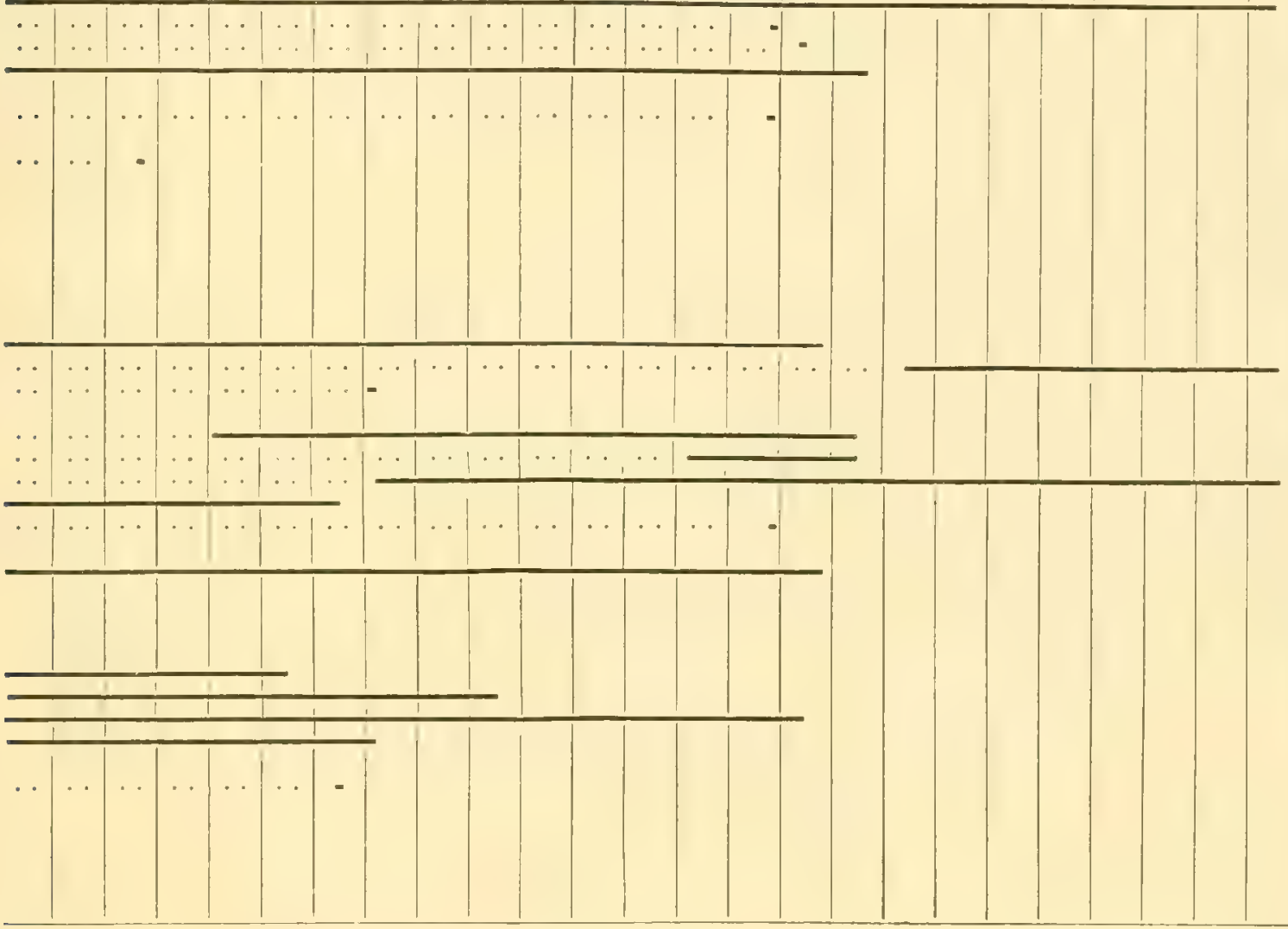


\section{RECORD OF SUBMARINE TOW-NET STATIONS OF THE UNITED STATES FISH COMMISSION STEAMER "ALBATROSS." *}

MARCh AND APRIL, 1891.

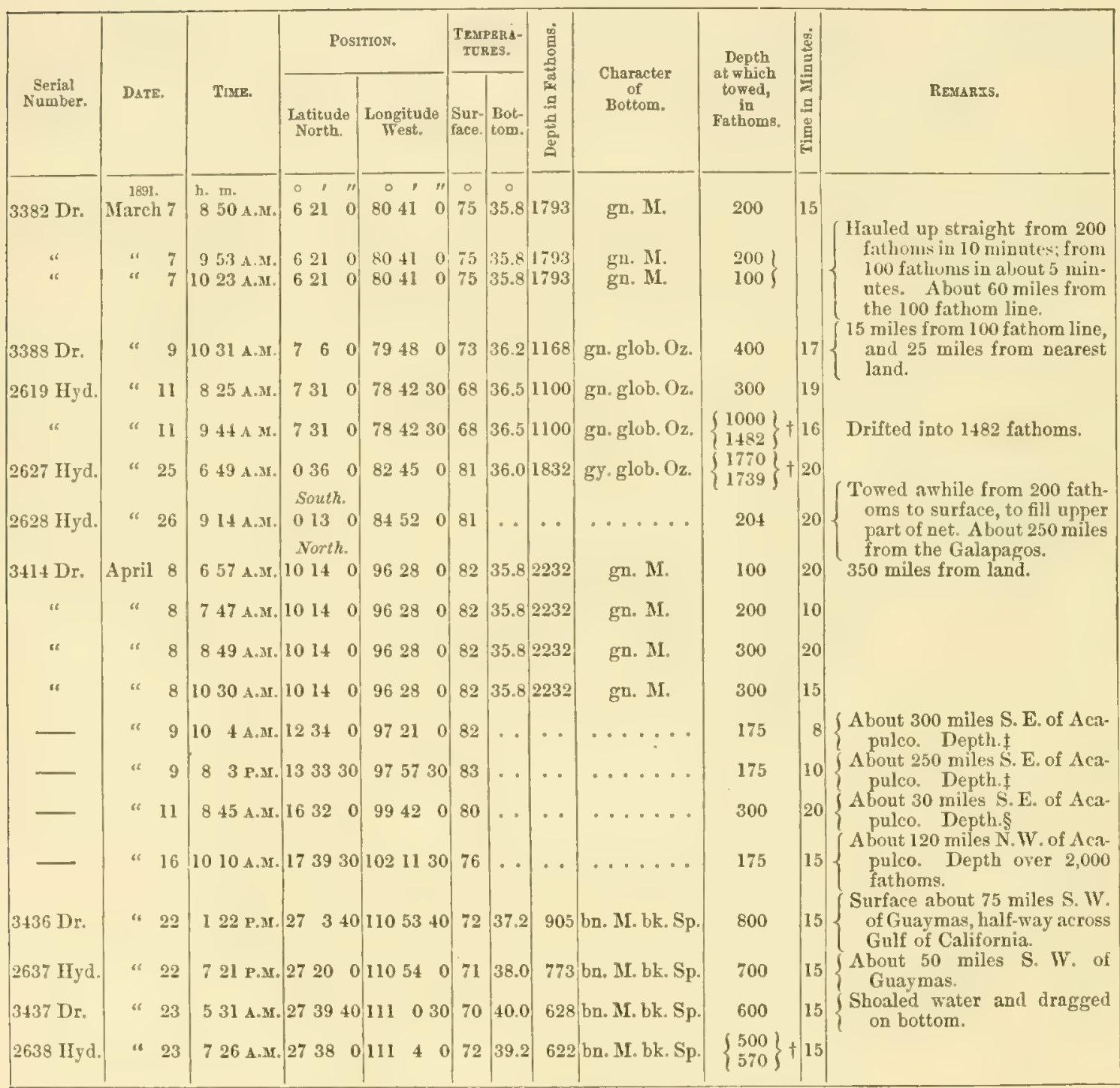

* Tanner tow-net at all Stations except Station 3382, March 7.

$\dagger$ Depth rarying between these points.

$\ddagger$ Between two Stations, over 2,000 fathoms.

$\S$ Between two Stations, about 500 fathoms. 


\section{RECORD OF DREDGING AND TRAWLING STATIONS OF THE UNITED STATES FISH COMMISSION STEAMER "ALBATROSS."}

\begin{tabular}{|c|c|c|c|c|c|c|c|c|c|c|}
\hline \multirow{2}{*}{ 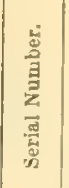 } & \multirow{2}{*}{\multicolumn{2}{|c|}{ Datz. }} & \multirow[b]{2}{*}{ Tare. } & \multicolumn{2}{|c|}{ Posmion. } & \multicolumn{2}{|c|}{$\begin{array}{l}\text { TEUPERA- } \\
\text { TURES. }\end{array}$} & \multirow{2}{*}{ 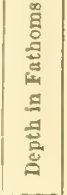 } & \multirow{2}{*}{$\begin{array}{c}\text { Character } \\
\text { of } \\
\text { Bottom. }\end{array}$} & \multirow[b]{2}{*}{ Remaris. } \\
\hline & & & & $\begin{array}{l}\text { Latitude } \\
\text { North. }\end{array}$ & $\begin{array}{l}\text { Longitude } \\
\text { West. }\end{array}$ & $\begin{array}{l}\text { Sur- } \\
\text { face. }\end{array}$ & $\begin{array}{l}\text { Bot- } \\
\text { tom. }\end{array}$ & & & \\
\hline & 1591. & & h. m. & 0,11 & $\circ, " 1$ & 。 & 0 & & & \\
\hline 3353 & " & 23 & $856 \mathrm{~A} . \mathrm{Mr}$. & $76 i 5$ & 80340 & 73 & 39.0 & 695 & gn. & Surface tow-net. \\
\hline 3354 & $" 6$ & 23 & 125 p.M. & 7945 & $8050 \quad 0$ & 78 & 46.0 & 322 & gu. M. & \\
\hline 3355 & & 23 & 31 P.M. & 71220 & 80550 & 81 & 54.1 & 182 & bk. G. Sh. & \\
\hline 3356 & " & 23 & 730 P.Mr. & 7930 & $81 \quad 830$ & 83 & 40.1 & 546 & sft. bl. MI. & $\left\{\begin{array}{l}\text { Surface tow-net. } 15 \text { miles from } \\
\text { Mariato Point. }\end{array}\right.$ \\
\hline 3357 & $"$ & 24 & 617 A.M. & 6350 & 81440 & 83 & 38.5 & 782 & gn. S. & Surface tow-net. \\
\hline 3358 & $" 6$ & $2 \pm 1$ & $1138 \mathrm{~A} M$ & $\begin{array}{lll}6 & 30 & 0\end{array}$ & $8144 \quad 0$ & 83 & 402 . & 555 & gn. S. & \\
\hline 3359 & “ & 24 & $2+$ P.M. & 62220 & $8152 \quad 0$ & 83 & 42.0 & 465 & rky. & \\
\hline $\begin{array}{l}3360 \\
3361\end{array}$ & “ & $\begin{array}{l}24 \\
25\end{array}$ & $\begin{array}{l}520 \text { I.M. } \\
733 \text { A.M. }\end{array}$ & $\begin{array}{lll}6 & 17 & 0 \\
6 & 10 & 0\end{array}$ & $\begin{array}{lll}82 & 5 & 0 \\
83 & 6 & 0\end{array}$ & $\begin{array}{l}83 \\
82\end{array}$ & $\begin{array}{l}36.4 \\
36.6\end{array}$ & $\begin{array}{l}1672 \\
1+71\end{array}$ & fne.bk. dk.gn.S. & Surface tow-net. \\
\hline 3362 & “ & 26 & 720 А.M. & $556 \quad 0$ & 851030 & 84 & 36.8 & 1175 & gn. M. S. rky. & $\begin{array}{l}\text { Intermediate net of Chun and } \\
\text { Petersen. }\end{array}$ \\
\hline 3363 & 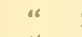 & 26 & +37 P.M. & $\begin{array}{lll}5 & 43 & 0\end{array}$ & $8550 \quad 0$ & 83 & 37.5 & 978 & wh. glob. Oz. & Surface tow-net. \\
\hline $336 \pm$ & " & 27 & $658 \mathrm{~A} \cdot \mathrm{M}$ & $\begin{array}{lll}5 & 30 & 0\end{array}$ & $86 \quad 830$ & 81 & 38.0 & 902 & yl. glob. Oz. & \\
\hline 3365 & 6 & 27 & 130 P.M. & $\begin{array}{ll}531 & 0\end{array}$ & 86310 & 85 & 37.0 & 1010 & yl. glob. Oz. & Surface tow-ne \\
\hline 3366 & $"$ & 27 & 84 P.M. & $\begin{array}{lll}5 & 30 & 0\end{array}$ & 86450 & 84 & 37.0 & 1067 & yl. glob. Oz. & S Darsite townet. \\
\hline 3367 & $"$ & 28 & 638 A.M & 53130 & 865230 & 82 & 57.1 & 100 & rky. & \\
\hline 3368 & $"$ " & 28 & 721 A.M. & $\begin{array}{lll}5 & 32 & 45\end{array}$ & 865430 & 82 & 58.4 & 66 & rky. & Surface tow-net. \\
\hline 3369 & 6 & 28 & 87 A.M. & 53245 & 865520 & 82 & 62.2 & 52 & Nullipore or rky. & At Cocos Island. Surface tow- \\
\hline 3370 & " & 281 & $103 \mathrm{~A} . \mathrm{Ir}$ & $536+0$ & 865650 & 84 & 54.8 & 134 & rks. \& S. & $\left\{\begin{array}{l}\text { An } \\
\text { net at night. }\end{array}\right.$ \\
\hline 3371 & IIarch & 1 & 749 A.M. & $\begin{array}{lll}526 & 20\end{array}$ & $\begin{array}{lll}86 & 55 & 0\end{array}$ & 82 & 39.0 & 770 & glob. $\mathrm{Oz}_{2}$ & 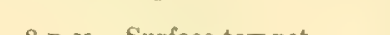 \\
\hline $\begin{array}{l}3372 \\
3373\end{array}$ & & $\begin{array}{l}1 \\
2\end{array}$ & $\begin{array}{ll}5 & 51 \text { P.M. } \\
10 & 33 \text { A.M. }\end{array}$ & $\begin{array}{ll}4+9 & 0 \\
4 & 0\end{array}$ & 861120 & 84 & 38.8 & 761 & gy. glob. $\mathrm{Oz}$. & 8 P. 3. Surface tow-net. \\
\hline 3374 & “ & 31 & & $\begin{array}{rrr}4 & 2 & 0 \\
2 & 35 & 0\end{array}$ & $\begin{array}{ll}8+53 & 0 \\
8353 & 0\end{array}$ & $\begin{array}{l}82 \\
80\end{array}$ & $\begin{array}{l}36.6 \\
36.4\end{array}$ & $\begin{array}{l}1877 \\
1823\end{array}$ & $\begin{array}{l}\text { br. M. bk. Sp. } \\
\text { gn. Oz. }\end{array}$ & \\
\hline 3375 & " & 4 & 636 A.3. & $234 \quad 0$ & 82290 & 78 & 36.6 & 1201 & $\mathrm{gy} \cdot \mathrm{glob} . \mathrm{Oz}$. & Surface tow-net. \\
\hline 3376 & “ & 4 & 427 P.M. & $\begin{array}{lll}3 & 9 & 0\end{array}$ & 8280 & 78 & 36.3 & 1132 & $\mathrm{gy} \cdot$ glob. Oz. & \\
\hline 3377 & " & $5 \mid$ & 838 A.M. & $\begin{array}{lll}3 & 56 & 0\end{array}$ & 814015 & 77 & 38.0 & 764 & M. & \\
\hline 3378 & “ & $5 \mid 1$ & 1145 A.M. & 35820 & 81360 & 78 & 55.9 & 112 & brk. sh. & \\
\hline 3379 & $"$ & 5 & 215 P.M. & 35940 & 81350 & 78 & $\therefore$ & 52 & rks. & \\
\hline 3380 & $"$ & 5 & 451 P.M. & $\begin{array}{lll}4 & 3 & 0\end{array}$ & $\begin{array}{lll}81 & 31 & 0\end{array}$ & 79 & 37.2 & 899 & rks. & \\
\hline 3381 & " & 6 & $838 \mathrm{~A} \cdot \mathbf{M r}$. & $\begin{array}{lll}456 & 0\end{array}$ & 805230 & 77 & 35.8 & 1772 & gn. $M$ & (Submarine tow-net. $8: 30$ P. \\
\hline 3382 & “ & 71 & $10 \$ 6$ A.M. & $621 \quad 0$ & 80410 & 75 & 35.8 & 1793 & gn. M. & $\left\{\begin{array}{l}\text { surface tow-net. }\end{array}\right.$ \\
\hline 3383 & " & 8 & 651 A.M. & $\begin{array}{lll}721 & 0\end{array}$ & $\begin{array}{lll}79 & 2 & 0\end{array}$ & 74 & 36.0 & 1832 & gn. glob. Oz. & \\
\hline 3384 & " & 8 & 120 P.M. & 73130 & $7914 \quad 0$ & 74 & 42.0 & 458 & ga. S. & \\
\hline 3385 & “" & 8 & 37 P.M. & 73236 & $79 \begin{array}{ll}76 & 0\end{array}$ & 72 & 45.9 & 286 & gn. M. & \\
\hline 3386 & " & 8 & $45+\mathrm{PBM}$ & 73312 & $79 \quad 17 \quad 15$ & 73 & 48.0 & 242 & fne. gy. S. & \\
\hline 3387 & " & 8 & 721 P.M. & $740 \quad 0$ & 791750 & 74 & 56.2 & 127 & fue. gy. S. & Surface tow-net. \\
\hline 3388 & $"$ & 9 & $64 \mathrm{I}$ A.M. & $\begin{array}{lll}7 & 6 & 0\end{array}$ & $\begin{array}{lll}79 & 48 & 0\end{array}$ & 73 & 36.2 & 1168 & gn. glob. Oz. & Submarine tow-net. \\
\hline 3389 & " & 9 & 210 P.M. & 71645 & 795630 & 74 & 48.8 & 210 & gu. M. & \\
\hline 3330 & " & 9 & 425 Г. .3. & 72610 & 795350 & 74 & 62.6 & 56 & fne. gy. S. G. & \\
\hline 3391 & $"$ & 9 & 715 Р. Мr. & 73340 & 794320 & 73 & 55.8 & 153 & gn. M. & \\
\hline 3392 & $"$ & 10 & $630 \mathrm{~A} .3 \mathrm{r}$ & 7530 & $7940 \quad 0$ & 73 & 36.4 & 1270 & hard. & Rhabdamina bottom. \\
\hline 3393 & " & 10 & 121 P.M. & $\begin{array}{ll}715 & 0\end{array}$ & $\begin{array}{ll}7936 & 0\end{array}$ & 74 & 36.8 & 1020 & gn. M. & \\
\hline 3394 & " & 10 & 543 P.M. & $\begin{array}{lll}7 & 21 & 0\end{array}$ & $\begin{array}{lll}7935 & 0\end{array}$ & 73 & 41.8 & 511 & dk. gn. MI. & \\
\hline 3395 & « & 11 & 220 P.3. & 73036 & $\begin{array}{lll}78 & 39 & 0\end{array}$ & 70 & 38.5 & 730 & rky. & \\
\hline 3396 & " & 11) & 515 P.M. & $\begin{array}{lll}7 & 32 & 0\end{array}$ & 783630 & 70 & 47.4 & 259 & hrd. gy. M. S. & \\
\hline
\end{tabular}


RECORD OF DREDGING AND TRAWLIYG STATIONS OF THE UNITED STATES FISH COMMISSION STEAMER "ALBATROSS." - Continued.

\begin{tabular}{|c|c|c|c|c|c|c|c|c|c|c|c|}
\hline \multirow{2}{*}{ 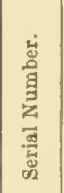 } & \multirow{2}{*}{\multicolumn{2}{|c|}{ Date. }} & \multirow[b]{2}{*}{ Trarg. } & \multicolumn{3}{|c|}{ Postrton. } & \multicolumn{2}{|c|}{$\begin{array}{c}\text { TEMPERA- } \\
\text { TURES. }\end{array}$} & \multirow{2}{*}{ 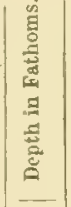 } & \multirow{2}{*}{$\begin{array}{l}\text { Character } \\
\text { of } \\
\text { Bottom. }\end{array}$} & \multirow[b]{2}{*}{ REMARES. } \\
\hline & & & & \multicolumn{2}{|c|}{$\begin{array}{l}\text { Latitude } \\
\text { North. }\end{array}$} & $\begin{array}{l}\text { Longitude } \\
\text { West. }\end{array}$ & $\begin{array}{l}\text { Sur- } \\
\text { face. }\end{array}$ & $\begin{array}{l}\text { Bot- } \\
\text { tom. }\end{array}$ & & & \\
\hline & 1891. & & h. m. & 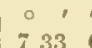 & & $\therefore \quad 1 "$ & $\begin{array}{c}0 \\
71\end{array}$ & $\begin{array}{c}0 \\
57.3\end{array}$ & 85 & stf. gn. M. brk. & urface tow-ne \\
\hline [3398 & Mitren & & 0.321 .010 & 7 & & & & & $15-3$ & $\mathrm{gn}, \mathrm{Oz}$ & S Surface tow-net, off Galera \\
\hline 3398 & & 23 & 316 P.M. & 17 & & 80210 & $8+$ & & 1013 & gn. Uz. & Y loint. \\
\hline 3399 & " & 24 & 637 A.M. & $\begin{array}{l}17 \\
\text { South. }\end{array}$ & & $81+0$ & 80 & 36.0 & 1740 & gn. Oz. & Surface tow-net. \\
\hline 3400 & “ & 27 & $610 \mathrm{~A} . \mathrm{Mr}$. & 036 & 0 & $8646 \quad 0$ & 81 & 36.0 & 1322 & lt. gy. glob. Oz. & Surface tow-net. \\
\hline 3401 & " & 28 & 445 A.M. & 059 & & 885830 & 82 & 43.8 & 395 & glob. $\mathrm{Oz}$ & \\
\hline 3402 & $"$ & 28 & 713 A.MI. & 05731 & & 89330 & 82 & 42.3 & 421 & K. glob. Oz. & \\
\hline 3403 & “ & 28 & 1019 A.3. & 0533 & & $8917 \quad 0$ & 82 & 43.3 & 384 & fne. gy.S.bk. Sp. & \\
\hline 340.4 & " & 28 & 116 P.3r. & 13 & 0 & 89280 & 83 & 43.2 & 385 & & \\
\hline 3405 & $"$ & 28 & 342 P.M. & 057 & 0 & $\begin{array}{lll}8938 & 0\end{array}$ & 83 & 60.0 & 53 & P. Co. Sh. & Tangles. \\
\hline 3406 & April & 3 & 647 A.M. & 016 & 0 & 902130 & 81 & 41.3 & 551 & R. & \\
\hline 3407 & “ & 3 & 1048 A.M. & $\begin{array}{l}04 \\
\text { North. }\end{array}$ & & 902430 & 81 & 37.2 & 885 & glob. $\mathrm{Oz}$. & Tangles. \\
\hline 3408 & " & 3 & 47 F.M. & 0123 & & 903230 & 83 & 39.5 & 681 & glob. $\mathrm{Oz}$. & Tangles. \\
\hline $3+109$ & " & 3 & $7 \pm+1 . .3$. & 0184 & & 90.310 & $\$ 2$ & 42.3 & 327 & l.k. S. & \} Taucles. Surface tow-net. Off \\
\hline $3+10$ & “ & 3 & $848 \mathrm{P}$ Y. & 019 & 0 & $9034 \quad 0$ & 82 & 44.2 & $\mid 331$ & bk. S. & f Bindlue Island, 4 miles west. \\
\hline 3411 & " & 4 & 735 A.3. & 051 & 0 & 9190 & 82 & 36.2 & 1189 & yl. glob. Oz. & \\
\hline $3+12$ & " & 4 & 611 P.M. & 123 & 0 & 91430 & 82 & 38.0 & 918 & R. & off Wenman Islands. \\
\hline 3413 & " & 5 & 834 A.3r. & 234 & 0 & 9260 & 82 & 360 & 1360 & glob. Oz. dk. Sp. & At noon, surface tow-net. \\
\hline 3414 & “ & 8 & 1114 A.3. & 1014 & 0 & 96280 & 82 & 35.8 & 2232 & gn. M. & $\begin{array}{l}\text { Submarine tow-net and surface } \\
\text { tow-net. }\end{array}$ \\
\hline $3+15$ & “ & 10 & 939 А.M. & 1446 & 0 & $98+0 \quad 0$ & 83 & 36.0 & 1879 & br. M. glob. Oz. & \\
\hline 3416 & " & 11 & 946 A.M. & 16323 & 30 & $99+240$ & 81 & 40.5 & 419 & fne. br. M. & \\
\hline 3417 & " & 11 & 1144 A.MI. & 1632 & 0 & $99+8 \quad 0$ & 82 & 40.6 & 493 & gn. M. & \\
\hline $3+18$ & $"$ & 11 & 257 A.M. & 1633 & 0 & 995230 & 82 & 390 & 660 & br. s. bk. Sp. & \\
\hline $3+19$ & $" 6$ & 11 & 559 P.x. & 16343 & 301 & 10030 & 81 & 39.0 & 772 & gn. M. bk. Sp. & Surface tow-net. \\
\hline $3+20$ & $"$ & 12 & 748 A.M. & 1646 & 0 ! & $100 \quad 820$ & 82 & 39.6 & 664 & dk. gn. M. & \\
\hline 3421 & $"$ & 12 & $1132 \mathrm{~A} . \mathrm{H}$. & 16472 & 201 & $100 \quad 010$ & 82 & 42.9 & 338 & dk. g & \\
\hline 3422 & $"$ & 12 & 1235 P.Mr. & 16473 & 30 & 995930 & 83 & 535 & 141 & ḡ. MI. & \\
\hline $3+23$ & 46 & 12 & 131 P.M. & 16473 & 30 & 995920 & 83 & 56.0 & 94 & gl & \\
\hline 3424 & $"$ & 18 & 1118 A.M. & 2115 & 0 & $10623 \quad 0$ & 76 & 38.0 & 676 & gy. S.bk. Sp. glob. & \\
\hline 3425 & “ & 18 & 214 P.M. & 2119 & 01 & 106240 & 76 & 39.0 & 680 & gn. M. \& S. & \\
\hline 3426 & 4 & 18 & 345 г.3. & 2121 & 0 & 106250 & 76 & 51.2 & 146 & rl & \\
\hline 3427 & “ & 18 & 43 P.M. & 21221 & $15 \mid 1$ & 106250 & 75 & 51.2 & 80 & rk & \\
\hline 3428 & $" 6$ & 18 & 640 P.M. & 21363 & 301 & 106250 & 76 & 48.1 & 238 & dk. gy. s. glob. & \\
\hline 3429 & "6 & 19 & 539 A.M. & 22303 & 301 & 10710 & 73 & $\begin{array}{ll}37 & 0 \\
9 & 0\end{array}$ & 919 & gn. II. glob, Oz. & \\
\hline $\left.\begin{array}{l}3.30 \\
3+31\end{array}\right]$ & "s & $\begin{array}{l}19 \\
20\end{array}$ & 327 P.M. & $\begin{array}{l}2316 \\
2359\end{array}$ & $\begin{array}{l}0.1 \\
0\end{array}$ & 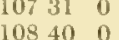 & $\begin{array}{l}73 \\
70\end{array}$ & $\begin{array}{l}37.9 \\
37.0\end{array}$ & $\begin{array}{r}852 \\
905\end{array}$ & bk. S. & \\
\hline 3432 & " & 20 & 238 P.M. & $24 \quad 223$ & 301 & 109320 & 70 & 37.8 & $\begin{array}{r}935 \\
1421\end{array}$ & br. M. bk. Sp. & \\
\hline 3433 & 66 & 21 & $63+$ A.M. & 25261 & 151 & $10948 \quad 0$ & 69 & 365 & 1218 & br. M1. bk. Sp. & \\
\hline 3434 & " & 21 & 1014 A.M. & 25293 & 301 & $10948 \quad 0$ & 70 & 364 & 1588 & br. M. bk. Sp. & - Surface tow-net. \\
\hline 3435 & " & 22 & 856 A.M. & 2648 & 01 & 1104520 & 70 & 37.3 & 859 & br. M. bk. Sp. & \\
\hline 3436 & "6 & 22 & 310 P.M. & 2734 & 0 & 1105340 & 72 & 37.2 & 905 & br. M. bk. Sp. & $\begin{array}{l}\text { Submarine tow-net and surface } \\
\text { tow-net. }\end{array}$ \\
\hline 3437 & $"$ & 23 & 54 A.M. & $\cdots \cdot$ & & $\cdots \cdots$ & 70 & 40.0 & 628 & br. MI. bk. Sp. & $\begin{array}{l}\text { the bottom. A bout } 50 \text { miles } \\
\text { south of Guaymas. }\end{array}$ \\
\hline
\end{tabular}




\section{EXPLANATION OF THE PLATES.}

PLATE A.

Fig. 1. Trachycarcinus corallinus FAX.

\begin{tabular}{|c|c|c|}
\hline "6 $1^{\alpha}$. & "6 & " \\
\hline$\because \quad 1^{b}$. & 6 & 66 \\
\hline " $1^{c}$. & 66 & 66 \\
\hline "1d. & 66 & " \\
\hline$\because 1^{e}$ & .6 & 6 \\
\hline$\therefore \quad 1 \%$ & "6 & 66 \\
\hline
\end{tabular}

Male. Natural size. Station 3418. Colored from life.

Male, denuded. Natural size. Station 3356 . Oral and antenual region. Enlarged.

Sternal region of male. Enlarged.

Abdomen of male. Enlarged.

Lesser cheliped of male. Enlarged.

Abdomen of an ovigerous female. $\times 2$. Station 3356 .

\section{PLATE B.}

Fig. 1. Galacantha rostrata A. MI. EDw. " $1^{n}$. " " " "
Natural size. Colored from life.

Lateral view of carapace. Natural size.

Male. Enlarged. Station 3375. Colored from life.

\section{PLATE C.}

Fig. 1. Polycheles sculptus pacificus Fdx. Natural size. Colored from life.

"10 "6 "6 "6

-2. Polycheles sculptus Sщтт.
First, second, and third abdominal somites, viewed from the side.

First, second, and third abdominal somites, viewed from the side. "Blake" Station 326 , off east coast of United States.

PLAT'E D.

Fig. 1. Nephropsis occidentalis $\mathbf{F}$ Ax.

\begin{tabular}{|c|c|c|c|}
\hline " $1^{a}$ & "6 & " & 66 \\
\hline " $1^{b}$ & "6 & " & s6 \\
\hline " 2 & Pontoplilus & occidentalis & FAx. \\
\hline " $2^{n}$. & w & 66 & $" 6$ \\
\hline$\therefore \quad 2^{3}$. & " & s6 & 66 \\
\hline $2^{c}$ & "6 & " & “ \\
\hline $2^{d}$ & 66 & "6 & 6 \\
\hline
\end{tabular}

MIale. Natural size. Station 3418. Colored from life.

Carapace from above.

Swimmeret.

Nat. size. Station 3382. Colored from life.

Carapace, lateral view.

First abdominal appendage.

Second abdominal appendage.

Third abdominal appendage. 


\section{PLATE E.}

Fig. 1. Gnathophyllum panamense FAx.

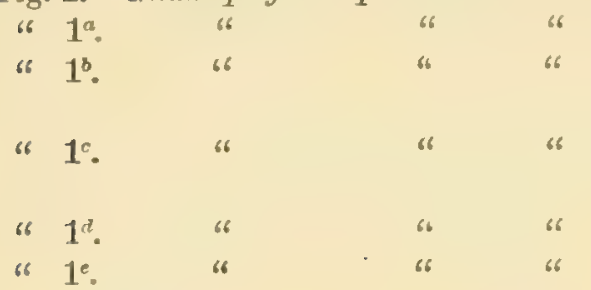

Female. $\times 2 \frac{1}{2}$. Colored from life.

Lateral view. More highly magnified.

Anterior part, from above. Still more enlarged.

End of the abdomen and posterior pair of abdominal appendages. Enlarged.

Rostrum in profile. Enlarged.

External maxilliped. Enlarged.
Fig. 1. Notostomus westergreni FAx.

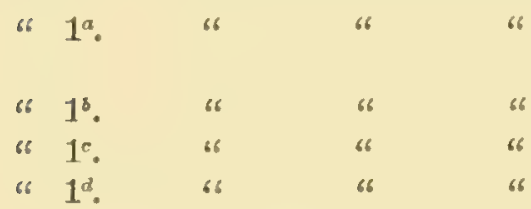

Fig. 1. Peneopsis diomedea Fax.

\begin{tabular}{|c|c|c|}
\hline $1^{a}$. & 66 & 66 \\
\hline $1^{b}$. & 68 & 16 \\
\hline $1^{\circ}$. & 66 & "6 \\
\hline $1^{d}$ & 66 & "6 \\
\hline
\end{tabular}

Fig. 1. Benthesicymus tanneri-FAx.

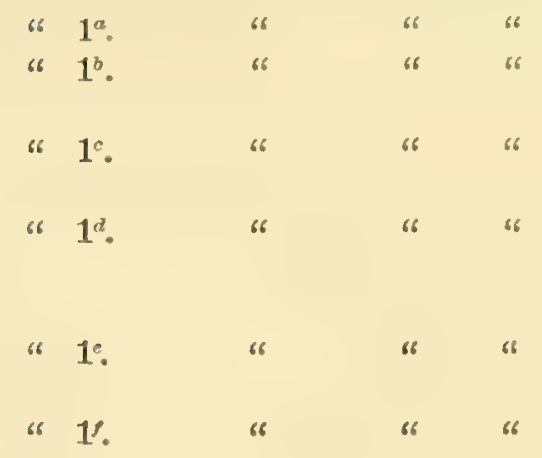

\section{PLATE F。}

Male. Natural size. Station 3399. Colored from life.

Anterior part of the carapace seen in profile. Enlarged.

Eye-stalk and eye. Enlarged.

Right antennal scale. Enlarged.

Telson and posterior pair of abdominal appendages. Slightly enlarged.

PLATE G.

Female. Natural size. Colored from life. Antennal scale.

First abdominal appendage of female.

Petasma of male.

Swimmeret.

\section{PLATE $\mathrm{H}$.}

Male. Natural size. Station 3435. Colored from life.

Carapace in profile. Natural size.

Sternum of the female. Enlarged. Station 3435 .

First pair of abdominal limbs and petasma of male. Enlarged. Station 3435.

Right first abdominal appendage of the female, outer side. Enlarged. Station 3435 .

Distal end of third maxilliped of male, first form. Enlarged. Station 3435.

Distal end of third maxilliped of male, second form. Enlarged. Station 3410. 


\section{PLATE J.}

Fig. 1. Gnathophausia brevispinis W.-M. $\times 1 \frac{3}{5}$. Station 3375. Colored from life.

" $1^{a}$. 6 " " " " $\quad$ " $\quad$ Dorsal view. More enlarged.

" $1^{b}$. " " " " " " $"$ "

" $1^{c}$. " " " " " $"$ "

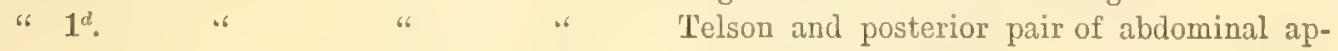
pendages. Enlarged.

"6 $1^{e}$. $66 \quad 66 \quad$ End of the telson. More highly magnified.

PLATE K.

Fis. 1. GnathophausiawillemoesiiG.O.SARs. Natural size. Station 3392 . Colored from life.

"2. Eucopia sculpticauda FAx.

$6 \quad 27646$

66366

6. 2640

62 2. $66 \quad 66$
Young female? $\times 2_{+}^{3}$. Station $2619 \mathrm{Hydr}$. Colored from life.

Telson and posterior pair of abdominal appendages. Enlarged.

Hinder part of the telson, more highly magnified.

Distal portion of one of the legs of the third pair, or third gnathopods. Eularged.

Distal end of one of the legs of the fourth pair (anterior pair of elongated legs). Enlarged.

\section{PLATE I.}

Fig. 1. Euprognatha granulata FAx. "1 $1^{a}$. "6 " "

"2. Anamathia occidentalis FAx.

"2 $2^{n}$. "6

"3. Sphenocarcinus agassizi RathB.

" 3 " " "
Female. Enlarged.

Antennal and oral region. Enlarged.

Male. Somewhat enlarged.

Ventral side. Somewhat enlarged.

Male. $\times 1 \frac{1}{5}$.

Anterior part, from below. $\times 1 \frac{1}{5}$.

\section{PLATE II.}

Fig. 1. Maiopsis panamensis FAx.

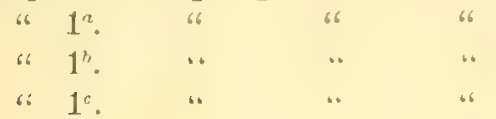

Fig. 1. Lambrus hassleri FAx.

* $1^{a}$, " "6 "6

"2. Tanthodes sulcatus FAx.

"2 $2^{\prime 2}$ "6 "6

"3. Panopers latus FAx.

"3". " " " "

"4. Panopeus tanneri FAx.

" 4 . 66 6 66
Male. $\frac{5}{8}$ natural size.

Antennal and oral region. Slightly reduced. Sternum and abdomen. 66

End of left chela, from inside. Nat. size.

\section{PLATE III.}

Female. Somewhat enlarged.

Male, from below.

Enlarged.

Antennal and oral region.

Male. Enlarged.

Antenual and oral region.

Male. Enlarged.

Antenual and oral region. 


\section{PLATE IV.}

Fig. 1. Achelous affinis FAx.

is $1^{a}$. s6 if as

"6 $1^{b}$. 6 64

"2. Gecarcinus malpilensis FAx.

"2u. "6

Fig. 1. Pinnixa panamensis FAx.

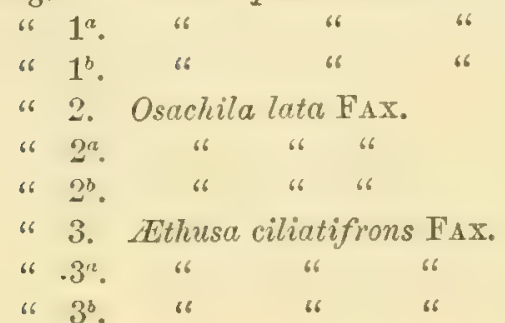

Fig. 1. Athusa late Ratri.

\begin{tabular}{|c|c|c|c|}
\hline & $\mathbf{1}^{a}$. & " & ، \\
\hline & $1^{b}$ & " & ، \\
\hline & 2. & Ethusina & smithiana FAx. \\
\hline & $2^{a}$ & 6 & 6 \\
\hline & 3. & Cymopolia & a tuberculata FAx. \\
\hline & $3^{n}$ & 86 & "6 \\
\hline & 4. & Cymopoli & ia fragilis RАтнв. \\
\hline & $4^{\prime \prime}$ & 6 & " \\
\hline
\end{tabular}

Fig. 1. Raninops fornicata FAx.

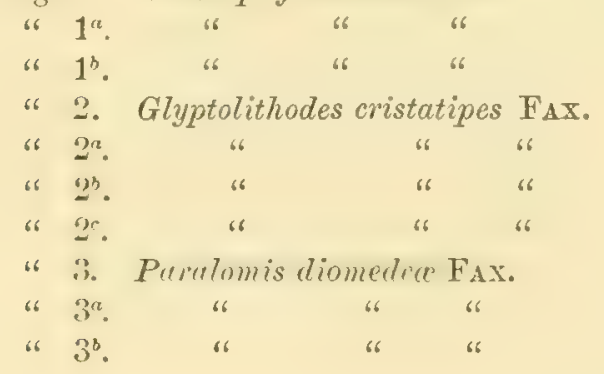

PLATE VIIT.

Fig. 1. Leptolithodes resper (FAx.).

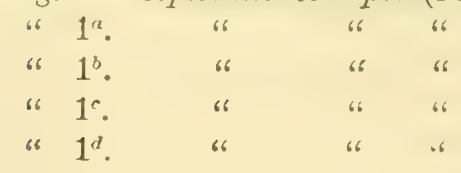

Male. $\times 1 \frac{1}{4}$ Station 3379 .

Antennal and oral region.

Abdomen of the male.

Male. Slightly reduced.

Front and oral region.

\section{PLATE V.}

Enlarged.

Cheliped.

Abdomen of the male.

Male. Somewhat enlarged.

From below.

Anterior part, from below.

Male. Somewhat enlarged.

Anterior part, from below.

Abdomen of the male.

\section{PLATE VI.}

Fernale. Slightly enlarged.

Antenual and oral region.

Abdomen of the female. Natural size.

Enlarged.

Abdomen of the male.

Male. Enlarged.

From below.

Male. Enlarged.

From below.

\section{PLATE VII.}

Enlarged.

Anterior part, from below.

Cheliped.

Male. Eularged.

Carapace, viewed from the side.

Second antenna.

Abdomen.

Female. Slightly reduced.

Abdomen of an ovigerous female. Nat. size.

Abdomen of a smaller female. Enlarged.

Female. About $\frac{3}{5}$ natural size

Abdomen, " $\frac{2}{3}$ " "

Rostrum in profile. Natural size.

Second antenna. $\times 1 \frac{1}{2}$.

A small portion of the dorsal surface of the carapace. More highly magnified. 
PLATE IX.

Fig. 1. Leptolithodes longipes (FAx.).

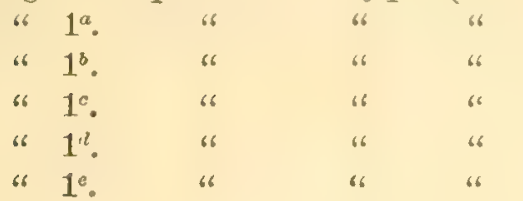

Male. Reduced nearly one half.

Abdomen of the female. Natural size.

Abdomen of the male.

"6 6

Rostrum in profile. $\times 1 \frac{1}{2}$.

Second antenna.

A small portion of the dorsal surface of the carapace. Much enlarged.

PLATE X.

Fig. 1. Lithodes panamensis FAx. Female.

$\begin{array}{ccccc}\text { " } & 1^{a} . & \text { " } & \text { " } & \text { " } \\ \text { " } & 1^{b} \text {. } & \text { " } & \text { " } & \text { " } \\ \text { " } & 1^{c} \text {. } & \text { " } & \text { " } & \text { " } \\ \text { " } & 2 \text { ithodes sp. } & & \end{array}$

"2. Lithodes sp.
Carapace, lateral view. Reduced.

Oral region.

Abdomen. Natural size.

Young. $\times 11$. Station 3425,680 fathoms.

\section{PLATE XI.}

Fig. 1. Cancellus tanneri Fax.

"1 $1^{a}$. "6 "6 6"

" $161^{b}$. " " " " "

" 1 . " " 40

$61^{\prime \prime} 66 \quad 66$

2. Eupagums californiensis BENEDICT
" 2

"

" $2^{b}$.

" $2^{r}$. 6

"2 2 . 6

"2. "

" $2^{d} . \quad$ "
66

“

"

“

"

(6
Male. Enlarged.

Viewed from below.

Second antenna.

End of one of the penultimate pair of thoracic appendages.

One of the appendages of the last thoracic pair.

Male. $\times 2 \frac{1}{5}$.

Anterior part of the carapace and cephalic appendages. More highly magnified, viewed from above.

Extremity of the abdomen, together with the posterior pair of appendages, viewed from the dorsal side.

End of antennule.

Portion of one of the antepenultimate pair of thoracic appendages.

Portion of one of the posterior pair of thoracic appendages.

Extremity of one of the posterior pair of thoracic appendages, external side.

\section{PLATE XII.}

Fig. 1. Pylopagurus longimanus FAx.

" $1^{a}$.

64

" $1^{b}$

64

Male. Enlarged.

Anterior part of the carapace and cephalic appendages.

Extremity of the abdomen, together with the posterior pair of appendages, viewed from the dorsal side. 
Fig. 1'. Pylopagumes longimanus FAx.

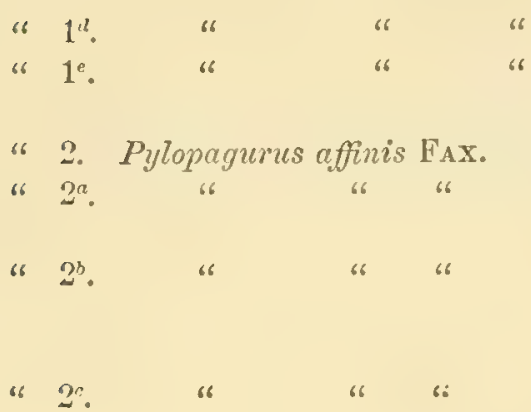

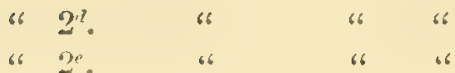

Carpus, propodite, and dactylus of right cheliped of a smaller specimen, outer face. Enlarged.

Penultimate thoracic appendage.

Extremity of one of the posterior thoracic appendages.

Male. Enlarged.

Anterior part of the carapace and cephalic appendages.

Extremity of the abdomen, together with the posterior pair of appendages, viewed from the dorsal side.

Posterior segment of the sternum, together with the basal segment of the posterior thoracic legs, showing the extruded vasa deferentia.

Penultimate thoracic appendage.

Posterior thoracic appendage.

\section{PLATE XIII.}

Fig. 1. Pylopagumus hirtimanus Fax.

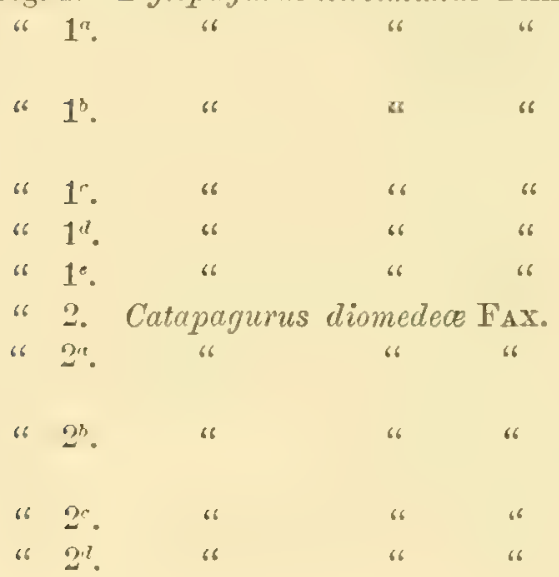

Enlarged.

Anterior part of the carapace and cephalic appendages.

Extremity of the abdomen and posterior pair of appendages.

Right chela, outer face.

Penultimate thoracic appendage.

Posterior thoracic appendage.

Male. Enlarged.

Anterior part of the carapace and cephalic appendages.

Extremity of the abdomen, together with the posterior pair of appendages.

Penultimate thoracic appendage.

Posterior thoracic appendage.

\section{PLATE XIV.}

Fig. 1. Spiropagurus occidentalis Fax.

" $1^{n}$.

" $1^{5}$

$1^{c} \cdot \quad$ "s

$1^{\prime \prime}$ " "

2. Puguristes fecundus Fax.

" $2^{a}$.

"6

“

$2^{8}$

$2^{c}$.

$2^{d}$.

6

"

6

“

6

6

' $2^{e}$.

66

"
Male. Enlarged.

Anterior part of the carapace and cephalic appendages.

Extremity of the abdomen, together with the posterior pair of appendages, dorsal side.

Penultimate thoracic appendage.

Posterior thoracic appendage.

Female. Enlarged.

Anterior part of the carapace and cephalic appendages.

Telson, dorsal face.

Penultimate thoracic appendage.

Extremity of penultimate thoracic appendage.

More highly magnified.

Posterior thoracic appendage. 


\section{PLATE XV.}

Fig. 1. Petrotisthes agassizii FAx. "1". "6 "6

"2. Pachycheles panamensis Fax.

" $2^{\text {" }}$.

"3. Pleuroncodes monodon M. EDw.?

" 3 " " " " " "

"6 " " " " "

" 33 " "
Male. Enlarged.

Right external maxilliped.

Female. Enlarged.

Left external maxilliped.

Male. $\times 1 \frac{1}{6}$.

Left chela, outer face.

Antennule.

External maxilliped.

\section{PLATE XVI.}

Fig. 1. II Inida obesa FAx.

$61^{\prime 2}$ " " " "

"2. Munida gracilipes FAx.

" $2 a$ " " " " "

" 2 . " 6 "6

Fig. 1. Munida refulgens FAX.

Fig. 1. Mrunida propinqua FAx. "1". "6 "6 "6

"2. Munidopsis vicina Fax.

" $2 \alpha .46$ "6

"3. Mrunidopsis ciliata W.-M.

"4. ITunidopsis agassizii Fax.

6 $4^{\text {n }}$ 6 6 6

\section{PLATE XIX.}

Fig. 1. Munidopsis hystrix FAx. "1". Munidopsis villosa FAx.

"3. Munidopsis sericea Fax.

6. $3^{n}$.

"6 6

Fig. 1. MInidopsis ornata FAx. $1^{a}$. 66 "6 "6

"2. MTunidopsis margarita FAx.

"3. MTunidopsis crinita Fax.

6) $3^{2}$. 66 66 6

Chela.

\section{PLATE XX.}

Male. $\times 11$.

External maxilliped.

Much enlarged.

Chela.

External maxilliped.

\section{PLATE XVII.}

Male. Nat. size.

\section{PLATE XVIII.}

Male. Somewhat enlarged.

External maxilliped.

Female. Much enlarged.

Cheliped.

Male. Sixth abdominal somite, telson, and last pair of appendages, much enlarged. Station 3353.

Female. Much enlarged.

Chela. More highly magnitied.

Enlarged.

Male. Enlarged.

Male. Enlarged.

External maxilliped.

Miale. Enlarged.

External maxilliped, viewed from below.

Enlarged.

Female. Highly magnified.

External maxilliped. 
PLATE XXI.

Fig. 1. Munidopsis scabra FAT.

" $1^{\text {. }}$. 6" "6 "

"2. IIunidopsis hamata FAx.

"2a. " " " "

" $2 a$ "

Enlarged.

External maxilliped.

Enlarged.

External maxilliped.

Side view.

\section{PLATE XXII.}

Fig. 1. Munidopsis tanneri FAX.

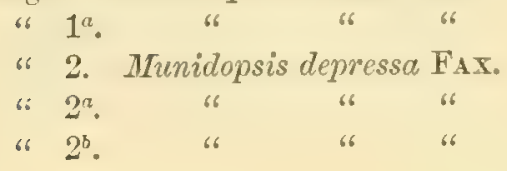

Enlarged.

External maxilliped.

Male. Enlarged.

External maxilliped.

Side view.

\section{PLATE XXIII.}

Fig. 1. Mrunidopsis quadrata FAx.

$\begin{array}{lllll}" & 1^{a} . & 6 & 6 & \text { "6 } \\ " & 1^{b} . & \text { "6 } & \text { "6 } & \text { " } \\ \text { " } & 1^{c} \text {. } & \text { " } & \text { " } & \text { "6 } \\ \text { " } & 2 . & \text { MIunidopsis } & \text { inermis } & \text { FAX. } \\ \text { " } & 2^{a} \text {. } & \text { "6 } & \text { " } & \text { " }\end{array}$

Male. Enlarged.

Side view.

External maxilliped.

Female. Enlarged.

Male. Much enlarged.

Carapace in profile.

\section{PLATE XXIV.}

Fig. 1. Mrunidopsis carinipes FAx.

$\begin{array}{lllll}\text { " } & 1^{a} . & \text { " } & \text { " } & \text { " } \\ \text { " } & 1^{b} \text {. } & \text { " } & \text { " } & \\ \text { " } & 2 . & \text { Munidopsis hendersoniana } & \mathrm{FAx} \\ \text { " } & 2^{n} \text {. } & \text { " } & \text { " } & \text { " } \\ \text { " } & 2^{8} \text {. } & \text { " } & \text { " } & \text { " } \\ 2 c & \text { " } & \text { " } & \text { " }\end{array}$

Enlarged.

External maxilliped.

Side view:

Female. Enlarged.

External maxilliped.

Anterior part, in profile.

Cheliped.

\section{PLATE XXV.}

Fig. 1. Galacantha diomedece FAx.

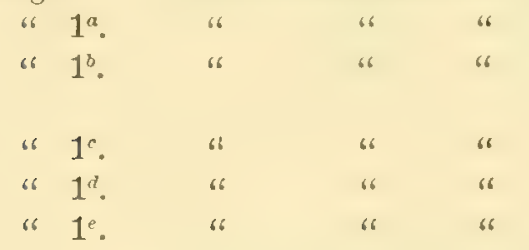

Male. Somewhat enlarged.

Carapace in profile.

Sixth abrominal somite, telson, and last pair of appendages of female.

External maxilliped.

Antennule.

End of one of the posterior thoracic appendages. Much enlarged.

"2. Gulacantha diomedece, var, parvispina FAx. Profile of carapace.

\section{PLATE XXVI.}

Fig. 1. Uroptychus nitidus occidentalis FAx. Female. Enlarged.

$\begin{array}{ccccccc}" & 1^{a} \text {. } & \text { " } & \text { " } & \text { " } & \text { " } & \text { End of abdomen. } \\ " & 2 . & \text { Uroptychus bellus } & \text { FAx. } & & \text { Male. Enlarged. } \\ " & 2^{a} \text {. } & \text { " } & \text { " } & \text { " } & & \text { Antennule. } \\ " & 2^{b} & \text { " } & \text { " } & \text { " } & & \text { External maxilliped. }\end{array}$


Fig. 3. Uroptychus pubescens FAx.

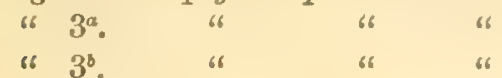

Fig. 1. Calastacus stilirostris $\mathrm{FAX}_{\mathbf{A}}$.

\begin{tabular}{|c|c|c|}
\hline "i $1^{a}$. & $" 6$ & " \\
\hline " $1^{b}$ & $" 4$ & "6 \\
\hline " $1^{c}$. & $" 6$ & " \\
\hline "6 $1^{d}$. & 6 & " \\
\hline " $1^{\circ}$. & $"$ & " \\
\hline "1f. & "6 & " \\
\hline
\end{tabular}

"2. Calocaris macandreo BeLL.

" 2a 6 6 "6

Fig. 1. Axius crista-galli FAx.

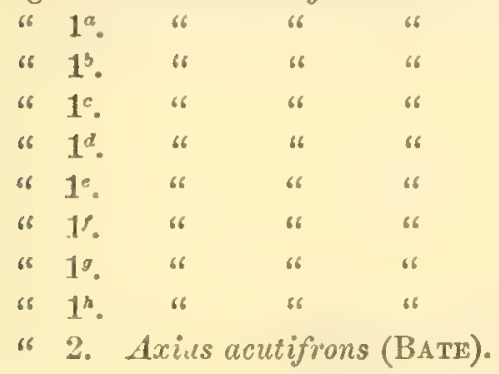

Fig. 1. Eryonicus spinulosus FAX.

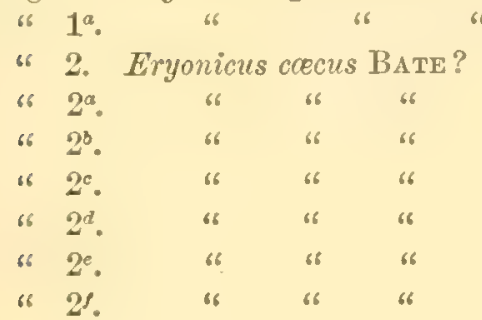

Fig. 1. Eryonicus caecus BATE?
Female. Enlarged.

Antennule.

External maxilliped.

\section{PLATE XXVII.}

Male. Enlarged.

Front and rostrum from above.

Swimmeret.

Antenna of the second pair.

First abdominal appendage of the male.

Second abdominal appendage of the male.

Third abdominal appendage of the male.

North Atlantic. Antenna of the second pair, viewed from above.

Antenna of the second pair, viewed from the side.

\section{PLATE XXVIII,}

Female. Enlarged.

Anterior part, viewed from above.

Rostrum in profile.

Swimmeret.

Antenua of the second pair.

Leg of fourth pair, male.

Leg of fifth pair, male.

First abdominal appendage, female.

Second abdominal appendage.

Female. Cheliped.

\section{PLATE XXIX.}

Dorsal view. Enlarged.

Lateral view. Enlarged.

Mandible. Adult male. Station 3375.

First maxilla, adult male.

Second maxilla, adult male.

First maxilliped, adult male.

Second maxilliped, adult male.

Third maxilliped, adult male. $a$, epipod.

Swimmeret, adult male.

\section{PLATE XXX.}

Front and oral region, adult male. Station 3375. $\alpha$, ophthalmic lobe. $a^{\prime}$, papilla of ophthalmic lobe. $\beta$, first antenna. $\gamma$, proximal segment of second antenna. $\gamma^{\prime}$, phymacerite. $\gamma^{\prime \prime}$, scaphocerite, or scale of second antenna. $\gamma^{\prime \prime \prime}$, fourth, or distal segment of antennal peduncle. $\delta$, mandible. $\delta^{\prime}$, distal segment of mandibular palp. $\epsilon$, moutl. $\zeta$, labrum. $\eta$, posterior wall of mouth. $\vartheta$, metastoma. 
Fig. $1^{a}$. Eryonicus coecus Bate?

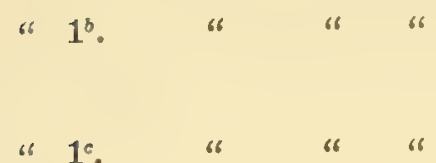

"1 $1^{d}$ " " " "

"1e. " " "

\begin{tabular}{|c|c|c|}
\hline $661^{\prime}$. & 66 & "6 \\
\hline $1^{g}$. & " & " \\
\hline
\end{tabular}

" $1^{h}$. " क "

" $1^{j}$. " 6 6

" 1 . " "

6 1 . 6 " 6 6

" $1^{m}$. 6 6 6

" $1^{n}$ " " "

Fig. 1. Polycheles tanneri Fax.

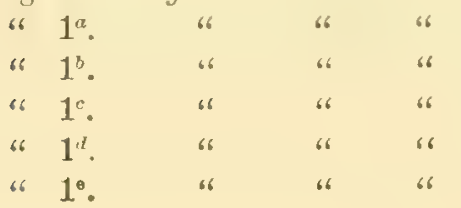

Front of same specimen, seen from above, $\alpha$, ophthalmic lobe. $\beta$, first antenna. $\gamma$, second antenna.

Front of a young individual $19 \mathrm{~mm}$. long, viewed from above. Station 3388. a, ophthalmic lobe.

Anterior part, viewed from the side. Adult male. Station 3375. a, ophthalmic lobe. $\beta$, first antenna. $\gamma$, second antenna. $\delta$, mandible. $\delta$, mandibular palp.

Ophtbalmic sinus, viewed from the side. Young individual $29 \mathrm{~mm}$. long. Station 3388. $\alpha$, ophthalmic lobe.

Face view of front of a young individual $19 \mathrm{~mm}$. long. Station 3388, a, ophthalmic lobe.

Fourth leg, adult male. Station 3375.

Fifth leg, adult male. Station 3375.

First abdominal appendage, female. Station 3377.

First abdominal appendage, adult male. Station 3375 .

Second abdominal appendage, adult male. Station 3375.

Third abdominal appendage, adult male. Station 3375.

First three abdominal segments and appendages from the side, young.

Gill of adult male.

\section{PLATE XXXI.}

Female. Dorsal view. Natural size. Female. Lateral view. Natural size. Antenna of first pair.

Distal end of fifth leg, adult female. Distal end of fifth leg, young female. Distal end of fifth leg, adult màle.

\section{PLATE XXXII.}

Fig. 1. Polycheles granulatus FAx.*

Female. Dorsal view. Natural size. Dorsal view. Natural size.

\section{PLATE XXXIII.}

Fig. 1. Polycheles nanus Sмгтн.

"6 1a. "6 "6 "

" $1^{b}$. 66 " " "

"2. Polycheles granuiatus FAX.

"2". " " " "

"3. Willemoesin inornata FAx.
Female in profile. Enlarged.

End of fifth leg, male.

End of fifth leg, female.

Female in profile. Natural size.

End of fifth les, female.

Lateral view. Natural size.

* The carapace is $2.3 \mathrm{~mm}$. too broad in the figure. 
PLATE XXXIV.

Fig. 1. Paracrangon areoluta FAx.

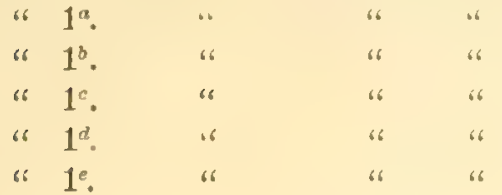

Fig. 1. Silerorrangon atrox FAx.

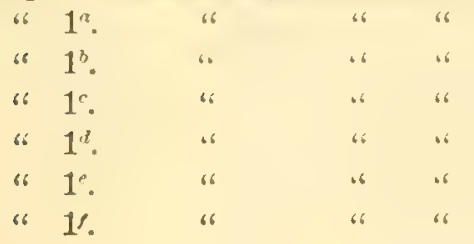

Fig. 1. Sclerocrangon procax FAx.

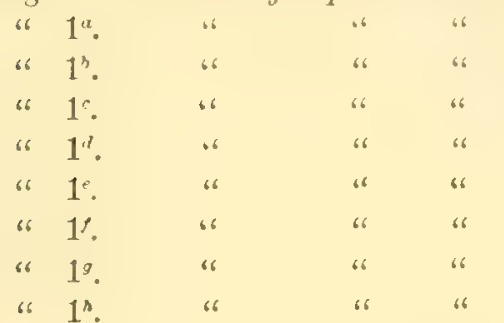

\section{PLATE XXXVI.}

Female. Dorsal view. Natural size. Female. Lateral view. Natural size. First antenna.

Second antenna.

First abdominal appendage of male. First abdominal appendage of female. Second abdominal appendage of male. Second abdominal appendage of female. Sternum of female.

\section{PLATE XXXVII.}

Fig. 1. Glyhhnerangon alate FAx.

\begin{tabular}{|c|c|c|}
\hline " $1^{a}$. & " & " \\
\hline “ $1^{b}$. & " & "6 \\
\hline " 1 1. & "6 & .. \\
\hline " $1^{d}$. & "6 & $"$ \\
\hline " 1 \% & 6 & " \\
\hline
\end{tabular}

Dorsal view. Natural size.

Lateral view. Natural size.

End of third leg.

End of fifth leg.

Second leg of left side.

Second leg of right side.

\section{PLATE XXXVIII.}

Fig. 1. Glyphocrangon spinulosa FAx.

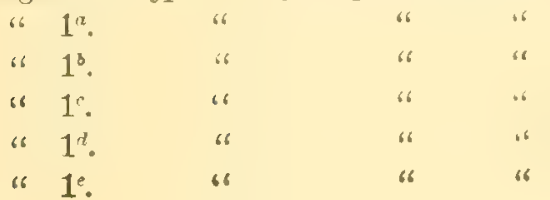

Female. Dorsal view. Natural size. Female. Tateral view. Natural size. End of third leg.

End of fifth leg.

Second leg of lett side.

Second leg of right side. 


\section{PLATE XXXVIII. ${ }^{\text {bis. }}$}

Fig. 1. Glyphocrangon loricata FAX.

$\begin{array}{lllll}66 & 1^{a} & 6 & 66 & 66 \\ 66 & 1^{b} & 66 & 66 & 66 \\ 66 & 1^{c} & 66 & 66 & 66 \\ 6 & 1^{d} & 66 & 66 & 66 \\ 6 & 1^{c} & 66 & 66 & 66\end{array}$

Male, Dorsal view. Station $3402 . \times 1 \frac{1}{4}$.

Male. Lateral view, Station 3402, $\times 1 \frac{1}{4}$.

Rostrum from above, more highly magnified.

Telson from above, more highly magnified.

End of third leg.

End of fifth leg.

\section{PLA'TE XXXIX.}

Fig. 1. Glyphocrangon sicaria FAX.

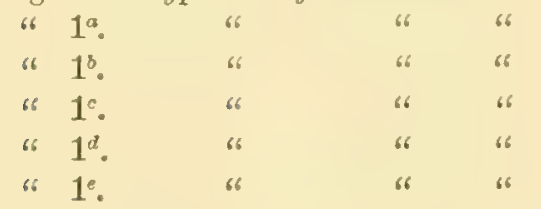

Fig. 1. Heterocarpus vicarins $\mathrm{F}_{\mathbf{A X}}$.

$\begin{array}{ccccc}" & 1^{a} & " & " & \text { " } \\ " & 1^{b} & \text { " } & \text { " } & \text { " } \\ " & 2 . & \text { Heterocarpus affinis } & \text { FAx. } \\ " & 2^{a} \text {. } & \text { " } & \text { " } & \text { " } \\ \text { " } & 2^{b} & \text { " } & & \text { " }\end{array}$

Fig. 1. Heterocarpus hostilis FAx.

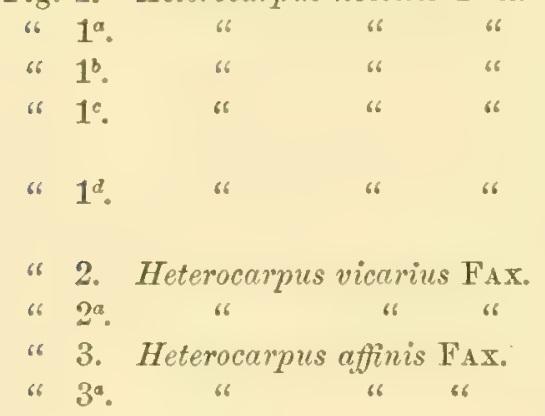

Dorsal view. Natural size.

Lateral view. Natural size.

End of third leg.

End of fifth leg.

Leg of second pair.

Leg of fourth pair.

\section{PLATE XL。}

Natural size.

Swimmeret.

Antennal scale.

Female. Natural size.

Swimmeret.

Antennal scale.

\section{PLATE XLI.}

Female. Natural size.

Swimmeret.

Antennal scale.

First abdominal appendage of right side, male.

Carapace of an abnormal female from Station 3395. Natural size.

Left leg of second pair.

Right leg of second pair.

Left leg of second pair.

Right leg of second pair.

\section{PIATE XLII.}

Fig. 1. Nematocarcinus agassizii FAx.

"19.

"f $1^{b}$.

"1 1 .

" $1^{d}$.

$\begin{array}{lll}\text { "6 } & \text { "6 } & \text { "6 } \\ \text { "6 } & \text { "6 } & \text { "6 }\end{array}$

Female. Natural size.

Distal part of leg of first pair.

Distal part of leg of second pair.

Distal part of leg of third pair.

Distal part of leg of fifth pair. 


\section{PLATE XLIII.}

Fig. 1. Acanthephyra cristata FAx.

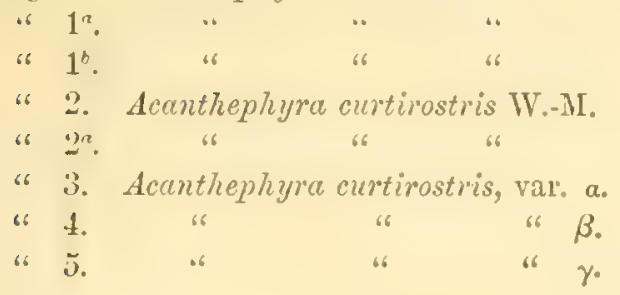

Enlarged.

Swimmeret.

Antemal scale.

Male. Carapace.

Swimmeret.

Carapace.

Carapace.

Carapace.

\section{PLATE XLIV.}

Fig. 1. Acanthephyra cucullata FAx.

. $1^{a}$. " . " " "

" 1 "

“2. Notostomus fragilis FAx.

" 2 ". " " " " "

6 23.6406
Male. $\times 1$ s.

Swimmeret.

Antennal scale.

Enlarged.

Swimmeret.

Antennal scale.
Fig. 1. Pasiphaeia americana Fsx.

\begin{tabular}{|c|c|c|c|}
\hline $1^{12}$ & "6 & 6 & 18 \\
\hline $1^{\mathrm{s}}$ & " & "6 & ، \\
\hline $1^{c}$. & " &. & * \\
\hline $1^{\prime}$. & . & . & . \\
\hline $1^{\circ}$. & ،. & " & ، \\
\hline 2. & Pasiphaeice & magna & FAX. \\
\hline $2 t$ & $" 6$ & " & " \\
\hline $2^{h}$. & .. & . & . \\
\hline 2 & . & .. & . \\
\hline
\end{tabular}

Fig. 1. Sicyonia afpinis EAX.

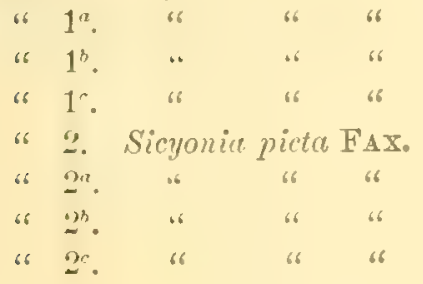

Fig. 1. Peneus balboce Fax.

\begin{tabular}{|c|c|c|c|}
\hline $1^{a}$. & " & " & "6 \\
\hline $1^{b}$. & ، & .6 & ." \\
\hline $1 \%$ & " & " & " \\
\hline 2. & Solenoce & $r a a g$ & ssiz \\
\hline $2^{a}$ & " & & $"$ \\
\hline $2^{b}$ & " & & 6 \\
\hline $2 c$ & " & & 66 \\
\hline
\end{tabular}

\section{PLATE XLV.}

$\times 2$.

Swimmeret.

Antennal scale.

Leg of third pair.

Leg of fourth pair.

Leg of fifth pair.

Natural size.

Swimmeret.

Antennal scale.

Abdominal appendage of first pair.

\section{PLATE XLVI.}

Female. Enlarged.

Rostrum.

Antennal scale.

Swimmeret.

$\times 11$

Rostrum.

Antennal scale.

Swimmeret.

PLATE XLVII.

Female. Natural size.

Swimmeret.

Antennal scale.

Gills.

Natural size.

Swimmeret.

Antennal scale.

Petasma of male. 


\section{PLATE XLVIII.}

Fig. 1. Haliporus nereus $\mathrm{F}_{\mathrm{AX}}$.

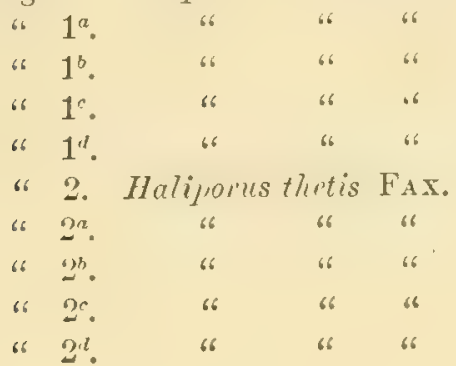

Fig. 1. Haliporus doris Fax.

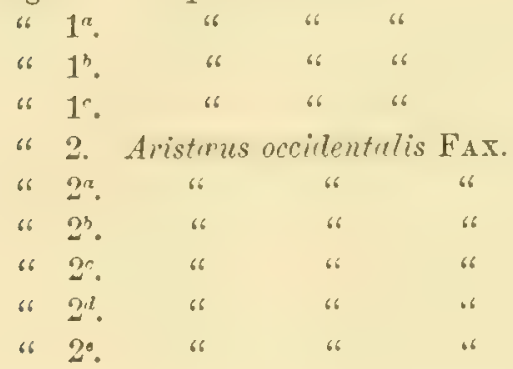

Fig. 1. II mipeneus triton FAx.

\begin{tabular}{|c|c|c|c|}
\hline $1^{a}$. & $"$ & " & " \\
\hline $1^{b}$. & " & $"$ & " \\
\hline 61 . & $" 6$ & " & " \\
\hline $61^{\prime \prime}$. & " & " & “ \\
\hline $6 \quad 1^{e}$. & "6 & $" 6$ & " \\
\hline
\end{tabular}

$\times 1 \frac{2}{3}$.

Sternum of female.

Antennal scale.

Swimmeret.

Abdominal appendage of first pair, male.

Female. $\times 1 \frac{1}{3}$.

Sternum of female.

Antennal scale.

Swimmeret.

Carapace viewed from above.

\section{PLATE XLIX.}

Enlarged.

Sternum of female.

Swimmeret.

Antennal scale.

Female. Natural size.

Sternum of female.

Swimmeret.

Antennal scale.

Carapace of male. Natural size.

Petasma of male.

\section{PLATE 'L.}

Male. Natural size.

Swimmeret of a female.

Sternum of a female.

Antenual scale of a male.

Petasma of a male.

Inner branch of second abdominal appendage of male.

Inner branch of second abdominal appendage of male.

\section{PLATE LT.}

Fig. 1. Sergestes edwardsii KR.

\begin{tabular}{|c|c|c|c|c|}
\hline & $1^{a}$. & $"$ & " & 6 \\
\hline 6 & $1^{6}$. & 6 & $"$ & "6 \\
\hline 66 & $1^{c}$ & " & " & " \\
\hline “ & $1^{d}$ & " & $" ?$ & " \\
\hline "6 & $1^{e}$. & "6 & $" 6$ & 66 \\
\hline "6 & 2. & Sergestes & inous & FAX. \\
\hline 6 & $2^{\alpha}$ & 6 & 6 & $"$ \\
\hline " & $2^{b}$. & " & 16 & $"$ \\
\hline 6 & $2^{c}$ & "6 & “6 & 6 \\
\hline 66 & $2^{t}$ & 66 & 66 & $" 6$ \\
\hline
\end{tabular}

Male. Much enlarged.

Swimmeret.

Anterior part of carapace, and eye.

Antennal scale.

Appendix of first antenna of male.

Petasma of a large male.

Female. Natural size.

Swimmeret.

Anterior part of carapace, and eye.

Antennal scale.

Gills. $p l$ ', posterior pleurobranchia of the twelfth somite. 


\section{PLATE LII.}

Fig. 1. Sergestes bisulcatus IV.-M.

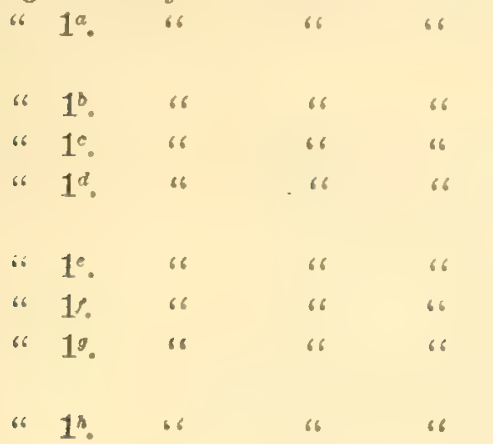

Fig. 1. Eucopia sculpticauda FAx.

$\begin{array}{lllll}\text { " } & 1^{a} . & 66 & 6 & 6 \\ \text { "6 } & 1^{b} . & 66 & 6 & 6 \\ \text { " } & 1^{c} . & 6 & 6 & 6 \\ \text { " } & 1^{\text {d. }} & 66 & 6 & 66\end{array}$

"2. Petelophthalnus "rmiger IV.-S.

$\begin{array}{lllll}\text { "6 } & 2^{a} & 6 & 66 & 66 \\ 6 & 2^{b} & 6 & 66 & 66 \\ \text { "6 } & 2^{c} & 6 & 66 & 66\end{array}$

Enlarged.

Anterior part of carapace. More highly magnified.

Swimmeret.

First antenna of male.

Part of first antenna of male, more enlarged to show the appendicular organ.

Antennal scale, male.

Antenna of first pair, female.

Part of antenna of first pair, female. More enlarged.

Petasma of male.

PLATE LIII.

Female. Enlarged.

Swimmeret.

End of telson, more highly magnified.

Front, eyes and antennæ, from above.

Second antenna.

Female. Cephalo-thorax, much enlarged.

"Blake" Station 29, Gulf of Mexico.

Swimmeret of same specimen.

Second antemna of same specimen.

Firstabdominal appendage of sawe spezimen.

\section{PLATE LIV.}

Fig. 1. Petalophthalmus pacificus FAX.

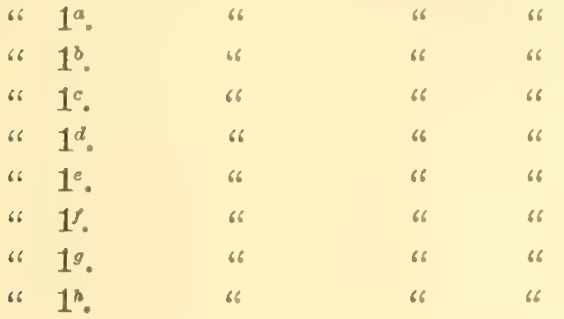

Male. Much enlarged.

Anterior part, from above.

Carapace from above.

Swimmeret.

Modified eye-stalk.

Second antenna.

First abdominal appendage.

Second abdominal appendage.

Fifth abdominal appendage.

\section{PLATE LV.}

Fig. 1. Scolophthalmus lucifugus FAx.

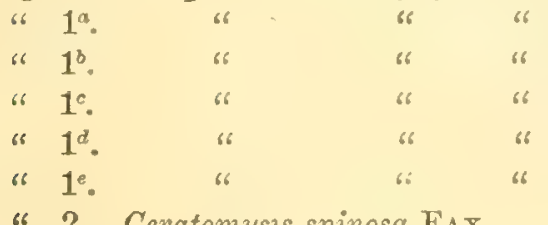

"2. Ceratomysis spinosa FA工.
Female. Much enlarged.

Anterior part, from above.

Carapace from above.

Swimmeret.

Second antenna.

Fifth abdominal appendage.

Female. Lateral view. Much enlarged. 


\section{I'IA'TE LVI.}

Fig. 1. Ceratomysis spinosa FAx.

\begin{tabular}{|c|c|c|}
\hline $1^{n}$ & 66 & $"$ \\
\hline $1^{b}$. & $" 6$ & " \\
\hline $1^{c}$ & $" 6$ & 6 \\
\hline $1^{d}$ & " & " \\
\hline $1^{c}$ & 66 & " \\
\hline $1^{f}$ & 6 & 36 \\
\hline
\end{tabular}

Female. Dorsal view. Much enlarged. First abdominal appendage, left side. Second abdominal appendage, left side. Third abdominal appendage, left side. Fourth abdominal appendage, left side. Fifth abdorninal appendage, left side. Fifth abdominal appendage, right side.

\section{PLATE LVII.}

Hydrographic Sketch of the Pacific, from the Gulf of California to Northern Ecuador, with the Track of the "Albatross," February 22 to April 23, 1891. 


\section{INDEX OF GENERA AND SPECIES.}

Nоте. - Names of species represented in the "Albatross" collection of 1891 are printed in capitals. Synonyms are printed in Italics. The figures in heavy type indicate the pages on which genera and species are described.

Acanthephyra, 159, 160, 241 .

acutifrons, 164, 167.

AGASSizit, $161,244,249,250,256,25 \%$, 262.

APpRoxima, 162, 244, 256, 258, 262.

armata, 160 .

batei, 167 .

benedicti, 166 .

BREVIROSTRIS, 167, 241, 257, 262.

ClistatA, 162, 256, 257, 262, Plate XLIIL, Fig. 1.

cucullata, 167, 256, 262, Plate XLIV., Fig. 1.

Curtirostris, 164, 244, 256, 257, 258, 262, Plate XLIII., Fig. 2.

curtirostris, var. a, 165, 259, Plate

XLIII., Fig. 3.

curtirostris, var. $\beta, 165,258,259$,

Plate XLIII., Fig. 1.

curtirostris, var. $\gamma, 165,256,259$,

Plate XLIII., Fig. 5.

debilis, 163.

gracilis, 163.

hæckelii, 160.

lanceocaudata, 160, 163, 164.

planipes, 166.

purpurea, 161, 244, 249.

sanguinea, 161, 244 .

sica, 161.

tenuipes, 166.

Acanthonyx petiverii, 235.

Achelous, 23.

AFFINIS, 23, 236, 256, 257, 260, Plate

IV., Fig. 1.

BREVIMANUS, 23.

depressifrons, 24, 236 .

SPINIMANUS, 23, 24, 235, 257, 260.
Actæa, 16.

Dovit, 16, 236.

labyrinthica, 17.

nodosa, 236.

setigera, 236 .

sulcata, 236.

Actromornha, 33.

Egreon, 134.

cataphractus, 134.

loricutus, 131.

Ethra scruposa, 237.

scutata, 237.

Ethusa, 27, 34, 241.

challengeri, 36 .

Ciliatifrons, 34, 256, 260, Plate V., Fig. 3.

gracilipes, 36 .

LATA, 35, 236, 257, 260, Plate VI., Fig. 1.

microphthalma, 35, 236 .

pubescens, $3 \tilde{\text {. }}$

simuatifions, 36 .

Ethusina, 27, 36, 241.

abyssicola, 36, 37, 243.

CHALLENGERI, 36, 37, 243, 258, 260 .

GRACILIPES, 36, 243, 257, 258, 260.

gracilipes, var. robusta, 36 .

sinuatifions, 36 .

smituina, 37, 243, 257, 260, Plate

VI., Fig. 2.

Alpheus, 155, 235.

heterocheles, 235.

minor, 235.

PANAMISNSIS, 155.

pelagicus, 160 .

spinifrons, 156 .

Amalopeneus, 208, 249. 
Amathia, 8, 10. agassizii, 10. carpenteri, 10. crassa, 10. hystrix, 10. modesta, 10. rissoana, 10 . tanneri, 10.

Anamathia, 8, 10,11, 241.

agassizii, 10. carpenteri, 8, 10, 11.

crassa, $10,11$.

hystrix, 10, 11 .

livermorii, 10.

modesta, 10.

occidentalis, 8, 258, 260, Plate I., Fig. 2.

pulchra, 10, 11 .

rissoana, 10, 11.

tanneri, 10.

umbonata, 10, 11 .

Anasimus fugax, 235 .

rostratus; 235.

Anoplonotus, 81. politus, 99.

Aratus pisoni, 235.

Arctomysis, 225.

A renæus, 22.

bidens, 22.

cribrarius, 236.

MEXICANUs, 22, 236.

Aristreomorpha, 197, 199.

giglioliana, 199.

rostridentata, 197, 199.

Aristceopsis, 197, 199.

armata, 197, 199.

edwardsiana, 199.

Aristæus, 194, 197, 202, 241.

antennatus, 195, 196, 198.

armatus, 196, 197, 199.

coralinus, 199.

coruscans, 197, 198, 252.

crassipes, 198.

edwardsianus, 196, 199.

foliccens, 196, 197, 199 .

occidentalis, 194, 258, 262, Plate

XLIX., Fig. 2.

rostridentatus, 196, 197, 199.

semidentatus, 196, 198 .

tomentosus, 196, 198.

tridens, 196, 199.
Aristæus virilis, 196, 198.

Astacus jamaicensis, 148.

Atyephyra, 160.

desmarestii, 160.

rosiana, 160 .

Axius, 103, 104, 241.

Acutifroxs, 103, 104, 243, 256, 262,

Plate XXVIII., Fig. 2.

armatus, 104.

CRISTA-GALLI, 104，256，262， Plate

XXVIII., Fig. 1.

stirhynchus, 103, 104.

Batrachonotus fragosus, 235. nicholsi, 235.

Benthesicymus, 203, 204, 208, 241.

ALTUS, $192,203,206,244,256,257,258$, 262.

bartletti, 206 .

brasiliensis, 206 .

iridescens, 207

moratus, 207.

TANNERI, 204, 205, 252, 254, 255, 256, 257, 258, 259, 262, Plate $\mathrm{H}$.

Benthocetes, 204.

Boreomysis, 221, 226, 242.

scyphops, 222.

Calappa, 45, 233.

convexa, 236.

galloides, 236.

Calastacus, 105, 241, 242.

stiljkostris, 106, 258, 262, Plate XXVII., Fig. 1.

Calcinus, 55 . obscurus, 55.

Callinectes arcuatus, 236.

bellicosus, 236 .

bocourti, 236 .

danæ, 236.

ornatus, 236.

toxotes, 236.

tumidus, 236.

Calocaris, 105, 106, 242. macandrex, 105, 106, Plate XXVII., Fig. 2.

Cambarus, 74 .

Campylonotus, 159.

Cancellus, 52. canaliculatus, 54 . parfaiti, 54 .

TANNeri, 52, 257, 260, Plate XI., Fig.1. 
Cancellus typus, 54.

Cancer, 16, 234.

borealis, 16, 234.

canaliculatus, 54.

cataphractus, 134.

cymodoce, 22.

grapsus, 30.

jamaicensis, 148.

LONGIPES, 16, 234, 240, 256, 260.

minutus, 29, 30.

Carcinus mænas, 235.

Caridina desmarestii, 160.

Carpilodes, 237. cinctimanus, 237.

Catapagurus, 57, 241.

australis, 59.

DIOMIEDE.E, 57, 256, 260, Plate XIII.,

Fig. 2.

gracilis, 59.

sharreri, 59.

Ceraphilus agassizii, 136.

Ceratomysis, 226, 227, 241, 242.

SPINOSA, 228, 252, 257, 262, Plate LV., Fig. 2, Plate LVI.

Chalaraspis, 219.

alata, 219.

unguiculata, 219.

unguifera, 219.

Cheraphilus, $13 t$.

catephractus, 134.

ferox, 134.

Chorilia, 11.

longipes, 11.

Chorilibinia, 237.

Clibanarius panamensis, 237. vittatus, 237.

Conobita, 52. COMPRESSUS, 52 .

Collodes granosus, 235. tenuirostris, 235. trispinosus, 235.

Crangon, 133.

Cronius ruber, 235.

Cyclomaia, 12.

Cymopolia, 38, 241.

dentata, 236.

dilatata, 39, 236 .

Fragilis, 40, 257, 260, Plate VI., Fig. 4.

TUBERCULATA, 38, 236, 256, 260, Plate VI., Fig. 3.

zonata, 39, 236.
Daira americana, 237. perlata, 237.

Deidamia, 125.

Dermaturus, 50.

Diptychus, 101.

bellus, 102.

nitidus, var. occidentalis, 101.

pubescens, 101.

Ebalia, 41, 241.

SP. INDET., 41, 256, 260.

Echinocerus, 45, 46.

cibarius, 45.

diomedece, $45,46$.

foramiuatus, 45,47 .

Eclytaspis, 219.

alata, 219.

Egeon. See Egæon.

Eiconaxius. See Iconaxius.

Elasmonotus, 81, 82, 83.

asper, 96.

brevimanus, 82 .

carinipes, 97.

edwardsii, 100.

latifrons, 81, 82, 99.

longimanus, 98.

marginatus, 100.

quadratus, 97.

Elassochirus, 55.

Ephyra, 159, 160.

compressa, 160.

hreckelii, 160.

pelagica, 160.

Ephyrina, 159, 166.

benedicti, 166.

Epialtus affinis, 235.

sulcirostris, 235.

Eriphia gonagra, 236. squamata, 236.

Eryon, 245.

Eryonicus, 108, 241.

c.ecUs, 108, 110, 116, 244, 256, 257, 258, 262, Ylate B, Fig. 2, Plate XXIX, Fig. 2, Plate XXX.

SPINUlosus, 110, 116, 244, 258, 262,

Plate XXIX, Fig. 1.

Ethusa. See Athusa.

Ethusina. See Ethusina.

Etcopia, 218, 219, 241, 248, 249, 252.

AUSTRALIs, 218, 219, 220, 245, 257, $258,259,262$. 
EuCOPIA SCULPTICAUdA, 219, 256, 258, 262, Plate K, Fig. 2, Plate LIII, Fig. 1.

Euctenota mexicana, 22.

Eumiersia, 159. ensifera, 156.

Eupagurus, 55. bouvieri, 57. CAliforviensis, 55, 257, 260, Plate XI., Fig. 2.

discoidulis, 61. smithii, -57 . tenuimanus, 55 . ungulatus, 63.

Euprognatha, 6. acuta, 7 . bifida, 7 . gracilipes, 7 . Granulata, 6, 235, 257, 260, Plate I., Fig. 1.

inermis, 7 . rastellifera, 7,235 .

Galacantha, 78, 79, 82, 241, 246. areolata, 79, 243.

bairdii, 83 .

bellis, 79 .

DIOMEDEस, 79, 243, 256, 257, 258, 259, 260, Plate XXV., Fig. 1.

DIOMEDEX, var. PARVISPINA, 80, 258, 259, Plate XXV., Fig. 2.

rostrata, 78, 80,81, 243, 2ã7, 258, 260, Plate B, Fig. 1.

spinosa, 80, 243.

talismanii, 79.

Galatea, 246.

Galathea monodon, 72 .

Galathodes, 81, 82, 83, 93.

abbreviatus, 87.

crinitus, 92.

latifrons, 82.

tridens, 82.

Galathopsis, 83.

Gecarcinus, 28.

malfilensis, 28, Plate IV., Fig. 2. quadratus, $28,29$.

ruricola, 29.

Gelasimus, 29, 235.

gracilis, 236.

heterocheles, 235.

macrodactylus, 29.

maracoani, 235.
Gelasimus pugnax, 236. SP. INDET., 29. stenodactylus, 235 . vocator, 235 .

Gennadas, 204, 207, 208, 241, 249. intermedius, 207. parvus, 244.

SP. INDET., 207, 244, 257, 259, 262.

Geograpsus lividus, 235 .

Ceryon quinquedens, 27.

Glyphocrangon, 137, 241. aculeata, 138, 142. acuminata, 144, 244. ALAtA, 137, 256, 258, 262, Plate XXXVII.

\section{сæca, 138.}

creescens, 146

gilesii, 144.

investigatoris, 138, 142.

longirostris, 143, 146.

loircata, 138, 140, 258, 262, Plate XXXVIII. bis.

мовтLIs, $142,145,244,256,257,258$, $259,262$.

regalis, 138, 142.

SICARIA, 144, 256, 262, Plate XXXIX. smithii, 138, 142.

SPINULOSA, 138, 257, 258, 259, 262,

Plate XXXVIII.

unguiculata, 144.

Glyptolithodes, 42.

Cristatipes, 43, 256, 260, Plate VII., Fig. 2.

G]yptoxanthus, 17. erosus, 236.

LABTRINTHICUS, 17, 236.

Gnathophausia, 215, 241, 252, 253.

BREVISPINIS, 216, 245, 257, 258, 262,

Plate $\boldsymbol{J}$.

dentuta, 216.

gracilis, 217.

gracilis, var. brevispinis, 216.

sarsii, 215, 245.

WILLEMORSII, $215,245,256,259,262$,

Plate K, Fig. 1.

ZOEA, 215, 244, 258, 262.

Gnathophyllum, 146.

elegans, 146, 147.

elegans, var. brevirostris, 147 .

fasciolatum, $14 i$.

pallidum, 147. 
Grathophrludi PANanexse, 146, Plate E. zebra, 147.

Gnatophyllum. See Gnathophyllum.

Goniopsis cruentata, 235.

Grapsus, 30.

altifrons, 30.

GRAPSUS, 30.

Haliporus, 188, 189, 190, 193, 241.

æqualis, 191, 252.

DoRIs, 191, 192, 193, 258, 262, Plate XIIX., Fig. 1.

lævis, 190, 244.

neptunus, 252.

NEREUS, 189, 191, 192, 193, 244, 256, 257, 258, 262, Plate XLVIII., Fig. 1.

obliquirostris, 191.

TIIETIS, 192, 258, 262, Plate XLVIII., Fig. 2.

Hansenomysis, 225, 226, 242. fyllæ, 225.

Hemicaridina, 160. desmarestii, 160.

Hemipeneus, 196, 197, 198, 200, 202, 241. carpenteri, 199, 203, 244, 252.

gracilis, 198.

semidentatus, 196, 198.

speciosus, 195.

SPINIDORSALIS, 19S, 200, 202, 203, 244, 257, 25s, 262, Plate L., Fig. 2.

tomentosus, 196.

TRITON, 199, 202, 244, 256, 257, 258, 262, Plate I., Fig. 1.

virilis, 196, 198.

Hepatus, 33, 34.

Hepomadus tener, 252.

Herbstia camptacantha, 236. depressa, 236.

Heteractea, 21. ceratopus, 236. LUNATA, 21, 236.

Heterocarpus, 148, 151, $155,241$. AFFINIS, 149, 151，154，244，259，262,

Plate XL., Fig. 2, Plate XLI., Fig. 3. alexandri, 149, 151.

alphonsi, 149, $153,244$. carinatus, $149,151$.

dorsalis, $149,-151,154$.

ensifer, 149, 151.

gibbosus, $149,150,151$.
Heterocarpus hostilis, $149,151,154,244$, 256, 257, 262, Plate XLI., Fig. 1.

lævigatus, 149 .

lavis, $149,151$.

oryx, 149, 151.

VICArIUS, 148, 256, 262, Plate XL., Fig. 1, Plate XLI., Fig. 2.

Heterocryptít granulata, 236. macrobrachia, 236. sp. non descr., 236.

Hippa emerita, 235̃.

Hippolyte desmarestii, 160. varians, 252.

Hoplophorus, 159.

Hyastenus, 10, 11. longipes, 11.

Hymenodora, 167, 168, 171, 241. duplex, 167.

GLACIALIS, $168,244,249,256,25 \%$, $259,262$.

gracilis, 169 .

Hymenopeneus, 191, 193.

Hypoconcha arcuata, 237.

panamensis, 237.

sabulosa, 237.

Hypopeltarium, 242.

Iconaxius, 103, 104, 241, 242. acutifions, 103, 104, 243.

farrece, 104.

Lambrus, 14.

HASSLERI, 14, 236, 257, 259, 260, Plate III., Fig. 1.

pourtalesii, 15, 16, 236.

verrillii, $15,16$.

Leander serrator, 254.

Lepidopa myops, 237. scutellata, 237 .

Leptodius floridanus, 236. occidentalis, 236 .

Leptolithodes, 45, 46, 47, 241.

aculeatus, 45, 47.

ASPER, 45, 47, 50, 243, 256, 260, Plate VIII.

LONGIPES, 45, 47, 48, 243, 257, 260, Plate IX.

multispinus, 50, 243.

Leptomithrax, 12.

Leptopodia, 5.

DEBILIS, 5, 235. 
Leptopodia modesta, 6 . sagittaria, 5, 6, 235.

Leucifer. See Lucifer.

Libinia macdonaldi, 236. spinimana, 236.

Lithodes, 50, 234, 241. agassizii, 51, 243.

diomedere, 243, 257, 258 .

grunulosus, 44.

grimaldii, 243.

maia, 52.

murrayi, 51, 52.

paramensis, 50, 256, 260, Plate $\mathrm{X}$., Fig. 1.

SP. IN Det., 51, 52, 259, Plate X., Fig. 2. turritus, 51 .

Lophactæa lobata, 236. rotundata, 236.

I.ucifer, 214. ACESTRA, 214. reynaudii, $214,215$.

Lysiosquilla desaussurei, 237. scabricauda, 237.

Maia, 12.

Maiella, 12.

Maiopsis, 11. Pavamensis, 13, 256, 260, Plate II.

Menippe, 21. FRONTALIS, 21, 236.

obtusa, 236.

mercenaria, 236.

Mesorrhœa gilli, 236. sexspinosa, 236.

Micropanope, 20. polita, 19, 20. pugilator, 20. sculptipes, 20 .

Microphrys weddellii, 235.

Miersia, 159, 160. agassizii, 161. pelagica, 160.

Mithrax armatus, 236. hispidus, 236. sinensis, 236. spinosissimus, 236. tuberculatus, 236.

Munida, 73, 74, 241, 246. caribbæa, 73. GRACILIPES, 77, 256, 260, Plate XVI., Fig. 2.
MIunida iris, 73,76 .

irrasa, 73,76 .

MICROPHTHALMA, $78,257,260$.

miles, 73,77 .

o Bes A, 73, 256, 260, Plate XVI., Fig. 1.

propinqua, 76, 256, 258, 260, Plate XVIII., Fig. 1.

REFUlgens，75，257，259，260, Plate XVII.

stimpsoni, $77,78,241$.

valida, 73,77 .

Munidopsis, 81, 241, 246, 251.

abbreviata, $87,243$.

AgassiziI, 88, 256, 260, Plate XVIII., Fig. 4.

ASPERA, $96,243,256,257,258,260$.

BAIRDII, $83,243,256,260$.

brevimana, $81,82,84,243$.

carintpes, 97, 243, 256, 260, Plate

XXIV., Fig. 1.

CILIATA, $82,84,85,243,256,257,260$,

Plate XVIII., Fig. 3.

crassa, 86, 243.

Crinita, 92, 256, 260, Plate XX., Fig. 3. curvirostra, 81 .

cylindrophthalma, 243.

DEpressa, 96, 259, 260, Plate XXII.,

Fig. 2.

edwardsii, 100, 101, 243.

erinacea, 89.

hamata, 95, 96, 256, 260, Plate XXI., Fig. 2.

HENDERSONIANA, 100, 243, 256, 260,

Plate XXIV., Fig. 2.

HYstrix, 89, 258, 259, 260, Plate XIX.,

Fig. 1.

INERMis, 98, 256, 260, Plate XXIII.,

Fig. 2.

latifrons, 93 .

LAtirostris, 82, 99, 243, 256, 260.

longimana, 98, 243.

MARgarita, 91, 258, 260, Plate XX.

Fig. 2.

marginata, 100.

nitida, 84, 243.

orxata, 87, 258, 260, Plate XX., Fig. 1. polita, 99 .

QUADratA, 97, 259, 260, Plate XXIII.,

Fig. 1.

SCABRA, 93, 94, 259, 260, Plate XXI.

Fig. 1. 
Munidopsis sericea, 90, 256, 260, Plate XIX., Fig. 3.

sharreri, 94.

spinifera, 89.

SUBSQUAMOSA, 85, 243, 257, 260.

SUIBSQUAMOSA ACULEATA, $86,243,256$, 260.

subsquamosa pallida, 85, 243.

TANNERI, 94, 256, 260, Plate XXII., Fig. 1.

tridens, 93.

tridentata, 93.

Vicins, 85, 243, 256, 257, 260, Plate XVIII., Fig. 2.

villosA, 86, 243, 256, 260, Plate XIX., Fig. 2.

Myra, 237.

Nautilograpsus, 29.

Naxia, 10.

Nematocarcinus, 156, 159, 241.

AGASSIZII, 158, 256, 257, 258, 259, 262, Plate XLII.

ENSIFER, 156, 244, 256, 257, 258, 259, 262.

Nephropsis, 127, 241, 243.

aculeatr, 128.

agassizii, 127, 128.

atlantica, 127, 128 .

carpenteri, 128.

commbiensis, 128 .

oCCIDENTALIS, 127, 243, 258, 259, 262,

Plate D, Fig. 1.

orientalis, 128 .

rosea, 128.

stewarti, 127, 128.

suhmi, 128.

Neptunus iridescens, 236.

mexicanus, 22 .

spinicarpus, 236.

Nika edulis, 252.

Notopus, 42.

atlanticus, 42.

dorsipes, 42.

ovalis, 42.

Notostomus, 170, 241, 253.

FRAGILIS, 170, 257, 262, Plate XLIV.,

Fig. 2.

patentissimus, $172,173,244$.

WESTERGRENI, 171，244，257，262, Plate F.
Ocypode, 233.

arenaria, 235.

Ethra. See Ethra.

Oplophorus. See Hoplophorus.

Orophorrhynchus, 81, 82, 83.

aries, 82.

hendersonianus, 100.

latifrons, 99.

nitidus, 84 .

spinosus, 82.

Osachila, 32.

acuta, 33.

LATA, 32, 259, 260, Plate T., Fig. 2.

stimpsonii, 33,34 .

tuberosa, 33,34 .

Othonia lherminieri, 236.

quinquedentata, 236.

sexdentata, 236.

Ozius, 21.

perlatus, 236.

reticulatus, 236 .

VERREAUXI, 21.

Pachycheles, 71.

barbatus, 72 .

Panamexsis, 71, Plate XV., Fig. 2.

rudis, 71 .

tuberculipes, 71 .

Paguristes, 66.

degueti, 237.

depressus, 237.

FECUNDUS, 66, 237, 257, 260, Plate

XIV., Fig. 2.

lymani, 68, 237.

sericeus, 237.

subpilosus, 68 .

Pagurodes pilifer, 59.

Falæmon, 148. JAMAICENSIS, 148.

Pandalopsis, 155, 241, 242.

AMPLA, 155, 244, 259, 262.

Pandalus, 149, 155. pelagicus, 160 .

Panopeus, 18. herbstii. 236.

LATus, 18, 236, 256, 260, Pl. III., Fjg. 3 .

politus, 20 .

tanneri, 19, 257, 258, 260, Plate III.,

Fig. 4.

validus, 236.

xanthiformis, 19,226 . 
Panulirus, 107.

SP. INDET., 107, 257, 262.

Paracrangon, 128, 241, 24:.

AREOLATA, 129, 259, 262, Plate

XXXIV.

echinata, 131.

hystrix, 131.

Paralomis, 44, 240.

aculeata, $45,47$.

aspera, 45,47 .

DIOMEDEE, 45, 46, 256, 260, Plate

VII., Fig. 3.

formosa, 4 .

granulosa, 44, 45, 46, 47.

longipes, $45,47,48$.

Paramithrax, 12.

Parapagurus, 68, 241.

abyssorum, 68, 245.

PILOSMIANUS AITSSORUMi, 68,243 , $245,256,257,258,259,260$.

Paratya, 160.

compressa, 160 .

Pasiphae, 173.

glaciulis, 168.

princeps, 175.

Pasiphaeia, 173, 241.

Acutifross, 175, 244, 258, 262.

AMERICANA, 173, 244, 256, 258, 262,

Plate XLV., Fig. 1.

cristata, $174,175,244$.

cristata americana, 173.

MAgNa, 176, 256, 262, Plate XLV., Fig. 2.

norvegica, 176.

PRINCEPS, $175,176,178,244,25 s, 262$.

tarda, $176,178$.

Pelia mutica, 236 .

pacifica, 236.

Penæus. See Peneus.

Peneopsis, 185, 187, 188, 241.

DIOMEDE.E, 185, 256, 257, 262, Plate G. ocularis, $187,188$.

Peneus, 181, 187, 241.

antennatus, 195, 197, 198.

BALBOF, 181, 257, 262, Plate XLVII.,

Fig. 1.

crassicomis, 185.

distinctus, 185.

edwardsianus, 196, 199.

foliaceus, 196, 199.

membranaceus, 184.
Peneus siphonoceros, 184.

Pentacheles, 108, 117, 118, 119.

beaumontii, 125.

euthrix, 119.

gracilis, 118.

lavis, 118.

nanus, 121.

obscurus, 118.

spinosus, 122 .

Pericera fossata, 236.

spinosissima, 236.

triangulata, 236.

trispinosa, 236.

Persephona, 237.

Petalophthalmus, 221, 223, 226, 241, 242 , $248,252$.

armiger, 221, 222, 223, 224, 245, l'late

LIII., Fig. 2.

PACIFICUS, 221, 222, 223, 245, 259, 262,

Plate LIV.

Petrolisthes, 69.

agassizit, 69, Plate XV., Fig. 1.

armatus, $70,235$.

edwardsii, 70 .

ocCIDENTALIS, 69, 70, 237.

sexspinosus, 70, 237.

similis, 70.

Philonicus, 188.

Phye, 175.

acutifrons, 175 .

alcocki, 175 .

princeps, 175 .

Phyllolithodes, 43.

Pilumnus, 21.

aculeatus, 236.

gemmatus, 236.

LIMOSUS, 21, 236.

lunatus, 21.

xantusii, 236.

Pinnixa, 30.

panamensis, 30, Plate V., Fig. 1.

Planes, 29.

clypeatus, 29.

MinUTUS, 30.

Platymera, 32.

californiensis, 32 .

GAUDICHAUDII, 32, 234, 256, 260.

Pleoticus, 188.

Plesiopeneus, 196, 197, 199. armatus, 196, 197, 199.

edwardsianus, 196, 199. 
Plesiopeneus foliaceus, 196, 199.

gigliolianus, 199.

rostridentatus, 196, 199 .

Pleuroncodes, 72, 73.

IoNodon, 72, 240, 256, 258, 260, Plate

XV., Fig. 3.

planipes, 72.

Podochela riisei, 235. vestita, 235 .

Polycheles, 108, 109, 110, 111, 112, 114, 115, $117,241,245$.

agassizii, 120.

beaumontii, 125.

debilis, 124.

euthrix, 119.

gracilis, 118.

GRAvulatus, 123, 257, 262, Pl. XXXII,

Fig. 1, Pl. XXXII., Fig. 2.

læris, $118,124$.

NANUs, 120, 121, 123, 244, 256, 257, 255, 262, Plate XXXIII., Fig. 1.

obscurus, 118.

sculptus, 121, 122, 123, 244, Plate C, Fig. 2.

SCULPTUS PACIFICUS, 122, 241, 256, 257 ,

258, 259, 262, Plate C, Fig. 1.

TANNERr, 119, 257, 258, 262, Plate XXXI. typhlops, 118, 119.

validus, 124 .

Pontocaris, 13 t.

Pontophilus, 131, 211.

abyssi, 131, 132, 244.

batei, 131, 132 .

challengeri, 132.

gracilis, 131, 132.

jacqueti, 134, 136 .

OCCIDENTAIIS, 131, 244, 256, 257, 258,

262, Plate D, Fig. 2.

Porcellane armate, 70.

Portunus spinimanus, 23.

Pylopagurus, 55, 61.

AfFivis, 64, 237, 256, 260, Plate XII.,

Fig. 2.

hirtimanus, 65, 237, 257, 260, Plate XIII, Fig. 1.

Lovgtmanus, 61, 237, 257, 260, Plate

XII., Fig. 1.

rosaceus, $65,66,237$.

ungulatus, 61, 63, 64, 237.

Quadrella, 237.

nitida, 237.
Ranilia angustata, 236. muricata, 236.

Raninops, 41. constricta, 42, 236.

ForNicata, 41, 236, 257, 260, Plate VII., Fig. 1.

stimpsoni, 42, 236 .

Remipes testudinarius, 237.

Rhachocaris agassizii, 138.

Rhinolithodes, 43. cristatipes, 43.

wosnessenskii, 43.

Sabinea, 131.

hystrix, 131.

princeps, 131.

Schizophrys, 12.

Sclerocrangon, 132, 241, 242.

agassizii, 134, 136, 242, 214.

angusticauda, 134.

ATRox $132,136,244,258,259,262$, Plate XXXV.

boreas, 134 .

ferox, $133,134,136,244$.

jacqueti, 134, 136.

PROCAX, 134, 135, 242, 244, 257, 258, 259, 262, Plate XXXVI.

salebrosa, 134, 244.

Scolophthalmus, 224, 226, 241, 242.

LUcifugus, 226, 258, 262, Plate LV.,

Fig. 1.

Scyra umbonata, 10.

Scyramathia, 10, 11.

carpenteri, 10, 11.

crassa, 10, 11.

umbonuta, 10, 11.

Sergestes, 208, 211.

EISULCATUS, 210,244,256, 258, 259, 262, Plate $\mathrm{I}_{\mathrm{II}}$.

EDWARDsi, 212, Plate LI., Fig. 1.

halia, 214.

INous, 208, 244, 257, 262, Plate LI.,

Fig. 2.

LONGISPINUS, 214.

mollis, 210, 244 .

OCULATUS, 214.

phorcus, 210.

robustus, 211.

Sicyonia, 179, 241.

AFFiNis, 179, 237, 257, 262, Plate

XLVI., Fig. 1.

carinata, 179. 
Sicyonia edwardsii, 179, 237.

lævis, 181.

ocellata, 180.

penicillata, 180.

PICTA, 180, 256, 257, 262, Plate XLVI., Fig. 2.

Solenocera, 183, 241.

AGASsIzIr, 183, 256, 262, Plate XLVII.,

Fig. 2.

crassicornis, 185.

distincta, 184, 185.

hextii, 185.

lucasii, 185.

philippii, 184.

siphonocera, 183, 184, 185.

Solenolambrus arcuatus, 236 .

typicus, 236.

Speocarcinus carolinensis, 236.

granulimanus, 236.

Sphenocarcinus, 7, 235.

AG.ASsizI, 7, 235, 257, 260, Plate I., Fig. 3.

corrosus, 8, 235.

Spiropagurus, 59.

iris, 60, 237.

occineytalis, 59, 237, 257, 260, Plate

XIV., Fig. 1.

Squilla, 230 .

BIFORMIS, 230, 237, 256, 262.

intermedia, 237.

panamensis, 237.

tenuirostris, 252.

Stereomastis, 109, 115, 118.

Systellaspis, 160, 163.

debilis, 163.

hreckelii, 160.

lanceocaudata, 160, 163.

Telmessus, 25.

Thoe erosa, 236.

puella, 236.

sulcata, 236.

Trachycarcinus, 25, 241, 242.

Corallinus, 26, 243, 256, 258, 260, Plate A.
'Trachycarcinus sp. non descr., 242, 243.

'Trapezia, 22, 237.

cœerulea, 22.

CYMODOCE, 22, 237.

formosa, 237.

miniata, 22.

nigrofusca, 237.

rufopunctata, 237.

Trichopeltarion, 25, 242.

Tropiocaris, 159, 166.

planipes, 166.

tenuipes, 166.

Tyche emarginata, 235.

lamellifrons, 235 .

Uhlias ellipticus, 236.

limbatus, 236.

Uroptychus, 101, 241.

Bellus, 102, 256, 262, Plate XXVI., Fig. 2.

insignis, 102.

nitidus, 101.

Nitidus Occidentalis, 101, 256, 260,

Plate XXVI., Fig. 1.

politus, 101.

PUbescens, 101，256，262， Plate XXVI., Fig. 3. uncifer, 101.

Willemoesia, 109, 111, 112, 114, 118, 119 , $125,241$.

forceps, $126,243$.

INORNATA, 125, 243,256, 257, 258, 262, Plate XXxII., Fig. 2, Plate XXXIII., Fig. 3.

leptodactyla, 118, 119, 125, 126, 127. 243.

Xantho denticulatus, 236.

stimpsoni, 236.

Xanthodes, 17, 241.

sulcatus, 17, 256, 260, Plate III., Fig. 2.

Xiphopeneus. 189. 


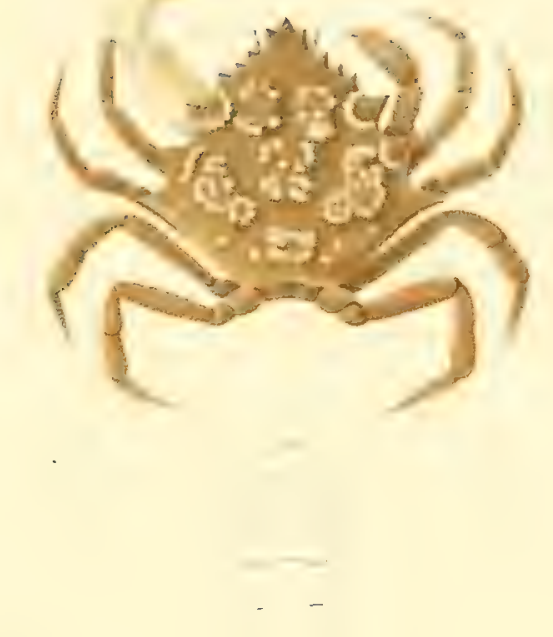




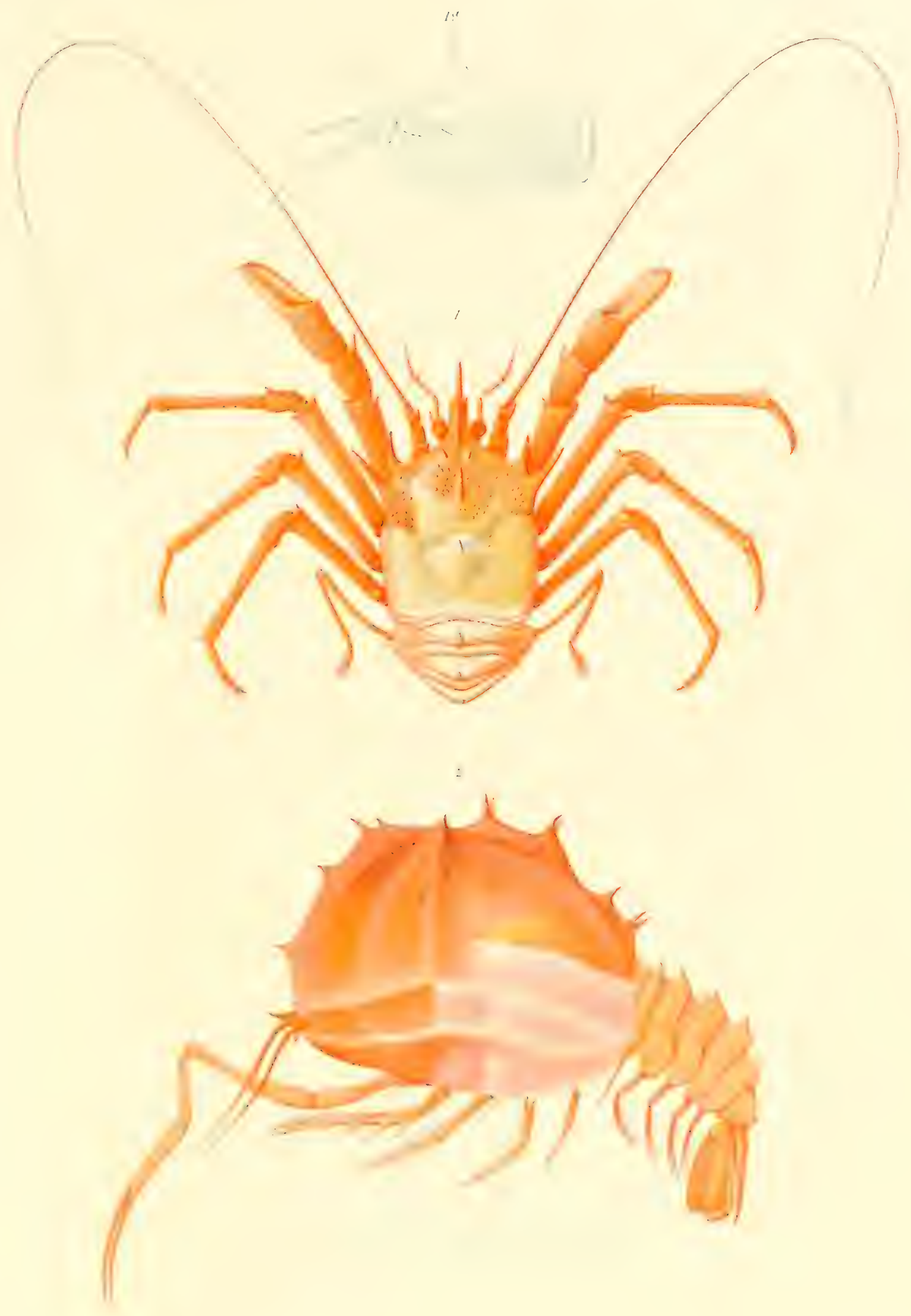



$$
\therefore \therefore \therefore=\because \because \because \& 1
$$

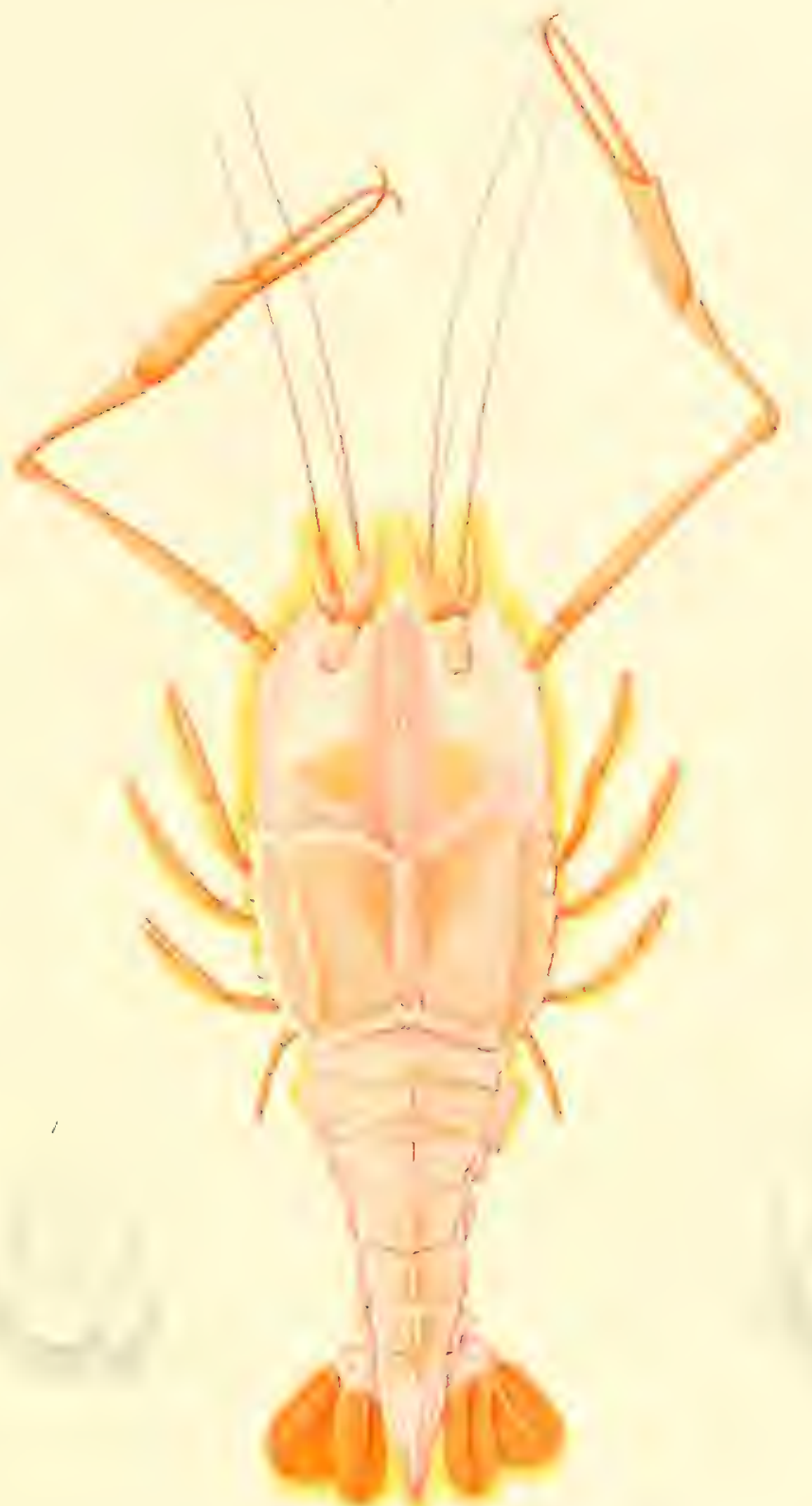


. 

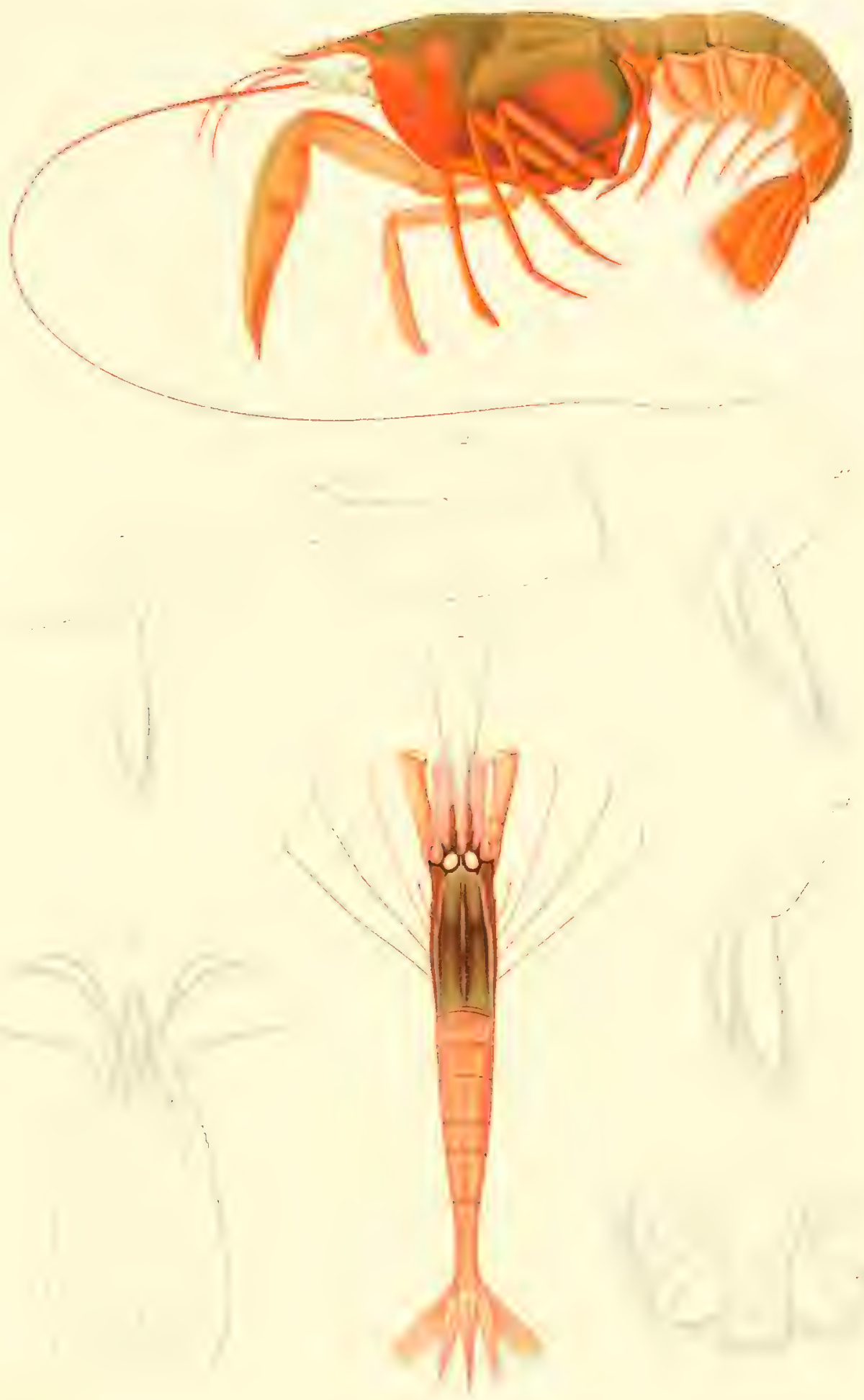




$$
f
$$




.


(5)
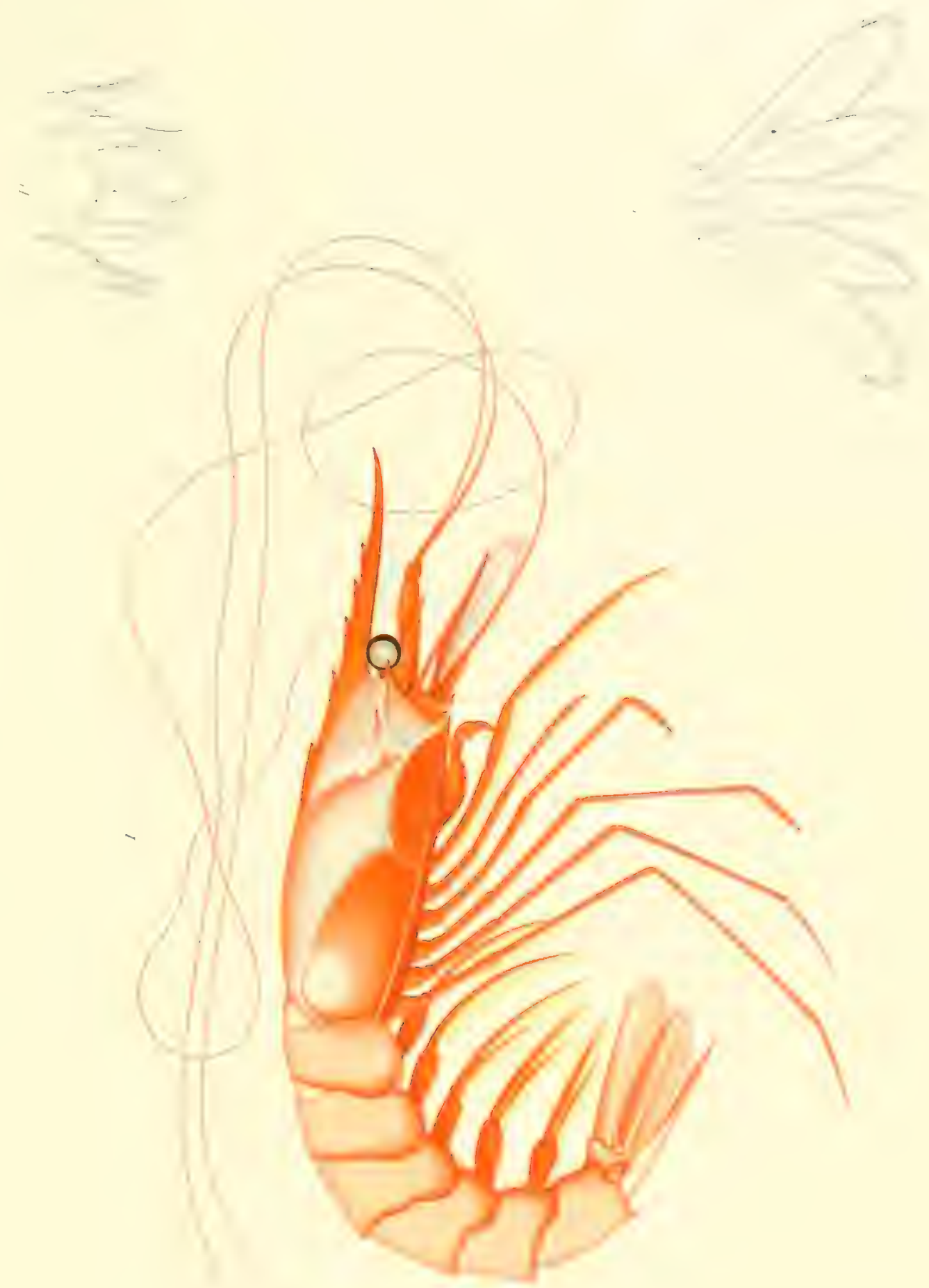

$\overline{0}$
$\square$
$\vdots$
$\vdots$
$\vdots$
$\vdots$
$=$

$=$

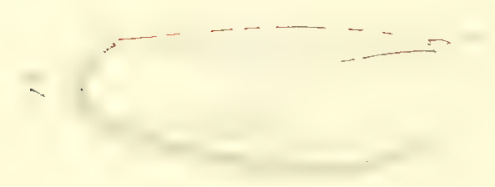




\section{.}



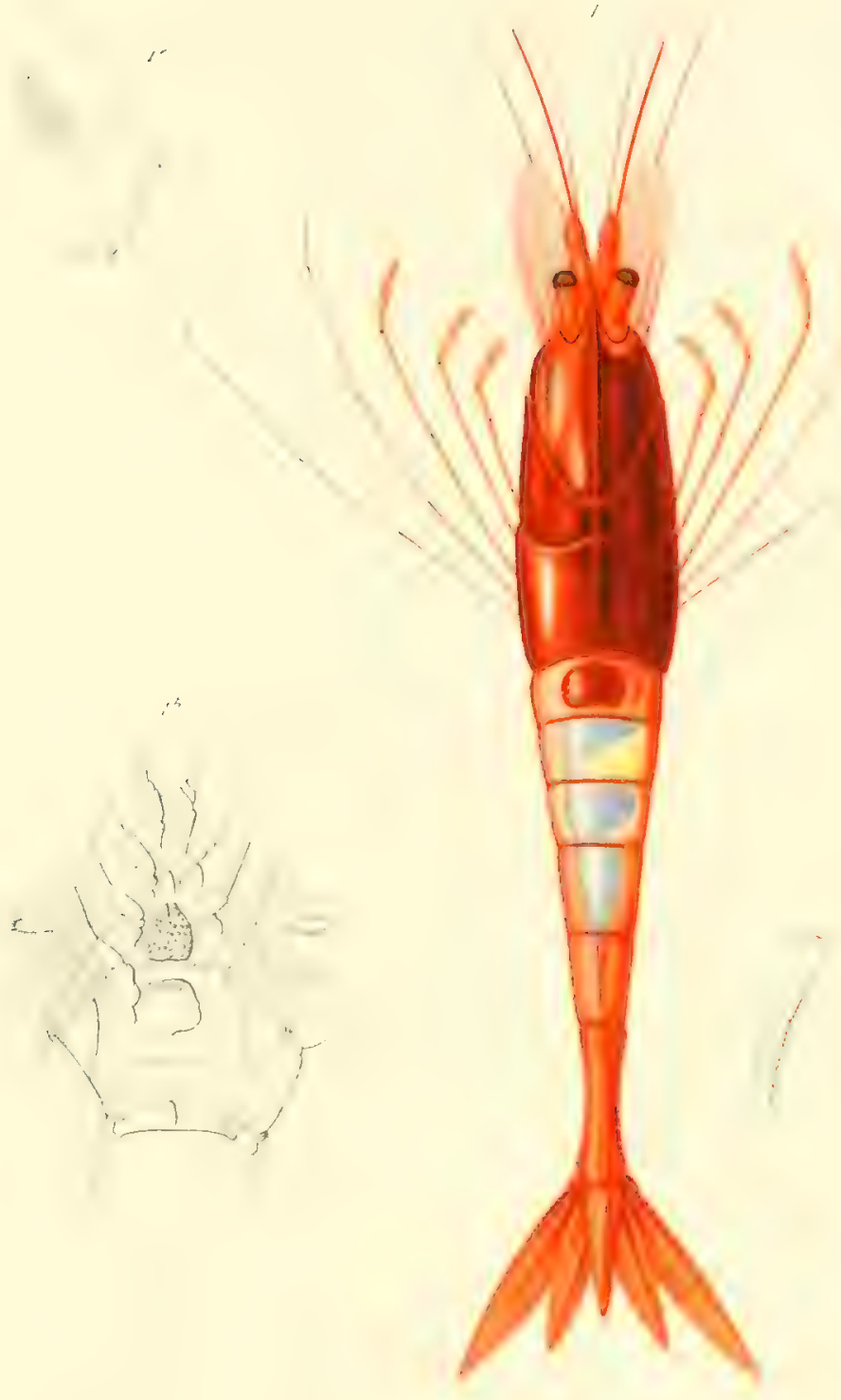


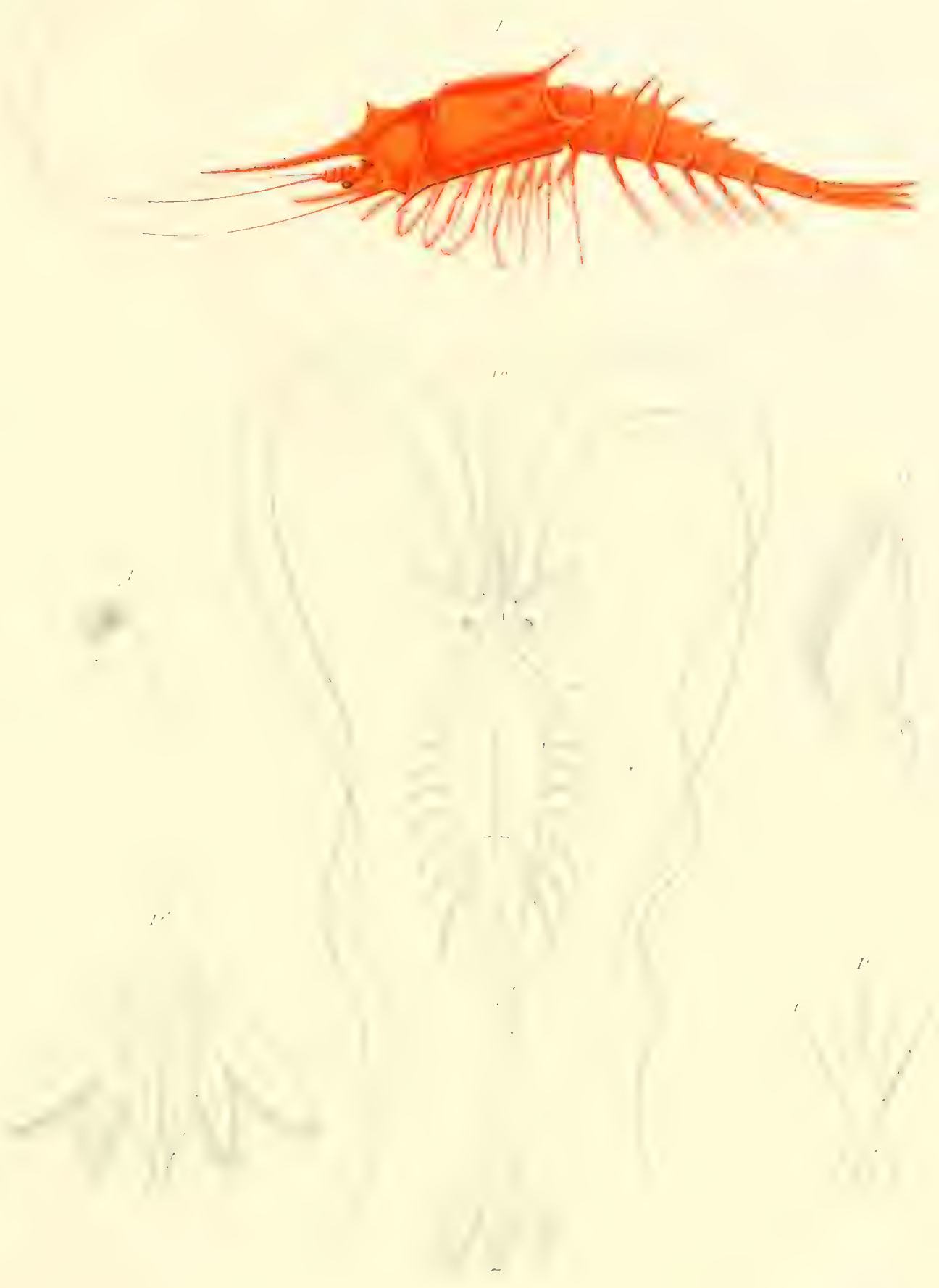


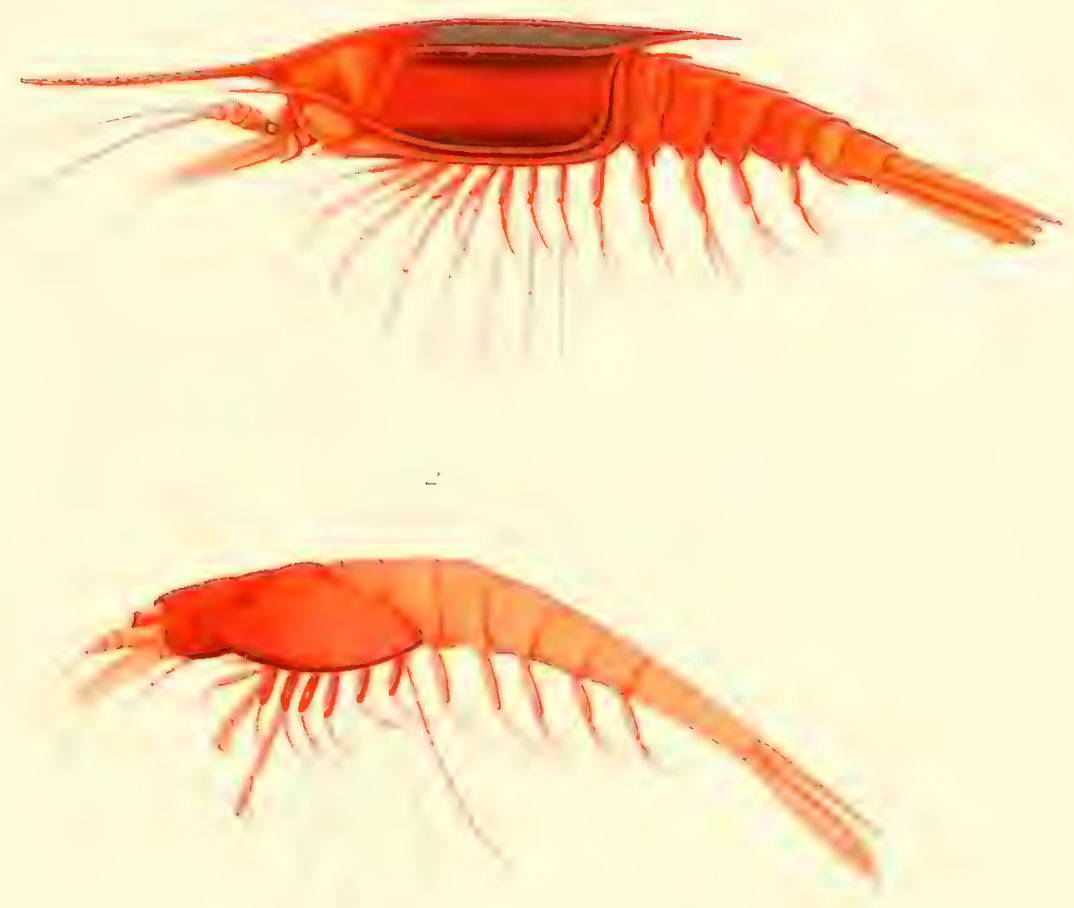

$\therefore$

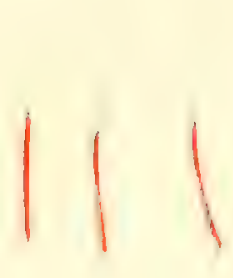





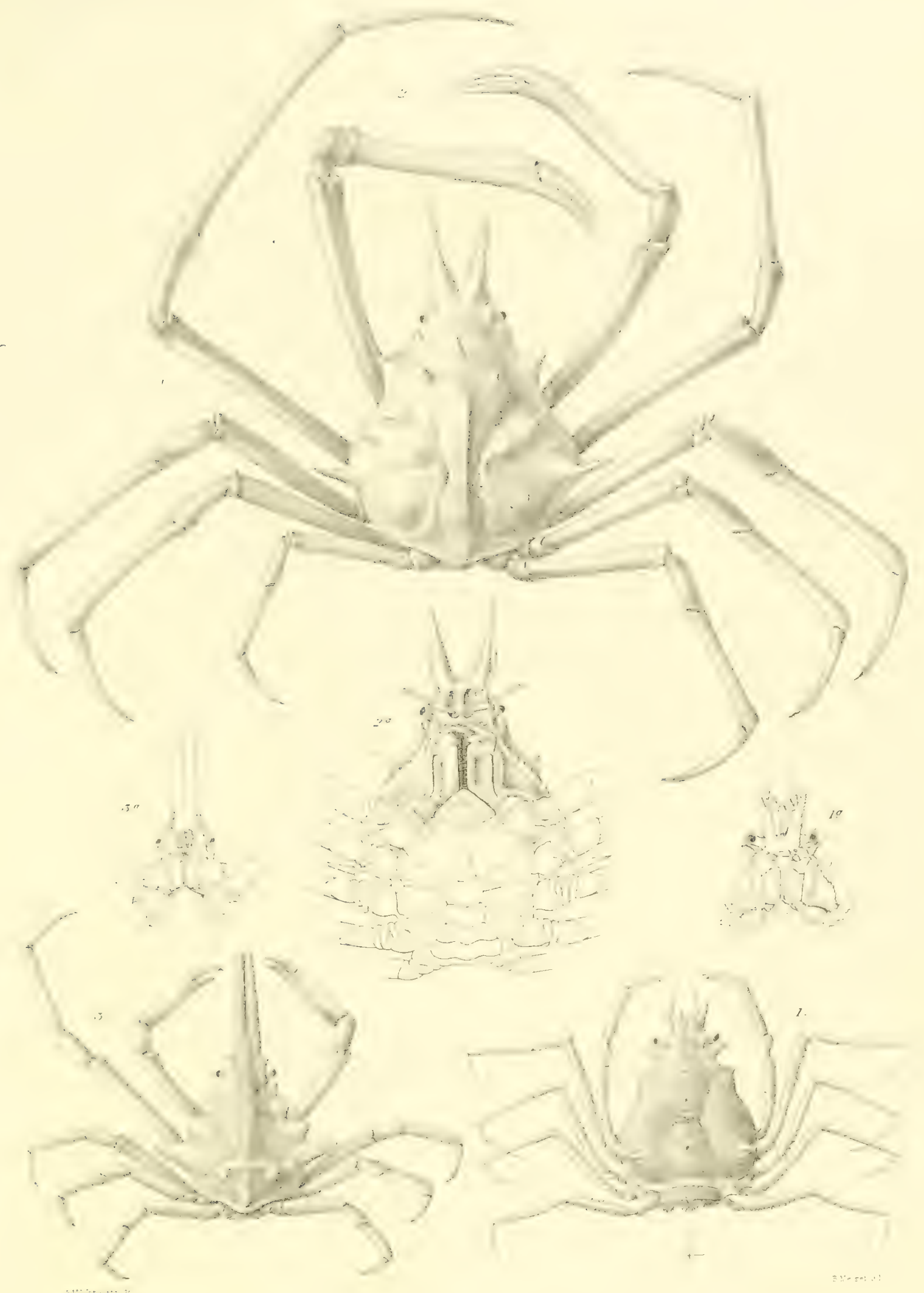




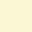




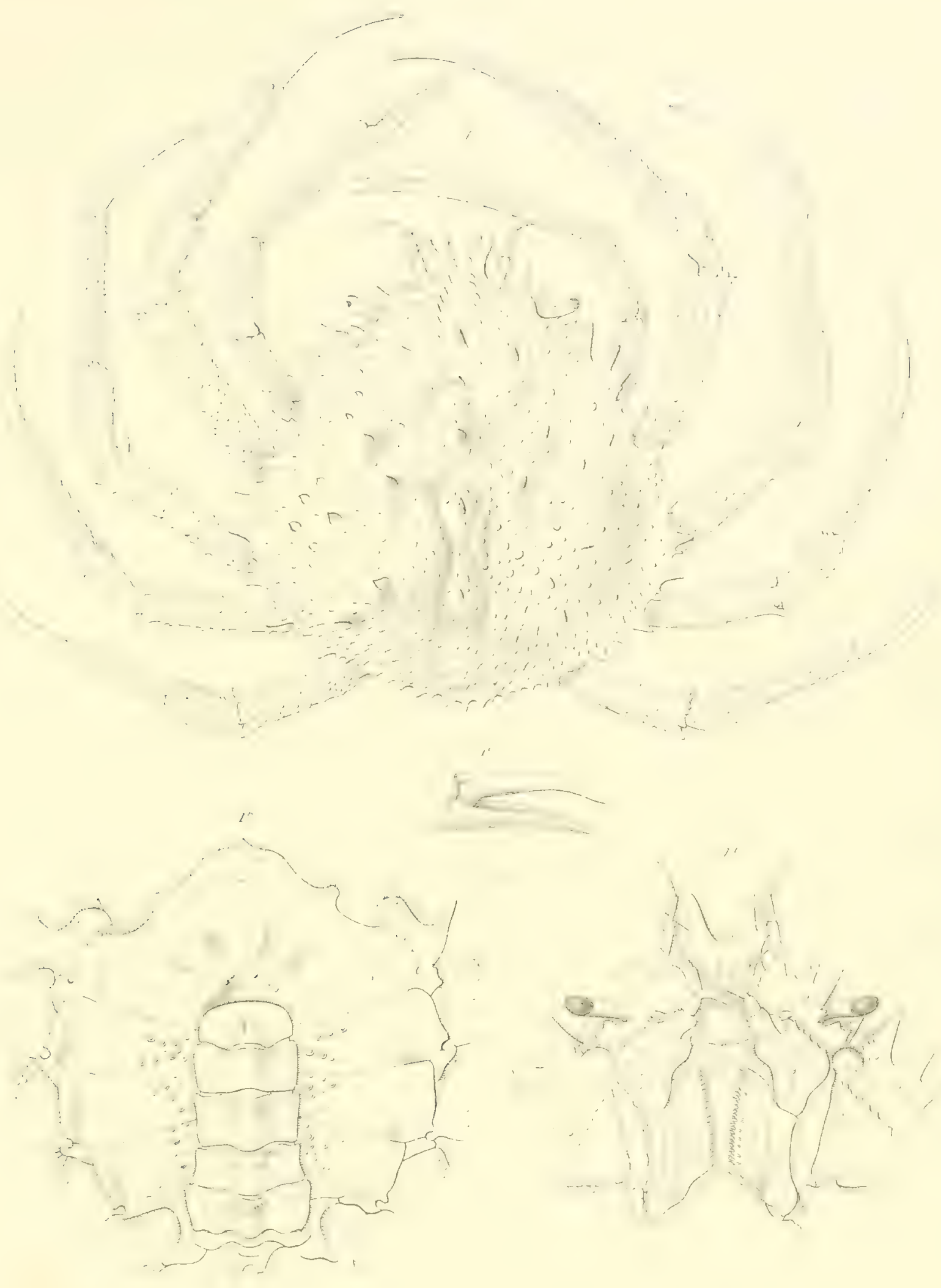



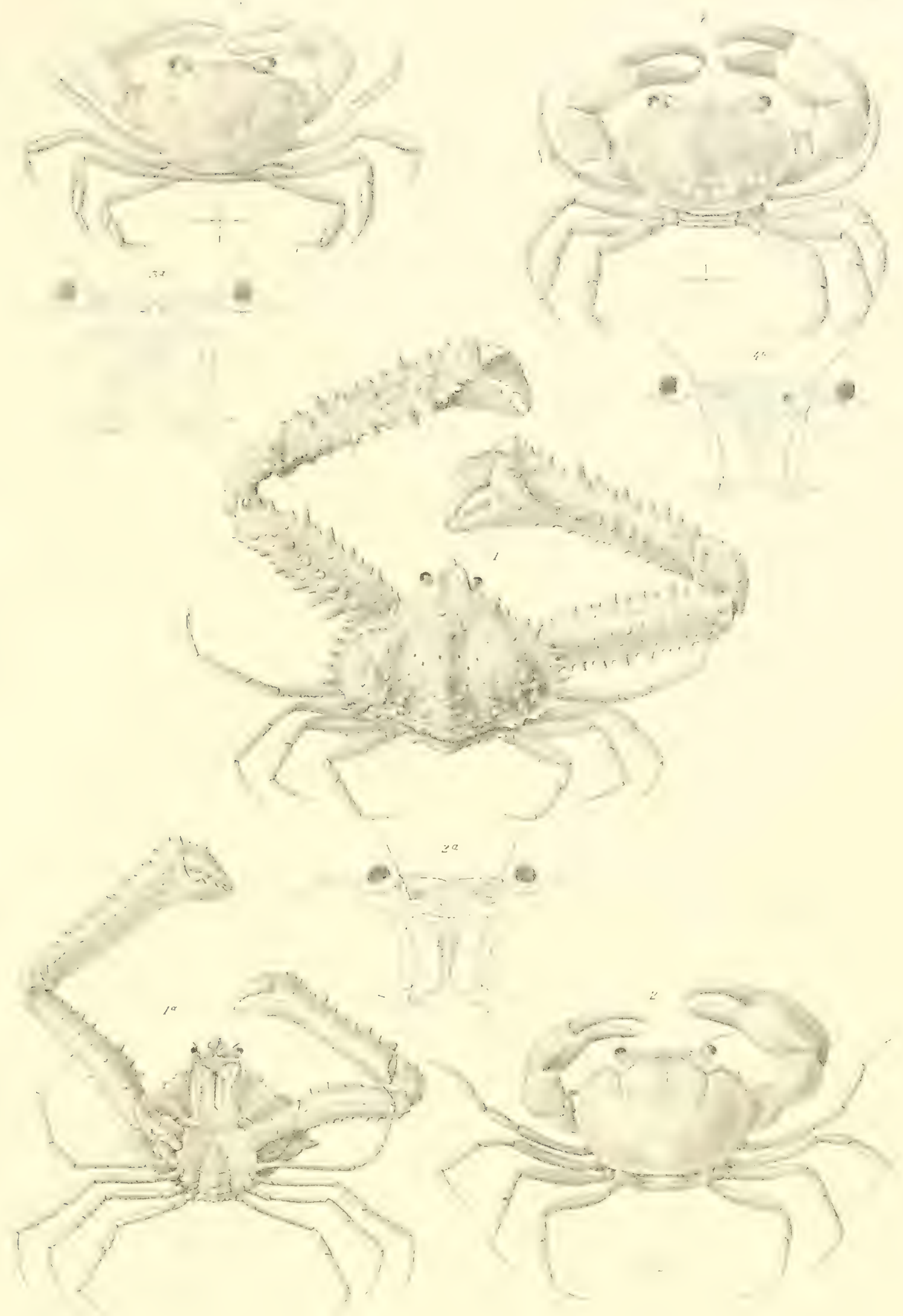


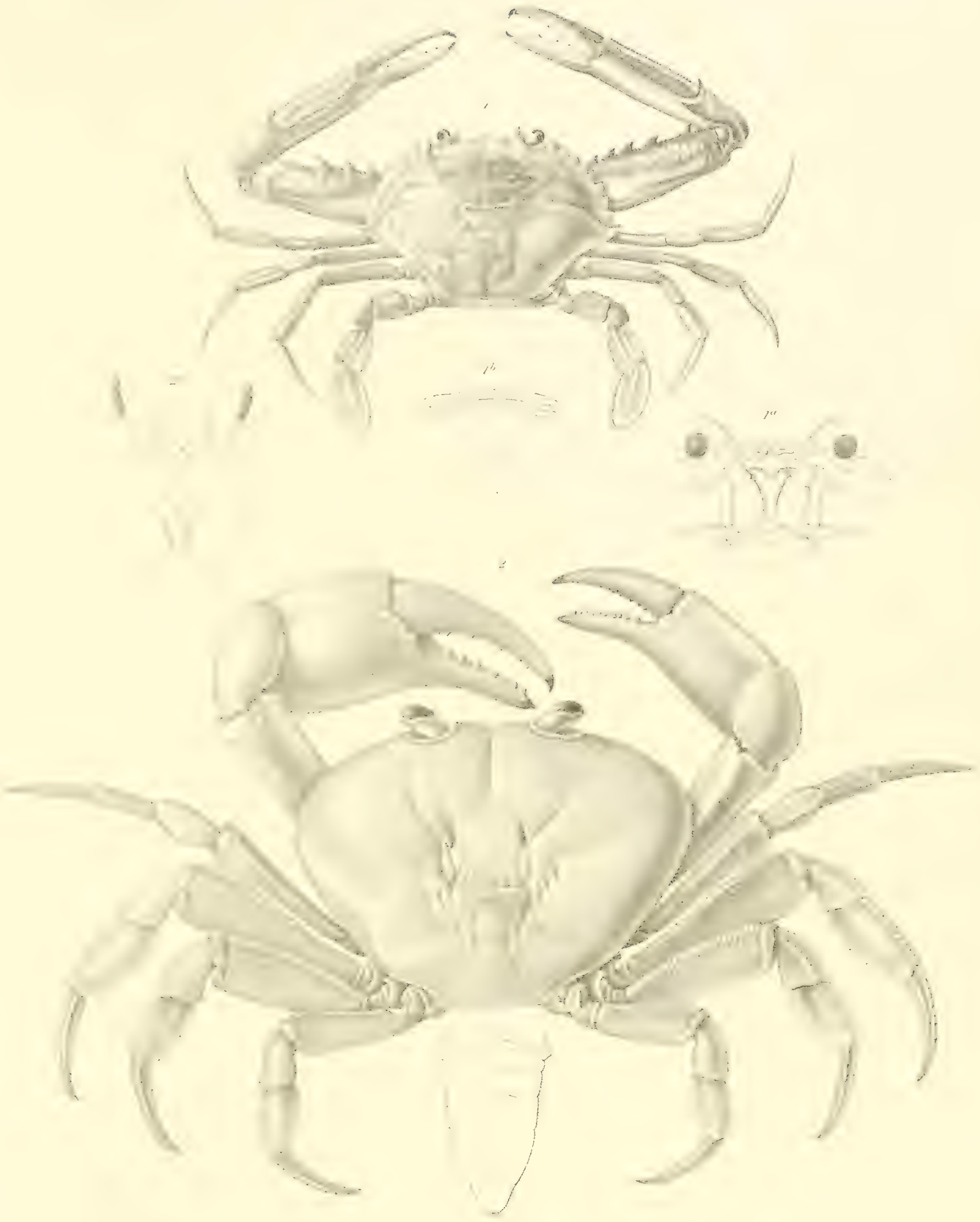


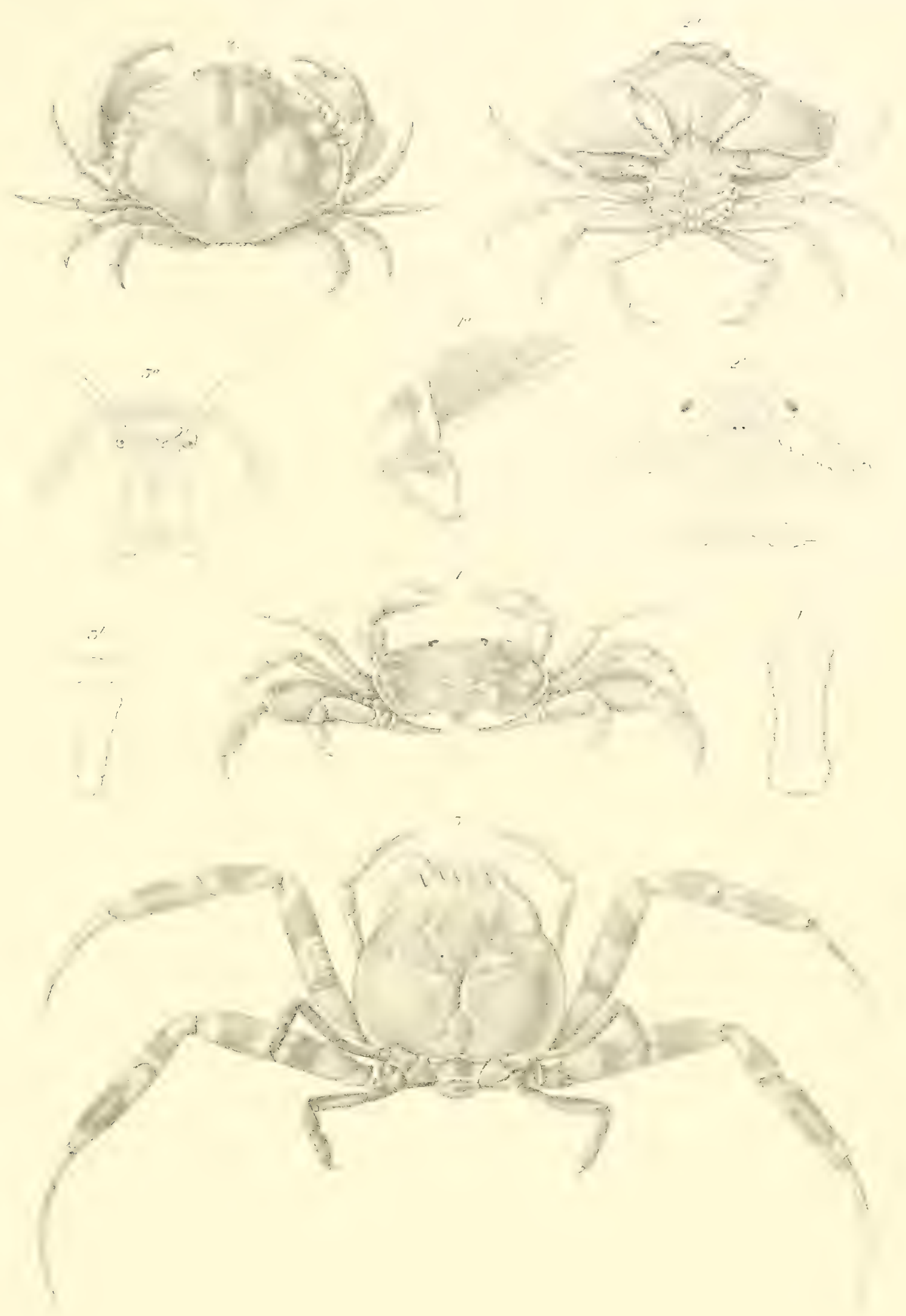



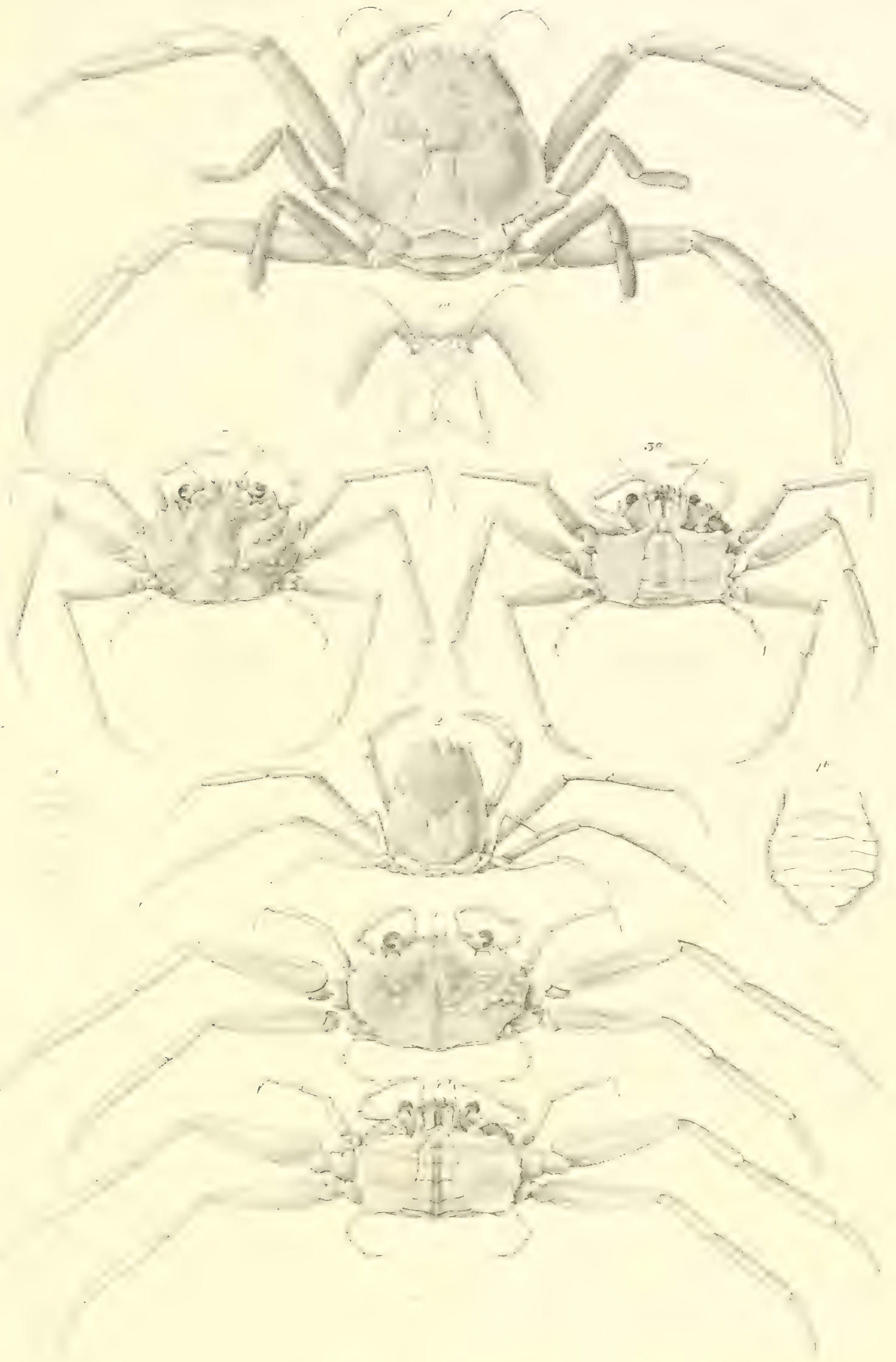





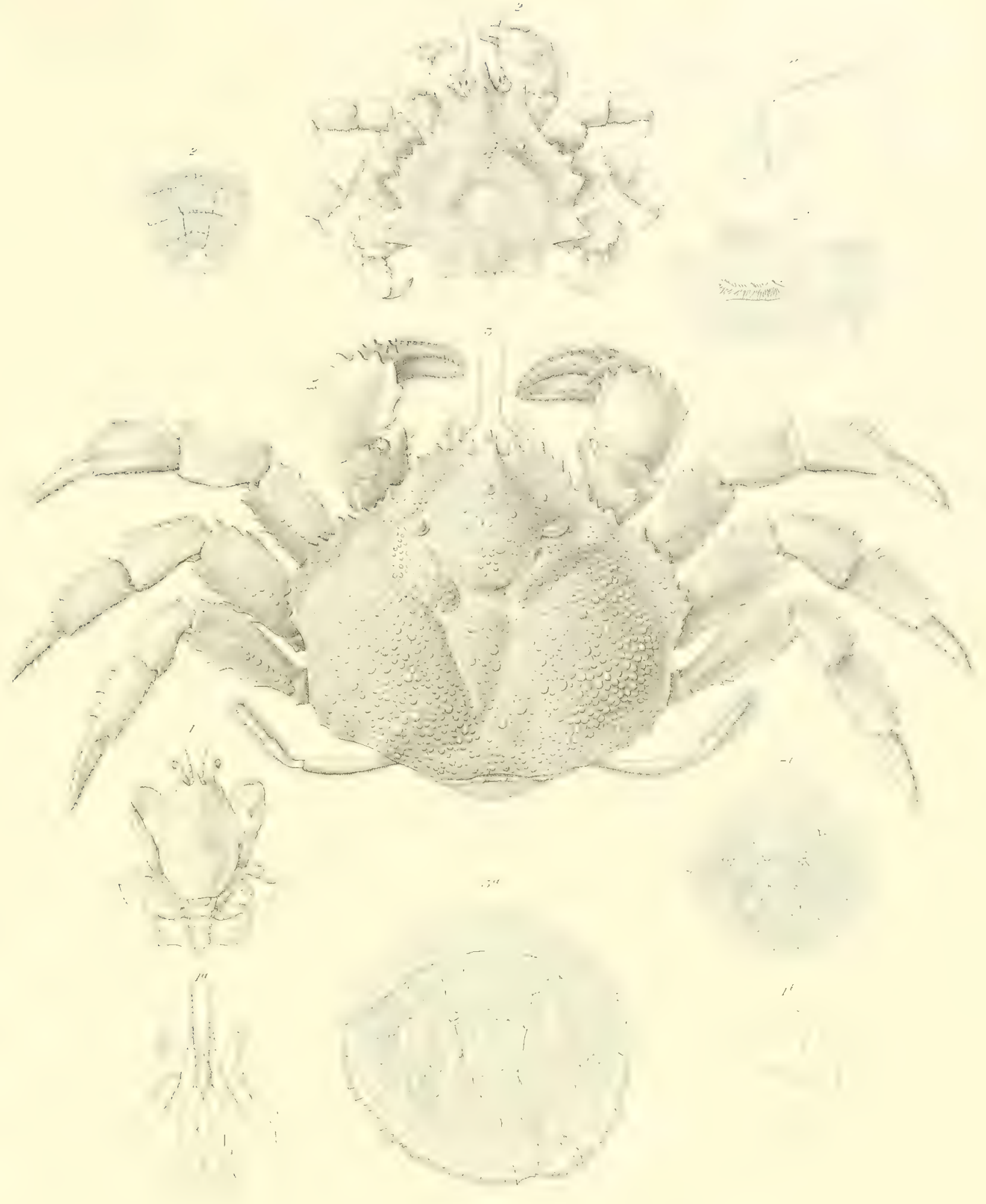





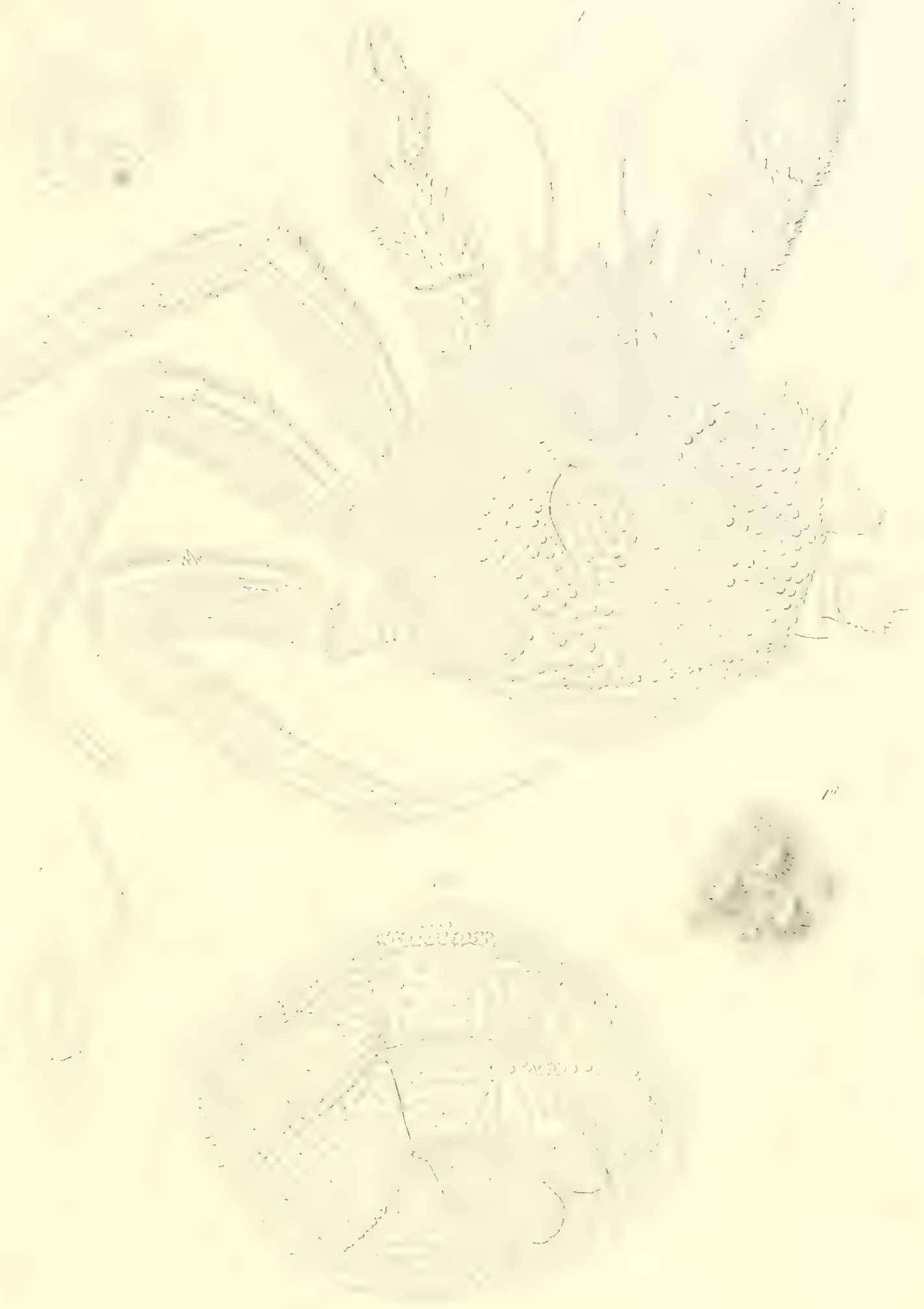




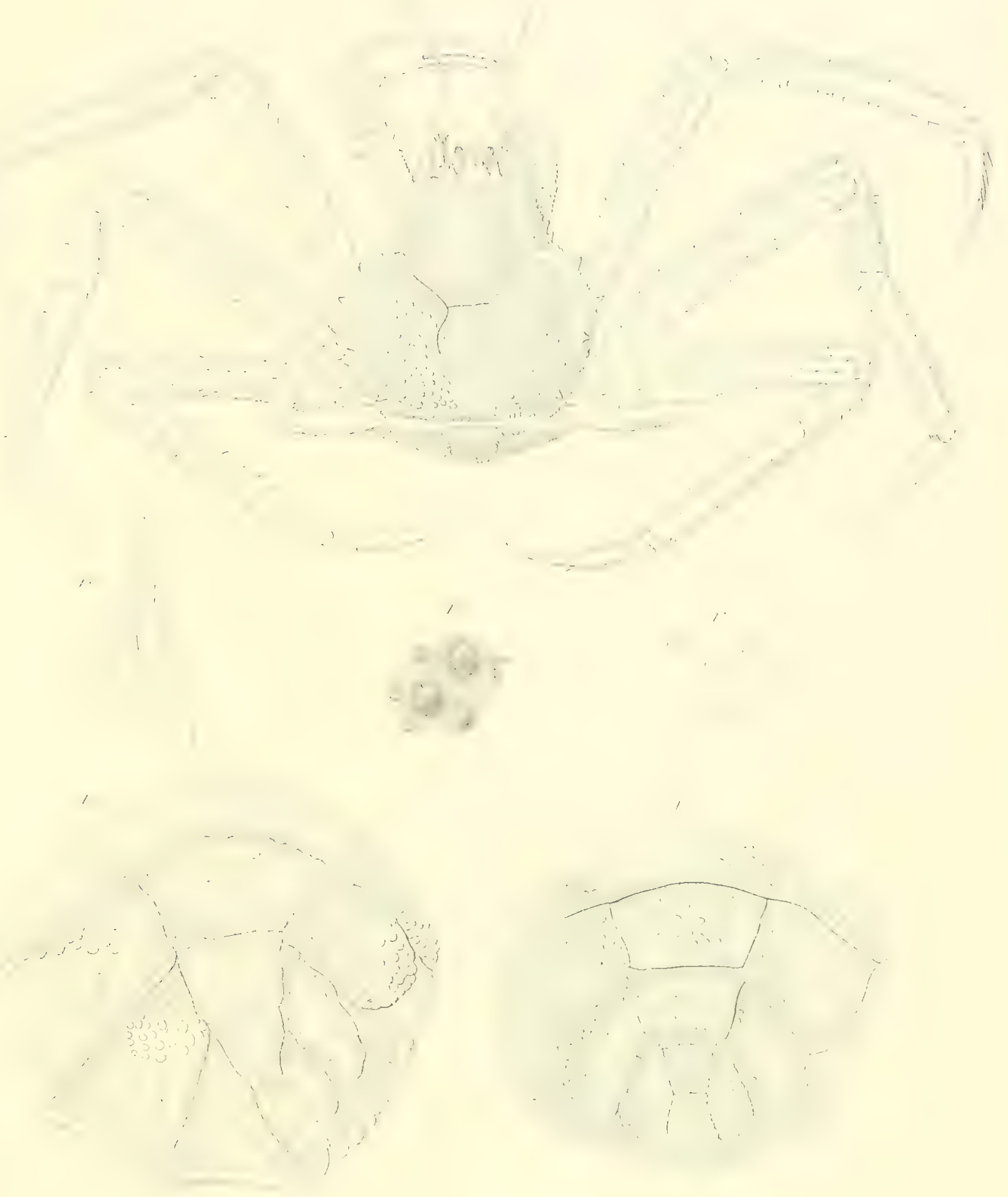



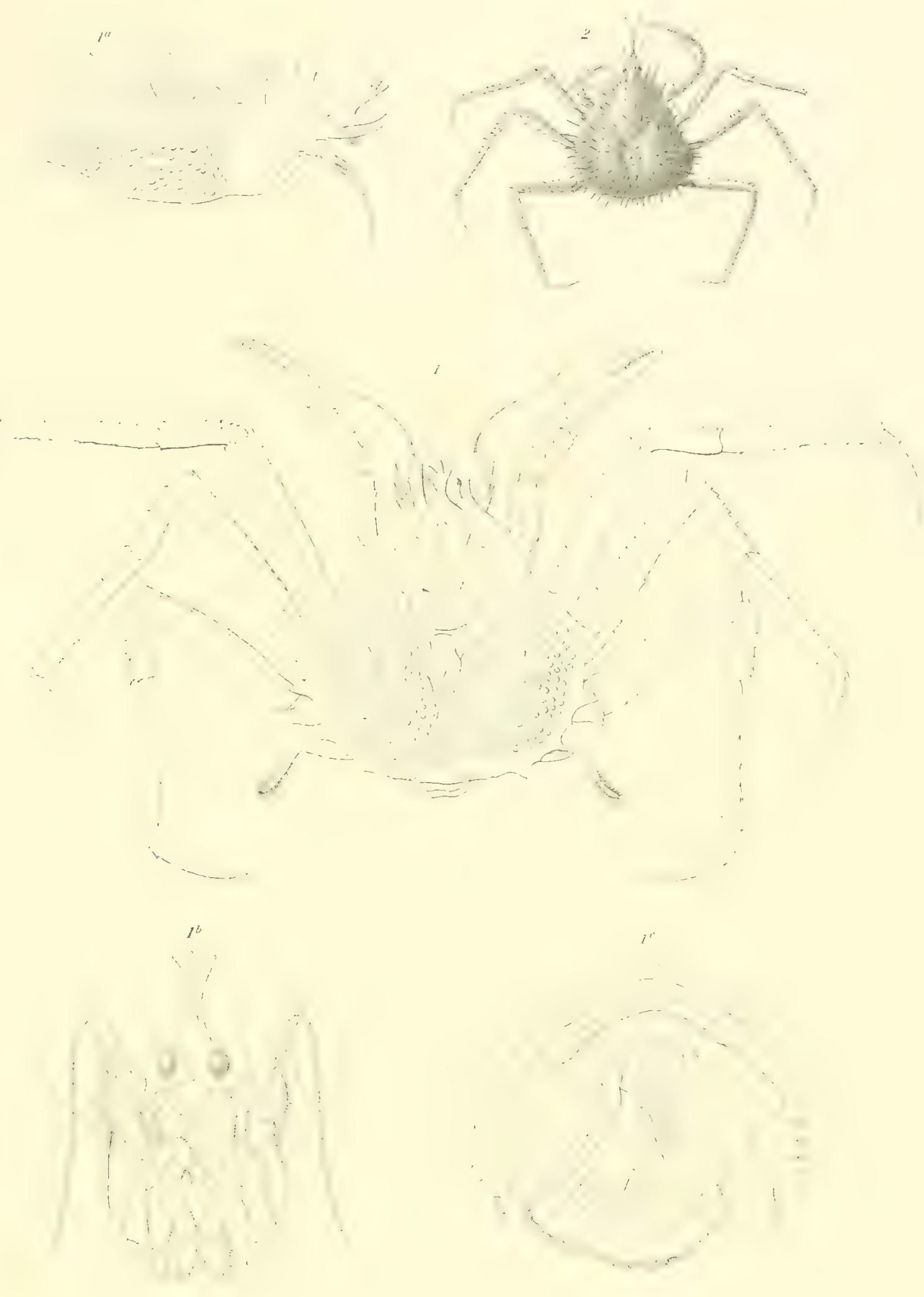




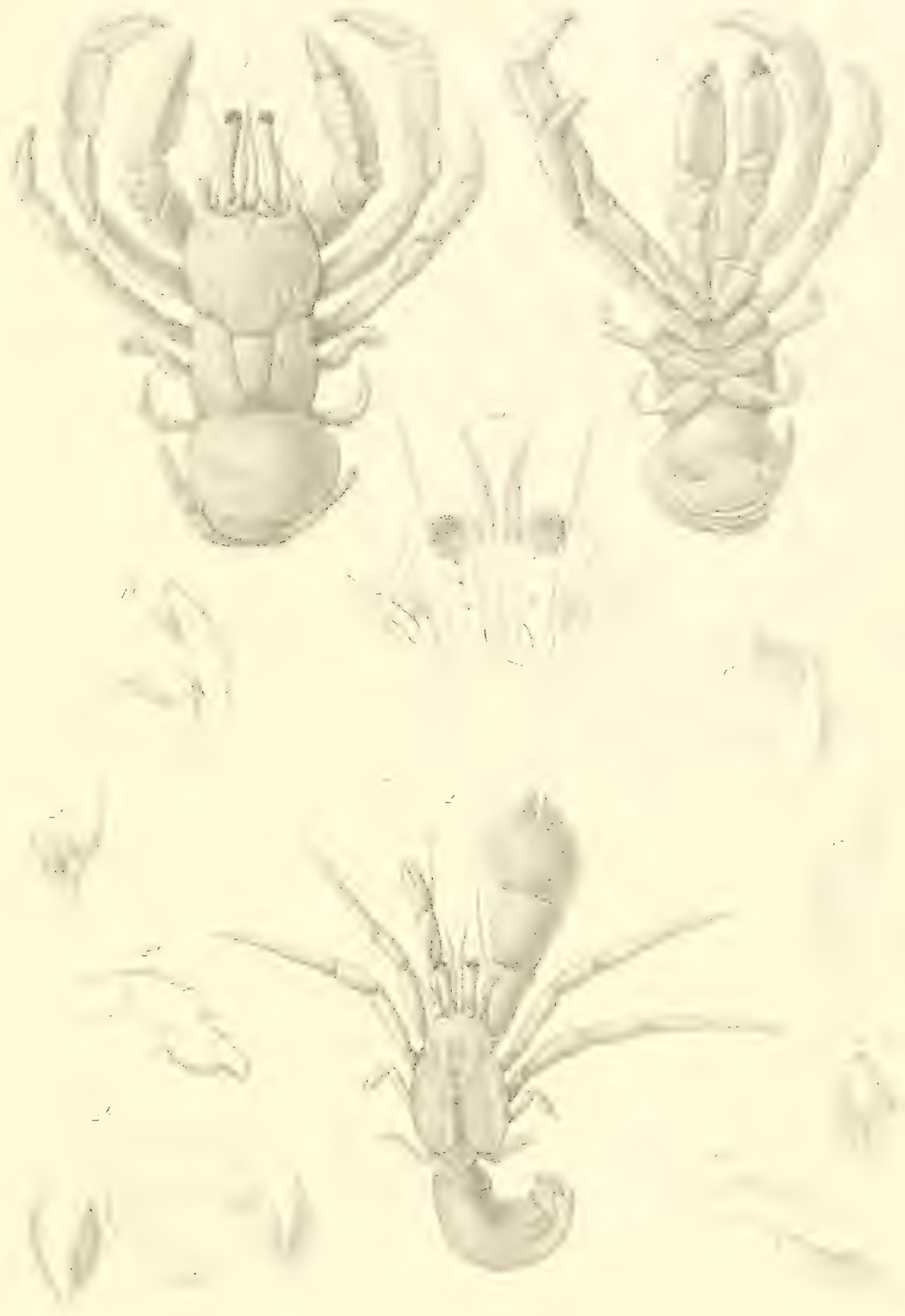


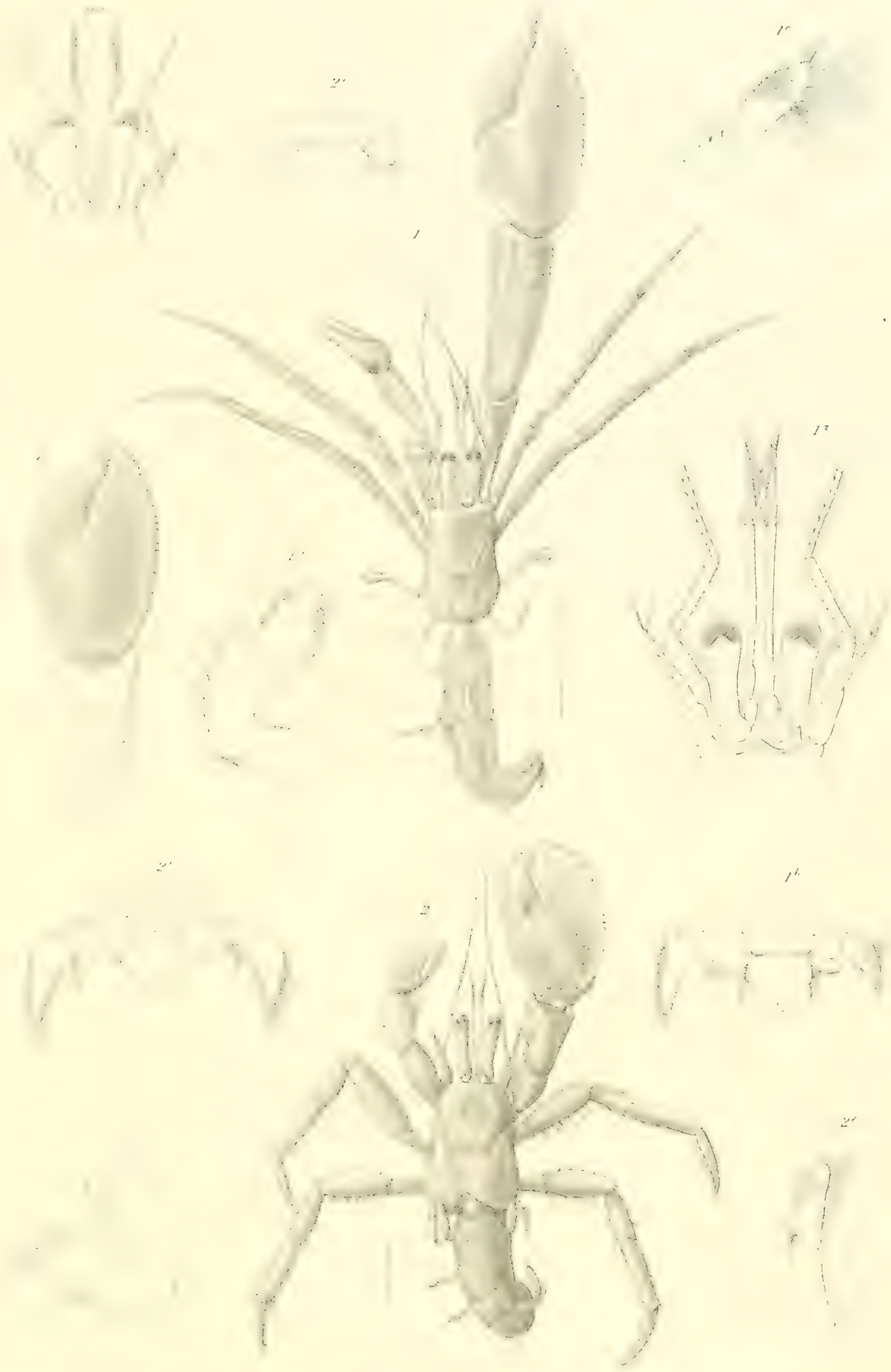



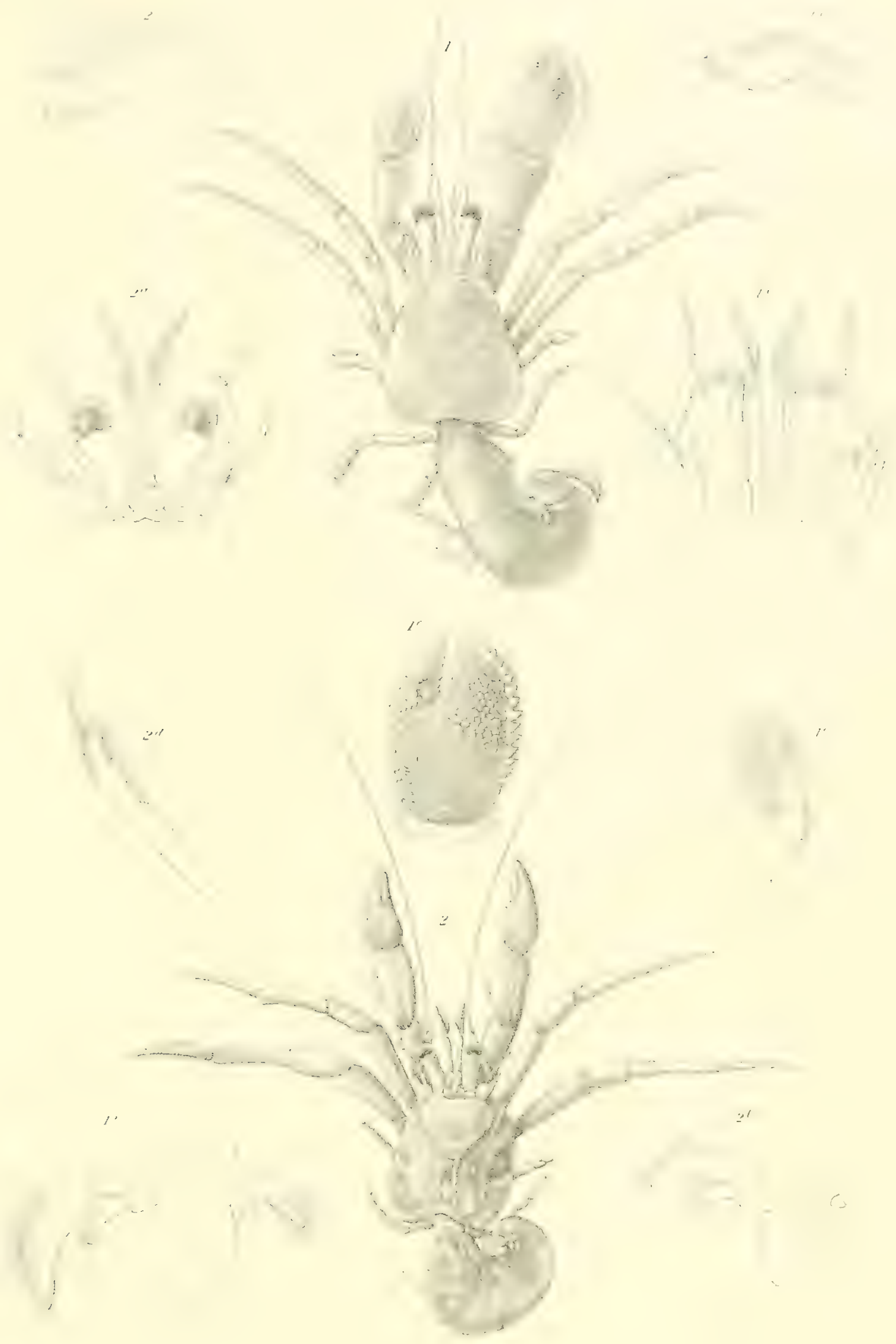





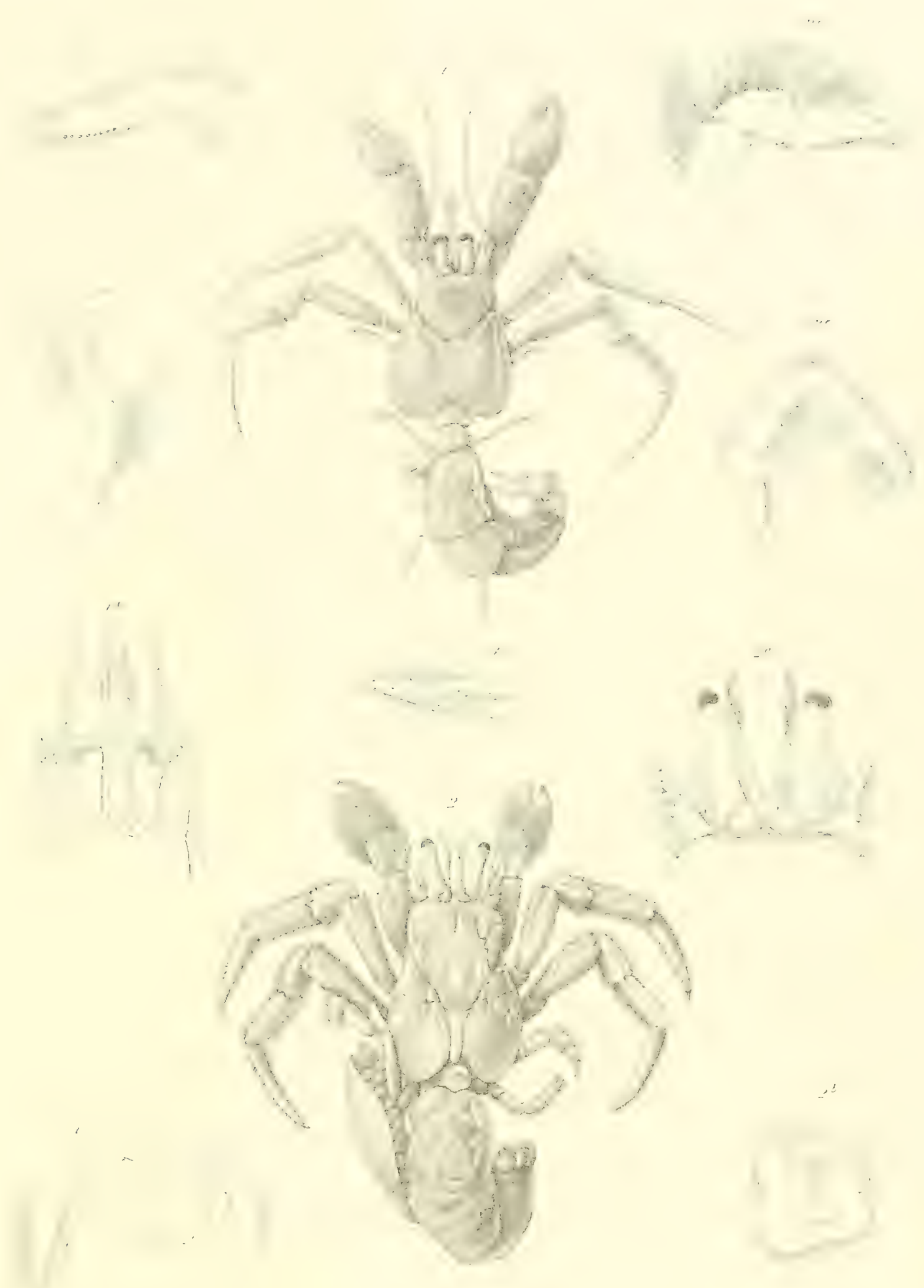





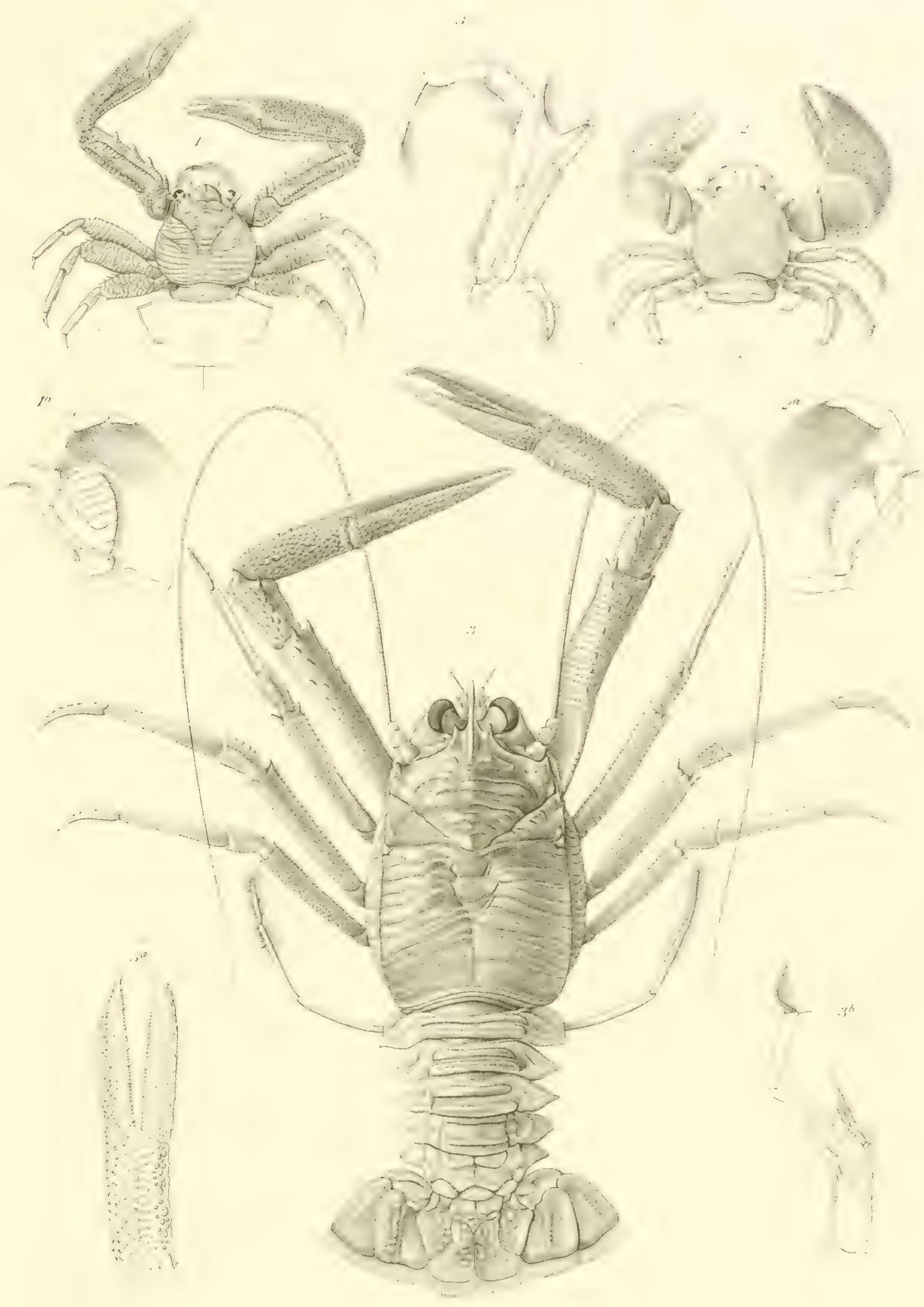





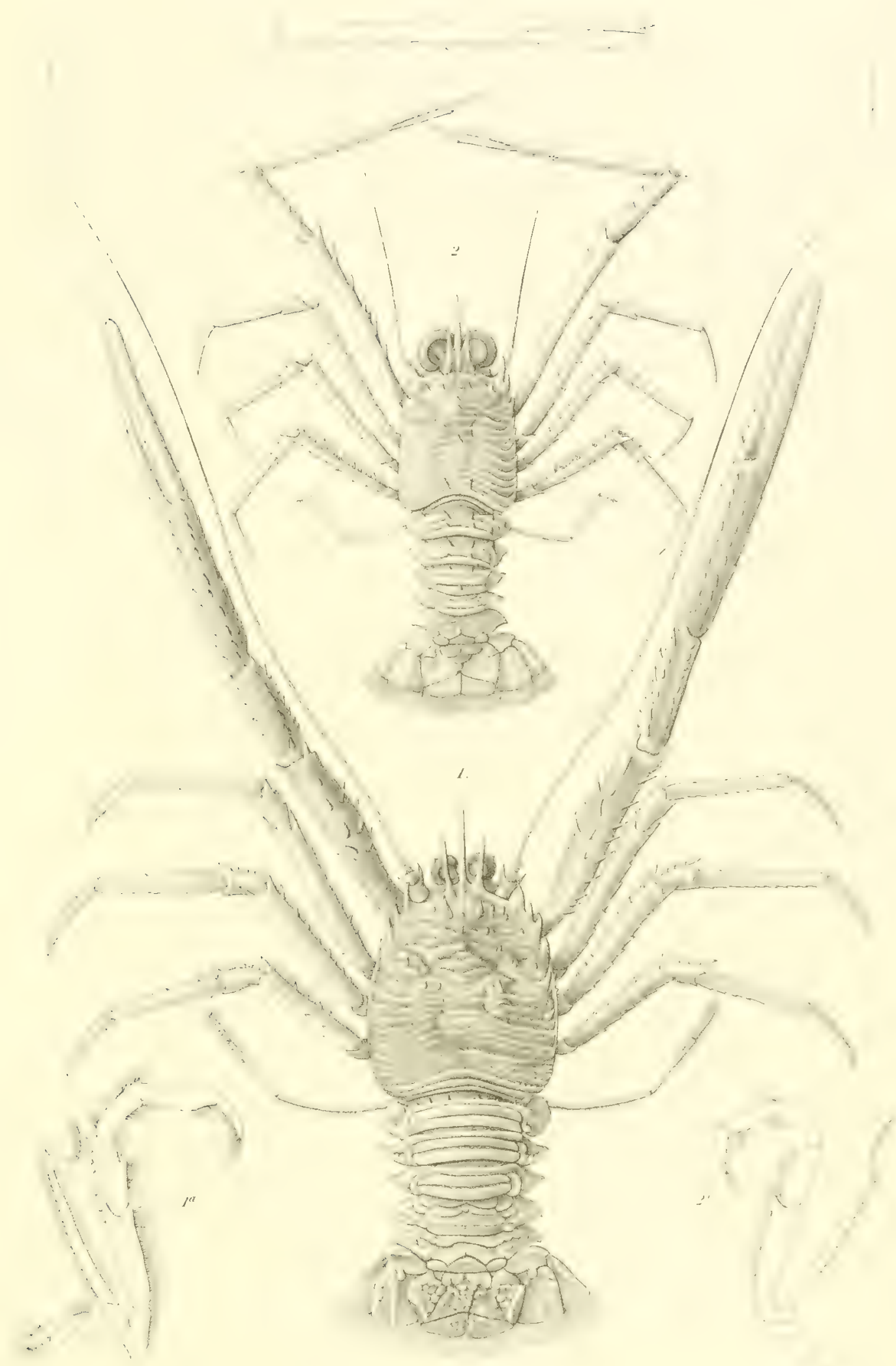

I MUNIDA OBESA ¿े MUNIDA GRACILIEEE 



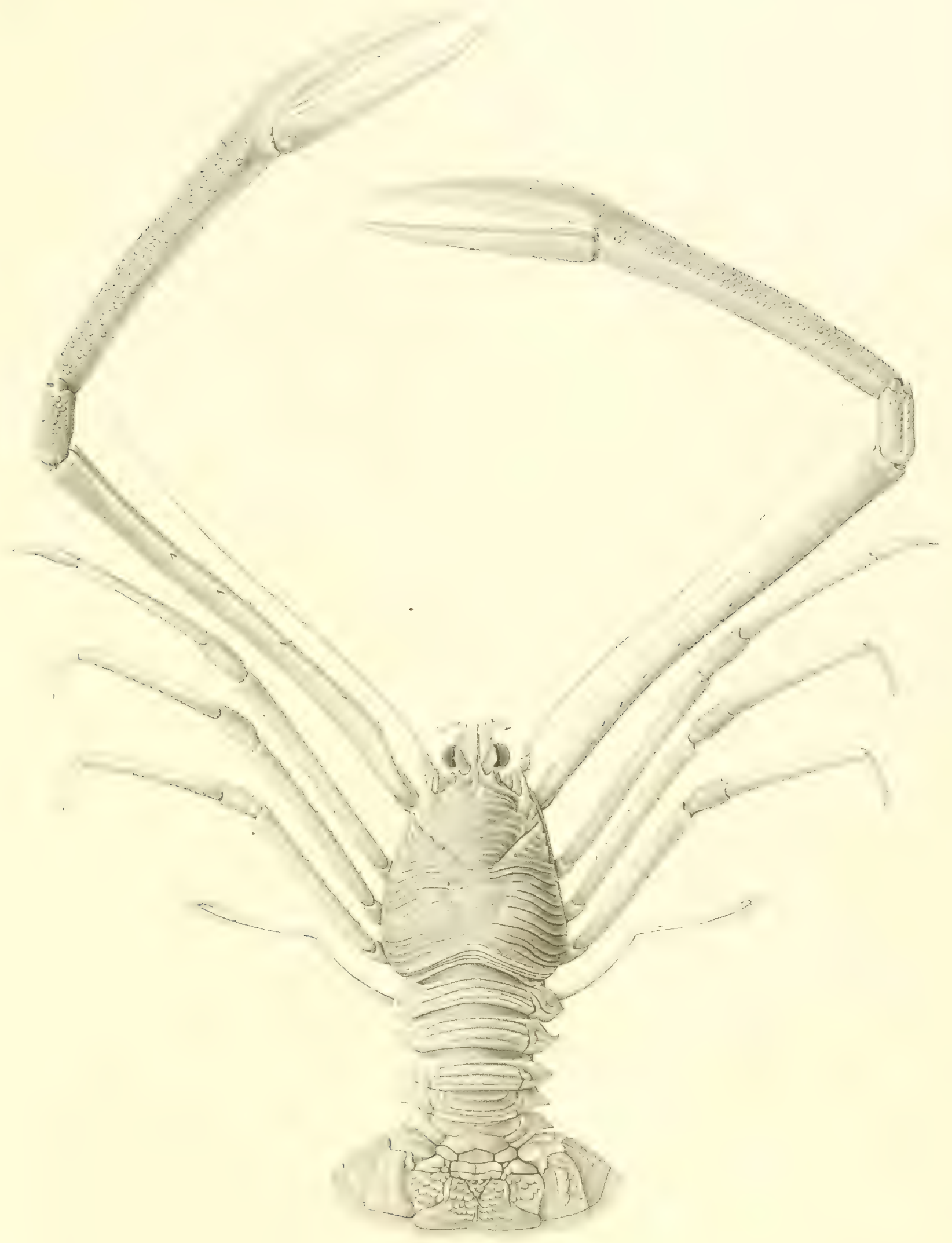




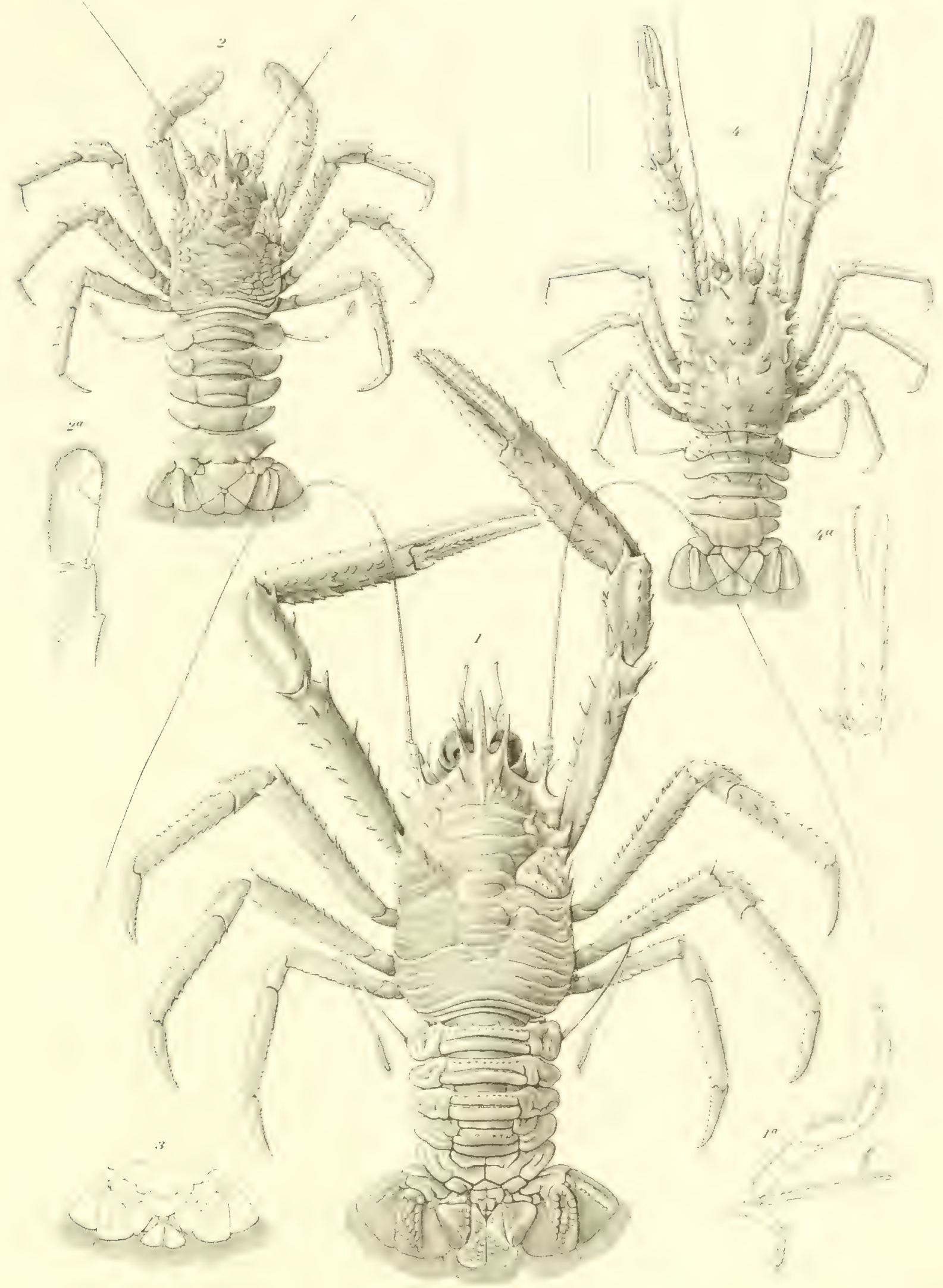





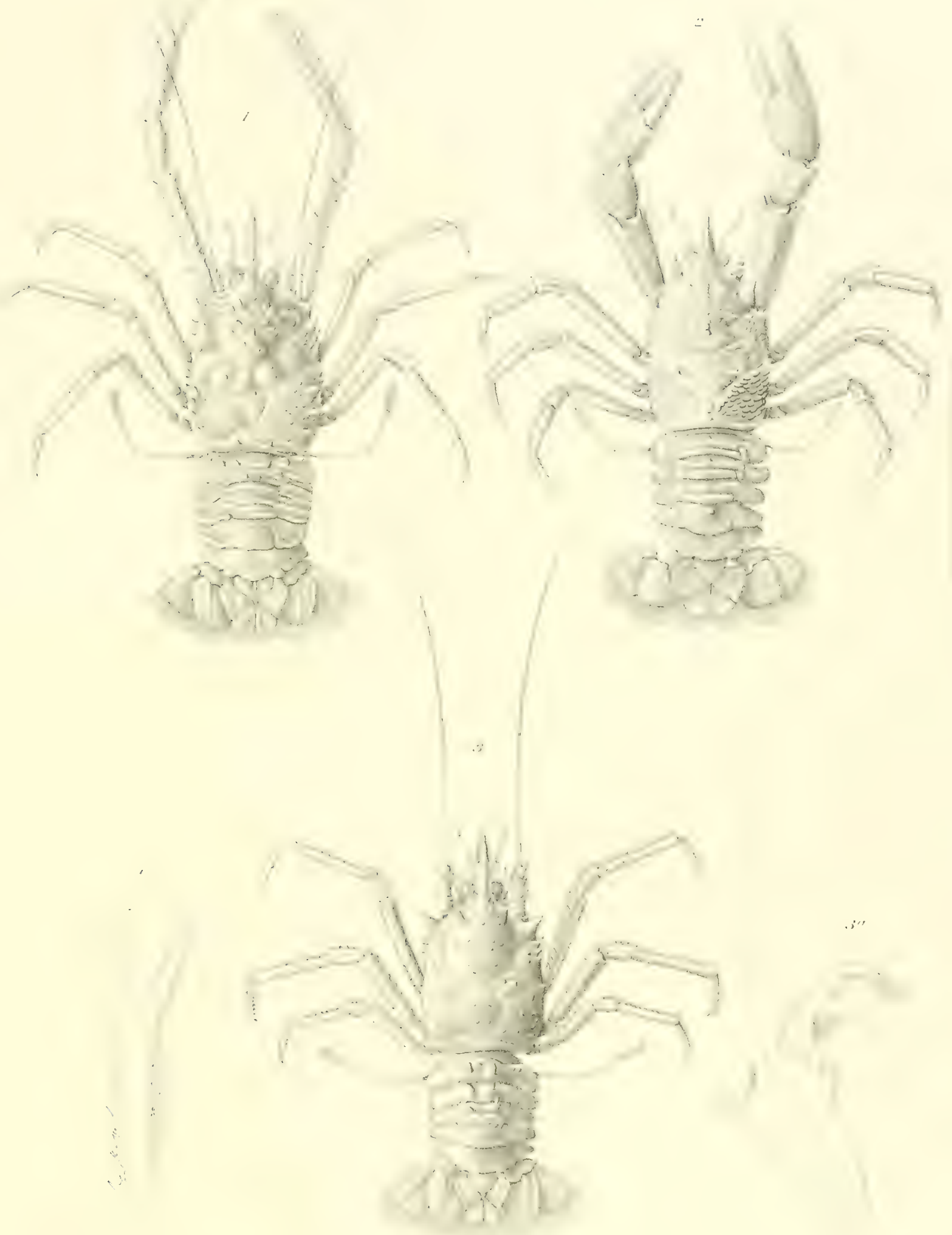





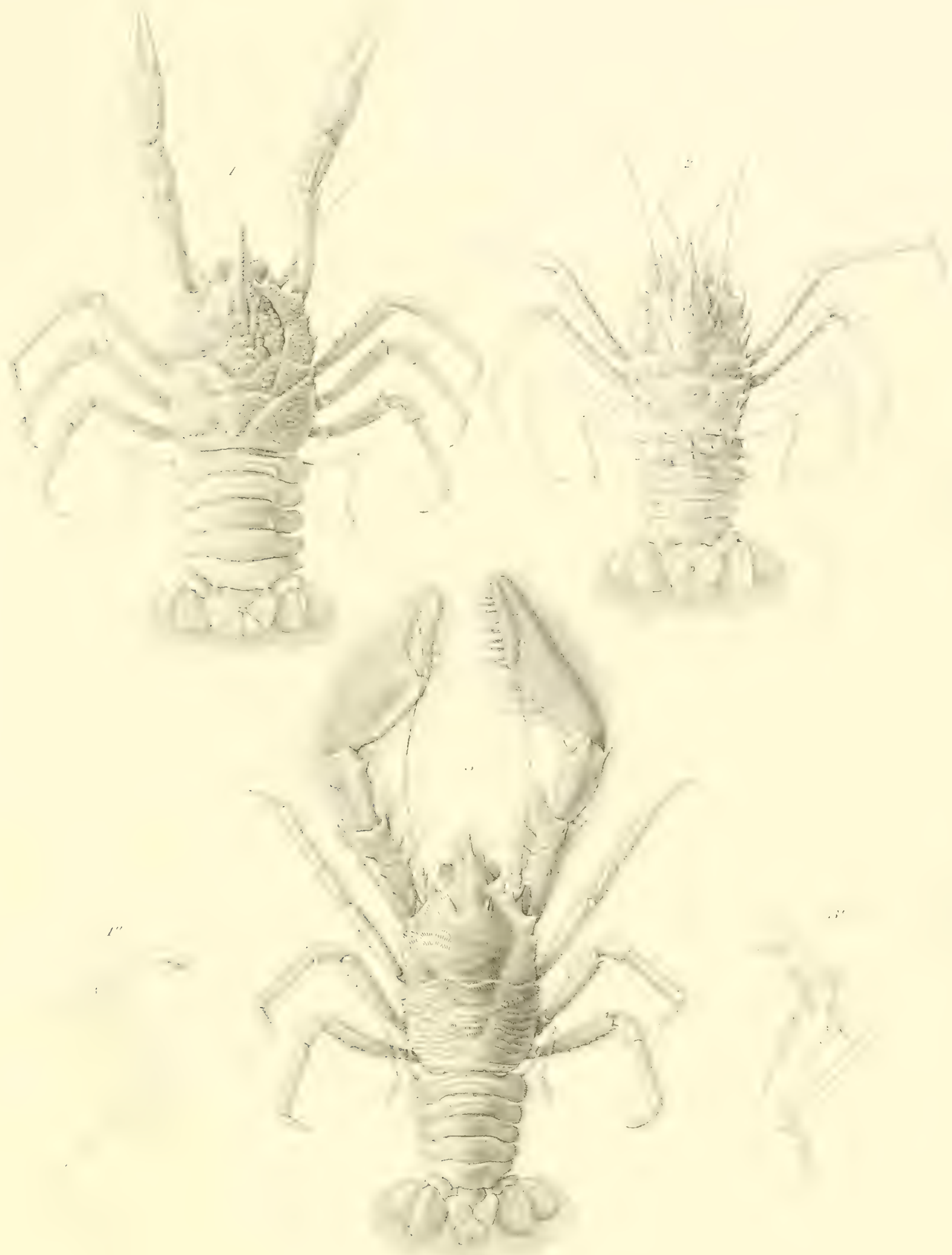





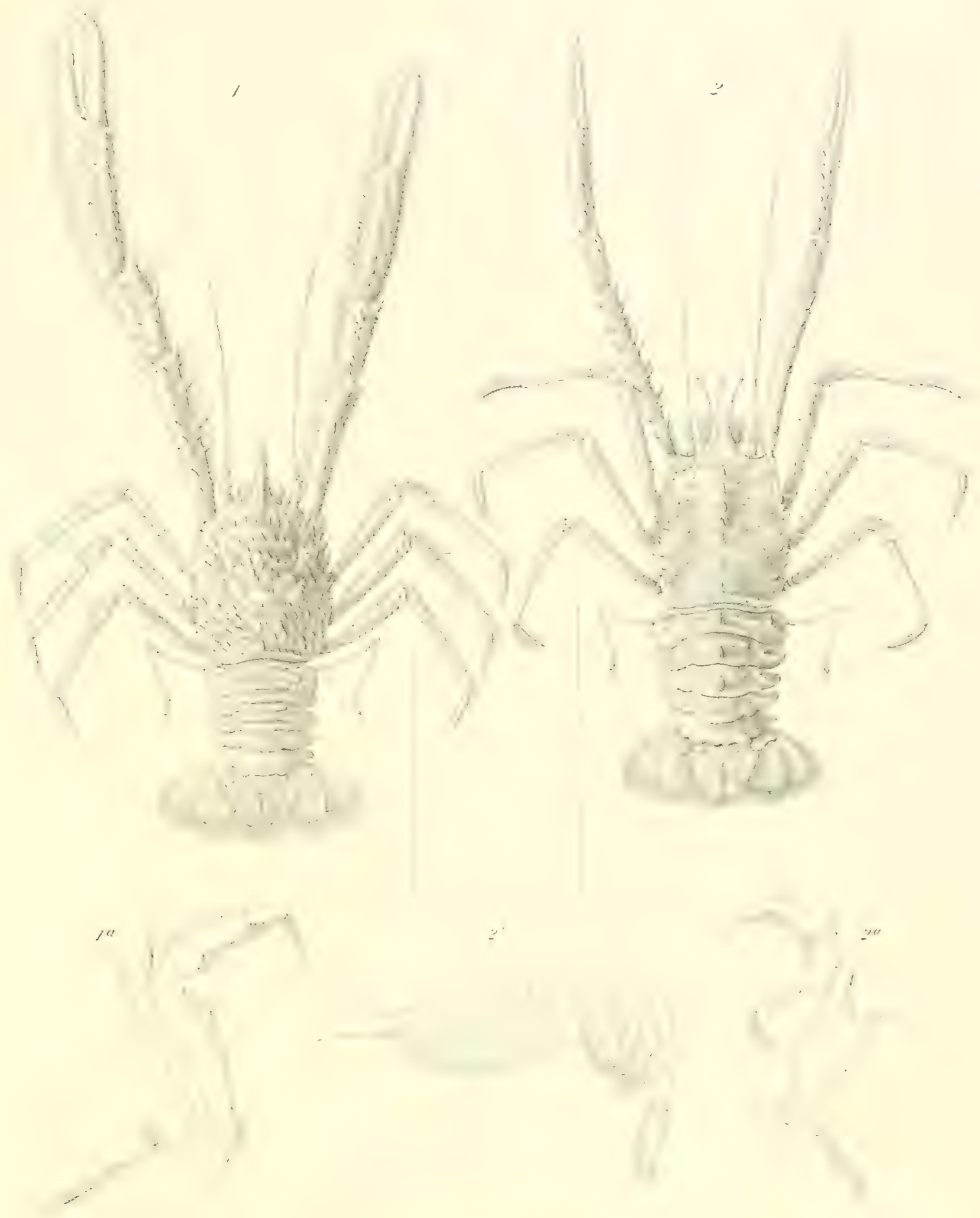




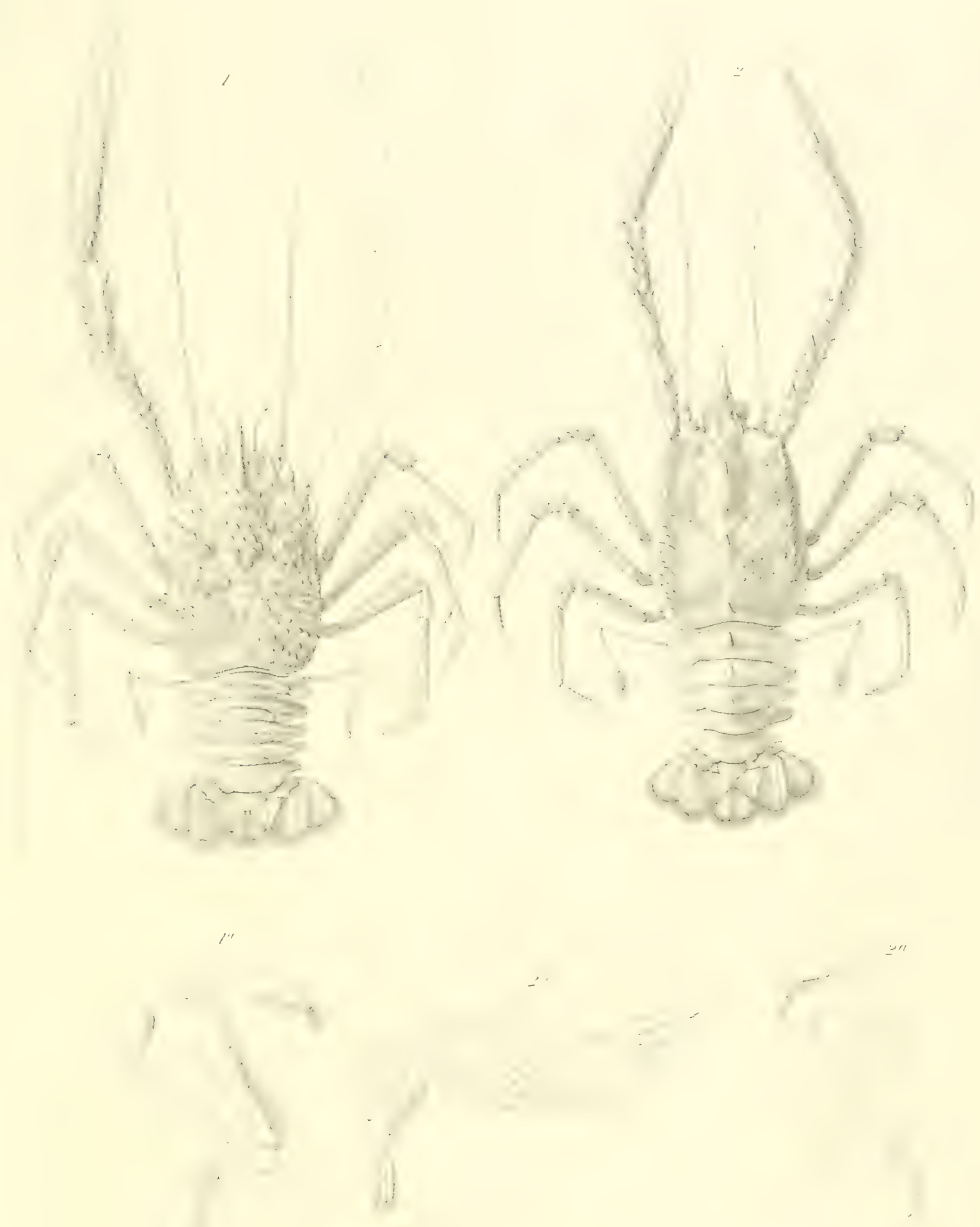





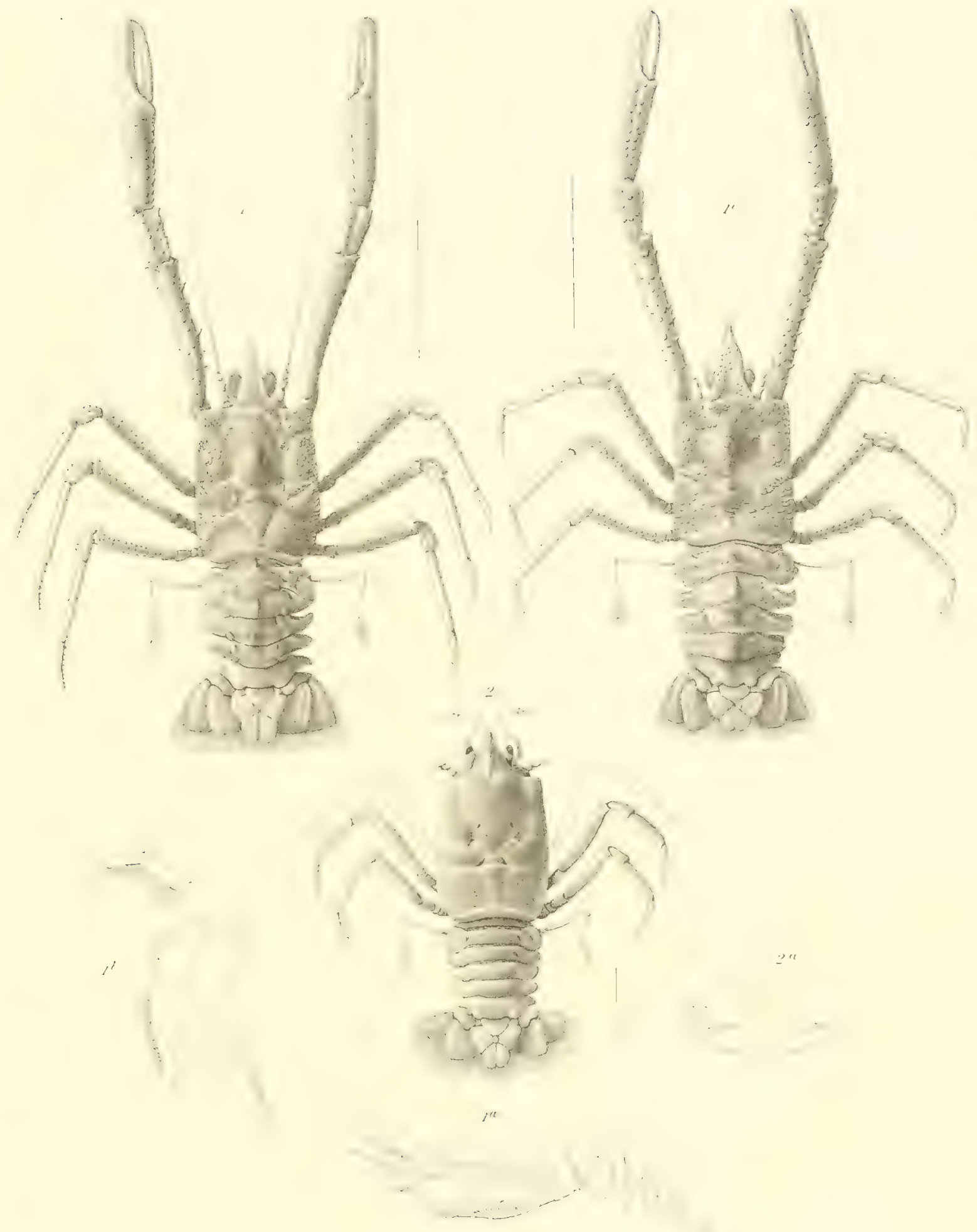





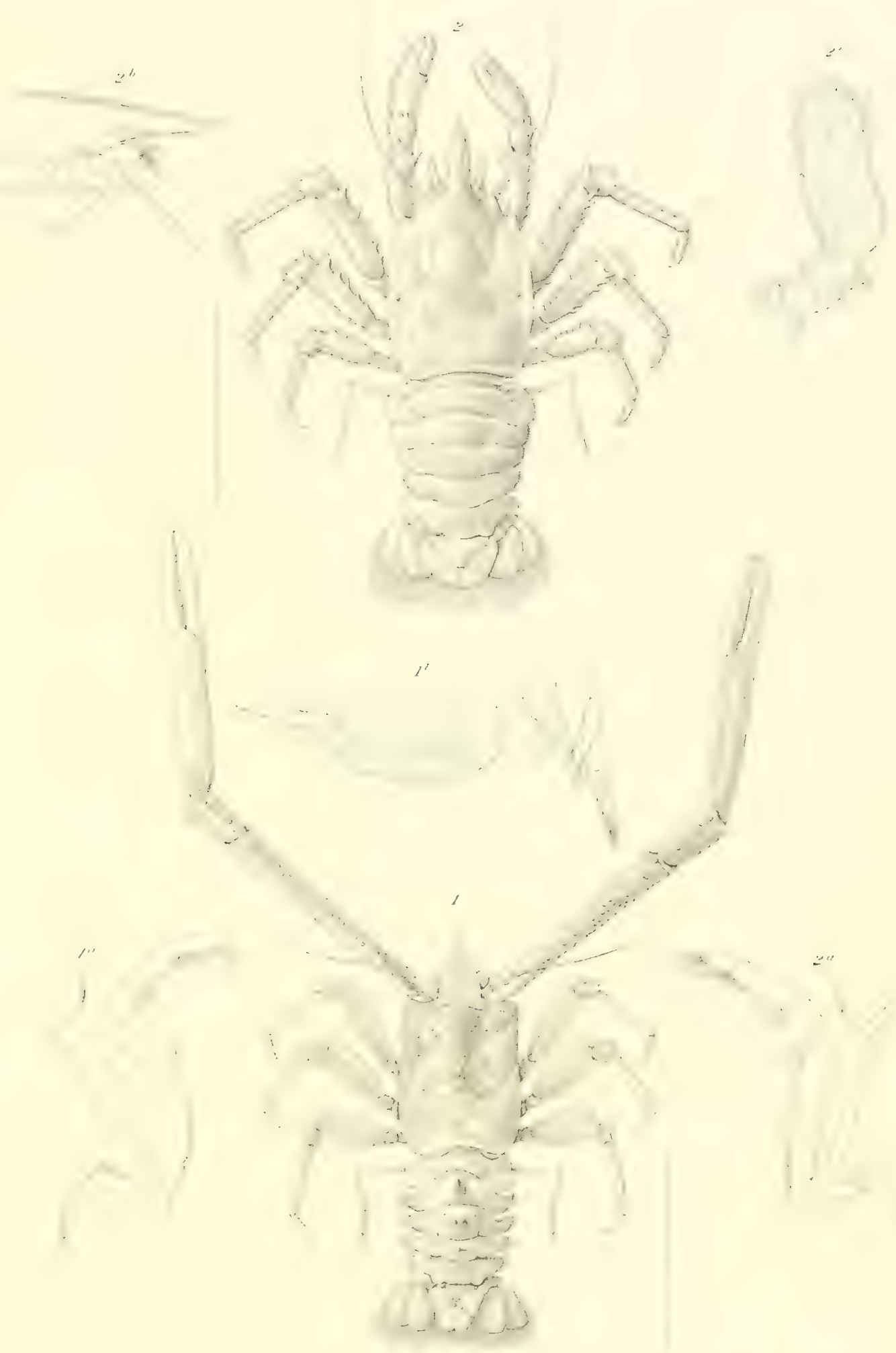




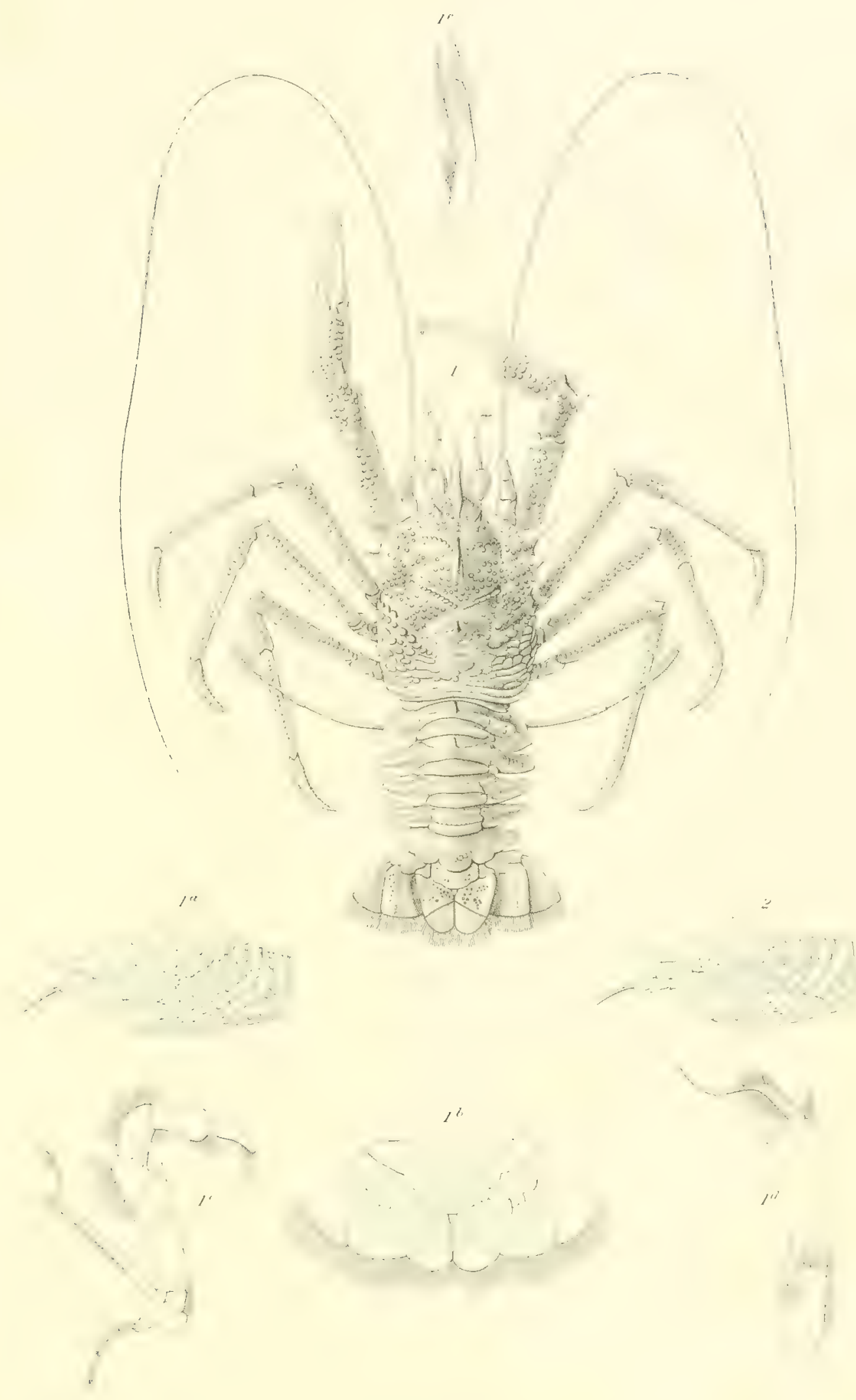

A.M Waglarerenn dè

1. GALACANTHA DIOMEDER. 2. GALACANTHA DIOMEDEF VAE. PARVISPINA 



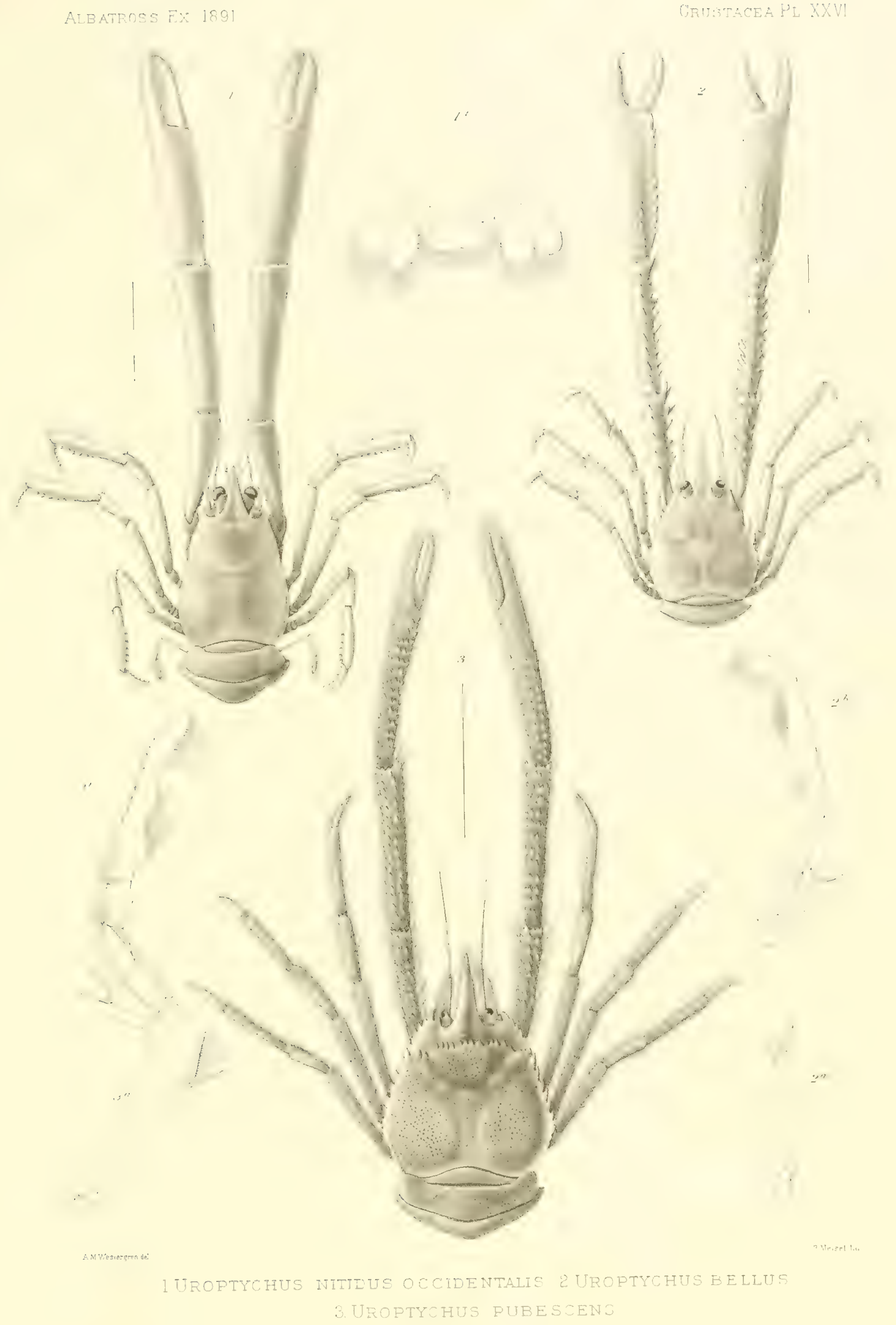




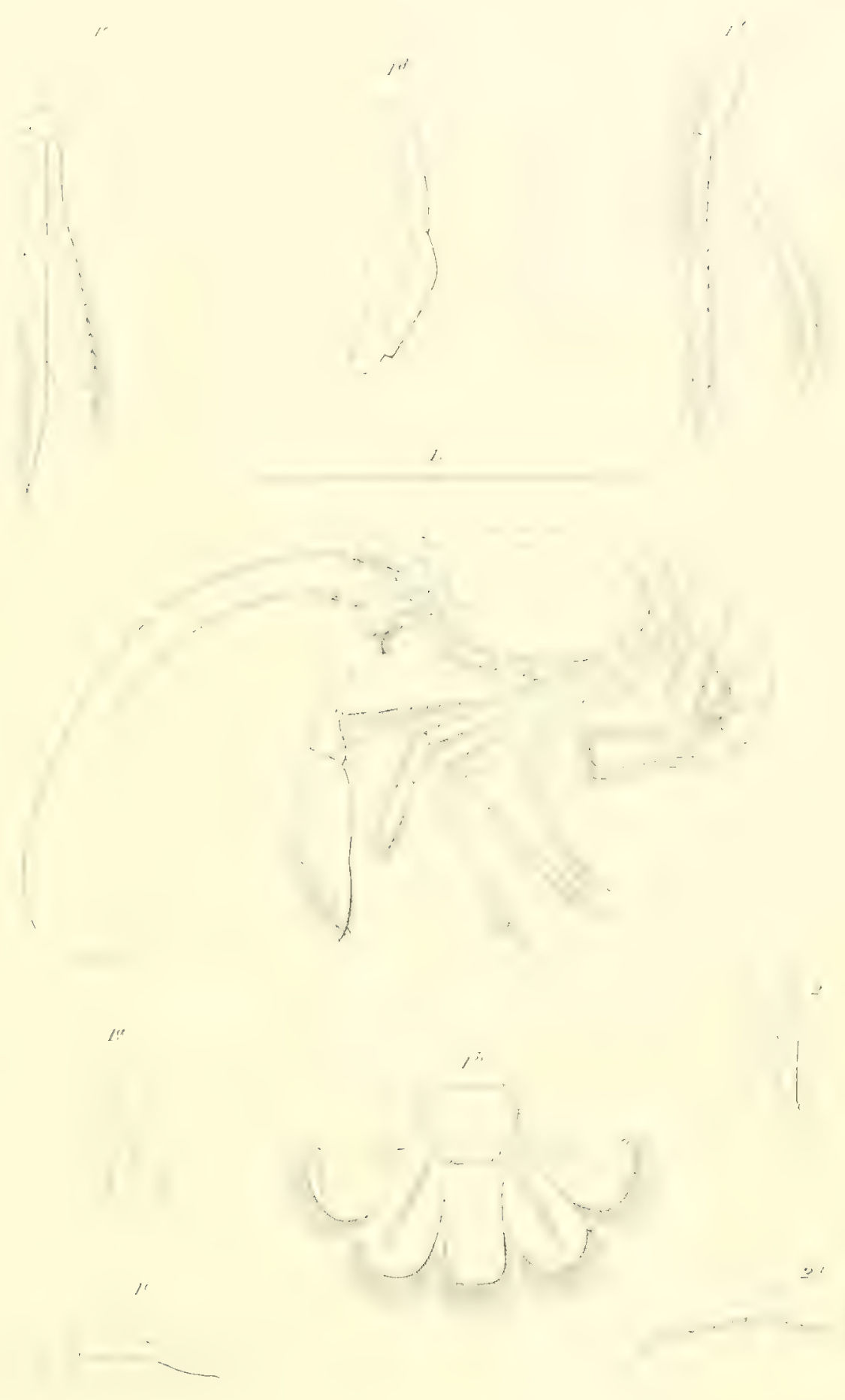



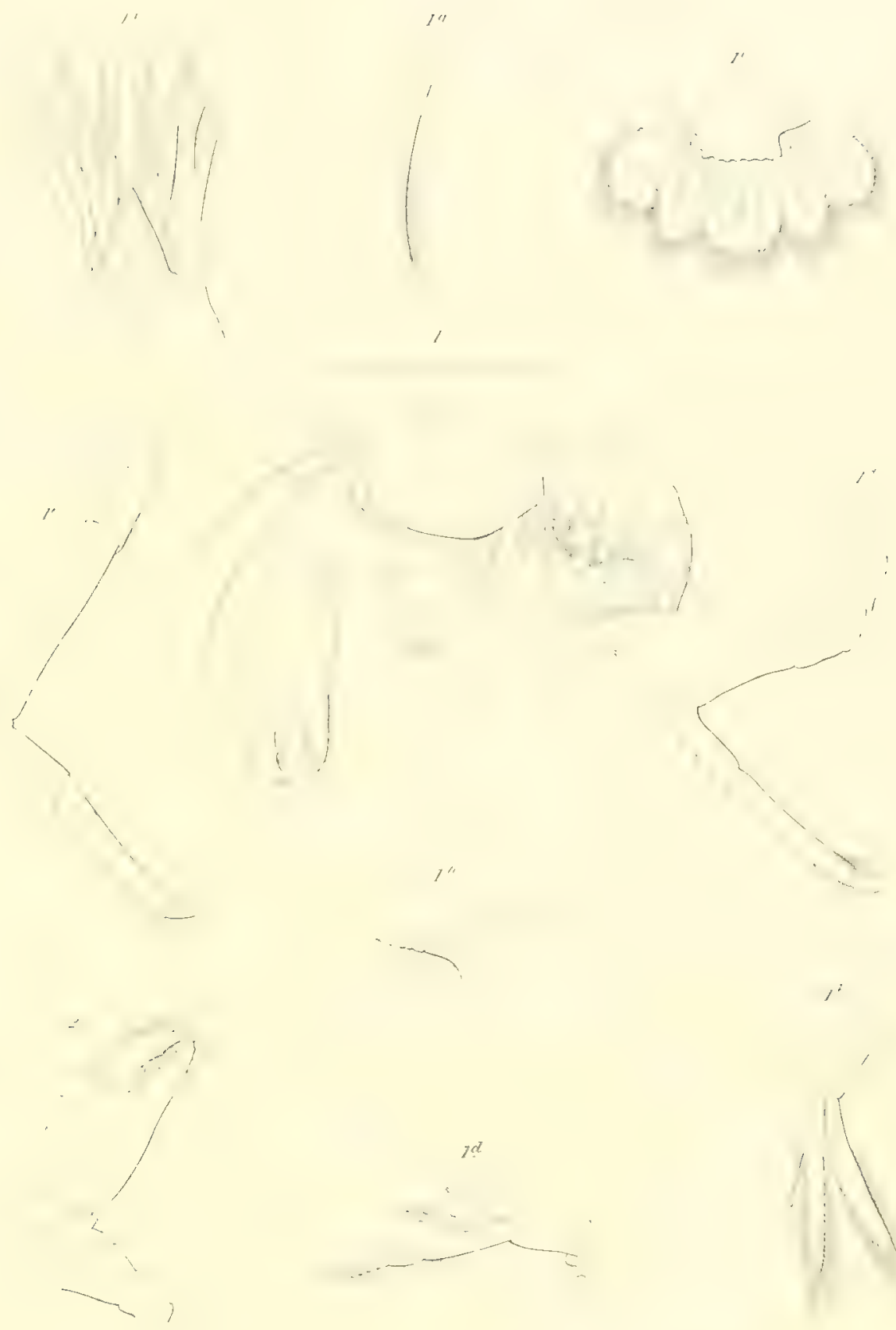

$\gamma^{2}$

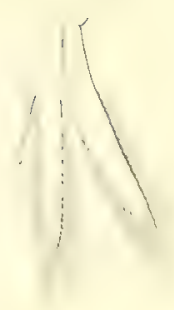




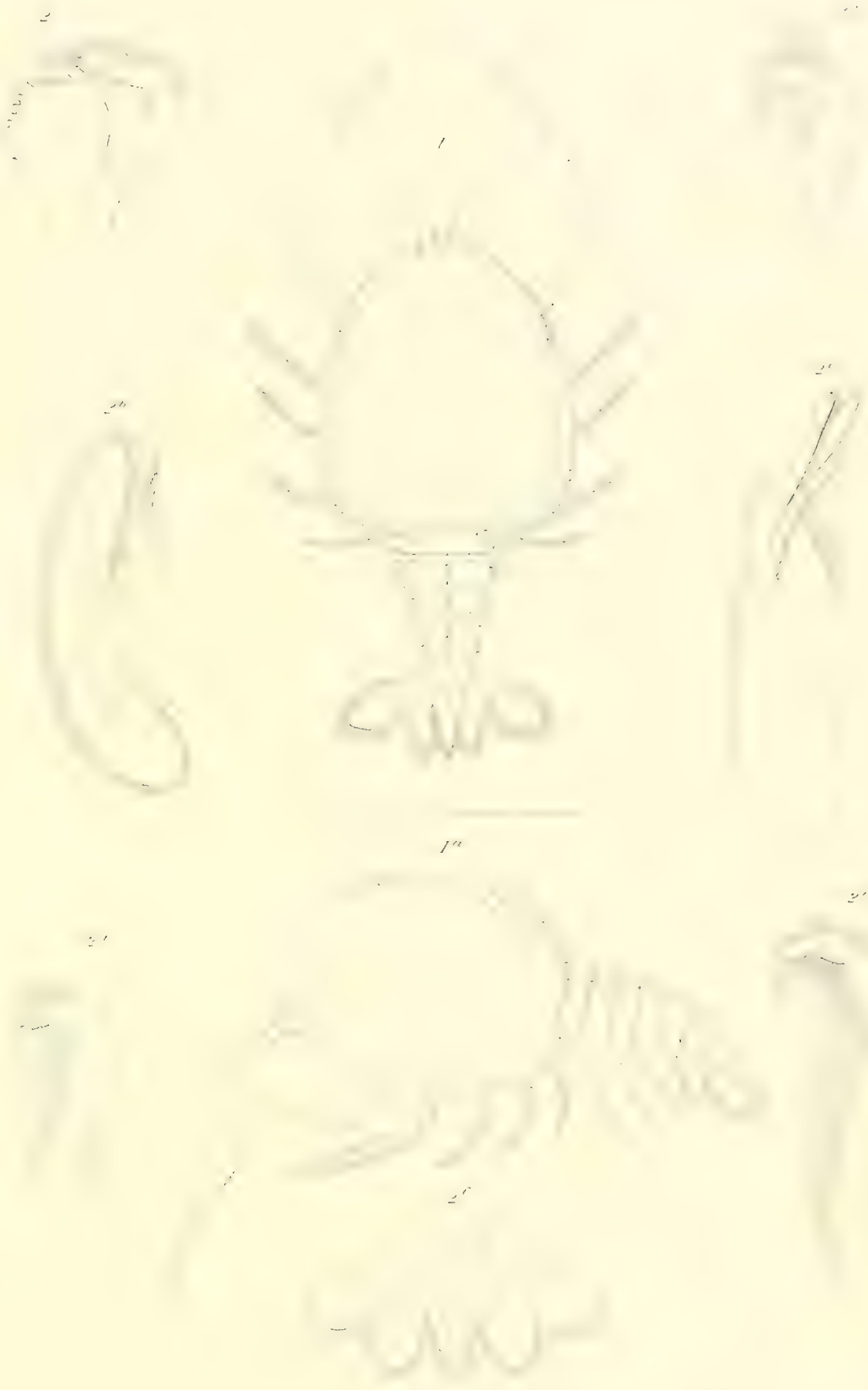



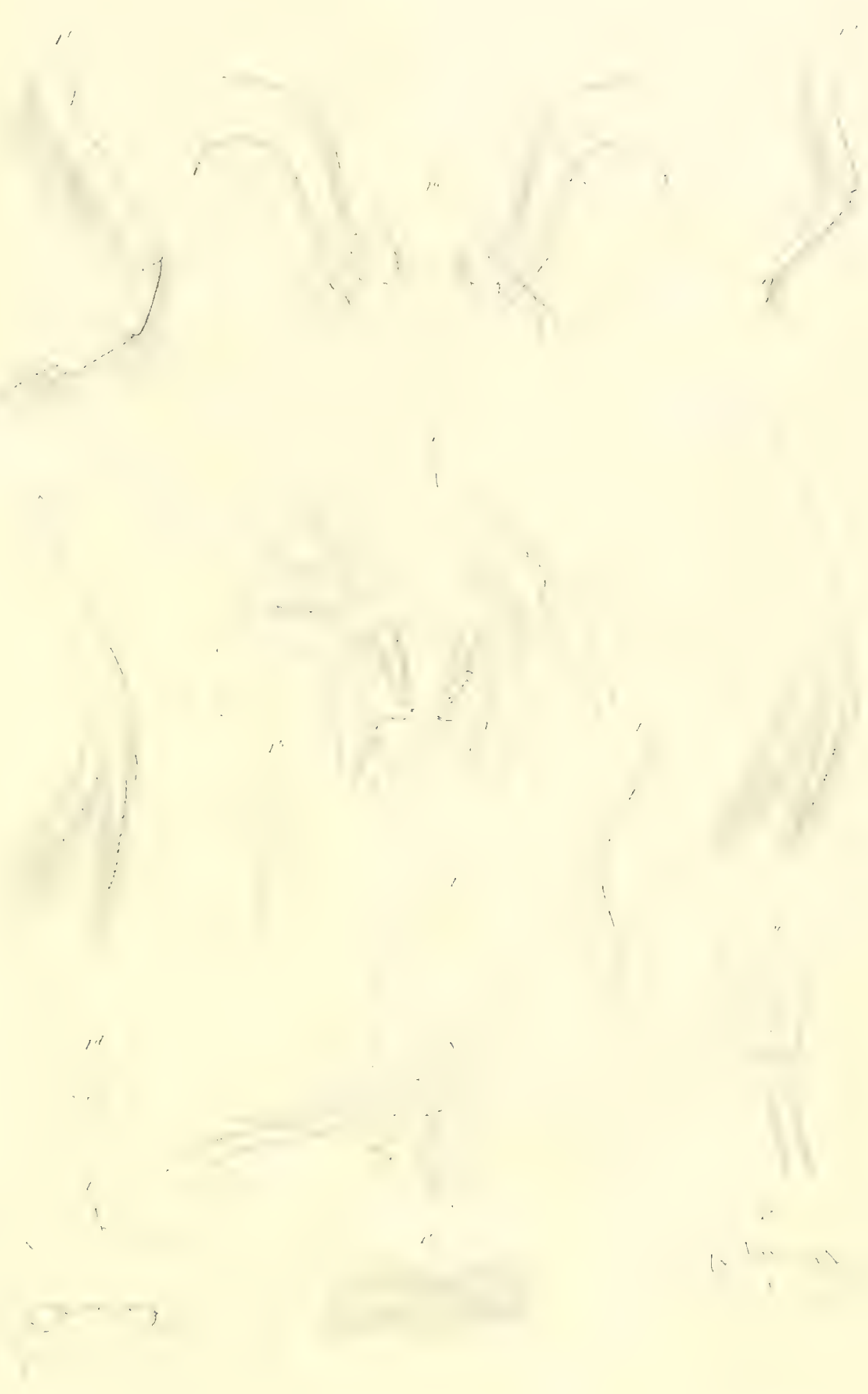




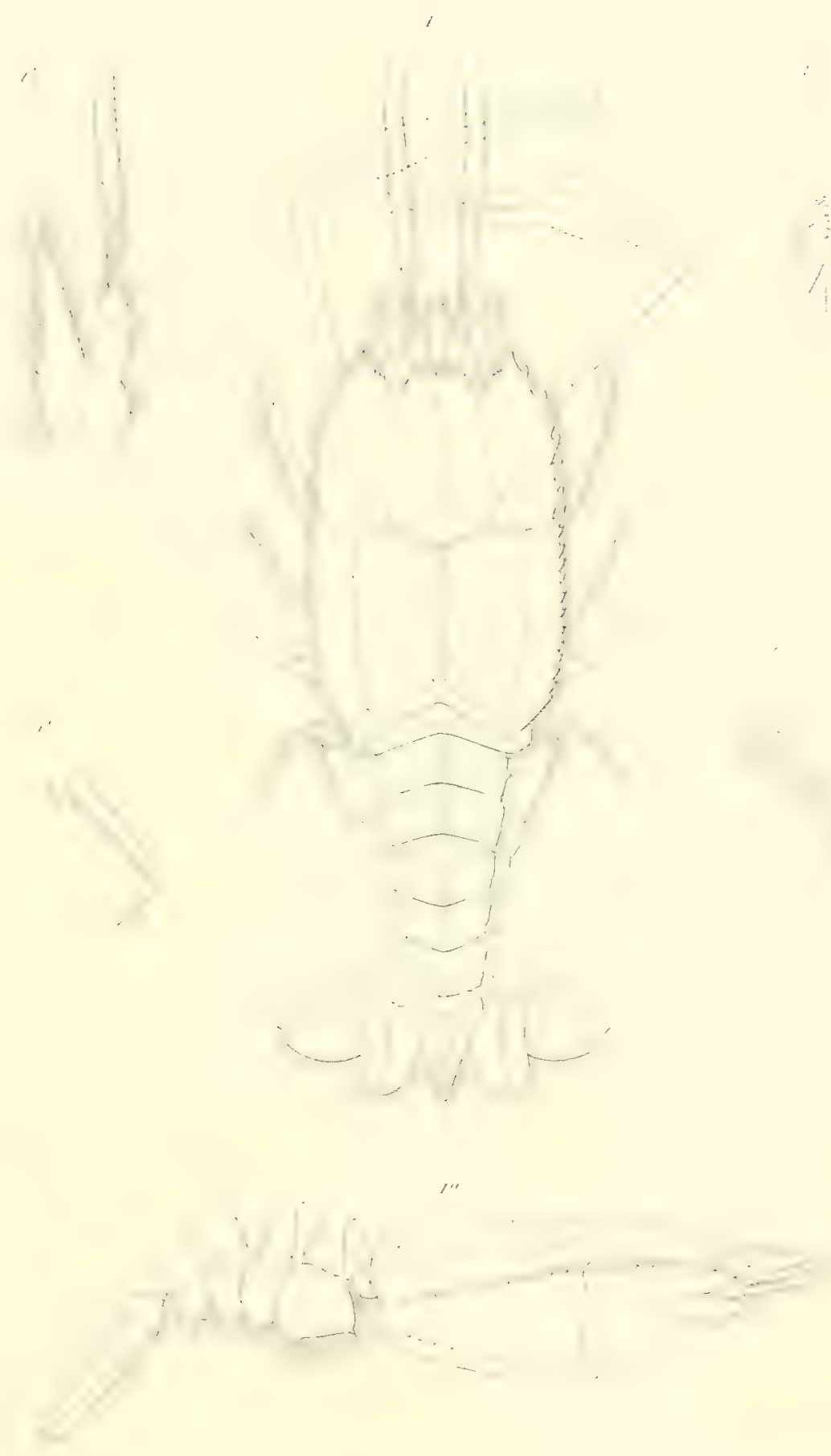



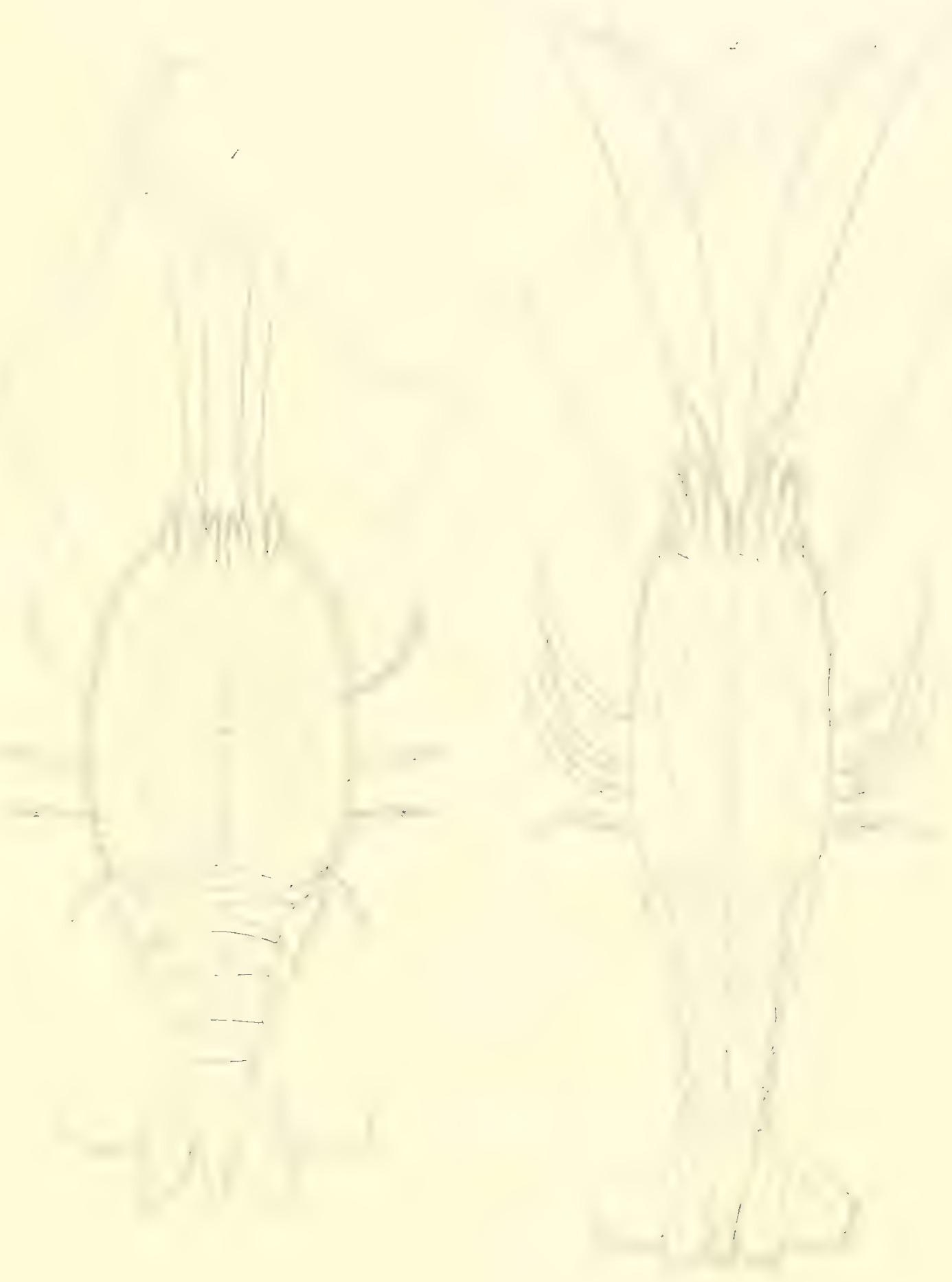

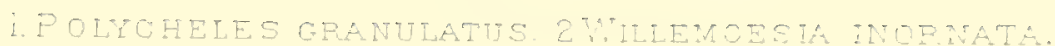




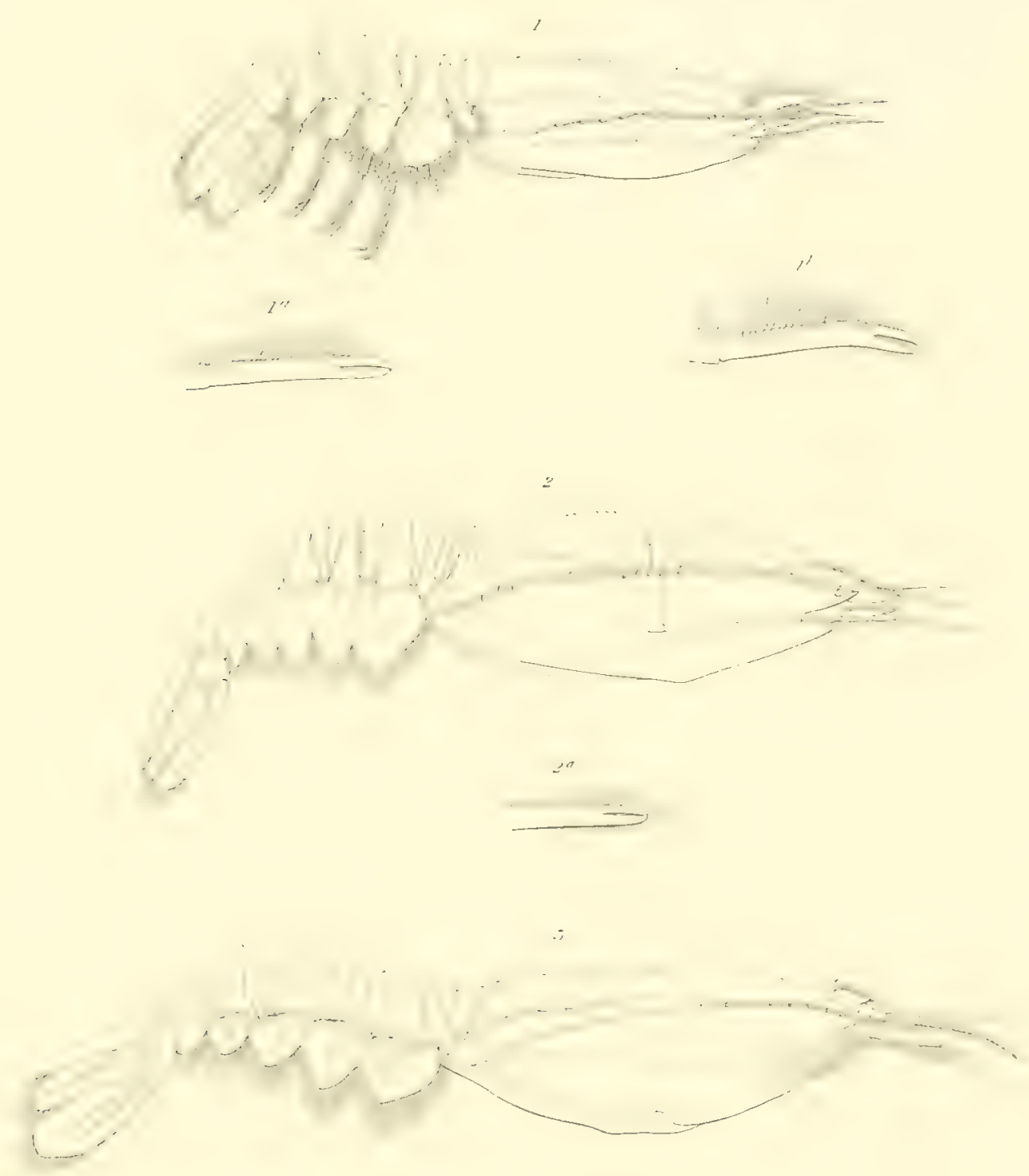



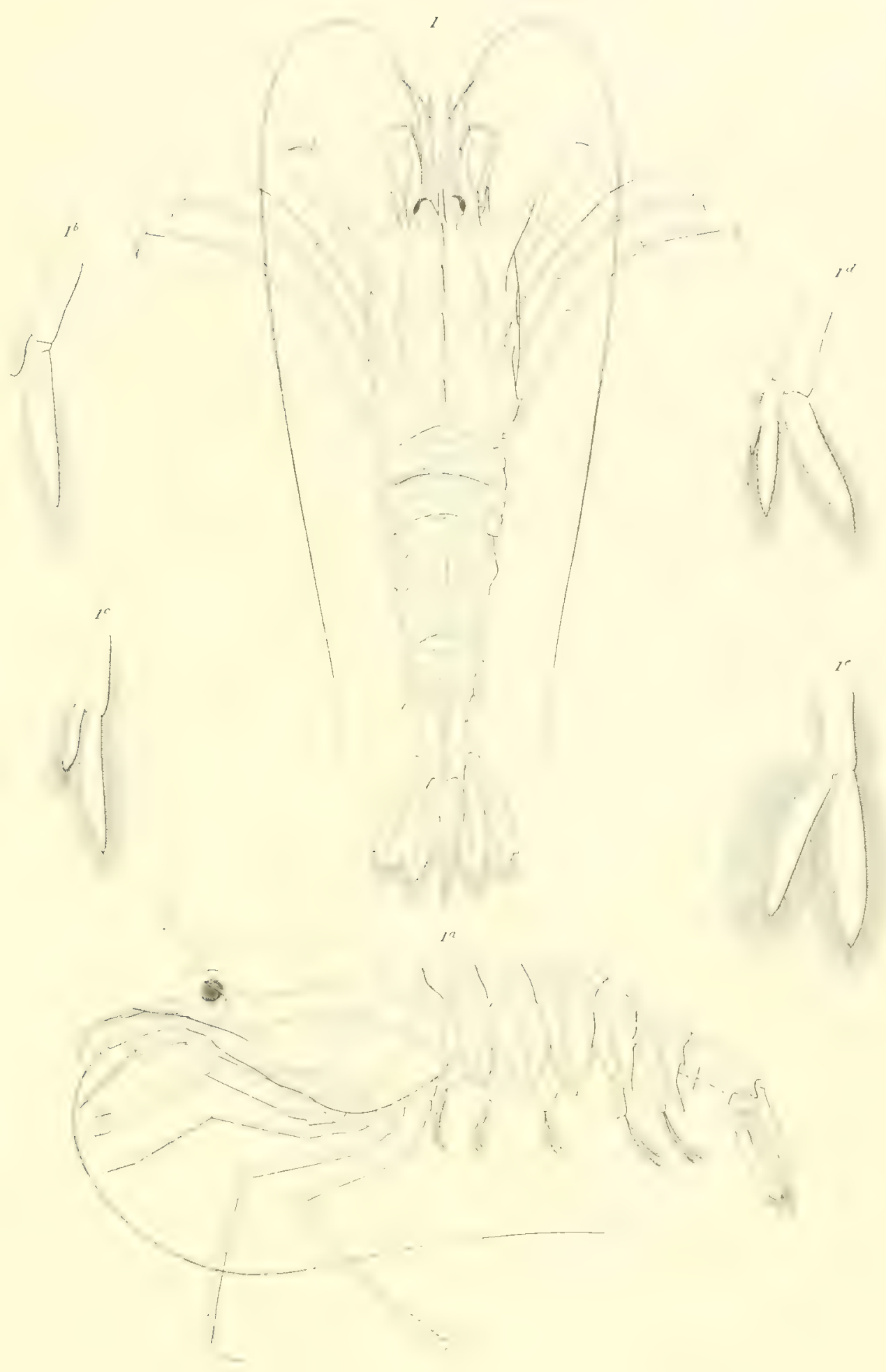




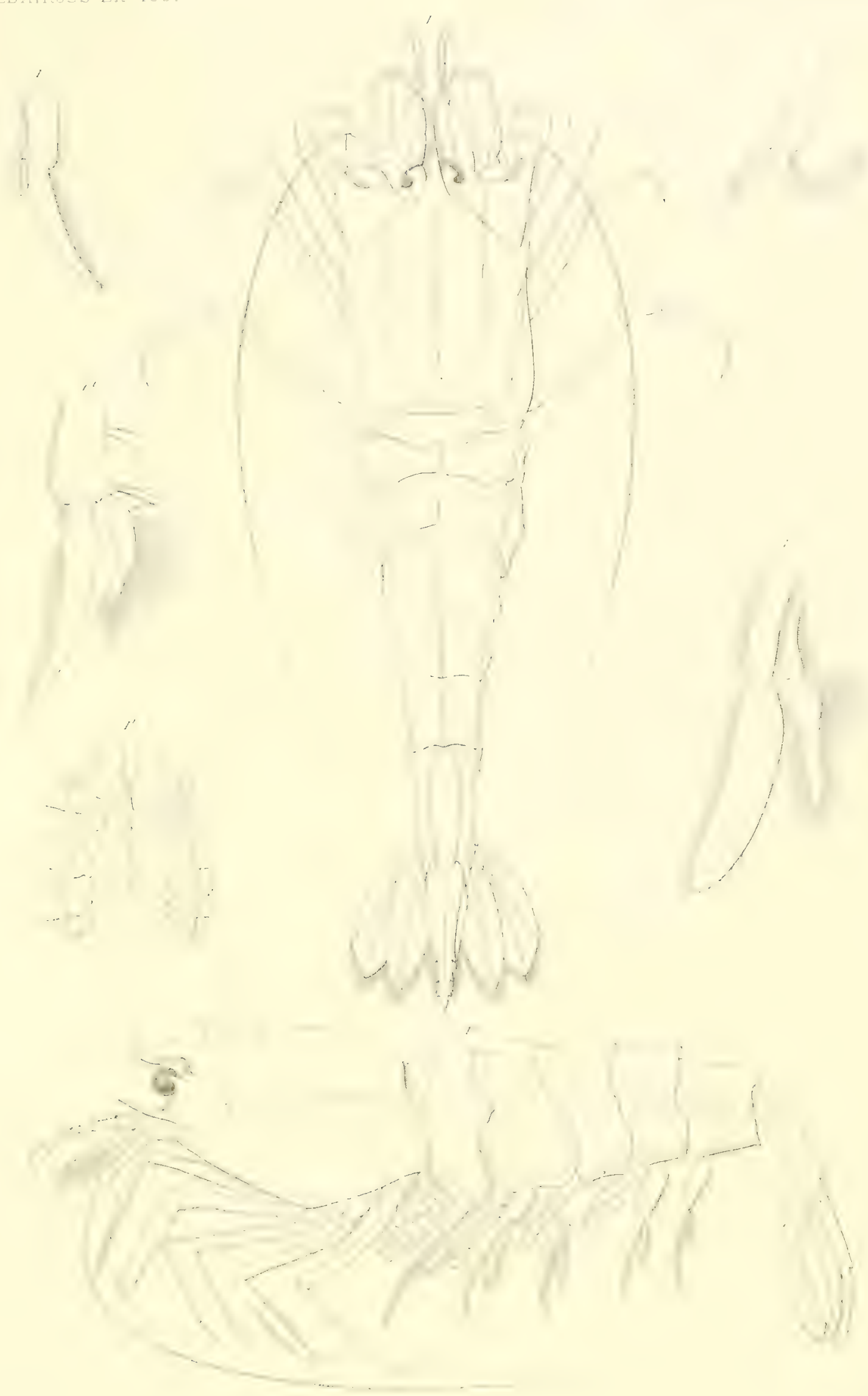



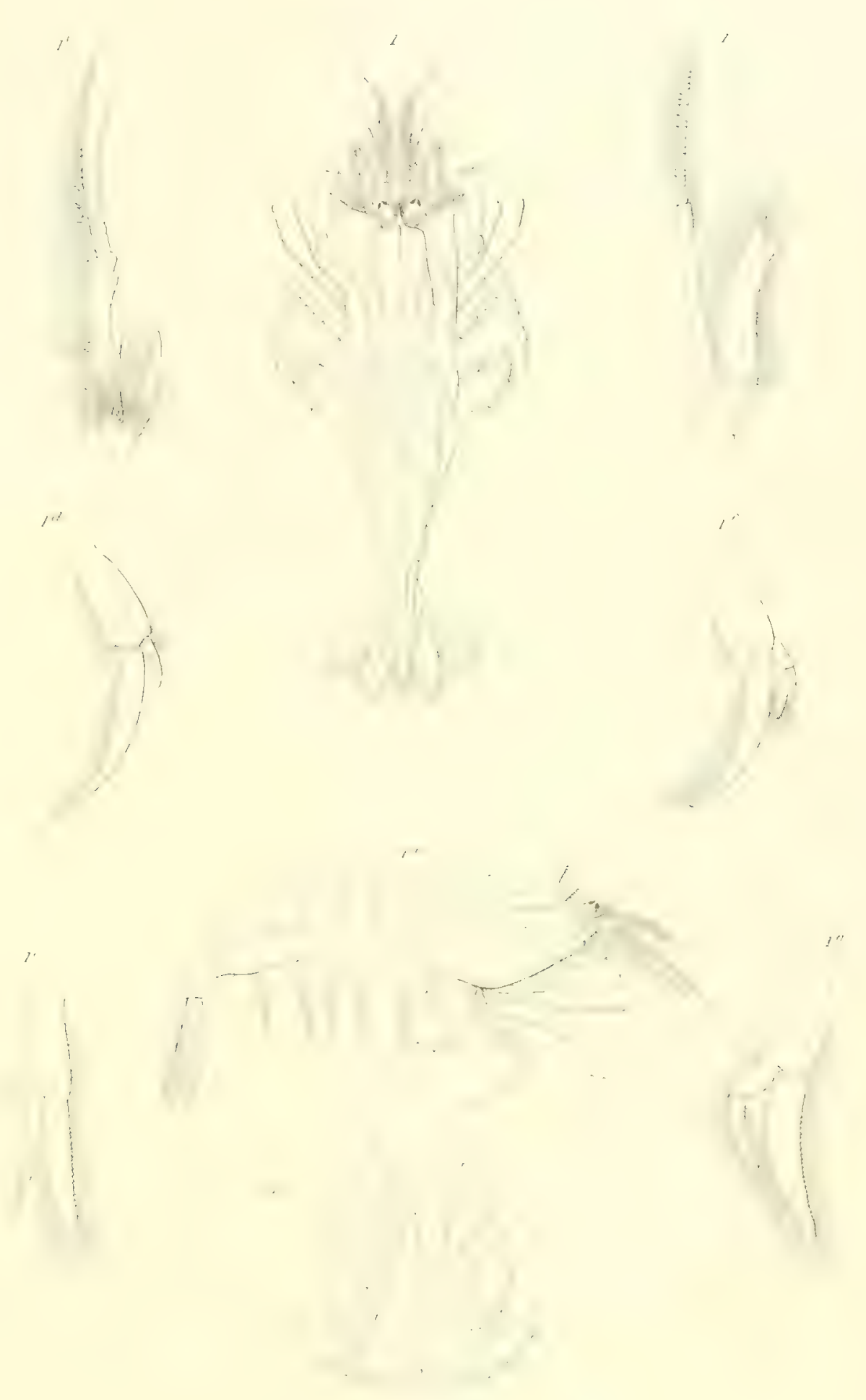





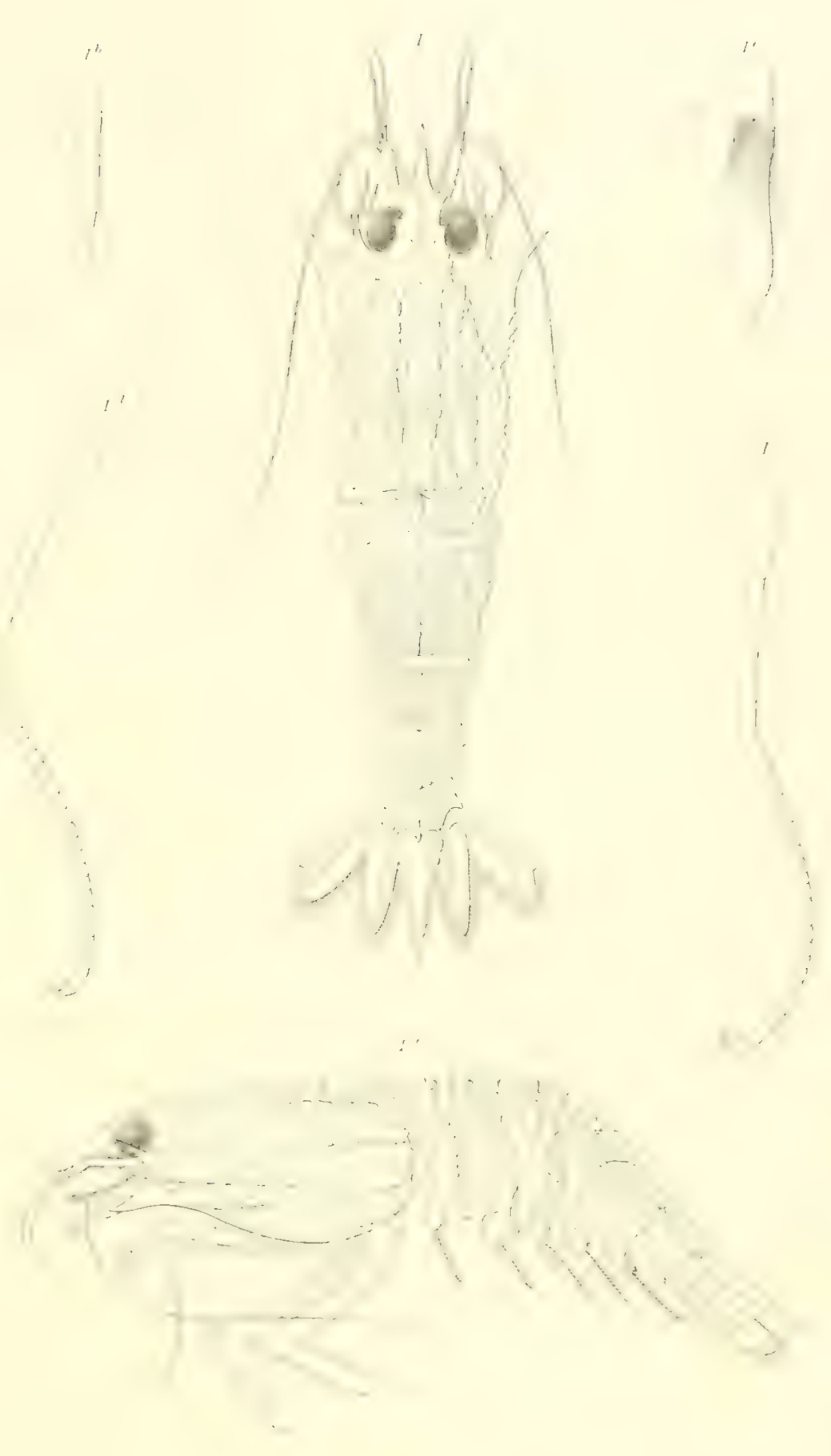


. 


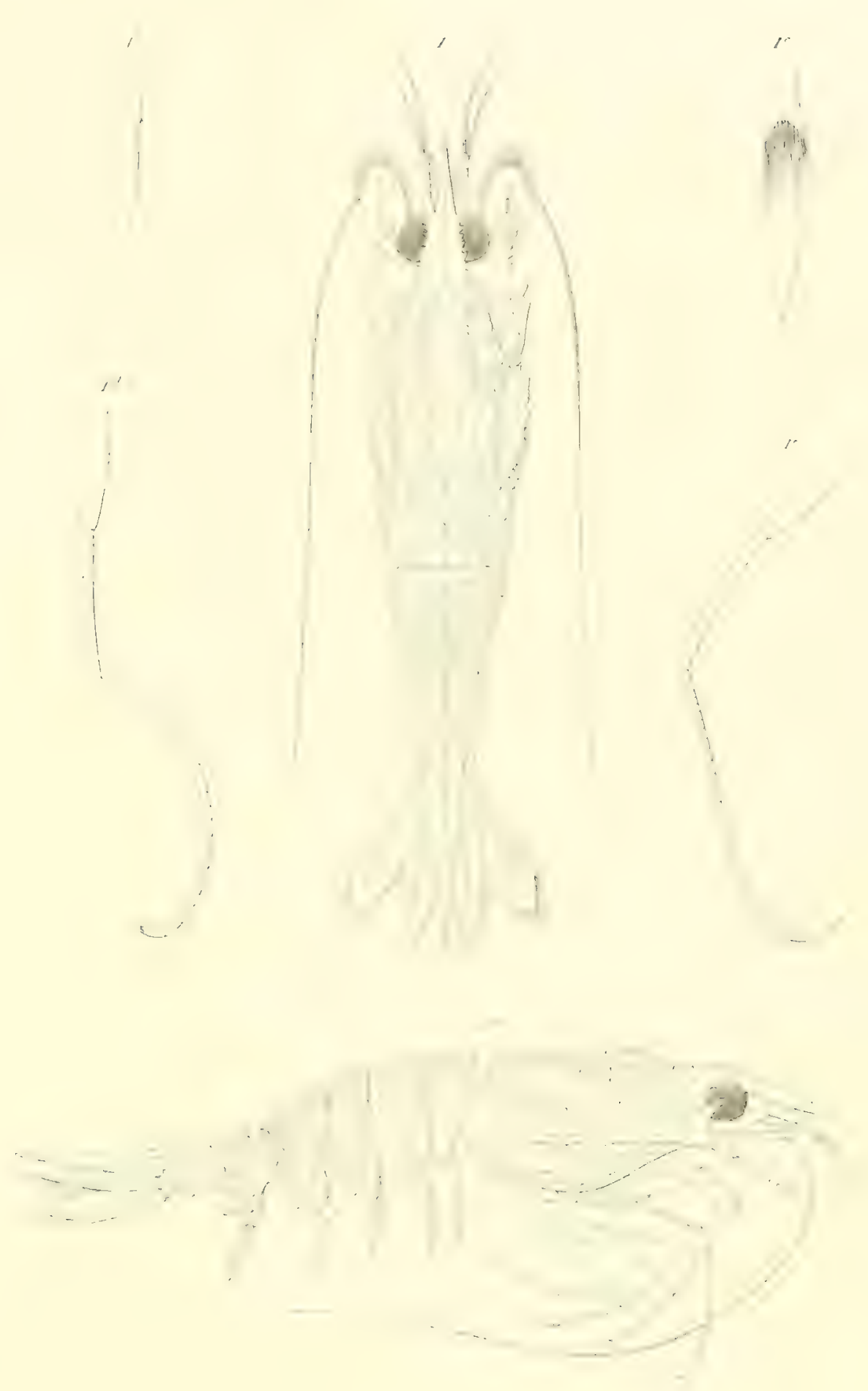




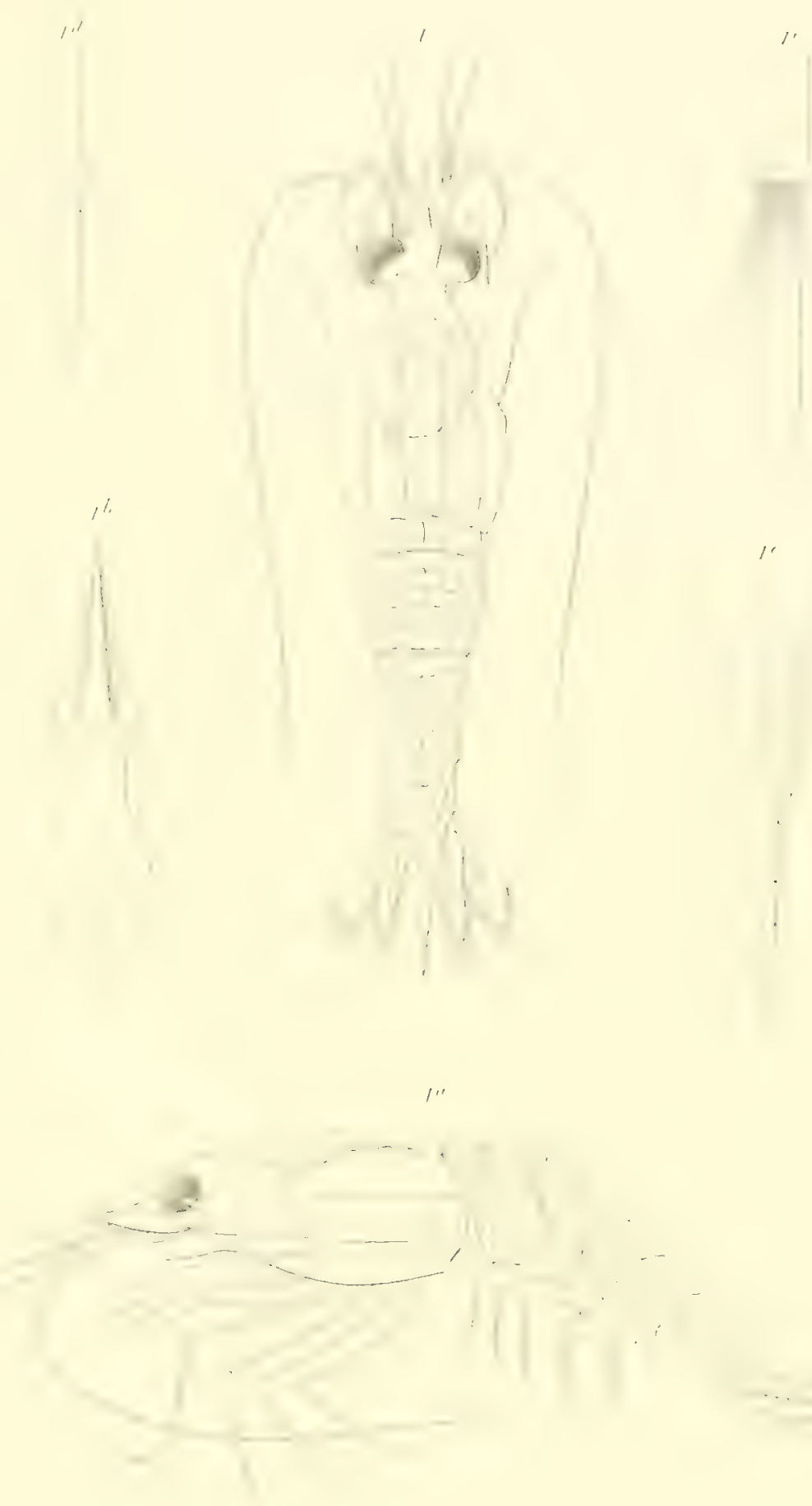


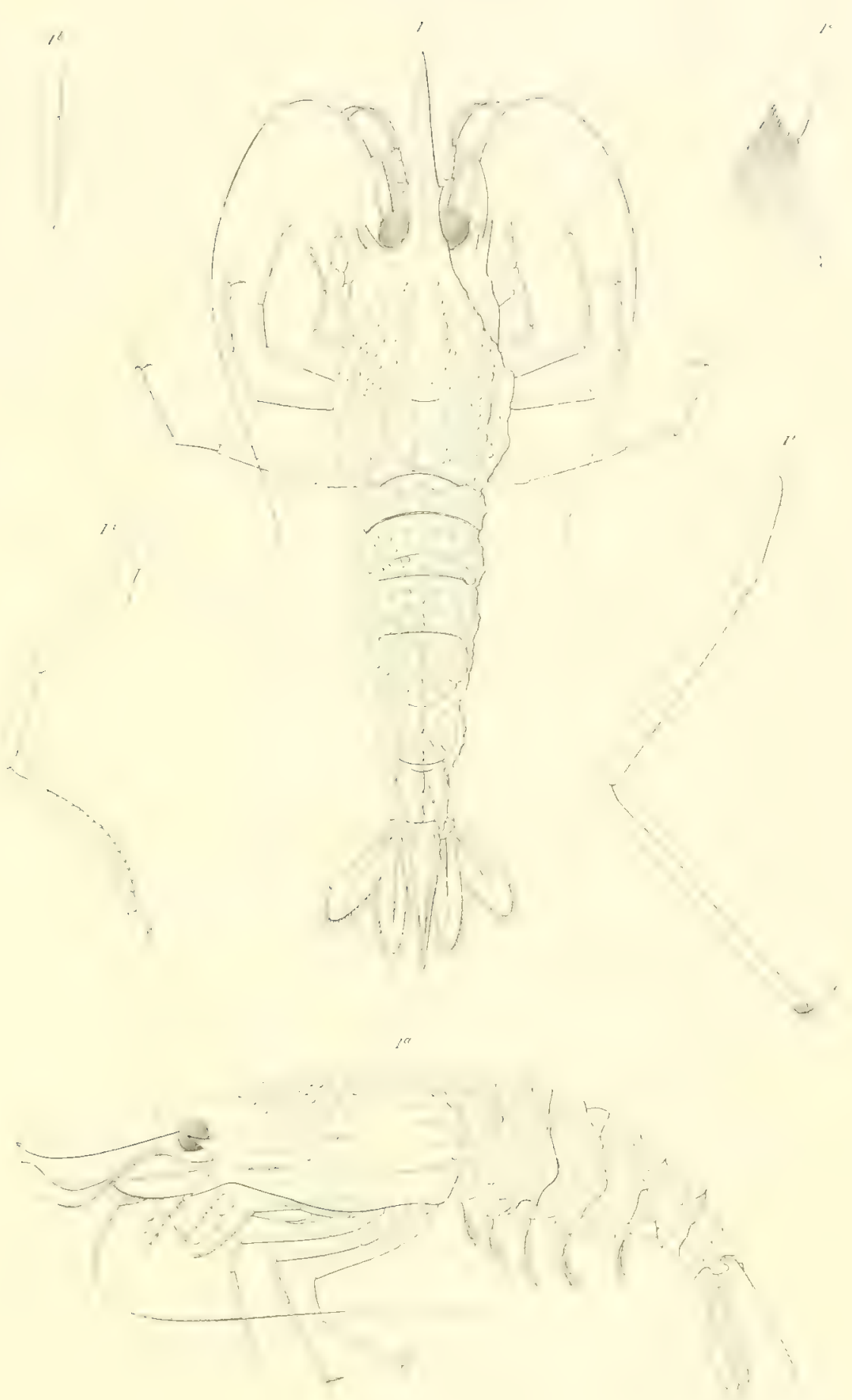





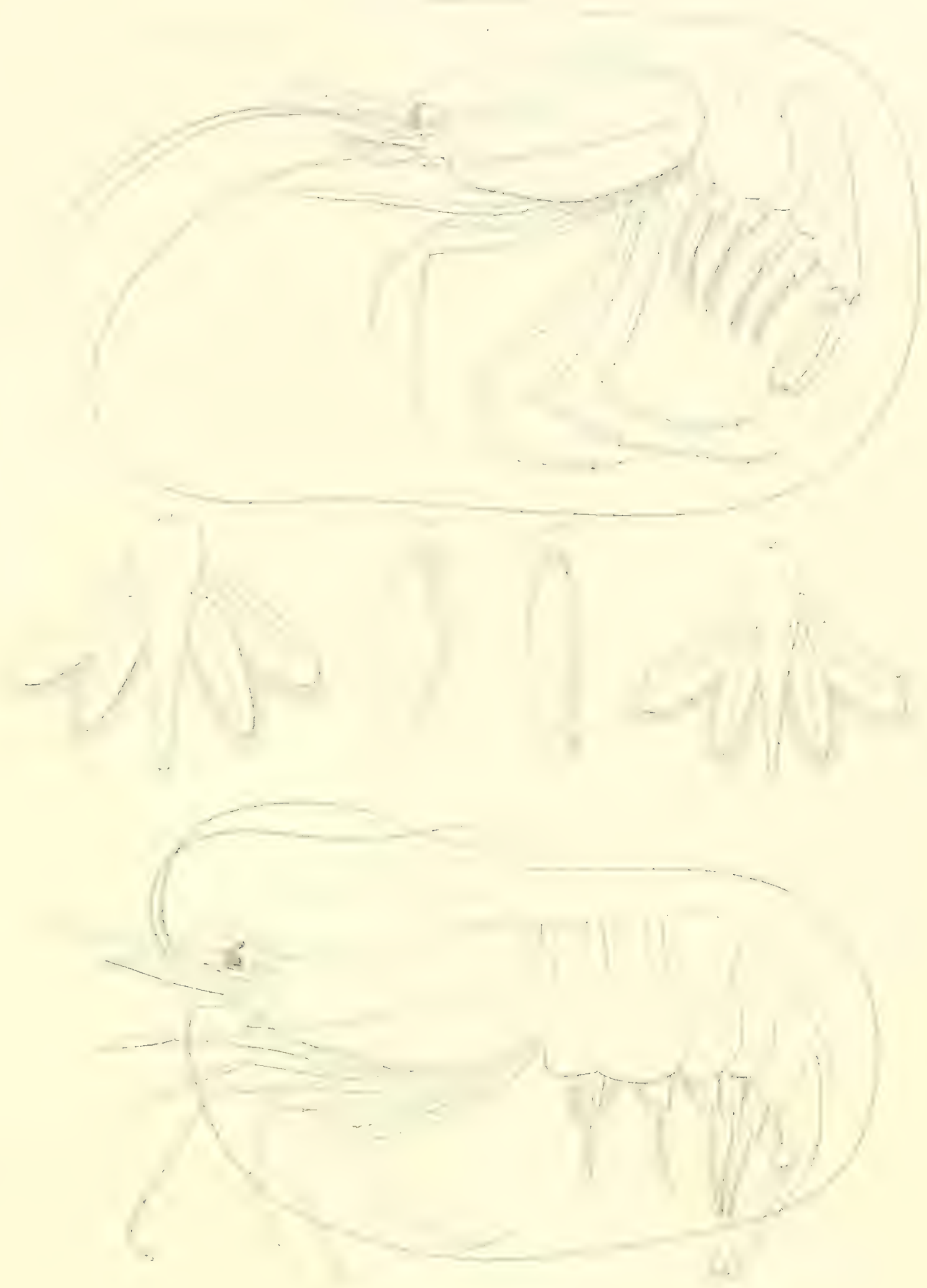




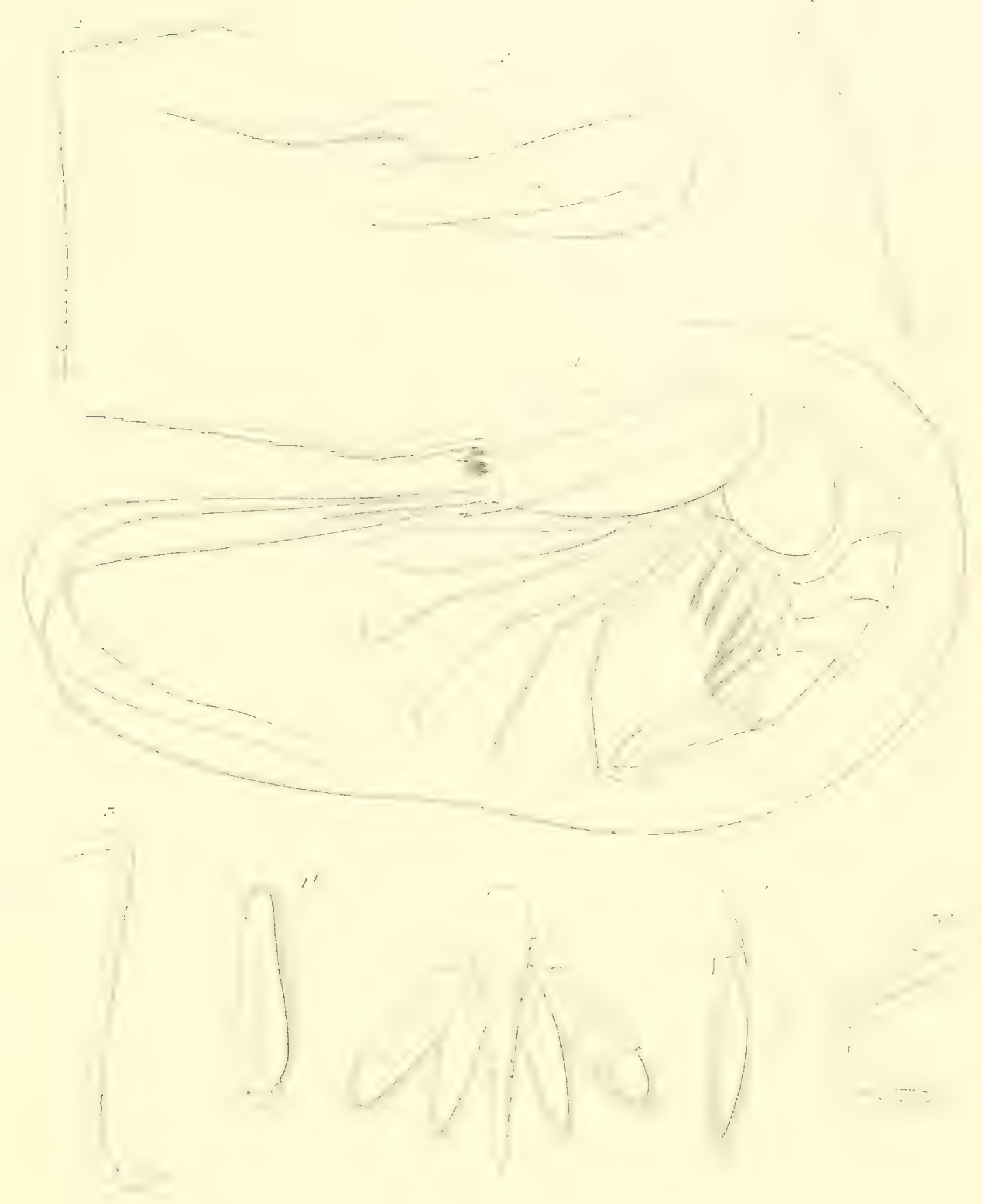




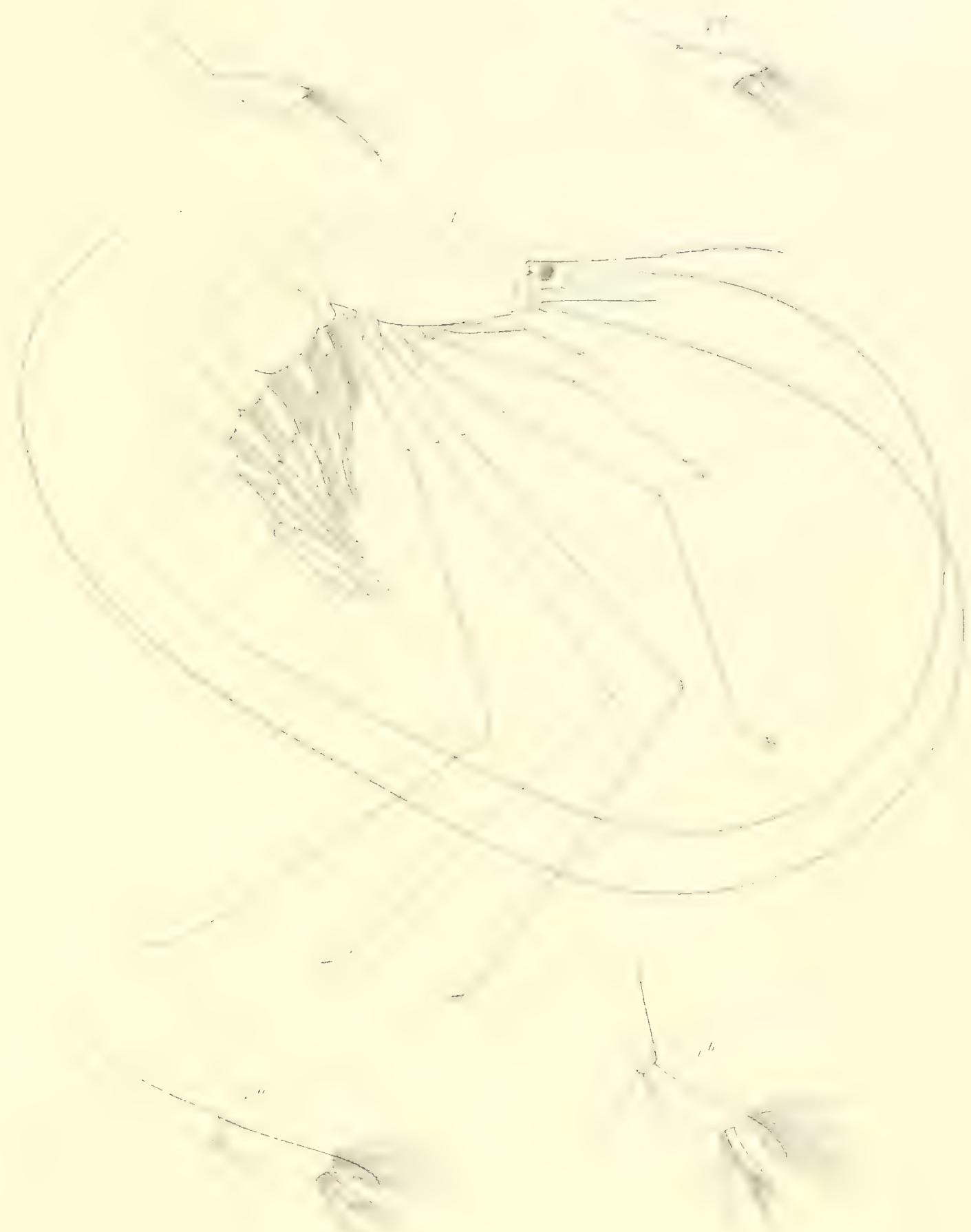





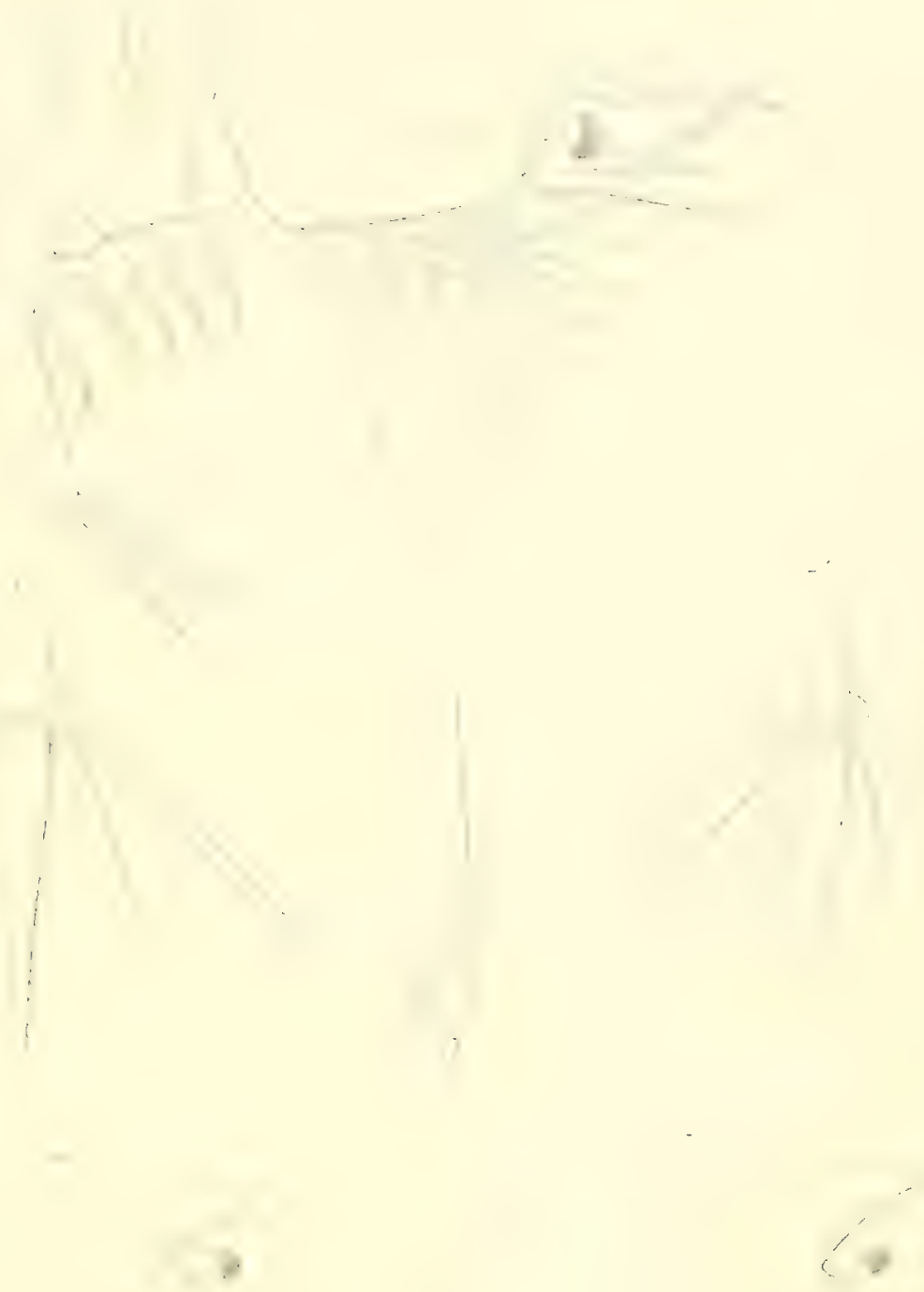




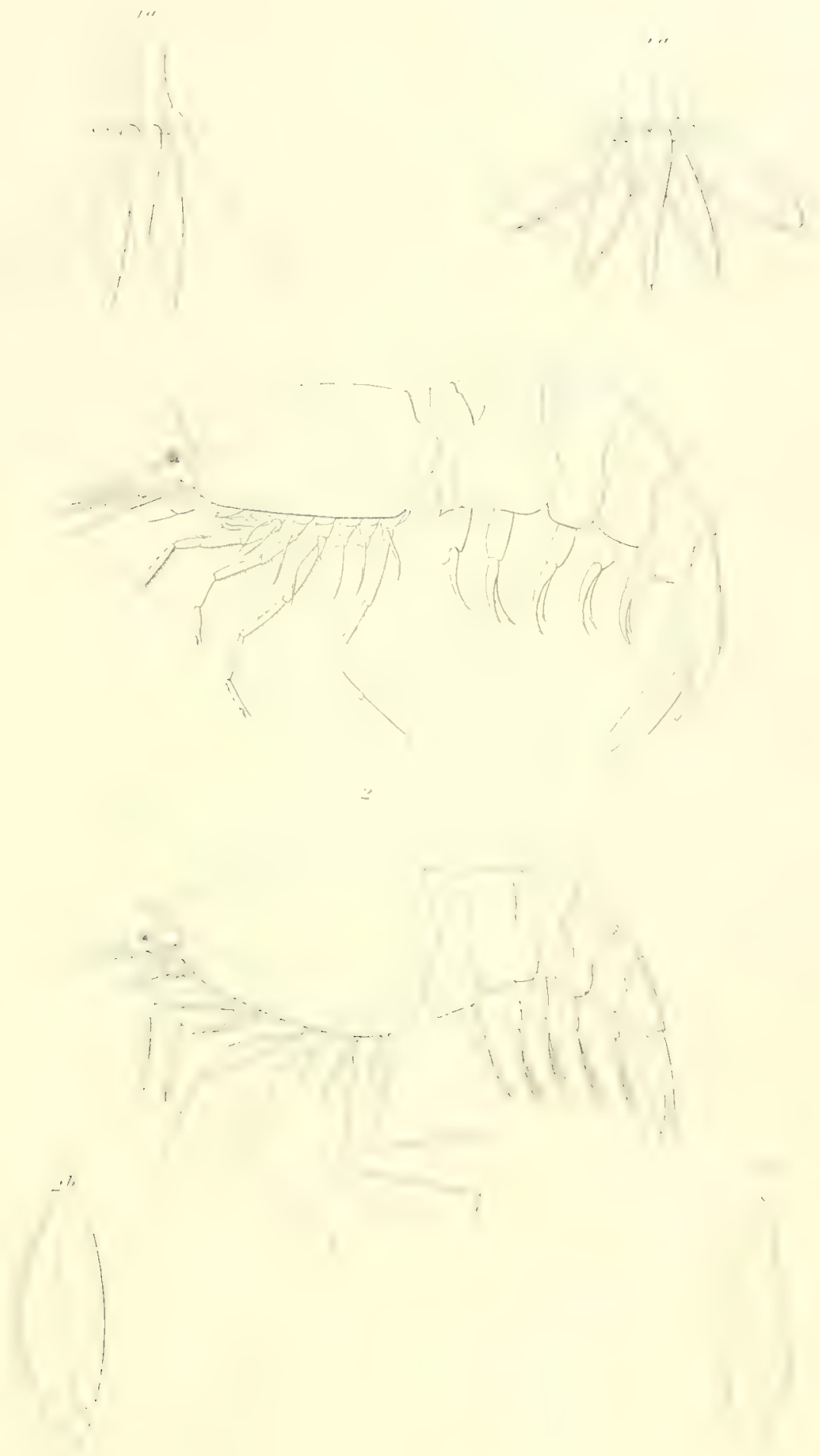

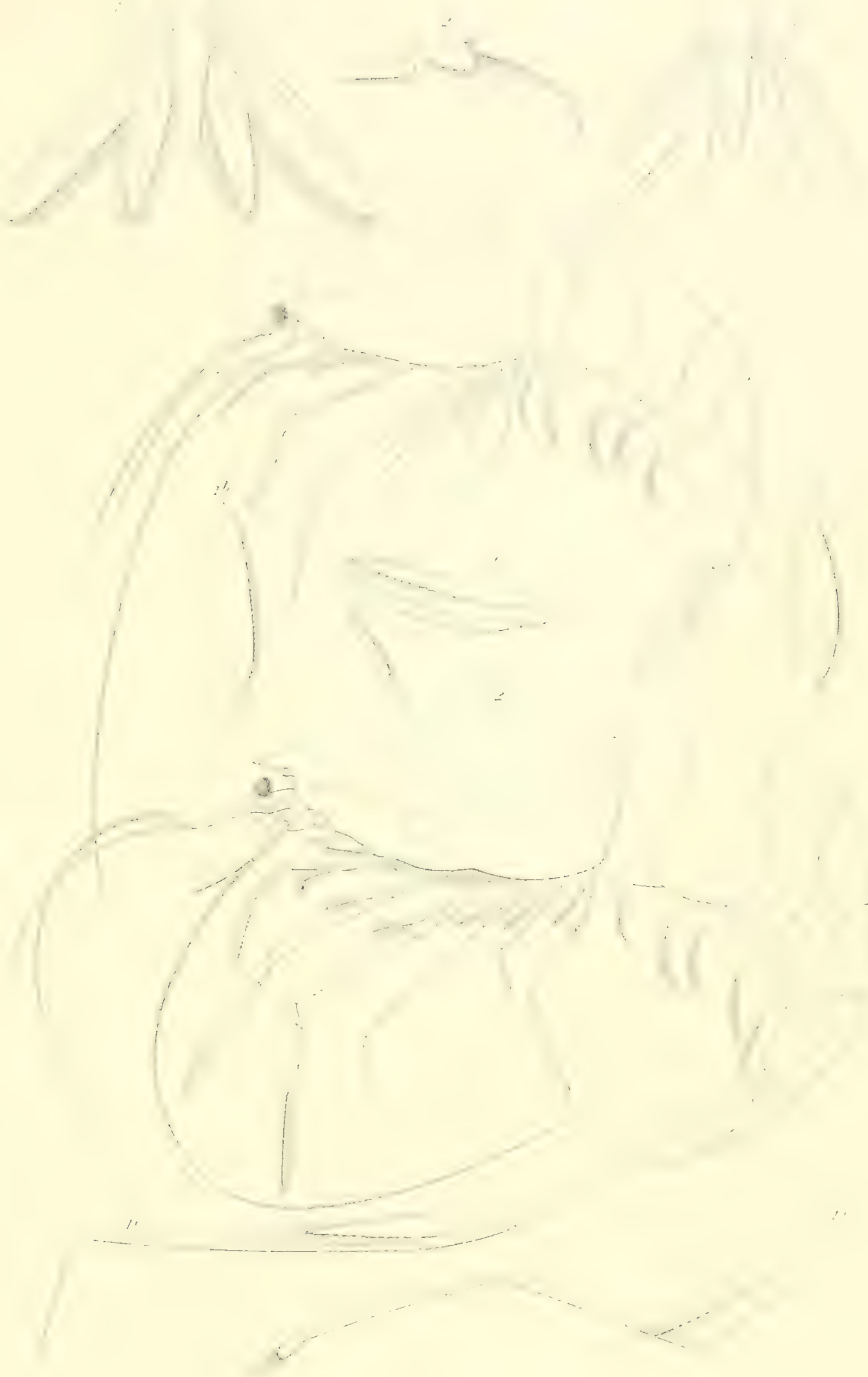

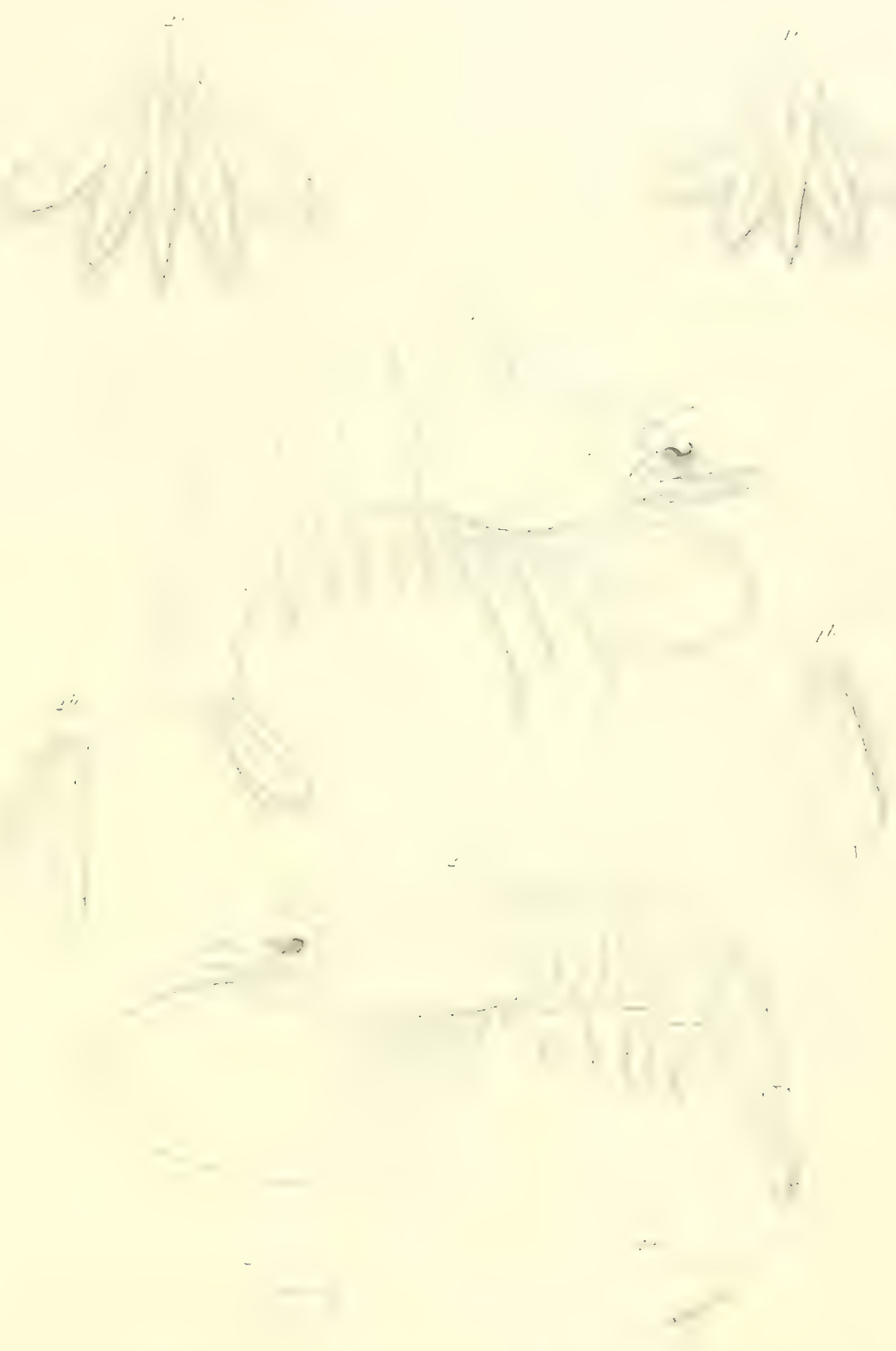



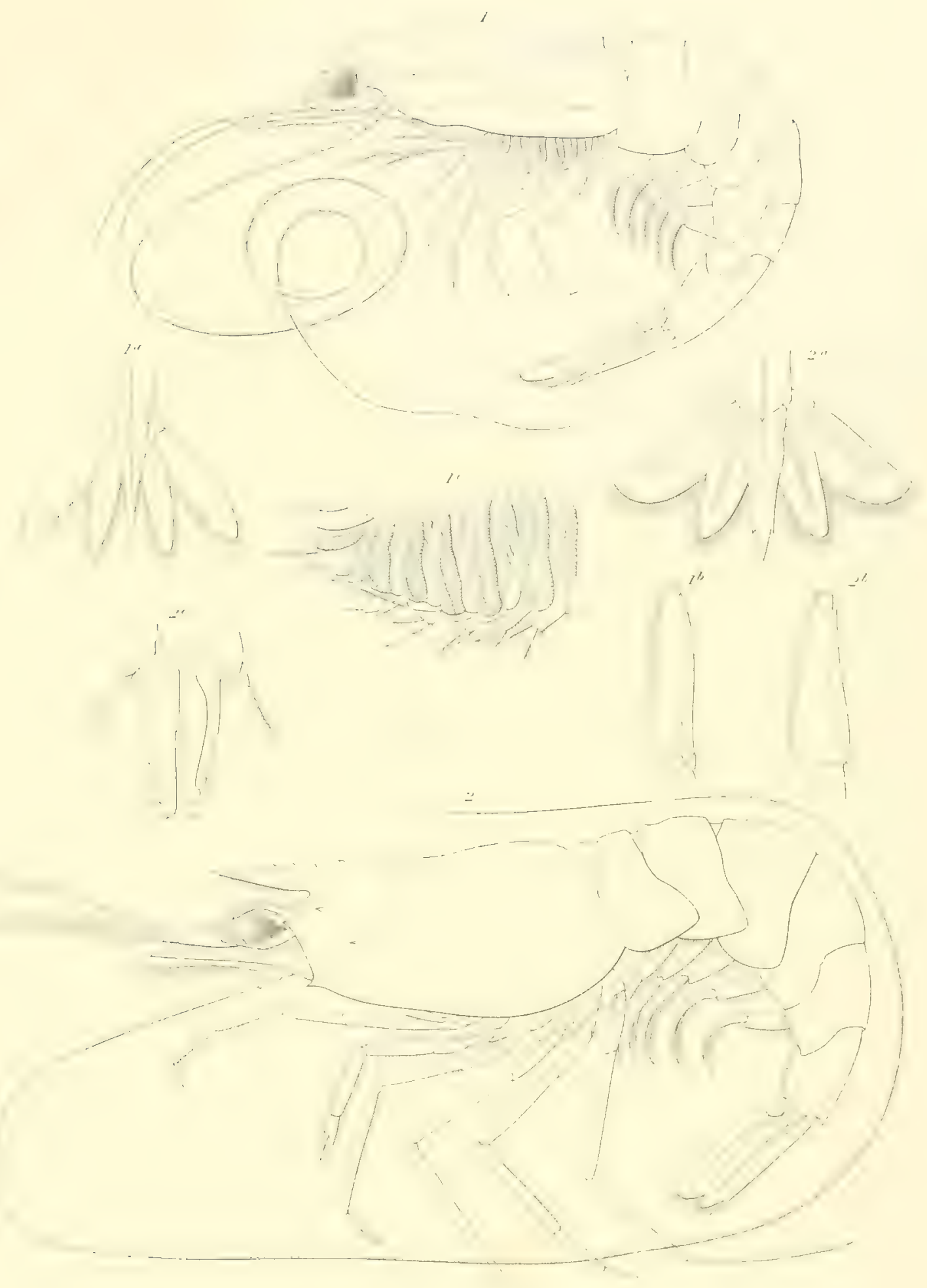





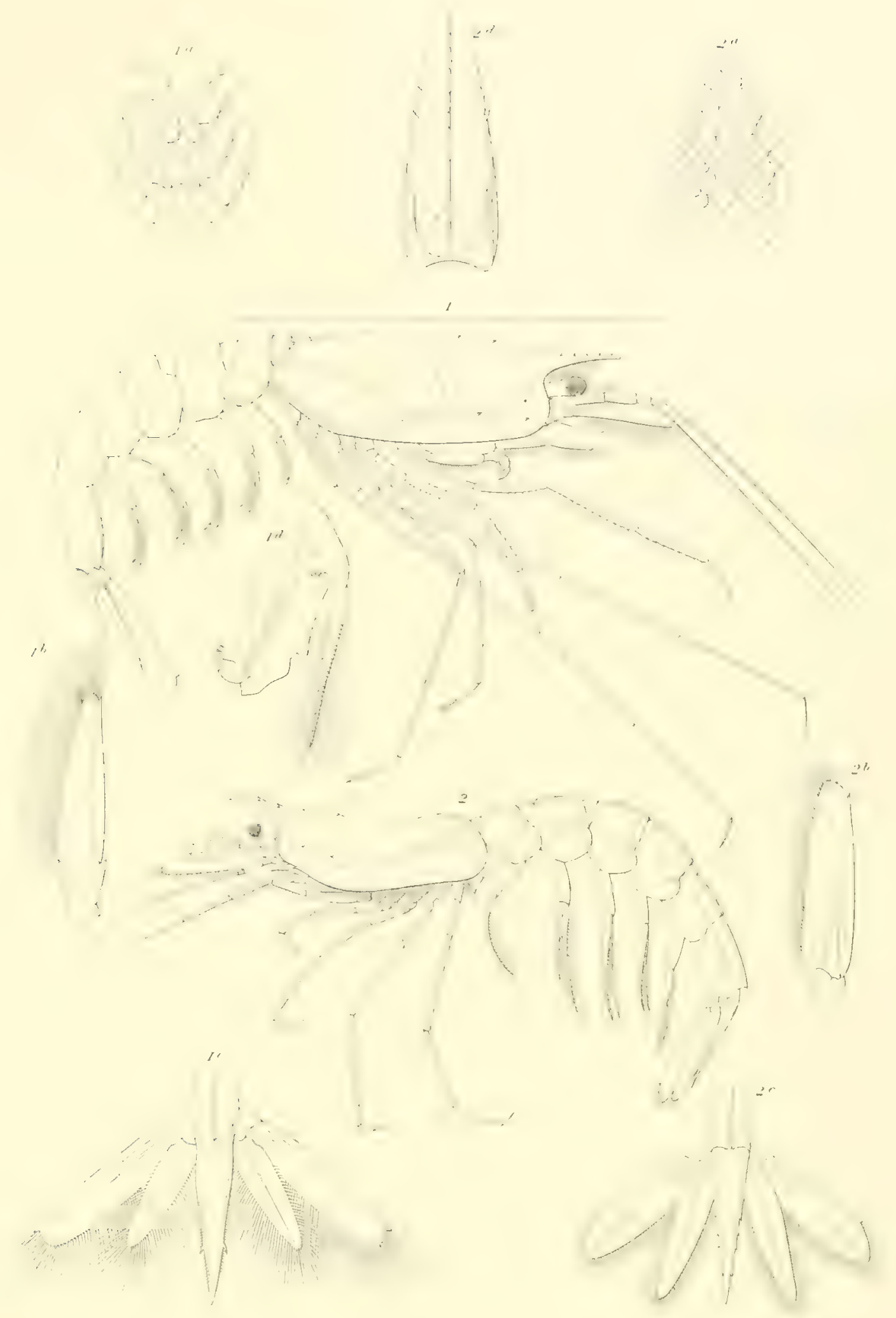




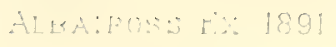

QRTSTACEATH XLIS

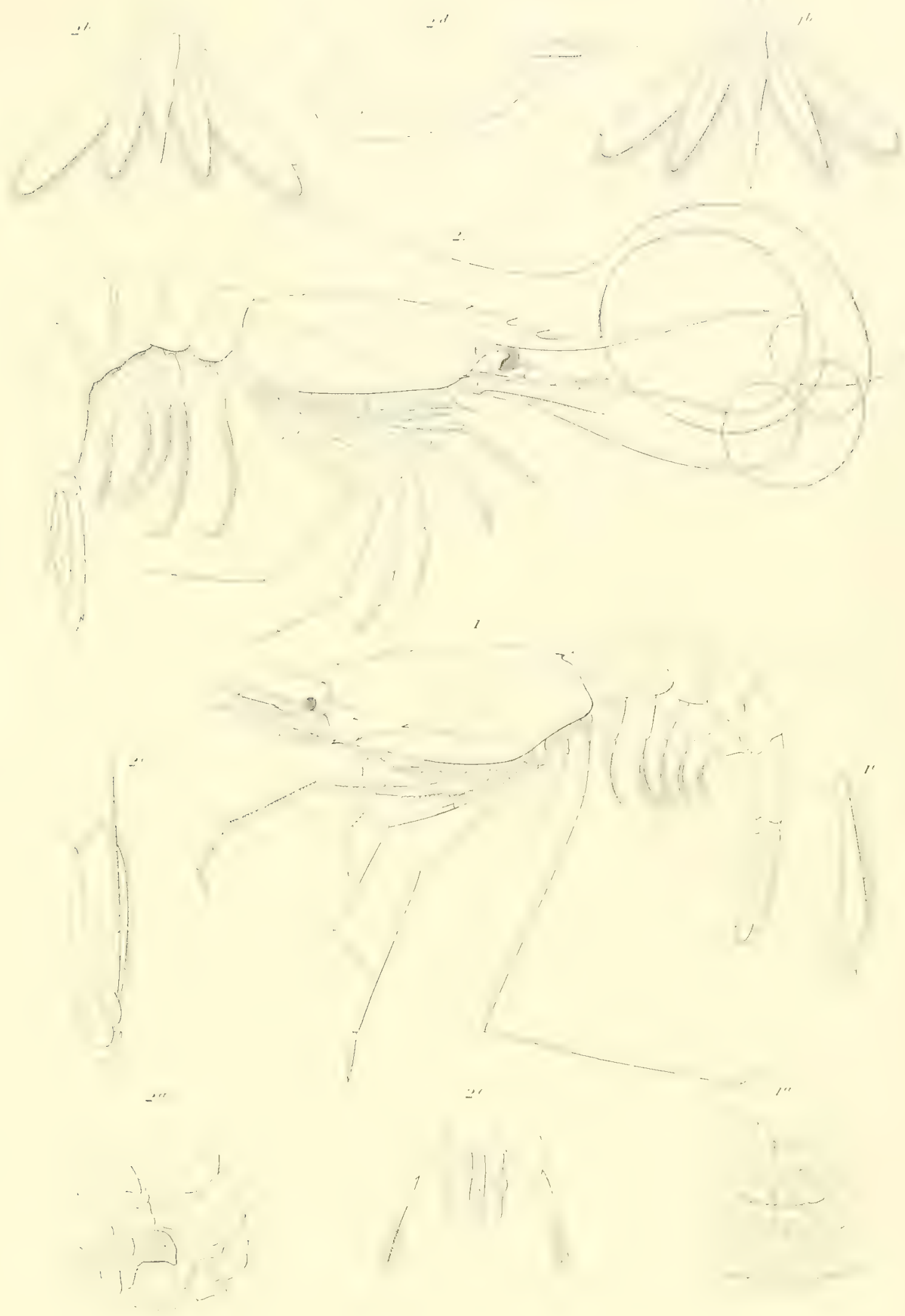

A Mi Westeper de:

1. HAIPORUS DORIS. 2. ARISTEUS OCUIDENTALIS. 


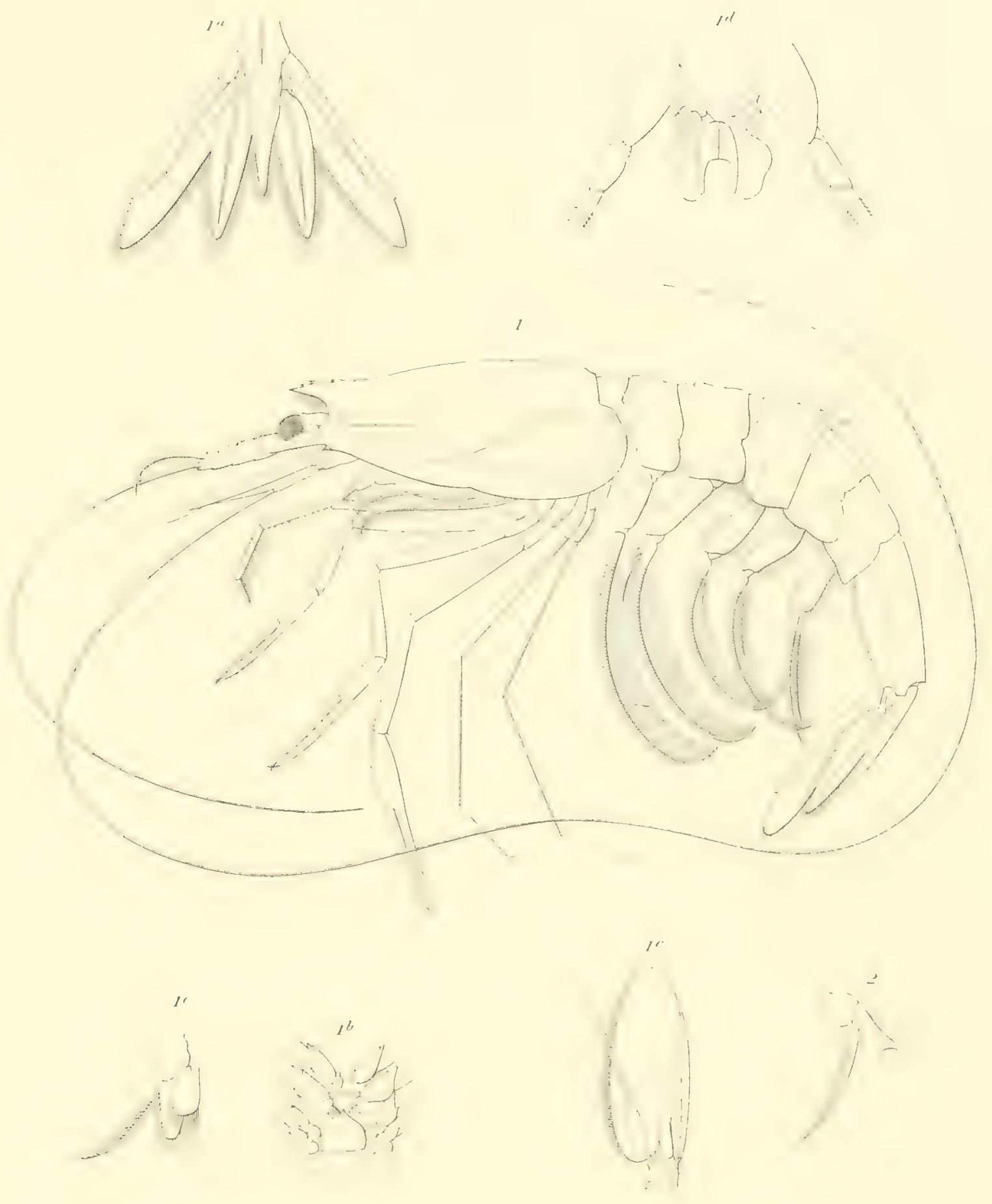

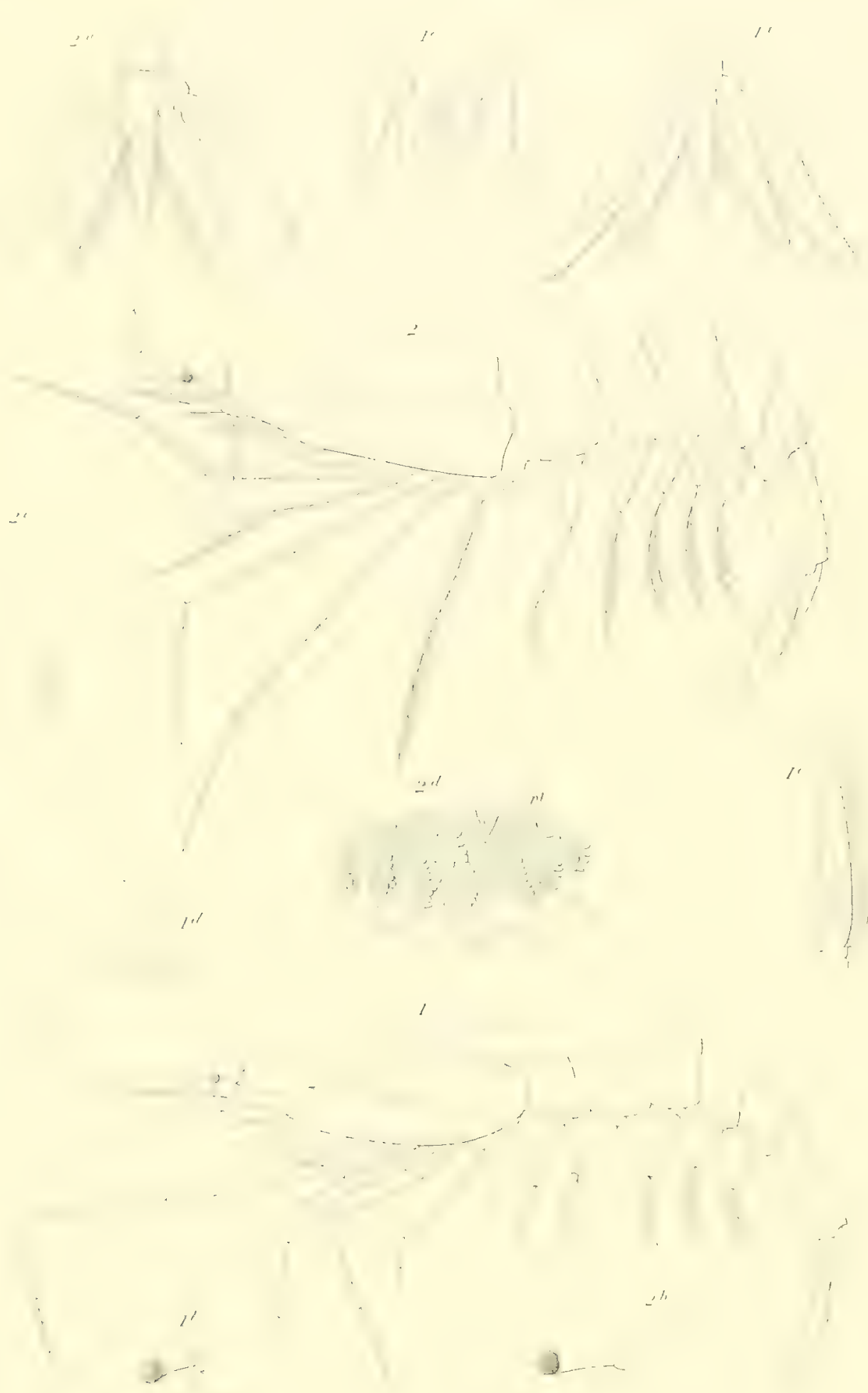

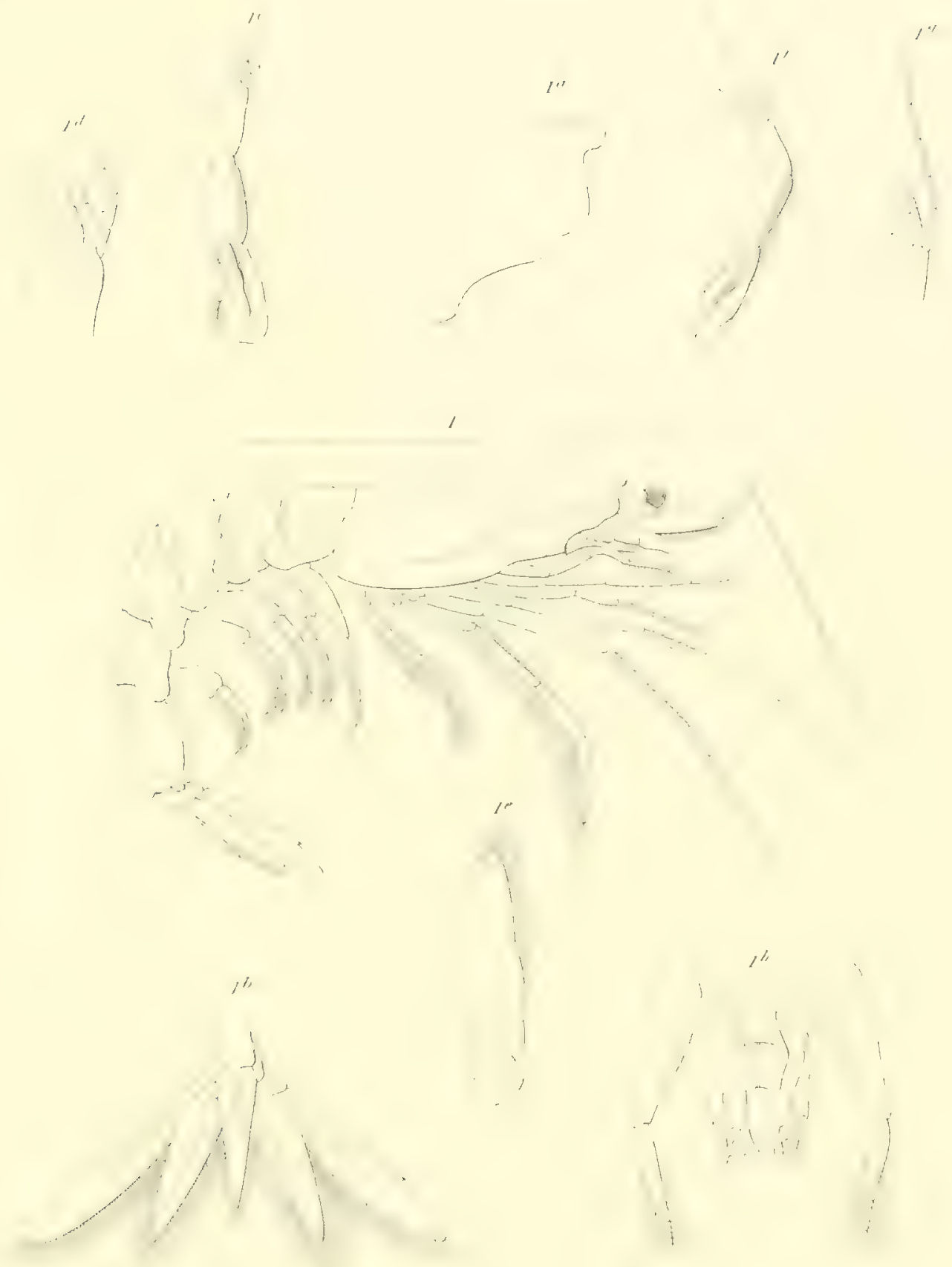


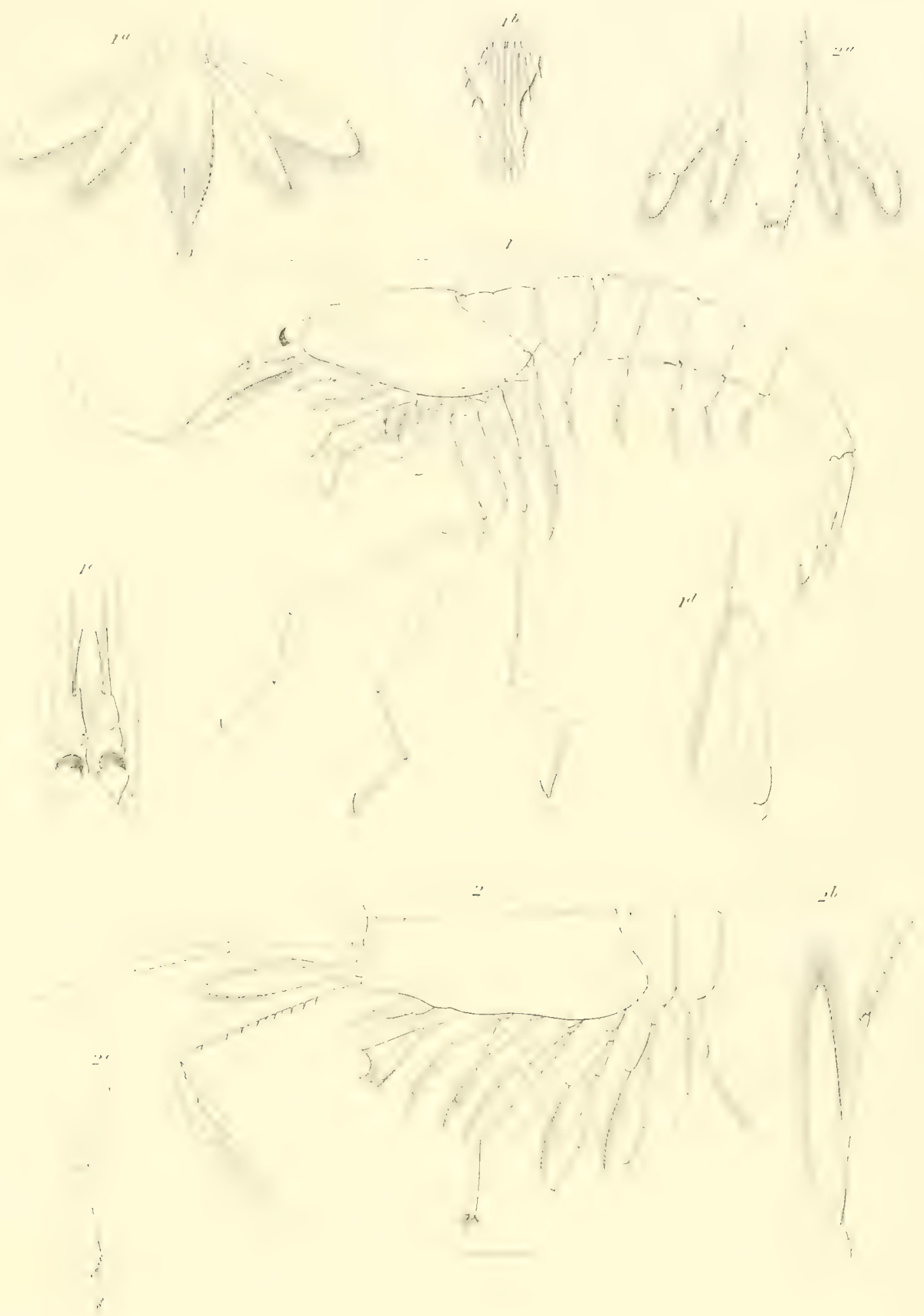


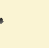



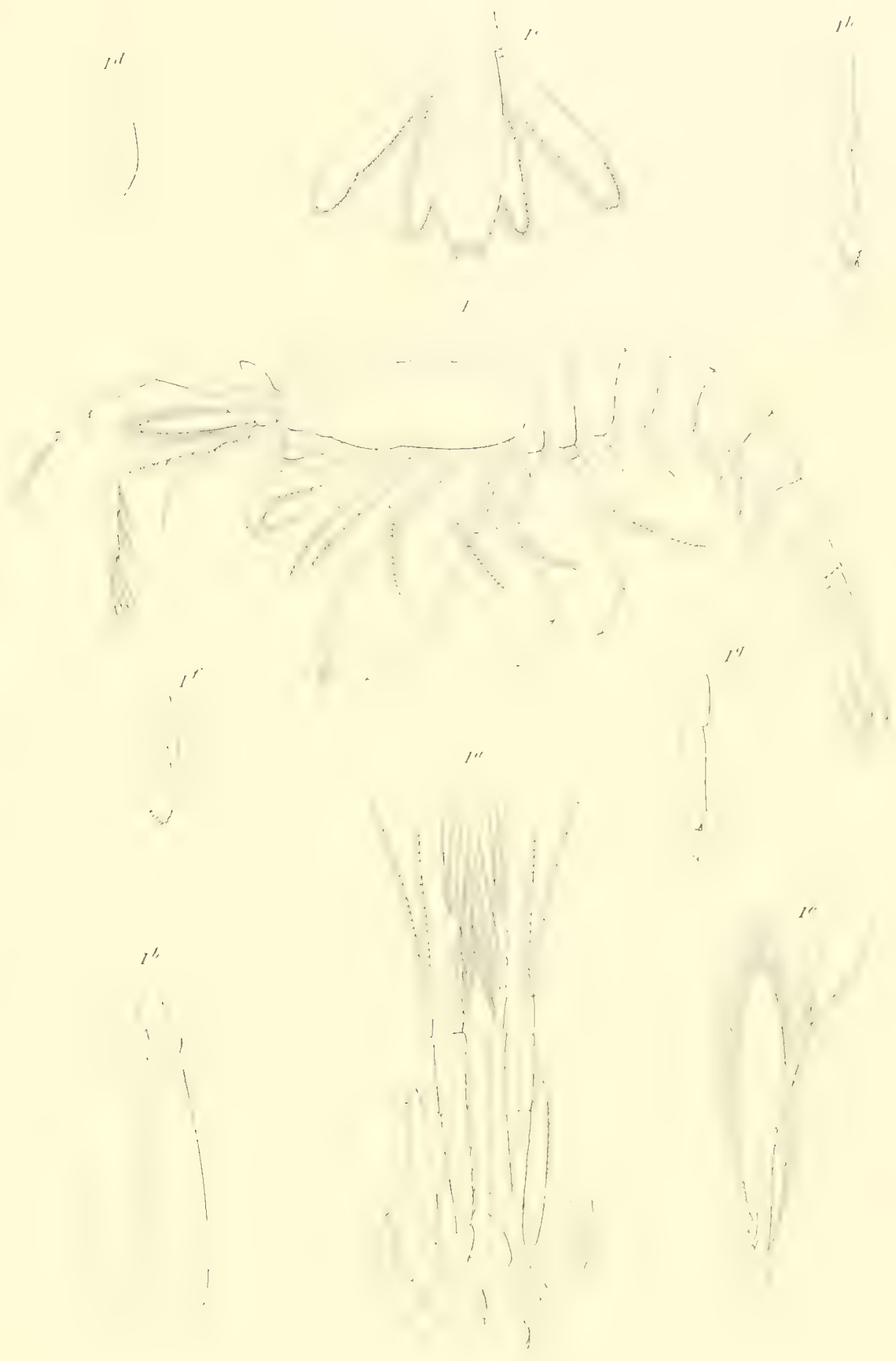



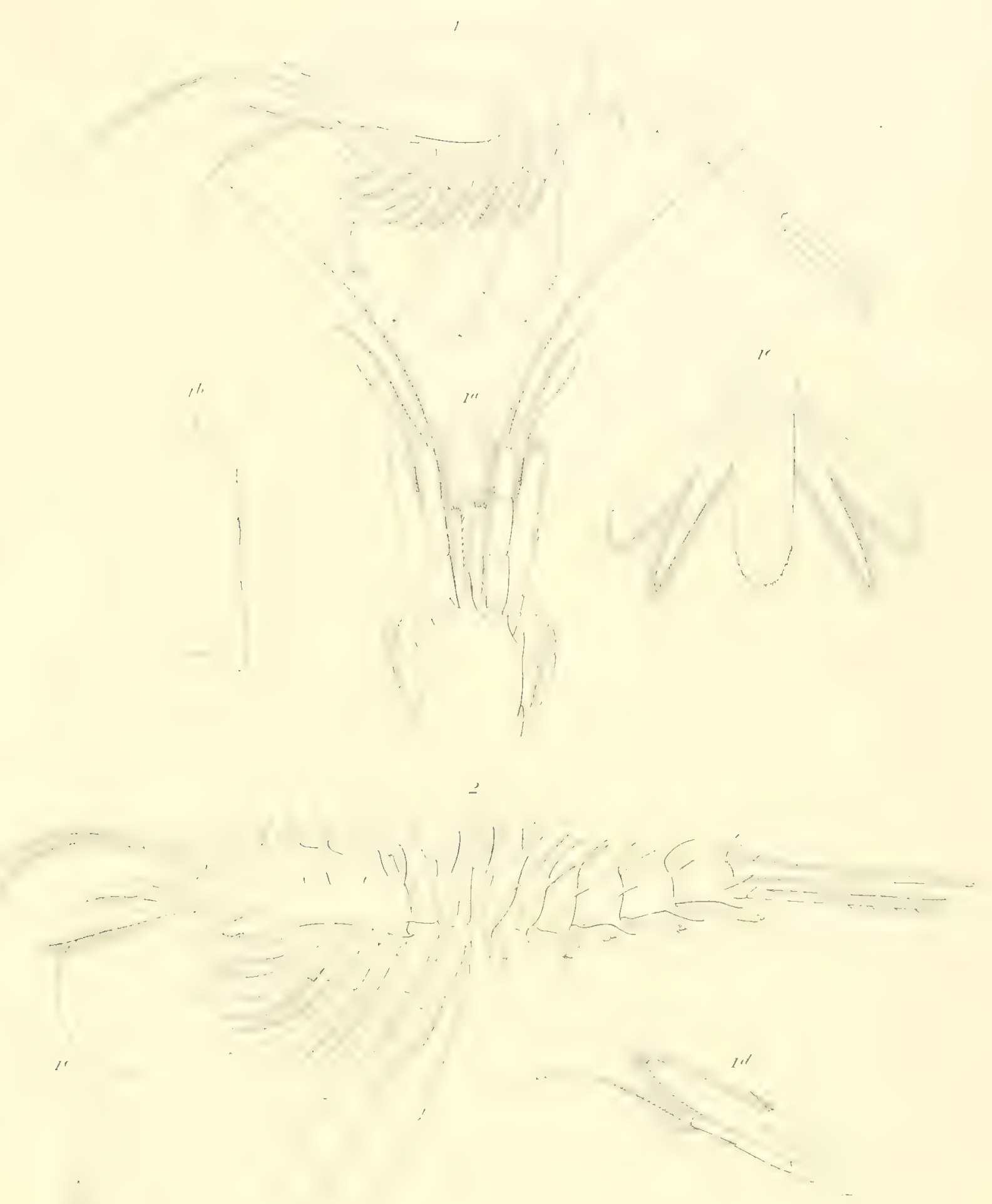




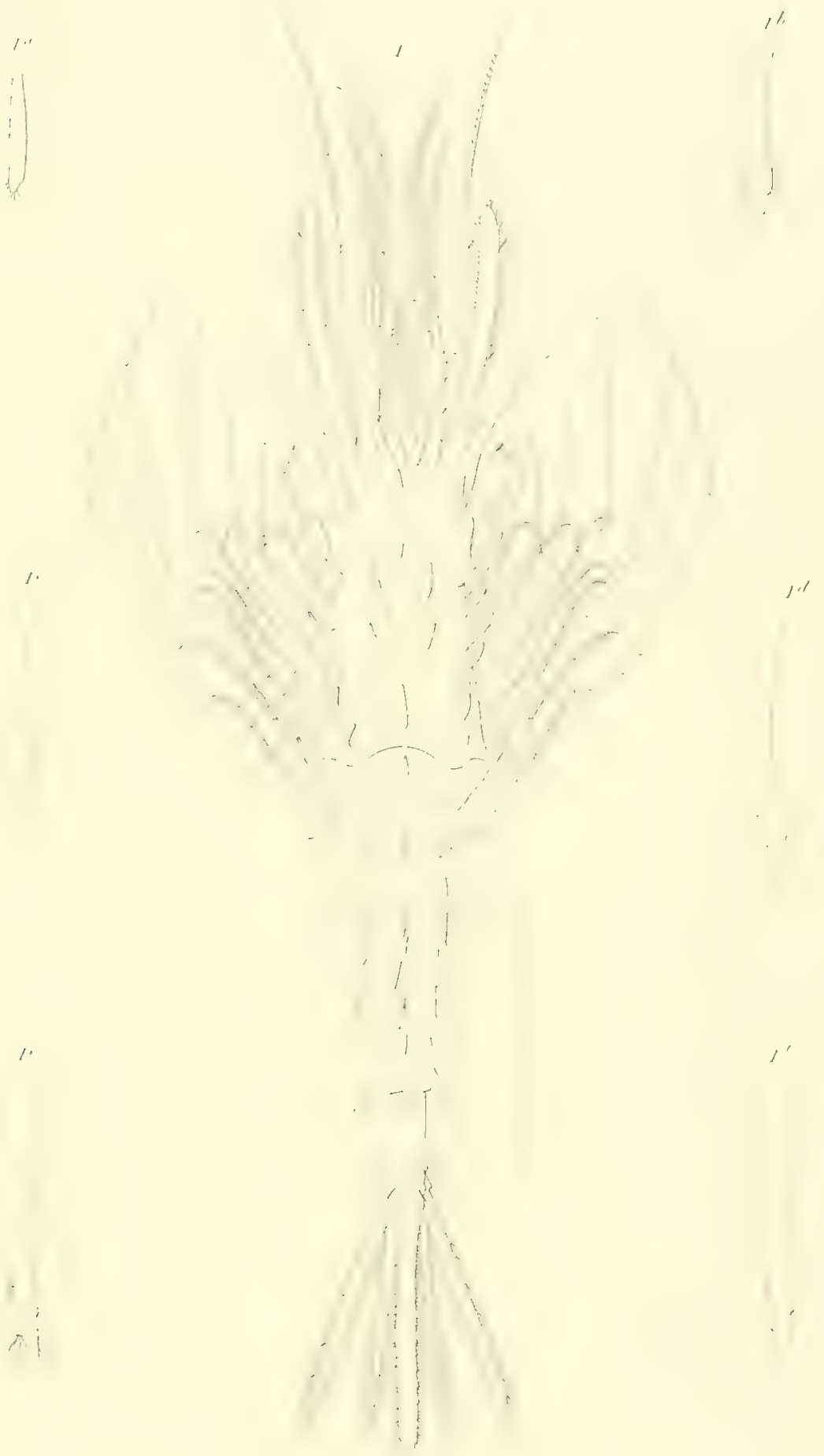
. 


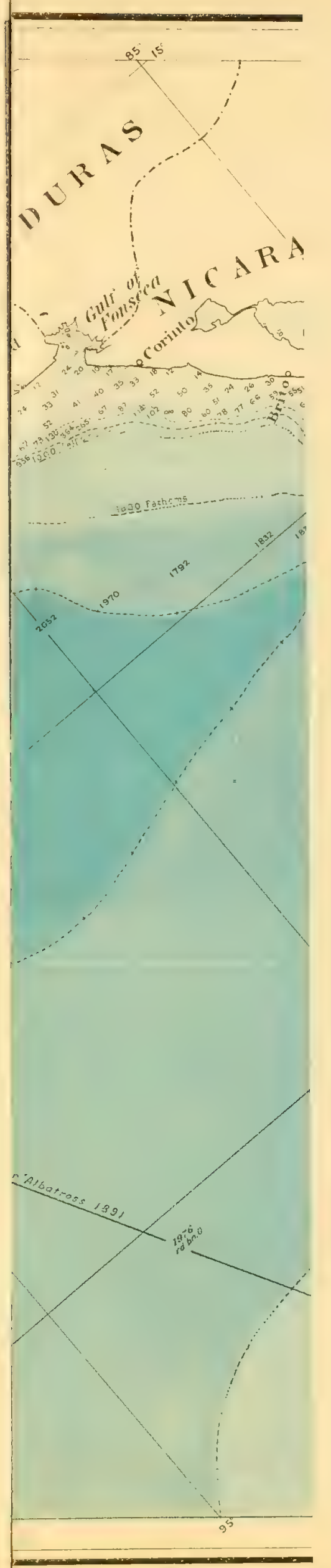





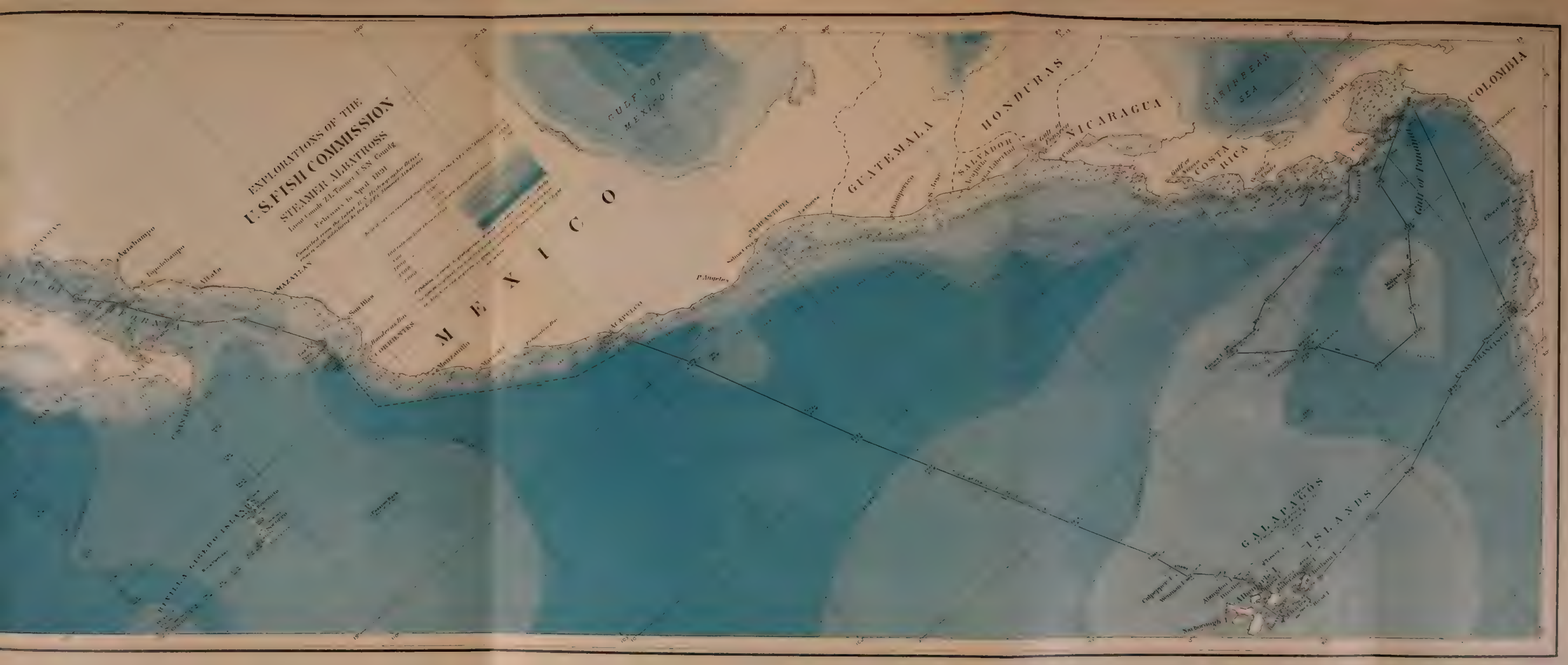



The following reports are in preparation on the Dredging Operations off the West Coast of Central America to the Galapagos, to the West Coast of Mlexico, and in the Gulf of Californic, in charge of ALExander AGassiz, carried on by the U. S. Fish Conmission Steamer "Albatross," during 1891, Lieut.-Commander Z. L. TANser, U. S. N., Commanding:-

A. AGASSIZ. II. 1 Geueral Sketch of the Expedition of the "Albatross," from February to May, 1891.

A. AGASSIZ, The Pelagic Fauna.

A. AGASSIZ. The Deep-Sea Panamic Fauna.

A. AGASSIZ. I. ${ }^{2}$ On Calamocrinus, a new Stalked Crinoid from the Galapagos.

A. AGASSIZ, The Echini.

.AS. E. BENEDICT. The Annelids.

R. BERGII. XIII. ${ }^{13}$ The Nudibranchs.

K. BRANIT. The Sagittr.

K. BRANDT. The Thalassicolæ.

C. CIIUN. The Siphonophores.

C. CHUN. The Eyes of Deep-Sea Crustncen.

S. F. CLARKE. XI.11 The Hydroids.

IV. H. DALL. The Mollusks.

C. B. DAVENPORT. The Bryozon.

IV. FAXON. VI., ${ }^{3}$ XV. ${ }^{15}$ The Stalk-eyed Cinstacea.

S. GARIIAN. The Fishes.

IV. GIESBRECIIT. The Copepods.

A. GOËS. III.* The Foraninifera.

H. J. II ANSEN. The Cirripeds and Isopords.

C. IARTLAUB. The Comatule.

IV. A. HELDMAN. The Ascidians.

S. J. HCKSON. The Antipathids.

IV. E. HOYLH. The Cephalopods.

G. VON KOCH. The Deep-Sea Corals.

C. A. KOFOID. Solenogaster.
R. VON LENDENFELD. The Phospliorescent Organs of Fishes.

H. LUDIVIG. IV., ${ }^{5}$ XII.12 'The Ilolothurians.

C. F. LÜTKEN. The Ophiuridæ.

O. MAAS. The Acalephs.

F. I. MARK. The Actinarians.

GEO. P. MERRILL. V. ${ }^{6}$ The Rocks of the Galapagos.

G. W. MÜLLER. The Ostracods.

JOIN MURRAY. The Bottom Specimeus.

ARNOLD ORTMANN. XIV. ${ }^{14}$ The Pelagic Schizopods.

ROBERT RIDGIVAY. The Alcoholic Birds.

P. SCHIEMENZ. The Pteropods and Heteropods.

IV. SCHIMKÉWTTSCH. VIIr. The Pycnogonidx.

s. H. SCUDDER. YII. The Orthoptera of the Galapagos.

IV. PEliCY SLADE.T. The Strrfishes.

I. STEJNEGER. The lieptiles.

Tи. STUDER X. ${ }^{10}$ The Alcyonarians.

C. II. TOWNSEND. The Birds of Cocos Island.

II. P. A. I'RAÜTSTEDT. The Salpidæ and Doliolide.

E. P. VAN DUZEE. The Halobatidx.

H. B. WARD. The Sipunculoids.

II. V. IVIISON. The Sponges.

IV. McM. WOODITOHTI. IX. ${ }^{9}$ The Planarians.

I Bull. M. C. Z., Vol. XXI., No. 4, June, 1891, 16 pp. ; and Vol. XXIII., No. 1, February, 1992,89 pp., 22 Plates.

2 Tem M. C. Zu Tol. XVII. No. 2, Jamuary, 1892, 95 pp., 32 Plates.

3 Bull. II. C. Z., Vol. XXIV., No. 7, August, 1893, 72 pp.

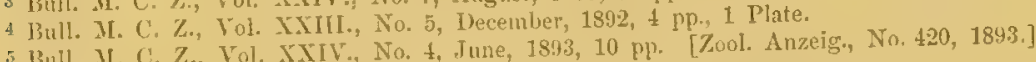

i) Bull. M. U. Z.. Fol. XYT. Nd. 13, July, 1893, 3 pr.

7. Vul XYr. No, 1, September, 1893, 25 pp. 3 Plates.

7 Bull. M. C. \%, Vul. XXV., No. 1, September, 189, 25 pp., 3 Platen.

( Bull

10 Bull. M. C. Z.. Vol. XXY. No. .5, January, 1894, $17 \mathrm{pp}$.

10 Bull. M. C. Z.. Vol. XX., No. ., Jamary, 189, 7 pp., 5 Plates.

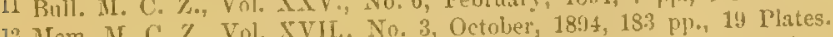

12 Mul II C Y. Vol. XXV. No. 10, Octover, 1894, 109 pp., 12 Plates.

1s Bull II. C. Z., Vol. XXV., No. 8, September, 1894, 13 pp., 1 Plate.

15 Yem. If C. Z., Vol. XVIIL., April, 1895, 292 pp., 67 Plates. 


\section{PUBLICATIONS}

OF TIE

\section{IIUSEUN OF COMPARATIVE ZOÖLOGY \\ AT IIARVARD COLLEGE.}

There have been published of the Bulletins Vols. I. to XXVI.; of the Mexorrs, Vols. I. to XVIII.

Vols. XVI. and XXVII. of the Bulletin, and Vols. XI. and XIX. of the Mesorns, are now in course of publication.

A price list of the publications of the Museum will be sent on application to the Director of the Muscum of Comparative Zoülogy, Cambrillye, Mass.

ALEXANDER AGASSI\%, Director. 




